Göttinger Beiträge zur soziologischen Biographieforschung

Hendrik Hinrichsen

\title{
Die Generation Oslo im Westjordanland
}

Historische Generationen

in prozesssoziologischer Perspektive

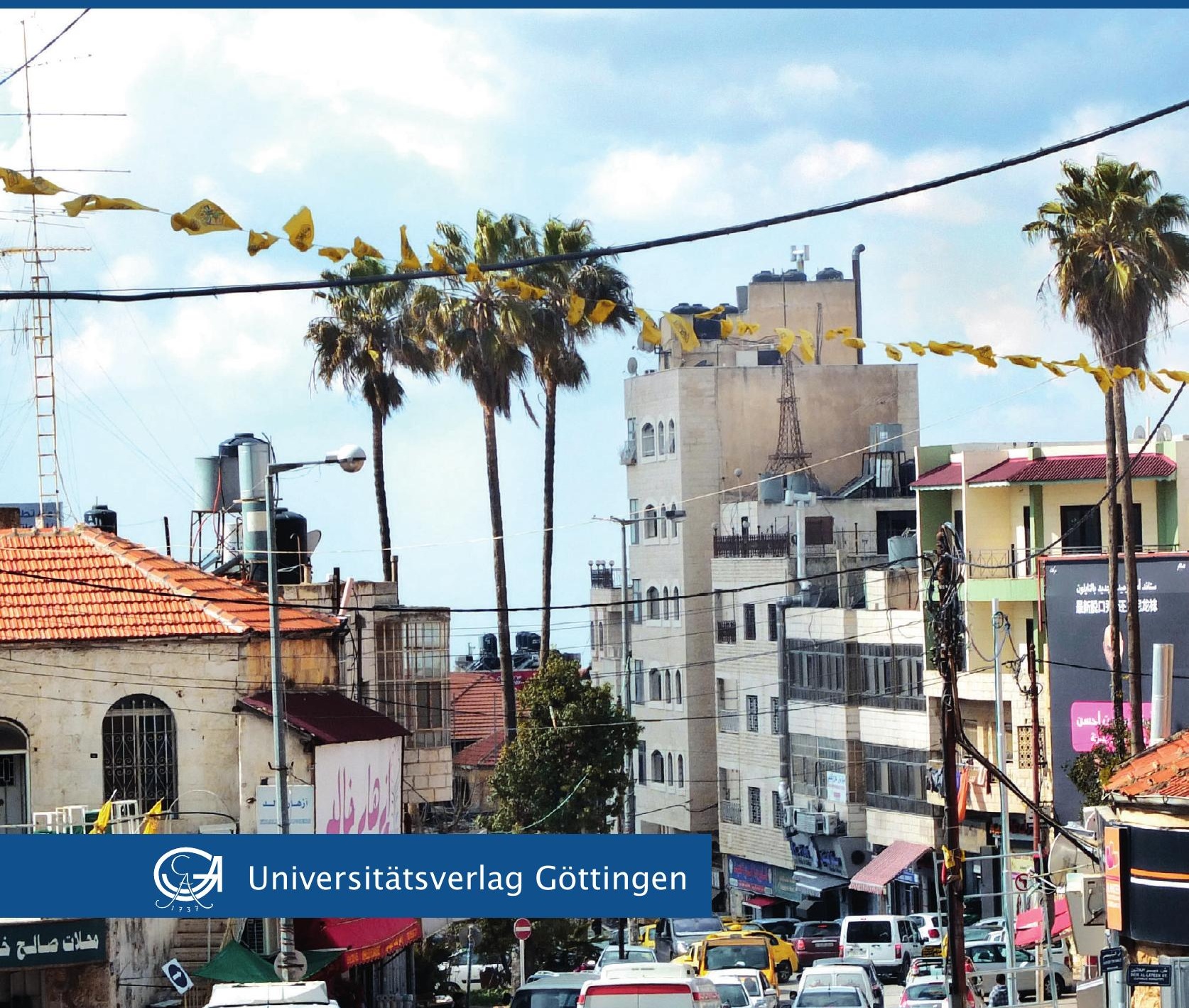



Hendrik Hinrichsen

Die Generation Oslo im Westjordanland

Dieses Werk ist lizenziert unter einer

Creative Commons

Namensnennung - Weitergabe unter gleichen Bedingungen

4.0 International Lizenz.

(c) (1) () 
erschienen als Band 3 in der Reihe „Göttinger Beiträge zur soziologischen Biographieforschung“ im Universitätsverlag Göttingen 2020 
Hendrik Hinrichsen

Die Generation Oslo im

Westjordanland

Historische Generationen in

prozesssoziologischer Perspektive

Göttinger Beiträge zur

soziologischen Biographieforschung Band 3

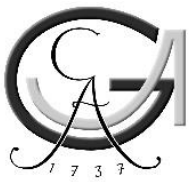

Universitätsverlag Göttingen 2020 


\section{Bibliographische Information der Deutschen Nationalbibliothek}

Die Deutsche Nationalbibliothek verzeichnet diese Publikation in der Deutschen Nationalbibliographie; detaillierte bibliographische Daten sind im Internet über $<$ http://dnb.dnb.de $>$ abrufbar.

„Göttinger Beiträge zur soziologischen Biographieforschung/Göttingen Series in Sociological Biographical Research“"

herausgegeben von

Prof. Dr. Maria Pohn-Lauggas_Ｅ-Mail: maria.pohn-lauggas@uni-goettingen.de

Prof. Dr. Gabriele Rosenthal_ E-Mail: g.rosenthal@uni-goettingen.de

Dr. Nicole Witte_ E-Mail: Nicole.Witte@uni-goettingen.de

Dr. Arne Worm E-Mail: arne.worm@uni-goettingen.de

Georg-August-Universität Göttingen

Methodenzentrum Sozialwissenschaften

Goßlerstr. 19

37073 Göttingen

Zugleich Dissertation an der Sozialwissenschaftlichen Fakultät der Georg-August-

Universität Göttingen unter dem Titel „Generation Oslo. Eine figurationssoziologische und biographietheoretische Studie zur Bildung historischer Generationen im Westjordanland““

\section{Kontakt}

Hendrik Hinrichsen

E-Mail: hendrik.hinrichsen@sowi.uni-goettingen.de

Dieses Buch ist auch als freie Onlineversion über die Homepage des Verlags sowie über den Göttinger Universitätskatalog (GUK) bei der Niedersächsischen Staats- und Universitätsbibliothek Göttingen (https://www.sub.uni-goettingen.de) erreichbar. Es gelten die Lizenzbestimmungen der Onlineversion.

Satz und Layout: Hendrik Hinrichsen

Titelabbildung: Stadtzentrum von Ramallah (Foto: Hendrik Hinrichsen)

(C) 2020 Universitätsverlag Göttingen

https:/ / univerlag.uni-goettingen.de

ISBN: 978-3-86395-458-1

DOI: https://doi.org/10.17875/gup2020-1328

eISSN: 2699-0997 


\section{Vorwort der Herausgeber*innen}

Im Rahmen der sozialkonstruktivistischen und wissenssoziologischen Biographieforschung, die am Methodenzentrum Sozialwissenschaften der Georg-AugustUniversität Göttingen in den letzten Jahren etabliert wurde, entstehen vielfältige innovative und sorgfältige, empirisch fundierte Forschungsarbeiten. Die Reihe soll dieser Entwicklung Rechnung tragen. Mit ihr wollen die Herausgeber*innen deutsch- und englischsprachigen Qualifikationsarbeiten, Forschungsarbeiten und entsprechenden Sammelbänden ein Forum bieten, die vorrangig im Bereich der Soziologie und methodisch im Umfeld des Methodenzentrums Sozialwissenschaften verortet sind. Veröffentlicht werden in der Reihe sowohl primär auf materiale Themen fokussierte Werke als auch solche, die sich vorrangig auf Methodenforschung und Methodenentwicklung konzentrieren.

Maria Pohn-Lauggas, Gabriele Rosenthal, Nicole Witte, Arne Worm 



\section{Inhaltsverzeichnis}

Vorwort der Herausgeber*innen................................................................

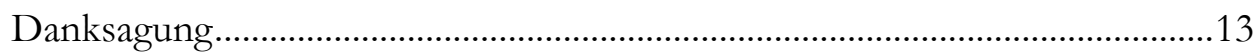

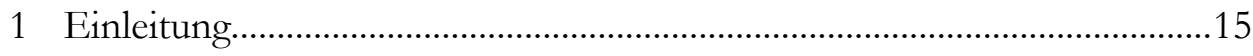

1.1 Forschungsgegenstand und Fragestellung ....................................................15

1.2 Kontext und Aufbau der Arbeit .......................................................................20

2 Historische Generationen aus figurationssoziologischer und biographietheoretischer Perspektive............................................................25

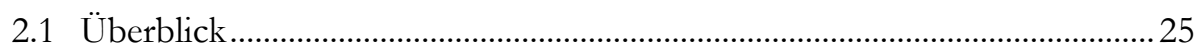

2.2 Mannheims Generationskonzept und dessen Rezeption in der (rekonstruktiven) Sozialforschung ................................................................2

2.3 Mannheims Generationskonzept im Kontext seines wissenssoziologischen Programms ....................................................................33

2.4 Figurationssoziologie im Anschluss an Norbert Elias ......................................38

2.5 Elias' Studien zu Generationenkonflikten ....................................................... 41 
2.6 Sozialkonstruktivistische Biographieforschung ........................................... 45

2.7 Historische Generationen aus biographietheoretischer Perspektive ........... 49

2.8 Graduelle Phänomene historischer Generationenbildung: ,Zwischengenerationen', ,stille Generationen', ,verlorene Generationen'.....

2.9 Zusammenführung: Eine figurationssoziologische und biographietheoretische Perspektive auf historische Generationen

3 Methoden und Stichprobe 57

3.1 Überblick .57

3.2 Fallstrukturen - Typenbildung - theoretische Stichprobenbildung 58

3.3 Sampleentwicklung im Westjordanland .61

3.4 Erhebungs- und Auswertungsinstrumente im Einzelnen .65

3.4.1 Methodenplurale Forschung mit ethnographischem und biographischem Ansatz .65

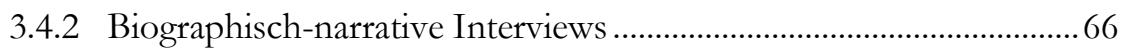

3.4.3 Teilnehmende Beobachtungen...........................................................69

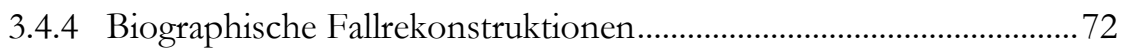

3.4.5 Sequenzanalysen auf Basis von Beobachtungsprotokollen .............. 75

4 Kollektivgeschichtliche Wandlungsprozesse im Westjordanland ab 1948 77

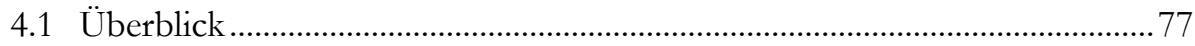

4.2 Der Erste Arabisch-Israelische Krieg 1948/49 und die Nakba ....................78

4.3 Das Westjordanland unter jordanischer Herrschaft...................................... 83

4.4 Die Besatzung Gazas und des Westjordanlandes durch Israel ab 1967 ...... 85

4.5 Erste Intifada 1987-1993

4.6 Die frühen Oslo-Jahre: Der ,Friedensprozess` und der Aufbau quasi-staatlicher Institutionen

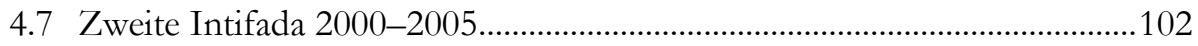

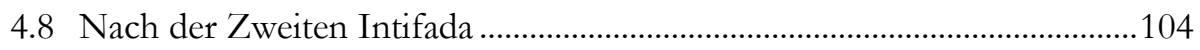

5 Forschung zu historischen Generationen in Palästina ............................ 107 
6 Die „Söhne des Lagers“ und die Generation Intifada in einer Flüchtlingslager-Gegend: Wir- und Sie-Bilder, Interaktionsdynamiken und biographische Verläufe

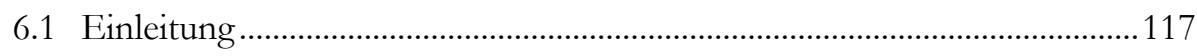

6.2 Die „Söhne des Lagers“: Eine Clique militanter junger Männer ................119

6.2.1 Überblick und Zugang.....................................................................119

6.2.2 ,Widerstandsbilanzierung': Deutungsmuster, Wir- und Sie-Bilder während der ersten Treffen 2013 ......................................122

6.2.3 Konstitutionsprozess und Interaktionsdynamik der Clique ............130

6.2.4 Zuspitzung des Marginalisierungserlebens .........................................141

6.2.5 Warum sprechen die jungen Männer mit uns? Unsere

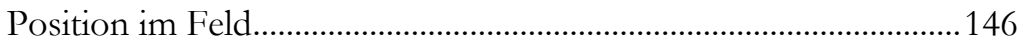

6.2.6 Zusammenfassung: Deutungsmuster, Interaktionsdynamik und Konstitutionsprozess der Clique.

6.2.7 Überleitung: Beobachtungen zur Generation Intifada im weiteren Interaktionsfeld der jungen Männer.

6.3 Falldarstellung Familie Sasour: „Unsere Erfahrung ist anders als eure Erfahrung"...

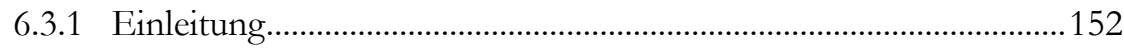

6.3.2 Thematische Felder und familiale Situation im Herbst 2013 .........153

6.3.3 Familien- und Lebensgeschichte......................................................156

6.3.4 Zusammenfassung: Familiale und lebensgeschichtliche Dynamik.

6.4 Falldarstellung Muna: „This thinking has changed dramatically in the Intifada“.

7 Die Rückkehrer in Ramallah: Wir- und Sie-Bilder, Interaktionsdynamiken und biographische Verläufe

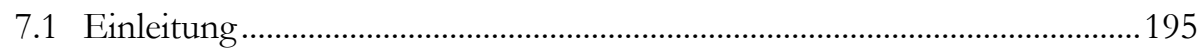

7.2 Die Rückkehrer: Eine Clique militanter junger Männer in Ramallah ........197

7.2.1 Überblick und Kontextualisierung......................................................197

7.2.2 Deutungsmuster, Wir- und Sie-Bilder in der Clique.........................199

7.2.3 Zusammenfassung: Deutungsmuster, Wir und Sie-Bilder der Clique.

7.3 Falldarstellung Familie Haziin: „Alles ist weggegangen nach ein paar Jahren hier" 
7.3.1 Thematische Felder und Interaktionsdynamiken im Interview ....213

7.3.2 Familien- und Lebensgeschichte .216

7.3.3 Zusammenfassung: Familiale und lebensgeschichtliche Dynamik 237

8 Die Altansässigen in Ramallah: Wir- und Sie-Bilder, Interaktionsdynamiken und biographische Verläufe 239

8.1 Einleitung .239

8.2 Die, wohlhabenden Städter': Die urbane altansässige Mittelschicht und die Generation Intifada in Ramallah

8.3 Falldarstellung Haitham: „I always avoid to talk to someone who belongs to a party about my own views“"

8.3.1 Thematisches Feld und Interaktionsdynamik im Interview

8.3.2 Familien- und Lebensgeschichte .250

8.3.3 Zusammenfassung: Familiale und lebensgeschichtliche Dynamik

9 Generationenfiguration und biographische Verlaufstypen in der Nachfolgegeneration Oslo....

9.1 Die Nachfolgegeneration Oslo .267

9.2 Generationenfiguration und Verlaufstypus in der Flüchtlingslager-Gegend 270

9.2.1 Diskussion der Generationenfiguration 270

9.2.2 Biographischer Verlaufstypus A: Von der Orientierung am ,Kampf auf der Straße' zur Verschärfung einer gesellschaftlichen Außenseiterposition

9.3 Generationenfiguration und Verlaufstypus unter den Rückkehrern in Ramallah.

9.3.1 Diskussion der Generationenfiguration

9.3.2 Biographischer Verlaufstypus B: Vom ,Kampf auf der Straße' zum gelingenden Arrangieren mit den Verhältnissen 289

9.4 Generationenfiguration und Verlaufstypus unter den Altansässigen in Ramallah 290

9.4.1 Diskussion der Generationenfiguration 290

9.4.2 Biographischer Verlaufstypus C: Risikovermeidung und Konzentration auf die Umsetzung von Lebenschancen. .293 
9.5 Figuration von Bevölkerung in den Flüchtlingslager-Gegenden und urbaner Mittelschicht

9.6 Die Nachfolgegeneration Oslo als graduelles Phänomen historischer Generationenbildung: Außenseitergeneration und Zwischengeneration

9.7 Integration einer biographietheoretischen und figurationssoziologischen Perspektive auf historische Generationen ........303

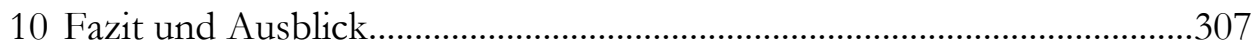

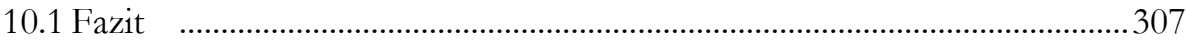

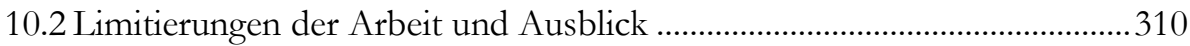

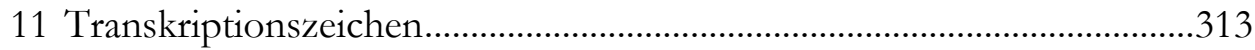

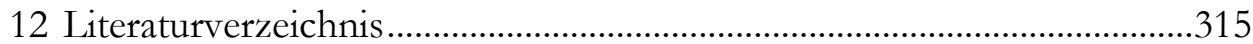





\section{Danksagung}

Mein herzlicher Dank gilt zuvorderst meinen Gesprächspartner*innen, Freund*innen und Bekannten im Westjordanland. Sie ließen mich an ihrem Alltag teilhaben und vertrauten mir auch in schwierigen Situationen ihre Geschichten an. Ohne sie wäre meine Forschung nicht denkbar gewesen. In besonderer Weise danken möchte ich Ahmad Albaba und seiner Familie, die mich beherbergten, mich in (zunächst) unvertrauter Umgebung unterstützten und mir den Rücken stärkten.

Meine Kolleg*innen und Freund*innen aus dem Forschungsprojekt trugen auf verschiedene Art und Weise zu den Erhebungen und Analysen bei, die in diese Arbeit eingegangen sind. Ihnen sei herzlich gedankt! Zu ihnen gehören Mariam Abdul Dayem, Ahmad Albaba, Dr. Artur Bogner, Filip Habib, Majd Qumsieh, Prof. Dr. Gabriele Rosenthal, Aida Saifi, Dr. Anan Srour, Dr. Nicole Witte, Dr. Arne Worm und Dr. Rixta Wundrak.

Ebenso zu danken habe ich den (ehemaligen) Kolleg*innen am Göttinger Lehrstuhl und den Teilnehmer*innen der Kolloquien und Forschungswerkstätten. Ihre kritischen Rückmeldungen und Anregungen zu meinen Kapiteln und Entwürfen waren nie bequem, aber immer hilfreich. Gedankt sei Eva Bahl, Dr. Johannes Becker, Doreen Blume-Peiffer, Lucas Cé Sangalli, Isabella Ensler, 
Henriette Lier, Kristina Meier, Miriam Schäfer, Katharina Teutenberg, Dr. Nicole Witte und Dr. Arne Worm.

Erstgutachterin war Prof. Dr. Gabriele Rosenthal. Ich danke ihr nicht nur für die über alle Maßen engagierte Betreuung meiner Arbeit, die sie mit offener und zielführender Kritik begleitet hat, sondern auch für die Gelegenheit, ,von der Pike auf bei ihr zu lernen. Ihre Art Soziologie zu betreiben, in der Feld und Studierstube gleichermaßen Platz haben, prägt mich zutiefst.

Ebenso danken möchte ich Prof. Dr. David Becker, dessen kritischer Lektüre ich wertvolle Ratschläge und Anregungen verdanke und der mich auf Dinge stoBen ließ, die ich zuvor nicht gesehen habe. Prof. Dr. Katharina Inhetveen möchte ich dafür danken, dass sie trotz der Kürze der Zeit mein Promotionsprojekt unterstützt und als dritte Prüferin bereitsteht.

Dr. Johannes Becker hat es auf sich genommen, meinen Dissertationsentwurf in Gänze zu lesen, ihm sei hier in besonderer Weise gedankt.

Ein gutes Stück Weg liegt zwischen Beginn und Ende dieser Forschung. Danken möchte ich meinen Eltern, deren stiller Intellektualität ich so vieles verdanke. Gewidmet sei diese Arbeit meiner Frau und meinem Sohn. Ihr gebt mir einen Platz im Leben. Ich freue mich auf das, was vor mir liegt. 


\section{Einleitung}

\subsection{Forschungsgegenstand und Fragestellung}

Die sozialwissenschaftliche und historische Generationenforschung blickt mit Vorliebe auf diejenigen Generationen, die vom Gang der Geschichte dramatisch hervorgehoben wurden. Sie untersucht etwa Erlebnisgenerationen, in deren Lebensspanne Phasen ausgeprägter kollektiver Gewalt- und Leidenserfahrungen fielen und die für das kollektive Gedächtnis ihrer Wir-Gruppen von maßgeblicher Bedeutung sind. Und sie blickt auf, glorreiche' Generationen, die im Gang der historischen Ereignisse Bewegungen und Revolutionen getragen und sich in Verteilungs- und Deutungskämpfen als Generation ,durchgesetzt ${ }^{\natural}$ haben. Generationen hingegen, die vom Gang der Ereignisse eher verdeckt wurden, die zwar vielleicht ,gekämpft', aber ,verloren' haben, die sich kein Gehör verschafften oder die zwischen ,großen' Generationen in unterschiedlichen historischen Phasen eine Zwischenstellung einnahmen, werden von der Forschung sehr viel seltener in den Blick genommen. ${ }^{1}$ Eine solche Generation, die man in einer noch näher zu präzisierenden Bezugnahme auf Norbert Elias als Außenseitergeneration bezeichnen

\footnotetext{
${ }^{1} \mathrm{Zu}$ dieser Einschätzung kommt zum Beispiel auch Bernd Weisbrod. Er plädiert dafür, stille ${ }^{`}$ Generationen vermehrt in den Fokus der Forschung zu rücken (2007: 31). Siehe in dieser Arbeit Kap. 2., insbesondere 2.9.
} 
könnte, steht im Zentrum dieser Forschungsarbeit - die sogenannte Generation Oslo. Die Bezeichnung Generation Oslo leitet sich aus dem ,Friedensprozess zwischen Israel und Palästinenser*innen ${ }^{2}$ in den 1990er Jahren ab, dessen wichtigste Vereinbarungen in der norwegischen Hauptstadt Oslo getroffen wurden. Sie bezeichnet grob diejenigen Palästinenser*innen, die im Zuge der Vertragsabschlüsse und der sozialen Transformationsprozesse, die diese für die palästinensischen Gebiete nach sich zogen, geboren wurden und aufwuchsen. Als Begriff wurde und wird er in sporadischer Weise in journalistischen Publikationen sowie in vereinzelten wissenschaftlichen Veröffentlichungen ${ }^{3}$ verwendet. Die Generation Oslo auf die mit ihr verbundenen Prozesse historischer Generationenbildung zu befragen, ist das Ziel dieser Forschungsarbeit.

Bevor ich mich der Fragestellung dieser Arbeit und dem Forschungsfeld konkreter zuwende, einige Bemerkungen zu der Frage, was historische Generationen eigentlich sind. Es werden darunter keine genealogischen Generationen, also eine Einteilung entlang von familialen Verwandtschaftskategorien, verstanden. Vielmehr werden Generationen hier in Bezug auf das Erleben kollektivgeschichtlicher Ereignisse gefasst. Ein bis heute zentraler Bezugspunkt für die Erforschung und wissenschaftliche Auseinandersetzung mit historischen Generationen ist ein 1928 erschienener Aufsatz von Karl Mannheim mit dem Titel „Das Problem der Generationen“. Im Kern geht es in Mannheims Generationskonzept darum, dass Gesellschaftsmitglieder politische oder soziale Ereignisse beziehungsweise bestimmte Phasen der Gesellschaftsgeschichte gemeinsam erleben - und zwar, mit Mannheims Worten, von derselben „Art der Bewusstseinsschichtung“ (1964: 536)4, von derselben Gesamtkonstellation der im Laufe eines Lebens gemachten Erfahrungen aus. Mannheims Diskussion des bekannten, dem Kunsthistoriker Wilhelm Pinder entliehenen Oxymorons von der „Ungleichzeitigkeit des Gleichzeitigen“ folgt diesem Gedankengang: Gleichzeitig lebende Gesellschaftsmitglieder erleben aufgrund ihrer in der Zeit unterschiedlich gelagerten Spannen von Erfahrungsbildung die gleichen' Ereignisse unterschiedlich. Diese entlang generationaler Zugehörigkeit geteilten Erfahrungshintergründe können dann mit mehr oder weniger weit gehenden generationalen Integrations- und Vergemeinschaftungsprozessen ver-

\footnotetext{
${ }^{2}$ In der Arbeit verwende ich den Asterisk $(*)$. Um den Bezeichneten möglichst gerecht zu werden, wird die Form allerdings nicht für Kontexte genutzt, in denen Männer dominieren, Frauen beziehungsweise Nicht-Männer aber dennoch ganz vereinzelt präsent sind oder waren. Dies gilt etwa für die palästinensischen Milizen oder die Soldaten, welche die israelischen Militäroperationen im Westjordanland durchführen. An diesen nahmen und nehmen in geringem Umfang auch Frauen teil. Um die männliche Dominanz in diesen Feldern jedoch nicht sprachlich zu verdecken, nutze ich auch für diese Kontexte das generische Maskulinum.

${ }^{3}$ Dies sind etwa die Arbeiten von Sunaina Maira (2013) und Jacob Høigilt (2016). Sie werden in Kap. 5 diskutiert.

${ }^{4}$ In dieser Arbeit basieren alle Zitationen Mannheims auf dem von Kurt Wolf 1964 herausgegeben Band „Wissenssoziologie“, mit Ausnahme der erst 1980 in „Strukturen des Denkens“ herausgegeben Schriften und des Konkurrenzaufsatzes von 1928.
} 
bunden sein. Dies kann in manifester Weise darin zum Ausdruck kommen, dass generationale Deutungsmuster und generationale Wir-Bilder explizit formuliert und durchgesetzt werden, was wiederum dazu beitragen kann, dass eine Generation zu einer auch kollektiv handlungsfähigen Gruppe wird. Oder die Integrationsund Vergemeinschaftungsprozesse kommen nur auf latenter Ebene zum Ausdruck, die beispielsweise lediglich umfasst, sich von Mitgliedern derselben Generation, ohne sich dessen bewusst zu sein, ,irgendwie ${ }^{6}$ eher verstanden zu fühlen und sich ihnen eher zugehörig zu fühlen. Hier bliebe die weitere Integration der Generation in Richtung Gruppe und kollektiver Handlungsfähigkeit weitgehend potentiell. Über Mannheim hinausgehend kann man festhalten, dass generationale Erfahrungen und generationale Integrationsprozesse gerade auch in konkreten Interaktionen entstehen - sowohl in Interaktionen von Mitgliedern derselben Generation als auch von Mitgliedern unterschiedlicher Generationen (Matthes 1985a; Rosenthal 2000). Historische Generationen bilden sich so auch in Generationenverbältnissen. Diese Verhältnisse zeichnen nicht nur unterschiedliche Erlebnisschichtungen, sondern auch mit diesen verwobene Machtchancen und Abhängigkeiten zwischen den Generationen aus. Ich spreche in diesem Zusammenhang im Anschluss an die Figurationssoziologie auch von Generationenfigurationen (Elias 1989).

Die Frage nach der Bildung historischen Generationen ist aber - und darauf insistiert auch Mannheim ganz besonders - eine empirische Frage. Der Gang der historischen Ereignisse ist nicht automatisch mit der Entstehung von historischen Generationen verbunden. Auch bei kollektivgeschichtlich hervorgehobenen ,dramatischen' Ereignisabläufen und gesellschaftlichen Umbrüchen ist jeweils die Frage zu stellen, ob sich generationale Erlebnisschichtungen ausbilden und es zu generationalen Integrations- und Vergemeinschaftungsprozessen kommt - oder eben nicht. Um zu einer Antwort auf diese Frage zu gelangen, ist gerade eine biographietheoretische Perspektive ein geeignetes Werkzeug. Die sozialwissenschaftliche Biographieforschung, die soziale Phänomene im Gesamtzusammenhang der Lebensgeschichte untersucht, bot und bietet einen ergiebigen Zugang, der die Relevanz generationaler Zugehörigkeit nicht voraussetzt, sondern gegebenenfalls empirisch entdeckt und darüber hinaus erlaubt, deren Herstellung und Wechselwirkung mit anderen Zugehörigkeiten und kollektiv- und lebensgeschichtlichen Kontexten zu rekonstruieren.

Im palästinensischen Kontext ist es sowohl in der Forschung als auch auf der Ebene alltagsweltlicher Konstruktionen nicht unüblich, Phasen der Kollektivgeschichte eng auf Generationen zu beziehen. Ahmad H. Sa'di und Lila AbuLughod (2007a) diskutieren etwa prägende Erlebens- und Tradierungsprozesse sowie die zentrale kollektive Bedeutung in der sogenannten Generation Nakba. ${ }^{5}$

\footnotetext{
5 Arabisch für „Katastrophe“. Bekannte arabische Bezeichnungen, Orts- oder Personennamen schreibe ich entsprechend ihrer geläufigen deutschen Schreibweise. Bei arabischen Begriffen und
} 
Die Generation Nakba umfasst diejenigen Palästinenser*innen, die vor und während des Ersten Arabisch-Israelischen Krieges zwischen 1947 und 1949 aus ihren Wohn- und Herkunftsorten im heutigen israelischen Staatsgebiet flohen und vertrieben wurden. In den $\mathrm{zu}$ ihr vorliegenden Forschungen unterbleibt allerdings meist eine genaue Bestimmung verschiedener generationaler Erlebnisschichtungen innerhalb der Erlebnisgeneration, die über eine allgemeine ,Zeugenschaft ${ }^{6}$ der Nakba hinausgehen (vgl. Kap. 5). Sa'di und Abu-Lughod sprechen auch davon, dass auf die Nakba-Generation verschiedene ,generations of resistance“ (2007a: 23) gefolgt seien. Ich werde im Verlauf der Arbeit noch detaillierter auf die einzelnen Phasen der palästinensischen Kollektivgeschichte zu sprechen kommen. Jedoch sei an dieser Stelle bereits angemerkt, dass die sogenannte Generation Intifa$\mathrm{da}^{6}$, deren Name sich aus dem palästinensischen Aufstand gegen die israelische Besatzung zwischen circa 1987 und 1993 herleitet, im palästinensischen Kontext am ehesten eine ,glorreiche' Generation darstellt. Ihre Mitglieder erlebten die sukzessive politische Mobilisierung breiter Teile der palästinensischen Bevölkerung im Westjordanland und im Gazastreifen in den 1970er und 1980er Jahren und partizipierten an ihr. Die hervorgehobene Stellung der Generation Intifada zeigte sich auch in meinen empirischen Analysen. Während historische Generationenbildung in der palästinensischen Gesellschaft im Zusammenhang mit der Ersten Intifada in der Forschung einige Beachtung erfahren hat, ist die kollektivgeschichtliche Phase seit den Oslo-Verträgen Mitte der 1990er Jahre trotz der umfassenden sozialen Transformationsprozesse, die diese begleiteten und begleiten, in dieser Hinsicht bisher kaum erforscht worden. In diesem Umstand liegt einer der Gründe, warum ich mich der Frage nach einer Generation Oslo zugewandt habe.

Die Ausgangsdefinition der in dieser Forschungsarbeit im Zentrum stehenden Generation Oslo war jedoch zunächst eher die einer Kohorte beziehungsweise einer Generationslagerung, um eine Kategorisierung Mannheims aufzugreifen. So verstand ich unter der Generation Oslo zunächst diejenigen, die in der Phase ab dem sogenannten Friedensprozess zwischen Israel und den Palästinenser*innen mit Beginn der 1990er Jahre geboren und aufgewachsen waren. Ziel dieser Forschungsarbeit wurde es dann, eine möglichst differenzierte Antwort auf die Frage zu geben, inwiefern es zur Ausbildung einer typischen Erlebnisschichtung, zu generationalen Integrations- und Vergemeinschaftungsprozessen in der Generation Oslo kam oder kommt sowie durch welche sozialen Prozesse sie gegebenenfalls erzeugt und vermittelt wurden. Diese Fragestellung ist, wie die weitere theoretische Ausdifferenzierung der historischen Generationskonzeption, selbst Resultat des Forschungsprozesses. Dies ist im Rahmen der rekonstruktiv verfahrenden Sozialforschung, in deren Kontext diese Arbeit steht, Teil der Forschungslogik: $\mathrm{Zu}$ Beginn meiner Forschung hatte ich eine allgemeine Forschungsfrage zu der

Wörtern, die im Deutschen nicht oder kaum geläufig sind, folge ich der Umschrift nach den Regelungen der Deutschen Morgenländischen Gesellschaft.

${ }^{6}$ Arabisch für „,sich erheben“, „abschütteln“. 
Kreuzung verschiedener Zugehörigkeiten im Westjordanland formuliert und zudem mehr oder weniger die Annahme verfolgt, der Differenzierung religiöser Zugehörigkeiten wäre hier ein stärkeres Gewicht zu geben. ${ }^{7}$ Mit der sich im empirischen Analyseprozess abzeichnenden Relevanz historisch-generationaler Zugehörigkeit stieß ich jedoch auf eine andere Spur.

Im Verlauf der Erfassung und Auswertung der im Westjordanland erhobenen Daten zeigten sich einige maßgebliche Aspekte, welche ich an dieser Stelle in einer Kurzfassung vorwegnehme und auf welche ich in dieser Forschungsarbeit im Detail eingehen werde: Eine in der Generation Oslo geteilte soziale Position ist es, gegenüber den vorangehenden Kampfgenerationen, insbesondere der Generation Intifada, nachgelagert zu sein. Ein zentrales Charakteristikum der typischen Erlebnisschichtung der Generation Oslo ist daher das Gefühl, ,im Schatten` der Generation Intifada zu stehen. Dieser ,Schatten' hat Folgen für die Lebensgeschichten, die Wir- und Sie-Bilder wie auch die biographischen Konstruktionen der Generation Oslo. Er ist unter anderem mit dem Erleben des generationalen Absinkens von Sinnchancen, also etwa Gefühlen der Sinnerfüllung, und zum Teil von Lebenschancen verbunden. Die Zugehörigkeit zur Generation Oslo ist zwar tendenziell in allen in dieser Generationslagerung vorgenommenen Fallrekonstruktionen für die Erlebnisschichtungen, Deutungs- und Handlungsmuster relevant, sie hat allerdings nicht unbedingt eine hervorgehobene biographische Relevanz. Die Position als nachgelagerte Generation Oslo steht in Wechselwirkung mit einem zentralen Trend in den gesellschaftlichen Transformationsprozessen, der sich im Westjordanland seit den Oslo-Verträgen Mitte der 1990er Jahre verstärkte - nämlich dem relativen Abstieg der Bevölkerung der Flüchtlingslager-Gegenden gegenüber Teilen der ,neuen“ urbanen Mittelschicht. Die biographische Bedeutung der Zugehörigkeit zur Generation Oslo ist, wie ich herausarbeiten werde, vermittelt durch die jeweilige Position im Verhältnis - oder genauer in der Figuration - dieser klassenbeziehungsweise schichtbezogenen Gruppierungen. Weiterhin steht die Zugehörigkeit zur Generation Oslo, auch dies zeigen meine Analysen, mit geschlechtlicher Zugehörigkeit in Wechselwirkung. Von mir herausgearbeitet wurde insbesondere die Bedeutung von Konstruktionsprozessen von Männlichkeit in sogenannten Ernsten Spielen (Meuser 2005), die in die Verhandlung der generationalen Zugehörigkeit hineinspielen. Meine Arbeit fokussiert in einem stärkeren Maße männliche als weibliche Generationszugehörigkeit und -verhältnisse, nimmt aber wiederholt auf geschlechtliche Parallelen und Unterschiede im Erleben und in der Verhandlung generationaler Zugehörigkeit Bezug. Schließlich sollen die empirischen Analysen auch dazu beitragen, die theoretische Konzeptualisierung von historischen Generationen zu schärfen. Dafür integriere ich, empirisch begründet,

\footnotetext{
${ }^{7}$ Meine Forschungen konnte ich im Rahmen des von der Deutschen Forschungsgemeinschaft (DFG) geförderten Projektes „Außenseiter und Etablierte zugleich. Palästinenser und Israelis in unterschiedlichen Figurationen" (2010-2015) unter der Leitung und Betreuung von Gabriele Rosenthal durchführen. Geschäftszeichen RO 827/16.
} 
eine figurationssoziologische und biographietheoretische Perspektive auf historische Generationenbildung.

Wie generationale und weitere Zugehörigkeiten biographisch relevant werden und zusammenwirken, habe ich im Westjordanland in verschiedenen Kontexten untersucht. Die Erhebungen konzentrierten sich auf eine FlüchtlingslagerGegend $^{8}$ sowie auf zwei städtische Kontexte in Ramallah, die miteinander verglichen werden. Zudem wurden sowohl die Cliquen beziehungsweise Peergroups der Biographen als auch die familialen Kontexte berücksichtigt.

\subsection{Kontext und Aufbau der Arbeit}

Zunächst stelle ich in Kapitel 2 konzeptionelle Überlegungen für die Erforschung historischer Generationen an. Dafür kombiniere ich eine figurationssoziologische und eine biographietheoretische Perspektive, deren zentrale Konzepte ich erörtere. Hierzu greife ich, nach einem kurzen Überblick (2.1), zunächst die klassische Konzeption Karl Mannheims zu historischen Generationen auf und gehe auf die Rezeption und die konzeptionelle Weiterentwicklung seines Konzepts in der Generationenforschung und der rekonstruktiven Sozialforschung ein (2.2). Zudem diskutiere ich dessen Parallelen zur Figurationssoziologie im Anschluss an Norbert Elias, die sich unter anderem im Fokus auf die Relation von Gruppen und Gruppierungen zeigen (2.3). Daran anschließend erörtere ich Elias' konzeptionelle Arbeiten zu den Etablierten-Außenseiter-Figurationen (2.4) und deren Anwendung auf Generationenverhältnisse und -konflikte (2.5). Gerade Elias' Überlegungen zur machtasymmetrischen Verflechtung von vor- und nachgelagerten Generationen und die damit verbundene Reduzierung von Lebens- und Sinnchancen über die Generationen waren für diese Arbeit analytisch zentral. Daran anschlieBend entfalte ich die Grundzüge einer biographietheoretischen Forschungsperspektive (2.6) und stelle die im Rahmen biographischer Forschung unternommene Generationenforschung vor (2.7). Eine der für diese Arbeit zentralen Stärken einer biographietheoretischen Perspektive besteht darin, die biographische Relevanz von Zugehörigkeiten und Erfahrungen sowie die etwaige Wechselwirkung und Überlagerung von Zugehörigkeiten zu berücksichtigen. ${ }^{9}$ Sie ermöglicht, auch graduelle

\footnotetext{
${ }^{8}$ In ihr wohnten und wohnen vorwiegend die Nachfahren jener Palästinenser*innen, die während der Nakba ins Westjordanland flüchteten oder in dieses vertrieben wurden. Das Lager, welches sich auf von der UN gepachtetem Territorium befindet, stellt das Zentrum dieser Gegend dar. Das Wohngebiet umfasst jedoch auch angrenzende Gebiete, die nach und nach von Familien aus dem Lager bezogen wurden. Daher spreche ich in dieser Arbeit von Flüchtlingslager-Gegenden.

${ }^{9}$ Die Annahme, dass mehrfache, sich kreuzende Zugehörigkeiten und soziale Positionen insbesondere in ihrer Wechselwirkung zu analysieren sind, wird auch von Forschungsansätzen vertreten, die sich auf das Konzept der Intersektionalität beziehen (vgl. Crenshaw 1991). Diese Ansätze weisen meiner Ansicht nach eine hohe Anschlussfähigkeit an den hier verfolgten figurationssoziologischen und biographietheoretischen Zugang auf, sofern sie nicht zu einem festgelegten Set an Ungleichheitskategorien tendieren, sondern die jeweilige empirische Bedeutung von Zugehörigkeiten dezi-
} 
Phänomene historischer Generationenbildung, also Ansätze generationaler Erlebnisschichtungen, Integrations- und Vergemeinschaftungsprozesse, herauszuarbeiten. Diese in der Generationenforschung kaum beachteten Zwischengenerationen oder ,stillen Generationen' thematisiere ich im Anschluss (2.8). Abschließend führe ich die theoretischen Perspektiven zu einer biographietheoretischen und figurationssoziologischen Perspektive auf die Erforschung historischer Generationen zusammen (2.9).

Im Kapitel 3 komme ich zu den in dieser Forschungsarbeit genutzten Methoden und der im Verlauf der Forschung zusammengestellten Stichprobe. Zunächst leite ich von den theoretischen Diskussionen in Kapitel 2 zu den methodologischen Fragen zur Typenbildung und zur theoretischen Stichprobenbildung in Kapitel 3 über (3.1-3.2). Anschließend diskutiere ich zuerst die Zusammensetzung der Stichprobe und das konkrete Vorgehen bei der Zusammenstellung der Stichprobe im Westjordanland (3.3). Danach gehe ich ausführlich auf die in dieser methodenplural konzipierten Arbeit genutzten interpretativen Erhebungs- und Auswertungsmethoden ein (3.4).

Mit dem Kapitel 4 führe ich in den historisch-geographischen Kontext der Forschungsarbeit ein. Ich erörtere zentrale kollektivgeschichtliche Wandlungsprozesse im Westjordanland ab 1948. In der Darstellung setze ich dort Schwerpunkte, wo die kollektivgeschichtlichen Prozesse besonders relevant für meine Frage nach Bildungsprozessen historischer Generationen waren und zentrale Hintergrundentwicklungen für die im Rahmen dieser Arbeit durchgeführten Fallrekonstruktionen skizzieren. Dies umfasst die Geschichte der palästinensischen Flüchtlingslager und der Flüchtlingsbevölkerung im Westjordanland sowie die Phase der jordanischen Besatzung (4.1-4.3), die breite politische Mobilisierung ab den 1970er und 1980er Jahren (4.4-4.5) und die mit den Oslo-Abkommen Mitte bis Ende der 1990er Jahre angestoßenen gesellschaftlichen Transformationsprozesse, die den kollektivgeschichtlichen Kontext für die Generation Oslo darstellen (4.6-4.8).

In Kapitel 5 diskutiere ich den Stand der Generationenforschung zu palästinensischen Gruppierungen in Palästina. Insbesondere zur Generation Intifada liegen Forschungsarbeiten vor, die explizit mit einem an Mannheim orientierten Konzept historischer Generationen arbeiten. Zur Phase nach den OsloAbkommen sind trotz der umfassenden sozialen Transformationsprozesse, die mit dieser Phase verbunden sind, bisher nur vereinzelt Arbeiten entstanden, die sich mit auf die Kollektivgeschichte bezogener Generationenbildung beschäftigen.

In den folgenden Kapiteln 6-8 stelle ich die empirischen Analysen vor. Die Erhebungen und Analysen konzentrieren sich auf eine Flüchtlingslager-Gegend sowie auf zwei sehr unterschiedliche Kontexte in Ramallah. Auch diesen Kapiteln

diert ,am Fall' rekonstruieren. Da ich darüberhinausgehend in dieser Arbeit berücksichtigen möchte, inwiefern sich Verflechtungen von sich mehr oder weniger integrierenden Gruppen und Gruppierungen im historischen Prozess zeigen, greife ich hier vorwiegend auf die Konzepte der Figurationssoziologie und der sozialkonstruktivistischen Biographieforschung zurück. 
ist jeweils eine kurze Kapiteleinleitung vorangestellt (6.1; 7.1; 8.1). In Kapitel 6 diskutiere ich eine Gruppierung von Außenseitern in ihrem familialen und weiteren Interaktionsfeld in einer Flüchtlingslager-Gegend. Sie nehmen, wie ich herausarbeiten werde, in den Interdependenzgeflechten, in denen sie sich bewegen, eine machtchancenarme Position ein - als ,Kämpfer für die palästinensische Sache', als Flüchtlinge und als Generation. Exemplarisch mache ich dies am Fall einer Freundesclique junger Männer sowie einer Familie eines der jungen Männer deutlich, für die ich Deutungsmuster, Wir- und Sie-Bilder, Erfahrungs- und Interaktionsgeschichten rekonstruiere. Für die Clique junger Männer (6.2) wird sich zeigen, dass der Konstitutionsprozess und die Interaktionsdynamik in der Clique eng mit der Involvierung in Straßenschlachten mit dem israelischen Militär und den Sicherheitskräften der Palästinensischen Autonomiebehörde (PA) verbunden sind. Die Interaktion zwischen den jungen Männern wiederum ist verwoben mit den Prozessen der Männlichkeitskonstruktion, der Verhandlung von Leidenserfahrungen und von innerbalb der palästinensischen Gesellschaft im Westjordanland erlebten gesellschaftlichen Marginalisierungen und Stigmatisierungen. Indem die jungen Männer ihren ,Einsatz für die palästinensische Sache und ihre erlebte gesellschaftliche Position gegeneinander aufrechnen, verhandeln die jungen Männer auch weitere Zugehörigkeiten - etwa zur Flüchtlingsbevölkerung in Abgrenzung zu einer im Sie-Bild unpolitischen, aber wohlhabenden Stadtbevölkerung. Anhand der Rekonstruktion der Familie eines der jungen Männer (6.3) wird deutlich, wie Interaktionsprozesse in der Clique und Interaktions- und Tradierungsprozesse in der Familie vor dem Hintergrund der Kollektivgeschichte ineinanderwirken. Die Rekonstruktion der langfristigen kollektiv- und familiengeschichtlichen Prozesse offenbart unter anderem, dass in der Elterngeneration eine Verhandlung von einerseits Partizipation in der politischen Mobilisierung der 1970er und 1980er Jahre und andererseits Steigerung der Lebenschancen eher gelang. In der Folge stellt die familiale intergenerationale Interaktion auch eine Interaktion zwischen historischen Generationen dar, in der Zugehörigkeit sowohl zur Generation Intifada als auch zur Generation Oslo aktualisiert und gegen die Intention der Beteiligten auch hierarchisiert wird.

In Kapitel 7 gehe ich auf eine Gruppierung von in Ramallah lebenden Rückkehrern - also von in den 1990er Jahren ins Westjordanland (re-)migrierten Palästinenser*innen - ein, die ich ebenfalls im familialen und weiteren Interaktionsfeld betrachte. Sie kennzeichnet gegenüber dem Kontext der Flüchtlingslager-Gegend eine deutlich höhere Ausstattung mit klientelistischen Chancen, also ein Einbezug in die Patronage-Netzwerke der PA, der auch die eigenen Lebenschancen erhöht, sowie die desillusionierenden Erfahrungen und Frustrationen, die mit der Migration ins Westjordanland verbunden sind. Exemplarisch diskutiere ich erneut eine Clique beziehungsweise Peergroup junger Männer (7.1-7.2) sowie den Fall einer Familie eines der jungen Männer (7.3) Auch sie beteiligten sich in ihrer Jugend und im jungen Erwachsenenalter an Straßenschlachten mit dem israelischen Mili- 
tär und den Sicherheitskräften der PA. Die von ihnen herausgebildeten Deutungsmuster und Wir- und Sie-Bilder ähneln zum Teil jenen in der Clique der Flüchtlingslager-Gegend, ein zentraler Unterschied liegt aber darin, dass sie hier keine als gesellschaftlich marginalisiert erlebte soziale Position zum Ausdruck bringen. Die jungen Männer bringen zudem eine stärkere Bereitschaft zur biographischen Reorientierung und zum ,Arrangieren' mit den Verhältnissen mit. Dies ist auch vor dem Hintergrund der gegenüber jener Clique aus der FlüchtlingslagerGegend nochmals deutlich stärkeren persönlichen und familialen Verbindungen in die PA zu interpretieren. Auch für diesen Forschungskontext diskutiere ich, wie Interaktionsprozesse in der Clique und Interaktions- und Tradierungsprozesse in der Familie ineinanderwirken. Es wird deutlich, wie vor dem Hintergrund des kollektiv- und familiengeschichtlichen Verlaufs, der von der Desillusionierung des Projektes der Migration ins Westjordanland geprägt ist, eine latente familiale Delegation zum Kampf auf der Straße entsteht. Umfassend wird analysiert, wie ihre generationale Position, Männlichkeitsentwürfe und die Nähe zu den klientelistischen Netzwerken der PA in den Biographien der Rückkehrer zusammenwirken.

In Kapitel 8 nehme ich im zweiten Kontext in Ramallah junge Männer und Frauen aus Familien urbaner Altansässiger in den Blick. Sie charakterisiert gegenüber den Kontexten der Flüchtlingslager-Gegend sowie gegenüber den Rückkehrern in Ramallah ein höheres Maß an Lebenschancen, also an ökonomischem und insbesondere kulturellem Kapital, das mit Hochschulbildung verbunden ist, sowie eine ausgeprägte biographische Orientierung, die auf die Realisierung der Lebenschancen fokussiert ist. Auch hier werden Deutungsmuster, Wir- und Sie-Bilder im Rahmen der Peergroup in den Blick genommen (8.2). In diesem Kontext spielt der Kampf auf der Straße keine Rolle, das Jugend- und junge Erwachsenenalter ist stärker von einem Fokus auf Bildungs- und berufliche Erfolge sowie hedonistische Freizeitaktivitäten im ,kosmopolitischen' Ramallah geprägt. In den Deutungsmustern werden das Erleben geringer politischer Handlungsmacht, generationale Wir- und Sie-Bilder und mit diesen verbundene Stigmatisierungen verhandelt. Exemplarisch diskutiere ich am Fall eines jungen Mannes aus einer Altansässigenfamilie (8.3), wie sich der Fokus auf eine Realisierung der eigenen Lebenschancen und die Distanzierung vom palästinensischen Politikbetrieb vor dem Hintergrund der kollektivgeschichtlichen, auch generationalen Position herstellen.

In Kapitel 9 werden die empirischen Ergebnisse zusammengeführt und in Bezug auf die Forschungsfrage dieser Arbeit, ob und inwiefern sich Prozesse historischer Generationenbildung in der Generation Oslo zeigen, diskutiert. In den Abschnitten 9.1-9.4 erörtere ich entlang der Forschungskontexte FlüchtlingslagerGegend, Rückkehrer in Ramallah und Altansässige in Ramallah die verschiedenen Aspekte der von mir rekonstruierten Generationenfiguration, welche die Generation Intifada und die Generation Oslo miteinander bilden. Im Detail gehe ich etwa auf intra- und intergenerationale Interaktion, figurationale Machtbalancen und Differenzen in der Erlebnisschichtung sowie in Wir- und Sie-Bildern ein. Dabei 
erfolgt die Darstellung jeweils sowohl auf der Ebene der Figuration der Generationen als auch auf der Ebene biographischer Verlaufstypen in der OsloGeneration. In Kapitelabschnitt 9.5 hebe ich die Verschiebungen in der Figuration von palästinensischer Bevölkerung in den Flüchtlingslager-Gegenden und Teilen der ,neuen' urbanen Mittelschicht, die in vermittelnder Weise auf die Generationenfiguration wirkt, gesondert heraus. Im Anschluss diskutiere ich unter Rückbezug auf die Mannheim'sche Generationenterminologie die Frage, inwiefern die Generation Oslo als graduelles Phänomen historischer Generationenbildung - etwa als eine Zwischengeneration beziehungsweise stille Generation - angesehen werden kann (9.6). Abschließend resümiere ich den Gewinn, den meine empirischen Analysen für eine Schärfung und Ausdifferenzierung der theoretischen Konzeptualisierung historischer Generationenbildung haben (9.7).

Im Fazit fasse ich die zentralen Ergebnisse dieser Arbeit knapp zusammen (10.1) und diskutiere die Limitierungen, denen die Forschungsergebnisse unterliegen (10.2). 


\section{Historische Generationen aus figurationssoziologischer und biographietheoretischer Perspektive}

\section{1 Überblick}

Im Folgenden möchte ich konzeptionelle Überlegungen für die Erforschung historischer Generationen darlegen. Dafür kombiniere ich eine figurationssoziologische und eine biographietheoretische Perspektive, deren zentrale Konzepte ich im Hinblick auf eine Analyse von graduellen Prozessen historischer Generationenbildung zusammenführe. Mit dem Generationskonzept Karl Mannheims diskutiere ich zunächst den zentralen und bis heute richtungsweisenden ,Klassiker ${ }^{6}$ der soziologischen Generationenforschung (2.2). Ich werde Mannheims Generationskonzept mit den von ihm eingeführten begrifflichen Differenzierungen, Mannheims Vorstellung von generationalen Erlebnisschichtungen sowie die von Mannheim nur am Rande erörterten unterschiedlichen Integrationsniveaus von Generationen zur Sprache bringen. In knappen Ausführungen werde ich auch auf die Rezeption des Mannheim'schen Generationskonzepts in der Generationenforschung, insbesondere in der rekonstruktiven Sozialforschung, eingehen. Daran anschließend möchte ich Mannheims Generationskonzept in den Kontext seiner späteren, noch in seiner, deutschen Phase' veröffentlichten wissenssoziologischen 
Schriften stellen (2.3). Dadurch wird eine Nähe der Ansätze Mannheims und der von Norbert Elias begründeten Figurationssoziologie erkennbar, die in der Generationenforschung wie auch in der Mannheim-Rezeption kaum wahrgenommen wurde und nur unter Elias-Schüler*innen eine gewisse Beachtung gefunden hat, obwohl die beiden Soziologen mehrere Jahre zusammengearbeitet haben. Es wird deutlich, wie in Mannheims Wissenssoziologie, wenn auch nicht im Zentrum stehend, eine Beschäftigung mit der relativen Stellung von Gruppen und Gruppierungen zueinander angelegt ist.

Im Weiteren stelle ich den prozess- oder figurationssoziologischen Ansatz Norbert Elias' vor (2.4). Besondere Beachtung sollen dabei Elias' Arbeiten zu Generationenkonflikten finden, die er in seine Etablierten-Außenseiter-Theorie einfasst. Mit diesen Arbeiten lässt sich insbesondere der Blick auf die Verflecbtung von verschiedenen Generationen miteinander und auf deren Machtbalancen schärfen (2.5). Anschließend greife ich die Forschungsperspektive der sozialkonstruktivistischen Biographieforschung auf, die, wie ich diskutieren möchte, verschiedene Vorteile für die Erforschung historischer Generationen mit sich bringt. Ich gehe daher in groben Zügen auf die Grundlagen der Biographieforschung ein, die in aktuellen Forschungsarbeiten zunehmend mit der Figurationssoziologie verbunden wird (2.6). Dann erörtere ich spezifischer die biographietheoretische Auseinandersetzung mit historischen Generationen, die einen der bisherigen Forschungsschwerpunkte in der Biographieforschung bilden (2.7). Die Perspektive der Biographieforschung steht auch für einen dezidiert empirischen Zugang zu historischen Generationen. So kann mit einem biographietheoretischen Zugang die lebensgeschichtliche Relevanz, aber auch die lebensgeschichtliche Irrelevanz oder Nachrangigkeit von historischer Generationenzugehörigkeit entdeckt werden, die ebenfalls erklärungsbedürftig ist beziehungsweise ihre spezifische ,Entstehungsgeschichte' hat. Daher möchte ich im Anschluss, auch jenseits der Biographieforschung, die Frage nach graduellen Phänomenen von Generationszusammenhängen und -einheiten aufwerfen, in denen sich Generationen nur in Ansätzen ausbilden (2.8). Genauer gehe ich auf sogenannte Zwischengenerationen, auch ,stille ${ }^{6}$ oder ,verlorene' Generationen genannt, ein, die in der Generationenforschung bisher wenig Beachtung gefunden haben. In einem Resümee (2.9) führe ich dann die in diesem Kapitel diskutierten theoretischen Perspektiven zu einer figurationssoziologischen und biographietheoretischen Erforschung der Bildungsprozesse historischer Generationen zusammen. 


\subsection{Mannheims Generationskonzept und dessen Rezeption in der (rekonstruktiven) Sozialforschung}

Mit seinem Aufsatz „Das Problem der Generationen“ legte Karl Mannheim 1928 eine Abhandlung vor, die zu den kanonischen Texten einer soziologischen, aber auch historischen und kulturwissenschaftlichen Generationenforschung zählt. Mannheims richtungsweisendes und auch in aktuellen Forschungsarbeiten häufig zitiertes Generationskonzept möchte ich im Folgenden explizieren. In seinem Aufsatz „Das Problem der Generationen“ sortiert und integriert Mannheim verschiedene zeitgenössische Debatten zur Generationenfrage. ${ }^{10}$ Er diskutiert und gewichtet die Beiträge einer positivistischen, eher französischen und auf ,Gesetze zielenden (Mentré) und einer ,romantisch-deutschen' Generationenforschung (Dilthey, Pinder). Mannheim versucht in der Aufnahme dieser ,Diskursstränge“ eine eher „formalsoziologische“ (1964: 524), also eine auch begriffliche und strukturelle Bestimmung des Generationenphänomens. Zentraler Bestandteil dieser begrifflichen Bestimmung - Mannheim spricht selbst nicht von historischen Generationen ${ }^{11}$ - ist seine Unterscheidung von Generationslagerung, Generationszusammenhang und Generationseinheit. Die Generationslagerung lehnt Mannheim an das Marx’sche Konzept der „Klasse an sich“ an. Während jedoch die ,Lagerung' von Klassen sich aus dem ökonomischen Gefüge einer Gesellschaft ergebe, bestimme sich die Generationslagerung durch „Naturgegebenheit“ (ebd.: 529). Letztere umfasse etwa Geburt und Tod und somit einen Austausch der Gesellschaftsmitglieder und das Erleben immer nur bestimmter historischer Abschnitte. In einer geteilten Lagerung befänden sich diejenigen Gesellschaftsmitglieder, die „im selben historisch-sozialen Raume - in derselben historischen Lebensgemeinschaft - zur selben Zeit" positioniert seien (ebd.: 542). Die Generationslagerung ist damit in der Mannheim'schen Begriffstrias derjenige Begriff, der noch am ehesten dem der Kohorte entspricht. Auf der Basis von geteilten Generationslagerungen können sich Generationszusammenhänge formieren:

„Während verwandte Generationslagerung nur etwas Potentielles ist, konstituiert sich ein Generationszusammenhang durch eine Partizipation der derselben Generationslagerung angehörenden Individuen am gemeinsamen

\footnotetext{
${ }^{10}$ Vgl. auch Laube 2004: 470.

${ }^{11}$ In nachvollziehbarer Weise grenzt Eckart Liebau Mannheims Generationskonzept als historischsoziologischen Generationenbegriff gegenüber einem genealogisch-familiensoziologischen und einem pädagogischen Generationenbegriff ab (1997: insb. 21 ff.). Unter Bezugnahme auf Mannheim findet außerdem der Begriff der politischen Generation häufige Verwendung (zum Beispiel Rintala 1968; Fogt 1982; Kohli 2000: 8; Herbert 2003). In dieser Arbeit nutze ich, sofern ich nicht spezifischer auf die Terminologie Mannheims, der Figurationssoziologie oder der sozialkonstruktivistischen Biographieforschung zurückgreife, den Begriff der historischen Generation, da er eine an Mannheim anschließende Generationenforschung aufruft, aber eine empirisch schwierig nachzuzeichnende Unterteilung von Generationen in politische, kulturelle usw. vermeidet (vgl. Rosenthal 2000: 162).
} 
Schicksal und den dazugehörenden, irgendwie zusammenhängenden Gehalten" (ebd.: 547).

Worin besteht dieses ,gemeinsame Schicksal'? Mannheim parallelisiert Generationszusammenhänge auch mit dem Begriff des „Zeitgeistes“ (ebd.: 558), welchen er allerdings als „dynamisches Spannungsverhältnis“ (ebd.) fasst. Generationszusammenhänge könnte man auch als ,dasjenige, worin sich bekämpft wird', paraphrasieren - eine stark relationale Begriffskonzeption, die klarer wird, wenn man den Begriff der Generationseinheit hinzunimmt. Generationseinheiten sind nach Mannheim „diejenigen Gruppen, die innerhalb desselben Generationszusammenhanges in jeweils verschiedener Weise diese Erlebnisse verarbeiten“ (ebd.: 544). Generationseinheiten wirken ,viel konkreter verbindend“ auf ihre Mitglieder als der Generationszusammenhang (ebd.: 547). Innerhalb eines Generationszusammenhangs können sich „mehrere, polar sich bekämpfende Generationseinheiten bilden“ (ebd.: 547). Mannheim spricht davon, dass sie „aufeinander, wenn auch kämpfend, abgestimmt sind, [und so] einen ,Zusammenhang“ bilden“ (ebd.). Mannheim deutet zudem an, dass die Einheiten nur in Kenntnis der Stellung zueinander - also in ihrem Verhältnis - verstanden und erklärt werden können (ebd.: 558). Als Beispiel für sich bekämpfende Generationseinheiten nennt Mannheim die konservativen und liberalen Jugendgruppen zu Beginn des 19. Jahrhunderts (ebd.: 548). Die Mitglieder einer Generationseinheit verbinde untereinander die „Verwandtschaft der Gehalte, die das Bewusstsein der einzelnen erfüllen“ (ebd.: 544), ohne dass diese dafür in direkten (face-to-face) Beziehungen interagieren müssten. Mannheim fasst diese verbindenden ,Gehalte ${ }^{6}$ auch als spezifische „Erlebnisschichtung“ (ebd.: 536; 548) oder als „Art der Bewusstseinsschichtung“ (ebd.: 536) der Generationen, die er unter Hinzunahme von in der zeitgenössischen Psychologie diskutierten gestalttheoretischen Überlegungen bestimmt. ${ }^{12}$

Für Mannheim waren die gestalttheoretischen Überlegungen zentral, weil sie die unterschiedliche, Wirkung' von ,gleichen` Erlebnissen auf Zeitgenoss*innen, die jedoch unterschiedlichen Generationen angehören, erklären können: Hinzutretende oder ,fehlende ${ }^{6}$ Erfahrungen haben in gestalttheoretischer Perspektive Folgen für die Bedeutung der anderen, in der Erlebnisschichtung organisierten Erfahrungen. Die Erfahrungen sind nicht bloß „durch Summation“ (ebd.: 537) verbunden, sondern bilden zusammen integrierte Ganzheiten - Gestalten -, die die ein-

\footnotetext{
12 Mit Mannheims Worten: „die moderne Psychologie stellt mit immer größerer Bestimmtheit fest, daß schon das menschliche Wahrnehmen, gestalthaft" orientiert ist" (ebd.: 545). Mannheim macht keine weiteren Quellenbezüge, es ist jedoch ausgesprochen naheliegend, dass er hier an die ,Berliner Schule' der Gestalttheorie mit Max Wertheimer, Wolfgang Köhler und Kurt Koffka und anderen, die ab Beginn der 1920er Jahre zusammenfand, anknüpft. Diese allgemeinen Bezüge macht Mannheim im Rahmen der Diskussion der ,einheitsstiftenden Faktoren“ von Generationen (ebd.: 545547), sie werden aber auch in impliziter Weise in den Abschnitten zur Erlebnisschichtung (ebd.: 536) und dem „natürlichen Weltbild“, in welchem er betont, dass „gesammelte Erlebnisse“ sich nicht „durch Summation“, sondern ,dialektisch“ akkumulieren (ebd.: 537), deutlich.
} 
zelnen Erfahrungen in ihrer Bedeutung bestimmen. Das heißt, die Mitglieder historischer Generationen werden verbunden oder getrennt durch das gemeinsame beziehungsweise unterschiedliche Gestalterleben (Mannheim ist hier nicht ganz eindeutig, ob er den gemeinsamen Gestaltcharakter des Erlebens und Handelns in der Generationseinheit, bereits im Generationszusammenhang oder erst in beiden gegeben sieht). Er bindet das Gestalterleben explizit nicht (nur) an das Individuum, sondern an die jeweilige (Generationen-)Gruppe: „Hineinwachsen in eine Gruppe bedeutet [...] die seelisch-geistigen Gehalte in jener Gestalt [zu] erfassen, in der sie für die Gruppe präsent sind“ (ebd.: 546). Auf den Gestaltcharakter von Erleben und generell von sozialen Abläufen, der auch in der soziologischen Biographieforschung diskutiert und weiterentwickelt wurde, werde ich in Abschnitt 3.7. erneut zu sprechen kommen.

Allerdings bilden sich, dies betont Mannheim, nicht zu jeder Lagerung Generationszusammenhänge und -einheiten aus (ebd.: 500). Mannheim macht im ,Generationsaufsatz' einige Anmerkungen zum Entstehungsprozess von Generationszusammenhängen und -einheiten und konzediert auch die Möglichkeit von lediglich Andeutungen oder Ansätzen - Mannheim spricht von „Keimen“ (ebd.: 551) oder „Generationsimpulse[n]“ (ebd.: 552), die auch „verdeckt“ werden können. Interessant sind zunächst Mannheims Ausführungen zum Zusammenhang von konkreten Gruppen und der Entstehung generationaler Deutungsmuster. Mannheim spricht davon, dass in einer Generationseinheit die ,generationsmäßigen Grundintentionen zumeist nicht freischwebend, ohne persönlichen Kontakt, sondern in konkreten Gruppen [...] sich herausstellen“ (ebd.: 547). Die „Grundintentionen" der Generationseinheit würden sich in konkreten Gruppen konstituieren, würden dann aber

„,auch über die über die konkrete Gruppe hinaus eine werbende und verbindende Gewalt besitzen, [dies] liegt der Hauptsache nach daran, dass sie mehr oder minder adäquater Ausdruck der betreffenden Generationslagerung sind, dass also auch außerhalb dieser Gruppe lebende, aber in verwandter Lagerung sich befindende Individuen in ihnen den ihrer Lagerung im historischen Raume entsprechenden Ausdruck finden“ (ebd.: 548).

So würde man dann der ,neuartigen ,Erlebnis-Schichtung ${ }^{6}$ [...] Ausdruck verleihen“" (ebd.). Das heißt, die in konkreten Interaktionszusammenhängen ausgehandelten, gestalthaften, generationalen Erfahrungsbestände und Deutungsmuster werden also, aufgrund einer erlebten ,Passung ${ }^{6}$ zum kollektivgeschichtlichen Kontext und der Position in diesem, auch außerhalb der konkreten Gruppe aufgegriffen und so zu den charakterisierenden Orientierungen einer Generationseinheit. Mannheim unterscheidet ferner verschiedene Integrations- und Reflexionsniveaus von Generationseinheiten: Jene, in denen das Mitglied „unbewusst“ im Sinne der Generationseinheit handelt und ,nur intuitiv von einer Zusammengehörigkeit weiß, diese aber noch nicht als Generationseinheit ins Bewusstsein hebt“, und 
jene, „wo die Generationseinheit als solche bewusst gewertet und gepflegt wird“ (ebd.: 550). Nur im letzten Fall dürften bei den Generationseinheitsmitgliedern explizite generationale Selbstthematisierungen anzutreffen sein.

Außerdem diskutiert Mannheim in Grundzügen, welche Bedingungen für die Formierung von Generationszusammenhängen und -einheiten - er nimmt im Textverlauf zunehmend den Begriff der Entelechie Wilhelm Pinders auf - förderlich oder hinderlich sind. Solche Bedingungen wären etwa die Folgen gesellschaftlicher Umbrüche, schnellen oder langsamen sozialen Wandels (ebd.: 551), das Vorhandensein ,kristallisierender Kollektivereignisse (ebd.: 552) oder „fluktuierender Formen der Vergesellschaftung" wie Salons und Kaffeehäuser (ebd.: 565). In Phasen, in denen es nicht zur Entfaltung von Generationszusammenhängen und -einheiten kommt, können aber von Mannheim so genannte Zwischengenerationen auftreten. Diese von Mannheim angedeuteten graduellen Phänomene von historischen Generationen werde ich in Abschnitt 2.9 ausführlicher aufgreifen.

Während Mannheims Generationskonzept auch in aktuellen Forschungsarbeiten häufig zitiert und meist auch seine analytische Trennung von Generationslagerung, Generationszusammenhang und Generationseinheit vorgestellt wird, werden Forschungsergebnisse eher selten unter expliziter Nutzung der Mannheim'schen Begriffstrias diskutiert. Dies mag auch daran liegen, dass, wie Kurt Wolff konstatiert, der Generationsaufsatz „in seinen Definitionen klarer sein“ (1964: 154) könnte. ${ }^{13}$ Wiederholt ist zudem der ,Bias' von Mannheims Generationskonzept in Richtung männlicher, bürgerlicher Jugendgruppen kritisiert worden (vgl. Benninghaus 2005) - allerdings ist dies womöglich eher eine mit der empirischen Blickrichtung als mit dem konzeptionellen Entwurf verbundene Problematik.

Einige in den letzten Jahren in der sozialwissenschaftlichen und geschichtswissenschaftlichen Forschung an Popularität gewinnende Perspektiven auf historische Generationen beschäftigen sich mit historischen Generationen mittels eines Fokus auf die Zirkulation und Durchsetzung generationaler Deutungsschemata also der manifesten Deutung, jemand, gehöre zu einer Generation. Diese Arbeiten setzen sich etwas von Mannheim ab. Je nach Schwerpunkt der Konzeptbildung werden historische Generationen $\mathrm{zu}$ Generationendiskursen (Aboim/Vasconcelos 2014), zu Generationen als Generationalismus oder Narrativ (White 2013), zu „Generation Doing“ (Bohnenkamp 2011) oder zu ,imagined communities"14 (Roseman 2005) gewendet. In dieser Diskussion tritt die bei Mannheim angelegte Frage der unterschiedlichen ,Erlebnisschichtungen', die ja seiner Auffassung nach auch nur implizit zum Ausdruck kommen können, in den Hintergrund. In der Konzentration auf die Zirkulation generationaler Deutungsschemata wird also eher die diskursive Ebene als die Ebene der Erfahrungsbil-

\footnotetext{
${ }^{13}$ So werden etwa die von Mannheim im Generationsaufsatz unternommenen Begriffsdefinitionen im ersten Textteil selbst nicht in Übereinstimmung mit den im zweiten Textteil definierten Begriffsinhalten zur Anwendung gebracht.

${ }^{14}$ Ein Bezug auf Benedict Andersons Charakterisierung der Nation (1983).
} 
dung betrachtet. Die Entstehung und Zirkulation von generationalen Wir-Bildern kann sicher zur Integration von Generationengruppen beitragen. Aber bei einer starken Konzentration auf die Zirkulationsebene generationaler Wir-Bilder besteht meines Erachtens auch die Gefahr für eine Betrachtung historischer Generationen im Sinne Karl Mannheims zu kurz zu greifen. Im Anschluss an Mannheim sind schließlich auch die Erfahrungsbildung (Erlebnisschichtung) und die mit der Erfahrungsbildung verbundenen, in ihrem Ausmaß jeweils differierenden Vergemeinschaftungs- und Integrationsprozesse für die Definition einer historischen Generation von Bedeutung. ${ }^{15}$

Das Generationskonzept Mannheims ist, trotz dessen Popularität, in den Sozialwissenschaften selten vor dem Hintergrund seiner anderen Arbeiten, seiner Wissens- und Kultursoziologie, interpretiert worden. Wenn das Generationskonzept überhaupt in Beziehung zu seinen anderen Schriften gesetzt wurde, dann eher zu seinen erstmals 1980 in „Strukturen des Denkens“ posthum von David Kettler, Volker Meja und Nico Stehr veröffentlichten Arbeiten. Eine ausführliche Rezeption der in „Strukturen des Denkens“ enthaltenen Schriften „Über die Eigenart kultursoziologischer Erkenntnis“ und „Eine soziologische Kultur und ihrer Erkennbarkeit" haben in der interpretativen beziehungsweise rekonstruktiven Sozialforschung Joachim Matthes (1985a) sowie insbesondere Ralf Bohnsack im Rahmen der Entwicklung der Dokumentarischen Methode (Bohnsack/NentwigGesemann/Nohl 2001) und einer Praxeologischen Wissenssoziologie (Bohnsack 2017) unternommen. Die Arbeiten in „Strukturen des Denkens“ wurden 1922 und vermutlich $1924^{16}$ von Mannheim angefertigt, von ihm jedoch nie zur Veröffentlichung freigegeben. Im Folgenden möchte ich auf ihre Rezeption kurz eingehen.

In seinem einschlägigen Aufsatz „Karl Mannheims ,Das Problem der Generationen', neu gelesen“" (1985a) interpretiert Joachim Matthes das Mannheim'sche Generationskonzept vor dem Hintergrund dieser 1980 herausgegebenen Schriften Mannheims. Matthes kommt zu der Einschätzung, dass Mannheim im Generationsaufsatz hinter diese frühen Schriften ,zurückfalle', weil er auf eine „genauere Bestimmung des ,konjunktiven Erfahrungsraums', jener ,perspektivischen' Welt der Verbegrifflichung, in der von Menschen existentiell geteilte Wahrnehmungen und Erfahrungen als solche generationeller Art auf für die Beteiligten (konjunktiv) gültige Bezeichnungen gebracht werden" (1985a: 365), verzichte. Statt sich von der formalsoziologischen begrifflichen Seite und der Seite zeitgenössischer wissenschaftlicher Debatten her zu nähern, hätte Mannheim der Frage nachgehen sollen, in welchen sozialen Beziehungen „im Bemühen um Selbstverortung,

\footnotetext{
15 Auch Monika Wohlrab-Sahr spricht in diesem Zusammenhang davon, dass bei Mannheim gerade die Auseinandersetzung mit „Erfahrungsgemeinschaften“ (2015: 13) vorbereitet sei. In diesen würden sich Personen ,unter Bezugnahme auf geteilte Erfahrungen und Sinndeutungen schlicht ,verstehen" und damit als zusammengehörig empfinden" (ebd.).

${ }^{16}$ Den wahrscheinlichen Entstehungszeitraum diskutieren Kettler/Meja/Stehr 1980: 19.
} 
Selbst-Bestimmung und Selbst-Verständigung“ (ebd.) generationale Selbst- und Fremdthematisierung entstehen und genutzt werden. Generationsbezogene Bedeutungskonstruktionen der Gesellschaftsmitglieder seien dabei auch in ihrer ,Leistung ${ }^{6}$ zu interpretieren, „,chronologisch gegeneinander versetzte Muster von Weltwahrnehmung wechselseitig identifizierbar [...] zurechenbar und ,verhandlungsfähig' zu machen" (ebd.: 369). Mannheim, mit seiner im Gruppenhaften verhaftet bleibenden Interpretation von Generationen, übersehe dies: „Nicht um ,Generationen“ als wie auch immer gestaltete und bestimmbare Gruppen geht es, sondern um generationelle Verhältnisse, in denen sich die Zeitlichkeitsstruktur des gesellschaftlichen Geschehens ,polyphon organisiert"“ (ebd.: 369). Matthes kritische Diskussion des Mannheim'schen Generationsaufsatzes gibt den wertvollen Hinweis, dass es zur Erforschung von Generationen einerseits des Blickes auf Generationenverhältnisse bedarf und es andererseits darauf ankommt, in Generationenverhältnisse die gesellschaftlich, vorliegenden' generationsbezogenen Bedeutungskonstruktionen zu rekonstruieren.

Die Anregung Matthes', Mannheims Generationskonzept vor dem Hintergrund seiner in den „Strukturen des Denkens“ veröffentlichten Schriften zu interpretieren, ist dezidiert von Ralf Bohnsack aufgenommen worden. Bohnsack und seine Kolleg*innen haben Mannheims Wissenssoziologie in Richtung der Dokumentarischen Methode und später einer Praxeologischen Wissenssoziologie (2017) weiterentwickelt. ${ }^{17}$ Für die Vertreter*innen der Dokumentarischen Methode liegt der Schlüssel für das Verständnis des Mannheim'schen Generationsaufsatzes in dem in „Strukturen des Denkens“ entfalteten Konzept des konjunktiven Erfahrungsraumes (Bohnsack/Schäffer 2002: 250). Dieses Konzept sei „die unabdingbare wissenssoziologische Fundierung seines Generationsaufsatzes" (ebd.) und kläre auch den von Mannheim ebendort herangezogenen Begriff der „Erlebnisschichtung“ (ebd.: 253). Der konjunktive Erfahrungsraum bildet in der Auffassung Bohnsacks eine besonders fundamentale, vorreflexive Dimension von Sozialität: „Unter denjenigen, die über (biographisch, also sozialisationsgeschichtlich bedingte) Gemeinsamkeiten hinsichtlich einer in selbstgelebter Praxis angeeigneter Erinnerung verfügen, also unter denjenigen, die über Gemeinsamkeiten der Erlebnisschichtung verfügen", sei ein unmittelbares, also konjunktives Verstehen möglich (ebd.: 253) - eben diejenigen bilden dann einen konjunktiven Erfahrungsraum (ebd.: 254). Die konjunktive Erfahrung sei praxisgebunden und atheoretisch, das heißt vorreflexiv oder implizit (ebd.). Um eine konjunktive Erfahrungsebene zu teilen, müsse man sich jedoch nicht kennen - gemeinsam' meint hier ,strukturident' (Bohnsack 1998: 113). Zwischen denjenigen, die diese Ebene nicht teilen, bestehe eine „durch Begrifflichkeiten vermittelte“ (Bohnsack/Schäffer 2002: 253) Kommunikation, sie würden einander nicht unmittelbar verstehen, sondern einander interpretieren (ebd.). Die Phänomenologische Soziologie im Anschluss an

${ }^{17} \mathrm{Zu}$ der Verbindung von Bourdieu und Mannheims Generationskonzept vgl. Eyerman/Turner 1998. 
Alfred Schütz und die Ethnomethodologie beschäftigt sich laut Bohnsack eher mit dem Bereich der kommunikativen Verständigung, ihnen fehle ein Modell konjunktiven Verstehens, wie es Mannheim vorgelegt habe (Bohnsack 1998: 113). Generationsmitglieder bilden aber einen solchen konjunktiven Erfahrungsraum. Generationen würden sich zwar auch in Generationenverhältnissen und in kommunikativer Abgrenzung zu anderen Generationen bilden, vorwiegend aber teilen sie eine konjunktive Erfahrungsebene (Bohnsack/Schäffer 2002: 255).

Bezogen auf das Mannheim'sche Generationskonzept lässt sich festhalten, dass die Vertreter*innen der Dokumentarischen Methode in der Auseinandersetzung mit Mannheims frühen erkenntnistheoretischen Schriften ein besonderes Gewicht auf die Reflexion einer generationalen Erfahrungsqualität gelegt haben. Meines Erachtens sprechen sie, und in ähnlicher Weise Matthes, mit diesem Fokus auf seine frühen Schriften Mannheim die bei diesem eigentlich angelegte Anschlussfähigkeit für genuin figurationssoziologische Fragen - wie sich Gruppen und Gruppierungen eigentlich bilden und in welchen Machtverhältnissen sie stehen $-\mathrm{ab}$. Denn zumindest in Ansätzen findet sich bei Mannheim durchaus eine Beschäftigung mit solchen Fragen, unter anderem in seiner Arbeit zum Konservatismus. Ich möchte im folgenden Kapitelabschnitt den Generationsaufsatz Mannheims in den Kontext dieser ,späteren“ wissenssoziologischen Schriften aus Mannheims ,deutscher Phase' rücken. Dies ist nicht der Ort, um eine umfassende Diskussion des komplexen wissenssoziologischen Programms Karl Mannheims vorzunehmen. Allerdings soll dieser Exkurs Hinweise auf eine Lesart des Generationskonzepts geben, die in dessen soziologischer Rezeption bisher wenig beachtet wurde: eine in der theoretischen Nähe von Karl Mannheim und Norbert Elias begründete, mögliche figurationssoziologische Akzentuierung des Mannheim'schen Generationskonzeptes.

\subsection{Mannheims Generationskonzept im Kontext seines wissenssoziologischen Programms}

Die Publikation des Generationsaufsatzes liegt zeitlich zwischen der Einreichung von Mannheims Habilitation über „Altkonservatismus“ im Jahr 192518, der Anfertigung seiner Schrift „Das Problem einer Soziologie des Wissens“ im selben Jahr und seinem Vortrag „Die Bedeutung der Konkurrenz im Gebiete des Geistigen“ 1928 auf dem deutschen Soziologentag in Zürich. Kurt Wolff spricht auch von einer „Wendung Mannheims zur Soziologie“ in diesen Arbeiten (1978: 301; 296). In seiner Schrift „Das Problem einer Soziologie des Wissens“ (1925) entwirft Mannheim Ansätze seiner Wissenssoziologie, in Auseinandersetzung mit, unter

\footnotetext{
${ }^{18}$ Ich zitiere aus einem 1964 erschienen Abdruck der 1927 veröffentlichten Kurzfassung. Zu den Differenzen zwischen der längeren Version der Habilitation und der Kurzfassung vgl. Kettler/ Meja/Stehr 1984.
} 
anderem, dem zeitgenössischen Positivismus, den Arbeiten Schelers sowie dem Historismus, vorwiegend Wilhelm Diltheys. Die Aufgabe der Wissenssoziologie, sofern sie über eine nur ideengeschichtliche Arbeit hinausgehen soll, sieht Mannheim insbesondere darin, ,nachzuweisen, ob denn zwischen den immanent herausgearbeiteten Denkstandorten und den sozialen Strömungen (sozialen Standorten) eine Korrelation, eine Entsprechung besteht“ (Mannheim 1964: 375). Die eigentliche soziologische Aufgabe bestehe darin, zu fragen, „welche sozialen Schichten jeweils hinter den geistigen Schichten stehen“ (1964: 385). Durch die von Mannheim in der Folge unternommene Diskussion dieser ,Korrelation“ ziehen sich - nicht nur in dieser Schrift - Absetzbewegungen Mannheims von marxistischen Kategorien wie Basis-Überbau, Klassenantagonismus und (ökonomischer) Interessenbegriff. Er versucht durch die Einführung des Begriffs einer geistigen Schicht zu einer komplexeren Bestimmung der sozialen und geistigen Standorte zu kommen, die auch stärker die Wechselwirkung zwischen beiden in den Blick nimmt.

Die Verbindungen zwischen geistigen und sozialen Standorten, von Mannheim auch „Funktionalitätsbeziehungen“ (1964: 378) ${ }^{19}$ genannt, fasst er etwa über das (ökonomische) ,Interesse ${ }^{6}$ hinausgehend in die ,breitere' Kategorie des „Engagiertsein[s]“ (1964: 378). In späteren Arbeiten ${ }^{20}$ versucht Mannheim die Korrelation von geistigen und sozialen Standorten auch mit dem Begriff des ,seinsverbundenen Denkens“ (Mannheim 1952: 227) im Sinne eines „etwaigen Hineinragens der sozialen Prozesse in das ,Geistige“، (1952: 230) zu fassen. In seinem Vortrag von 1928 nennt Mannheim Konkurrenzbeziehungen als Beispiel für solche sozialen Prozesse. Dort bezeichnet er das ,seinsverbundene Denken“ (2009 [1928]: 87), welches gerade auch geistes- und sozialwissenschaftliche Wissensbestände umfasse, als ,eingebettet und getragen vom Macht- und Geltungstrieb konkreter Gruppen“ (ebd.: 90). An anderer Stelle formuliert Mannheim ähnlich: „Die Weltauslegung ist zumeist Korrelat der Machtkämpfe einzelner Gruppen“ (ebd.: 91; vgl. 1952: 232).

Führt man sich diese Anlage der Mannheim'schen Wissenssoziologie - unter anderem mit ihrem Fokus auf die Wechselwirkung von geistigen und sozialen Standorten sowie auf Machtkämpfe von Gruppen in sozialen Prozessen - vor Augen, liegt der Gedanke an sowohl die Deutungs- und Machtkämpfe von Generationseinheiten aus dem Generationsaufsatz als auch die unten ausführlich vorgestellte figurationssoziologische Perspektive Norbert Elias' recht nahe. Auch ein Blick auf Mannheims umfassendste empirische Umsetzung seines wissenssoziologischen Programms - seine Habilitationsschrift „Das konservative Denken“ von

\footnotetext{
${ }^{19}$ Mannheim spricht in anderen Arbeiten relativ synonym von Entsprechung, Funktion, Wechselwirkung (vgl. Wolff 1978: 292).

${ }^{20}$ Der Aufsatz ist in die dritten Auflage von „Ideologie und Utopie“ integriert worden, ich zitiere nach dieser Auflage. Auf die unter anderem in diesem Aufsatz deutlich werdende Verbindung von Generationskonzept und Wissenssoziologie hat auch Kurt Wolff hingewiesen (1964: 53).
} 
1925 - stützt diese Lesart und macht die hier vorgestellten Gedankengänge greifbarer. Was er mit der Untersuchung des konservativen Denkstils anstrebt, umreißt Mannheim folgendermaßen:

„Die spezifische Morphologie dieses Denkstils zu bestimmen, seine historischen und sozialen Wurzeln zu rekonstruieren, den Gestaltwandel dieses Denkstils in Verbindung mit den sozialen Schicksalen der tragenden Gruppen zu verfolgen [...] bildet die Aufgabenkette einer darauf ausgerichteten wissenssoziologischen Fragestellung“" (1964: 408).

Die Zielsetzung, ,das konservative Denken“ auch mit Hilfe der „,sozialen Schicksale der tragenden Gruppen“ (ebd.) zu analysieren, setzt Mannheim mit einer Betrachtung des „romantisch-ständischen Denkstandortes“ (ebd.: 447) in Preußen Anfang und Mitte des 19. Jahrhunderts in einem ,Zeitquerschnitte“ (ebd.: 447) als eine ,Spielart' konservativer Denkstandorte um. Das Preußen dieser Zeit sei von einer „partiellen Auflockerung des Bündnisses zwischen Adel und Bürokratie bestimmt" (ebd.: 451). Während in dieser historischen Phase in Preußen, im Vergleich zu Frankreich, bürgerliche Gruppierungen kaum formiert seien (ebd.: 449 f.) - in noch stärkerem Maße gelte dies für proletarische Schichten - liege das Spannungsverhältnis im Zuge kapitalistischer Transformationen eher zwischen Adel und Bürokratie beziehungsweise Königtum:

„Der buerokratisch-absolutistische Staat, getragen vom Beamtentum, setzt Reformen durch, die im Interesse des kapitalistisch werdenden Staates notwendig sind; er setzt sie nur zum Teil durch im Interesse des niederen Volkes, zugleich aber auch bis zu einem gewissen Grade gegen den Adel und dessen Positionen“" (ebd.: 451).

Zum Spannungsverhältnis von Adel und Bürokratie trete eine gewisse Allianzbildung zwischen Adel und ,freischwebenden Intellektuellen“21 (ebd.: 454), insbesondere bürgerlichen Schriftstellern, hinzu, die im Zuge des Bündnisses teilweise zu „Rechtfertigungsdenkern“ (ebd.: 457) werden. Mannheim diskutiert die geistigen und sozialen Grundlagen, ${ }^{22}$ aufgrund derer dieses Bündnis möglich wird, und erörtert ausführlich, inwiefern ältere oder aus anderen geographischen Kontexten kommende Denkstile dabei aufgenommen und transformiert werden: „Die ideo-

\footnotetext{
${ }^{21}$ Mannheim greift hier bereits diesen Begriff auf, der insbesondere aufgrund späterer Arbeiten zur „freischwebenden Intelligenz" mit ihm verbunden wird; er selbst führt den Begriff hier auf Alfred Weber zurück.

22 Mannheim streift hier verschiedene Aspekte, die die relative Gruppenstellung der Kleinbürger, insbesondere das mit der Aufklärung konfrontierte ,protestantische Pfarrhaus' (ebd.: 455), und deren Spannungsbalance mit dem Adel betreffen. In Preußen sei das Spannungsniveau zwischen Adel und Bürgertum und die damit verbundene Integration des Bürgertums noch relativ gering gewesen (ebd.: 449 f.). Die bürgerlichen Romantiker hätten die ,richtige' Distanz zum Adel für die geistige Auseinandersetzung mit diesem gehabt (ebd.: 470 f.). Mannheim führt dafür die Relevanz des Aufstiegs ,zum Adel hin' für die „Wunschträume“ der bürgerlichen Romantiker und die damit verbundene „Apologie des Mittelalters“ im romantisch-ständischen Denken an (ebd.: 471).
} 
logische Reaktion auf die Aufklärung verbindet sich mit der sozialen Reaktion des Adels: die Romantik wird ständisch, und das altständische Denken wird romantisch" (ebd.: 451). ${ }^{23}$

Zusammenfassend kann man sagen, die ,geistigen Gehalte' der Romantik werden von Mannheim bezogen auf eine Verschiebung der Gruppierungskonstellation von Adel, Beamtentum und bürgerlichen, romantischen Intellektuellen in Preußen im Verlauf der ersten Hälfte des 19. Jahrhunderts und damit gerade aus dem Verbältnis von bestimmten Gruppierungen zu anderen Gruppierungen bestimmt. Bestandteil der von Mannheim vorgenommenen wissenssoziologischen Analyse ist hier, so kann man wohl formulieren, zumindest in Ansätzen die Analyse eines gesellschaftlichen Gruppierungsgeflechts über eine längere historische Periode. Mannheim ist zwar vorgeworfen worden - und dies wohl nicht ganz zu Unrecht -, dass er in seiner Habilitationsschrift die Analyse des kollektivgeschichtlichen Kontexts, in welchem romantisch-ständisches Denken steht, gegenüber der Darstellung der romantisch-ständischen Wissensbestände vernachlässigt habe und seine Befunde daher eigentlich „den Ansprüchen einer schichtspezifischen Zurechnung nicht genügen" (Hofmann 1996: 81). Dies ist ein Vorwurf, der Mannheims Arbeiten auch an anderer Stelle treffen mag (vgl. Barboza 2009: 67 f.). Allerdings wird meiner Ansicht nach dennoch gerade in dieser von Mannheim als Teil der wissenssoziologischen Perspektive geforderten „soziologischen Analyse“ eine Verwandtschaft mit der von Norbert Elias vertretenen figurationssoziologischen Perspektive erkennbar, die ja gerade die sich verändernden machtasymmetrischen Relationen zwischen Gruppen und Gruppierungen und deren nicht intendierte Konsequenzen über einen längeren Zeitabschnitt in den Blick nimmt. ${ }^{24}$ Diese Verwandtschaft kommt unter anderem im Verstehen und Erklären von geistigen Gehalten in der Wechselwirkung mit tragenden Gruppierungen und insbesondere aus der Stellung zu anderen Gruppierungen, im Denken in Prozessen und Relationen sowie im Nachzeichnen historischer Abläufe, aber etwa auch im Konzept des ,Engagiertseins“ zum Ausdruck. In noch etwas allgemeinerer Weise hat Richard Kilminster die ansonsten wenig beachtete Nähe von Mannheim und Elias herausgearbeitet (1993; 2007). Er sieht grundlegende Parallelen in den Wer-

\footnotetext{
${ }^{23}$ Diese Verbindung ist nach Mannheims Urteil vornehmlich in den Schriften Adam Müllers zur Entfaltung gebracht (ebd.: 483).

${ }^{24}$ Karl Mannheim und Norbert Elias waren einander in den 1920er und 1930er Jahren beruflich und freundschaftlich verbunden (Kilminster 1993: 82 f.). Beide waren in ihrer ,Heidelberger Zeit ${ }^{\star}$ Mitte der 1920er Jahre in Austausch getreten. Mannheim war in Heidelberg Privatdozent gewesen, Elias war 1925 (wieder) nach Heidelberg gekommen und war bei Alfred Weber als Habilitant angenommen worden. Elias folgte dann aber Mannheim nach Frankfurt, der an das Institut für Sozialforschung berufen worden war. Dort war Elias von 1930 bis 1933 einer der Assistenten Mannheims. Mannheim und Elias hatten die gemeinsame Betreuung mehrerer Promotionsarbeiten begonnen, unter anderen von Nina Rubinstein und Kurt Wolff, die aber aufgrund der Machtübernahme der Nationalsozialisten und der Flucht ins Exil überwiegend nicht abgeschlossen werden konnten (Ilieva 2010: 126 ff.).
} 
ken Mannheims und Elias und hebt unter anderem gerade die Überschneidungen im relationalen Denken hervor (1993: 88 ff.; vgl. zu diesem Punkt auch Rehberg 1979: 147). Insgesamt entdeckt Kilminster gerade in Mannheims Texten von 1925 bis 1933 erhebliche Konvergenzen zwischen Elias' Werk und der Mannheim'schen Wissenssoziologie (Kilminster 1993: 86).

Welche Bedeutung hat der hier entfaltete wissenssoziologische Kontext nun für Mannheims Generationskonzept? Mannheim sortiert sein Generationskonzept selbst in sein wissenssoziologisches Programm ein. In dem oben bereits zitierten resümierenden Aufsatz über, Wissenssoziologie' schreibt er, dass die Generationslagerung eine der vielen Kollektiveinheiten sei, „aus denen Spannungen zwischen verschiedenen Weltauslegungs- und Wissensarten hervorgehen können“ (Mannheim 1952: 232). ${ }^{25}$ Man denke an dieser Stelle auch an die oben ausgeführte Konzeption sich bekämpfender und auf diese Weise verbundener Generationseinheiten. ${ }^{26}$ Den Generationsaufsatz durchzieht meines Erachtens auch an anderer Stelle die noch etwas allgemeiner angelegte Frage der Wechselwirkung von ,Denkstandorten' und ,sozialen Standorten' - auch wenn dies nicht ganz offensichtlich ist. In einigen Passagen ist dies greifbar, etwa in der Diskussion der, inhärenten Tendenz der Lagerung, dort aber formuliert in den Begriffen der Tradition und der Lagerung. ${ }^{27}$ Liest man nun Mannheims Generationskonzept vor dem Hintergrund der in diesem Exkurs gegebenen Hinweise auf seine späteren wissenssoziologischen Schriften, so bedarf es einer Analyse der generationalen Erlebnisschichtungen der Generationszusammenhänge und -einheiten auch vor dem Hintergrund der Verflechtungen und Machtkämpfe von Generationsgruppen (und anderen Gruppen und Gruppierungen) im sozialen (historischen) Prozess. Welcher Gewinn entsteht aus dieser Akzentuierung für die hier vorliegende Forschungsarbeit? Dieser Blick auf Formierungsprozesse historischer Generationen hat sich - in Kombination mit einer biographietheoretischen Perspektive - in meiner Arbeit als sehr hilfreich für das ,Aufschließen“ des in den Kapiteln 6-8 vorgestellten empirischen Materials erwiesen und ist Resultat der Pendelbewegung zwischen Empirie und Theorie (vgl. Kap. 3). Dieser Blick ist

\footnotetext{
${ }^{25}$ Lutz Niethammer meint dagegen: ,im Generationsaufsatz geht es nicht um eine Soziologie des Wissens, sondern des Willens“ (2009: 22).

${ }^{26}$ Auch in seinem Aufsatz zur „Bedeutung der Konkurrenz im Gebiete des Geistigen“ vermerkt Mannheim in den vorangestellten Leitsätzen den „Wettbewerb der Generationen“ (2009: 82), diskutiert dann im Vortrag die Problematik der Konkurrenz aber nicht in direktem Bezug auf Generationenverhältnisse, sondern stellt eher Konkurrenz- und Generationenbeziehung nebeneinander. An dieser Stelle ist ein Abdruck des Aufsatzes von 2009 zitiert, da in der bisher zitierten Ausgabe von Kurt Wolff von 1964 zwar der Aufsatz abgedruckt, die Leitsätze aber nicht mit angegeben sind. ${ }^{27}$ Mannheim weist dort - analog zur Absage an das ,epochenmäßige“ Denken in „,Das Problem einer Soziologie des Wissens“ (1964: 375) - auf die Bedeutung der gesellschaftlichen Gruppenverhältnisse zueinander, auf die Relevanz der „Lagerung der betreffenden Schichten im gesamtsozialen Spielraum“ (529) hin. Im selben Abschnitt betont er - im Grunde als Variante des in „Das Problem einer Soziologie des Wissens“ explizierten „soziologischen Funktionswandels“ (und -verlusts) (ebd.: 384) -, dass ,Traditionen' bei veränderter Lagerung der sozialen Schicht womöglich nicht ,gehalten werden (ebd.: 529).
} 
zudem durchaus in Mannheims späterer ,deutscher ${ }^{6}$ Wissenssoziologie angelegt und, dies soll im folgenden Abschnitt deutlich werden, in der Figurationssoziologie Norbert Elias' mitgeführt und ausdifferenziert.

\subsection{Figurationssoziologie im Anschluss an Norbert Elias}

Im Kern der von Norbert Elias begründeten figurationssoziologischen oder prozesssoziologischen Perspektive steht die Analyse von Wandlungen strukturiertungeplanter, machtdifferenzieller Verflechtungen von Individuen, Gruppen und Gruppierungen - und damit die Analyse der namensgebenden Figurationen. Die zentralen Grundannahmen einer Soziologie im Anschluss an Norbert Elias lassen sich am Begriff der Figuration aufzeigen, welchen Elias in „Was ist Soziologie?“ (1970) eingeführt hat. Elias versucht dort, einer dichotomen Vorstellung von Individuum und Gesellschaft, in der sich beide als einander äußerliche ,Objekte gegenüberstehen, einen konsequent relationalen Begriff entgegenzusetzen (Elias 1970: 139 ff.). Der Begriff der Figuration zielt auf das Verbältnis von sozialen Einheiten zueinander beziehungsweise auf die Netzwerke, die sie bilden. Elias spricht auch von einem „Interdependenzgeflecht" (1977a: LXVIII), in dem Individuen, Gruppen und Organisationen miteinander verbunden und voneinander abhängig sind. Den Figurationsbegriff nutzt Elias für die Fassung von Netzwerken auf ganz unterschiedlichen ,Fallebenen': Sowohl überschaubare Interaktionszusammenhänge wie Schulklassen, Familien oder Wirtshausgäste, aber auch Bewohner*innen einer Stadt oder verschiedene Staaten bilden Figurationen (1970: 143). In einer Figuration sind die miteinander verflochtenen Individuen oder Gruppen in höherem oder geringerem Maße voneinander abhängig. Aus den mehr oder weniger reziproken Abhängigkeiten der Positionen in der Figuration ergibt sich ein je nach Konstellation mehr zu dieser oder zu jener Position neigendes Machtdifferenzial. Elias zufolge sind Figurationen grundsätzlich von einer "Machtbalance“ (1970: 143) gekennzeichnet. Damit legt er, analog zum Figurationsbegriff, auch seinen Machtbegriff als dezidiert relational an.

Figurationen und ihre Machtbalancen sind also keine statischen Gebilde, sondern sowohl die Machtbalancen der Gruppen und Gruppierungen als auch der Charakter ihrer Verflechtungen wandeln sich ständig. ${ }^{28}$ Dabei geht es Elias auch darum, den empirischen Spannungs- und Konfliktcharakter von Verflechtungen und ihrer Dynamik theoretisch zu berücksichtigen (1970: 193):

„Gruppen im Aufstieg suchen ihre Lage zu verbessern im Kampf mit anderen, die ihnen den Aufstieg verwehren; bereits aufgestiegene versuchen das, was sie haben, gegen den Ansturm der neuen Gruppen zu behaupten; wieder andere steigen $\mathrm{ab}$. Inmitten dieses ständigen Auf und $\mathrm{Ab}$ ist es beinahe un-

\footnotetext{
${ }^{28}$ Spannungen und offene Konflikte sind dabei eher im Fall der Verringerung des Machtdifferenzials zu erwarten (Elias 1977c: 130).
} 
vermeidlich, daß die Art und Weise, wie die darin verwickelten Mitglieder solcher Gruppen soziale Geschehnisse erleben, wie sie über sie denken, von der unaufhörlichen Bedrohung ihrer Lebensweise, ihres Lebensstandards und vielleicht sogar ihres Lebens selbst aufs tiefste affiziert sind“ (Elias 1983: 27).

Zwei Aspekte möchte ich anhand dieser ausführlich zitierten Passage diskutieren. Zum einen muss man hier einer intentionalistischen Auffassung dieser Verflechtungen und Positionskämpfe vorbeugen. Auch wenn die Gruppen und Gruppierungen auf eine Verbesserung oder den Erhalt ihrer figurationalen Positionierung zielen mögen, muss dies in keiner Weise das Resultat der Wandlungsrichtung der Figuration sein, vielmehr ist sogar das Gegenteil möglich (1970: 161). Das Positionsspiel und der Charakter der Verflechtungen der Gruppen sowie die Wandlungsrichtung und deren Konsequenzen sind im Ganzen ungeplant und sind häufig von den involvierten Gruppen und Individuen auch unerkannt - dennoch sind sie strukturiert: In seinem Hauptwerk „Der Prozess der Zivilisation“ (1977a; 1977b) zeichnet Elias nach, wie sich im Verlauf der europäischen Geschichte, unter anderem im Zusammenspiel des Kampfes zwischen Adel, Bürgertum und Königen beziehungsweise Zentralgewalten, und aufgrund der immer komplexer werdenden Interdependenzketten der einbezogenen Individuen und Gruppen eine langfristige, von niemandem beabsichtigte, sozio- und psychogenetische Wandlung ergab: Monopolisierungsprozesse, insbesondere die Herausbildung von Gewalt- und Steuermonopolen, und damit Staatsbildungsprozesse auf der soziogenetischen Ebene (1977a; 1977b) und eine Wandlung des ,psychischen Haushalts` der Gesellschaftsmitglieder in Richtung einer allmählichen Umwandlung von Fremd- zu Selbstzwängen, eine Verschiebung von Scham- und Peinlichkeitsgrenzen und eine Tendenz zur Langsicht auf der psychogenetischen Ebene (1977a; 1977b). Der Blick auf sein Hauptwerk verdeutlicht, dass bei Elias, und in der von ihm ausgehenden figurationssoziologischen Tradition, eher zeitlich und räumlich (sehr) weit ausgreifende Wandlungsprozesse von Verflechtungszusammenhängen in den Blick genommen werden. Dennoch diskutiert Elias auch, etwa in seiner Arbeit zu Mozart (1993), biographische, also historisch deutlich kürzere Wandlungsprozesse, die er jedoch streng in Wechselwirkung mit langfristigen Wandlungsprozessen sieht - bereits die Formulierung „Bürgerliche Musiker in der höfischen Gesellschaft" (1993: 17) verweist darauf.

In diesem Zusammenhang möchte ich auf einen zweiten Aspekt der oben ausführlich zitierten Passage zu sprechen kommen: das ,Erleben“ und ,Denken` der in die Verflechtungen involvierten Individuen. Die Bedeutungskonstruktionen der Individuen, ihre Wir- und Sie-Bilder und ihre Wissensbestände stehen mit der eigenen Position in der Figuration und der figurationalen Gesamtdynamik in Wechselwirkung. Die „persönliche Identität“, so formuliert Elias, „bestimmt sich im Zusammenhang mit den ,Wir'- und ,Sie‘-Beziehungen seiner Gruppe und seiner Stellung innerhalb der Einheiten, von denen er ,Wir ${ }^{6}$ und ,Sie ${ }^{6}$ sagt $^{\text {“ }}$ (Elias 1970: 139). Wir-, Selbst- und Sie-Bilder sowie Wissensbestände oder ,Erlebnis- 
schichtungen' sind nicht einfach nur Resultate der figurationalen Dynamik, sondern sie wirken selbst auf die Dynamik beziehungsweise die Neigungen der Machtbalancen ein. Elias verdeutlicht dies unter anderem in seinen Arbeiten zu Etablierten-Außenseiter-Figurationen, die er auch in seinen Forschungen zu Generationenverhältnissen und -konflikten nutzt. In diesen, von einer mehr oder weniger starken Machtasymmetrie gezeichneten Gruppenbeziehungen sind, wie in Figurationen überhaupt, Wir-, Selbst- und Sie-Bilder immer Ausdruck und Gestaltungsmittel des Verhältnisses zueinander. Elias und Scotson (1993) verdeutlichen diesen Aspekt unter anderem in ihrer Gemeindestudie zu einer Figuration von Altansässigen und Zugezogenen in einem Vorort Leicesters Ende der 1950er Jahre. Die Machtbalance ist in jener Figuration aufgrund der längeren Ortsansässigkeit, also aufgrund eines gegenüber den Zugezogenen höheren Gruppenalters und der damit verbundenen Chance auf Gruppenintegration, zugunsten der Altansässigen geneigt. Sie sind in der Lage, den Kontakt der eigenen Mitglieder mit den Zugezogenen zu verhindern, den Zugezogenen den Zugang zu statushohen gesellschaftlichen Positionen zu verwehren (ebd.: 12), und sie sind zu einer erfolgreichen, Organisation' von Stigmatisierung fähig, die dafür sorgt, dass die Zugezogenen die negativen Fremdzuschreibungen der Etablierten als lähmende Selbstzuschreibungen annehmen (ebd.: 9). Allein in den figurationalen Eigenschaften, also in den mit der Gruppenintegration verbundenen Chancen auf Gruppensolidarität und Sozialkontrolle der Mitglieder, in der Entstehung eines positiven Wir- beziehungsweise Selbstbildes und Gruppencharismas sowie eines komplementären negativen Sie-Bildes und Gruppenschande, liegen die Machtchancen der Etablierten (ebd.: 9 ff.; 16 f.). Denn hinsichtlich sozio-ökonomischer oder anderer Zugehörigkeitskategorien unterschieden sich Altansässige und Zugezogene in der Gemeindestudie kaum. In Wechselwirkung mit dem Ausmaß der Machtasymmetrie zwischen Etablierten und Außenseitern, hier Altansässigen und Zugezogenen, stehen wiederum die Möglichkeiten der Außenseiter, die Stigmatisierung zu ,managen': Diese reichen von apathischen Reaktionen, demonstrativer Bestätigung des Stigmas (ebd.: 215) bis zur erfolgreichen Organisation von Gegenstigmatisierung $^{29}$ und der Ausbildung einer Gruppentradition ${ }^{30}$. Generell ist hier die Integration einer Gruppe beziehungsweise Gruppierung Ausdruck und Quelle ihrer Machtchancen (Bogner 2003: 173).

Elias hat die mit der Etablierten-Außenseiter-Theorie verbundenen Überlegungen auf mehrere andere Forschungsarbeiten, unter anderem auf seine Studien

\footnotetext{
${ }^{29} \mathrm{Zu}$ einer empirisch fundierten Verbindung von Elias mit Erving Goffmans Arbeiten zu Stigmamanagement (1975) und der Arbeit von Bethany Coston und Michael Kimmel zu Stigma und Männlichkeit (2012) vgl. Worm/Hinrichsen 2015.

${ }^{30}$ Diese umfasst ebenfalls ein kollektives Gedächtnis mit spezifischen Vorstellungen und Bildern der eigenen Geschichte. Man denke hier auch an die von Mannheim analysierte „Apologie des Mittelalters" der Romantiker-Generationseinheit.
} 
zu Generationenkonflikten in der Weimarer Republik und im Nachkriegsdeutschland, übertragen. Auf diese Studien zu Generationenkonflikten möchte ich im Folgenden eingehen.

\subsection{Elias' Studien zu Generationenkonflikten}

Im Rahmen der in „Studien über die Deutschen“ (1989) zusammengestellten Arbeiten diskutiert Elias unter anderem die Verflechtung von Generationengruppen und -gruppierungen aus figurationssoziologischer Perspektive, die er auch hier als ungeplante, von den Beteiligten häufig nicht bewusst gemachte, spannungsgeladene Prozesse (ebd.: 316; 321) fasst. Er betrachtet dabei insbesondere zwei Fälle konflikthafter Generationenverhältnisse: die Figuration von Erster-Weltkriegsund jüngerer Nachkriegsgeneration in der Weimarer Republik und die Figuration von Zweiter-Weltkriegs- und jüngerer Nachkriegsgeneration in der ,Bonner Republik'. Elias greift in der Diskussion der Fälle jedoch immer wieder über den spezifisch deutschen Kontext hinaus. Weiterhin stellt er zahlreiche allgemeine Überlegungen zur sozialen Dynamik von Generationenkonflikten an, auf die ich mich hier konzentriere.

Elias fasst die Generationenkonflikte als Variante der oben diskutierten Etablierten-Außenseiter-Beziehungen. Die nachgelagerten Generationen sieht er gegenüber den vorgelagerten Generationen in einer Außenseiterposition, welche für erstere eine „Abdrosselung von Lebens- und Sinnchancen“ (ebd.: 322) gegenüber der vorgelagerten Generation bedeute:

„Die Verengung und Erweiterung der Lebens- und Sinnchancen im allgemeinen und der Laufbahnchancen im besonderen für die jeweils jüngeren Generationen einer Gesellschaft ist ein Vorgang, der zweifellos die Machtbalance zwischen den Generationen aufs stärkste affiziert" (ebd.: 320).

Elias hat hier den ,klassischen“ Mechanismus von Etablierten-AußenseiterBeziehungen im Blick: Aufgrund ihres höheren Gruppenalters und der damit verbundenen Chance zur Gruppenintegration und zur Besetzung von Statuspositionen schließt die ältere Generationsgruppe (meist nicht intendiert und unerkannt) die Positionen gegenüber der nachgelagerten Generation, und die Bilanz der gegenseitigen Abhängigkeiten neigt sich zugunsten der älteren Generation. ${ }^{31}$ Elias diskutiert jedoch nicht nur die Lebenschancen im Sinne beruflicher Laufbahnchancen, „Besitzchancen“ (ebd.: 318) oder mit politischem Einfluss verbun-

\footnotetext{
${ }^{31}$ Auch die umgedrehte Variante einer zeitlich vorgelagerten Außenseitergeneration und einer zeitlich nachgelagerten Etabliertengeneration ist denkbar. In dieser Konstellation würde dann aber der ,übliche Vorteil von älteren Generationen, der sich aus ihrem gegenüber den jüngeren Generationen größeren Gruppenalter und den damit verbundenen höheren Integrationschancen ergeben, von anderen Prozessen überlagert werden müssen.
} 
dener gesellschaftlicher Positionen, ${ }^{32}$ sondern explizit auch sogenannte Sinnchancen (ebd.: insbes. 318-320; 324-327):

„Für die jüngeren Generationen verknappen sich die Lebenschancen, besonders auch die Chancen, mit denen sich individuell das Gefühl der Sinnerfüllung verbindet, und der Druck der Etablierten- auf die Außenseitergruppen, also zum Beispiel (aber nicht nur) der höherstehenden älteren auf die von ihnen abhängigen jüngeren Generationen, steigt" (ebd.: 319 f.).

Der Begriff der Sinnchancen wird von Elias nur näherungsweise gefasst. Er geht davon aus, dass „politische Doktrinen im 20. Jahrhundert“ zu einem „integralen Element" dessen geworden sind, ,was für Menschen sinnvoll ist und dementsprechend sowohl Sinnerfüllung wie Sinnentleerung möglich macht" (ebd.: 326). Elias vergleicht diese Involvierung mit den ,religiösen Glaubenskämpfen früherer Jahrhunderte“ und spricht von einer „sinngebenden Funktion des Kampfes für die eigenen politischen Ideale“ (ebd.: 327) und von einer „Befriedigung in der Hingabe" an selbige (ebd.: 300). An anderer Stelle bemerkt Elias, dass das Absinken von Lebens- und Sinnchancen für die nachgelagerte Generation sich ,in dem, was man unbestimmt als das Lebensgefühl einer Periode bezeichnet" (ebd.: 320), verdeutliche. Hier kann man zudem einen von Elias in den Arbeiten zum Generationenkonflikt nicht aufgegriffenen, aber an anderer Stelle diskutierten Aspekt von Etablierten-Außenseiter-Beziehungen ergänzen:

„Die eigentümliche Fixierung der Wunschrichtung von Menschen in einer Außenseiterposition an die Anerkennung und Rezeption durch ihr Establishment führt dann dazu, daß sich ihr Tun und Lassen auf dieses Ziel als Zentrum ihrer Sinnerfüllung einstellt“" (Elias 1993: 50).

Die Außenseiter sind also, und dies ist auch in generationalen EtabliertenAußenseiter-Beziehungen möglich, auf die Deutungsmuster der Etablierten und die damit verbundenen Standards für Sinnerfüllung bezogen und messen sich an diesen.

Da ein Befund aus meinen empirischen Analysen, die ich in den Kapiteln 6-8 diskutiere, den hier vorgestellten Überlegungen nahekommt, greife ich kurz vor: Im Westjordanland lässt sich über die verschiedenen Gruppierungszugehörigkeiten von Flüchtlingen, Rückkehrern und Altansässigen hinweg ein Erleben des Absinkens von Sinnchancen in der ,Erlebnisschichtung' der palästinensischen Generation ,nach Oslo' feststellen. Die Mitglieder dieser Generation messen beziehungsweise orientieren sich an den in der Vorgängergeneration ausgefochtenen Kämpfen in der politischen Mobilisierung der 1970er und 1980er Jahre, insbesondere der Ersten Intifada. Auch ein mit anderen Zugehörigkeiten wechselwirkendes Verschieben von Lebenschancen, das sich im Zuge der sozialen Transformation

\footnotetext{
32 Für den Kontext im Westjordanland vgl. Fußnote 115.
} 
,nach Oslo' ergeben hat, konnte rekonstruiert werden (vgl. Kap. 6-8; vgl. die Diskussion in Kap. 9).

Einen weiteren Aspekt dieser Prozesse von Generationenkonflikten, der im Zusammenhang mit meinen empirischen Analysen von Bedeutung ist, möchte ich ebenfalls hervorheben. Er wird von Elias im Zusammenhang mit der Spannung zwischen älteren Wehrmachtsoffizieren und jüngeren Freikorps-Kämpfern in der Weimarer Republik diskutiert (ebd.: 322 ff.). Elias weist darauf hin, wie Generationenkonflikte aufgrund der Figuration der Generationengruppen mit anderen Gruppen latent bleiben beziehungsweise wie sie sich in der ,Auslebung' auf andere Gruppen - auf einen ,gemeinsamen Gegner“" (ebd.: 324) - verlagern können:

„Der latente Generationenkonflikt im Verhältnis der relativ jungen Freikorpsführer und ihrer Gefolgschaft zu den älteren Establishments der Reichswehrführung und der Spitzengruppen war unauslebbar [...]. Bei allen Interessenunterschieden jedoch hatten diese jüngeren und älteren Generationen eine gemeinsame Front" (ebd.: 323 f.).

Schließlich streift Elias' Arbeit zu den Generationenkonflikten auch die Frage, inwiefern generationale Zugehörigkeiten mit anderen Zugehörigkeiten wechselwirken können. Elias geht davon aus, dass sich in den von ihm diskutierten Fällen die Generationenkonflikte stärker in bürgerlichen als in proletarischen Gruppen zeigen, da erstere einerseits ausgeprägtere Laufbahnerwartungen haben (können) als letztere und sich die generationale soziale Schließung für bürgerliche Gruppen daher stärker darbietet (ebd.: 321). Andererseits, so Elias, haben politische Ideale für bürgerliche Gruppen eine größere Relevanz für das Empfinden von Sinnerfüllung als für proletarische Gruppen (ebd.: 300). Generationale Zugehörigkeit und klassen- beziehungsweise schichtbezogene Zugehörigkeit bestimmen hier also die spezifische figurationale Positionierung ,jungbürgerlicher Generationen“ (ebd.: 303). Es komme gerade darauf an, den Beitrag generationaler EtabliertenAußenseiter-Beziehungen zur Dynamik von Gruppen- und Gruppierungsgeflechten herauszuarbeiten, ohne gesellschaftliche Schichtenkämpfe und Machtverlagerungen auf diese zu reduzieren (ebd.: 320). Elias ist zudem der Auffassung, dass diese Generationenverhältnisse und die damit verbundenen Konflikte sich durchaus innerhalb von Familien, etwa zwischen Eltern und Kindern abspielen können, aber nicht müssen (ebd.: 316). Es ist ebenso möglich, dass sich die gesellschaftlichen Generationenkonflikte nicht in der eigenen Familie realisieren, aber dennoch für die eigene Erfahrungsbildung und Deutungsmuster von erheblicher Bedeutung sind.

Ich greife nun das in Kapitelabschnitt 2.2 und 2.3 diskutierte Mannheim'sche Generationskonzept wieder auf. Wir hatten mit Blick auf seine späteren wissenssoziologischen Schriften festgehalten, dass es bei Generationenphänomenen einer Analyse der generationalen Erlebnisschichtungen der Generationszusammenhänge und -einheiten auch vor dem Hintergrund der Verflechtungen und Machtkämpfe von 
Generationengruppen im historischen Prozess bedarf. Diese Perspektive kann man mit der hier vorgestellten figurationssoziologischen Perspektive weiter ausdifferenzieren. $\mathrm{Zu}$ fragen wäre nach den Figurationen, insbesondere den EtabliertenAußenseiter-Beziehungen, von Generationengruppen und -gruppierungen, ihrer Wechselwirkung sowohl mit anderen Gruppen als auch mit den Wir-, Selbst- und Sie-Bildern, überhaupt nach den Erlebnisschichtungen der verflochtenen Individuen und den unintendierten und unerkannten Auswirkungen dieser Verflechtungen. Für den Kontext dieser Arbeit sollten - neben einem Verständnis von Generationenverhältnissen als potentielle Etablierten-Außenseiter-Beziehungen generell - außerdem die von Elias im Rahmen der Studien zu Generationenkonflikten diskutierten Aspekte der ,Abdrosselung von Sinnchancen' oder des Erlebens von ,Sinnentleerung` sowie der möglichen Latenz von Generationenkonflikten im Blick behalten werden.

In einer beiläufig vorgenommenen Bewertung urteilt Van Krieken über die Studien zu den Generationenkonflikten: „Elias fleshed out and expanded on Mannheims arguments“ (1998: 115). Allerdings kann meines Erachtens eine figurationssoziologische Erforschung von Generationenverhältnissen auch Gefahr laufen, die Bedeutung der Erlebnisschichtung von Generationen und die Relevanz der je nach Generationseinheit unterschiedlichen gestalthaften Organisation der Erlebnisse zwar nicht zu übergehen, aber in der empirischen Analyse etwas unterzubetonen. Zudem sind, dies wurde in diesem Abschnitt wiederholt thematisiert, Individuen in der Regel gleichzeitig in unterschiedliche Gruppen und Gruppierungen eingebunden (zum Beispiel als ,jungbürgerliche Außenseitergeneration), die Gruppierungszugehörigkeiten können miteinander in Wechselwirkung stehen und in unterschiedlichen biographischen und kollektivgeschichtlichen Phasen unterschiedlich relevant für das Erleben und die Sinn- und Lebenschancen der Individuen sein. Es ist daher für die sozialwissenschaftliche Erkenntnis zentral, wie Elias formuliert, ,als Insider zu wissen, wie Menschen ihre eigene und andere Gruppen erfahren" (Elias 1983: 30; Hervorhebung d. Verf.). ${ }^{33} \mathrm{Im}$ methodischen Vorgehen gilt es dann nachzuvollziehen, in welchen figurationalen Verflechtungen die Gesellschaftsmitglieder stehen, wie sich diese verändern und wie sie erlebt werden.

Aus diesen und anderen Gründen liegt es nahe, der Frage nach der Relevanz der Verflechtungen von Generationengruppen und -gruppierungen in einem sozio-historischen Kontext im Rahmen der Rekonstruktion von Biographien nachzugehen. Das Verhältnis von figurationssoziologischer und biographietheoretischer Perspektive ist einerseits durch die zahlreichen Parallelen zwischen beiden Ansätzen charakterisiert, andererseits können sie sich gegenseitig ergänzen. So formulieren Artur Bogner und Gabriele Rosenthal, dass zum einen mit einer figurationssoziologischen Perspektive „in der Biographieforschung die einzelnen Menschen

33 Zu Elias’ Bevorzugung qualitativer Methoden vgl. Dunning/Hughes 2013: 150. 
noch konsequenter in ihren Verflechtungen mit anderen Menschen, Gruppierungen, Gruppen“ (2017: 43) gesehen werden können und dass zum anderen durch eine biographietheoretische Perspektive ,in figurationssoziologischen Untersuchungen weiterhin (und vielleicht in mancher Hinsicht verstärkt) die einzelnen Individuen in ihren Verhaltens- und Handlungszusammenhängen und mitsamt ihren ,subjektiven“ Perspektiven in den Blick“" genommen werden können (ebd.). Auch Peter Alheit (2018) hat kürzlich den Gewinn einer Kombination beider Ansätze unterstrichen. Im Rahmen der soziologischen beziehungsweise sozialkonstruktivistischen Biographieforschung sind zudem bereits zahlreiche Forschungsarbeiten erschienen, die die Erforschung der Prozesse historischer Generationenbildung ins Zentrum stellen beziehungsweise prominent behandeln und zum Teil auch eine Diskussion und Weiterentwicklung des Mannheim'schen Generationskonzepts vorgenommen haben. Im Folgenden stelle ich daher die wesentlichen Grundannahmen der soziologischen beziehungsweise sozialkonstruktivistischen Biographieforschung vor.

\subsection{Sozialkonstruktivistische Biographieforschung}

Die jüngere Diskussion und theoretische wie methodologische Weiterentwicklung der soziologischen beziehungsweise sozialkonstruktivistischen Biographieforschung ist eng verbunden mit der Konjunktur interpretativer Ansätze ${ }^{34}$ in den Sozialwissenschaften seit den 1970er Jahren. Mit den interpretativen Ansätzen teilt die Biographieforschung die Auffassung, bei der Erforschung sozialer Phänomene sei von Bedeutungskonstruktionen und, subjektiven' Perspektiven der Forschungssubjekte auszugehen.

Eine biographietheoretische Forschungsperspektive, die die Erforschung sozialer Phänomene im Rahmen der Rekonstruktion von Lebensgeschichten verfolgt, hat sich im kritischen Austausch mit dem sich seit den 1970er und 1980er Jahren ausdifferenzierenden Feld interpretativer beziehungsweise rekonstruktiver Forschungsansätze als eigener Forschungszweig etabliert. ${ }^{35}$ Der Ansatzpunkt der sozialkonstruktivistischen Biographieforschung ist im Anschluss an Alfred Schütz und die phänomenologische Wissenssoziologie in der Alltagswelt beziehungsweise der alltäglichen Lebenswelt lokalisiert worden (Fischer/Kohli 1987: 27), jenem

\footnotetext{
${ }^{34}$ Als theoretischer Bezugspunkt ist hier, neben der, Wiederentdeckung' der verstehenden Soziologie Max Webers, George Herbert Meads und der bereits mit biographischen Methoden arbeitenden Chicago School, der Ethnomethodologie, dem Symbolischen Interaktionismus und der Grounded Theory, insbesondere der an Alfred Schütz anschließende Sozialkonstruktivismus Berger/Luckmanns zu nennen. Für eine Diskussion der Relevanz der Grounded Theory und des Symbolischen Interaktionismus für die Biographieforschung vgl. Appitsch/Inowlocki 2000.

${ }^{35}$ Nicht verstanden als Bindestrichsoziologie oder ,biographische Methode', sondern als Biographieforschung, ,in der empirische Forschung und Theorieaufbau betrieben [werden], die sich wesentlichen Traditionen und zentralen Eigendefinitionen des Fachs Soziologie verpflichtet wissen" (FischerRosenthal 1990: 11).
} 
Bereich, in dem Gesellschaftsmitglieder auf Basis ihrer Sinnauslegungen in „,natürlicher Einstellung" (Schütz/Luckmann 1975: 23 ff.), das heißt auf Basis fraglos gültiger Erlebens- und Handlungsroutinen (Typisierungen), handeln und interagieren. In sozialkonstruktivistischer Perspektive legen die Gesellschaftsmitglieder die Sozialwelt in interaktiven Prozessen beständig aus, und zwar unter steter Spannung zwischen einem Rückgriff auf ,bestehende' internalisierte Sinngehalte im subjektiven Wissensvorrat und einer Anpassung, Neuaushandlung und Institutionalisierung der Sinngehalte (Schütz/Luckmann 1975). ${ }^{36}$
„Die für den einzelnen konkrete Aufordnung der Alltagswelt erfolgt in einem zeitlich strukturierten Schema, seiner individuellen Biographie, in der sozial vorgegebene Schemata realisiert oder variiert werden. Die sich in historischen Dimensionen verändernde Alltagswelt wird dabei zum einen als geordneter Erfahrungsraum erlebt, zum anderen eignen ihr ,Leerstellen', die auslegungs- bedürftig sind“" (Fischer/Kohli 1987: 29).

Für die Biographieforschung in besonderem Maße interessant sind dabei die Realisierung und Variation alltagsweltlich weiter ausgreifender Schemata oder Verkettungen von Erlebens- und Handlungssequenzen und die damit verbundenen Orientierungsleistungen einerseits und andererseits gerade deren ,Scheitern' beziehungsweise Krisenhaft-Werden in biographisch relevantem Ausmaß. In sozialkonstruktivistischer Perspektive wird, entgegen der Kritik an deren ,egologischem ${ }^{6}$ Charakter, ${ }^{37}$ die Sozialwelt nicht , nur vom Subjekt her ${ }^{6}$ bestimmt. Berger und Luckmann etwa verstehen „Gesellschaft als ständigen dialektischen Prozess [...] von Externalisierung, Objektivation und Internalisierung“" (Berger/Luckmann 2007: 139). Das heißt, das dialektische Verhältnis von Gesellschaft und Subjekt kommt in vielfachen, parallel laufenden Prozessen zum Ausdruck, in denen subjektiver Sinn veräußert, in gegenseitigen Verstehensvorgängen zunehmend intersubjektiv geteilt, routinisiert und zu einem gesellschaftlichen Wissensvorrat verfestigt sowie wiederum in den subjektiven Wissensvorrat eingepflegt wird. Analog schaut die Biographieforschung auf das „dialektische Verhältnis von lebensgeschichtlichen Erlebnissen und Erfahrungen und gesellschaftlich angebotenen Mustern“ (Fischer-Rosenthal/Rosenthal 1997: 411).

Diese in einer sozialkonstruktivistischen Perspektive mitgeführte, prozesshafte und dialektische Auffassung von Biographie ist unter anderem in der Auseinandersetzung mit der Objektiven Hermeneutik Ulrich Oevermanns weiter ausdifferenziert worden. Neben anderem wurde der, dynamische Strukturbegriff ${ }^{\star}$ der Objektiven Hermeneutik (Oevermann et al. 1979: 423; 1981: 50), in welchem die

\footnotetext{
${ }^{36}$ Für eine konzise Diskussion der zentralen phänomenologischen Konzepte „Sinn“, „Bewusstsein“, „Typisierung“, „Erfahrung“, „Handlung“, „natürliche“ und „,wissenschaftliche Einstellung“ vgl. Luckmann 2003.

${ }^{37}$ Für eine Diskussion der Kritik am egologischen Charakter der Schütz’schen Soziologie vgl. Srubar 1979 .
} 
Verwicklung von ,Subjektivem“ und ,Gesellschaftlichem' in differenzierter Weise aufgehoben ist, in der sozialkonstruktivistischen Biographieforschung aufgegriffen. ${ }^{38}$ Als dynamische Strukturen fasst Oevermann „Strukturen mit eigener Bildungsgeschichte“ (Oevermann 1981: 35), das heißt Strukturen mit einer Chronologie von wiederholten Auswahlen (Strukturreproduktion) und Neu-Auswahlen (Strukturtransformation) von Handlungen in einem sich auch mit den Auswahlen verändernden Feld von Handlungsmöglichkeiten (Oevermann 1996: 72). ${ }^{39}$ Biographien sind in dieser $W$ eise verstandene Strukturen: Für Biograph*innen ${ }^{40}$ ergeben sich die - im Zeitverlauf wiederum sich wandelnden - Handlungsoptionen mit der Zugehörigkeit zu, dem Eintritt in beziehungsweise Austritt aus sowie der Position in Milieus, Familien, ethnischen, klassen- oder geschlechtsbezogenen Gruppierungen, beruflichen Stellungen, Bildungsinstitutionen oder der Zugehörigkeit zu historischen Generationengruppen und -lagerungen (als ein in einer bestimmten historischen Periode Lebender). Aus diesen Handlungsmöglichkeiten werden in Biographien - oftmals nach einem bestimmten Muster, das sich unter anderem wiederum im sich im Lebensverlauf aufbauenden und reorganisierenden Wissensvorrat und Relevanzsystem begründet - Handlungsoptionen ausgewählt oder ausgelassen beziehungsweise abgewählt, ohne dass dies den involvierten Subjekten bewusst sein oder in den ,Wahlen' ein biographischer Handlungsplan realisiert sein muss. So sind die Handlungsoptionen und die Muster, nach denen aus ihnen ausgewählt wird, meist nicht oder nur kaum bewusst, sie sind in unterschiedlichen Graden latent (Oevermann et al. 1979: 367 ff.). Dies schließt gerade auch die mögliche Auswahl von Handlungsoptionen ein, deren Folgen nicht intendiert waren oder überblickt wurden. Die Fallstruktur einer Biographie ist in dieser Lesart - in Anlehnung an den Oevermann'schen Strukturbegriff - das Muster der Aus- und Abwahlen vor dem Hintergrund sich öffnender und schließender, begrenzter Handlungsoptionen über die Lebenszeit, also eine Art Prozesslogik. Deutlich wird hier, wie in der Biographie nicht nur Individuum und Gesellschaft, sondern auch deren Verflechtung, oder Dialektik, sichtbar wird. Die mit dem Begriff der Verflechtung bereits angedeutete Brücke zur Figurationssoziologie ist nicht schwer zu schlagen: Deutlich werden, wie Artur Bogner und Gabriele Rosenthal (2017: 54 f.)

\footnotetext{
${ }^{38}$ Für eine frühe Rezeption der objektiven Hermeneutik in der Biographieforschung vgl. Rosenthal 1987: 143-209; Fischer/Kohli 1987: 43 ff.

${ }^{39}$ Oevermann spricht hier auch von vier Ebenen: Zunächst die Ebene der bedeutungsgenerierenden Regeln (von allgemeinen, in der Funktionsweise der Sprache liegenden Regeln bis Angemessenheitsregeln und Normen in Milieus, Familien und anderen Gruppen), in denen die Spielräume oder Optionen für Handlungen abgesteckt werden. Die zweite Ebene umfasst die Auswablen, die aus den Handlungsmöglichkeiten getroffenen werden. Mit der dritten Ebene bezeichnet Oevermann die Angebbarkeit der Auswahlen als typisches Muster beziehungsweise als Algorithmus. Auf der vierten Ebene schließlich liegt der subjektiv intendierte Sinn, der die angeführten Mechanismen empirisch in jeweils unterschiedlichem Ausmaß, in der Regel aber kaum (für sich) rekonstruiert hat (Oevermann 1991: 271). Für eine knappe Darstellung der Parameter vgl. Maiwald 2013: 189 ff.

${ }^{40}$ In Oevermanns Lesart ist dann Biographie eine Fallebene unter anderen, auf der zur Strukturbildung fähige autonome Handlungszentren angesiedelt sein können (Oevermann 1981: 6 f.).
} 
für das Verhältnis von Subjekt und Figuration diskutieren, die sich wandelnde Involvierung der Biograph*innen in verschiedene Figurationen, die Grade der Autonomie gegenüber der Einbindung in dieselben sowie die Muster der Verwendung von ,Spielräumen'. Im Zuge dieses Verständnisses von Biographie von einem „Mikro-Prozess“ in einem „Makro-Prozess“ zu sprechen, wie Elias dies in seiner Arbeit zu Mozart getan hat (Elias 1993: 59), liegt nahe.

Hierzu drei knappe methodische Bemerkungen, auf die ich in Kapitel 3 ausführlicher eingehen werde: Die Verflechtung von Individuum und Gesellschaft näherungsweise als Prozesslogik zu benennen, ist Ziel der biographischen Analyse und, in der Bezugnahme auf eine sozialwissenschaftliche Fragestellung, Ziel der Typenbildung (vgl. Kap. 3.2). Die Varianten dieser Verflechtungen als ,Antworten“ auf eine Fragestellung möglichst erschöpfend zu erfassen (empirisch gibt es mal mehr, mal weniger solcher ,Antworten') ist wiederum Ziel einer theoretischen Verallgemeinerung gegenüber einer statistischen (vgl. Kap. 3.2-3.3). Methodisch macht diese Auffassung von Biographie zudem eine Rekonstruktion der biographischen ,Wahlen' wie auch der Handlungsoptionen - etwa in den jeweiligen kollektivgeschichtlichen Kontexten, in denen sich die Biographie entfaltet - notwendig. In diesem Zusammenhang ist auch der anhaltende Trend zu MehrgenerationenStudien in der Biographieforschung zu sehen, der es ermöglicht, über einen längeren Zeitraum kollektiv-, familien- und lebensgeschichtliche Prozesse zu rekonstruieren. ${ }^{41}$

In der Diskussion des Mannheim'schen Generationskonzepts in Abschnitt 2.2 habe ich Mannheims stellenweise Aufnahme gestalttheoretischer Überlegungen für die Frage der Erlebnisschichtung von Generationengruppen thematisiert. In der sozialkonstruktivistischen Biographieforschung ist von Gabriele Rosenthal ebenfalls auf die für Mannheim zeitgenössischen Arbeiten, vornehmlich die ,Berliner Schule der Gestalttheorie der 1920er Jahre und zu Beginn der 1930 Jahre (Wertheimer, Koffka, Lewin), zurückgegriffen worden. Die in diesen Arbeiten vorgestellten gestalttheoretischen Überlegungen sind von Rosenthal, insbesondere in der Auseinandersetzung mit den phänomenologischen Arbeiten Aron Gurwitschs (1975), zu einer gestalttheoretischen Auffassung von Erlebens-, Erinnerungs- und Erzählprozessen weiterentwickelt worden (1995). ${ }^{42}$ Hier ist der Gedanke zentral, dass die Episoden sozialer Abläufe (meist) ${ }^{43}$ nur in der Kenntnis der Gestaltverbindung von Episode und Gesamtprozess interpretierbar sind. Bei der Untersuchung von lebensgeschichtlichen Verläufen und Erzählungen hat dies zur Folge, soziale Phänomene nur im Gesamtzusammenhang der Lebensgeschichte

\footnotetext{
${ }^{41}$ Für einen Überblick über familiale Mehrgenerationenstudien im Rahmen der jüngeren Biographieforschung vgl. Rosenthal/Hinrichsen 2017.

${ }^{42}$ Die stärker erzählanalytischen Bestandteile der Argumentation und deren methodische Konsequenzen stelle ich in Kapitel 3 vor.

${ }^{43}$ Außer, in gestalttheoretischer Perspektive, bei sogenannten Und-Verbindungen, wo Episoden nur aufeinander folgen (Wertheimer 1922).
} 
verstehen und erklären zu können (Rosenthal 2009: 49). Das heißt, soziale Phänomene sind im Kontext unter anderem der Fragen zu erforschen, wie frühere biographische Phasen auf spätere Phasen wirken, wie spätere Phasen auf die Erinnerung von früheren und die Vorstellung von späteren wirken, wie Erlebenssequenzen in verschiedenen Lebensbereichen miteinander wechselwirken.

Aus einer biographietheoretischen Perspektive die Formierungen historischer Generationen zu erforschen, um die Brücke zur Ausgangsfrage des Kapitels zu schlagen, heißt daher, dies mittels der Rekonstruktion von Biographien - hier im Sinne des sozialkonstruktivistischen, dynamisch-strukturtheoretisch und gestalttheoretisch informierten Konzepts von Biographie - zu unternehmen. Die mit dieser Perspektive verbundenen Vorteile für die Erforschung historischer Generationen sind in der sozialkonstruktivistischen Biographieforschung diskutiert worden, wobei auch der Mannheim'sche Generationsansatz weiterentwickelt wurde. Diese Weiterentwicklung möchte ich im Folgenden ausführen.

\subsection{Historische Generationen aus biographietheoretischer Perspektive}

Im Bereich der Biographieforschung wurde von Martin Kohli das Mannheim'sche Generationskonzept mit einer Neuveröffentlichung einer (stark gekürzten) Fassung des Generationsaufsatzes bereits 1978 in die Diskussion gebracht. Bis heute sind zahlreiche Forschungsarbeiten aus biographietheoretischer Perspektive erschienen, die die Frage nach historischer Generationenbildung ins Zentrum stellen oder prominent ,mitbehandeln' (Bude 1987; Rosenthal 1987; Becker 2013). ${ }^{44}$

Ich möchte hier insbesondere auf Gabriele Rosenthals Forschungsarbeiten eingehen, die eine konzeptionelle Weiterentwicklung des Mannheim'schen Generationskonzepts im Rahmen der Biographieforschung betreiben. Rosenthal (1997, 2000) hat Mannheims Generationskonzept im Sinne einer stärkeren Berücksichtigung von „,interaktiven und lebenslangen Prozessen“ (1997: 58) erweitert. In Bezugnahme auf Matthes (1985a) plädiert Rosenthal ebenfalls dafür, auf Generationenverbältnisse zu schauen. Sie schlägt ein Konzept vor, „,in dem sich Generationen sowie ihre Einheiten im interaktionellen Prozess mit anderen Generationen bilden“ (1997: 58). Rosenthal zeigt außerdem auf, wie familiale Generationen und historische Generationen ineinandergreifen können. In der Interaktion zwischen Familienmitgliedern und im familialen Dialog können historische Generationserfahrungen und -zugehörigkeiten ausgehandelt und erzeugt werden. Dabei könne gerade auch die Verhandlung familialer Delegation zum konstitutiven Erfahrungsbestand einer historischen Generation gehören (ebd.: 59 f.). Und tradierte, übermittelte Erfahrungen können für die Zugehörigkeit zu Generationen wichti-

\footnotetext{
${ }^{44}$ Heinz Budes Arbeit zur Generation der Flakhelfer gehört zu den ersten Arbeiten einer ,neueren biographietheoretischen Generationenforschung (1987: insbes. 33 ff.; 179 ff.).
} 
ger sein als selbsterlebte (ebd.: 60). Es gelte sich auch vom Fokus auf die gestaltdefinierende Potenz von Erfahrungen in der Jugend zu lösen, der bei Mannheim andeutungsweise bemerkbar ist, insbesondere jedoch in der Rezeption des Mannheim'schen Generationskonzepts entstand. Die Erfahrungen, die die Zugehörigkeit zu einer historischen Generation stiften, können, aber müssen nicht in der Phase der Jugend gemacht werden (ebd.: 62). Rosenthal verbindet ihre Anstöße zu einer Weiterentwicklung des Mannheim'schen Konzepts auch mit einer kritischen Einschätzung zum Stand der sozialwissenschaftlichen Generationenforschung. In dieser sei eine inflationäre Verwendung des Generationslabels und eine Anwendung ,jenseits einer empirisch fundierten [...] Konzeptbildung“ (ebd.: 57) zu beobachten. Stattdessen komme die Nutzung des Generationslabels eher dem der Kohorte nahe (ebd.). An anderer Stelle spricht Rosenthal von ,am Schreibtisch ${ }^{6}$ entworfenen Generationen (2000: 164). Man könne, so Rosenthal, nicht generell davon ausgehen, dass sich in jeder historischen Periode entsprechende historische Generationen ausbilden (1997: 61): „Vielmehr sind historische Phasen vorstellbar, in denen Klassen- oder Geschlechtszugehörigkeit bei der Konstitution eines Zusammenhangs dominanter sein können" (ebd.). Dabei könne eine historischgenerationale Zugehörigkeit auch mit anderen Zugehörigkeiten wechselwirken (ebd).

Insgesamt bedarf es laut Rosenthal daher einer biographietheoretischen Perspektive auf historische Generationenbildung, da grundsätzlich immer erst empirisch zu bestimmen sei, ob, und wenn ja, welche biographischen (kollektivgeschichtlichen) Erfahrungen in welchen lebensgeschichtlichen Phasen in welchen Interaktionsbeziehungen konstitutiv für Generationszusammenhänge und -einheiten werden - oder eben nicht werden (ebd.: 62). Dass es in bestimmten historischen Phasen zu keiner Ausbildung von historischen Generationen kommt, sei im Grunde ebenso klärungsbedürftig, wie die Entstehung von historischen Generationen. Dieser Frage möchte ich mich im folgenden Abschnitt zuwenden.

\subsection{Graduelle Phänomene historischer Generationenbildung: ,Zwischengenerationen', ,stille Generationen', ,verlorene Generationen'}

Unter welchen Bedingungen kommt es gerade nicht dazu, dass sich historische Generationszusammenhänge und -einheiten ausbilden? Und inwiefern treten wie ich sie nenne - graduelle Phänomene, also Ansätže von Generationszusammenhängen und -einheiten auf und unter welchen Bedingungen geschieht dies? In der Generationenforschung wird diesen Fragen selten dezidiert nachgegangen. Es finden sich einige Arbeiten zu sogenannten Zwischengenerationen, stillen oder verlorenen Generationen, die mehr oder weniger stark um diese Thematik kreisen. 
Mannheim selbst streift dieses Thema in seinem Generationsaufsatz, auch wenn seine Ausführungen insgesamt recht allgemein bleiben. Auf einige seiner Anmerkungen zu dieser Frage bin ich bereits in Abschnitt $2.2 \mathrm{zu}$ sprechen gekommen: Die verschiedenen Integrations- und Reflexionsniveaus von Generationseinheiten, die Mannheim andeutet, berühren diese Frage. Generationseinheiten, in denen die Mitglieder „nur ,intutitiv“ voneinander wissen“, sind vermutlich kollektiv geringer integriert und kollektiv weniger handlungsfähig als Generationseinheiten, in denen explizit generationale Wir-Bilder verhandelt werden. Des Weiteren nennt Mannheim verschiedene Konstellationen, die dazu beitragen können, dass es zu keiner Ausbildung von historischen Generationen kommt, etwa die Geschwindigkeit sozialen Wandels, die Kristallisationswirkung historischer Ereignisse oder die Abwesenheit von enger geknüpften Interaktionszusammenhängen innerhalb der Generation (Tischgesellschaft, Salons und Kaffeehäuser). Laut Mannheim können Generationenimpulse aufkommen, die aber von anderen sozialen Prozessen überlagert werden können. In diesem Zusammenhang kommt auch Mannheim auf sogenannte „Zwischengenerationen“ (1964: 540, 552) zu sprechen. Dieser Gedanke Mannheims ist in Abschnitt 2.2 noch nicht aufgegriffen worden: Zwischengenerationen liegen dann vor, wenn sich die Ansätze für eine neue Generationenbildung zeigen, sich diese aber an bereits formierten Generationszusammenhängen und -einheiten orientieren, obwohl sie sich in deren Erlebnisschichtungen nicht voll wiederfinden. Sie

„schließen sich möglicherweise einer früheren Generation an, die die Formung bereits vollzogen hat, oder sie verbinden sich einer späteren Generation, die einer jüngeren Formung fähig ist [...] So können oft frühere oder spätere Generationsimpulse und -regungen durch das Vorhandensein einer geprägten Form fremder Generationen verdeckt werden“ (ebd.: 552).

Mit diesen Ausführungen Mannheims, die insgesamt rudimentär bleiben, sind einige Hinweise auf graduelle generationale Phänomene gegeben. Insgesamt können die Ausführungen Mannheims hier als Anregung für folgende Gedanken genommen werden, die sich in meiner Rekonstruktion zur Generation Oslo offenbart haben: Historische Generationenbildung kann sich auch in den Erfahrungsbeständen und Zugehörigkeitsentwürfen und -gefühlen der Generationsmitglieder zwar zeigen, aber von anderen Erfahrungsbeständen und Wir- und Sie-Bildern überlagert oder durch andere Generationszusammenhänge und -einheiten dominiert werden. Generationale Vergemeinschaftungsprozesse deuten sich daher unter Umständen nur an.

Mannheim greift in einer kurzen Passage außerdem die GenerationenTypologie des Literaturhistorikers Julius Petersen auf (ebd.: 559 ff.). Dessen Typologie spielt verschiedene Passungen von Persönlichkeitsdispositionen und allgemeinen Tendenzen der generationalen Bildungsprozesse durch. Bei einem führenden Generationstyp entsprechen die ,Anlagen' der historisch-generationalen Dy- 
namik weitgehend. In diesem Fall wäre zu erwarten, dass beide Aspekte in ein gegenseitiges Steigerungsverhältnis geraten, welches in einem Erleben von Resonanz, von ,sich ausdrücken können' mündet. Im ,umgelenkten Typus“ hebt das Zusammenspiel aus Anlagen und generationalen Tendenzen bestimmte Aspekte der Persönlichkeitsdispositionen gegenüber anderen hervor. Im „unterdrückten Typus" schließlich, dessen Anlagen den generationalen Bildungsprozessen in keiner Weise entsprechen, sind mühevolle Anpassung oder Isolation die Folge. Mannheim kritisiert zu Recht den etwas schematischen und wenig soziologisch ausdifferenzierten Charakter der Typologie. Aber mit dem Rekurs auf Petersen weist Mannheim dennoch auf eine durchaus heterogene Verhandlung der generationalen Bildungsprozesse in den Lebensgeschichten der Gesellschaftsmitglieder hin, auch auf eine möglicherweise passive und abwehrende Verhandlung. ${ }^{45}$

In der Forschungsliteratur haben solche graduellen Phänomene von Generationenbildungen vergleichsweise geringe Berücksichtigung gefunden. Auf diesen Umstand wurde auch in der Forschung selbst verwiesen. So hat Bernd Weisbrod in einem resümierenden Aufsatz zur Generationenforschung angeregt, dass ,silent generations" wieder stärker in den Blick genommen werden sollten (2007: 31). Unter „silent generations“ beziehungsweise stillen Generation versteht Weisbrod

„die schon von Karl Mannheim so genannten ,Zwischengenerationen', die keinen hegemonialen Deutungsanspruch geltend machen konnten. Dabei haben diese, stillen' Generationen auf ihre Weise vielleicht mehr zum gesellschaftlichen Wertewandel beigetragen als die polarisierenden Generationen im Sinne Karl Mannheims, die im Begriff der ,politischen Generationen` weiterleben“ (2005: 5).

Diese Zwischengenerationen würden in ihrer Bedeutung für soziale Transformationsprozesse allgemein unterschätzt. Die Anregung Weisbrods, stille Generationen beziehungsweise Zwischengenerationen verstärkt in den Fokus der Forschung zu rücken, ist meines Wissens bisher nur vereinzelt explizit aufgenommen worden, etwa in den Forschungen von Sillies zur Generation Pille (2009) und von Jõesalu zur sowjetischen Generation in Estland (2016).

Neben diesen Verweisen auf Zwischengenerationen oder stille Generationen finden sich in der Generationenforschung auch einige Arbeiten, die, mal mehr mal weniger zentral, die Bezeichnung, verlorene Generation' verwenden. Schwerpunktmäßig wird dieser Begriff für die mit dem Ersten Weltkrieg und der Zwischenkriegszeit verbundenen Generationen verwendet. Detlev Peukert zum Beispiel hat im Zusammenhang mit den „letzten geburtenstarken Jahrgängen vor 1914“ in Deutschland, „die ihre Jugend in der Weltwirtschaftskrise erlebten“, davon gesprochen, dass diese „eine ,überflüssige‘ oder ,verlorene 'Generation“ (Peukert 1985: 328) seien. Alexander Honold hat im Zusammenhang mit der Zwi-

\footnotetext{
${ }^{45}$ Heinz Bude hat den analytischen Wert diskutiert, den der Mannheim'sche Rekurs auf Petersen für die Generationenforschung haben kann (2008: 192 f.).
} 
schenkriegsliteratur auf die Bedeutung des ,Labels` der ,Verlorenen Generation“ in der Prosa verwiesen (2005).

Verlorene Generationen und Zwischengenerationen beziehungsweise stille Generationen weisen konzeptionell nicht notwendig in dieselbe Richtung. So kann das Erleben von Abstieg, Leid und Entsagung oder Desorientierung ja gerade als geteilte generationale Erfahrung relevant werden, die zu einer Integration und Vergemeinschaftung der Generation führen kann. Mit ,verlorenen Genrationen sind daher nicht unbedingt graduelle Phänomene historischer Generationenbildung beziehungsweise Zwischengenerationen im Sinne Mannheims gemeint. Eine von Ulrike Jureit gegebene Definition von verlorenen Generationen weist jedoch in diese Richtung und betont darüber hinaus die Bedeutung öffentlicher Resonanz für die Bildung historischer Generationen. Sie definiert, im Rahmen eines Interviews, verlorene Generationen als auf der „Suche nach Vergemeinschaftung, nach Zugehörigkeit [...], die sich nicht öffentlich artikulieren kann, die wenig Möglichkeit hat sich zu artikulieren, wahrgenommen zu werden, einen Sprecher zu finden, der solche Aufmerksamkeiten auf sich zieht" (2013: 13). Jureit lässt hier offen, ob generational geteilte Erlebnisschichtungen die ,Suche" nach generationaler Vergemeinschaftung mitbedingen und ob dies auch mit generationalen Dominanzverhältnissen zusammenhängen kann.

Generell sind graduelle Phänomene, also Ansätze historischer Generationenbildung, in der sozialwissenschaftlichen und historischen Generationenforschung nur am Rande thematisiert worden. Die verschiedenen Begriffe, die in diesem Zusammenhang Verwendung gefunden haben - Zwischengenerationen, stille Generationen - kreisen allgemein um nicht voll formierte, um liminale, nichtdominante Generationen. Dieses Forschungsdesiderat ist für die Stoßrichtung dieser Arbeit interessant, da sich die von mir erforschte Generation Oslo, wie ich im Verlauf der Arbeit zeigen werde, als graduelles Phänomen historischer Generationenbildung diskutieren lässt. Blickt man mit einer figurationssoziologischen und biographietheoretischen Perspektive auf die Verflechtungen und Machtverhältnisse von Generationen, auf den Grad ihrer generationalen Integration und Vergemeinschaftung sowie auf die mehr oder weniger stark generational bedingten Erfahrungsgeschichten, Deutungsmuster, Wir- und Sie-Bilder, werden solche graduellen Phänomene historischer Generationenbildung leichter sichtbar.

\subsection{Zusammenführung: Eine figurationssoziologische und biographietheoretische Perspektive auf historische Generationen}

Welche Fragen sind nun im Sinne einer figurationssoziologischen und biographietheoretischen Perspektive auf historische Generationen zu stellen? In meiner Arbeit verbinde ich Karl Mannheims Generationskonzept und dessen Wissensso- 
ziologie mit Norbert Elias' Arbeiten zu Generationenfigurationen und den Arbeiten zur historischen Generationenbildung in der sozialkonstruktivistischen Biographieforschung. Die Kernkonzepte und Begriffsbildungen der vorgestellten Ansätze, die sich zum Teil überlappen und dennoch unterschiedliche Aspekte akzentuieren und ausdifferenzieren, kombiniere ich hier im Hinblick auf eine Erforschung historischer Generationen. Demzufolge ist bei der Erforschung historischer Generationen zu fragen, ob und inwiefern geteilte Erlebnisschichtungen, Deutungsmuster und Wir- und Sie-Bilder von Mitgliedern einer Generationengruppierung oder -gruppe in der Verflechtung mit anderen Gruppierungen und Gruppen (sowohl Generationenfigurationen als auch anderen) in einer historischen Periode ausgebildet werden. Mitglieder einer Generationengruppierung leben nicht nur zur selben Zeit, sondern sie teilen, empirisch in unterschiedlichem Ausmaß, Erfahrungen oder, in Mannheims Worten, Erlebnisschichtungen. Diese Erfahrungen können sowohl eine als ähnlich erlebte Ausstattung mit Sinn- und Lebenschancen als auch geteilte Erfahrungen von Exklusion und Stigmatisierung umfassen. Werden geteilte Erfahrungen ausgebildet, geht damit gegebenenfalls eine Integration und Vergemeinschaftung der Generationengruppierung in Richtung Gruppe einher, die auch kollektiv handlungsfähig werden kann. Dies kann man sich durchaus als Kontinuum mit einer gering integrierten Generationengruppierung am einen Pol und einer integrierten Generationengruppe am anderen Pol vorstellen. Mit zunehmendem Integrationsgrad der Generationengruppierung in Richtung Gruppe kann man umso eher von Generationseinheiten im Mannheim'schen Sinne sprechen, also von gruppenartigen Phänomenen, in denen die Generationsmitglieder intuitiv oder manifest, voneinander wissen'. Dabei können auch nochmals enger gezogene konkrete Gruppen innerhalb von Generationseinheiten eine Rolle spielen (Mannheims Beispiel der Tischgesellschaft).

Welche geteilten generationalen Erfahrungen die Gesellschaftsmitglieder machen, welche Deutungsmuster, Wir- und Sie-Bilder sie ausbilden und inwiefern sie sich in Richtung einer Gruppe integrieren, hängt auch von der relativen Stellung ihrer Generationengruppierung beziehungsweise von der „Lagerung der betreffenden Schichten im gesamtsozialen Spielraum“ (Mannheim 1964: 529) ab. Diese relative Gruppenstellung übersetzt sich in die Ausstattung der Mitglieder der Generationengruppierung mit Machtchancen - also die mehr oder weniger gegenseitigen Abhängigkeitsverhältnisse mit den Mitgliedern anderer Gruppen. Die Machtchancen sind, figurationssoziologisch konsequent, immer als Ausdruck von sowie in ihrer Eimwirkung auf die Gruppen- und Gruppierungsverflechtungen insgesamt zu sehen und stehen mit den Erfahrungen, Deutungsmustern, Wir- und Sie-Bildern der Gruppenmitglieder in Wechselwirkung. Die Beziehung von Machtchancen und Erfahrungsbildung kommt auch darin zum Ausdruck, andere Gruppierungsmitglieder überhaupt zu erkennen und sich ihnen gegenüber zugehörig füblen zu können. Auch die möglichen Formen des ,Stigma-Managements', die mögliche Organisation von (Gegen-)Wir-Bildern und (Gegen-)Stigmatisierung 
und die Ausbildung einer Gruppentradition sind an das Verhältnis der Machtchancen gebunden. So sind auch dominierte und nur in Ansätzen ausgebildete und integrierte Generationengruppen möglich - sogenannte Außenseitergenerationen im figurationssoziologischen Sinne.

Die Ausbildung von Generationengruppen und deren Verflechtung ist dynamisch. Die Verflechtungen von Gruppierungen und deren Machtbalancen entstehen und wandeln sich im kollektivgeschichtlichen Prozess ganz überwiegend in ungeplanter Weise. Je nachdem wie kurz- oder langfristig sich dieser Wandel vollzieht, bildet er sich in den Lebensgeschichten der Gesellschaftsmitglieder dergestalt ab, dass diese in bestimmten lebensgeschichtlichen Phasen und Bereichen in bestimmten Interaktionen bestimmte Erfahrungen ausbilden und in ihren lebensgeschichtlichen Wissensvorrat einpflegen. Dabei sind Gesellschaftsmitglieder beziehungsweise die Erfahrungen, die sie ausbilden, in der Regel in mehrere Figurationen verwoben. Im Sinne einer empirischen Rekonstruktion historischer Generationen ist daher zu fragen, wie dominant beziehungsweise biographisch relevant die Involvierung in Generationenfigurationen gegenüber anderen Verflechtungen beziehungsweise Zugehörigkeiten ist. Generationen können in historischen Phasen die Erfahrungen der Gesellschaftsmitglieder in dominanter Weise prägen und von erheblicher Bedeutung für die Wir- und Sie-Bilder, die Zugehörigkeitsgefühle und die Ausstattung mit Lebens- und Sinnchancen sein. In anderen historischen Phasen kann ihre Relevanz hinter andere Zugehörigkeiten zurücktreten und von diesen überlagert werden oder auch völlig irrelevant sein. Damit liegt es nahe, historische Generationsbildungen auch als graduelle Phänomene zu berücksichtigen, also als mehr oder weniger ausgeprägte und biographisch relevante generationale Erlebnisschichtungen, Deutungsmuster und Wir- und Sie-Bilder. Das Konzept der Zwischengenerationen in Anschluss an Karl Mannheim weist in die Richtung solcher gradueller Phänomene. Insgesamt ist für die Erforschung historischer Generationenbildung zu fragen, inwiefern Biograph*innen generationale Erlebnisschichtungen ausbilden und Mitglieder einer integrierten beziehungsweise sich integrierenden Generationengruppierung oder Generationengruppe sind oder werden. 



\section{Methoden und Stichprobe}

\section{1 Überblick}

In diesem Kapitel möchte ich einen Überblick über die Erhebungs- und Auswertungsmethoden geben, die ich im Rahmen dieser Forschungsarbeit genutzt habe, sowie auf den Prozess und die Zusammenstellung der Stichprobe eingehen, die meinen Analysen zugrunde liegt. Zunächst führe ich im Anschluss an das vorangegangene Kapitel methodologische Bezugspunkte zur Fallstruktur, Typenbildung und zur theoretischen Stichprobenbildung fort (3.2). Daraufhin diskutiere ich die Zusammensetzung meiner Stichprobe und schildere den Prozess, in welchem ich die Stichprobe im Westjordanland nach und nach zusammengestellt habe (3.3). Im Anschluss gehe ich im Einzelnen auf die genutzten Erhebungs- und Auswertungsverfahren und deren Anwendung im Westjordanland ein (3.4). Die im Rahmen dieser Arbeit genutzten Verfahren umfassen teilnehmende Beobachtungen, biographisch-narrative Interviews, biographische Fallrekonstruktionen und Sequenzanalysen von Beobachtungsprotokollen. Insgesamt folgte die Stichprobenbildung sowie die Nutzung der Erhebungs- und Auswertungsverfahren den Prinzipien der Offenheit und der Kommunikation, wie sie von Hoffman-Riem (1980) für eine interpretative beziehungsweise rekonstruktive Sozialforschung formuliert worden sind. 


\subsection{Fallstrukturen - Typenbildung - theoretische Stichprobenbildung}

Im vorangegangenen Kapitel habe ich diskutiert, inwiefern eine biographietheoretische und figurationssoziologische Perspektive ermöglicht, Prozesse historischer Generationenbildung zu verstehen und zu erklären. Es ist dargelegt worden, dass eine solche Erforschung historischer Generationen eine Rekonstruktion des jeweils spezifischen Prozesses anstrebt, in dem Individuum und Gesellschaft verflochten sind. Ziel des Forschungsprozesses ist, zumindest annäherungsweise, die Analyse von Prozessstrukturen beziehungsweise Fallstrukturen, wie sie in der Tradition der interpretativen beziehungsweise rekonstruktiven Sozialforschung verstanden werden. Es ist nicht das Ziel dieser Forschungsarbeit, die umfassende methodologische Diskussion zur theoretischen Verallgemeinerung und Typenbildung in der sozialwissenschaftlichen Forschung $\mathrm{zu}$ rekapitulieren. Dennoch möchte ich an dieser Stelle einige einordnende methodologische Orientierungspunkte nennen, die dem rekonstruktiven Forschungsprozess dieser Arbeit zugrunde liegen und die mit der Wahl der Methoden in Zusammenhang stehen.

Einen Orientierungspunkt für den rekonstruktiven Forschungsprozess dieser Arbeit bilden die Überlegungen zu wissenschaftlicher Typenbildung, wie sie in der phänomenologischen Wissenssoziologie, im Besonderen von Alfred Schütz unternommenen wurden. Die Bildung wissenschaftlicher Typen erfordert eine Rekonstruktion der Typisierungen, die von den Gesellschaftsmitgliedern im Alltag ausgehandelt und zur Anwendung gebracht werden, und die deren Deutungen und Handlungen bestimmen. Die wissenschaftliche Typenbildung soll auf diesen alltäglichen Typisierungsprozessen aufbauen und mit diesen abgestimmt sein, wie die sogenannten Postulate der subjektiven Interpretation und der Adäquanz, die von Schütz (1971: 39 ff., 49 ff.) aufgestellt wurden, einfordern. Schütz spricht in diesem Zusammenhang von „Konstruktionen zweiten Grades“ (ebd.: 7). Die Typisierungsprozesse und die damit verbundenen Verstehensvorgänge auf der Alltagsebene und in der Wissenschaft ähneln sich generell, haben jedoch einige unterschiedliche Bedingungen. So wird die wissenschaftliche Typenbildung unter den Bedingungen systematisch kontrollierter Verstehensprozesse erreicht, die sich unter anderem durch die partielle Ausschaltung von Handlungsdruck und den Rückgriff auf sozialwissenschaftliches Sonderwissen im Rahmen einer theoretischen Einstellung auszeichnen (Soeffner/Hitzler 1994: 33 ff.; Luckmann 2003: 24 ff.). Zudem müsse wissenschaftliche Typenbildung Anforderungen an Eindeutigkeit und logische Konsistenz genügen (Schütz 1971: 49 f.), die im Alltagshandeln nicht gegeben sind.

Einen weiteren methodologischen Bezugspunkt für diese Forschungsarbeit bildet das Verständnis von Fallstrukturen und genetisch-strukturalen Typen, wie es bereits in Kapitel 2.6 hergeleitet wurde. Grundlegend ist das Verständnis von Fallstrukturgeneralisierungen, wie es in der Objektiven Hermeneutik diskutiert 
wird (Oevermann 2000: 58). Außerdem folge ich der Auslegung der methodologischen und wissenschaftstheoretischen Arbeiten Kurt Lewins zur nichtnummerischen Verallgemeinerungslogik und zur Typenbildung (Lewin 1967 [1927]), wie sie von Gabriele Rosenthal und anderen geleistet wurde (Bude 2006; Rosenthal 2011: 73 ff.). Hier werden unter Fallstrukturen empirisch auftretende ${ }^{46}$ Wirkungszusammenhänge verstanden, die ,hauptverantwortlich ' das jeweilige Fallgeschehen hervorbringen. Im Auswertungsprozess werden diejenigen Komponenten und deren Komposition ausgemacht, die für das empirisch-konkrete Gebilde eines Falles von größerer Bedeutung sind als dessen andere Komponenten. Die Bedeutung der Komponenten wird nicht an deren nummerisches Auftreten im Fallgeschehen oder in der Stichprobe gebunden. Die Komponenten und ihre Komposition, die Fallstruktur, sind für das empirische Sosein des Falles auch dann verantwortlich, wenn für das Sosein anderer Fälle andere Komponenten verantwortlich sind (Lewin 1967 [1927]: 18 f.). Verallgemeinert wird in dieser Logik ,von einem konkreten Fall auf alle gleichartigen Fälle“ (ebd.: 15). Das heißt, verallgemeinert wird auf diejenigen Fälle, die durch den gleichen Wirkungszusammenhang strukturiert werden. Dieses Verständnis von Fallstrukturen beruht auch auf einem in der rekonstruktiven Sozialforschung gängigen, bereits im vorangegangenen Kapitel rekapitulierten Verständnis des Ineinandergreifens von ,Subjektivem ' und ,Gesellschaftlichem', von Besonderem und Allgemeinem. Im Fallgeschehen, etwa in einer Biographie, ist Allgemeines immer schon mitdokumentiert und daher prinzipiell und mit der Nutzung interpretativer Erhebungs- und Auswertungsverfahren rekonstruierbar (Wernet 2006: 19). Indem die Fallstrukturen auf eine Fragestellung bezogen werden, gehen sie schließlich in die Konstruktion von Typen ein. Von genetisch-strukturalen Typen kann man dann sprechen, wenn es nicht (nur) um eine Zusammenstellung von typischen Eigenschaften, sondern auch um eine Rekonstruktion der Genese geht, also der Prozesse, die den Fall hervorgebracht haben (vgl. Rosenthal 2011: 75).

Nun ist als weiterer Orientierungspunkt des rekonstruktiven Forschungsprozesses die Ebene der Stichprobenbildung berührt. In dieser Forschungslogik ist es nicht Ziel der Stichprobenbildung, eine Wiederholung der Merkmalsverteilung der Grundgesamtheit zu erreichen, wie dies in einem standardisierten Verfahren der Fall wäre. Vielmehr soll, näherungsweise, eine Abbildung aller Fallstrukturen beziehungsweise Typen zu einer Fragestellung erreicht werden - man kann auch von den empirisch im Feld auftretenden Varianten der ,Antworten' auf eine Fragestel-

\footnotetext{
${ }^{46}$ Mit dem Verweis auf das empirisch Auftretende weiche ich von einem Typenverständnis ab, wie es manchmal im Anschluss an Max Weber unter Idealtypen verstanden wird. Webers Ausführungen insbesondere im ,berühmten' Objektivitätsaufsatz können dahingehend verstanden werden, Typen relativ abgehoben vom empirischen Geschehen zu konstruieren. Idealtypen werden, in den Worten Webers, ,gewonnen durch einseitige Steigerung eines oder einiger Gesichtspunkte und durch Zusammenschluß einer Fülle von [...] stellenweise gar nicht, vorhandenen Einzelerscheinungen“. Siehe in diesem Zusammenhang auch Elias' Kritik am Weber'schen Konzept des Idealtypus 1977b: 457 ff.; Diskussion bei Kilminster 2007: 165.
} 
Methoden und Stichprobe

lung sprechen (Bude 2006: 61).47 Diese Überlegungen gehen auch auf das sogenannte theoretische Sampling nach Glaser und Strauss (2008 [1967]) zurück. Thre theoretische Stichprobenbildung richtet sich in Abgrenzung zur statistischen Stichprobenbildung an sich sukzessive im Forschungsverlauf herausbildenden theoretischen Kategorien aus. Der Forschungsprozess folgt einer Pendelbewegung zwischen nicht klar abgetrennten, schwerpunktmäßigen Phasen der Erhebung und Auswertung. In Abhängigkeit von generierten ,Zwischenergebnissen', also der sich herausbildenden Theorie, werden weitere Sampling-Entscheidungen getroffen sowie Methodennutzung und Fragestellung angepasst. Der Forschungsprozess zielt damit forschungslogisch auf eine ,theoretische Sättigung“ (Glaser/Strauss 2008 [1967]: 61 f.), die forschungspraktisch allerdings selten erreicht wird.

Wird, wie in dieser Forschungsarbeit, im Rahmen eines theoretischen Samplings mit biographisch-narrativen Interviews und biographischen Fallrekonstruktionen gearbeitet, kommt ein weiterer Aspekt hinzu: Die Überlegungen zum theoretischen Sampling sind von Glaser und Strauss vor dem Hintergrund eines vorwiegend ethnographischen Forschungsvorgehens mit teilnehmenden Beobachtungen gemacht worden. In der Arbeit mit biographisch-narrativen Interviews und biographischen Fallrekonstruktionen kann es sinnvoll sein, eine Unterscheidung von erster und zweiter theoretischer Stichprobe zu treffen. Während die erste Stichprobe alle erhobenen Daten beinhaltet, umfasst die zweite Stichprobe alle ausführlichen biographischen Fallauswertungen. Im Forschungsprozess werden dann wiederholt Entscheidungen über eine mögliche Erweiterung beider Stichproben getroffen (Rosenthal 2011: 87 ff.). Diese Trennung von erster und zweiter theoretischer Stichprobe wurde auch im Rahmen dieser Forschungsarbeit vorgenommen.

Generell sind in einem rekonstruktiven Forschungsprozess, und so war es auch im Rahmen dieser Arbeit, der Prozess der Stichprobenbildung, die Entwicklung und Konkretisierung der Fragestellung und die Typenbildung aufeinander bezogen. Im Folgenden möchte ich auf die Zusammensetzung meiner Stichprobe und auf den Prozess der Stichprobenbildung im Westjordanland eingehen.

\footnotetext{
${ }^{47}$ Die theoretisch zumindest denkbare Konstellation, dass man mit jedem rekonstruierten Fall auf einen neuen, von den bisherigen untersuchten Fällen gänzlich verschiedenen Wirkungszusammenhang stößt und damit so viele Typen wie Fälle konstruieren könnte, ist ein Grenzfall.
} 


\subsection{Sampleentwicklung im Westjordanland}

Die Stichprobe, die dieser Forschungsarbeit zugrunde liegt, ist eine Teilmenge der umfassenderen Stichprobe, die im Rahmen des zwischen 2010 und 2015 von der DFG geförderten Forschungsprojektes „Außenseiter und Etablierte zugleich: Palästinenser und Israelis in unterschiedlichen Figurationen“ unter der Leitung von Gabriele Rosenthal von meinen Kolleg*innen und mir erhoben wurde. In der Gesamtstichprobe des Forschungsprojektes liegen neben zahlreichen ethnographischen Interviews und Beobachtungen für das Westjordanland insgesamt 108 biographisch-narrative Interviews vor (überwiegend aus den Regionen um und in Ramallah und Bethlehem). ${ }^{48}$ Darunter sind mit einer Anzahl von 53 circa die Hälfte der Interviews mit Flüchtlingen beziehungsweise deren Nachkommen geführt worden. Ungefähr ein Drittel der Interviewten sind Frauen. Die Interviews wurden zunächst mittels des Schneeballprinzips nach Begegnungen im Rahmen von teilnehmenden Beobachtungen sowie über (palästinensische) Kolleg*innen und Freund*innen organisiert, später wurde gezielt nach den von mir im Folgenden explizierten Kriterien gesampelt. Zu allen Interviews wurden Memos angefertigt (Rosenthal 2011: 92 f.). Die Interviews dauerten zwischen eineinhalb und neun Stunden und wurden meist in mehreren Sitzungen geführt.

Die Einbettung der Stichprobe meines Promotionsprojektes in die Stichprobe des Gesamtforschungsprojekts hatte zur Folge, dass von mir Daten im Westjordanland erhoben wurden, die nicht in diese Qualifikationsarbeit eingingen, und umgekehrt Daten von mir ausgewertet und für diese Qualifikationsarbeit genutzt wurden, die nicht von mir erhoben worden waren. Auch wenn die Zusammenstellung der ersten Stichprobe des Forschungsprojektes auch anderen ,Strängen“ der Theorieentwicklung gefolgt ist, hat sie dennoch für mein Teilprojekt ebenfalls als erste Stichprobe gedient. Im Rahmen des theoretischen Samplings für meine Promotionsarbeit habe ich also wiederholt während des Forschungsprozesses abgewogen, inwiefern es analytisch gewinnbringend wäre, entweder Fälle aus der Stichprobe des Forschungsprojektes für mein Promotionsvorhaben zu ziehen und zu analysieren, und ob es nötig wäre, die Stichprobe des Gesamtprojektes für die Analysen meines Promotionsprojektes zu erweitern. In dieser Hinsicht waren der Samplingprozess des Gesamtprojektes und der meines Promotionsprojektes verschränkt.

In der Forschungsarbeit habe ich in der zweiten Stichprobe fünf ausführliche Fallrekonstruktionen durchgeführt und sieben Globalanalysen angefertigt. Bei den Analysen wurde neben den biographisch-narrativen Interviews insbesondere auch auf Daten aus den teilnehmenden Beobachtungen zurückgegriffen. Sowohl die ausführlichen Fallrekonstruktionen, da sie Eltern- und Kindergeneration derselben

\footnotetext{
${ }^{48} \mathrm{Im}$ Forschungsprojekt wurden außerdem in Ostjerusalem und Israel Erhebungen durchgeführt. In Ostjerusalem wurden 62 biographisch-narrative Interviews und in Israel 52 biographisch-narrative Interviews durchgeführt (insbesondere in Haifa und Jaffa).
} 
Familien umfassen (Kap. 6.3; 7.3; 8.3), wie auch die Globalanalysen, da sie ganz überwiegend in derselben Peergroup angesiedelt sind (vgl. Kap. 6.2; 7.2), sind in der Darstellung zum Teil stark ineinander verschränkt. Die anderen von meinen Kolleg*innen und mir erhobenen Interviews und Beobachtungen sowie die Auswertungen, die von meinen Kolleg*innen und mir im Rahmen des Forschungsprojektes vorgenommen und zum Teil publiziert wurden, aber im Rahmen dieser Arbeit nicht explizit diskutiert werden, sind als Hintergrundwissen eingegangen, ohne dass sie konkret einzelnen Fallrekonstruktionen zugeordnet werden können. Die von mir selbst durchgeführten Datenerhebungen verteilen sich auf insgesamt vier Feldaufenthalte, von März bis April 2013, von September bis Oktober 2013, von September 2014 bis April 2015 sowie im August 2015. Insgesamt war ich circa elf Monate im Feld. An dieser Stelle möchte ich das Vorgehen bei der Stichprobenbildung und die damit verbundenen sozialen Verflechtungen, denen ich im Westjordanland nachgespürt habe, diskutieren.

Ausgangspunkt meiner Stichprobenbildung für mein Promotionsprojekt, und gleichzeitig das empirische Herzstück meiner Forschungsarbeit, waren eine Clique junger Männer, ihre Familien und ihr soziales Umfeld in einer FlüchtlingslagerGegend im Westjordanland. Die mit diesem Kontext verbundenen empirischen Analysen stelle ich ausführlich in Kapitel 6 dar. Das empirische Material, das ich im Zusammenhang mit der Clique und ihrem Umfeld erhoben habe, und die daraus entstandenen Analysen sind gegenüber den anderen in dieser Arbeit ebenfalls berücksichtigten Forschungskontexten in Ramallah als umfassender und tiefer einzuschätzen. In meinen Beobachtungen und Analysen stellte sich unter anderem heraus, dass in der biographischen Phase, in der sich die jungen Männer damals befanden, die Involvierung in Straßenschlachten mit dem israelischen Militär, welches häufig in die Flüchtlingslager-Gegend kam, um Verhaftungen durchzuführen, von großer Relevanz für die Erfahrungsbildung und Deutungsmuster der jungen Männer war. Die Relevanz schlug sich auch in der biographischen Bedeutung des Cliquenzusammenhangs nieder, der (zunächst) den wesentlichen Kontext für die Involvierung in die Straßenschlachten bildete. Daher folgten meine Kolleg*innen und ich in der Stichprobenbildung zunächst dem Cliquenkontext, kamen mit den jungen Männern enger in Kontakt, besuchten sie regelmäßig im Lager und führten Interviews. Dabei folgten wir sozusagen den Kontaktpräferenzen der jungen Männer, was bedeutete, dass wir Freunde und Bekannte - die Generationsgenossen - als Interviewpartner berücksichtigten. Von den jungen Männern wurden sie zum Teil explizit, etwa aufgrund ihrer in den Augen der Freunde ,interessanten" Inhaftierungsgeschichten, vorgeschlagen. Nach und nach versuchten wir aber auch, gerade gegen diese Kontaktpräferenzen beziehungsweise Relevanzen der Cliquenmitglieder ,anzusampeln'. So nahmen wir auch Familienmitglieder der jungen Männer aus unterschiedlichen Generationen umfassend in die Stichprobe auf. Dies entsprach zwar nicht unbedingt den Vorstellungen der jungen Männer und unterlief sicher auch den Blick auf mich als Altersgenossen bezie- 
hungsweise als ,einer von ihnen' (der ohnehin nur sehr begrenzt gegeben war), wurde aber dennoch von ihnen toleriert und zum Teil durch Kontaktherstellung und Terminkoordination unterstützt. ${ }^{49}$

Bei der Stichprobenbildung folgten meine Kolleg*innen und ich dann im weiteren Verlauf folgenden Strategien: Einerseits ging es darum, dem Interdependenzgeflecht beziehungsweise den Figurationen nachzuspüren, in welchen die jungen Männer standen und stehen - auch über die sozialen Nahbereiche Clique, die Familien und den Lagerkontext hinaus, die wir in der Stichprobenziehung nach und nach verließen. Wir versuchten, Mitglieder gerade jener Gruppierungen in die Stichprobe aufzunehmen, die für die Erfahrungsbildung der jungen Männer zentrale Interaktionspartner waren und/oder an denen sie sich in ihren Deutungsmustern und Wir- und Sie-Bildern orientierten - sowohl im positiven als auch im negativen, abgrenzenden Sinne. Um an dieser Stelle einmal auf die empirischen Analysen und die Ergebnisdiskussion vorzugreifen: Dies betrifft zum Beispiel die in der Interaktion mit Familienmitgliedern deutlich werdende Relevanz des Verhältnisses zur Generation Erste Intifada (vgl. Kap. 6). Dies betrifft auch das Verhältnis der jungen Männer zu ,den Städtern', die aus Sicht der jungen Männer ,nicht für die palästinensische Sache kämpfen'. Diese Sie-Bilder und die Verflechtungen, die sie unter Umständen zum Ausdruck bringen, wurden für uns zu einer Art Samplingempfehlung. Wir nahmen zum Beispiel die Altansässigen in die Stichprobe auf, auf deren Biographien und Deutungsmuster die Sie-Bilder der Clique zugeschnitten waren (vgl. Kap. 8).

Außerdem folgten wir bei der konkreten Zusammenstellung der Stichprobe auch der im theoretischen Sampling üblichen Strategie, nach minimal und maximal kontrastiven Fällen zu suchen. Ziel ist hier die Berücksichtigung von Fällen, bei denen man bei oberflächlicher Anschauung zunächst erwartet, dass sie sehr ähnlich beziehungsweise gänzlich verschieden ,funktionieren' und so die in der Entwicklung befindlichen theoretischen Kategorien schärfen (Glaser/Strauss 2008 [1967]: 55 ff.; Schütze 1983: 287). Die eben genannten urbanen Altansässigen konnten aufgrund ihres ökonomischen und kulturellen Kapitals und ihres Fokus darauf, biographisches Risiko im Hinblick auf die ,palästinensische Sache` zu vermeiden, als maximaler Kontrast zu der Clique aus der Flüchtlingslager-Gegend erwartet werden. Ein weiterer Erhebungskontext wurde als deutlicher Kontrast zu den jungen Männern in der Flüchtlingslager-Gegend erwartet. Dies betraf ,Städter', die ,kämpften', die also trotz ihres Wohnortes mit den jungen Männern aus der Flüchtlingslager-Gegend die Erfahrung der Involvierung in die Straßenschlachten teilen. Hier haben wir erneut eine Clique von jungen Männern sowie deren Familien erhoben und ausgewertet (vgl. Kap. 7). Als Mitglieder der städtischen Mittelschicht und als Kinder von sogenannten Rückkehrern mit Verbindungen zur PA stehen sie allerdings in einer deutlich anderen gesellschaftlichen

${ }^{49} \mathrm{Im}$ Rahmen des Kapitels 6.2.5 gehe ich umfassender auf die Position meiner Kolleg*innen und mir in der Clique ein. 
Methoden und Stichprobe

Position, wie sich auch in der biographischen Verhandlung der Involvierung in die Straßenschlachten zeigt. Zum Teil waren letztere und deren Familien bereits von meinen Kolleg*innen bei Feldaufenthalten 2010 und 2011 interviewt worden, waren also bereits in der ersten theoretischen Stichprobe vorhanden. Diese wurde von mir in weiteren Erhebungen 2014 und 2015 ergänzt. Außerdem erhoben wir einige minimal kontrastive Fälle, die auf eine Verdichtung des Samples in den Flüchtlingslager-Gegenden zielten: Es wurden Daten zu Bewohner*innen anderer Flüchtlingslager erhoben. Insgesamt sind in fünf verschiedenen Flüchtlingslagern im Raum um Bethlehem und Ramallah Interviews geführt und Beobachtungen durchgeführt worden. Diese Erhebungen bestätigen ganz überwiegend die Ergebnisse dieser Forschungsarbeit (vgl. Worm/Hinrichsen/Albaba 2015; vgl. Kap. 9). Außerdem wurden in der Flüchtlingslager-Gegend, in der auch die jungen Männer aus der Clique lebten, Daten zu jungen Männern und Frauen erhoben, die sich nicht in die Straßenschlachten involvierten. Dieses Datenmaterial wird im Rahmen dieser Arbeit nur am Rande diskutiert, ist zum Teil aber für andere Veröffentlichungen ausgewertet worden (Hinrichsen/Rosenthal/Worm 2013; Hinrichsen 2017; vgl. Kap. 9). Zusammenfassend wurde in der Stichprobenbildung einerseits versucht, den Beziehungsgeflechten oder Figurationen nachzuspüren, die sich im Feld darboten. In Verbindung mit diesem Vorgehen folgten wir andererseits einer Logik des maximal und minimal kontrastiven Fallvergleichs.

Im Verlauf der Stichprobenentwicklung konkretisierte sich zudem meine Forschungsfrage. Zunächst hatte ich nur eine allgemeine Forschungsfrage nach der Wechselwirkung von verschiedenen Zugehörigkeiten im Westjordanland formuliert und zudem angedacht, der Differenzierung religiöser Zugehörigkeiten ein stärkeres Gewicht zu geben. In diesem Bereich liegen auch zwei meiner in der Anfangsphase meiner Dissertationsarbeit gemeinsam mit meinen Kolleg*innen verfassten Veröffentlichungen (vgl. Hinrichsen/Becker/Rosenthal 2015; Rosenthal/Hinrichsen/Becker 2015). Im Forschungsverlauf und im Zuge der bereits skizzierten Stichprobenentwicklung deckte ich dann nach und nach die Relevanz einer historischen Generationenzugehörigkeit für die Lebensgeschichten, die Verflechtung der Generationengruppen und deren spezifisches Zusammenwirken mit anderen Zugehörigkeiten auf. 


\subsection{Erhebungs- und Auswertungsinstrumente im Einzelnen}

3.4.1 Methodenplurale Forschung mit ethnographischem und biographischem Ansatz

In dieser Forschungsarbeit wurden Erhebungen und Auswertungen mit biographisch-narrativen Interviews und biographischen Fallrekonstruktionen mit teilnehmenden Beobachtungen und Sequenzanalysen von Beobachtungsprotokollen kombiniert. Diese Methodenkombination, die in einigen Forschungsarbeiten der Chicago School ihre soziologiegeschichtlichen Vorläufer hat (Thomas/Znaniecki 1918), ist auch in der jüngeren Biographieforschung in verschiedenen Arbeiten erprobt und produktiv genutzt worden (Köttig 2004; Brandhorst 2015; Pape 2016; Becker 2017). Auch Beiträge, die die Kombination beider Forschungsperspektiven in ihren methodologischen und methodischen Implikationen diskutieren, liegen vor (Dausien/Kelle 2009; Köttig 2018; Becker 2017; Bahl/Worm 2018; Becker/Rosenthal in Vorbereitung). Einer der Gewinne einer Kombination liegt in der unterschiedlichen Schwerpunktsetzung der Methoden: Während bei teilnehmenden Beobachtungen die Analyse von Interaktionsprozessen im Vordergrund steht, die Forscher*innen im Feld erleben, versucht eine biographische Perspektive die Rekonstruktion längerfristiger Prozesse der Erfahrungsbildung. Tendenziell benennt der Fokus der einen Perspektive das Defizit der anderen Perspektive: Stehe ich bei der Teilnahme an Interaktionen, auch bei längeren Teilnahmen, vor der Frage, wie sich die Interaktionsvorgänge aus den Interaktionsgeschichten der Akteure und ihren in anderen Zusammenhängen erworbenen Erfahrungsbeständen verstehen und erklären lassen, bin ich im Kontext von Interviews stärker mit der Frage konfrontiert, inwiefern meine Analysen durch Prozesse retrospektiver Erfahrungsrekapitulation und Perspektivität erschwert werden. Daher schließe ich mich der Einschätzung von Dausien/Kelle an:

„Eine Berücksichtigung der Biographizität sozialer Interaktionen dürfte zu dichteren ethnographischen Beschreibungen und Analysen führen; umgekehrt bedeutet eine systematische Reflexion der Situiertheit des intersubjektiven sense making in konkreten Interaktionen zweifellos einen Gewinn für die Biographieforschung“" (2009: 190).

Beide Perspektiven können sich in dieser Weise gegenseitig ergänzen, nämlich dadurch, dass sie sich gerade darin treffen, unterschiedliche Facetten derselben sozialen Prozesse und Verflechtungen zu rekonstruieren (Bahl/Worm 2018). Einer Methodenkombination mit dieser Zielsetzung, die einer figurationssoziologischen und einer biographietheoretischen Perspektive sehr entspricht, folge ich in dieser Forschungsarbeit. 
Methoden und Stichprobe

\subsubsection{Biographisch-narrative Interviews}

Das biographisch-narrative Interview wurde in den 1970er Jahren von Fritz Schütze und dem Arbeitskreis Bielefelder Soziologen (1977, 1983) entwickelt. Zentraler Gedanke des biographisch-narrativen Interviews ist die Hervorlockung von „Stegreif-Erzählungen eigenerlebter Erfahrungen“ (Schütze 1976: 225). Im biographisch-narrativen Interview wird einerseits versucht, den Interviewten möglichst breiten Raum zur Entwicklung der eigenen Perspektive zu geben, um so ein Datenmaterial zu erzeugen, in welchem die Konstruktionen und Relevanzen der Forschungssubjekte durchgängig dokumentiert und damit rekonstruierbar sind. Zum anderen zielt das biographisch-narrative Interview vorwiegend darauf, im Interview spontane, das heißt nicht eingeübte Narrationen zu evozieren. Bei einer Stegreiferzählung und vor allem einem Prozess des Erzählens von Geschichte zu Geschichte erhöht dies die Chance, auf deren Basis das Erleben vergangener Handlungsabläufe rekonstruieren zu können. Erzählungen sind daher nach Schütze

„diejenigen vom thematisch interessierenden faktischen Handeln abgehobenen sprachlichen Texte, die diesem am nächsten stehen und die Orientierungsstrukturen des faktischen Handelns auch unter der Perspektive der Erfahrungsrekapitulation in beträchtlichem Maße rekonstruieren“" (1977:1).

Schütze geht davon aus, dass eine in diesem Sinne verstandene Fähigkeit zu erzählen Teil des basalen Kompetenzerwerbs in der Primärsozialisation ist und ,auch in ihrem Fertigkeitsniveau relativ schichtunabhängig verteilt ist" (Schütze 1987: 245). Das narrative Interview richtet sich dann in der Interviewführung, in der Phaseneinteilung des Interviews, in der Eingangsfrage und den Fragetechniken im Nachfrageteil an diesen erzähltheoretischen Überlegungen aus. ${ }^{50}$

Die im Rahmen meiner Forschungsarbeit durchgeführten biographischnarrativen Interviews wurden entweder in englischer Sprache oder in arabischer Sprache mit Hilfe eines Übersetzers oder einer Übersetzerin geführt. Die Interviews wurden aufgezeichnet und transkribiert. Arabische Transkripte wurden ins Deutsche übersetzt. Viele der Interviews habe ich gemeinsam mit meinem Kollegen Ahmad Albaba geführt, der das Arabische für mich übersetzte. Meine Arabischkenntnisse erlaubten mir zudem eine eigenständige Arbeit mit den Transkripten und Protokollen. Die Übersetzungen von Textpassagen, die für die Auswertung besonders bedeutsam waren, weil sie zum Beispiel für eine Auswertung im Rahmen von Feinanalysen vorgesehen waren, wurden im Detail mit meinen muttersprachlich Arabisch sprechenden Kolleg*innen abgestimmt. Zum Teil wurden Transkripte mehrfach übersetzt. Differenzen zwischen den Transkripten, den

\footnotetext{
${ }^{50}$ Fritz Schütze hat mit der Narrationsanalyse ein Verfahren zur Auswertung narrativer Interviews vorgelegt, welches von Gabriele Rosenthal zum Verfahren biographischer Fallrekonstruktionen weiterentwickelt wurde (vgl. Kap. 3.4.4).
} 
mündlichen Übersetzungen im Interview und den Transkriptübersetzungen oder zwischen verschiedenen Versionen der Transkriptübersetzungen wurden in den Auswertungsprozess soweit möglich einbezogen. Ein einfaches Beispiel für eine deutliche Differenz zwischen Transkripten und mündlichen oder schriftlichen Übersetzungen, die meinen Kolleg*innen und mir begegnete, ist die Übersetzung des Wortes al-yahūd, also „die Juden“, mit „Israelis“, die eine sprachliche Differenzierung zwischen ,Juden“ und „Israelis“ nachträglich einführt. In dieser Übersetzung kam meist eine Kenntnis der Verhandlung des Nahostkonfliktes im ,Westen' und eine Orientierung an ihr zum Ausdruck. ${ }^{51}$

$\mathrm{Zu}$ den geführten Interviews wurden Memos angefertigt, auf deren Grundlage entschieden wurde, welche Interviews in die zweite Stichprobe gezogen, also im Rahmen biographischer Fallrekonstruktionen ausgewertet werden sollten. Die Memos und die Ergebnisse der Fallrekonstruktionen bildeten entsprechend des Forschungsvorgehens in einem theoretischen Sample die Grundlage für die Frage, ob und in welche Richtung erste und zweite Stichproben einer Erweiterung bedürfen.

In der methodischen Diskussion um das (biographisch-)narrative Interview ist gelegentlich dessen Einsatz im Globalen Süden problematisiert worden. Zum Beispiel Joachim Matthes diskutierte im Anschluss an Forschungen in Singapur, inwiefern sich die bei narrativen Verfahren mitlaufenden erzähltheoretischen Grundlagen auf gesellschaftliche Kontexte im Globalen Süden übertragen lassen. Dies könne auch

„zu einer ausdrücklichen oder eingeschlossenen ,Anthropologisierung“ des Erzählens führen, die abstrakt als Grundeigenschaft zwischenmenschlichen Handels nimmt, was konkret an einer bestimmten Erscheinungsform von Erzählen ablesbar wird, wobei sich dann die Wahrnehmung der Vielfalt kultureller Erscheinungsformen von Erzählen schnell und unbemerkt auf die enumerative Feststellung von Variationen auf ,eine‘ Grundform des Erzählens reduziert“" (1985b: 313).

Ohne an dieser Stelle der Komplexität dieser Debatte ${ }^{52}$ voll gerecht werden zu können, sei angemerkt, dass meine Kolleg*innen und ich in unseren Forschungstätigkeiten im arabischen Raum und in anderen Regionen im Globalen Süden nicht feststellen konnten, dass die Arbeit mit biographisch-narrativen Interviews erheblich eingeschränkt gewesen wäre oder prinzipiell anders ,funktioniert` hätte. Immer wieder machten meine Kolleg*innen und ich die Erfahrung, dass Erinnerungs- und Erzählprozesse in den lebensgeschichtlichen Interviews

\footnotetext{
51 Zum analytischen Umgang mit Differenzen zwischen mündlichen und schriftlichen Übersetzungen vgl. Inhetveen 2012.

52 Diese Diskussion ist zum Beispiel auch mit den von Alois Hahn diskutierten Biographiegeneratoren (1987), die unter anderem die Tradition der Beichte umfassen, verbunden. Es stellt sich die Frage, inwiefern diese in anderen gesellschaftlichen Kontexten im Globalen Süden gegeben sind.
} 
zugelassen wurden und ,gelangen؛. Wurde sich in den Interviews nicht auf Erinnerungs- und Erzählprozesse eingelassen, stand dies in der Regel mit rekonstruierbaren Faktoren in Zusammenhang, die nicht auf die Erscheinungsformen von Narrationen oder narrativen Grundkompetenzen zurückgeführt werden konnten. An anderer Stelle haben wir unter anderem mit Bezug auf das Westjordanland diskutiert, welche Konstellationen es unseren palästinensischen Gesprächspartner*innen gelegentlich erschwerten, in den Interviews in einen Erinnerungsund Erzählprozess einzutreten (Hinrichsen/Rosenthal/Worm 2013). Zu diesen Konstellationen gehörte die manchmal schwierige Vereinbarung von in der Erinnerung gegenwärtig werdenden Erlebnissen und in der Gegenwart des Interviews wirksamen diskursiven Regeln und Anforderungen an die Vertretung nationaler Wir-Bilder. Diese mit der Vertretung eines nationalen Wir-Bildes verbundenen diskursiven Regeln - der von uns so benannte homogenisierende und harmonisierende Wir-Diskurs - wurden gelegentlich gegenüber Forscher*innen aus dem westlichen Ausland präsentiert, aber auch gegenüber anderen Palästinenser*innen in Stellung gebracht (Rosenthal 2015). Die Möglichkeiten und die Bereitschaft, sich bei bestimmten Themen oder biographischen Phasen sowie im Interview generell auf Erinnerungs- und Erzählprozesse einzulassen, standen und stehen unter anderem mit der gesellschaftlichen Stellung beziehungsweise, genauer, der figurationalen Positionierung der Interviewpartner*innen im Westjordanland in Zusammenhang (ebd.).

Auch die Auswirkungen, die die Arbeit mit Übersetzer*innen im Interview hatte, waren damit verknüpft. Eine Rolle spielte zum Beispiel, ob die durch Übersetzung entstehenden Pausen im Interview von den Interviewpartner*innen dazu ,genutz $t^{\varsigma}$ wurden, sich den eigenen Erinnerungen verstärkt zuzuwenden, oder ob sie dazu genutzt wurden, das Gesprochene aus der Gegenwartsperspektive heraus stärker zu kontrollieren und zu ,planen'. Darüber hinaus galten und gelten im Westjordanland verschiedene auch in der Interviewsituation wirksame Angemessenheitsregeln, die den Interviewverlauf und Erinnerungs- und Erzählprozesse mitbedingen. Neben vielen anderen Aspekten umfassen diese beispielsweise die sich aus den jeweiligen Geschlechtskonstruktionen ergebenden Interaktionsregeln mit Konsequenzen für die Interaktionseröffnung, die Wahl der Interviewer*in oder die Bewegung im privaten Raum, die sich je nach Familie, Generation und Milieu, aber auch nach gegebener Vertrautheit mit den Interviewpartner*innen und der gemeinsamen Interaktionsgeschichte wiederum erheblich unterscheiden können. Ein weiteres Beispiel für die in der Interviewsituation wirksamen Interaktionsregeln sind die ,Strategien', mit denen die Gesprächspartner*innen jeweils versuchten, die Interviewer*innen und Übersetzer*innen nach sozialen Zugehörigkeiten zu kategorisieren, wie dies Gabriele Rosenthal exemplarisch für religiöse Zugehörigkeit diskutiert hat (2012). Gerade ein interpretatives beziehungsweise rekonstruktives Forschungsvorgehen ermöglicht, solche im Feld geltenden Regeln 
herauszuarbeiten, analytisch zu nutzen und sich im Forschungsverlauf auf diese einzustellen.

\subsubsection{Teilnehmende Beobachtungen}

In dieser Forschungsarbeit wurde während der verschiedenen Feldaufenthalte zwischen 2013 und 2015, insbesondere während meines längeren Aufenthalts von August 2014 bis April 2015, mit teilnehmenden Beobachtungen gearbeitet. Als Bestandteil einer ethnographischen Forschungsstrategie hat die teilnehmende Beobachtung ihre Wurzeln in der ethnologischen Forschung und, was die Soziologie betrifft, vor allem in der Chicago School (Lüders 2008: 385). Das Ziel teilnehmender Beobachtungen ist das Miterleben von sozialen Phänomenen, Interaktionsvorgängen und Akteuren in ihren „natural settings“ (Walsh 2004: 228). Das Handeln von Akteuren soll gerade in den Alltagskontexten beobachtet und erlebt werden, in denen es sich für gewöhnlich vollzieht. Dafür nehmen die Forschenden mit unterschiedlichem Involvierungsgrad an den Handlungsvollzügen teil, ihre eigenen Motive und Handlungsplanungen verstricken sich mit dem Feld und seinen Akteuren (Spradley 1980: 58 ff.). Idealerweise vollzieht sich ein Prozess, in dem Akteure sowie Handlungsvollzüge und -kontexte nach und nach verstanden und sukzessive vertrauter werden.

Anfängliche Irritationen und Krisen werden nach Möglichkeit produktiv gewendet im Sinne einer Anregung von Verstehensprozessen und einer Vertiefung in das Feld. Mit fortschreitendem Vertraut-Werden wird allerdings eine verstehende, reflexive Distanzierung zum Geschehen tendenziell schwieriger, daher ist die Dokumentation dieses Prozesses entscheidend. Von hervorgehobenem analytischen Interesse ist bereits der Feldzugang, also der Kontaktaufbau und die ,ersten Schritte in das Feld. Da sich an dem ,Weg', über den man tiefer ins Feld gelangt, in der Regel bereits wesentliche Charakteristika und Dynamiken desselben ablesen lassen, ist er analytisch von wesentlicher Bedeutung (Wolff 2008: 339). Wie der Feldzugang kann auch die (sich verändernde) Position der Forschenden im Feld ein ,Steinbruch' für das Verständnis des Feldes sein. Meine Position in den verschiedenen Forschungskontexten im Westjordanland und deren Wandel sowie die an mich gerichteten Zuschreibungen und Abgrenzungen werde ich im Rahmen der empirischen Diskussion, sofern sie analytisch gewinnbringend sind, zum Thema machen. Den jeweiligen Feldzugang zu den unterschiedlichen Akteuren und Interviewpartern*innen thematisiere ich jeweils im Zusammenhang mit den konkret diskutierten Fällen (Kap. 6-8). An dieser Stelle möchte ich zunächst einen allgemeinen Eindruck von meinen Feldaufenthalten im Westjordanland vermitteln und knapp auf die unterschiedlichen Kontexte, in denen ich teilnehmende Beobachtungen durchgeführt habe, eingehen.

Bei meinen Feldaufenthalten verbrachte ich zwischen 2013 und 2015 insgesamt circa elf Monate im Westjordanland. Bei meinen Feldaufenthalten 2013 wohnte ich in einem Hotel beziehungsweise in einer gemieteten Wohnung in der 
Methoden und Stichprobe

Nähe der Flüchtlingslager-Gegend, in der die jungen Männer und ihre Familien lebten. Bei meinem längeren Feldaufenthalt 2014-2015 wohnte ich in einer anderen Flüchtlingslager-Gegend, die circa eineinhalb Autostunden von der ersten entfernt lag. Die Familie eines Freundes, selbst palästinensischer Flüchtling, lebte und lebt dort in einer informellen Siedlung, die in den 1950er Jahren am Rande eines offiziellen Flüchtlingslagers von Flüchtlingen, die keine Parzellen im benachbarten Flüchtlingslager zugeteilt bekommen hatten, gebaut worden war (vgl. Kap. 4.2). Sie vermieteten mir ein Zimmer im Haus der Familie, in welchem ich zwischen September 2014 und April 2015 lebte. Neben meinen Erhebungen haben auch die vielen Erlebnisse und informellen Gespräche in der Familie und in der Nachbarschaft zu meinem Verständnis des Feldes erheblich beigetragen.

Bei meinen Beobachtungen in der Flüchtlingslager-Gegend, in der die jungen Männer und ihre Familien lebten, versuchte ich während meiner Aufenthalte möglichst regelmäßig im Miteinander der Clique präsent zu sein. Wir trafen uns bei den Freunden oder im Café, unterhielten uns, aßen und rauchten gemeinsam, ,hingen rum' oder besuchten gemeinsam Veranstaltungen. Meine regelmäßigen Besuche erlaubten mir einen Einblick in die Aushandlungs- und Interaktionsprozesse in der Clique. Meine Anwesenheit war gerade dafür gewinnbringend, die Verhandlung und Validierung von relevanten Ereignissen im Alltagsleben der Clique zumindest gelegentlich ,in actu' erleben zu können. In Kapitel 6.2.4 diskutiere ich beispielsweise die Verhandlung eines Heiratsantrages, den einer der jungen Männer aus der Clique bei der Familie seiner Freundin vorgebracht hatte und der von der Familie abgelehnt worden war. In den von mir diskutierten Aushandlungsprozessen wird deutlich, wie dieses Ereignis gemeinsam in die in der Clique kursierenden Deutungsmuster , ihrer' gesellschaftlichen Marginalisierung eingefasst wurde.

Einen wesentlichen Bereich des Alltagshandelns, der für die jungen Männer eine bedeutende Rolle spielte, wurde von mir jedoch nicht teilnehmend beobachtet - nämlich die direkte Involvierung der Cliquenmitglieder in die Straßenschlachten mit dem israelischen Militär und den Sicherheitskräften der PA. Auch wenn ich während meiner Aufenthalte gelegentlich mit dem Gedanken spielte, einmal ,nachts mit rauszugehen', waren mir letztlich die damit verbundenen Risiken zu hoch. Dennoch blieb es während meiner Feldaufenthalte nicht aus, dass ich die Militäroperationen und Straßenschlachten wiederholt aus der Perspektive des Anwohners oder Zuschauers erlebte, wenn ich im Westjordanland reiste oder wenn es in meinem unmittelbaren Wohnumfeld zu Auseinandersetzungen zwischen israelischen Soldaten und jungen Männern aus ,meinem Viertel kam. Im Zuge dieser Erlebnisse veränderte sich auch mein Erleben. Zum Beispiel stiegen zu Beginn bei dem Gedanken daran, dass sich in wenigen Metern Luftlinie SchieBereien abspielten, panische Gefühle in mir auf und es plagte mich die Frage, ob der Wandbeton im Fall der Fälle wohl die Kugeln aufhalten würde - Ängste, denen von meinen Nachbar*innen auch mit Witzen und Spott begegnet wurde 
(„,wirf dich nächstes Mal im Zimmer auf den Boden“). Allmählich gelangte ich zu der Haltung, mich durch die Explosion von Gasgranaten oder den Gewehrschüssen der Soldaten möglichst nicht vom Lesen oder Schlafen abhalten zu lassen.

Auch erlebte ich die ambivalente Verhandlung der nächtlichen Aktionen unter Nachbar*innen und Familienmitgliedern, die zwischen stolzen Bemerkungen wie „heute Nacht kam der Widerstand aus unseren Vierteln“ und Kopfschütteln über die vermeintliche Sinnlosigkeit dieser Aktionen rangierte. Am helllichten Tag im Stau stehend erlebte ich die Sorge, bei unvorhergesehen entstehenden Auseinandersetzungen in die Schusslinie zu geraten. Als Nachbar erfuhr ich die Trauer und die Wut, die sichtbar wurde, wenn die Straßenschlachten Todesopfer forderten. Und ich erlebte die Angst, dass bekannte und geliebte Menschen in Ostjerusalem zur falschen Zeit an der falschen Bushaltestelle warten könnten. ${ }^{53}$ Kurzum, ich erlebte in Ansätzen eine Veralltäglichung jenes Zustands, der sich hinter dem euphemistischen Begriff der ,Sicherheitslage im Westjordanland verbirgt - und dies in einer von meinen palästinensischen Freunden und Bekannten so benannten ,ruhigen Phase'. Und, dies ist ganz zentral, natürlich immer in der privilegierten Position, mich mit meinem deutschen Pass diesen Lebensumständen jederzeit entziehen zu können.

Bei meinen Beobachtungen wurde mir auch deutlich, wie weit entfernt sich diese Ereignisse in den Restaurants und Bars von Ramallah anfühlen können, was einer meiner palästinensischen Bekannten in folgende Wort fasste: ,in Ramallah I don't feel oppressed“ (vgl. Kap. 8.2). In Ramallah führte ich - und zum Teil auch meinen Kolleg*innen - Beobachtungen im Familien-, Freundes- und Bekanntenkreis sowohl der Clique junger Männer aus Rückkehrerfamilien als auch in den Kreisen der Altansässigen durch. In der Clique der Rückkehrer und ihren Familien, die ich in Kapitel 7 diskutiere, führten insbesondere meine Kolleg*innen Beobachtungen in deren Sportverein und in den Cafés, in welchen einige der jungen Männer aus der Stadt arbeiteten, durch. Ich selbst kam, dies habe ich bereits erwähnt, mit der Clique der Rückkehrer aus Ramallah und ihren Familien erst ab 2014 bei meinen gezielten Nacherhebungen in Kontakt.

In den Familien-, Freundes- und Bekanntenkreis meiner Gesprächs- und Interviewpartner*innen aus Altansässigenfamilien führte ich ebenfalls Beobachtungen durch. Dazu hatte ich insbesondere durch die Teilnahme an Freizeitaktivitäten Gelegenheit. Bei Treffen im Café oder Park, beim Wandern im Umland Ramallahs oder bei Partys in angemieteten Festsälen in Ramallahs Hotels, bei Besuchen in den Familien oder Restaurantbesuchen (vgl. Kap. 8.2). Einige Bekannte waren Kunststudierende und unterhielten in der Nähe meines Wohnortes ein Atelier, wo

\footnotetext{
${ }^{53} \mathrm{Im}$ Kontext der israelischen Militäroperation in Gaza 2014 war es zu einer Phase von palästinensischen Aufständen und vermehrten Attentaten zunächst insbesondere in Jerusalem gekommen, die ihren Höhepunkt zwischen Juli und August 2014 hatten. Während meines Feldaufenthalts 2014 gab es auch Attentate, bei denen von Palästinensern Fahrzeuge in Passanten oder Menschenmengen etwa in der Nähe von Bushaltestellen - gesteuert wurden.
} 
Methoden und Stichprobe

sie sich regelmäßig auch abends mit Freund*innen zum Musikhören und Trinken trafen. Insgesamt bekam ich so einen umfassenden Einblick in das Leben von Ramallahs, Mittelschicht'.

Generell strebten meine Kolleg*innen und ich an, die genutzten Erhebungsinstrumente - so auch die Beobachtungen - an den Fällen zu kombinieren. Das heißt, wir versuchten, mit unseren Interviewpartner*innen auch im Alltag Zeit zu verbringen und mit unseren primären Interaktionspartner*innen auch Interviews zu führen. Insgesamt ermöglichten mir meine Beobachtungen und Feldaufenthalte neben der Erhebung von Datenmaterial im engeren Sinne auch die Aneignung von „Regelwissen“ (Oevermann 1986: 19), also von generellem Kontextwissen zu den im Feld gültigen Regeln und Wissensbeständen.

\subsubsection{Biographische Fallrekonstruktionen}

Diejenigen Fälle, die in die zweite theoretische Stichprobe gezogen wurden, wurden mittels des Verfahrens der biographischen Fallrekonstruktion nach Gabriele Rosenthal (1995; 2011) ausgewertet.

Ein fallrekonstruktives Verfahren kann gegenüber einem subsumptionslogischen Vorgehen wie folgt abgegrenzt werden (Oevermann 1981: 4). In einem subsumptionslogischen Vorgehen werden einerseits über die Abläufe des einzelnen Falles - dessen sequenzielle Gestalt - hinweg und andererseits im Fallvergleich über verschiedene Fälle hinweg Hypothesen gebildet und kategorisiert. Im Gegensatz dazu werden in einem fallrekonstruktiven Vorgehen entlang der sequenziellen Gestalt des einzelnen Falles Hypothesen gebildet und getestet und so sukzessive Fallstrukturen herausgearbeitet. Auch das Analyseverfahren biographischer Fallrekonstruktionen zielt auf die Rekonstruktion von Fallstrukturen, wie sie in Kapitel 2.6 definiert wurden. In rekonstruktiven Verfahren wird in der Regel ein Vorgehen mit Sequenzanalysen mit einem abduktiven Schlussverfahren kombiniert.

Sequenzanalysen basieren auf der Annahme, dass soziale Wirklichkeit immer einen Prozesscharakter hat. ${ }^{54}$ Empirische Fälle stellen immer ein ablaufendes Geschehen dar, in dem sich Prozesse des Auswählens und Auslassens von Optionen oder ,Pfaden' vollziehen (vgl. Kap. 2). Ein entsprechendes Erhebungsvorgehen vorausgesetzt, ist es das Ziel von Sequenzanalysen, protokollierte Abläufe und deren innere Logik zu rekonstruieren. Ausgehend von den einzelnen Sequenzen werden möglichst erschöpfend Hypothesen gebildet und am weiteren Fallgeschehen, also strikt in der Abfolge des Geschehens, ,abgetestet'. Durch den Abgleich mit dem Fallgeschehen werden Hypothesen Zug um Zug bestätigt, ausdifferenziert oder falsifiziert - die Frage ist also, welche Lesarten sich letztendlich durchsetzen. Die Hypothesenbildung und -prüfung ist bereits an den einzelnen Sequen-

\footnotetext{
${ }^{54} \mathrm{Zu}$ den verschiedenen Verfahren in der rekonstruktiven Sozialforschung, die Sequenzanalysen nutzen, vgl. Reichertz 2016: 259 ff.
} 
zen möglichst erschöpfend durchzuführen und erfolgt durch eine Hintereinanderschaltung von abduktiven, deduktiven und induktiven Schlüssen im Rahmen eines abduktiven Verfahrens, wie es von Charles Sanders Peirce entwickelt wurde (1980 [1933]). Das Vorwissen der Forschenden wird hier in Form von Hypothesen unter anderen Auslegungsvarianten an das Fallgeschehen herangetragen. Jo Reichertz bemerkt dazu: ,[S]trikte Sequenzanalysen führen dazu, dass alle geltenden oder für uns gültigen Vorurteile, Urteile, Meinungen und Ansichten in der Regel schnell zusammenbrechen“ (2011: 3). Die Sequenzanalyse sei ein Verfahren ,zur Zerstörung der gesamten sozialen Vorurteile der Interpreten - auch wenn dies nicht immer gelingt" (ebd.). In gleicher Weise müssen auch Hypothesen, die aus den sozialwissenschaftlichen Sonderwissensbeständen abgeleitet werden, in ihrer Erklärungskraft immer erst in Schlussfolgen am Fallgeschehen ,abgetestet' werden. Dieses abduktiv-sequenzielle Auswertungsvorgehen lässt sich auf verschiedene Datenarten übertragen und wird auch dann, wenn Beobachtungsprotokolle, Interviews und Protokolle von Gruppendiskussionen die Datengrundlage bilden, in prinzipiell gleicher Weise angewendet. Auch das Analyseverfahren biographischer Fallrekonstruktionen geht in diesem Sinne abduktiv-sequenziell vor.

Biographische Fallrekonstruktionen basieren meist zu einem großen Teil auf Datenmaterial, das auf der Rekapitulation von Erfahrungen fußt. In Interviews oder vergleichbaren Gesprächssituationen getroffene Äußerungen, die auf Erinnerungen basieren, werden für Aussagen über die Vergangenheit genutzt. Dieser Umstand ist in der Biographieforschung untersucht und umfassend theoretisch reflektiert worden (Schütze 1984; Rosenthal 1995). In ihren Forschungen hat Gabriele Rosenthal, gestützt auf die Arbeiten von Aron Gurwitsch, Alfred Schütz und Edmund Husserl sowie der ,Berliner Schule ${ }^{6}$ der Gestaltheorie (vgl. Kap. 2.6), diese Frage als ein dialektisches Spannungsverhältnis von Erleben, Erinnern und Erzählen diskutiert. Dabei wird deutlich, dass auf Erinnerungen basierende Erzählungen Textbestandteile und -fragmente enthalten können, die an vergangenen Prozessen orientiert sind und durchaus der Perspektive, mit der aus der Gegenwart auf dieselben geblickt wird, widersprechen können. ${ }^{55}$ Diese Textbestandteile ermöglichen, mal mehr, mal weniger umfassend, die Rekonstruktion vergangener Erlebens- und Handlungspassagen. Um diesem Spannungsverhältnis von Erleben, Erinnern und Erzählen Rechnung zu tragen, wird in biographischen

\footnotetext{
55 Rosenthal greift die auch von Gurwitsch genutzten, aber von Husserl (1976) geprägten Begriffe „Noesis“, den Akt der Zuwendung, und „Noema“, den sich der Zuwendung darbietenden ,vermeinten' Gegenstand auf. Einerseits bestimmt die Gegenwartsperspektive, die Noesis, die Auswahl und die Gestalt von Erinnerungen und ist so für das Erinnerungsnoema konstitutiv (Rosenthal 2010: 208). Andererseits ist das Noema durch seine gestalthafte Verweisung auf andere Noemata strukturiert und bestimmt so die Noesis (Rosenthal 2010: 208, 21; Rosenthal 1995: 39). Auf Basis dieser Dialektik wird es möglich, dass „Komponenten der erinnerten Situation vorstellig werden, die mit der Gegenwartsperspektive nicht kompatibel sind, nicht dem Präsentationsinteresse und den Regeln der gegenwärtig wirksamen sozialen Diskurse entsprechen“ (Rosenthal 2010: 201).
} 
Fallrekonstruktionen eine zunächst analytisch getrennte Auswertung von erzählter und erlebter Lebensgeschichte vorgenommen.

Das Verfahren umfasst sechs Auswertungsschritte (Rosenthal 2011: 186 ff.). Der erste Auswertungsschritt besteht in der Analyse biographischer Daten. Zunächst werden die biographischen Daten, inklusive der kollektiv- und familiengeschichtlichen Daten, unter Absehung der kontextualisierenden Aussagen der Interviewpartner*innen auf ihre mögliche biographische Bedeutung hin analysiert. Diese Vorgehensweise soll ein vorschnelles Einlassen auf die Bedeutung, die Biograph*innen ihrer Lebensgeschichte und deren Phasen sowie den Ereignissen aus der Gegenwart geben, verhindern. Dieser Auswertungsschritt benötigt in der Regel eine erhebliche Literatur-, Archiv- und Recherchearbeit, um den biographischen Prozess in den jeweiligen sozio-historischen Kontext einzubetten. ${ }^{56}$ Ziel des Schrittes ist es, eine Strukturhypothese, oder zumindest Hypothesen wahrscheinlicher Strukturkomponenten, für den Verlauf der Biographie und deren Erleben in der Vergangenheit zu erstellen.

Der zweite Auswertungsschritt ist die Text- und thematische Feldanalyse. Er zielt auf die Rekonstruktion sogenannter thematischer Felder, deren Konzeption im Anschluss an wiederum Aron Gurwitsch sowie Wolfram Fischer (1978) ebenfalls phänomenologisch-gestalttheoretische Überlegungen zugrunde liegen. Mit einem thematischen Feld werden die Gesamtanordnung und die Struktur der gegenseitigen Verweisungen von Äußerungen und Themen bezeichnet, die in einem Interview oder einem Gespräch genannt oder gerade nicht genannt beziehungsweise ausgelassen wurden. Erst im Hinblick auf diese Verweisungsstruktur sind einzelne Äußerungen und Interviewpassagen sinnhaft, daher ist ihre Rekonstruktion zentraler Teil dieses Auswertungsschrittes. Im Zuge dieses Schrittes werden auch Interaktionsdynamiken während des Interviews, dessen Rahmung durch die Interviewten und die mögliche Veränderung der Rahmung während des Interviews sowie Zuschreibungen an die Interviewenden rekonstruiert, die die Bedeutungskonstruktionen mitbedingen können. Datengrundlage für diesen Auswertungsschritt ist in der Regel eine auf Basis des Transkriptes erstellte Sequenzierung des Interviewtextes.

Die dann folgenden Auswertungsschritte zielen auf eine Rekonstruktion der erlebten Lebensgeschichte und das Zusammenbringen beider Analyseebenen. Vor dem Hintergrund der Strukturhypothese, die im ersten Auswertungsschritt analysiert wurde, und der Rekonstruktion der Gegenwartsperspektive im zweiten Schritt werden nun einzelne Textpassagen daraufhin befragt, welche Rückschlüsse sie auf das Erleben und die funktionale Bedeutsamkeit für die Biographie in der Vergangenheit zulassen. Von besonderer Bedeutung sind hier deutlich narrativ ausgestaltete Textpassagen, die eine Rekonstruktion vergangener Ereignis- und Erlebensabläufe erleichtern. Sogenannte Feinanalysen werden genutzt, um anhand

${ }^{56} \mathrm{Zu}$ diesem Auswertungsschritt vgl. insbesondere Radenbach/Rosenthal 2012. 
von Transkriptpassagen (bisher nicht entdeckte) latente Sinngehalte offenzulegen und bestehende Lesarten und Strukturhypothesen auszudifferenzieren. In weiteren Auswertungsschritten werden die Ergebnisse der Rekonstruktion des erzählten und des erlebten Lebens nochmals systematisch aufeinander bezogen und als Fallstruktur formuliert. Indem die Fallstruktur auf die Fragestellung der Forschungsarbeit bezogen wird, erfolgt die Typenbildung (für diese Arbeit vgl. Kap. 9). Die auch von mir im Rahmen dieser Arbeit durchgeführten Globalanalysen stellen verdichtete, oberflächlichere Versionen von Fallrekonstruktionen dar, die aber mittels derselben Auswertungsschritte durchgeführt werden (Rosenthal 2011).

\subsubsection{Sequenzanalysen auf Basis von Beobachtungsprotokollen}

Die teilnehmenden Beobachtungen und Eindrücke im Feld wurden in Beobachtungsprotokollen und in einem Feldtagebuch dokumentiert. In der ethnographischen Forschungsliteratur finden sich zahlreiche Handreichungen und Richtlinien zur Protokollierung und Analyse von Beobachtungen, die je nach Feldkontext und angestrebtem Standardisierungsgrad differieren. Ich habe mich an Gabriele Rosenthals praxisorientierten Vorschlägen für die Protokollierung und Auswertung von Beobachtungen orientiert, die eine Basis für eine rekonstruktive Auswertung von Beobachtungen bilden sollen (2011: 108-121). Für die Protokollierung empfiehlt sie neben der Notierung von Kontext- und Rahmendaten (zu Ort, Zeit, Interaktionsteilnehmer*innen und grober Ablaufstruktur) die Konzentration auf wenige einzelne, aber dafür in der Ablaufgestalt möglichst umfassend protokollierte Interaktionsabläufe innerhalb der Gesamtbeobachtung. Ein solches Vorgehen ermöglicht am ehesten eine zumindest partielle Rekonstruktion der Sequenzialität von Interaktionen, was ich zu berücksichtigen versuchte. Von besonderem Interesse sind auch Krisensituationen, in denen die im Feld geltenden Regeln und deren Verhandlung sichtbar werden können (wie zum Beispiel im Fall der in Kap. 6.2.4 diskutierten Ablehnung eines Heiratsantrags). Die Protokolle wurden von mir möglichst zeitnah nach den Beobachtungen verfasst. Zum Teil nutzte ich auch Pausen, etwa Zigaretten- oder Toilettenpausen, um erste Notizen, insbesondere Zitate, ins Handy zu tippen. Oft gelang mir eine Protokollierung allerdings erst abends nach einem langen Tag im Feld. Ein Spezifikum der für diese Arbeit analysierten Beobachtungen ist auch - gerade während der ,frühen' Beobachtungen im Jahr 2013 - deren Durchführung in Teams mit wechselnder Zusammensetzung. Dies erschwerte zu Beginn etwas den Beziehungsaufbau, ermöglichte aber das Austesten der mit der Zusammensetzung des Teams variierenden ,Reaktionsweisen' im Feld und schlug sich auch in der Protokollierung der Beobachtungen nieder. So wurden die Protokolle separat verfasst und zusammengeführt oder wurden später von den Kolleg*innen ergänzt und ermöglichten auch auf diese Weise Kommentierungen und Diskussionen zu unterschiedlichen Perspektiven und Fokussierungen (Knoblauch 2001: 131). 
Methoden und Stichprobe

Die Beobachtungsprotokolle waren insgesamt von sehr unterschiedlicher Beschaffenheit und wurden in unterschiedlicher Weise für den Auswertungsprozess berücksichtigt. Manchmal dienten Beobachtungsprotokolle auch nur dazu, Kontextinformationen zu Akteur*innen oder generell Hintergrundwissen zum Feld zu dokumentieren. Hier war insbesondere das Feldtagebuch dienlich, welches ich besonders in den ersten Wochen intensiv pflegte. Während ich gerade zu Beginn auch mit der Notierung und Aneignung von Kontext- und Regelwissen beschäftigt war, wurden meine Protokolle mit der Zeit selektiver und die Einschätzung von Ereignissen als, ungewöhnlich' fiel mit der zunehmenden Kenntnis der Biographien und der Interaktionsgeschichten leichter.

Die Protokolle und Notizen aus den Beobachtungen insgesamt brachte ich gemeinsam mit den aufgenommenen Interviews und Notizen in eine große chronologische Ordnung. Dies half mir unter anderem, die Akzentverschiebungen in den Gesprächen mit den jungen Männern aus der Flüchtlingslager-Gegend über einen Zeitraum von zweieinhalb Jahren zu erkennen, in denen nicht nur eine Veränderung unseres Verhältnisses deutlich wurde, sondern auch eine moderate Verschiebung in den Themen und Relevanzen, die in der Clique verhandelt wurden (vgl. Kap. 6.2). An ausführlichen, auch ins Detail gehenden Beobachtungsprotokollen, bei denen ich in der Lage gewesen war, zumindest einzelne Interaktionsund Gesprächsabläufe in ihrem Ablauf zu protokollieren, nahm ich zum Teil Feinanalysen im Sinne eines rekonstruktiven Forschungsvorgehens vor. Wie auch im Rahmen der biographischen Fallrekonstruktionen erfolgte die Auswertung der erhobenen Daten wenn möglich in Auswertungsgruppen.

Abschließend möchte ich noch auf mein Vorgehen bei der Maskierung der erhobenen Daten eingehen. Um die Anonymität meiner Gesprächs- und Interviewpartner*innen zu garantieren, habe ich nicht nur die Namen, sondern auch weitere Charakteristika, wie Wohn- und Geburtsorte, Familienmitglieder, Berufe und so weiter verändert, um mögliche Rückschlüsse auf die Personen zu verhindern. Damit geht auch einher, auf eine Nennung der Flüchtlingslager-Gegenden oder der Viertel in Ramallah zu verzichten. Es wurde darauf geachtet, bei der Maskierung keine strukturrelevanten Komponenten der Fälle zu verändern. 


\section{Kollektivgeschichtliche Wandlungsprozesse im Westjordanland ab 1948}

\section{1 Überblick}

In diesem Kapitel möchte ich einen Überblick über die kollektivgeschichtlichen Wandlungsprozesse im Westjordanland ab 1948 geben. Dieser Überblick dient dazu, die wesentlichen kollektivgeschichtlichen Entwicklungen, die mit den rekonstruierten Fällen integral verwoben sind, zu diskutieren und nachzuzeichnen. Wo diese besonders relevant für meine Fragestellung nach Bildungsprozessen historischer Generationen sind oder zentrale Hintergrundinformationen zum Verständnis der Fälle geben, habe ich in der Darstellung entsprechende Schwerpunkte gesetzt. Ausführlich gehe ich auf die politische Mobilisierung im Westjordanland ab den 1970er Jahren ein, die mit den von mir rekonstruierten Erfahrungsgeschichten eng verknüpft ist. Ein Hauptaugenmerk lege ich auf die mit den OsloAbkommen Mitte bis Ende der 1990er Jahre angestoßenen gesellschaftlichen Transformationsprozesse, die mit Prozessen historischer Generationenbildung in der Generation Oslo verknüpft sind. So wirken unter anderem die politische Mobilisierung ab den 1970er Jahren und die in den 1990er Jahren verstärkt hervorgetretenen Transformationsprozesse auf die Entstehung einer Generationenfiguration im Westjordanland hin, wie meine empirischen Analysen zeigen und in diesem Kapitel bereits konturiert wird. Des Weiteren werde ich die Geschichte der paläs- 
tinensischen Flüchtlingslager und der Flüchtlingsbevölkerung im Westjordanland, die einen der Schwerpunkte meiner Erhebungen bilden, im Verlauf des Kapitels immer wieder zur Sprache bringen und ins Verhältnis zu den skizzierten gesellschaftlichen Wandlungsprozessen setzen. Außerdem sind zum Teil bereits Ergebnisse meiner empirischen Analysen in die Darstellung des Kapitels eingegangen.

Der Aufbau des Kapitels ergibt sich daher wie folgt. In Kapitelabschnitt 4.2 beginne ich mit einer knappen Darstellung des Ersten Arabisch-Israelischen Krieges und der Nakba. Im Rahmen dieses Abschnitts gehe ich überleitend und zeitlich etwas vorgreifend auch auf den administrativen Kontext und die Entwicklung der Flüchtlingslager ein. In Kapitelabschnitt 4.3 führe ich knapp in die jordanische Zeit ein, also jene Phase bis 1967, in welcher das Westjordanland unter jordanischer Kontrolle stand. Anschließend diskutiere ich ausführlich zentrale gesellschaftliche Entwicklungen während der ersten zwei Dekaden der israelischen Besatzung des Westjordanlandes ab 1967, die palästinensische politische Mobilisierung im Westjordanland ab den 1970er Jahren und die Erste Intifada von 1987 bis circa 1993 (4.4-4.5). In Kapitel 4.6 gehe ich auf die Oslo-Verträge im Rahmen des sogenannten Friedensprozesses und insbesondere auf die gesellschaftlichen Transformationsprozesse ab Mitte der 1990er Jahre ein, die diese anstießen und förderten. Abschließend erörtere ich die Zweite Intifada von 2000 bis circa 2005 (4.7) und die kollektivgeschichtlichen Entwicklungen danach (4.8), die für das Westjordanland eine bis zum Zeitpunkt der Abfassung dieser Arbeit (2019) andauernde Phase kennzeichnen, in welcher erneute massive bewaffnete Auseinandersetzungen zwischen Palästinensern, dem israelischen Militär und israelischen Siedlern ausblieben.

\subsection{Der Erste Arabisch-Israelische Krieg 1948/49 und die Nakba}

Nach dem Ersten Weltkrieg zogen Frankreich und Großbritannien im Bilad AsSham beziehungsweise in der Region Großsyrien im östlichen Mittelmeerraum, in welcher auch die Region Palästina ${ }^{57}$ liegt, nach kolonialen Einflusssphären geordnete, neue Grenzverläufe. Die Absprachen für eine koloniale Neuordnung der Region waren zwischen den beiden europäischen Mächten wesentlich im sogenannten Sykes-Picot-Abkommen von 1916 während des Ersten Weltkriegs getroffen worden. In dieser Zeit war die Niederlage des Osmanischen Reiches, zu welchem die Region vor dem Krieg gehört hatte, bereits absehbar gewesen. Nach dem Krieg kam Palästina im Rahmen eines 1922 ratifizierten Völkerbundmandats unter britische Herrschaft. Das Mandatsgebiet umfasste zunächst auch das östlich des Jordans gelegene Transjordanien, letzteres wurde jedoch bereits 1923 als Emi-

\footnotetext{
${ }^{57}$ Für eine historiographische Diskussion der Konjunktur der Regionalbezeichnung „Palästina“ vgl. Doumani 1992: 9 f.
} 
rat Transjordanien ausgegliedert und 1946 formal von Großbritannien unabhängig. Die jüdisch-zionistischen und die arabischen Bevölkerungsteile Palästinas hatten mit dem Beginn der britischen Mandatszeit Hoffnungen auf jeweilige nationale Unabhängigkeiten verbunden, was unter anderem eine Folge der mehrgleisigen britischen Bündnispolitik während des Ersten Weltkrieges war. ${ }^{58}$ Im Fortgang der Mandatszeit war es jedoch zu zunehmender Segregation und Konkurrenz zwischen dem wachsenden Jischuw, ${ }^{59}$ also der jüdischen Bevölkerung, und der arabischen Bevölkerung sowie zu einer Zunahme der Spannungen und gewaltsamen Konflikte zwischen den Gruppierungen und mit der britischen Mandatsmacht gekommen, insbesondere im Verlauf des Jahres 1929 sowie im Arabischen Aufstand 1936 bis 1939 (Tessler 2009: 184, 233 ff.). Nach dem Zweiten Weltkrieg vertieften sich die Konfliktlinien erneut: Zur Eskalation der Situation kam es insbesondere, nachdem die UN im November 1947 als Resolution einen Teilungsplan für Palästina verabschiedet hatte, der von arabischer Seite vehement abgelehnt wurde. Die Konflikte bewegten sich mit Anschlägen und bewaffneten Auseinandersetzungen von Mandatstruppen, jüdischen und arabischen Paramilitärs in Richtung eines Bürgerkrieges (Cohen 1982: 229 ff., 301 ff.). Nach dem Abzug der britischen Mandatstruppen im Mai 1948 riefen jüdisch-zionistische Gruppierungen die israelische Unabhängigkeit aus, woraufhin die arabischen Staaten Ägypten, Syrien, Libanon, Irak und Transjordanien Israel den Krieg erklärten. Die Kampfhandlungen hielten bis ins Frühjahr 1949 an. Von Februar 1949 bis Juli 1949 wurden nach und nach Waffenstillstandsabkommen zwischen Israel und den arabischen Staaten geschlossen.

Im Ersten Arabisch-Israelischen Krieg sowie in den Spannungen und bewaffneten Konflikten im Mandatsgebiet im Vorfeld hat die Frage der palästinensischen Flüchtlinge ihren Ausgangspunkt: nämlich in der später als Nakba bezeichneten Flucht und Vertreibung von ungefähr 700.000 Palästinenser*innen aus dem späteren israelischen Staatsgebiet. Die Nakba wurde in den folgenden Jahrzehnten zum zentralen Bestandteil des palästinensischen kollektiven Gedächtnisses und ist bis heute einer der Kristallisationspunkte der Deutungskämpfe und diskursiven Auseinandersetzungen um die israelische Staatsgründung und den sogenannten Nahostkonflikt. ${ }^{60}$ Der Erste Arabisch-Israelische Krieg und die Nakba können den-

\footnotetext{
${ }^{58}$ Die verschiedenen Abkommen umfassen neben dem Sykes-Picot-Abkommen die BalfourErklärung und die Hussein-McMahon-Korrespondenz der Jahre 1915/16, in denen jeweils der jüdischen beziehungsweise arabischen Seite Unterstützung der Unabhängigkeitsbestrebungen signalisiert wurden.

${ }^{59}$ Mit Jischuw wird die jüdische Gebietsbevölkerung in Palästina vor der israelischen Staatsgründung bezeichnet. Während der britischen Mandatsperiode wuchs die jüdische Immigration nach Palästina bereits in den 1920er Jahren deutlich (Krämer 2006: 216 f.).

${ }^{60} \mathrm{Im}$ Zusammenhang mit den diskursiven Auseinandersetzungen, auch im Wissenschaftsbetrieb, ist die Arbeit von Neil Caplan „The Israel-Palestine Conflict. Contested Histories“ (2010) zu empfehlen, da sie, neben einer Darstellung der Geschichte des Nahostkonflikts, gerade auch eine gelungene
} 
noch - und zum Teil sicherlich gerade deswegen - als relativ gut erforscht gelten. In der geschichts- und sozialwissenschaftlichen Forschungsliteratur wurden der Kriegsverlauf, die Truppen- und Fluchtbewegungen, das Ausmaß und die ,Varianten' von Vertreibungen sowie die Verübung von Massakern an der Zivilbevölkerung ausführlich rekonstruiert. Insbesondere sind hier die Arbeiten von Benny Morris $(1988 ; 2004)$ hervorzuheben. ${ }^{61}$

Nach dem Krieg zerstörte die israelische Armee die von den palästinensischen Flüchtlingen verlassenen Dörfer - insgesamt etwa 400 - größtenteils und unterband Versuche von Palästinenser*innen, in die bisherigen Siedlungsgebiete zurückzukehren (Khalidi 1992). Die Routen der flüchtenden Palästinenser*innen führten diese häufig in die anliegenden arabischen Staaten, insbesondere nach Syrien, in den Libanon, nach Jordanien und Ägypten sowie ins nach dem Krieg ägyptisch verwaltete Gaza beziehungsweise jordanisch besetzte Westjordanland. Welche Flüchtlingsgruppierungen tendenziell in den Lagern lebten, hing wesentlich von deren gesellschaftlichem Status und den entsprechenden Ressourcen und Familiennetzwerken vor der Flucht ab. Die Notablen und die städtische Bevölkerung - darunter große Teile der christlichen Bevölkerung - wohnten nach der Flucht erneut eher in den Städten. Die Flüchtlingslagerbevölkerung hatte wiederum mit größerer Wahrscheinlichkeit einen ländlichen, bäuerlichen Hintergrund und hatte mit der Flucht nun ihre bisherige Lebensgrundlage, ihr Farmland, verloren.

Zunächst versuchten verschiedene Hilfsorganisationen, insbesondere das Rote Kreuz, eine rudimentäre Versorgung der umherziehenden Flüchtlingsgruppierungen sicherzustellen. Zur Versorgung der Flüchtlinge wurde dann 1949 die United Nations Relief and Works Agency for Palestine Refugees in the Near East, kurz UNRWA, gegründet. Die UNRWA baute in den umliegenden arabischen Staaten ab Ende der 1940er Jahre dutzende Flüchtlingslager auf, heute sind es insgesamt 58 offizielle Lager. ${ }^{62}$ Die Bewohner*innen der Flüchtlingslager lebten zunächst in Zeltstädten, die aber bis Ende der 1950er Jahre vollständig durch einfache Steinbauten ersetzt wurden. Die Größe der Steinbauten hing von der jeweiligen Famili-

Bestandsaufnahme der zentralen neuralgischen Punkte der Deutungskämpfe um und Perspektiven auf diese Geschichte darstellt.

${ }^{61} \mathrm{Zu}$ einer knappen Bewertung der Arbeit von Morris siehe auch Krämer 2006: 411. Eine wissenschaftlich stärker umstrittene, aber häufig zitierte Arbeit ist „The Ethnic Cleansing of Palestine“ (2006) von Ilan Pappe, die gegenüber Morris’ Arbeiten stärker den intentional-strategischen Charakter der Vertreibung der arabischen Bevölkerung durch die jüdischen Paramilitärs unterstreicht. ${ }^{6}$ Die Jahre der Gründungen der UNRWA-Lager nach der Nakba liegen mit wenigen Ausnahmen zwischen 1948 und 1955. Die Anzahl der Lager veränderte sich über die Zeit, was wesentlich mit dem Krieg von 1967 und Grenzscharmützeln in den Folgejahren zusammenhängt (Al-Husseini 2013: 238). Im Westjordanland flüchteten im Zuge des Krieges zahlreiche Bewohner*innen des Nuweimeh Lagers im Jerichoer Umland, das nach dem Krieg von der UNRWA als bisher einziges Lager aufgegeben wurde. Im ebenfalls in Jericho gelegenen Aqbat Jaber Lager reduzierte sich die Bewohner*innenzahl aufgrund von Flucht massiv. Im Ostjordanland wurden für die Aufnahme der Flüchtlinge sechs neue Lager gegründet, andere, insbesondere grenznahe Lager wurden verlegt. 
engröße ab. ${ }^{63}$ Neben dem Aufbau von Unterkünften und der Versorgung mit Nahrungsmitteln waren und sind bis in die Gegenwart die von der UNRWA unterhaltenen Sozial-, Gesundheits- und insbesondere Bildungsprogramme - im Westjordanland sind dies vor allem Schulen bis zum neunten Schuljahr - für die Flüchtlingsbevölkerung wichtig. Das Spektrum der Leistungen der UNRWA reduzierte sich mit den Jahrzehnten deutlich (Feldman 2012: 390 f.). Ihre Leistungen konnten und können auch von außerhalb der Lager lebenden, registrierten Flüchtlingen in Anspruch genommen werden. Zudem waren die Flüchtlingslager - anders als zum Teil spätere, für andere Flüchtlingsgruppierungen von der UNHCR betriebene Flüchtlingslager - nicht grundsätzlich auf eine Trennung von Flüchtlingsbevölkerung in den Lagern und ansässiger Bevölkerung angelegt (Al Husseini 2011: 5). Das Land, auf welchem die Lager errichtet wurden, wurde von den staatlichen oder privaten Besitzer*innen gepachtet, meist für 99 Jahre.

Die Flüchtlingslager entstanden in der Regel an jenen Orten, an welchen sich größere Flüchtlingsgruppen aufgrund der Nähe zu Verbindungstraßen und Wasserquellen sowie etwaiger Akzeptanz beziehungsweise Tolerierung durch die ansässige Bevölkerung niedergelassen hatten. ${ }^{64}$ Die Flüchtlingslager lagen und liegen daher auch häufig in der Nähe urbaner Räume und veränderten die Bevölkerungsstruktur dieser Räume zum Teil drastisch. Auch im Westjordanland, in welchem heute insgesamt neunzehn Lager liegen, ist dies der Fall. So wurden beispielsweise im Umland Ramallahs drei Flüchtlingslager gegründet, ebenso im Umland Bethlehems. Zudem bildeten sich bereits in den 1950er Jahren in der Nähe der Lager informelle Siedlungen von Flüchtlingen, die aufgrund der Kapazitätsgrenzen nicht mehr in die Lager kamen. ${ }^{65}$ Mit der Zeit wurden die Lager häufig Teil der angrenzenden städtischen Räume. Misselwitz (2010) diskutiert den Verlauf der informellen Urbanisierung der Lager im Westjordanland und identifiziert verschiedene Phasen. Grob vollzog sich die Urbanisierung von relativ großzügiger Anlegung von Parzellen und öffentlichen Räumen in den Lagern in den 1940 und 1950er Jahren bis zu stark zunehmender vertikaler und horizontaler Verdichtung der

\footnotetext{
${ }^{63}$ Eine Familie bis fünf Personen hatte einen Raum, eine Familie ab sechs Personen zwei Räume zur Verfügung. Weitere Räume durften eigeninitiativ hinzugefügt werden. Außerdem war den Familien auf ihren Parzellen Gemüseanbau und Ähnliches gestattet (Jabr 1989: 76).

${ }^{64}$ Meinen Gesprächspartner*innen im Westjordanland zufolge sind aufgrund der geringeren ,Aufnahmebereitschaft ${ }^{`}$ der Bevölkerung Hebrons während beziehungsweise nach der Nakba keine Flüchtlingslager im unmittelbaren städtischen Umland entstanden.

${ }^{65} \mathrm{Im}$ Westjordanland habe ich selbst circa ein halbes Jahr in einer solchen informellen Siedlung gelebt (vgl. Kap. 3.4.3). Dieses Viertel glich hinsichtlich der dichten Bebauung und ungenügenden Infrastruktur dem benachbarten Flüchtlingslager. Die Bewohner*innen waren aber häufig von einigen privilegierten Regelungen für die Flüchtlinge im ,eigentlichen` Lager, etwa der Kulanz der Stadt gegenüber der Begleichung von Stromkosten, ausgenommen. Da die Siedlung auch nicht auf von der UNRWA gepachtetem Land errichtet worden war, hatte sie in der Vergangenheit mehr Auseinandersetzungen mit den lokalen privaten Landbesitzern. Die Siedlung wurde und wird sporadisch in die Wahlen für das Lagerkomitee einbezogen. Für eine Forschung spezifisch zu einer solchen Siedlung in Amman vgl. Sawalha 1996.
} 
Lager ab den 1990er Jahren. Diese Entwicklung wurde aber unterbrochen von Perioden der infrastrukturellen ,Entlastung ${ }^{6}$ durch den Auszug von Familien aus dem Lager - den Umzug in angrenzende Bezirke oder aber auch aufgrund erneuter Flucht von Teilen der Lagerbevölkerung im Zusammenhang mit dem Krieg von 1967 sowie von Arbeitsmigration in die Golfregion (siehe unten).

Auch jener Lagerkontext, in welchem das in Kapitel 6 ausführlich diskutierte empirische Material erhoben wurde, ist mehr oder weniger mit dem angrenzenden urbanen Raum verwachsen. In den die Lager umgebenden Nachbarschaften lebt häufig (auch) ein großer Anteil an Familien, die in der zweiten oder dritten Generation aus dem ,eigentlichen' Lager ausgezogen sind. Sie bleiben aber durchaus dies ist jeweils eine empirische Frage - deutlich eingebunden in die mit dem Lager verbundenen sozialen Netzwerke. Die umliegenden Nachbarschaften teilen jedoch nicht unbedingt jene infrastrukturellen Mängel, die die Lager mit enger Bebauung und häufig ungenügender und störanfälliger Strom-, Wasser- und Abwasserversorgung bis heute charakterisiert. Der Umfang des durch die UNRWA gepachteten Landes, auf dem die Lager errichtet wurden, hat meines Wissens nach jedoch über die Jahrzehnte keine Ausweitung erfahren. Um dieser, heterogene Infrastrukturverhältnisse umfassenden Ausdehnung der Lager gerecht zu werden, spreche ich in dieser Arbeit in einer etwas sperrigen, aber präziseren Formulierung von Gegenden der Flüchtlingslager oder Flüchtlingslager-Gegenden. Diese begriffliche Regelung korrespondiert auch mit den alltagsweltlichen Konstruktionen: Die von mir untersuchte Clique junger Männer aus einer Flüchtlingslager-Gegend bestand sowohl aus innerhalb als auch aus außerhalb des Kernlagers lebenden und aufgewachsenen jungen Männern. So griffen auch Mitglieder der Clique, die nie im ,eigentlichen' Lager gewohnt, in diesem jedoch durchaus viel Zeit verbracht haben, in Selbstbezeichnungen auf den Begriff „ibn al-muhaīyam“, also „Sohn des Lagers", zurück.

Vor dem Hintergrund dieser Urbanisierungsprozesse ist es schwierig, verlässliche und aussagekräftige Zahlen über die Gesamtzahl der in den Lager-Gegenden lebenden Bevölkerung zu finden. Den Angaben der Palästinensischen Statistikbehörde zufolge waren im Jahr 2014 ein Viertel (25,4 Prozent) der palästinensischen Bevölkerung des Westjordanlandes registrierte palästinensische Flüchtlinge (PCBS 2014: 60). Von diesen offiziell registrierten Flüchtlingen lebte laut dieser Zahlen 2014 wiederum ein knappes Viertel in den Flüchtlingslagern (ebd.: 284). Auf Basis der Regelungen der UNRWA ist es möglich, den Flüchtlingsstatus an die Nachkommen registrierter männlicher Flüchtlinge weiterzugeben, das heißt der Status kann patrilinear ,vererbt' werden. In dieser Arbeit folge ich bei der Bezeichnung „palästinensischer Flüchtling“ der Definition der UNRWA, ich bezeichne also auch die Nachkommen der während der Nakba geflohenen und vertriebenen Palästinenser*innen als Flüchtlinge. Damit bilde ich auch den alltagssprachlichen 
Gebrauch des Begriffs „Flüchtling“ in der palästinensischen Gesellschaft im Westjordanland ab. ${ }^{66}$

Ich komme nun zur kollektivgeschichtlichen Phase nach der Nakba zurück, in welcher das Westjordanland in der Folge des Krieges nach 1948/49 unter jordanische Herrschaft geriet.

\subsection{Das Westjordanland unter jordanischer Herrschaft}

In der Folge des Ersten Arabisch-Israelischen Krieges war das Westjordanland von jordanischen Truppen besetzt und in das jordanische Staatsgebiet integriert worden. Auch Ostjerusalem mit der Altstadt und dem Haram ash-Sharif beziehungsweise dem Tempelberg waren nun unter jordanischer Kontrolle. Jordanien annektierte das besetzte Gebiet 1950 offiziell, allerdings ohne dass der Annexion eine entsprechende internationale Anerkennung folgte.

Nicht nur aufgrund des Zuzugs der Flüchtlinge aus dem Territorium des neugegründeten israelischen Staates, sondern auch aufgrund des Hinzukommens des Westjordanlandes und dessen altansässiger Bevölkerung zum Staatsgebiet veränderte sich die Bevölkerungs- und auch Gesellschaftsstruktur (Trans-)Jordaniens nach 1948/49 massiv. Vor dem Ersten Arabisch-Israelischen Krieg betrug die Bevölkerung Transjordaniens laut Schätzungen circa 340.000 (Brand 1988: 150). Nach dem Krieg kamen bis zu 900.000 Palästinenser*innen als Flüchtlinge und Bewohner*innen des Westjordanlandes hinzu. ${ }^{67}$ Von den etwa 900.000 Palästinenser*innen waren circa 450.000 Flüchtlinge aus dem späteren israelischen Staatsgebiet, von denen ein knappes Drittel in den von der UNRWA aufgebauten Lagern lebte. Allerdings erhöhte sich die Zahl der Bewohner*innen in den Lagern in den ersten Jahren sukzessive aufgrund des Zuzugs weiterer palästinensischer Flüchtlinge (ebd.). Die Flüchtlingsbevölkerung lebte zunächst ganz überwiegend im Westjordanland; 19 der zu jener Zeit 24 palästinensischen Flüchtlingslager in Jordanien befanden sich dort. In den 1950er und 1960er Jahren setzte eine Abwanderung von Palästinenser*innen, nicht nur von Flüchtlingen, sondern auch von Altansässigen, ins Ostjordanland, insbesondere nach Amman, ein. Für diese Wanderungsbewegungen wird unter anderem die wirtschaftspolitische Bevorzugung des Ostjordanlandes gegenüber dem Westjordanland durch den jordanischen Staat, etwa in der Ansiedelung von Industrie, verantwortlich gemacht (Kossaifi 1980: 38).

\footnotetext{
${ }^{66}$ In der arabischen Bezeichnung wäre „Flüchtling“ übersetzt „lāğge'“ beziehungsweise „lăği'“, oder eben auch, wie angegeben „Sohn des Lagers“ beziehungsweise „Tochter des Lagers“, also „ibn almuhaīyam“ oder „bint al-muhaīyam“ (vgl. Kap. 6).

${ }^{67}$ Für eine Diskussion der zum Teil stark variierenden Schätzungen der Bevölkerungszahlen Transjordaniens und des Westjordanlandes in den 1940er Jahren sowie der Zahl der palästinensischen Flüchtlinge, die Ende der 1940er Jahre nach (Trans-)Jordanien flüchteten, vgl. Brand 1988: 254 f.
} 
Für das Leben in den Flüchtlingslagern orientierten sich die Flüchtlinge einerseits an der vor 1948 gelebten familialen und dörflichen Ordnung, die sich aber andererseits in der neuen Konstellation nach der Flucht mit der Zeit veränderte. Stéphanie Latte-Abdallah bemerkt in ihrer Arbeit zu familialen Beziehungen in Flüchtlingslagern in Jordanien: ,the village of origin became the new extended family of exile" (2011: 277). Zum Teil wurden dabei auch erweiterte familiale Beziehungen und Zugehörigkeiten zu den Hamulehs ${ }^{68}$ mit Blick auf die gemeinsamen Herkunftsorte reinterpretiert. Nach dem Vorbild der jeweiligen Herkunftsdörfer bildeten sich in den Lagern ebenfalls Nachbarschaften und Viertel. Auch Heiratsmuster folgten häufig (und folgen zum Teil bis heute) diesen familialen Zugehörigkeiten. In dieser Phase waren mit den Familien und Nachbarschaften verbundene lokale Führer und Autoritäten, die sogenannten Mukhtare, auch für den Kontakt zu und die Einflussnahme durch jordanische Behörden auf die Flüchtlinge zentral (Sawalha 1996: 350).

Das Verhältnis der Flüchtlinge in den Lagern zur altansässigen Bevölkerung war in der Anfangszeit regelmäßig von Auseinandersetzungen um die Landnutzung und anderen Spannungen geprägt. Stigmatisierungen der Flüchtlinge durch die ansässige Bevölkerung - etwa als ,Diebe ${ }^{6}$ von Ernteerträgen oder allgemein aufgrund ihres Status als ,Landlose - waren nicht selten (Shamir 1980: 149 f.). Die wirtschaftliche Einbindung der Flüchtlinge in die jordanische Ökonomie gelang aufgrund der schlechten wirtschaftlichen Lage - zunächst kaum und sorgte für eine gerade in den ersten zwei Dekaden große Abhängigkeit der Flüchtlingsbevölkerung von den Versorgungsleistungen der UNRWA. In der Forschungsliteratur wurde auch gelegentlich darauf hingewiesen, dass etwaige Umsiedlungspläne auf erheblichen Widerstand der Flüchtlinge stießen (Aruri 1972: 45; Al Husseini 2011: $6 \mathrm{f}$.).

Insgesamt setzte die jordanische Führung, sowohl unter Staatsoberhaupt Emir Abdallah als auch unter dem ab 1953 regierenden König Hussein, auf eine Integration der palästinensischen Bevölkerung, während sie gleichzeitig versuchte, palästinensischem Partikularismus entgegenzuwirken. Den Flüchtlingen und den Bewohner*innen des Westjordanlandes wurden volle Staatsbürgerschaftsrechte zugestanden. Parallel wurde Versuchen der Selbstorganisation palästinensischer Flüchtlingsgruppen bereits in den 1950er Jahren repressiv begegnet und entsprechende Kongresse zur Frage der Flüchtlinge, Versammlungen und Flüchtlingsorganisationen nur sehr punktuell und mit gesicherten Loyalitätsverhältnissen zum haschemitischen Königshaus zugelassen (Plascov 1981: 53 ff.). In die politisch instabile Phase Jordaniens in den 1950er Jahren - etwa die Ermordung Emir Abdallahs 1951 oder die innenpolitische Konfrontation von Sulaiman Nabulsi und König Hussein und den damit verbundenen angeblichen Putschversuch von Truppenteilen in Zarqa im April 1957 - war die Flüchtlingsbevölkerung allerdings

\footnotetext{
${ }^{68} \mathrm{Im}$ palästinensischen Kontext die Bezeichnung für Clan. Für einen Überblick über die Forschung
} zu palästinensischen Hamuleh vgl. Rothenberg 1999. 
nicht in besonderem Maße involviert (Plascov 1981: 60). Die Bedeutung der Flüchtlingsbevölkerung und der Flüchtlingslager als Rekrutierungs- und Organisationskontext für die PLO wuchs erst im Laufe der 1960er Jahre und für das Ostjordanland insbesondere nach dem Krieg von 1967, im sogenannten Jordanischen Bürgerkrieg 1970/71, spielten sie dann eine entscheidende Rolle.

Von größerer Bedeutung für die politischen Dynamiken in Jordanien in den 1950er und 1960er Jahren war die panarabistische Mobilisierung im arabischen Raum, die auch große Teile der jordanischen Bevölkerung erfasste. Insbesondere mit dem Aufstieg des ägyptischen Staatsoberhauptes Gamel Abdel Nasser wird die Konjunktur panarabistischer Orientierung, in welcher die Palästinafrage im Rahmen eines gesamtarabischen Nationalismus verhandelt wurde, in Verbindung gebracht. Von jener Mobilisierung erfasst wurden in Jordanien gerade auch die in der neuen staatlichen Bürokratie beschäftigten urbanen gebildeten Mittelschichten (Anderson 2005: 83). Zum Beispiel waren im zu jener Zeit noch stärker christlich geprägten Ramallah in der altansässigen Bevölkerung unter anderem die Ba'ath Partei oder die Kommunistische Partei populär (Mishal 1978: 104). Die Niederlage der arabischen Staaten gegen Israel im Krieg von 1967 sorgte allerdings dafür, dass der Panarabismus als Mobilisierungsrahmen im besetzten Westjordanland sowie generell im arabischen Raum erheblich an Kraft verlor. Diese Rahmungsveränderung der ,palästinensischen Frage' in Jordanien zeigt sich auch in dem von mir diskutierten Fall Hussam, in welchem sich eine in der Familie gegebene panarabistische Orientierung und Sympathien für Nasser in Richtung einer Identifikation mit palästinensischem Nationalismus und der PLO verschoben (vgl. Kap. 7.3).

\subsection{Die Besatzung Gazas und des Westjordanlandes durch Israel ab 1967}

Im Zuge des Arabisch-Israelischen Krieges von 1967 wurde das Westjordanland inklusive Ost-Jerusalem von Israel besetzt. In diesem auch als Naksa (arab.: „Rückschlag") oder aufgrund seiner nur wenige Tage umfassenden Kampfhandlungen auch Sechs-Tage-Krieg genannten militärischen Konflikt bekämpften sich vom fünften bis zum zehnten Juni 1967 Israel auf der einen und Ägypten, Syrien und Jordanien auf der anderen Seite. Den Kriegsbeginn markierten die israelischen Luftschläge gegen die ägyptische und syrische Luftwaffe. Diesem vorausgegangen waren Grenzkonflikte - unter anderem die Sperrung der Straße von Tiran für israelische Schiffe durch Ägypten und die Mobilmachung von ägyptischen Truppenverbänden. Am Ende der Kampfhandlungen, die mit einer massiven Niederlage der arabischen Seite endeten, hatte Israel neben dem Westjordanland auch den ägyptischen Sinai, den zuvor ägyptisch kontrollierten Gazastreifen sowie die syrischen Golanhöhen besetzt. Jordanien hielt seinen Anspruch auf das West- 
jordanland bis 1988, also bis in die Erste Intifada, aufrecht. ${ }^{69}$ Der Krieg bedeutete für circa 250.000 Palästinenser*innen die Flucht beziehungsweise Vertreibung aus Ostjerusalem, dem Gazastreifen und dem Westjordanland (Bowker 2003: 81). Viele waren bereits Flüchtlinge von 1948 und hatten zuvor in Flüchtlingslagern im Westjordanland gelebt.

Mit der Kontrolle über den Gazastreifen und das Westjordanland standen nun zusätzlich circa eine Million Palästinenser*innen unter israelischer Herrschaft. Zur zivilen Verwaltung der besetzten Gebiete unter dem Oberkommando des israelischen Militärs nutzte Israel die bereits bestehende administrative Infrastruktur, sorgte etwa für eine Weiterbeschäftigung der bereits in der jordanischen Bürokratie tätigen Palästinenser*innen. ${ }^{70}$ Auch die Mukhtars, unter jordanischer Herrschaft bereits in einer ähnlichen Rolle, wurden nun verstärkt in die Verwaltung und Kontrolle der palästinensischen Gebiete eingebunden und fungierten als mit Privilegien und Alimentierung versehene Vermittler zur palästinensischen Bevölkerung (Ma'oz 1984: 14). Außerdem wurden die israelischen Streitkräfte und der israelische Inlandsgeheimdienst „Shin Bet“ (,Shabak') stark in die sicherheitspolitische Kontrolle der Palästinenser*innen eingebunden. Eine besondere Bedeutung spielten und spielen hier die Regelung durch Militärverordnungen und die Militärgerichtsbarkeit, die fortan für die nicht-israelische Gebietsbevölkerung, nicht jedoch für die israelischen Siedler zuständig waren. Das israelische Oberkommando erließ in den folgenden Jahren eine große Zahl an Militärverordnungen, die zum Teil auf älteren osmanischen, britischen und jordanischen Gesetzen basierten und diese abänderten, annullierten oder ersetzten. Die Militärverordnungen regelten weit über den sicherheitspolitischen Bereich hinaus den Alltag der palästinensischen Bevölkerung (Gordon 2008: 27; Halper 2015: 161 ff.). ${ }^{71}$ Trotz dieser Trennung vom israelischen Rechtssystem wurde formal das Oberste Gericht Israels für die palästinensische Bevölkerung zuständig.

Bereits in den ersten Wochen kristallisierten sich jene Regelungen heraus, die zu den roten Fäden der Besatzungspolitik bis zur Ersten Intifada wurden (Gazit 1995: 51).72 Unter anderem ist hier die relativ offene israelische Mobilitätspolitik für die besetzten Gebiete zu nennen: Häufig auch als Politik der ,offenen Brücken` bezeichnet, erlaubte die israelische Verwaltung (weiterhin) ein hohes Maß an Mo-

\footnotetext{
${ }^{69} \mathrm{Ab} 1983$ bereitete Jordanien eine stärkere administrative Trennung vom Westjordanland vor. Dafür wurden die sogenannten grünen und gelben Pässe eingeführt, die unter anderem an der Grenze Westjordanlandbewohner*innen kenntlich machten (Ababsa/Daher 2011: 3).

${ }^{70}$ Die Gehälter der in der Verwaltung Beschäftigten wurden weiterhin von Jordanien übernommen.

${ }^{71}$ Die Militärverordnungen regelten zum Beispiel den Besitz und die Weitergabe von Land, die Bepflanzung von Feldern, den Transport von Waren, sie umfassten Pressezensur, den Besitz von Büchern, das Tragen oder Zeigen nationaler Symboliken etc.

72 Das Buch von Shlomo Gazit mit dem Titel „The Carrot and the Stick“ (1995) ist ein ebenso häufig zitiertes wie aufschlussreiches Werk zu den ersten Jahren der Besatzung. Nach dem Krieg von 1967 war Gazit von Moshe Dayan mit der Leitung der Koordinationsgruppe für die Besatzungspolitik betraut worden, zwischen 1974 und 1978 war er Chef des Militärgeheimdienstes.
} 
bilität von Waren und Personen in das jordanisch verbliebene Ostjordanland sowie ins israelische Staatsgebiet. Gleichzeitig konsolidierten sich bereits in dieser Phase zu Beginn der Besatzung die Kontroll- und Repressionsmaßnahmen, die gegenüber der palästinensischen Bevölkerung zum Einsatz kamen und kommen allerdings in unterschiedlichen Phasen in unterschiedlichem Ausmaß. Um nur ein kurzes Beispiel zu geben: Die Maßnahmen der israelischen Sicherheitsbehörden gegen die Bevölkerung von Nablus anlässlich eines Generalstreiks am 19. September 1967 lesen sich mit Ausgangssperren, ,lock downs' der öffentlichen Infrastruktur (öffentliche Verkehrsmittel, Telefonleitungen und Ähnlichem), Entzug von ,Privilegien', Verhaftungen und Verhören sowie Hausdurchsuchungen, „to increase the level of harassment“ (Gazit 1995: 279 f.), wie das Einmaleins der sicherheitspolitischen Maßnahmen, die bis zur Repressionsverschärfung der IronFist-Politik Mitte der 1980er Jahre zur Anwendung kamen. Gerade in den ersten Jahren der Besatzung im Westjordanland, in welcher die trotzdem nur moderate palästinensische Mobilisierung gegen die israelische Besatzung stärker gegeben war als im Verlauf der relativ, ruhigen' ersten Hälfte der 1970er Jahre, waren auch Deportationen von Aktivist*innen und lokalen Führern ein häufiges Mittel (Lesch 1979)..$^{73}$ Allerdings kam es auch in den vergleichsweise ruhigen 1970er Jahren zu Konfrontationen zwischen Palästinenser*innen, israelischen Sicherheitskräften und Siedler*innen oder zu größeren antiisraelischen Demonstrationen im Westjordanland, etwa anlässlich der Tötung mehrerer PLO-Kader - Hintermänner des Olympiaattentats 1972 - in Beirut durch den israelischen Geheimdienst im März 1973.

Wenn auch von der israelischen Regierung nie offiziell angenommen, wurde der Allon-Plan ${ }^{74}$ zur Grundlage für die israelische Kolonisierung des Westjordanlandes in der ersten Besatzungsdekade (Shapira 2015: 317). Die Kolonisierung konzentrierte sich, unter anderem aus Erwägungen heraus, die auf Grenzverteidigung und ,strategische Tiefe ${ }^{6}$ des israelischen Territoriums zielten, auf das Jordan$\mathrm{tal}^{75}$ sowie die Gebiete um Jerusalem. Ostjerusalem wurde hingegen de facto annektiert. Mit dem Wahlsieg des Likud in den israelischen Parlamentswahlen im Jahr 1977, mit dem erstmals seit der Staatsgründung die bis dahin politisch dominierende Arbeitspartei abgelöst wurde, intensivierte sich der Siedlungsbau in den palästinensischen Gebieten. Während die jährlichen Zuwachsraten der Siedler*innen vor der Regierungsbildung des Likud 770 Personen umfasste, waren es

\footnotetext{
${ }^{73}$ Im Gazastreifen kam es mit der Stationierung israelischen Militärs aufgrund der stärkeren Präsenz bestehender palästinensischer Milizen Ende der 1960er Jahre in sehr viel stärkerem Maße als im Westjordanland auch zu bewaffneten Auseinandersetzungen: „It took a massive operation accompanied by the demolition of nearly 14,000 houses, the relocation of 25,000 civilians and the uprooting of hundreds of citrus groves before the Israeli army could gain control in 1971“" (Sayigh 1989: 22).

${ }^{74}$ Benannt nach dem damaligen stellvertretenden israelischen Ministerpräsidenten Jigal Allon.

${ }^{75}$ Die PLO hatte in den 1960er Jahren insbesondere von den Flüchtlingslagern in Jordanien aus Attacken auf israelisches Gebiet durchgeführt. Gerade die ersten Siedlungen entlang des Jordantals dienten unter anderem der Grenzsicherung.
} 
zwischen 1977 und 19845400 neue Siedler*innen jährlich (Benvenisti 1986: 46). Gerade Anfang der 1980er Jahre gab es einen deutlichen Anstieg der Siedler*innen im Westjordanland: von 12.424 im Jahr 1980 auf 42.600 im Jahr 1984 (ebd.). Das Westjordanland inklusive Jerusalem - orientiert an den historischen jüdischen Provinzen Judäa und Samaria genannt ${ }^{76}$ - blieb auch in den folgenden Jahren zentraler Fokus für die Kolonialisierung der besetzten Gebiete. Der Siedlungsbau im Gazastreifen (bis 2005), auf dem Sinai (bis 1982) sowie auf den Golanhöhen blieb gegenüber jenem im Westjordanland marginal.

Zudem wurden die besetzten Gebiete in den israelischen Wirtschaftsraum integriert. In der Forschungsliteratur wird häufig auf den asymmetrischen Charakter der Integration verwiesen (Zureik 1980: 60; Roy 1987; Farsakh 2005). Jener asymmetrische Einbezug umfasste etwa einseitige Handelsregelungen und Investitionshindernisse für die palästinensischen Gebiete, darunter die Erschwerung von Direktinvestitionen, die Abschirmung des israelischen Marktes gegenüber palästinensischen Waren und die Schließung arabischer Banken in den Gebieten (Roy 1987: 72, 79). Teil der Integration der Gebiete in den israelischen Wirtschaftsraum war außerdem die Öffnung des israelischen Arbeitsmarktes für palästinensische Arbeitskräfte. Sie bekam für die Beschäftigungsstruktur in der palästinensischen Bevölkerung in den besetzten Gebieten schnell eine zentrale Bedeutung. Schon in den 1960er und frühen 1970er Jahren war eine massive Zunahme von in Israel beschäftigten Palästinenser*innen zu verzeichnen. So lag die Zahl bereits 1974 bei circa 40.000 Personen, was zu jener Zeit ungefähr einem Drittel der palästinensischen Erwerbsbevölkerung und mehr als der Hälfte aller abhängig Beschäftigten im Westjordanland entsprach (Heller 1980: 191). Die Öffnung des israelischen Arbeitsmarktes hatte einen erheblichen Einkommenszuwachs und eine Zunahme an Beschäftigungsmöglichkeiten gerade für die ärmeren Teile der palästinensischen Gesellschaft zur Folge: „Consequently, many lower-class families began, for the first time, to enjoy some measure of prosperity and financial security" (Heller 1980: 194). Von dieser Entwicklung profitierten gerade auch diejenigen Palästinenser*innen, die in den Flüchtlingslagern oder in ländlichen Gegenden lebten. Don Peretz spricht hier auch von einer Angleichung von Flüchtlingen und NichtFlüchtlingen in den besetzten Gebieten: „While labour at the bottom of the social scale, including many refugees, has improved its living standards, middle class and professional Palestinians, and the well-to-do, have often suffered a decline“ (Peretz 1977: 64).

Die gestiegenen Einkommen der Flüchtlingsbevölkerung sorgten zudem einerseits für zunehmende Bauaktivitäten in den Lagern und andererseits für einen vermehrten Auszug von Familien. Misselwitz spricht für diese Phase auch von einer „Erosion der etablierten Grenzen innerhalb des Flüchtlingslagers“ (2010:

\footnotetext{
${ }^{76}$ Die Bezeichnung, Region Judäa und Samaria' war bereits ab Dezember 1967 von der israelischen Militärverwaltung als eine Bezeichnung für diese Gebiete offiziell eingeführt worden, sie wurde aber erst nach dem Wahlsieg des Likud 1977 verstärkt administrativ genutzt.
} 
210), wodurch sich die bereits erwähnte interne Differenzierung nach Herkunftsdörfern und -regionen deutlich abschwächte. Zwei weitere Folgen der Öffnung des israelischen Arbeitsmarktes für die palästinensische Gesellschaft möchte ich noch kurz nennen. Zum einen fiel mit den profitablen Einkommensmöglichkeiten aus abhängiger Beschäftigung der Anteil des landwirtschaftlich bestellten Landes in den ländlichen Gegenden des Westjordanlandes - und machte dieses anfälliger für israelische Enteignung, die, auf Basis osmanischer Landgesetze, sich auch an Nutzungsgrad und -dauer des Landes orientierte (Gordon 2008: 129). Zum anderen begünstigten die guten finanziellen Einkommensmöglichkeiten einen Autonomiezuwachs von jüngeren Palästinenser*innen gegenüber familialen und dörflichen Autoritäten (Migdal 1980). Die verbesserte finanzielle Situation vieler Palästinenser*innen in den 1970er und 1980er Jahren gründete zudem in der Arbeitsmigration in die boomenden ölfördernden Golfstaaten und in den geleisteten Rücküberweisungen an im Westjordanland verbliebene Verwandte. Im Verlauf der 1980er Jahre schwächte sich die sukzessive Besserstellung von Palästineser*innen aber aufgrund der schwächelnden Wirtschaft in Israel und den damit verbundenen hohen Inflationsraten ab (vgl. Kimmerling/Migdal 2003: 294 f.).

Parallel zeichnete sich in der palästinensischen Bevölkerung im Westjordanland wie auch in Gaza schätzungsweise ab Mitte der 1970er Jahre ein Prozess umfassender, sukzessive an Wucht gewinnender politischer Mobilisierung gegen die israelische Besatzung ab, der sich im Laufe der 1980er Jahre zu einem breiten gesellschaftlichen Aufstand auswachsen sollte - der sogenannten Ersten Intifada. Ein bedeutsamer ,hot $\operatorname{spot}^{`}$ dieser zivilgesellschaftlichen Mobilisierung waren die von der israelischen Besatzungsverwaltung in den 1970er Jahren gegründeten palästinensischen Universitäten - etwa die Al Najah Universität in Nablus oder die Bir-Zeit Universität (bis 1976 ein College) nördlich von Ramallah. Die erstmalig 1972 von Studierenden der Bir-Zeit Hochschule ins Leben gerufenen Komitees für Freiwilligenarbeit wurden wichtige Ausgangspunkte für die Politisierung der palästinensischen Bevölkerung (Hasso 2005: 22 f.). Die typischen Tätigkeitsfelder dieser Komitees, etwa ,land reclamation, tree planting, fruit picking, road paving, painting, and neighborhood cleanup" (Hasso 2005: 22), brachten die urbane Bevölkerung mit der Landbevölkerung und der Bevölkerung in den FlüchtlingslagerGegenden in Kontakt. Neben Landwirtschaftskomitees entstanden unter anderem medizinische Versorgungs- und Frauenkomitees. Von der israelischen Besatzungsverwaltung wurden diese Komitees zunächst toleriert und zum Teil gefördert - auch mit dem Gedanken einer lokalen ,Abfederung ${ }^{6}$ der Besatzungsfolgen (Gordon 2008: 153). Die Komitees wurden schnell von den in der PLO organisierten Parteien beziehungsweise deren Jugendorganisationen, zum Beispiel der Shabiba der Fatah, aufgegriffen, ohne allerdings in (engerem) Kontakt mit der PLO in der Diaspora zu stehen. Insbesondere im Gazastreifen waren außerdem, in ihrer politischen Rahmung allerdings weniger sichtbar, islamische Wohltätigkeitsorganisationen und -netzwerke, die auch Kindergärten, studentische Organi- 
sationen und Sportvereine umfassten, Teil der zivilgesellschaftlichen Mobilisierung. Für die (spätere) politische Mobilisierung ist hier insbesondere das einflussreiche „al Mujamma al Islamye“ aus dem Umfeld der palästinensischen Muslimbrüder zu nennen, welches 1973 von Sheikh Ahmed Yassin, einer der späteren Gründungsfiguren der Hamas, initiiert wurde. Diese islamischen Wohltätigkeitsorganisationen zogen dabei weit weniger Aufmerksamkeit von Seiten der israelischen Sicherheitsbehörden auf sich als vergleichbare Institutionen der PLO (Milton-Ewards/Farrell 2010: 47). Ab Mitte der 1980er Jahre nahmen diese mit dem palästinensischen Zweig der Muslimbrüder verbundenen Gruppierungen an den aufkommenden Massendemonstrationen teil (Baumgarten 2006: 47).

In der Forschungsliteratur ist wiederholt darauf hingewiesen worden, dass die Komitees generell und die mit ihnen einhergehenden sozialen Netzwerke im Besonderen in erheblichem Maße zur Organisation und Dauer der späteren Ersten Intifada beitrugen (siehe unten). Ab Ende der 1970er Jahre versuchte die israelische Verwaltung mit den sogenannten Dorfligen alternative Lokalverwaltungen parallel zur zivilen Verwaltung der palästinensischen Gebiete - aufzubauen, die auch darauf ausgelegt waren, der politischen Mobilisierung entgegenzuwirken und dafür die soziale Differenzierung von städtischer und Landbevölkerung zu ,nutzen' (Gordon 2008: 111). Die Dorfligen wurden mit sukzessive erweiterten, administrativen Kompetenzen (unter anderem der Gewährung von Arbeits-, Reiseund Aufenthaltsgenehmigungen) ausgestattet und zum Teil bewaffnet. Insgesamt konnten sich die Dorfligen, deren Mitglieder schnell als Kollaborateure mit der israelischen Besatzung galten, in regional recht unterschiedlichem Ausmaß, insgesamt aber kaum etablieren (Tamari 1983: 49 ff.).

Teil des israelischen Umgangs mit der politischen Mobilisierung in den palästinensischen Gebieten war auch eine Verschärfung der Kontroll- und Repressionsmaßnahmen im Rahmen der sogenannten Iron-Fist-Politik ab August 1985. Die Maßnahmen umfassten neben vermehrten Kontrollen und Verhaftungen unter anderem, nach dreijähriger Aussetzung, die Wiedereinführung und ausgiebige Nutzung der Verwaltungshaft, ${ }^{77}$ Deportationen sowie einen vermehrten Rückgriff auf Hauszerstörungen und -versiegelungen (Abu Shakrah 1986). Außerdem wurden bereits zu Beginn der 1980er Jahre Bürgermeister palästinensischer Städte und Ortschaften, die sich an der nationalen Mobilisierung beteiligt hatten, entlassen und durch israelische Militärs ersetzt. Die seit den 1970er Jahren an Fahrt gewinnende politische Mobilisierung in den palästinensischen Gebieten und die zuneh-

\footnotetext{
77 Die Verwaltungshaft, auch Administrationshaft genannt, geht auf eine 1945 von der britischen Mandatsmacht eingeführte Militärverordnung zurück. Im Rahmen der Verwaltungshaft ist es möglich, Verhaftete ohne Anklage und Gerichtsverfahren für bis zu sechs Monate festzusetzen. Da außerdem eine Verlängerung der Verwaltungshaft möglich ist, gibt es faktisch keine Höchstdauer (vgl. Rosenfeld 2004: 237).
} 
mende Konfrontation mit den israelischen Sicherheitsbehörden und den israelischen Siedler*innen kulminierte ab Ende der 1980er Jahre in einem breiten gesellschaftlichen Aufstand - der sogenannten Ersten Intifada.

\subsection{Erste Intifada 1987-1993}

Auslöser der Massenproteste der Ersten Intifada war ein Verkehrsunfall zwischen israelischen Militärfahrzeugen und zwei Sammeltaxis am Grenzübergang Erez zwischen dem Gazastreifen und Israel im Dezember 1987, bei dem vier palästinensische Insassen starben. Die mit dem Begräbniszug verbundenen Massendemonstrationen und Straßenschlachten zwischen palästinensischen Jugendlichen und dem israelischen Militär breiteten sich zunächst über die Flüchtlingslager im Gazastreifen und dann im Westjordanland aus. Der Aufstand erfasste jedoch bereits innerhalb der ersten Wochen auch Dörfer und Stadtviertel: „Palestinians also responded by demonstrating and clashing with the Israeli army, and within a few weeks the entire West Bank and Gaza were inflamed with resistance, thus easing the pressure on the camps“ (Yahya 1990: 102). Während der Beginn der Ersten Intifada in der Regel mit dem genannten Auslöseereignis gleichgesetzt wird, ist das Ende der Ersten Intifada schwieriger zu bestimmen, wird aber häufig mit dem Beginn der Oslo Verhandlungen 1993 angegeben.

Die Erste Intifada war zum einen durch Straßenschlachten oder ,Konfrontationen' zwischen Palästinenser*innen, insbesondere Jugendlichen, auf der einen Seite und dem israelischen Militär sowie den israelischen Siedler*innen auf der anderen Seite geprägt. Um einen Eindruck von den Demonstrationen und StraBenschlachten der frühen Phase der Intifada zu geben, möchte ich hier eine längere Passage aus Daoud Kuttab’s Aufsatz „A Profile of the Stonethrowers“ zitieren:

„Stone throwing is normally carried out as part of a large demonstration. Demonstrations may arise in response to a particular Israeli action: arrests, provocations, closing the entrance to a camp, injuring camp residents, and the like. [...] In some cases the stone throwing is carried out by small, welltrained teams. More often it is undertaken by a large group of people, including adults, both men and women, who are participating to protest actions taken by settlers against camp residents, for example“ (Kuttab 1988: 15).

Auch wenn die nachträgliche Mythologisierung der sogenannten aṭfal al-hị̆āāa, der „Kinder der Steine“ (vgl. Swedenburg 2003: 173), und die große mediale Beachtung der Konfrontationen auch in der westlichen Öffentlichkeit sowie die damit verbundenen Klischeebildungen den Blick dafür verstellen können: Die Straßenschlachten und der mit ihnen verbundene ,Druck der Straße ${ }^{6}$ auf das israelische Militär und die israelischen Siedler*innen waren ein zentraler Bestandteil der Aufstandsdynamik. Auch Yezid Sayigh teilt diese Einschätzung: „the decisive factor that first disrupted the Israeli control system and then made mass transfor- 
mation possible has been the part played by the young stone-throwers" (1989: 37). Auch zahlreiche meiner Interview- und Gesprächspartner*innen im Westjordanland waren in die Massendemonstrationen und Straßenschlachten der Ersten Intifada involviert gewesen (vgl. Kap. 6; 8). Die Straßenschlachten und Massendemonstrationen stellten die israelischen Sicherheitsbehörden vor erhebliche Probleme: „For the first time since the occupation began, the Israeli forces lost control of the population in the occupied territories" (Kimmerling/Migdal 2003: 295).

Teil der Mobilisierung der palästinensischen Bevölkerung waren weiterhin Kündigungen von in der Besatzungsadministration beschäftigten Palästinenser*innen und die von großen Teilen der Bevölkerung getragenen Streiks, Steuerund Warenboykotte. ${ }^{78}$ In diesem Zusammenhang waren auch die im letzten Abschnitt bereits erwähnten palästinensischen Universitäten und Komitees ein wichtiger Faktor (Hiltermann 1990: 146). ${ }^{79}$ Zum Teil auf diesen Netzwerken aufbauend, wurden in Komitees die Demonstrationen und Streiks koordiniert, angesichts der Repressionsversuche der israelischen Sicherheitsbehörden wurden über die Komitees Nahrungsmittel und Dinge des täglichen Bedarfs gesammelt und verteilt oder wurden Schul- und Hochschulkurse als Ersatz für die geschlossenen Bildungseinrichtungen organisiert (Robinson 1997). Ein gut erforschtes Beispiel für die kommunale Organisation von Steuerboykotten und gleichzeitig ein Beispiel für die breite Beteiligung der christlichen Bevölkerung am Aufstand ist die Mobilisierung in dem im Bethlehemer Umland gelegenen Dorf Beit Sahour (Robinson 1997; Qumsiyeh 2011: 143 ff.). Ein weiteres Beispiel für die Einbindung unterschiedlicher palästinensischer Gruppierungen in den Aufstand sowie für die Rolle des durch die Straßenschlachten erzeugten ,Drucks der Straße' sind die Auseinandersetzungen um die Öffnungszeiten der palästinensischen Händler*innen und (Klein-)Ladenbesitzer*innen, auch „Krieg der Läden“ genannt, in denen jeweils das israelische Militär und die ,Steinewerfer" eine Öffnung beziehungsweise Schließung der Läden zu erwirken versuchten. Dass sich die Händler*innen und Ladenbesitzer*innen, sonst sehr auf ihre ökonomischen Interessen bedacht, temporär am Aufstand beteiligten, wertet Salim Tamari (1990) als einen der zentralen Momente in der Aufstandsdynamik. Mit ihrer Beteiligung wurde offenkundig, dass

\footnotetext{
${ }^{78}$ Der Mobilisierungsbreite entsprechend bewertet Asef Bayat die Erste Intifada als „one of the most grassroots-based mobilizations in the Middle East of the past century“ (2010: 6).

${ }^{79}$ Das Ausmaß der Mobilisierung an den Hochschulen in den 1980er Jahren im Vorfeld und während der Intifada bringt Robinson folgendermaßen auf den Punkt: „Politicized Palestinians coming out of local universities constituted the core of the new Palestinian elite and provided the catalyst for social and political change in the occupied territories, from the building of mass organisations to the intifada $[. .$.$] Incoming students at Palestinian universities prior to the intifada were$ actively recruited to one or another political faction. Given the intensely politicized atmosphere of Palestinian society in the 1980s, such factional activity could be expected" (1997: 27). Während der Ersten Intifada wurde die Bir Zeit Universität von der israelischen Besatzungsverwaltung ab Januar 1988 für 4 Jahre geschlossen, jedoch entstand schnell ein informelles Kurssystem, dass eine Form von alternativer Universitätslehre zu gewährleisten suchte (ebd.: 106 f.).
} 
sich ganz verschiedene palästinensische Gruppierungen, auch in der urbanen, bessergestellten palästinensischen Bevölkerung, in den Aufstand einbinden lassen würden (Tamari 1990: 164 f.). In diesen städtischen Gruppierungen der Händler*innen und Ladenbesitzer*innen, Lehrer*innen und Ärzt*innen sind die Familien der in dieser Arbeit in Kapitel 8 diskutierten Fälle verortet.

Insgesamt intensivierte die politische Mobilisierung vor und während des Aufstandes in Komitees und Parteigruppen, bei Demonstrationen und Straßenschlachten - dem erwähnten Trend in den Freiwilligenkomitees in den 1970er Jahren folgend - den Austausch zwischen zuvor stärker distanzierten Gruppierungen der palästinensischen Gesellschaft aus der Lager-, Stadt- und Landbevölkerung (Robinson 1993: 302). Spätestens seit Januar 1988 versuchte eine sogenannte Vereinigte Nationale Führung des Aufstandes in den besetzten Gebieten den Aufstand zu koordinieren. Dieses Komitee war mit rangniederen Aktivist*innen aus den PLO-Fraktionen besetzt - wobei in den palästinensischen Gebieten den linken Parteien - der DFLP, der PFLP und der Kommunistischen Partei - gegenüber der Fatah ein größeres Gewicht zukam als bei den exilierten PLO-Kadern (Kimmerling/Migdal 2003: 299 f.). Auch war der Einfluss der ExilPLO auf die Vereinigte Führung zunächst begrenzt (Bröning 2013: 61). In Handzetteln, die verteilt sowie ihre Inhalte über das Radio verbreitet wurden, wurden Aufstandsziele wie die Boykottierung der israelischen Besatzungsverwaltung, israelischer Produkte und Steuererhebungen, Angriffe auf jüdische Siedler*innen oder kommerzielle Streiks formuliert und - mal mit größerem, mal mit kleinerem Erfolg - koordiniert (ebd.). Unter dem Eindruck der ersten Massendemonstrationen im Gazastreifen war bereits im Dezember 1987 im Umkreis der palästinensischen Muslimbrüder die palästinensische Hamas gegründet worden, die sich ebenfalls aktiv in den Aufstand einschaltete.

Bei ihren Versuchen, den Aufstand zu unterdrücken, griffen die israelische Armee und die anderen israelischen Sicherheitsorgane nun extensiv auf jene Mittel zurück, die bisher in der Besatzungsverwaltung zum Einsatz gekommen waren. Lisa Hajjar bemerkt dazu, nicht nur für die Erste Intifada, sondern für die gesamte Besatzungsperiode bis zur Zweiten Intifada:

„although force and violence have been integral components of the state's strategies to maintain order and control and to thwart and punish resistance, the main mode or model of rule has been, law enforcement' rather than ,war"“ (Hajjar 2005: 27).

Die Besatzungsverwaltung verhängte Ausgangssperren, erhöhte Strafmaße etwa für die Mitgliedschaft in den Komitees, zerstörte und versiegelte Häuser ${ }^{80}$ und schloss, zum Teil für mehrere Jahre, Universitäten und Schulen. Sie überzog die

\footnotetext{
${ }^{80}$ Eine auf Gesetze der britischen Mandatszeit zurückgehende Straf- und Abschreckungsmaßnahme, bei der Häuser oder Teile von Häusern, in denen Attentäter wohnten, zerstört oder unbewohnbar gemacht werden. Für eine Diskussion der Maßnahme während der Ersten Intifada vgl. Silver 2010.
} 
besetzten Gebiete mit einem Netz an stationären und mobilen Checkpoints und Wachstationen, welche häufig an den Zugängen zu den Flüchtlingslagern, Stadtvierteln und Dörfern errichtet wurden, die besonders intensiv in die Intifada involviert waren. Bereits zu Beginn der 1990er Jahre führte Israel das System von Aufenthaltsgenehmigungen für das israelische Kernland ein, das dann insbesondere ab der Zweiten Intifada rigide zur Anwendung kam und weiterhin gilt.

Weiterhin waren Massenverhaftungen ein zentrales Mittel, um den Aufstand zu unterdrücken. Im Rahmen der Ersten Intifada wurden insgesamt etwa 100.000 Palästinenser*innen inhaftiert (Neslen 2011: 122). Aufgrund des Ausmaßes politischer Inhaftierung von Palästinenser*innen, insbesondere in den Hochphasen während der Ersten und Zweiten Intifada, sind Inhaftierungen keine marginalisierte Erfahrung in der palästinensischen Gesellschaft im Westjordanland. Im Rahmen der Konfrontationen, der Kontrollen an Checkpoints und der Verhaftungen wurde es zu einer insbesondere von jungen Männern geteilten Erfahrung, von israelischen Soldaten geschlagen worden zu sein: „One would be hard pressed to find a young male Palestinian under occupation who has not been beaten or who does not personally know someone who has been" (Peteet 1994: 35). Zum Teil wurden Palästinenser*innen, insbesondere in den der Haft vorgelagerten Verhörphasen, auch von israelischem Sicherheitspersonal gefoltert. ${ }^{81}$ Während der Konfrontationen und Massendemonstrationen waren auch immer wieder Todesopfer zu beklagen, insgesamt wurden 1.409 Palästinenser*innen von Israelis und in der gleichen Zeit 271 Israelis von Palästinenser*innen getötet (Neslen 2011:122). Dennoch kann man im Rahmen der Ersten Intifada durchaus von einem gegenüber früheren und späteren Konfliktphasen relativ geringen Entgrenzungsgrad der von den Konfliktparteien eingesetzten Gewaltmittel sprechen. So spielten Aktionen wie die von der PLO in den 1970er Jahren unter anderem auch in Israel durchgeführten Entführungen und Attacken auf israelische Zivilist*innen oder die späteren Selbstmordattentate während der Oslo-Verhandlungen und der Zweiten Intifada in der Ersten Intifada noch kaum eine Rolle.

Im Zusammenspiel der politischen Mobilisierung in der palästinensischen Gesellschaft in den 1980er Jahren mit den israelischen Repressionsversuchen des Aufstandes erhöhten sich auch die gesellschaftlichen Status- und Autoritätsgewinne, die mit der Involvierung in die Straßenschlachten, Demonstrationen und Komitees, mit Inhaftierungs- und Gewalterfahrungen, also mit einer Erfahrungsgeschichte oder ,Karriere' im palästinensischen ,Widerstandsprojekt', in der palästinensischen Gesellschaft verbunden waren. Julie Peteet diskutiert, wie diese Leidenserfahrungen in die Geschlechtsentwürfe junger Männer integriert wurden und wie sich deren Machtchancen und das ihnen in Familie, Nachbarschaft und Öffentlichkeit entgegengebrachte Ansehen erhöhten (1994). In der Forschung sind auch die Auswirkungen diskutiert worden, die die mit dem Aufstand verbundene

${ }^{81}$ Zur Frage von Folter während der Befragungen und der Haft vergleiche die differenzierte Besprechung von Hajjar (2005: 68 ff.). 
Politisierung auf Heiratsmuster in der palästinensischen Gesellschaft hatte. Während der 1980er Jahre war die politische Orientierung von „far greater relevance [...] in evaluating the desirability of a potential spouse " Johnson/Abu Nahleh/Moors 2009: 16).

Insgesamt ist die zivilgesellschaftliche Mobilisierung in der Phase vor und während der Ersten Intifada wiederholt erforscht und unter anderem in ihrer Auswirkung auf die patriarchalen Strukturen in der palästinensischen Gesellschaft - etwa aufgrund der Integration von Frauen in die Komitees und der in der politischen Mobilisierung aufgewerteten Rolle von jüngeren gegenüber älteren Männern - diskutiert worden. Die Erste Intifada ist wiederholt, und etwas zu enthusiastisch, auch als soziale Revolution bezeichnet worden. ${ }^{82}$ Die Verschiebung der gesellschaftlichen Status- und Autoritätsgewinne, die sich im Laufe der politischen Mobilisierung in den 1970er und 1980er Jahren ergab, zeigte sich auch innerhalb der Flüchtlingslager-Gegenden. Die Involvierung in die Mobilisierung wurde grundlegend dafür, wem in den Flüchtlingslagern Ansehen und auch politische Macht zukam: „Since the end of the 1970s, we have witnessed the emergence of a new elite [in den Lagern] whose legitimacy is based on the Palestinian national struggle“ (Hanafi 2009: 509).

Eine für diese Forschungsarbeit zentrale Entwicklung ist außerdem, dass die Erste Intifada im Rahmen einer historischen Generationsbildung (im Anschluss an Karl Mannheim) erlebt und an ihr partizipiert wurde (vgl. Kap. 2; 6; 8). Die Formierung der historischen Generation im Zusammenhang mit der Ersten Intifada ist in der Forschungsliteratur wiederholt beobachtet und hervorgehoben worden (vgl. Kap. 5). Im empirischen Teil dieser Arbeit (vgl. Kap. 6-8) sowie im Ergebniskapitel (Kap. 9) diskutiere ich ausführlich die Folgen, die die Formierung einer historischen Generation Intifada ${ }^{83}$ für eine ,nachgelagerte' Generation Oslo im Rahmen einer Figuration von historischen Generationen hat. So besteht eine der Folgen darin, dass die Generation Oslo in indirekter Weise, und ohne dass dies von den Beteiligten intendiert wäre, bezüglich ihres ,Beitrags für die palästinensische Sache' an der vorgelagerten Kampfgeneration gemessen wird - was die Mitglieder der Generation Oslo biographisch zu verhandeln haben.

Ab circa 1990 verlor die Erste Intifada zunehmend an Kraft. Dafür sorgten neben den Repressionsversuchen des israelischen Militärs auch an Relevanz gewinnende interne Konfliktlinien sowie eine Wirtschaftskrise, die das Westjordanland (und auch Gaza) in der Folge des Aufstandes erfasst hatte. Im Laufe der Intifada begannen kleinere palästinensische Gruppen, die Sabotageakte, Messer-

\footnotetext{
82 Für die Bezeichnung als „social revolution“ vgl. Giacaman/Johnson 1989: 160. Für die Diskussion der möglichen Erweiterung der Spielräume junger Frauen, auch kritisch, vgl. Hammami 1990; Jad 1998; Jean-Klein 2003. Der zunehmende Druck auf unverschleierte Frauen in den letzten Jahren der Intifada, der auf eine Kampagne der Hamas zurückging, aber auch über das islamistische Milieu hinausgehend aufgegriffen wurde, gibt einen Eindruck von dem Kampf um in Bewegung geratene Geschlechterverhältnisse in der Intifada.

83 Zur Bezeichnung Generation Intifada vgl. Fußnote 121.
} 
angriffe und Entführungen, insbesondere von israelischen Soldat*innen und Siedler*innen, durchführten, gegenüber der Massenmobilisierung eine größere Rolle zu spielen als in den ersten zwei Jahren des Aufstandes (Kimmerling/Migdal 2003: 301). Im weiteren Verlauf nahm außerdem die Zahl der Angriffe auf und Tötungen von Personen, die der Kollaboration mit Israel verdächtigt wurden, sukzessive zu (ebd.: 13). Zwischen 1987 und 1993 wurden etwa 750 bis 950 Palästinenser*innen, die unter diesem Verdacht standen, von anderen Palästinenser*innen getötet (B'tselem 1994: 9). Auch die wirtschaftliche Lage war in den palästinensischen Gebieten infolge des Aufstandes prekär. Zu den schwierigen ökonomischen Bedingungen trugen auch Ereignisse außerhalb Israels und der palästinensischen Gebiete bei. Im Zweiten Golfkrieg von 1990 bis 1991 hatte sich Yassir Arafat zunächst auf die Seite Saddam Husseins geschlagen. Diese Position hatte die ,alten“ PLO-Kader, die seit dem israelischen Libanonfeldzug 1982 in Tunis stationiert waren und die seit der Auflösung der Sowjetunion Ende 1991 ohnehin an internationaler Unterstützung verloren hatten, weiter isoliert. Die arabischen Staaten froren infolge der Parteinahme Arafats für Saddam Hussein die Finanzhilfen für die PLO ein, die zum Teil auch der Bevölkerung in den palästinensischen Gebieten zugutegekommen waren. Die ,alten' PLO-Kader hatten bereits während der 1970er und 1980er Jahre begonnen, die in die politische Mobilisierung in den palästinensischen Gebieten involvierten Aktivist*innen als Konkurrent*innen zu sehen (Sahliyeh 1988: 58 f.). In dieser Situation zu Beginn der 1990er Jahre gerieten also sowohl die im Aufstand mobilisierte Bevölkerung in den besetzten Gebieten als auch die exilierten PLO-Kader zunehmend in die Defensive. Außerdem war durch die Jahre der Intifada auch der israelischen Öffentlichkeit vor Augen geführt worden, welche Gefahren und ,Kosten' mit der Aufrechterhaltung der Besatzung der palästinensischen Gebiete verbunden waren (Gordon 2008: 169). Insgesamt führten diese Dynamiken in eine Konstellation, in der der sogenannte Friedensprozess der 1990er Jahre zwischen der PLO und Israel möglich wurde.

\subsection{Die frühen Oslo-Jahre: Der ,Friedensprozess' und der Aufbau quasi-staatlicher Institutionen}

Die Annäherung von Israel und der PLO kam zu Beginn der 1990er Jahre zunächst im Rahmen der Madrider Konferenz 1991 und der Geheimverhandlungen ab 1992 zustande, die dann in die direkte Aufnahme von Verhandlungen und die Osloer Abkommen zwischen 1993 und 1995 mündeten. ${ }^{84}$ Die zentralen, in den

\footnotetext{
${ }^{84}$ Die Abkommen waren im Einzelnen die „Oslo I“ genannte Prinzipienerklärung über die vorübergehende Selbstverwaltung im September 1993, das Pariser Protokoll über wirtschaftliche Beziehungen im April 1994, das Gaza-Jericho-Abkommen im Mai 1994, das Protokoll zur vorbereitenden Übertragung von Befugnissen und Verantwortlichkeiten im August 1994, das „Oslo II“ genannte
} 
Abkommen getroffenen Vereinbarungen waren die gegenseitige Anerkennung Israels und der PLO und der Aufbau der Palästinensischen Autonomiebehörde (PA) als quasi-staatliche Institution der Palästinenser*innen sowie die Einteilung des Westjordanlandes in Zonen, mit denen auch der Hoheitsbereich der PA definiert wurde. Im Gebiet der A-Zone, in der ein Großteil der palästinensischen Bevölkerung des Westjordanlandes lebte und lebt und welches auch die meisten palästinensischen Städte umfasst, liegt die administrative und sicherheitspolitische Zuständigkeit bei der PA. Das Gebiet umfasst rund 18 Prozent der Gesamtfläche des Westjordanlandes.

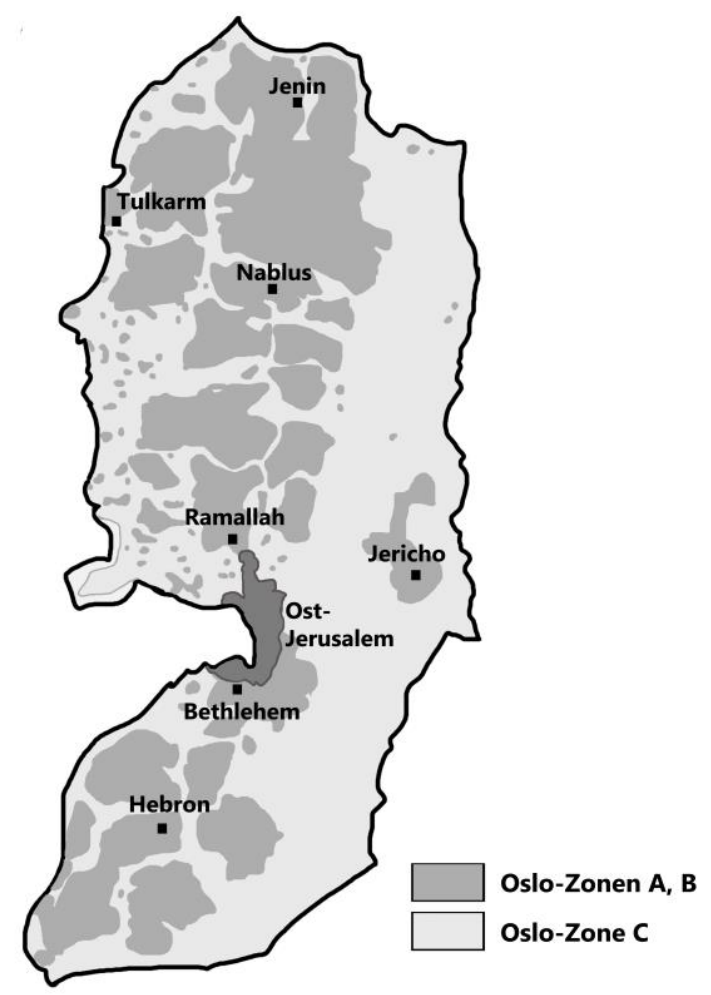

Zonenaufteilung im Westjordanland ${ }^{85}$ (Zonen A und B zusammengefasst)

Interimsabkommen über das Westjordanland und den Gazastreifen im September 1995, das Hebron-Protokoll im Januar 1997, das Wye-Abkommen im Oktober 1998 und das Sharm-el-SheikhMemorandum im September 1999. Andere palästinensische Parteien, darunter die PFLP, der islamische Jihad und die Hamas, lehnten und lehnen die Oslo-Vereinbarungen bis heute ab.

85 United Nations Office for the Coordination of Humanitarian Affairs occupied Palestinian territory, West Bank Access Restrictions December 2012, 2013, 
In der B-Zone, die etwa 22 Prozent umfasst, liegt die administrative Zuständigkeit bei der PA und die sicherheitspolitische bei Israel. In der C-Zone, die ungefähr 60 Prozent umfasst und in welcher die meisten israelischen Siedlungen im Westjordanland liegen, liegt die administrative und sicherheitspolitische Hoheit bei Israel. ${ }^{86}$ In den C-Gebieten, in welchen 2014 circa 380.000 israelische Siedler*innen und etwa 100.000 Palästinenser*innen lebten, entstand ein doppeltes Rechtssystem, bei dem die israelischen Siedler*innen unter israelisches Zivilrecht, die palästinensischen Bewohner*innen jedoch weiterhin unter israelisches Militärrecht fielen (Gazit 2015). Als Institutionen der Autonomiebehörde wurden verschiedene Ministerien und Sicherheitsbehörden sowie ein palästinensisches Parlament, der palästinensische Legislativrat, aufgebaut. ${ }^{87}$ Vereinbart wurde außerdem eine Kooperation zwischen israelischen und palästinensischen Sicherheitsbehörden, die unter anderem den Austausch von Informationen und die Koordination bei Verhaftungen betraf und betrifft. Aus den Osloer Abkommen ausgeklammert und für eine spätere Klärung aufgeschoben waren der Status Ostjerusalems und der israelischen Siedlungen sowie die Frage, inwiefern und in welchem Umfang es zu einer ,Rückkehr‘ der palästinensischen Flüchtlinge kommen kann.

Die mit den Abkommen verbundene territoriale Neuordnung des Westjordanlandes sowie der Aufbau quasi-staatlicher Institutionen stießen für das Westjordanland weitreichende gesellschaftliche Transformationsprozesse an. In den 1990er Jahren setzte eine Migration von Palästinenser*innen aus der Diaspora in die nun unter der Teilhoheit der PA stehenden palästinensischen Gebiete ein. Überwiegend waren diese Immigrant*innen, die im Westjordanland „Rückkehrer“ (,al- 'à'idīn“) genannt wurden, PLO-Mitglieder und deren Familienmitglieder, die zuvor in anderen Ländern in der Region, etwa in Tunesien, im Libanon oder Jordanien gelebt hatten. Sie besetzten nun Positionen in der im Aufbau befindlichen PA. Aber auch Palästinenser*innen, die nicht direkt mit der PLO verbunden waren, migrierten in der zweiten Hälfte der 1990er Jahre, als ein palästinensischer Nationalstaat am Horizont zu stehen schien, in diese Gebiete. Zahlen, die den Umfang und die soziale Zusammensetzung der Rückkehrer angeben würden, liegen kaum vor. Einige Schätzungen gehen von 200.000 Rückkehrenden in den Oslo-Jahren aus. ${ }^{88}$ Genauere Zahlen, etwa zur in Ramallah prominenten Gruppierung der USA-Rückkehrer oder zu den im Zweiten Golfkrieg aus Kuweit über ,Zwischenetappen“ - zum Beispiel Jordanien - ins Westjordanland geflüchteten Palästinenser*innen, sind meiner Kenntnis nach nicht verfügbar.

https://commons.wikimedia.org/wiki/File:West_Bank_Dec_2012.jpg <letzter Zugriff 20.05.17>; eigene Anpassung.

86 Allerdings führten und führen die israelischen Sicherheitsbehörden und das israelische Militär dennoch, auch nach der Zweiten Intifada, Operationen in palästinensischen Ortschaften und Städten durch, die in der A-Zone liegen.

${ }^{87}$ Der Legislativrat wurde bisher nur 1996 und 2006 gewählt.

${ }^{88}$ Für eine Diskussion verschiedener Schätzungen siehe Hanafi 2007: 33 f. 
Während des Aufbaus der Ministerien, Sicherheitsdienste und anderer Regierungsorganisationen wurde eine große Zahl an zu besetzenden Positionen geschaffen. Die Zahl der Beschäftigten in der palästinensischen Bürokratie überstieg schnell jene der Verwaltung, die zuvor unter dem Kommando des israelischen Militärs mit der Administration der palästinensischen Gebiete betraut gewesen war. Letztere hatte etwa 20.000 Stellen umfasst, im Verlauf der 1990er Jahre wuchs die Zahl der Beschäftigten auf etwa 70.000 an (Giacaman et al. 2003: 64). Die Vergabelogik von Posten lässt sich dabei durchaus als „compensation for revolutionary heroism, current political support or both" (ebd.) interpretieren. Dies wurde und wird gerade an der personellen Besetzung der neu geschaffenen palästinensischen Sicherheitsdienste sichtbar. Nigel Parson spricht im Zusammenhang der Konzentration der ,locals' unter anderem im Präventiven Sicherheitsdienst, einem der Sicherheitsdienste der PA, davon, dass diese eine „fairly uniform experience of the first intifada" aufweisen (Parsons 2005: 154). Andere Sicherheitsdienste, zum Beispiel die „Force 17“ - eine zu Beginn der 1970er Jahre entstandene Leibwächtermiliz der Fatah und nun eine Einheit der palästinensischen Autonomiebehörde zum Schutz des Präsidenten -, seien hingegen heterogen besetzt. Für Aktivist*innen der Ersten Intifada, von denen viele Haftstrafen in israelischen Gefängnissen verbüßt hatten, waren mit dem Aufbau der PA so durchaus Chancen auf eine Beschäftigung im palästinensischen Sicherheitsapparat verbunden (Bornstein 2001a: 563). Dabei bestand diese Option zwar in stärkerem $\mathrm{Maße}$, aber nicht ausschließlich für Fatah-Mitglieder beziehungsweise Personen, die sich in Fatah-Netzwerken bewegten. Gerade in ihrer Aufbauphase wurden durchaus auch Mitglieder beziehungsweise Personen aus dem Umfeld der linken Parteien (PFLP, DFLP) in die PA integriert (Taraki 2008: 69). Diese Integration von ehemaligen Intifada-Veteran*innen einerseits und ehemalig exilierten PLOKadern andererseits in die PA spiegelt sich auch in dem von mir im Rahmen dieser Forschungsarbeit erhobenen Sample wider (Kap. 6-8; insbes. 7). Wie ich zeigen werde, differieren mit dem unterschiedlichen Ausmaß, mit dem die diskutierten Fälle aufgrund ihrer Position als Rückkehrer oder ihrer Generationenzugehörigkeit in die Netzwerke der PA eingebunden sind, unter anderem ihre Lebenschancen deutlich. Insgesamt kann man mit der Etablierung der PA-Bürokratie auch von einer Neustrukturierung von Patronage-Netzwerken in der palästinensischen Gesellschaft des Westjordanlandes und einer veränderten und stärkeren Relevanz von (erweiterten) familialen Beziehungen oder Hamulehs sprechen. Nahla Abdo kam Ende der 1990er Jahre, ebenfalls ausgehend von der Besetzungslogik von Positionen in der PA (,,thank you gifts" for past service“), zu der Einschätzung: „These appointments represent an emerging trend in Palestinian political culture: the reinvention of clan or tribal allegiance" (1999: 40 f.). Diese Restrukturierung und Stärkung von Patronage-Netzwerken ab der Oslo-Phase sind unter dem Begriff des Neopatrimonialismus diskutiert worden (vgl. Brynen 1995). 
Im Prozess des palästinensischen Institutionenaufbaus sind die Flüchtlingslager meist nicht in die Administration der sie umgebenden Stadtviertel und Ortschaften einbezogen worden und nehmen zum Beispiel auch nicht an den jeweiligen Kommunalwahlen teil (Hanafi 2010: 21). Die Frage der politischen Vertretung der Lagerbevölkerung ist sehr komplex und je nach Lager sehr unterschiedlich meist sind gewählte Lagerkomitees und klientelistische Führungseliten in die Repräsentation der Lager eingebunden (ebd.: 10 f.). Die PA-Polizei betritt die Lager, auch jene in der A-Zone gelegenen, in der Regel nicht, was auch am aktiven Widerstand der (männlichen) Jugendlichen in den Lagern gegen das ,Policing ${ }^{6}$ begründet ist. In diesem Zusammenhang diskutiere ich in Kapitel 6 eine Clique junger Männer aus einer Flüchtlingslager-Gegend, die sich stark in die Auseinandersetzungen und Straßenschlachten nicht nur mit dem israelischen Militär, sondern auch mit den Sicherheitskräften der PA involviert. Die besagten, mit der PA verbundenen Patronage-Netzwerke erstrecken sich aber auch in die Lager hinein. So zeigte und zeigt sich auch in den Flüchtlingslagern der teilweise Einbezug von ehemaligen Intifada-Veteranen in die PA - sei es in Form von Anstellungen oder durch Einbindung in die entstehenden Netzwerke.

Der Aufbau und der Unterhalt der PA-Institutionen wurde und wird von einem hohen finanziellen Aufkommen einer internationalen Gebergemeinschaft gestützt. Die europäischen Staaten sind die größten Geber, gefolgt von den USA und Japan. Zwischen 1994 und 2000 zahlte die Gebergemeinschaft circa 3.2 Milliarden US-Dollar aus, was ungefähr dem jährlichen Bruttosozialprodukt der palästinensischen Gebiete entsprach (Farsakh 2009: 32 f.). Das Aufkommen fließt dabei nicht nur in den Unterhalt der PA, sondern auch in einen wachsenden NGO-Sektor. Ich möchte an dieser Stelle keinen ausführlichen Überblick über die Entwicklung des palästinensischen NGO-Sektors geben. Zwei Angaben des Palestine Economic Policy Research Institute (MAS) sollen aber einen Eindruck von der anhaltenden Vitalität des NGO-Sektors auch nach den von einer Aufbruchsstimmung geprägten 1990er Jahren geben. So stieg die Zahl der im Westjordanland und Gaza ansässigen NGOs zwischen 2000 und 2007 um über 40 Prozent (MAS 2007: 25). Die Zahl der Gesamteinnahmen stieg zwischen 1999 und 2006 von circa 112.000.000 US-Dollar auf circa 223.000.000 US-Dollar jährlich und verdoppelte sich damit (MAS 2007: xii). Der Anteil der Finanzierung durch ausländische Geber stieg im gleichen Zeitraum von 45 Prozent auf 60 Prozent (ebd.: 17). Angestoßen durch die Oslo-Vereinbarungen entstand so ein großer, professionalisierter ${ }^{6}$ NGO-Sektor. Dieser war im Gegensatz zur palästinensischen Zivilgesellschaft der 1980er und 1990er Jahre nicht mehr primär auf die Unterstützung des palästinensischen, Widerstandsprojektes', sondern an westlichen Geberkriterien ausgerichtet (Jad 2008: 100). An anderer Stelle hebt Jad die Differenzen des professionalisierten NGO-Sektors gegenüber der Zivilgesellschaft der 1980er Jahre hervor: 
„The older mass organisations were open-access structures with public agendas, aiming to mobilise the largest number of students, workers, women, and youth into organisations serving each of these sectors. The newer ones, in contrast, are active in cities, run by an urban middle-class elite, and are smaller entities, dependent upon foreign funding““ $(\operatorname{Jad} 2007: 624)$.

Die an den Komitees der 1980er Jahre noch aktiv beteiligte Land- und Flüchtlingslagerbevölkerung wurde in der transformierten Zivilgesellschaft eher marginalisiert (ebd.).

Mit der Immigration der Rückkehrer und dem Aufbau und Wachstum von PA-Bürokratie und NGO-Sektor veränderten sich die urbanen Zentren des Westjordanlandes, insbesondere Ramallah, in dem die neue urbane Mittelschicht vorwiegend angesiedelt ist. Im Stadtbild Ramallahs tauchten ab Mitte der 1990er Jahre zunehmend Restaurants, Bars, Kinos und Fitnesscenter auf, die auch von einer steigenden Anzahl von westlichen Expats genutzt wurden. Ramallah erlebte in der zweiten Hälfte der 1990er Jahre einen Bauboom (Weizmann 2007: 127). Der Aufbau und Unterhalt der Bürokratie der PA sowie einer großen NGO-Landschaft trug im Westjordanland ganz erheblich dazu bei, dass sich, vorwiegend in Ramallah, eine neue urbane Mittelschicht formierte: „This [der Aufbau des öffentlichen Sektors], plus the expansion of the NGO sector, drove the growth of a middle class in the oPt“" (Turner 2014: 43; vgl. Challand 2009: 186). In dieser heterogenen urbanen Mittelschicht kann tendenziell von einer Beschäftigung von Rückkehrern in der PA und von Altansässigen im NGO-Sektor gesprochen werden (Hilal 2010: 32). Diese Formierung einer neuen urbanen Mittelschicht, in ihrer Entstehung angestoßen und gefördert durch die veränderten politischen Rahmenbedingungen der Oslo-Vereinbarungen, zeigt sich auch in den in dieser Arbeit diskutierten empirischen Befunden. Deutlich wird sie unter anderem in den sehr unterschiedlichen Lebenswelten und Lebenschancen der in Kapitel 6 gegenüber den in Kapitel 7 und 8 exemplarisch diskutierten Fällen, die auch für eine unterschiedliche lebensgeschichtliche Verhandlung der geteilten Zugehörigkeit zur Generation Oslo stehen.

Generell war und ist eine Folge der mit den Oslo-Abkommen verbundenen gesellschaftlichen Transformationsprozesse - auch darauf werde ich in den weiteren Kapiteln dieser Arbeit ausführlich zu sprechen kommen -, dass sich die Figuration von urbaner Mittelschicht und den Flüchtlingslager-Gegenden zuungunsten letzterer verändert hat. Die zunehmende Differenz und Verschiebung von Machtbalancen zwischen städtischen und peripheren Gruppierungen im Westjordanland betrifft sicher auch die ländliche Bevölkerung: „Since the 1990s however, villages have gradually become peripheral pockets that are difficult to reach, unlikely places of employment and difficult places of residency if one works in town“ (Wick 2011: 45 f.). Sie steht allerdings nicht im Zentrum dieser Forschungsarbeit. Die zunehmende Differenz zwischen den urbanen und den nicht-urbanen Lebenswelten zeigt sich auch in der Häufigkeit, mit welcher die Bevölkerung in der 
Peripherie in ihrem Alltag mit der Präsenz des israelischen Militärs konfrontiert ist. Die Wahrscheinlichkeit, von Verhaftungsoperationen der israelischen Sicherheitsbehörden oder Ähnlichem betroffen zu sein oder solche im eigenen Wohnumfeld beziehungsweise in der Nachbarschaft zu erleben - dies wurde mir während meiner längeren Feldaufenthalte schnell deutlich -, ist in den Flüchtlingslagern an der Peripherie der urbanen Zentren und in einigen ländlichen Räumen deutlich höher als in den Städten. Diese hier skizzierten Transformationsprozesse, die mit den Oslo-Vereinbarungen angestoßen und vertieft wurden, prägten und prägen auch die Zeit während und nach der Zweiten Intifada.

\subsection{Zweite Intifada 2000-2005}

Der Oslo-Prozess war gegen Ende der 1990er Jahre weitestgehend zum Erliegen gekommen. Bereits getroffene Vereinbarungen zwischen Israel und Palästinenser*innen, zum Beispiel im Rahmen des Wye-Abkommens im Oktober 1998, wurden nicht umgesetzt. Erneute Verhandlungen im Juli 2000 über einen finalen Status in Camp David wurden abgebrochen. Währenddessen hatte sich der israelische Siedlungsbau in den palästinensischen Gebieten in den 1990er Jahren fortgesetzt und sogar deutlich intensiviert. Während des Friedensprozesses führten palästinensische Gruppierungen, insbesondere die Hamas und der islamische Jihad, wiederholt Anschläge auf israelische Militärs und Zivilist*innen durch. ${ }^{89}$ Sowohl die israelische als auch die palästinensische Seite waren ,innenpolitisch ${ }^{`}$ unter Druck, national-religiöse und islamistische Gruppierungen opponierten massiv gegen die Abkommen. Auslöser der Zweiten Intifada war der Besuch Ariel Scharons, in dieser Zeit als Politiker des Likud in der Opposition, auf dem Haram ash-Sharif beziehungsweise Tempelberg in der Jerusalemer Altstadt im September 2000. Während der Demonstrationen nach dem Besuch starben bei Auseinandersetzungen zwischen Protestierenden und israelischen Sicherheitskräften vier Personen. Die Demonstrationen und Konfrontationen griffen auf das Westjordanland und Gaza über, bereits in den ersten Tagen kam es auch zu bewaffneten Auseinandersetzungen zwischen dem israelischen Militär und palästinensischen Paramilitärs. Die ersten Wochen der Zweiten Intifada waren zwar durchaus von Großdemonstrationen und Straßenschlachten geprägt, insgesamt wurde die Zweite Intifada bis zu ihrem Ende 2005 jedoch von keiner annähernd mit der Ersten Intifada vergleichbaren politischen Mobilisierung der palästinensischen Bevölkerung getragen und der Aufstand militarisierte sich schnell. ${ }^{90}$ Palästinensische Mili-

\footnotetext{
${ }^{89}$ Auch jüdische Gruppierungen beziehungsweise Täter aus dem national-religiösen Milieu führten in den 1990er Jahren Attentate durch, etwa den Anschlag auf das Abrahamsgrab beziehungsweise die Abrahamsmoschee im Februar 1994 oder die Tötung des israelischen Ministerpräsidenten Jitzchak Rabin im November 1995.

${ }^{90}$ Für einen Vergleich der Ersten und der Zweiten Intifada sowie eine Diskussion der Faktoren, die zu einer schnellen Militarisierung des Aufstandes beitrugen, vgl. Hammai und Tamari 2001: $12 \mathrm{ff}$.
} 
zen - etwa die al-Aqsa-Brigaden und die Izz al-Din al-Qassam-Brigaden - verübten im Verlauf der Zweiten Intifada zahlreiche Anschläge auf israelisches Sicherheitspersonal und Zivilist*innen. Regelmäßig wurden israelische Ortschaften und Siedlungen mit Schusswaffen und Raketen beschossen. Die israelische Armee setzte zum Teil Panzer und ihre Luftwaffe sowie insbesondere Scharfschützen ein.

„Instead of a widespread campaign of civil disobedience, the second Intifada consisted largely of violent resistance, including the use of suicide bomb attacks. Israel likewise adopted a more direct violent strategy, which included massive raids, assassinations, and extensive home demolitions in addition to checkpoints, curfews, and other forms of political, social, and economic oppression" (Norman 2010: 31).

Norman spricht hier auch von einem „cycle of violence“, in welchem die Konfliktparteien ihren Gewalteinsatz jeweils mit dem Gewalteinsatz der anderen rechtfertigten (ebd.). Insgesamt wurden zwischen September 2000 und Dezember 2008 1063 Israelis durch Palästinenser*innen und in den besetzten Gebieten 4835 Palästinenser*innen durch Israelis getötet. ${ }^{91}$ Im März und April 2002 rückte die israelische Armee im Rahmen einer umfassenden Militärkampagne in das Westjordanland ein und besetzte zahlreiche palästinensische Städte, darunter Ramallah, Bethlehem, Nablus und Jenin, für mehrere Wochen. Die durchgeführten Hausdurchsuchungen und Ausgangssperren betrafen hunderttausende Palästinenser*innen. Mit der Zweiten Intifada kam nun das von Israel bereits in der Ersten Intifada eingeführte System von Grenzsperrungen und Aufenthaltsgenehmigungen rigoros zur Anwendung. Die palästinensische Bevölkerung im Westjordanland und Gaza war nun weitetestgehend vom israelischen Kernland abgeschnitten. Während der Zweiten Intifada begann Israel auch mit dem Bau der zum Teil aus Zäunen, zum Teil aus Betonmauern und Wachtürmen bestehenden Sperranalage, die entlang von jüdischen Siedlungen im Westjordanland und in Jerusalem hochgezogen wurde.

Der Fokus auf die militärische Auseinandersetzung in meist räumlich relativ begrenzt bleibenden Gefechten und die fehlende politische Mobilisierung sorgten in der breiten palästinensischen Bevölkerung für eine im Vergleich zur Ersten Intifada sehr unterschiedliche Betroffenheit und Involvierung in die Zweite Intifada:

„Most West Bank Palestinians, except in the sense that they offered moral support or were the victims of Israeli military raids, related to the armed aspects of the intifada as observers rather than participants. Many an evening would be spent glued to the television screen, switching from one channel to

\footnotetext{
91 Die Zahlen basieren auf den Statistiken von Betselem zu den Opfern vor der Operation „,Gegossenes Blei“ der israelischen Streitkräfte in Gaza im Dezember 2008 und Januar 2009. https://www.btselem.org/statistics/fatalities/before-cast-lead/by-date-of-event <letzter Zugriff 15.6.2018>.
} 
the next, trying to gather news from events that were happening just miles away“ (Kelly 2008: 357).

Kelly spricht hier auch von einem während der Zweiten Intifada viel stärkeren Fokus vieler palästinensischer Zivilist*innen darauf, „, to live what passed for ,ordinary lives““ (ebd.: 353). Er betont, dass der Alltag vieler Palästinenser*innen von langen Wartezeiten, der erheblichen Schwierigkeit zu reisen beziehungsweise überhaupt mobil zu sein und von Phasen der Langeweile während der Ausgangssperren geprägt war.

Die im Alltagserleben präsenten Mobilitätseinschränkungen durch die Ausgangssperren, Checkpoints und Grenzschließungen hatten auch massive Auswirkungen auf die palästinensische Wirtschaft. Das Bruttosozialprodukt der palästinensischen Gebiete brach während der Jahre der Zweiten Intifada ein und die Armutsrate stieg stark an (Ajluni 2003). Mit der Zweiten Intifada wurde der Zugang der Palästinenser*innen, gerade jüngerer Männer, zum israelischen Arbeitsmarkt erheblich eingeschränkt und ist es bis heute. Beim gleichzeitigen Aufbau eines öffentlichen Sektors und NGO-Sektors im Westjordanland kann man auch von einer ökonomischen Entwicklung zuungunsten von Frauen und von jüngeren Männern mit geringerem Bildungsgrad und zugunsten von älteren Männern und Männern mit höherem Bildungsgrad während und nach der Intifada sprechen (Olmsted 2008). Insgesamt kann man festhalten, dass die Zweite Intifada im Vergleich zur Ersten Intifada in deutlich geringerem Ausmaß auf einer aktiven Involvierung und Mobilisierung der palästinensischen Bevölkerung beruhte. Als Ende der Zweiten Intifada wird häufig die Vereinbarung einer Waffenruhe zwischen dem israelischen Ministerpräsidenten Ariel Scharon und dem palästinensischen Präsidenten Mahmoud Abbas im Februar 2005 angegeben.

\subsection{Nach der Zweiten Intifada}

Während der Zweiten Intifada war im November 2004 Yassir Arafat gestorben und Mahmoud Abbas war ihm 2005 auf den Posten des Präsidenten der palästinensischen Autonomiebehörde und im Vorsitz der PLO gefolgt. Im Januar 2006 wurden Wahlen für den palästinensischen Legislativrat durchgeführt. Die Hamas, die die Wahlen 1996 noch boykottiert hatte, nun aber ebenfalls angetreten war, erlangte bei den Wahlen die absolute Mehrheit der Sitze und ungefähr 44 Prozent der Gesamtstimmen. Eine zunächst von der Hamas gebildete Regierung scheiterte - unter anderem daran, dass die USA und die europäischen Staaten die Zahlungen an die PA einstellten und sich öffentlich hinter die Fatah stellten. Eine im Anschluss gebildete sogenannte Regierung der nationalen Einheit bestehend aus Hamas und Fatah scheiterte ebenfalls und mündete schließlich in einen bewaffneten Konflikt zwischen Milizen der Fatah und der Hamas von Dezember 2006 bis Juni 2007. Folge der Kämpfe war eine de facto Aufteilung der palästinensischen 
Gebiete in einen Herrschaftsbereich der Hamas im Gazastreifen und ein unter Kontrolle der Fatah stehendes Westjordanland. Diese Kämpfe halten bis heute (2019) an. Im Gazastreifen führte das israelische Militär in den Folgejahren verschiedene Militärkampagnen - insbesondere Angriffe durch die israelischen Luftstreitkräfte - durch, etwa die Operation „Gegossenes Blei“ von Dezember 2008 bis Januar 2009, die Operation „Wolkensäule“ im November 2012 und die Operation „Schutzlinie“ von Juli bis August 2014. Die Zahl der alleine im Verlauf der Operation „Schutzlinie“ getöteten Palästinenser*innen übersteigt mit circa 19002100 Toten jene der insgesamt während der Ersten Intifada getöteten Palästinenser*innen. Den israelischen Militäroperationen gingen unter anderem der Beschuss von israelischen Ortschaften mit Raketen durch palästinensische Gruppierungen aus dem Gazastreifen voraus.

Für das Westjordanland ergab sich, anders als im Gazastreifen, eine bis zum Zeitpunkt der Abfassung dieser Arbeit andauernde Phase, in welcher massive bewaffnete Auseinandersetzungen zwischen Palästinenser*innen, dem israelischen Militär und israelischen Siedler*innen ausblieben. ${ }^{92}$ Phasen der relativen Ruhe wechselten und wechseln sich ab mit Phasen des ,Aufflammens' von Straßenschlachten und Konfrontationen, von Anschlägen palästinensischer Gruppierungen sowie Angriffen von Siedler*innen und begrenzten israelischen Militäroperationen. Und auch in Phasen relativer Ruhe blieb und bleibt der Alltag im Westjordanland, allerdings regional in sehr unterschiedlichem Ausmaß, geprägt von Konfrontationen und israelischer Militärpräsenz, etwa im Rahmen von Verhaftungsoperationen (vgl. Kap. 6-7). Die in den Osloer Abkommen als Zwischenschritt konzipierte administrative Aufteilung des Westjordanlandes, die limitierte Verwaltungshoheit der PA und die Sicherheitskooperation zwischen der PA und israelischen Behörden blieb mehr oder weniger in Kraft. Die diskutierten sozialen Transformationsprozesse im Westjordanland, darunter die Veränderung der urbanen Zentren, insbesondere Ramallahs, die Bedeutung der PA und die Restrukturierung der an sie gebundenen Patronage-Netzwerke, die hohe Präsenz westlicher NGOs und Expats, der mit der Formierung einer neuen urbanen Mittelschicht verbundene relative Macht- und Statusverlust anderer palästinensischer Gruppierungen, hielten an. Der israelische Siedlungsbau setzte sich auch nach der Zweiten Intifada fort. Ende des Jahres 2015 lebten im Westjordanland (ohne Ostjerusalem) etwa 383.000 israelische Sieder*innen in 127 vom israelischen Innenministerium anerkannten Siedlungen sowie in circa 100 informellen Siedlungsaußenposten. Ab 2007, mit der Regentschaft Salam Fayyads als Ministerpräsident der PA, wird auch von einem zunehmend repressiven Agieren der Sicherheitsdienste der PA, unter anderem von willkürlichen Verhaftungen und Folter von Gefangenen, gesprochen (Sayigh 2011: 18 ff.; Tartir 2017).

\footnotetext{
92 Im Vorfeld der „Operation Schutzlinie“ rückte die israelische Armee anlässlich der Entführung und Tötung dreier israelischer Jugendlicher auch ins Westjordanland ein - es war die umfassendste israelische Militärkampagne im Westjordanland seit der Zweiten Intifada.
} 
Man kann unter Hinzunahme der Befunde dieser Arbeit, die ich noch ausführen werde, für das Westjordanland vielleicht von einer ,bleiernen Zeit' sprechen, in der das Erleben von Stagnation, der romantisierende Blick auf vergangene kollektivgeschichtliche Phasen politischer Mobilisierung und die Vertiefung von palästinensischer Binnendifferenzierung im Vordergrund stehen. Diese kollektivgeschichtliche Phase umfasst, dies sei an dieser Stelle noch angemerkt, trotz des möglichen Erlebens von Stillstand und Beklemmung, die Fortführung und Vertiefung sozialer Transformationsprozesse. 


\section{Forschung zu historischen Generationen in Palästina}

Im vorangegangenen Kapitel habe ich bereits auf die Existenz einiger Arbeiten in der sozialwissenschaftlichen und geschichtswissenschaftlichen Generationenforschung hingewiesen, die sich mit historischen Generationen in den palästinensischen Gebieten auseinandersetzen. Auf diese Arbeiten möchte ich im Folgenden näher eingehen. Einen Schwerpunkt der Forschungen zu palästinensischen Generationen stellt die Generation Intifada dar. Mit meiner Arbeit zu historischer Generationenbildung , nach Oslo' stoße ich hingegen in ein Forschungsdesiderat. So verwenden bestehende Forschungsarbeiten zu dieser Phase zwar zum Teil den Begriff der „Generation Oslo“, orientieren sich jedoch nicht an einem historischen Generationskonzept. Die vorgestellten Forschungen sollen vor dem Hintergrund der in Kapitel 2 eingeführten Grundzüge historischer Generationenbildung - der generationalen Erfahrungsbildung im Sinne Mannheims, der Bedeutung von Generationenverhältnissen und intergenerationaler Interaktion sowie etwaiger Wechselwirkungen der generationalen Zugehörigkeit mit anderen Zugehörigkeiten - diskutiert werden. Generell gehe ich mit meiner Forschung - dies sei an dieser Stelle bereits angemerkt - mit der Berücksichtigung von Generationenverhältnissen und der Wechselwirkung mit anderen gesellschaftlichen Differenzlinien, im Westjordanland etwa jener zwischen Flüchtlingen und altansässiger Bevölkerung, auch im Hinblick auf die Konzeptualisierung historischer Generatio- 
nen über die bestehenden Forschungen zu historischen palästinensischen Generationen hinaus.

Eine Berücksichtigung historischer Generationenbildung findet sich in Ansätzen bereits in Rosemary Sayighs wegbereitender Forschungsarbeit zu palästinensischen Flüchtlingen, die sie in den 1970er Jahren durchgeführt hat. Die Arbeit basiert zwar auf Erhebungen im Libanon, aufgrund des Pioniercharakters der Forschung zu palästinensischen Flüchtlingen möchte ich sie hier dennoch kurz erörtern. Die Untersuchung ist als Ethnographie zu den Perspektiven und Lebensumständen von in den Flüchtlingslagern lebenden Flüchtlingen angelegt und berücksichtigt dabei, wenn auch eher am Rande, unterschiedliche generationale Erfahrungsbildungen. Sayigh stellt drei auf die Kollektivgeschichte bezogene Generationen heraus, die sie wiederholt aufgreift: ,jeel Falasteen, the generation formed in Palestine; jeel al-nekba the generation formed by the Disaster; jeel al thawra, the generation formed by the Revolution of 1965“" (1979: 58; vgl. ebd.: 149, 166 ff.). Die drei Generationen - Generation Palästina, Generation Nakba und Generation Revolution - differenziert Sayigh nach politischen Haltungen, nach dem Erleben der Position in der ,Aufnahmegesellschaft ${ }^{\star}$ und implizit auch nach der generationalen Lagerung relativ zur Nakba. Sie nennt aber keine den jeweiligen Generationen zugeordneten Geburtsjahre. Die Generation Palästina, die im Vergleich zu den anderen Generationen die Periode vor der Nakba über längere Phasen als Erwachsene erlebt hat, bleibt an den Loyalitätsverhältnissen und Führungsfiguren der Mandatszeit orientiert. Während die Generation Palästina die neueren, oppositionellen Parteien - etwa die kommunistischen Strömungen - als „divisive and anti-religious“ (ebd.: 149) gesehen haben, habe sich die Generation Nakba an ihnen orientiert (ebd.). Die Generation Nakba wird im Weiteren von Sayigh kaum herausgearbeitet. Deutlich ausführlicher konturiert sie hingegen die Generation Revolution, die mit der Konsolidierung und größeren Sichtbarkeit der palästinensischen Parteien der PLO und deren Milizen - den Fedaijin - in den 1960er und 1970 er Jahren verbunden ist. So spricht Sayigh hier auch wiederholt von der namensgebenden „Revolution of 1965“ (ebd.: 147) in Anlehnung an die erste größere Attacke, die Milizionäre der Fatah am 1. Januar 1965 auf israelischem Territorium durchführten, indem sie eine Sabotage der israelischen Landeswasserleitung versuchten. ${ }^{33}$ Für die Generation Revolution sei die Erfahrung, in den Lagern und in einer marginalisierten Stellung in der libanesischen Gesellschaft zu leben, deutlich prägender gewesen als für die Generation Palästina:

„All they had ever known was the camps [...]. Childhood experiences of hostility from Lebanese neighbors had imprinted on many of them a sense of exclusion, almost pariahdom. For camp Palestinians of this generation the Revolution brought a new identity which they eagerly grasped: Palestinian, strug-

\footnotetext{
${ }^{93} \mathrm{Zu}$ denken ist hier an die Anschläge und Grenzscharmützel der 1960er und 1970er Jahre - etwa die Schlacht von Karameh (vgl. Fußnote 141) -, aber zum Beispiel auch den zwischen PLO-Milizen und der jordanischen Armee ausgetragenen Jordanischen Bürgerkrieg 1970/71.
} 
gler, revolutionary. [...] Instead of being part of a despised, marginal group of ,displaced persons' Palestinians now adopted en masse the role of the vanguard of the Arab revolution, strugglers against imperialism, closely linked with other Third World struggles“ (ebd.: 166).

Diese unterschiedliche Wirksamkeit der Erfahrungen sorgte dafür, dass die Generation Revolution in viel stärkerem Maße das entstehende Wir-Bild eines Revolutionärs aufnahm als andere Generationen. Ihre Mitglieder konstruierten dieses Wir-Bild auch in Abgrenzung gegen die Generation Palästina, die sie als passiv erlebte (ebd.: 167). Damit berücksichtigt Sayighs Forschung - im Gegensatz zu späteren Forschungen - auch, zumindest in Ansätzen, die Wirksamkeit von Generationenverbältnissen. Insgesamt nimmt die Generationenfolge allerdings eine randständige Position in Sayighs Pionierforschung ein. Die generationsprägenden Erfahrungen und Haltungen sind nur knapp umrissen und bleiben relativ implizit. Dies gilt insbesondere für das von ihr angedeutete Generationenverhältnis. Weiterhin vollzieht Sayigh keine klare analytische Trennung von familialen und historischen Generationen.

Im großen Korpus an sozialwissenschaftlicher und geschichtswissenschaftlicher Forschungsliteratur zur politischen Mobilisierung in den palästinensischen Gebieten in den 1970er und 1980er Jahren sind auch einige Arbeiten mit einem Fokus auf Prozesse historischer Generationenbildung in dieser Phase entstanden. Einige dieser Arbeiten greifen explizit auf Mannheims historisches Generationskonzept zurück. Hervorzuheben sind hier insbesondere die Arbeiten von John Collins (2004) und Loren Lybarger (2005; 2007). Die Arbeit von Collins stellt jene Gruppen von männlichen (damals) Jugendlichen ins Zentrum, die während der Intifada stark mobilisiert und in die Straßenschlachten und andere Aktionen involviert waren. Er stützt seine Analysen auf Interviews mit palästinensischen Flüchtlingen, die er 1997 im an Nablus angrenzenden Flüchtlingslager Balata erhoben hat. Diese Flüchtlinge waren ganz überwiegend zwischen 1970 und 1975 geboren. Collins bezieht sich in seiner Arbeit explizit auf Mannheims Generationskonzept und versucht, sowohl die generationale Erfahrungsbildung als auch die retrospektive Erfahrungsbearbeitung und die diskursive Funktion der spezifischen Rahmung von Erfahrungen als generational herauszuarbeiten (2004: 13). Er identifiziert drei Handlungskontexte der Jugendlichen, die für die Mobilisierung zentral waren: Gefängnis, Schule und Straße. Die Darstellung der Kontexte, die den Charakter von ,,spaces of political agency“ tragen würden, sei von dem Fokus auf ,political awakening and mobilization“ (ebd.: 142) gekennzeichnet. Die Erzählungen zu Schule und Straße vermittelten einen Eindruck davon, inwiefern die politische Mobilisierung während der Intifada beide Kontexte gleichermaßen erfasst und $\mathrm{zu}$ einem durchgehenden politischen Betätigungsfeld mit breiter Beteiligung gemacht habe: „this collapsing of boundaries helped democratize a political subculture that had been previously open only to dedicated activists associated with particular factions“ (ebd.: 151). Die Jugendlichen wurden im Zuge dessen zu 
Akteuren, die weit über ihren Status als Jugendliche hinaus Handlungsmacht für sich reklamieren und ausüben konnten - beispielhaft hierfür war die Macht, Kontrollen und Durchsuchungen von Lehrer*innen durchzuführen, die Schließung von Geschäften zu erwirken oder in Konflikten zwischen Nachbar*innen oder Familienmitgliedern die Rolle von Vermittlern einzunehmen. Collins spricht hier auch von einer „inversion of generational authority“ (ebd.: 160). Allgemein kommt in den Erfahrungen ein generationales Wir-Bild zum Ausdruck:

„If these young people possess a kind of generational consciousness, they do so because they have linked their collective identity less to their age and more to the historical experiences and memories of political action that they all share" (ebd.: 161).

Die Erzählungen zum Gefängnis wiederum seien sehr stark davon bestimmt, Handlungsmacht zu demonstrieren, und seien daran gebunden, eine gerade mit Entmächtigung verbundene biographische Phase retrospektiv zu bearbeiten. Inwiefern verschiedene Zugehörigkeiten die generationalen Erfahrungen vermitteln und welche Rolle Generationenverhältnisse spielen, wird von Collins hingegen nur am Rande thematisiert. Auch die Bedeutung der ganz vorwiegend männlichen Zusammensetzung seines Samples diskutiert er kaum.

Auch Loren Lybarger $(2005 ; 2007)$ greift in seiner Forschungsarbeit zu politischer Identitätsbildung explizit Mannheims Generationskonzept im Zusammenhang mit der Ersten Intifada auf. Seine Forschungen stützen sich auf Erhebungen in zwei Flüchtlingslagern in Gaza und dem Westjordanland hauptsächlich zwischen 1999 und 2000. Lybarger differenziert zwischen zwei sozio-politischen Hauptmilieus. Er spricht von einem säkular-nationalistischen Milieu, dem zunächst die panarabistisch orientierten Gruppierungen zuzuordnen seien, später seien auch die Fatah und die, linken' Parteien hinzugetreten. Das andere Milieu, das etwa zunächst die Muslimbruderschaft, dann den islamischen Jihad und die Hamas, Hibz Tahrir und andere Gruppierungen umfasste, bezeichnet er als islamistisches Milieu. Diese beiden politischen Hauptmilieus wiederum periodisiert Lybarger mit Hilfe des historischen Generationskonzepts. Er hebt insbesondere die Generation Intifada hervor, ihre Geburtsjahre setzt er grob von Anfang der 1960er bis Anfang 1970er Jahre an. Im Zuge der Formierung der Generation Intifada hätten sich entlang der politischen Milieus zwei wesentliche Generationseinheiten ausgebildet:

„the first Intifada shakes established political formations and fragments the political field, producing the opposing secular-nationalist and Islamicnationalist tendencies. This fragmentation is generational, in the Mannheimian sense. It appears among the young activists (late teens to mid-20s) who come of age during the destabilization and coincides with the parallel mobilization of the secularist and Islamist milieus. The resulting divide produces a field of interaction and interpenetration. This field encompasses vari- 
ous institutional sites (neighborhoods, university campuses, etc.) that mediate between the crosscutting tendencies. Within these sites, individuals negotiate the competing socio-political orientations, producing a range of polarized and amalgamated solidarities“" (2005: 147).

Die Konkurrenz der Generationseinheiten entlang der Milieus innerhalb der Generation Intifada sorgte Lybarger zufolge für eine milieuübergreifende Neuverhandlung ihrer Deutungsmuster und Wissensbestände in den von ihm benannten Interaktionskontexten, etwa den palästinensischen Hochschulen in den palästinensischen Gebieten: „Both secular nationalists and Islamists had to negotiate the conflicting moral political demands of the two generational units, or tendencies“ (2007: 53). Das damit verbundene Wechselspiel von Abgrenzung und Annäherung schlage sich auch in den Identitätsentwürfen der von ihm untersuchten Aktivist*innen nieder, die er unter vier verschiedene Typen subsummiert: „At least four types of orientation emerged among my informants: sheer secularism; sheer Islamism; liberal Islam; and Islamic secularism“ (2005: 149; vgl. 2007: 236 ff.). Insgesamt trägt Lybargers Studie partiell der ,Binnendifferenzierung' der palästinensischen Gesellschaft Rechnung, indem sie in den verschiedenen politischen Milieus verschiedene Generationseinheiten ausmacht. Allerdings bleiben weitere, möglicherweise mit generationaler Zugehörigkeit interagierende Differenzlinien, etwa geschlechtlicher Zugehörigkeit, insbesondere aber die Unterschiede zwischen dem Kontext der palästinensischen Flüchtlingslager und den urbanen oder ländlichen Räumen und deren Verhältnis fast gänzlich ausgeblendet. So untersucht Lybarger - wie auch Collins - ganz überwiegend die Generationenbildung in der Bevölkerung der Flüchtlingslager und diskutiert deren Verhältnis zu anderen gesellschaftlichen Gruppierungen nicht. Zwar könnte dies möglicherweise Ausdruck einer relativ geringen Bedeutung des Wir-Bildes als Flüchtlinge in den erhobenen Interviews und Gesprächen der Generation Intifada sein - darauf deuten jedenfalls auch die Ergebnisse meiner Forschungsarbeit hin (vgl. Kap. 6.3.; 6.4; 9.2; Hinrichsen 2017) -, explizit thematisiert wird dies von Lybarger jedoch nicht.

Eine Arbeit, die eine dezidiert weibliche historische Generationenbildung im Zusammenhang mit der Mobilisierung der 1970er und 1980er Jahre in den Fokus rückt, ist die von Frances Hasso (2001). Ihre Studie basiert auf Erhebungen, die sie bei um 1965 geborenen Aktivistinnen des Palestinian Federation of Women's Action Committee (PFWAC) durchgeführt hat. Die Komiteeföderation war 1978 von Frauen, die in der DFLP aktiv waren, gegründet worden „for the dual purposes of gaining national liberation and improving women's gender status“ (2001: 590). Hasso hat Interviews und Nachinterviews 1989 und 1995 in Gaza, dem Westjordanland und Ostjerusalem geführt; ganz überwiegend lebten die Frauen in Städten und Dörfern, nicht jedoch in Lagern. In ihrer Studie argumentiert sie, dass die Involvierung in die Komiteearbeit in den 1980er Jahren eine formative Phase für die Aktivistinnen gewesen sei. So bildeten ,these former participants a ,feminist generation' that is differentiated by its egalitarian gender ideology and 
sense of self-efficacy“ (2001: 587). Hassos Arbeit weist Bezüge auf Mannheims Generationskonzept auf, die aber allgemein bleiben (ebd.: 587 f.). Die Involvierung der Frauen in die Komiteearbeit habe eine Erweiterung ihrer eigenen Spielräume und Ressourcen - etwa eine Verringerung familialer Kontrolle von Mobilität, aber auch die Verringerung finanzieller Abhängigkeit - zur Folge gehabt. In diesem Zusammenhang hätten sich wesentliche politische Haltungen und ein Erleben von Handlungsmacht und Selbstwirksamkeit in der Lebensführung ausgebildet, die auch nach dem Ende der Involvierung und nach dem Kollabieren des Komitees ab Beginn der 1990er Jahre Bestand gehabt hätten und auch in einem generationalen Wir-Bild zum Ausdruck kämen:

„For many women, engagement with the PFWAC dramatically reconstituted their gender ideologies, political worldviews, sense of the possible, and selfdefinitions. For these women, involvement also produced a strong sense of cohort or generational consciousness - a feeling that their individual potential was redefined as a result of their collective existence and power [...] They often referred to themselves as ,the daughters of the [Palestinian Federation of Women's Action] committees' (banaat al-lijan) and believed that they were very different from other women who had not been active in the PFWAC" (ebd.: 600).

Hasso diskutiert, wie die Frauen unter den gegebenen gesellschaftlichen Bedingungen navigierten. Die Frauen der PFWAC charakterisiere eine Wertschätzung eines eigenen Einkommens, verbunden mit der Möglichkeit, sich durch Erwerbsarbeit im öffentlichen Raum zu bewegen, eine ausgesprochene Bildungsorientierung sowie eine stärker egalitäre Anlage von familialen Beziehungen und Partnerwahl (einen pragmatischen Verzicht auf Heirat eingeschlossen). Auf weitere Abgrenzungen und Sie-Bilder, die zum Beispiel auch auf intergenerationale Verhältnisse und Interaktionen verweisen könnten, kommt Hasso aber nicht zu sprechen.

Des Weiteren gibt es einige Forschungsarbeiten zur politischen Mobilisierung in den 1970er und 1980er Jahren und zur Intifada, die zwar den Begriff „Generation Intifada" aufgreifen, die aber nicht mit einem historischen Generationskonzept arbeiten. Zu diesen Arbeiten gehört die Studie von Sylvie Mansour (1996), die sich mit den Auswirkungen der Ersten Intifada auf palästinensische Schulkinder sowie auf die Institution Schule konzentriert. Dazu gehört auch die Arbeit von Laetitia Bucaille (2004), die als eine Mischform journalistischer Reportage und wissenschaftlicher Untersuchung angelegt ist. Bisweilen ergibt sich bei diesen Arbeiten der Eindruck einer recht ad hoc getroffenen, allein vom kollektivgeschichtlichen Verlauf abgeleiteten Definition von Generationen (etwa bei Schäbler 2011: 67).

Während manche der diskutierten Arbeiten ihre Ergebnisse auf Erhebungen gründen, die neben dem Westjordanland auch in Gaza und Ostjerusalem durchgeführt wurden, liegen auch Untersuchungen vor, die sich im engeren Sinne auf palästinensische historische Generationenbildung in Ostjerusalem oder in Israel 
konzentrieren. Johannes Becker (2013; 2017) bezieht sich in seiner Arbeit zu historischen Generationen unter Palästinenser*innen in der Jerusalemer Altstadt dezidiert auf Mannheims Generationskonzept. Er arbeitet insbesondere die von ihm so genannte Jordanische Generation heraus, eine Generationseinheit von Männern, die von ihren Armutserfahrungen der jordanischen Zeit und den Erfahrungen des ökonomischen Aufstiegs nach Beginn der israelischen Besatzung geprägt ist, welche ihre Deutungsmuster, Wir- und Sie-Bilder bestimmen. Er setzt sie von der nachfolgenden Intifada-Generation ab und beschreibt deren Verhältnis und intergenerationale Aushandlungen in der Gegenwart (2017: 182-188). Dan Rabinowitz and Khawla Abu-Baker arbeiten in ihrer Studie (2005) eine „stand-tall generation“ von israelischen Palästinenser*innen - häufig Frauen heraus, die zum Jahrtausendwechsel in Israel politisch aktiv wurden. Die um 1975 Geborenen traten selbstbewusst für eine größere Sichtbarkeit von Palästinenser*innen in Israel ein.

Trotz vielfacher Bezüge in der Forschungsliteratur auf die Generation Nakba und deren wiederholt betonte Bedeutung für ein palästinensisches kollektives Gedächtnis ist sie meines Erachtens kaum dezidiert im Hinblick auf historische Generationenbildung untersucht worden. Neben geschichtswissenschaftlichen Arbeiten sind gerade in jüngerer Zeit einige sozialwissenschaftliche Studien entstanden, die die Nakba auch aus erinnerungstheoretischer Perspektive erforschen (Sa'di/Abu-Lughod 2007b; Damir-Geilsdorf 2008; Kassem 2011; Al-Hardan 2016). Überwiegend werden in diesen Arbeiten, wenn auch nicht immer im Zentrum stehend, die konkreten Erfahrungen, Erinnerungen und Perspektiven der Nakba-Generation selbst berücksichtigt. Die Erfahrungsbildung und die Erinnerungspraxis werden im Hinblick auf die Folgen für die familiale Tradierung, in ihrem vergeschlechtlichten Charakter und in ihrer Rolle für nationale Wir-Bilder und das kollektive Gedächtnis bestimmt. Allerdings unterbleibt meist eine genaue Bestimmung generationaler Erfahrungen, die über die allgemeine ,Zeugenschaft ${ }^{\circ}$ der Nakba hinausgehen und eine weitere Ausdifferenzierung der Erfahrungsbildung innerhalb der Erlebnisgeneration vornehmen würde. So werden Differenzen innerhalb der Erlebnisgeneration, die zum Beispiel mit dem Alter, den jeweiligen Phasen der Nakba und weiteren Umständen, unter denen Flucht und Vertreibung erlebt wurden, in Zusammenhang stehen könnten (und entsprechende Folgen für die Lebenswege und die familiale Interaktion hätten), nicht weiter in ihren unterschiedlichen generationsbildenden Erfahrungstypiken aufgezeigt. Verweise auf Mannheim bleiben entsprechend meist kursorisch (vgl. Al-Hardan 2016: 99).

Die Arbeiten zu palästinensischen Generationen beziehen sich ganz überwiegend auf Zeiträume vor den Osloer Abkommen, also auf Zeiträume vor Mitte der 1990er Jahre. Zwei Arbeiten, die sich explizit mit der Phase nach den OsloVerträgen und nach der Zweiten Intifada beschäftigen, sind „Jil Oslo“ (2013) von Sunaina Maira und „Fatah from Below: The Clash of Generations in Palestine“ (2016) von Jacob Høigilt. Beide Untersuchungen greifen das Konzept historischer 
Generationen aber nicht explizit auf und stellen auch keine Bezüge auf Mannheim her. Aufgrund ihrer Bezugnahme auf die Phase ,nach Oslo' möchte ich die beiden Studien kurz vorstellen.

Zwar trägt Mairas Forschungsarbeit den Generationenbegriff im Titel - „Jil“ ist der arabische Ausdruck für „Generation“ - das zentrale Anliegen ihrer Arbeit und ihre Kernkonzepte sind jedoch anders gelagert. Maira orientiert sich an den Cultural Studies der Birmingham School und möchte eine ,neue palästinensische „youth subculture“ (2013: 19) herausarbeiten, die mit den Kulturpraktiken des Grafitti und insbesondere des Hip-Hop verbunden sind. Ihre Analysen basieren auf Erhebungen, insbesondere Interviews, die sie bei mehrmonatigen Feldaufenthalten 2012 und 2013 im Westjordanland sowie in Ostjerusalem und Haifa durchgeführt hat. Mit ihrer Forschung wolle sie die Frage stellen,

„if Palestinian hip hop has lent itself to the politicization of a new generation of youth and the formation of an alternative public sphere and what it represents to young Palestinians, both within and outside of the hip hop subculture" (ebd.: 11).

Dabei arbeitet sie heraus, inwiefern in der Jugendkultur über die Kulturpraktiken ein nationales Selbstverständnis konstruiert und dieses in dezidierter Abgrenzung zu den üblichen politischen Lagern und der Oslo-Architektur entworfen wird. Die Jugendkultur integriere in stärkerem Maße Palästinenser*innen aus Israel und aus der Diaspora sowie Palästinenser*innen in den palästinensischen Gebieten. Sie greift dabei auch die sogenannte Jugendbewegung auf, die sich in den palästinensischen Gebieten und in Israel vor dem Hintergrund der Proteste und Bewegungen der arabischen Welt 2011 konstituiert hatte und mit der ein loses Netzwerk von Aktivist*innen und Künstler*innen verknüpft war. ${ }^{94}$ Es stand mit der ,neuen Jugendkultur in Verbindung, konnte jedoch nicht entscheidend an Momentum gewinnen.

Die Studie von Jacob Høigilt (2016) setzt sich unter anderem ebenfalls mit der Jugendbewegung und den mit ihr verbundenen Aktivist*innen auseinander. Sie basiert auf zwischen 2011 und 2013 geführten Interviews in verschiedenen Städten und Orten im Westjordanland. Seiner Auffassung nach kommt in der Jugendbewegung ein „Clash of Generations“ (2016: 456), auch unter FatahAktivist*innen, zum Ausdruck, der es mit sich bringe, dass die jüngere Generation vom sogenannten Friedensprozess und dem neopatriarchalen und autoritären Politikstil der PA abrückt. Der ,erneuerte ",right based, non-violent activism“ (ebd.: 466) - Høigilt wie auch Maira verweisen hier beispielhaft auf die Kampagne um das sogenannte Bab al-Shams im Januar $2013^{95}$ - ist eine der Strategien bezie-

\footnotetext{
${ }^{94}$ Für einen Überblick, welche kleineren Gruppierungen und Initiativen Maira zur Jugendbewegung zählt, vgl. 2017: 176.

${ }^{95}$ Ungefähr 200 palästinensische Aktivist*innen und Aktivist*innen aus dem Ausland hatten im Januar 2013 eine Zeltstadt, das Bab al-Shams, im vom Israel verwalteten E1-Gebiet im Jerusalemer
} 
hungsweise Reaktionen der jüngeren Generation auf die Bedingungen der OsloPeriode. Sowohl Høigilt als auch Maira betonen die zunehmende Vernetzung der Aktivist*innen mit den sogenannten 48ern, also den Palästinenser*innen in Israel. Über diese Aspekte hinausgehend werden die Jugendbewegung und ihre Aktivist*innen jedoch nicht in ihrer gesellschaftlichen Position und in den gesellschaftlichen Machtverhältnissen, in denen sie stehen, bestimmt. Andere Umgangsweisen mit den gesellschaftlichen und politischen Bedingungen der Oslo-Phase werden von Maira gar nicht diskutiert. Høigilt allerdings stellt neben dem neuen, ,nicht gewaltsamen Aktivismus' zwei weitere ,Verhandlungen' der gesellschaftlichen Bedingungen knapp vor, die er als „exodus from politics“ (ebd.: 466) und als „uncoordinated and violent outburst of anger" (ebd.: 469) bezeichnet. Den ,Rückzug von der Politik ' diskutiert Høigilt ausführlicher in einer gemeinsam mit Mona Christophersen und Åge A. Tiltnes verfassten Veröffentlichung (2012). Dort bemerken sie: „Widespread discontent with their situation among the youth does not translate into increased political interest or engagement" (ebd.: 1). Als einen der Gründe nennen sie unter anderem die Demobilisierung von GraswurzelAktivismus, die damit zusammenhänge, dass die internationale Entwicklungshilfe ,bequeme' unpolitische Kultur- und Sozialprogramme bevorzuge. Im Zuge der Repression der israelischen und der PA-Sicherheitsbehörden finde sich außerdem eine

„widespread culture of fear in regard to political activity, so resourceful youth resort to less dangerous cultural and social activism, while the most critical voices choose political exit rather than confrontation with the authorities.[...] Palestinian youth do not seem to think that their situation is desperate enough to warrant any large-scale departure from the political routine and instead invoke the concept of sumud (resilience) or simply try to realise their full human potential as a silent form of resistance, leaving the political initiative in the hands of their leaders" (2012: 1).

Hier spielen also politische Repression, für Teile der Bevölkerung noch akzeptable sozio-ökonomische Lebensumstände sowie die Tendenz der Jugend, größere biographische Risiken zu vermeiden und die Entfaltung ihres „full human potential“ als Widerstand zu rahmen, zusammen. Diese Aspekte gehen auch in die Richtung der Strukturkomponenten eines von mir in dieser Arbeit diskutierten biographischen Verlaufstsypus (vgl. Kap. 8; 9.4). Dieser wird von mir jedoch als ein Typus unter anderen Typen diskutiert und gerade auch als Ausdruck einer generationalen Position, eingebettet in die Wandlungen generationaler und anderer Figurationen und Machtverhältnisse im Westjordanland interpretiert (vgl. Kap. 9). Die dritte

Umland errichtet und waren nach zwei Tagen durch das israelische Militär geräumt worden. Ziel der Aktion war es unter anderem, die Umgangsweise der israelischen Behörden mit sogenannten AuBenposten israelischer Siedlungen, die sich von der Umgangsweise mit den Bab al-Shams unterscheidet, zu spiegeln. 
von Høigilt benannte Umgangsweise mit den gesellschaftlichen und politischen Bedingungen der Oslo-Phase, der ,uncoordinated and violent outburst of anger", mit der er auch auf die regelmäßigen Straßenschlachten und ,Konfrontationen“ anspielt (2016: 470), werden kaum weiter ausgeführt oder erklärt. Ohne Høigilts Kategorisierung vollständig zu übernehmen, sei hier darauf verwiesen, dass gerade die beiden zuletzt genannten Umgangsweisen mit der Oslo-Phase auf etwas deuten, was ich in meiner Forschungsarbeit umfassend herausarbeite und in ihrer Entstehung erkläre - nämlich eine Position in einer Generationenfiguration und ihre spezifische Verhandlung im Rahmen typischer biographischer Verläufe, in denen mehrere Zugehörigkeiten und gesellschaftliche Positionen zusammenwirken (vgl. Kap. 6-9).

Insgesamt konzentriert sich die Forschung zu historischen palästinensischen Generationen, wenn sie sich mit den palästinensischen Gebieten beschäftigt, auf die politische Mobilisierung der 1970er und 1980er Jahre und die mit dieser verbundenen Generation Intifada. Studien, die sich stärker auch im weiteren Sinne mit historischen Generationen seit den Oslo-Abkommen beschäftigen, liegen nur vereinzelt vor. Tendenziell wird in der palästinensischen Generationenforschung nur kursorisch auf das Mannheim'sche Generationskonzept zurückgegriffen, es dient zum Teil eher einer Einteilung nach Kohorten oder der Benennung von sehr breit definierten Erlebnisgenerationen. Zudem bleibt es gelegentlich vage, an welche Aspekte der Erfahrungsbildung die Mitgliedschaft in den Generationen gebunden wird. Gerade die Bedeutung von Generationenverbältnissen und intergenerationaler Interaktion ist kaum oder nur am Rande in den Blick genommen worden. Daher gehe ich mit meiner Forschung und ihrem Fokus auf Generationenverhältnisse, verstanden als Figurationen, sowie mit der Berücksichtigung der Wechselwirkung von Generationenverhältnissen mit weiteren Figurationen, im Westjordanland gerade zwischen Flüchtlingen und altansässiger Bevölkerung, über die bestehenden Forschungen zu historischen Generationen in den palästinensischen Gebieten hinaus. Eine Betrachtung historischer Generationen aus dezidiert figurationssoziologischer und biographietheoretischer Perspektive ist auch in diesem Kontext ein Novum. Im Folgenden möchte ich nun in die Diskussion der empirischen Analysen, die im Rahmen dieser Arbeit unternommen wurden, einsteigen. 


\section{Die „Söhne des Lagers“ und die Generation Intifada in einer Flüchtlingslager-Gegend: Wir- und Sie-Bilder, Interaktionsdynamiken und biographische Verläufe}

\subsection{Einleitung}

Mit diesem Kapitel beginne ich die Darstellung und Diskussion der Fallrekonstruktionen und empirischen Analysen meiner Forschung. Das Kapitel ist in zwei Unterkapitel gegliedert. Im folgenden Kapitelabschnitt 6.2 möchte ich zunächst die Deutungsmuster, Wir- und Sie-Bilder sowie die Interaktionsdynamik in einer Clique junger Männer (Geburtsjahrgänge 1989-1993) aus einer FlüchtlingslagerGegend im Westjordanland vorstellen. Für die Mitglieder der Clique, ausnahmslos Flüchtlinge, lässt sich ab der Frühadoleszenz ein biographischer Prozess zunehmender politischer Militanz nachzeichnen. Kollektivgeschichtlich liegt dieser in einer von keinen massiven Auseinandersetzungen geprägten Phase zwischen 2007 und 2014 (vgl. Kap. 4.8). Der biographische Prozess zunehmender Militanz äußert sich unter anderem in der starken Involvierung in Straßenschlachten mit dem israelischen Militär und mit den Sicherheitskräften der PA sowie, bei den meisten jungen Männern, auch in teils mehrjährigen Inhaftierungen in israelischen Gefängnissen. Dieser Prozess war ab dem jungen Erwachsenenalter außerdem zu- 
nehmend damit verbunden, sich innerbalb der palästinensischen Gesellschaft als marginalisiert zu erleben und in den Interdependenzgeflechten, in denen sie sich bewegten, eine machtchancenarme Position einzunehmen - als ,Kämpfer für die palästinensische Sache , als Flüchtlinge und als Generation. Die Interaktionsprozesse in der Clique und die verhandelten Wir- und Sie-Bilder - etwa ihre Abwertung von ,Städtern' oder ihre Beschwerde über das gesunkene Ansehen von Märtyrern und Inhaftierten - verweisen auf die Position der jungen Männer in den verschiedenen Figurationen, in die sie verflochten sind. Im Verlauf des Kapitels 6 sowie in der Zusammenschau mit den weiteren empirischen Kapiteln (6.2-8.3) und der Ergebnisdiskussion (Kap. 9) werde ich herausarbeiten, inwiefern die jungen Männer eine mit spezifischen Lebens- und Sinnchancen verbundene historisch-generationale Position einnehmen, in welcher sie mit der Generation Intifada in einer Generationenfiguration verflochten sind.

Im folgenden Unterkapitel 6.2 gehe ich zunächst auf den Feldzugang ein und gebe, aufgrund der Vielzahl der zur Sprache kommenden Personen, einige wichtige biographische Angaben zu drei jungen Männern, die ich Musa, Samad und Yousef genannt habe und die im Zentrum dieses Kapitels stehen (6.2.1). Im Anschluss (6.2.2) gehe ich auf das erste ausführliche Gespräch mit Musa und Samad aus der Clique sowie auf verschiedene Gespräche und Interaktionen mit den jungen Männern während der ersten Feldaufenthalte 2013 ein. In diesen werden das in der Clique geteilte Deutungsmuster ,Marginalisierung verdienter Kämpfer ${ }^{\star}$ und die mit dem Deutungsmuster verbundenen Wir- und Sie-Bilder deutlich, die ausführlich vorgestellt werden. In dem Deutungsmuster verhandeln die jungen Männer, wie ich bereits angedeutet habe, verschiedene Zugehörigkeiten, etwa ihren Flüchtlingshintergrund in Abgrenzung zu den städtischen Mittelschichten. Im darauffolgenden Abschnitt (6.2.3) gehe ich dann auf die Relevanz der Beteiligung an den Straßenkämpfen und der Gefängnisaufenthalte für den Konstitutionsprozess der Clique und die Interaktionsdynamik unter den jungen Männern ein. Dabei werde ich zum einen die Relevanz der Interaktionsdynamiken in der Clique für die Männlichkeitskonstruktionen der jungen Männer diskutieren, orientiert an Michael Meusers Arbeiten zu „Ernsten Spielen“ (2005). Zum anderen erörtere ich Hinweise auf die in Ansätzen deutlich werdende Verschiebung der biographischen „Funktion' der Clique von einer, Widerstands'- zu einer Leidensgemeinschaft. Eng damit verbunden ist das Marginalisierungserleben der jungen Männer, welches zunehmend innerhalb der Clique verhandelt wurde und welches sich über den Zeitraum unserer Bekanntschaft bis 2015 deutlich verstärkte (6.2.4). In Abschnitt 6.2.5 reflektiere ich, warum und auf welche Weise sich der Kontakt zu den jungen Männern über den Zeitraum von zweieinhalb Jahren vertiefte und erhalten blieb und welche Position ich ihnen gegenüber einnahm. Daraufhin fasse ich die wesentlichen Befunde zur Clique in einem Kapitelfazit nochmals zusammen (6.2.6). Abschließend leite ich auf das familiale und das weitere Interaktionsfeld der jungen Männer über (6.2.7). 
In Unterkapitel 6.3 setze ich die diskutierten Interaktionsdynamiken und Deutungsmuster in der Clique zu langfristigen kollektiv-, familien- und lebensgeschichtlichen Prozessen ins Verhältnis. Ich arbeite die familialen Tradierungsprozesse und die intergenerationalen Interaktionen, in denen familiale Aufträge erlebt und dann in Familie und Clique verhandelt werden, heraus. Dabei sind die Tradierung der familialen Fluchtgeschichte in der Nakba und insbesondere die Interaktion zwischen Familienmitgliedern, die die Mobilisierung der 1970er und 1980er Jahre als Jugendliche oder junge Erwachsene erlebt und in dieser gekämpft haben - der Generation Intifada -, und den jungen Männern, die diese ,verpasst ${ }^{6}$ haben und ihnen nachfolgen, entscheidend. Dabei entsteht - so viel sei an dieser Stelle bereits angedeutet - eine implizite Hierarchisierung historischer Generationen. Insgesamt illustriert Kapitel 6 die Rekonstruktion der Schnittstellen und der Wechselwirkung von kollektivgeschichtlichen und biographischen Prozessen in der Elterngeneration wie auch in der Kindergeneration in der FlüchtlingslagerGegend und zwar sowohl im familialen Interaktionsfeld als auch im Interaktionsfeld der Peergroup.

\subsection{Die „Söhne des Lagers“: Eine Clique militanter junger Männer}

\subsection{1 Überblick und Zugang}

Der Kontakt mit der Clique junger Männer ergab sich im Zuge eines Feldbesuchs meiner Kolleg*innen und mir im Flüchtlingslager Jaddaliya im März 2013. Ich hatte das Lager schon im Rahmen früherer Forschungen im Jahr 2010 besucht und kam nun als Teil eines vierköpfigen Forschungsteams, bestehend aus Gabriele Rosenthal, Ahmad Albaba, Arne Worm und mir, erneut nach Jaddaliya. Um ein Gruppengespräch mit Kindern und Jugendlichen aus Jaddaliya zu führen, waren wir in ein Café in der Nähe des Lagereingangs gegangen. Als Arne Worm, Ahmad Albaba und ich nach dem Gespräch auf die Veranda traten, um eine Zigarette zu rauchen, wurden wir von zwei jungen Männern angesprochen. Die beiden jungen Männer, die ich im ersten Eindruck auf höchstens 20 Jahre schätzte, hatten gesehen, wie wir mit der Gruppe die Straße vor dem Lagereingang überquert hatten, und uns beim Verlassen des Cafés abgepasst. Sie stellten sich mit ihren Vornamen Samad und Musa vor und fragten uns auf Arabisch, was wir denn von den Kindern wollten. Ahmad Albaba stellte uns mit den knappen Worten vor, dass wir ein Team von der Universität Göttingen in Deutschland seien und dass es uns um Lebensgeschichten von Palästinensern gehe. Samad antwortete daraufhin, dass sie sich ebenfalls gerne mal mit uns unterhalten würden, ohne spezifischer darauf einzugehen, welches Anliegen sie hatten. Ahmad antwortete ihnen, dass wir heute leider keine Zeit mehr hätten, da wir zurück in die Stadt müssten, aber dass wir 
gerne Telefonnummern austauschen könnten, um uns an einem der nächsten Tage zu treffen.

In der Folge dieser kurzen Begegnung lernten wir Samad, Musa und die anderen Freunde aus der Clique in den nächsten Wochen sowie bei einem weiteren Feldaufenthalt im Herbst 2013 kennen. Während 2013 noch verschiedene palästinensische und deutsche Kolleg*innen in wechselnder Zusammensetzung mit den jungen Männern in Kontakt waren, führten ab 2014 Ahmad Albaba und ich den Kontakt weiter. Die Beziehung zu den jungen Männern intensivierte sich während mehrerer Feldaufenthalte bis Herbst 2015, insbesondere während meines halbjährigen Feldaufenthaltes ab September 2014. Ich war für insgesamt elf Monate im Feld, lebte selbst nicht im Flüchtlingslager der jungen Männer, sondern in einem anderen Lager weiter im Norden des Westjordanlandes und kam insbesondere in der zweiten Jahreshälfte 2014 häufig ,zu Besuch` (vgl. Kap. 3.3.; 3.4.3). Vor allem mit Samad, Musa und Yousef blieb der Kontakt über den gesamten Zeitraum erhalten. Über sie lernten wir zügig weitere Freunde kennen - insgesamt waren es acht bis zehn junge Männer, die den engeren Kreis der Clique ausmachten. Im Verlauf der verschiedenen Feldaufenthalte führten meine Kolleg*innen und ich biographisch-narrative Interviews mit den jungen Männern sowie zum Teil mit ihren Familienmitgliedern und Nachbar*innen. Bei zahlreichen ,informelleren Besuchen verbrachten wir aber auch einfach Zeit mit ihnen, ,hingen rum, besuchten gemeinsam Freunde oder Veranstaltungen im Ort und erhielten so einen Einblick in die alltäglichen Interaktionszusammenhänge, in denen sich die jungen Männer bewegten.

Ihre Lebenswege teilten und teilen, dies wurde schnell klar, einige Gemeinsamkeiten: Sie alle sind Enkel der Nakba-Generation, haben also einen palästinensischen Flüchtlingshintergrund. Alle lebten entweder mit ihren (Herkunfts)Familien im eigentlichen Flüchtlingslager oder in einem der angrenzenden Viertel. Während Samad (geb. 1993) bei seiner Familie im Lager lebte, war die Kernfamilie Musas (geb. 1991) Mitte der 1990er Jahre in einen Neubau in ein an das Lager in östlicher Richtung angrenzendes Wohnviertel gezogen. Yousefs (geb. 1993) Kernfamilie war zur selben Zeit ebenfalls in dieses Viertel gezogen, allerdings nicht aus dem angrenzenden Lager, sondern aus einem anderen Flüchtlingslager aus der Nähe Hebrons. Zu Yousefs Familie wie zu ihm selbst liegt eine ausführliche Fallrekonstruktion vor, die ich in Kapitel 6.3 darlege. Die Familien Khaleds (geb. 1990), eines Cousins Musas, und Mahmouds (geb. 1992) - beide kommen in diesem Kapitel ebenfalls zur Sprache - lebten und leben im Lager. Außerdem erstreckten sich die Netzwerke mit Mitgliedern der erweiterten Familie, Freunden und Bekannten in allen Fällen sowohl in die eigentliche Lager-Gegend als auch in die angrenzenden Viertel.

Um auf die Rekonstruktion der Deutungsmuster vorzugreifen, sei hier angemerkt, dass alle jungen Männer auf das Wir-Bild als Flüchtling oder das ebenfalls häufig verwendete „Sohn des Lagers“ (,ibn al-mubaīyam“) zurückgriffen - unab- 
hängig davon, ob ihr Wohnort und der ihrer Familien im eigentlichen Lager oder in den angrenzenden Vierteln lag. Die Bezeichnungen Flüchtling und Sohn des Lagers wurden von den jungen Männern mehr oder weniger synonym verwendet, auch wenn der Begriff Sohn des Lagers beziehungsweise Tochter des Lagers im Vergleich mit der Bezeichnung Flüchtling nicht die familiale Fluchtgeschichte, sondern den Wohnort und tendenziell die Position in der, Aufnahmegesellschaft akzentuiert. Alle jungen Männer kannten sich aufgrund des kleinräumlichen Charakters der Lager-Gegend seit ihrer Kindheit ,vom Sehen'. Näher bekannt waren sie nach und nach im Jugendalter ungefähr ab 2006 geworden. Zum Bespiel Musa und Yousef hatten sich über Sportaktivitäten und ein Nachbarschaftszentrum, in welchem die Eltern der jungen Männer zum Teil engagiert waren (vgl. Kap. 6.3.3), angefreundet. Mahmoud, Samad und Yousef wiederum waren erst direkt über die Involvierung in Straßenschlachten in engeren Kontakt gekommen (vgl. Kap. 6.2.3).

Alle Mitglieder des engeren Freundeskreises beziehungsweise der Clique hatten sich mit Beginn ihrer Frühadoleszenz, in der Regel gemeinsam, häufig an gewaltsamen ,Konfrontationen' oder Straßenkämpfen sowohl mit den israelischen Sicherheitskräften als auch mit den Sicherheitskräften der PA beteiligt. Die Involvierung in die Straßenschlachten führte für die meisten jungen Männer zu mehrjährigen Inhaftierungen in israelischen Gefängnissen; zum Teil waren sie auch für einige Tage oder Wochen in Gefängnissen der PA inhaftiert. Musa war mit 17 Jahren für circa eineinhalb Jahre in israelischen Gefängnissen inhaftiert worden. Samad wurde mit 18 Jahren inhaftiert und verbrachte knapp zwei Jahre in israelischer Haft. Yousef war einige Monate nach Samad in einem israelischen Gefängnis inhaftiert worden und war zwei Wochen vor unserem ersten Kontakt mit den jungen Männern im Frühjahr 2013 entlassen worden. Mahmoud wiederum hatte bis zu Beginn des Jahres 2015 ,nur einige Tage in einem Gefängnis der PA gesessen und war nie in einem israelischen Gefängnis inhaftiert gewesen. Die jungen Männer haben keine oder eher ,schlechte' Schulabschlüsse, die ein Universitätsstudium unmöglich machen. Die Jahre nach der Schule beziehungsweise die Zeit nach ihrer Rückkehr aus der Haft war für sie überwiegend mit Arbeitslosigkeit oder prekärer, illegaler Beschäftigung als Tagelöhner auf Baustellen oder in Restaurants in Israel verbunden. Im Zeitraum unserer Bekanntschaft ab dem Frühjahr 2013 bis Herbst 2015 gelang es ihnen kaum, sich beruflich zu etablieren.

In den Gesprächen mit den jungen Männern wurden die von ihnen erlebten Straßenkämpfe sowie die Verhaftungen und Gefängnisaufenthalte ausführlich thematisiert. In anderen Gesprächen und Interviews mit Palästinenser*innen im Westjordanland hatte ich als Teil des bereits erwähnten Forschungsteams das Bemühen unserer Interviewpartner beobachten können, vor uns als ,Repräsentanten' der sogenannten westlichen Welt gerahmte Gesprächspartner ein palästinensisches Wir-Bild zu konstruieren, in welchem das Leiden, der Palästinenser' unter der israelischen Besatzung betont, die Spannungen und Konflikte zwischen ver- 
schiedenen Gruppierungen innerhalb der palästinensischen Gesellschaft jedoch bagatellisiert wurden (vgl. Kap. 3.4.2; Hinrichsen et al. 2013; Rosenthal 2015). Die hier genannten jungen Männer fallen jedoch nicht in diese Kategorie. Ihnen ging es nicht darum, ihr ,Leiden unter der israelischen Besatzung im Rahmen eines homogenisierenden nationalen Wir-Bildes zu betonen. Die Thematisierung der Konfrontationen, der Gefängnisaufenthalte und der Verhaftungen war vielmehr in ein Deutungsmuster eingebettet, in welchem sie ihren ,Einsatz für die palästinensische Sache' einer von ihnen zunehmend als marginalisiert und entmächtigt erlebten gesellschaftlichen Position in der palästinensischen Gesellschaft des Westjordanlandes gegenüberstellten. Dieses Deutungsmuster und die darin verhandelten Zugehörigkeiten der jungen Männer werden bereits in den ersten Treffen und Gesprächen im Jahr 2013 deutlich, auf welche ich im Folgenden eingehen möchte.

\subsection{2 ,Widerstandsbilanzierung`: Deutungsmuster, Wir- und Sie-Bilder während der ersten Treffen 2013}

Noch am Abend des Tages nach dem ersten Aufeinandertreffen vor dem Café verabredeten Ahmad und Samad am Telefon einen Besuch bei den jungen Männern im Lager. Ahmad fragte ihn bereits bei dieser Gelegenheit, ob er bereit wäre, uns ein Interview ,,̈̈ber die Lebensgeschichte“ zu geben, was dieser ohne größere Nachfragen bejahte. Am darauffolgenden Tag trafen Ahmad Albaba und Arne Worm ${ }^{96}$ - ich hatte für diesen Tag bereits einen anderen Interviewtermin - Samad und Musa am Eingang des Flüchtlingslagers, die sie dort abholten und sie freundlich begrüßten. Die beiden jungen Männer führten sie zum Haus von Samads Familie, die im Lager lebt. Das Haus, welches ich erst bei einem späteren Feldaufenthalt besuchte, liegt im sehr dicht bebauten, am Hang gelegenen Teil des Lagers. Es ist ein für die Gebäude in diesem Teil des Lagers typischer, etwas verwinkelter Rohbetonbau, dem man ansieht, dass seit Einführung der Steinbauten durch die UNRWA Ende der 1950er Jahre nach und nach weitere Stockwerke und Anbauten hinzugefügt wurden. Der Eingangsbereich führt in einen hell gekachelten, mit einer goldgelben Sofagarnitur und Tischen ausgestatteten Empfangsraum. Dort saß bereits ein weiterer junger Mann, Mahmoud, der Ahmad Albaba und Arne Worm die Hand schüttelte. Die beiden setzten sich, Musa hatte bereits Platz genommen. Samad schlug vor ihnen Tee zu kochen und verschwand in der Küche im hinteren Teil des Hauses. Musa verwickelte Ahmad sofort in ein Gespräch über unser Forschungsprojekt. Er fragte ihn, ob es um „Normalisierung“ (,altațbī' ") gehe, „sie“ - er meinte sich und die anderen jungen Männer - seien nämlich konsequent gegen Normalisierung. Musa spielte hier auf den im Westjordanland seit den 2010er Jahren immer populärer werdenden ,Antinormalisierungs'Diskurs an. Die in diesem Diskurs hervortretenden Positionen und Akteure sind

\footnotetext{
${ }^{96}$ Die folgende Darstellung beruht auf der Analyse des Transkripts des Gesprächs sowie den ausführlichen Beobachtungsnotizen von Arne Worm und Ahmad Albaba.
} 
sehr heterogen. In etwa lässt sich die Antinormalisierungs-Haltung als Verweigerung von (auch indirekter) Kooperation und Kontakt mit israelischen Institutionen und zivilgesellschaftlichen Gruppen, die sich nicht konsequent für Widerstand gegen die israelische Besatzung und gegen die Diskriminierung und Benachteiligung von Palästinenser*innen positionieren, angeben (vgl. Heÿn/Schroeder 2015). Musa fuhr fort:

Musa: ,also es geht darum dass sie Kinder von beiden Seiten zusammenbringen und die Beziehung zwischen ihnen verwischt ihre Prinzipien und diese Werte und sie so aufwachsen dass die palästinensischen Kinder nicht an die Märtyrer denken und das Leid durch diese Begegnung [...] deswegen hat Samad auch euch angesprochen damit er verhindert dass die Kinder in normalisierende Programme geraten“"

Sie selbst würden Versuche, Kinder von beiden Seiten, also von israelischer und palästinensischer Seite, zusammenzubringen und so zur ,Normalisierung ${ }^{6}$ der Beziehungen beizutragen, ablehnen. Im Folgenden entwickelte sich das Gespräch zu einer Art Gruppendiskussion. Musa hatte dabei den höchsten Redeanteil. Samad schaltete sich jedoch immer wieder mit eigenen „Beiträgen“ ein, Mahmoud hingegen, der gelegentlich durch Nicken Zustimmung bekundete, sprach während des Gesprächs fast gar nicht. Samad und Musa führten im Folgenden eigenständig Themen ein, Ahmad Albaba und Arne Worm stellten nur wenige Nachfragen.

Als Samad mit Salbeitee zurückkehrte, stimmte er in Musas Ausführungen ein. Sie würden die Kinder aus dem Lager davon abhalten wollen, normale Beziehungen mit israelischen Kindern aufzubauen, weil sie sonst manipuliert würden. Daraufhin sprach wieder Musa. Für ihn stelle die Normalisierung eine Strategie unter verschiedenen ,israelischen Kampfmethoden“ seit der „Nakba“ dar. Eine Methode sei direkte Gewalt, wie etwa in Deir Yassin ${ }^{97}$, eine zweite sei zum Beispiel das ,Abkaufen' der Staatsbürgerschaft ${ }^{98}$ und eine dritte Methode sei die Normalisierung. Man müsse aber weiter ,für die palästinensische Sache` kämpfen, vielleicht werde „nicht diese Generation, aber die nächste Palästina befreien“.

In den Ausführungen Samads und Musas zur ,Normalisierung' deutete sich zunächst ein thematisches Feld an, dass sich mit einem ,Einschwören' der palästinensischen Jugend auf Ansprüche auf ,das Land' und der Stärkung einer als geschwächt empfundenen, nationalen Kampfbereitschaft ${ }^{\star}$ sowie der Inszenierung eigenen Wissens um, Widerstandsthematiken“ umreißen lässt. Den ,Kampf für die palästinensische Sache verstanden sie dabei als jeweiligen ,Generationenauftrag', dem aber, so die Auffassung der jungen Männer, in ihrer Generation schwer

\footnotetext{
${ }^{97}$ Musa rekurriert hier auf die Tötung von circa 100-120 Bewohner*innen Deir Yassins durch Truppen der Irgun und Lehi während des Ersten Arabisch-Israelischen Krieges 1948/49 (Morris 2004: 238 f.), die als „Massaker von Deir Yassin“ in den palästinensischen Diskurs eingegangen ist. ${ }^{98} \mathrm{Im}$ Lager kursierten Gerüchte, die israelischen Behörden hätten Bewohner*innen Geld dafür angeboten, dass sie das Westjordanland verlassen.
} 
nachzukommen sei. Auf Arne Worms anschließende Frage, ob die Normalisierung auch Erwachsene betreffe, setzte Musa zu einem längeren Monolog an. Knapp zusammengefasst antwortete er, dass Erwachsene aus finanziellen Interessen daran teilnehmen würden, aber bei Kindern würden sich die Gedanken verändern. Ohne eine weitere Frage abzuwarten, führte er aus, dass es „,in der Vergangenheit" anders gewesen sei, weil

Musa: ,wenn man die Jahre zurückgeht die Verhaftungen waren jedes Jahr im Lager die ganze Zeit gerade hier im Lager und über die Jahre ist es weniger geworden ich sage $=$ nicht $=$ es ist nur schlecht aber es zeigt den Mangel an Bewusstsein [...] Jugendliche, Kinder denken jetzt mehr an Reisen ins Ausland, Frieden und solche Sachen [...] aber wir dürfen nicht vergessen, dass wir Palästinenser in Haft haben, dass wir unsere Märtyrer nicht vergessen [...] für mich sind das Recht auf Rückkehr und der Kampf gegen die Besatzung Werte die man nicht verlieren soll“.

Mit dem von Musa hier erneut angedeuteten Topos, Vergessen der Häftlinge und Märtyrer ${ }^{\varsigma}$ und der ,drohenden Gefahr ${ }^{`}$ einer ,Entwertung ${ }^{6}$ des ,Kampfes gegen Israel' entwarf Musa nun verstärkt das Bild eines gesellschaftlichen Kontextes, in dem politische Hafterfahrungen und überhaupt, Widerstandsbeteiligung' geringe und tendenziell schwindende gesellschaftliche Beachtung und Würdigung erfahren. In Abgrenzung zu einer in dieser Hinsicht besseren Vergangenheit skizzierte er eine, für die Erfüllung des zuvor angedeuteten Generationenauftrags des, nationalen Befreiungskampfes' schwierige, kollektivgeschichtliche Gegenwart. Im direkten Anschluss an diese Sequenz und ohne weitere Zwischenfrage thematisierte Musa die Marginalisierung Jugendlicher aus den Flüchtlingslagern:

Musa: „Wenn du jetzt eine tiefgreifende Untersuchung machen willst, wäre es gut, einen Vergleich zu machen zwischen dem Leben im Flüchtlingslager und dem Leben in der Stadt. Für mich nach meiner Entlassung aus dem Gefängnis habe ich den Traum, das Meer zu sehen; mein Freund hier möchte mal ins Ausland reisen [...] unser Traum ist einfach, in einem besseren Zustand zu leben; der größte Wunsch der Flüchtlinge ist Arbeit“.

Im Anschluss an eine Passage zur schwindenden Bedeutung und Wertschätzung von ,Haft und Märtyrern' führte Musa also die Differenzen in den Lebenschancen (,Arbeit', ,besserer Zustand', ,Reisen ) von Jugendlichen aus den Flüchtlingslagern gegenüber den Jugendlichen aus der städtischen palästinensischen Bevölkerung des Westjordanlandes ein. Mit Musas Wechsel auf die Ebene persönlicher Erfahrungen (,meine Entlassung ${ }^{6}$ etc.) deutet sich an, dass er mit dem Sprechen über Häftlinge, den Widerstand gegen Israel und die fehlenden Arbeitsmöglichkeiten für Flüchtlinge auch über sich spricht. Dabei deutet er auch eine Rahmung seiner Erfahrungen als exemplarisch für eine Wir-Gruppe von Jugendlichen aus den Flüchtlingslagern an. Hier ist bereits ein wesentlicher Aspekt des von den jungen Männern geteilten Deutungsmusters erkennbar, der hier jedoch noch vergleichs- 
weise implizit und in Allgemeinbegriffen formuliert ist: Die Teilnahme an ,Widerstandsaktionen', erlebte Verhaftungen oder hier die Zeit im Gefängnis werden als geleisteter ,Einsatz für die palästinensische Sache` gegenüber der eigenen, als benachteiligt wahrgenommenen gesellschaftlichen Position aufgerechnet und mit dieser kontrastiert. Innerhalb dieser Aufrechnung wird dann, wie noch deutlicher werden wird, eine wahrgenommene Benachteiligung als Flüchtling beziehungsweise als Bewohner der Flüchtlingslager-Gegenden gegenüber anderen gesellschaftlichen Gruppierungen verhandelt.

Dieser Logik folgend schwenkten Samad und Musa im weiteren Verlauf des Gesprächs stärker in eine Thematisierung von erlebter Marginalisierung ein. So fuhr Musa fort, indem er über einige Ereignisse in der letzten Zeit, in welchen er sich als Flüchtling benachteiligt gefühlt habe, sprach:

Musa: „das schwierigste für einen Sohn des Lagers ist es eine Arbeit zu bekommen (3) eine von den merkwürdigen neuen Sachen ist dass, also es gibt palästinensische Geschäfte die Kredite vergeben wie Banken aber eine ihrer Bedingungen ist, oder die erste Bedingung ist dass man nicht aus dem Lager sein darf".

Interviewer: „Man soll nicht aus dem Lager sein?““

Musa: ,Ja, du sollst aus der Stadt sein oder vom Dorf aber nicht aus dem Lager".

Samad: ,Ja es ist eine Art Diskriminierung““.

Musa: „Es gibt wenige Geschäfte die Kredite an ihn [Sohn des Lagers] vergeben, ich hatte mich beworben für einen Kredit bei diesem neuen Geschäft in der Stadt und um akzeptiert zu werden musste ich meine Adresse ändern im Ausweis zu der Gegend hier statt Jaddaliya".

Samad: ,als dürfte der Sohn des Lagers nicht wie die anderen leben“.99

Samad sprach im Anschluss darüber, dass es an den Checkpoints auch eher Probleme gebe, wenn man eine Lageradresse im Ausweis stehen habe. Wenn er nur gefragt werde, woher er sei, gebe er immer Ramallah an und nicht das Lager. Musa meinte dann, vor Kurzem habe es wieder Konflikte um die unbezahlten Stromrechnungen der Flüchtlinge gegeben: „Vor einiger Zeit gab es Auseinandersetzungen zwischen uns und der PA weil sie wollen dass der Sohn des Lagers seine Stromrechnungen bezahlt." Musa spielte hier darauf an, dass die Lagerbewoh-

\footnotetext{
${ }_{99} \mathrm{Ob}$ diese Regelungen in der geschilderten Weise existieren und ob sie mit Erwägungen in $\mathrm{Zu}$ sammenhang stehen, dass für die Flüchtlinge bereits alternative Institutionen der UNRWA für Mikrokredite und Ähnliches verfügbar sind, ist mir nicht bekannt. Allerdings sind an dieser Stelle auch nicht diese Regelungen selbst, sondern deren Deutung und Bewertung durch Musa und Samad interessant, da sie die wahrgenommene Benachteiligung als ,Söhne des Lagers' und Flüchtlinge verdeutlichen.
} 
ner*innen nicht für ihren Stromverbrauch zahlen, was aber zu Interessenkonflikten und gelegentlichen Spannungen mit anderen Teilen der palästinensischen Bevölkerung führt - unter anderem deshalb, weil die Kosten gelegentlich auf an die Lager angrenzenden Gemeinden umgelegt werden. ${ }^{100}$ Die Kostenübernahme wird unter anderem mit dem vermeintlich temporären Charakter der Flüchtlingslager und der möglichen Rückkehr der Flüchtlinge in Herkunftsregionen der Familien im heutigen israelischen Staatsgebiet gerechtfertigt. Auch Samad kam kurz auf diese Argumentationsfigur zu sprechen: Ihr eigentliches Zuhause sei nicht ,hier', sondern im Herkunftsort seiner Familie im heutigen Israel. Sie würden „,irgendwann zurückkehren“, fügte er hinzu. Die Lager auf die Bezahlung verpflichten zu wollen sei daher nicht fair, es gebe ohnehin, so Samad, „Benachteiligung zwischen dem Sohn der Stadt und dem Sohn des Lagers zwischen Flüchtlingen und NichtFlüchtlingen“.

Als die PA vor einigen Monaten versucht habe, die Lager auf eine Bezahlung der Rechnungen in der Zukunft zu verpflichten, hätten sie und andere jungen Männer aus dem Lager einige Straßen in der Nähe des Lagers besetzt, sagte Musa. Daraufhin sei es zu heftigen Konfrontationen mit der Polizei der palästinensischen Sicherheitsbehörden gekommen.

Musa: ,das Lager ist anders als andere wegen der Hauptstraße hast du das gesehen das ist eine wichtige Straße die die Städte verbindet mit den anderen Hauptstraßen äh Städten wenn es ein Problem gibt dann schließen die Leute direkt die Hauptstraße es geht nicht darum Ärger zu machen für die Leute die die Straße fahren aber es es geht darum eine Nachricht zu schicken an die PA dass wir da sind um zu protestieren, aber die PA versucht jetzt einen neuen Weg“.

Musa fuhr fort, die PA könne die Lager eigentlich nicht betreten, aber insgesamt

Musa: „gab es zwei Versuche das Lager zu stürmen aber sie sind total zurückgeschlagen worden von den šabāb, ${ }^{101}$ also sie hatten mehr Verluste als wir (lacht) )“.

Interviewer: „Ihr wart dabei?“

Samad: „Ich war sogar verhaftet wegen dieser Sache“.

\footnotetext{
100 Außerdem trägt die informelle Ausnahme der Lager ganz erheblich zu hohen Ausständen bei, die die palästinensische Seite bei israelischen Stromversorgern hat, was auch als politisches Druckmittel dient. Im Januar 2013 war eine Vereinbarung zwischen Salam Fayyad, dem damaligen palästinensischen Ministerpräsidenten, und den Verwaltungskomitees der Lager im Westjordanland getroffen worden, die darauf zielte, die informelle Ausnahme der Lager aus den Zahlungen für Elektrizitätsverbrauch bei Verzicht auf alle bisherigen Ansprüche zu beenden. Daraufhin war es zu Protesten und Auseinandersetzungen zwischen Lagerbewohner*innen, Sicherheitskräften der PA und Bewohner*innen angrenzender Gemeinden in verschiedenen Regionen im Westjordanland gekommen.

101 Arabisch: Männliche Jugendliche/,Jungs‘.
} 
Als Arne Worm fragte, ob sie alle dabei gewesen seien, bejahten dies alle, auch Mahmoud. Als Arne Worm nachfragte, wie er das in der vorangegangenen Bemerkung gemeint habe, die PA versuche einen neuen Weg, antwortete Musa, die PA würde Personen aus dem Lager „einkaufen“, die hier geachtet seien, weil sie „Kämpfergeschichten“ hätten. Diese Personen würden dann versuchen, auf die jungen Männer im Lager Druck auszuüben. Als „die Behörden gekommen“ seien, hätten diese Personen sehr viel Macht bekommen, sowohl in den Behörden als auch im Lager. Es seien nicht nur Fatah-Leute, sondern auch Unabhängige und viele von der PFLP dabei. Musa spielte hier auf den Aufbau der PA in den 1990er Jahren und die Kooptierung von Teilen der Aktivist*innen der Ersten Intifada durch die PA und deren Einbezug in die Patronage-Netzwerke, die auch in die Lager reichten, an (vgl. Kap. 4.6). Ahmad Albaba und Arne Worm versuchten, etwas mehr zu diesen Akteuren im Lager, von denen sich Musa und Samad abgrenzten, zu erfahren, aber die beiden ließen sich bei diesem Gespräch nicht auf eine konkretere Benennung dieser Akteure ein. Diese hier von Samad und Musa angedeutete Kritik an den ,behördennahen' Akteuren mit ,Kämpfergeschichten innerhalb des Flüchtlingslagers wurde über die nächsten Feldaufenthalte mit zunehmendem Vertrauensaufbau, aber auch mit wachsender Frustration über die eigene biographische Situation expliziter (vgl. Kap. 6.2.4).

Resümiert man die in diesem Gespräch deutlich werdenden thematischen Felder und Präsentationsinteressen, wird Folgendes sichtbar. Für Musa und Samad mag der Anlass, uns vor dem Café anzusprechen, darin bestanden haben, eine mögliche Teilnahme von Kindern aus dem Lager an „normalisierenden Programmen" verhindern zu wollen. Im ersten Gespräch wie auch in den biographischnarrativen Interviews, die wir in den folgenden Tagen, Wochen, Monaten mit ihnen führten, betonten sie dabei die ihrer Ansicht nach weiterhin bestehende ,Notwendigkeit des Kampfes gegen Israel ${ }^{6}$ und sorgten sich um die politische ,Widerstandsbereitschaft' der ,Jugend'. Uns anzusprechen ermöglichte den jungen Männern auch, für sich eine Sprecher- und Autoritätsposition im Hinblick auf ,Widerstandsthematiken' zu reklamieren und ihr ,politisches Wissen' und ihre Vertrautheit mit ,Widerstandsthematiken' zu inszenieren - zu denken wäre hier an Musas ,Exkurs' zu den verschiedenen ,israelischen Kampfmethoden'. Sie deuten damit auch ein Wir-Bild als ,Kämpfer für die palästinensische Sache` an. Dieses Wir-Bild wird dabei aber einer als marginalisiert erlebten gesellschaftlichen Position (,nicht reisen können'; ,schwer einen Job zu finden'; , als Flüchtlinge und Söhne des Lagers gegenüber den Städtern diskriminiert sein') innerhalb der palästinensischen Gesellschaft des Westjordanlandes gegenübergestellt. Die Logik folgt einem Deutungsmuster, das die jungen Männer bedienen und das ich ,Marginalisierung verdienter Kämpfer' genannt habe.

Die Verhandlung weiterer Zugehörigkeiten mittels des Wir-Bilds der ,marginalisierten Kämpfer` und der damit verbundenen Sie-Bilder zeigen sich auch in zahlreichen anderen Gesprächen mit den jungen Männern, wie etwa der im Folgenden 
kurz geschilderten Feldszene. Wenige Tage nach dem ersten Treffen mit Musa, Samad und Mahmoud waren wir mit den jungen Männern zum gemeinsamen Abendessen verabredet. Bei dieser Gelegenheit sah ich selbst Musa und Samad zum ersten Mal nach der kurzen Begegnung einige Tage zuvor. Wir setzten uns auf die Veranda desselben Cafés an der Hauptstraße, welches wir als Treffpunkt vereinbart hatten, und bestellten Tee, um auf die anderen zu warten. Musa und sein Cousin Khaled trafen gemeinsam ein, ich gab ihnen die Hand und beide stellten sich kurz mit Namen vor. Wir warteten noch auf Yousef und einige andere, die ebenfalls mit uns essen wollten. Musa und Khaled bestellten noch einen Kaffee und setzten sich zu uns. Nach kurzem Small-Talk fragte Khaled uns, wo wir denn gerade wohnten. Auf unsere Antwort, dass wir in der Stadt in einem Hotel wohnten, fragte er, „bei allem Respekt“, wieso wir dort wohnten. Dann setzte er zu einer längeren ,Beschwerde“ über die Stadtbewohner an. Die Leute aus der Stadt seien nicht aktiv, würden nicht demonstrieren und würden sie im Lager diskriminieren, weil sie sagen würden, das Land gehöre nicht den Lagerbewohnern, sondern ihnen. Die Stadtbewohner würden sagen, das Land der Lagerbewohner sei in Israel, dorthin sollten sie gehen. Auch Khaled ging dann, wie bereits Musa in unserem ersten Gespräch, auf den Konflikt um die unbezahlten Stromkosten ein und schob hinterher, dass „die“ das Land nicht verteidigen würden. Diese Abgrenzung gegenüber ,den Städtern` zeigte sich bei den jungen Männern auch generell gegenüber Ramallah: Als später am Abend das Gespräch auf einen Bekannten von uns in Ramallah kam, verzogen die jungen Männer das Gesicht. Musa meinte, sie würden Ramallah nicht mögen. Yousef ergänzte, dort würden nur reiche Leute wohnen und Ausländer würden denken, dass alles in Ordnung sei in Palästina, weil sie nur Ramallah sähen. Die Politik würde nur noch aus Ramallah gesteuert, aber was würden sie dort schon vom Lager wissen. Auch an der PA ließen sie kein gutes Haar, diese stelle inzwischen eine „zweite Besatzung“ dar, die Probleme mit den Behörden seien größer als diejenigen mit Israel.

Diese geschilderte Szene wie auch die anderen hier vorgestellten Treffen und Gespräche im Jahr 2013 stehen beispielhaft für viele Gespräche mit den jungen Männern. Sie machten zwar ihre Ablehnung ,normalisierender Programme“, ihr Beharren auf dem ,Recht auf das Land' und ihre Überzeugung vom militanten Kampf gegen die Besatzung deutlich - gerade in den ,frühen' Gesprächen und Interviews im Jahr 2013 sind die jungen Männer auch noch um eine Demonstration ihres politischen Wissens und eine Selbstinszenierung als Kämpfer bemüht. Jedoch verlagerte sich der Fokus in den Gesprächen schnell in Richtung einer Thematisierung der eigenen Stellung innerbalb der palästinensischen Gesellschaft. Auch wenn sich die Komponenten des Deutungsmusters ,Marginalisierung verdienter Kämpfer bei den nächsten Feldaufenthalten, Gesprächen und Interviews noch stärker konturierten und zum Teil anders akzentuiert wurden, wurden dessen zentrale Komponenten größtenteils bereits bei diesen ersten Treffen im Jahr 2013 deutlich. 


\section{Zusammenfassung: Die ,Widerstandsbilanzierung' im Deutungsmuster ,Marginalisierung verdienter Kämpfer"}

In dem rekonstruierten Deutungsmuster, den Wir- und Sie-Bildern, die sich durch die Gespräche und Interviews mit den jungen Männern ziehen, wird mehrerlei deutlich sichtbar.

(a) Dass sie ihre Involvierung in die Straßenkämpfe und die erlebten Verhaftungen als geleisteten ,Einsatz für die palästinensische Sache' gegenüber der eigenen, als benachteiligt und entmächtigt wahrgenommenen Position aufrechnen und mit dieser kontrastieren. Sie konstruieren ein Wir-Bild als ,marginalisierte Kämpfer. Den Kampf gegen die israelische Besatzung und den Einsatz für das Recht auf Rückkehr der Flüchtlinge entwerfen sie als Auftrag an jede junge Generation, dem eben aber in ihrer kollektivgeschichtlichen Periode aufgrund des nachlassenden ,Einsatzes für die palästinensische Sache` und der geringeren Wertschätzung für Gefangene und Märtyrer schwerer nachzukommen sei.

(b) Die jungen Männer verliehen ihrer Auffassung Ausdruck, dass die Bevölkerung der Lager-Gegenden von der israelischen Besatzung stärker betroffen und in den Widerstand gegen diese stärker involviert, gegenüber der städtischen, mittelständischen palästinensischen Bevölkerung benachteiligt sei und von dieser marginalisiert werde. Das Deutungsmuster konstruiert einen Gegensatz zwischen dem Wir-Bild einer für das, palästinensische Widerstandsprojekt' engagierten und von der israelischen Besatzung betroffenen, aber gesellschaftlich marginalisierten Bevölkerung der Lager-Gegenden und dem komplementären Sie-Bild einer unpolitischen, aber privilegierten Stadtbevölkerung („kämpfen nicht“; „,reiche Leute“; „diskriminieren Flüchtlinge“ etc.).

(c) Außerdem deuteten die jungen Männer ihre Marginalisierung auch als einen Vorgang innerhalb der Gegenden der Flüchtlingslager. Diese Marginalisierung werde von der lokalen ,Führungselite', also von einigen in die PA integrierten Aktivist*innen der Ersten Intifada („Sie haben Kämpfergeschichten“; sind ,gekauft“ und „haben Einfluss") betrieben. Auf den von dieser Gruppierung ausgehenden „Schimpfklatsch“ (Elias/Scotson 1993: 49) gegenüber den jungen Männern gehe ich in Abschnitt 6.7 ein. Allerdings sind die jungen Männer in den Gesprächen im Jahr 2013 mit uns zunächst sehr zurückhaltend, was die Thematisierung dieser Marginalisierung innerhalb der Lager-Gegenden und der daran beteiligten Personen betrifft. Dies ist in der relativen sozialen Nähe der Personen zu den jungen Männern im Lager einerseits und der starken Machtasymmetrie gegenüber diesen Personen andererseits begründet.

(d) Für den Mangel an ,Einsatz für die palästinensische Sache‘ und ihre eigene Marginalisierung machen die jungen Männer außerdem - eng verbunden mit ihrer Auffassung von ,den Städtern' und den PA-Kadern in den Lagern - generell die PA verantwortlich, die sie als ,zweite Besatzung“ bezeichnen, und die nichts für die Flüchtlinge tue. Insgesamt wird die PA von den jungen Männern massiv abgewertet. 
Die Aufrechnungslogik, die dem Deutungsmuster der jungen Männer zugrunde liegt, erinnert daran, was Loren Lybarger in seiner Arbeit zur Generation Intifada bezüglich deren „record of resistance“ (2007: 134), also deren Widerstandsbilanz, erörtert hat. Den Aktivist*innen der Ersten Intifada hatten ihre biographischen „Kampfgeschichten“ zu Ansehen und zu Status- und Machtpositionen in den Lager-Gegenden und auch in der palästinensischen Gesellschaft generell verholfen (vgl. Kap. 4.5). In Anlehnung daran kann man im Zusammenhang der Deutungsmuster der Clique junger Männer von einer Widerstandsbilanzierung sprechen - eine in der Clique interaktiv hergestellte Aufrechnung der eigenen Kampfgeschichte mit dem eigenen gesellschaftlichen Status. In ihren Bilanzierungen kommen sie im Unterschied zu den Kämpfern der Ersten Intifada und zur Mobilisierung der 1970er und 1980er Jahre - aber zu dem Ergebnis, dass ihre Kampfgeschichten ihnen in der gegenwärtigen kollektivgeschichtlichen Periode nicht zu einer geachteten gesellschaftlichen Statusposition verhelfen, sondern, im Gegenteil, so ihre Deutung, zu einer marginalisierten gesellschaftlichen Position.

\subsubsection{Konstitutionsprozess und Interaktionsdynamik der Clique}

Im Folgenden möchte ich die Interaktionsdynamik zwischen den jungen Männern und im Konstitutionsprozess der Clique diskutieren. Die in den Deutungsmustern, Wir- und Sie-Bildern deutlich werdende Widerstandsbilanzierung ist mit der Involvierung in die Straßenschlachten und die Inhaftierungserfahrungen der jungen Männer verbunden. Diese wiederum hängen eng mit den Interaktionsdynamiken in der Clique und mit dem Prozess, in dem sich die Clique konstituiert und integriert hat, zusammen. Die Involvierung in die Straßenschlachten geschah und geschieht im Rabmen der Clique, und sie wurde und wird, genau wie die Inhaftierungserfahrungen, im Kontext der Clique verhandelt und bearbeitet. Dabei spielt der Cliquenzusammenhang auch für die Konstruktion von Männlichkeit eine bedeutende Rolle, die ich im Folgenden besonders berücksichtigen werde. Außerdem vollzieht sich in der Clique im Zeitraum unserer Bekanntschaft in Ansätzen auch eine Verschiebung von einer, Widerstands's zu einer Leidensgemeinschaft, in welcher die zunehmend marginalisierte gesellschaftliche Stellung der jungen Männer und die damit verbundene Frustration und das Erleben von Stigmatisierung verhandelt und gedeutet werden. Auf diesen Aspekt gehe ich vor allem in Abschnitt 6.7 ein.

,Austauschbarkeit der Erfahrungen: Präferenzen im Umgang und in den Interaktionsabläufen während der Interviews

Unter welchen Umständen die jungen Männer die Gespräche und Interviews mit uns führten, wer bei den Gesprächen außerdem anwesend war und welche weiteren Gesprächspartner*innen uns von den jungen Männern vermittelt wurden, sagt uns bereits einiges über die Relevanzen der Clique sowie die Struktur der Interak- 
tionen unter ihnen und der Auswahlkriterien für Interaktionspartner. Auf die Umstände der ersten Interviews mit den jungen Männern, die wir während unseres ersten Feldaufenthaltes im Frühjahr 2013 geführt haben, möchte ich kurz eingehen: Das biographische Interview mit Samad fand direkt im Anschluss an die eingangs ausführlich dargelegte Diskussion mit Musa und Samad statt. Dieses Interview verlief folgendermaßen. Arne Worm und Ahmad Albaba hatten das vorangehende Gespräch mit der Frage unterbrochen, ob Samad, wie am Telefon vereinbart, weiterhin bereit wäre, ihnen ein lebensgeschichtliches Interview zu geben. Als Samad zustimmte, fragte Ahmad Albaba, ob es auch einen Ort gebe, wo es ,etwas ruhiger' sei. Samad bot sein Zimmer an. Die Rahmung der nun folgenden Situation als Interview mit Samad und Ahmads Frage nach einem ruhigeren Ort verstanden die jungen Männer offensichtlich nicht dahingehend, Samad nun zu einem privateren Gesprächssetting Gelegenheit zu geben. Jedenfalls gingen alle gemeinsam, auch Musa und Mahmoud, in Samads Zimmer. Samad nahm auf dem Bett Platz und legte sich hin, Mahmoud setzte sich an das Bettende. Musa, Arne Worm und Ahmad Albaba setzten sich dem Bett gegenüber auf die Stühle neben dem Schreibtisch. Während des Interviews kam ein weiterer Freund der Clique dazu, Yousef. Er war zu diesem Zeitpunkt 20 Jahre alt und war gerade vor zwei Wochen aus dem Gefängnis entlassen worden. Das Interview wurde wie auch die meisten späteren - in Anwesenheit von Freunden geführt, jedoch nicht, bis auf die Gegenwart zweier jüngerer Cousins von Samad, in Anwesenheit weiterer Familienmitglieder. So waren bei den Interviews mit den jungen Männern generell weder Verwandte aus der Elterngeneration noch Geschwister anwesend, obwohl die Gespräche überwiegend in den Familienhäusern der jungen Männer stattfanden. Bei den Gesprächssettings mit ihnen waren aber häufig (bei späteren Zusammenkünften nicht immer) Freunde anwesend. Sie waren geschlechts- und generationshomogen und durch einen recht hohen Informalitätsgrad im Umgang miteinander gekennzeichnet. So schlief Yousef etwa während des Interviews mit Ibrahim im selben Raum im Bett.

Diese Charakteristika der Gespräche verweisen nun zum einen auf den Umgang männlicher Jugendlicher untereinander, die sich als Freunde täglich sehen und viel Zeit miteinander verbringen. Sie geben auch einen Hinweis darauf, dass wir - meine Kollegen und ich - von den jungen Männern zunächst eher in einer ihnen ähnlichen geschlechtlichen und vor allem generationalen Zugehörigkeit verortet wurden. Sie weisen jedoch auch über diese Sozialität adoleszenter männlicher Peergroups hinaus: In der Präsenz der Freunde beim Erzählen der Lebensgeschichte, der Informalität sowie in vereinzelten Bemerkungen anderer während der Interviews deutete sich an, dass die jungen Männer ihre Biographien zu einem gewissen Grad als ,austauschbar ${ }^{\varsigma}$ oder füreinander repräsentativ erlebten - in dem Sinne, dass die Erfahrungen des einen auch die Erfahrungen des anderen ausdrücken beziehungsweise ihnen Gehör verschaffen. So wurden unsere Interviews von Musa bei einer Gelegenheit mit der Bemerkung kommentiert, wir könnten noch 
weitere Interviews führen, aber die Geschichten würden dieselben bleiben. Diese vermeintliche Austauschbarkeit wurde auch daran deutlich, dass die jungen Männer uns auf eigene Initiative ausschließlich Freunde, die ebenfalls in die Straßenkämpfe involviert waren oder für einige Zeit in israelischen Gefängnissen gesessen hatten, als Gesprächspartner vermittelten. So schlugen sie uns vor, Yousef aufgrund seiner Inhaftierung bei der PA oder einen Cousin Musas aufgrund seiner inzwischen ausgeheilten Kopfverletzung zu interviewen, die er bei einem Streifschuss durch einen israelischen Soldaten erlitten hatte. Erst auf unseren ausdrücklichen Wunsch hin, nach Möglichkeit auch mit Familienangehörigen von ihnen Interviews zu machen, kam dann der Kontakt zu den Familienmitgliedern der jungen Männer zustande. In der Vermittlung dieser Gespräche waren sie wiederum bei denjenigen Familienmitgliedern deutlich enthusiastischer, die eine ,Kampfgeschichte ${ }^{6}$ im Rahmen der politischen Mobilisierung der 1970er und 1980er Jahre aufweisen konnten - Musas Mutter mehr als Musas Vater oder Yousefs Vater eher als seine Mutter. Auf die Bedeutung dieser sogenannten Generation Intifada in der Elterngeneration der jungen Männer komme ich ausführlich in Kapitel $6.3 \mathrm{zu}$ sprechen. Selbst im weiteren Freundeskreis der jungen Männer lernte ich zudem bis 2015 niemanden kennen, der keinen Flüchtlingshintergrund hatte.

Zugleich ergibt sich durch die Anwesenheit von anderen in den Interviews auch eine gewisse Gesprächskontrolle: Mit den Straßenkämpfen oder Inhaftierungen verbundene Zweifel, Reue oder Schuldgefühle gegenüber den Eltern wurden, zwar insgesamt selten, nie aber in Anwesenheit der anderen jungen Männer geäuBert. ${ }^{102}$ Insgesamt verweisen diese Umstände der Interviews und Gespräche, die Vermittlung weiterer Gesprächspartner und das sukzessive für uns nachvollziehbar werdende soziale Umfeld beziehungsweise Netzwerk der jungen Männer bereits auf die Bedeutung des gemeinsamen Erfahrungshintergrundes der Beteiligung an den Straßenschlachten und der Inhaftierungserfahrungen sowie der, Widerstandsbilanzierung ${ }^{6}$ und der geteilten Wir-Bilder als ,marginalisierte Kämpfer für die Zusammensetzung und die Integration der Clique.

\section{Straßenschlachten als Ernste Spiele: Männlichkeitskonstruktionen und homosozialer Raum}

Aber wodurch war den jungen Männern überhaupt die Gelegenheit gegeben, sich in diesem Umfang in die Straßenschlachten zu involvieren? Die Gelegenheit ergab sich für sie, weil das Flüchtlingslager und die angrenzenden Nachbarschaften häufig Schauplatz von Auseinandersetzungen zwischen israelischen Soldaten und Palästinenser*innen waren und sind. Man kann in diesem Zusammenhang vielleicht von den Gelegenheitsstrukturen für die Involvierung in die Straßenkämpfe in der sozio-historischen Phase seit den Oslo-Verträgen und der Zweiten Intifada nach 2005 sprechen (vgl. Kap. 4.8). Diese Phase kennzeichnet eine hohe Diffe-

102 Vgl. hierzu das biographisch-narrative Interview mit Yousef in Kapitel 6.3.2. 
renz in der Häufigkeit und Intensität von ,Konfrontationen“ zwischen den relativ ruhigen urbanen Ballungszentren, insbesondere Ramallah, und einigen LagerGegenden, sogenannten Berührungspunkten an den Checkpoints und der Sperranlage sowie manchen ländlichen Gegenden, was wiederum auch mit der in den Oslo-Verträgen festgelegten Zonenaufteilung des Westjordanlandes in Zusammenhang steht (vgl. Kap. 4.6). Viele der Auseinandersetzungen zwischen dem israelischen Militär und Palästinenser*innen in den Lager-Gegenden entstehen, außer im Kontext von Demonstrationen, bei Verhaftungsoperationen der israelischen Armee, die zum Ziel haben, „gesuchte“ Personen in ihren Häusern zu verhaften. Die Operationen sind hinsichtlich eingesetzter Truppenstärke und räumlichem Umfang sehr unterschiedlich. Bei groß angelegten Razzien werden ganze Orte abgesperrt und parallel eine Vielzahl an Hausdurchsuchungen durchgeführt. Häufiger sind jedoch kleinere Operationen, wo nur wenige Soldaten und Fahrzeuge im Einsatz sind. Die Operationen finden meist nachts beziehungsweise in den frühen Morgenstunden statt, um die Aufmerksamkeit und etwaige Gegenwehr gering zu halten. Insbesondere lokale männliche Jugendliche aus dem Lager und den angrenzenden Vierteln, darunter die Freunde aus der Clique, versuchen dann durch Straßensperren sowie das Werfen von Steinen und Molotow-Cocktails die Verhaftungen zu stören oder zu verhindern. ${ }^{103}$ Je nach Umfang der Operation und Beteiligung der jungen Männer können die ,Konfrontationen` auch sehr kleinräumig bleiben. Die von israelischer Seite bei den kleineren Konfrontationen zum Einsatz gebrachten Gewaltmittel reichen vom Einsatz von Gas- und Tongranaten und gummiummantelten Geschossen bis zum Einsatz scharfer Munition.

Die Konfrontationen mit den Sicherheitskräften der PA, zu denen es auch immer wieder kam und kommt - und an denen die jungen Männer wie bereits erwähnt ebenfalls beteiligt waren - gibt es seit dem Aufbau der verschiedenen Sicherheitsdienste der Behörde Mitte der 1990er Jahre. Die jungen Männer tragen mit den Straßenschlachten dazu bei, dass die Lager nicht oder nur unter Inkaufnahme erheblicher ,Kosten' von der palästinensischen Polizei und anderen PASicherheitsdiensten betreten werden können. Außerdem üben sie durch die Besetzung von Schnellstraßen etc. bei Interessenkonflikten zwischen der Lagerbevölkerung und anderen gesellschaftlichen Gruppierungen Druck auf die PA aus. Dies ist neben den oben genannten Konflikten um die Stromrechnungen auch bei Wohnraumkonflikten zwischen der Lagerbevölkerung und angrenzenden Gemeinden der Fall. Die jungen Männer tragen so auch dazu bei, die Machtressourcen der Flüchtlingslagerbevölkerung gegenüber anderen Gruppierungen in der palästinensischen Gesellschaft zu sichern und die partielle politische Autonomie der Lager zu erhalten. Vermutlich liegt in diesen Machtchancen der jungen Männer einer der Gründe, warum sie, wenn auch zurückhaltend, überhaupt Kritik

\footnotetext{
${ }^{103}$ Meine Kenntnisse und Einschätzungen zu den Straßenschlachten basieren auch auf meinem persönlichen Erleben als Nachbar, wie ich in Kapitel 3 zu den Feldaufenthalten bereits ausgeführt habe (vgl. Kap. 3.4.3).
} 
äußern können an der mit hohen Machtchancen versehenen Gruppierung ehemaliger Erste-Intifada-Aktivist*innen in der Lager-Gegend, die nun der PA nahestehen.

An den Konfrontationen beteiligten sich die jungen Männer nicht ,jeder für sich', sondern die Beteiligung wurde im Fall der hier vorgestellten Clique auch zu einer Gruppenunternehmung. Zum Teil wurden die jungen Männer auch erst im Kontext der Konfrontationen miteinander bekannt. Als etwa Mahmoud bei einer Gelegenheit darüber sprach, wie er Samad und Yousef kennengelernt hatte, erzählte er, sie hätten sich „das erste Mal getroffen nachts auf der Straße als man die Molotow-Cocktails aufteilen musste“, und seien dann - ungefähr ab 2006 mit 13 bis 15 Jahren - näher bekannt geworden. In den Gesprächen mit den jungen Männern wurde insbesondere das ,gemeinsam nachts Rausgehen' als etwas hervorgehoben, das dazu geführt habe, dass man sich kennengelernt habe. Für die Teilnahme an den Konfrontationen sprachen sich die jungen Männer über ihre Handys und über Facebook ab. Die Zufahrtswege des israelischen Militärs zum Lager variierten nicht sehr stark und wurden meist von anderen Anwohner*innen beobachtet und in den sozialen Medien geteilt, oder die jungen Männer wurden, insbesondere nachts, von anderen Freunden und Bekannten in Kenntnis gesetzt. Der Ablauf der Konfrontationen wurde dabei von den Cliquenmitgliedern organisiert. Gelegentlich hatten sie bereits im Vorfeld Steine auf geeignete Wurfgröße zerstückelt, die Molotow-Cocktails vorbereitet und in Verstecken im Lager vorgehalten. Gelegentlich kamen und kommen auch Schleudern und Ähnliches zum Einsatz. Die jungen Männer aus der Clique waren aber nach meinem Kenntnisstand, zumindest bis zum Zeitpunkt der Interviews, nie in den Einsatz von Schusswaffen oder die Durchführung von Anschlägen auf israelische Zivilist*innen involviert. Allerdings versuchten sich einige der jungen Männer, wie zum Beispiel Mahmoud, der mit uns im Interview darüber sprach, später am Bau von simplen Sprengkörpern, die auf zusammengesammelten Schießpulverresten basierten (einer davon war ihm beim Bau explodiert, wodurch er leichte Verbrennungen an den Händen davontrug). Die jungen Männer waren in ihren Aktionen, soweit ich dies überblicken konnte, nicht parteilich organisiert, auch wenn sie selbst mit bestimmten Parteien, insbesondere der PFLP, sympathisierten.

Die Konfrontationen waren auch in unserem Beisein häufiger Gegenstand der Unterhaltung in der Clique. Einmal war ein Freund aus der Clique bei einer Konfrontation von einem israelischen Armeejeep angefahren worden und hatte eine leichte Verletzung am Bein davongetragen. Von dem Vorfall hatte einer der anderen Freunde einen Videomitschnitt gemacht, der bei einem unserer Besuche, während wir mit einer größeren Gruppe in Yousefs Zimmer saßen, herumgezeigt wurde. Das Video wurde allgemein mit Lachen und Bemerkungen, er sei „verrückt" („mağnūn"), quittiert. Musa machte dabei die Bemerkung, dies könne gar nicht so wehgetan haben, aber der Freund wolle wohl die Rente einstreichen, was für allgemeine Erheiterung im Raum sorgte. Ich verstand dies als eine Anspielung 
auf die kleine Rente, die die PA für ,durch die Besatzung Verletzte' bezahlt. Musa spielte in seinem etwas neckischen Scherz mit der Verweigerung der Anerkennung der von dem Freund erlittenen Schmerzen und des von ihm geleisteten ,Einsatzes bei den Konfrontationen. Diese kurze Feldszene aus einem Feldaufenthalt im Herbst 2014 deutet an, dass im Rahmen der Clique das Handeln der jungen Männer bei den Konfrontationen besprochen und bewertet wurde.

Dies macht auf einen wichtigen Aspekt der Konfrontationen und Straßenschlachten aufmerksam: Sie sind (auch) männliches Risikohandeln vor männlichem Peer-Publikum. Das Handeln der jungen Männer im Kontext der Konfrontationen lässt sich als eines der von Michael Meuser (2005) diskutierten „Ernsten Spiele“ verstehen. Bei sogenannten Ernsten Spielen findet unter Einsatz beziehungsweise unter Gefährdung des eigenen Körpers ein Wettbewerb unter männlichen Jugendlichen - hier die Teilnahme an und das Sich-Trauen von riskanten Aktionen gegen das israelische Militär und die PA-Polizei - statt (Meuser 2005: 313). Diese Ernsten Spiele stellen einen Kontext für den Erwerb und die Erprobung von Männlichkeit dar (ebd.: 319 ff.). Mit Bezug auf Norbert Elias’ Ausführungen zu Trinkritualen und Mensur im Verbindungswesen (Elias 1989: 125 ff.) diskutiert Meuser, wie paradoxer Weise hier gerade der Wettkampf Solidarität unter den Teilnehmenden stiftet (Meuser 2005: 318). Der Wettkampf schafft ein Zusammengehörigkeitsgefühl und ein Wir-Bild und grenzt die Gruppe nach auBen ab. Dass die Teilnahme an den Konfrontationen für die jungen Männer vor allem ein Gruppenerlebnis ist, bei welchem sie sich als kollektiv-handelnd erleben, wird in den Gesprächen, in denen die jungen Männer über die Konfrontationen sprechen, sehr deutlich. So auch in dem folgenden, längeren Zitat aus einem Gespräch mit Yousef:

Yousef: „es gibt sehr viele Situationen wir wir wussten einmal dass die Armee im Lager ist, dann sind wir runtergegangen wir sind runtergegangen ohne dass die Eltern davon wussten wir sind runter und bekamen Anrufe von den Jungs dass die Jeeps in der Gegend sind wir waren neun oder elf šabāb dann haben wir die Molotows geholt von da wo wir die versteckt hatten und haben vorbereitet und wir haben die Steine vorbereitet also auch die großen Steine in kleinere gebrochen so dass du sie halten kannst (2) und da an dem Tag wir wussten dass die Armee auf der anderen Seite vom Lager war und sind gelaufen ein bisschen und dann war der Jeep vor uns wir haben Steine geworfen und die anderen haben gerufen während sie Gasbomben geworfen haben, dann waren die Armee fertig und wollten dann los das Lager verlassen aber ehh der Jeep war so breit dass er nicht dass er feststeckte in einer schmalen Gasse also zwischen den Wänden wir waren so euphorisch also werfen $=$ werfen $=$ werfen, wegen der vielen Würfe auf sie haben sie eine Menge Bomben geworfen der Jeep konnte sich immer noch nicht bewegen, und blieb also nicht bewegt werfen Tongranaten und Gas und während wir geworfen hatten sind die Soldaten aus dem Jeep und Richtung Hauptstraße gegangen dann sind sie vor uns gekommen der Jeep kann sich weiterhin nicht 
bewegen und dann haben wir die šabāb rufen gehört dass die Soldaten hinter uns sind sie riefen Vorsicht, es war so dass andere Jeeps kamen von hinten um dem festgefahrenen zu helfen, wir mussten in die Gasse flüchten“.

Die geschilderte Situation entwickelt sich dahingehend, dass sich der israelische Jeep im Lager festfährt und die Soldaten auf die jungen Männer mit scharfer Munition schießen, um den Wagen zu decken, woraufhin sich diese zurückziehen. Das Zitat verdeutlicht die Rahmung der Konfrontationen als Gruppenereignis (,wir sind gelaufen'; ,wir haben geworfen') und die autonome Planung und Durchführung der Konfrontationen durch die jungen Männer. Die Andeutung, die Eltern hätten nichts davon gewusst, weist darauf hin, dass die Straßenschlachten auch einen Kontext darstellen, in denen Autonomie gegenüber den Eltern und anderen Erwachsenen erlebt werden kann (vgl. Kap. 6.3). Manchmal sprachen die jungen Männer auch davon, bei den Konfrontationen von einem „Geist“ („arrūḥ“) der Gruppe getragen zu werden, der auch dafür sorge, dass man keine Angst habe. Selbst beim Werfen der Molotow-Cocktails, bei dem die Gefahr höher sei, von den israelischen Soldaten anvisiert zu werden, sei dies so. Auf meine Frage, ob es gefährlich sei, die Molotow-Cocktails zu werfen, antwortete Yousef:

Yousef: „Das kam so mit den Steinen wir haben nicht gesagt heute werfen wir Molotows aber dann findest du einen Molotow in deiner Hand und du musst ihn werfen, also anzünden und werfen“.

Interviewer: „das ist nichts Besonderes?“

Yousef: „Ne ist normal [...] vielleicht ist es gefährlich aber du kannst es werfen kein Problem, ich hatte dir erzählt es ist der Geist der Gruppe unter den Jungs und in der Atmosphäre kannst du alles machen“.

Ein Charakteristikum der Ernsten Spiele ist, wie Meuser hervorhebt, ihre Homosozialität (Meuser 2005: 313 ff.). Einerseits waren die jungen Männer bei den Konfrontationen in Bezug auf Geschlechts- und Alterszugehörigkeit, in der Clique zudem in Bezug auf den Flüchtlingshintergrund , unter sich'. Es gab bei den Konfrontationen und Straßenkämpfen keine Teilnahme älterer Männer und, anders als dies in Ansätzen in der Ersten Intifada gegeben war, ${ }^{104}$ auch keine von jüngeren Frauen. Wenn ich gegenüber den jungen Männern diese Differenz in der Beteiligung von Frauen gegenüber der Ersten Intifada ansprach, war ihnen dieses Thema eher unangenehm. Andere „Jungs“ würden es „,ausnutzen“, wenn Frauen dabei seien, war eines der Argumente, welches ich in diesem Zusammenhang zu hören bekam. Die jungen Männer aus der Clique selbst sanktionierten tendenziell das Mitwirken von weiblichen Verwandten bei ,Widerstandsthematiken', wie in der folgenden Feldszene exemplarisch deutlich wird. Im November 2014 waren Ahmad Albaba und ich gemeinsam mit Samad zu Besuch bei seiner Nachbarin im

${ }^{104}$ Zur Einbindung von Frauen in die Mobilisierung vgl. Kap. 4.4-4.5. 
Lager, die von den jungen Männern aufgrund ihres starken Engagements in der Ersten Intifada und ihrer Inhaftierungserfahrungen „Genossin Fatima“ genannt wurde. Ich führte ein Interview mit Fatima, in dem sie insbesondere auf ihre politisch aktive Phase in der Ersten Intifada zu sprechen kam. Bei dem Gespräch waren auch Samad und weitere Freunde sowie Aseel, eine Cousine Samads anwesend, die wiederum mit Fatima angeheiratet verwandt war. Fatima sprach unter anderem über ihr Engagement in den Komitees der Ersten Intifada, ${ }^{105}$ für die sie als junge Frau auch zu Parteitreffen im benachbarten Ort ging, und über ihre Beteiligung an den Konfrontationen. Als ich Fatima fragte, was sie denke, warum junge Frauen heute nicht so involviert seien, unterbrach Aseel die Unterhaltung und beschuldigte Samad, sie von politischen Aktivitäten abzuhalten. Er verhindere, dass sie zu Demonstrationen und politischen Veranstaltungen gehe oder sich auf Facebook zur PA äußere. Samad rechtfertigte sich mit dem Verweis auf die Gefährlichkeit solcher Aktionen, und ein handfester Streit entbrannte, bei dem sich beide laut ins Wort fielen. Dass diese Fragen in dieser relativ offenen Form thematisierbar waren, war der Präsenz Fatimas und der relativ egalitären Orientierung der jungen Männer und ihrer Familien geschuldet. Gleichzeitig verdeutlicht die Episode aber exemplarisch die Exklusion junger Frauen von den ,Aktionen durch die jungen Männer aus der Clique.

Die Clique ist auch im Hinblick auf den Flüchtlingshintergrund der jungen Männer homogen. Das ,eigentliche' Lager als Wohnort ist kein entscheidendes Kriterium, um das Freundschaftsnetzwerk und die Zugehörigkeitskonstruktionen der jungen Männer zu bestimmen. Ich habe eingangs schon darauf hingewiesen, dass viele der Cliquenmitglieder, unter anderen Musa und Yousef, gar nicht im Flüchtlingslager, sondern in einem der angrenzenden, infrastrukturell verglichen mit dem ,eigentlichen' Lager deutlich besseren Wohnvierteln bei ihren Familien lebten. Obwohl in diesen Wohnvierteln auch Jugendliche ohne Flüchtlingshintergrund lebten, deren Familien aus umliegenden Dörfern zugezogen waren, war aber, soweit ich dies überblicken konnte, kein junger Mann ohne Flüchtlingshintergrund Teil der Clique. Und alle Cliquenmitglieder, auch darauf habe ich schon hingewiesen, bedienten das Wir-Bild als Flüchtling oder als Sohn des Lagers. Anscheinend kam es in der Lager-Gegend auch gelegentlich zu Auseinandersetzungen zwischen Gruppen junger ,Flüchtlinge` mit Gruppen junger Männer ohne Flüchtlingshintergrund. Zwar sprachen die jungen Männer aus der Clique nicht mit mir über diese Ereignisse, aber ihre Eltern hatten mir gegenüber auch von Ereignissen berichtet, in welchen es zu offenen Konflikten im Viertel zwischen den Gruppierungen gekommen war.

Des Weiteren ist die Clique junger Männer homosozial in dem Sinne, dass die jungen Männer füreinander die „entscheidenden signifikanten Anderen in Prozessen der Ausbildung und Bestätigung von Werthaltungen, Einstellungen und Ori-

105 Zur Mobilisierung in den im Laufe der 1970er Jahre sukzessive aufgebauten zivilgesellschaftlichen Komitees vgl. Kap. 4.4. 
entierungen“ (Meuser 2005: 314) sind. Zentral ist die Peergroup dabei auch für die „narrative Vergewisserung und kommunikative Validierung“" des Risikohandels (ebd.: 313). Ein Beispiel für die kommunikative Validierung der Involvierung in die Straßenkämpfe innerhalb der Clique ist die oben geschilderte Feldszene, in der die jungen Männer den Videomitschnitt von der Verletzung eines der jungen Männer kommentieren. Diese kommunikative Einbettung der Beteiligung an den Konfrontationen innerhalb der Clique deutet sich aber auch in den ,Heldengeschichten' an, die in der Clique kursierten - etwa Bemerkungen über Freunde, die sich wenig empfindlich gegenüber israelischem Tränengas zeigten oder die sich besonders nahe an die israelischen Militärjeeps heranwagten. So sprach Yousef wertschätzend über einen Freund, dass dieser trotz eines verletzten Armes viele Steine halten könne und ,wenn er sehr nah an den Jeep kommt dann schlägt er mit der Hand auf das Fenster, er ist leidenschaftlich dabei er wurde drei Mal verhaftet.“ Die Funktion, die Yousef und die anderen jungen Männer hier einnehmen, ist die des Anerkennung zollenden männlichen Peer-Publikums (ebd.: 313). Auch das eingangs analysierte, erste längere Gespräch mit Samad, Musa und Mahmoud ist ein Beispiel dafür, wie interaktiv, Werthaltungen', die die Involvierung in die Konfrontationen und die Gefängnisaufenthalte legitimieren (Kampf und Märtyrer als, Wert $^{\circ}$ ), hergestellt und sich gegenseitig versichert werden. Mit der Konstruktion von Männlichkeit eng verbunden, aber nicht allein in dieser aufgehend, sind die Aktionen und Diskussionen zwischen den Freunden in der Clique auch als generelle Prozesse adoleszenter Entwicklungsaufgaben zu sehen, in denen die jungen Männer ihre Selbstbilder im Verhältnis zu Wir-Bildern bilden und sich in letzteren verorten.

Generell verdeutlichen die genannten Aspekte - das Kennenlernen über die nächtlichen ,Konfrontationen', die gemeinsame Durchführung und kommunikative Validierung der Straßenkämpfe, ihre Homosozialität in Bezug auf geschlechtliche Zugehörigkeit, Flüchtlingshintergrund und Widerstandsbeteiligung -, dass die Teilnahme an den Straßenkämpfen eng mit den Interaktionsdynamiken in der Clique verbunden war und ist.

\section{Andeutung der Relevan₹ der Inhaftierungserfahrungen}

Einen vergleichbaren Stellenwert nehmen auch die Inhaftierungserfahrungen der jungen Männer ein. Zum Teil waren die jungen Männer zur selben Zeit in denselben Gefängnissen inhaftiert und haben sich dort sozusagen wiedergetroffen. Einige haben auch gemeinsam an Hungerstreiks teilgenommen, wie ich in Kapitel 6.3 anhand der Biographie Yousefs ausführlich diskutiere. Dass auch die Inhaftierungserfahrungen für die Clique integrierend wirken, deutet sich in verschiedenen Interaktionen mit den jungen Männern an. Musa bemerkte etwa bei einer Gelegenheit, er habe zwar auch andere Freunde, aber es sei „schon enger mit denen die auch im Gefängnis waren“. Als Yousef bei einem Gespräch darauf kam, wie er Musa kennenlernte, der ja zwei Jahre älter als Yousef ist, meinte Yousef, ihre Be- 
ziehung sei „stärker geworden als er aus dem Gefängnis entlassen wurde“. Die Gestaltung des häufigsten Treffpunktes der jungen Männer, das Zimmer Yousefs im Haus seiner Eltern, unterstreicht die Bedeutung der ,Widerstandsthematiken“ und der Gefängnisaufenthalte für die Clique. In dem Zimmer, das etwas abseits des Wohnbereiches der anderen Familienmitglieder liegt und über einen separaten Eingang verfügt, saßen wir häufig mit den anderen zusammen. Die Jungs hatten das Zimmer mit Fahnen geschmückt und politische Slogans an die Wände geschrieben. Außerdem hatten sie einige Inhaftierungsdaten der jungen Männer auf den Wänden vermerkt. Auch eine Art Abschiedsbrief, den Samad am Abend vor seiner Verhaftung verfasst hatte, ${ }^{106}$ hatte für eine Weile an der Wand geklebt, war dann aber bei einer Hausdurchsuchung von israelischen Soldaten konfisziert worden. Die Wände in Yousefs Zimmer waren sukzessive zu einer Art Chronik für die Clique geworden.

Die Hafterfahrungen waren zwar auch für die Männlichkeitskonstruktionen der jungen Männer und das Wir-Bild als ,Kämpfer‘ bedeutsam, allerdings lässt sich an deren Verhandlung in der Clique auch ein weiterer Aspekt aufzeigen. So stellt die Clique auch eine Leidensgemeinschaft dar. Die Verhaftungs- und Gefängniserfahrungen sind mit erheblichen Belastungen und schwierigen Erfahrungen der jungen Männer verbunden. Diese wurden zwar insgesamt selten angesprochen, allerdings wurden sie eher, darauf deuten meine Rekonstruktionen hin, gegenüber anderen Freunden aus der Clique als gegenüber Familienmitgliedern thematisiert. Musa sprach etwa in dem eingangs schon erwähnten lebensgeschichtlichen Interview, bei welchem auch andere junge Männer aus der Clique zugegen waren, relativ offen über die Schläge durch israelische Wärter in der Haft. Gleichzeitig gab er an, dass er mit seinen Eltern noch nie über diese Schläge gesprochen habe. Auch bei anderen Gelegenheiten kamen, wenn auch nur in begrenztem Ausmaß, die mit den Verhaftungen, der, Verhörzeit' und der Inhaftierung verbundenen Ängste und belastenden Erfahrungen zur Sprache, etwa erniedrigende Schläge oder Schlafstörungen aufgrund einer drohenden erneuten Verhaftung (vgl. Kap. 6.2.4). Mit zunehmendem ,Cliquenalter ${ }^{6}$ und anhaltender Involvierung in die Straßenschlachten erhöht sich die Wahrscheinlichkeit, dass die jungen Männer in den Straßenschlachten verletzt oder gar getötet werden. Diese Erfahrungen steigern die biographische Verstrickung in die Straßenschlachten eher, als dass sie einer Distanzierung Vorschub leisten. Diese Dynamik diskutiere ich ausführlich in der Falldarstellung zur Familie und Biographie Yousefs in Kapitel 6.3.

Schließlich sind die Inhaftierungserfahrungen und die Involvierung in die StraBenschlachten auch in die Prozesse der Hierarchiebildung und der Ausbildung von Statuspositionen innerhalb der Clique eingebunden. Musa war als erster der Freunde inhaftiert gewesen und hatte auch aufgrund dieses Umstandes sowie

${ }^{106}$ Das israelische Militär hatte versucht ihn zu verhaften und hatte das Wohnhaus seiner Familie durchsucht, er war jedoch nicht zu Hause gewesen und hatte sich in der Folge eine Nacht bei Yousef versteckt gehalten, bevor er am darauffolgenden Tag verhaftet wurde. 
seines ,politischen Wissens', welches zum Teil auf die politischen ,Schulungen' im Gefängnis zurückgeht (vgl. Kap. 6.3.3), und seiner rhetorischen Fähigkeiten eine Autoritätsrolle in der Clique. Wie im oben dargestellten ersten Treffen übernahm Musa auch bei zahlreichen weiteren Gesprächen eine Sprecherrolle, die ihm von den anderen auch zugestanden wurde. Bei einer Gelegenheit, bei welcher ich mit Samad, Yousef und Musa und einigen anderen in einem Restaurant zu Abend aß, bat Samad Musa ganz explizit darum, mir die Pariser Protokolle ${ }^{107}$ zu erklären, da er ,solche Dinge` immer gut darlegen könne. Auch ,politisches Wissen' und Rhetorik - etwa die Verwendung des Klassenbegriffs - wurden in der Clique also wertgeschätzt.

\section{Zusammenfassung: Konstitutionsprozess und Interaktionsdynamik.}

Insgesamt wurde die Relevanz der Straßenkämpfe und der Gefängnisaufenthalte für den Konstitutionsprozess und den Interaktionszusammenhang der Clique deutlich. Die jungen Männer haben sich meist erst über die Involvierung in die Straßenkämpfe oder im Zuge der Hafterfahrungen näher kennengelernt. Die Freunde teilen, Widerstandserfahrungen', die in der Clique angeeignet, verhandelt und gedeutet werden. Die Clique bietet einen homosozialen Kontext für die Konstruktion von Männlichkeit, die in den Straßenkämpfen unter den Augen der Clique erprobt und in der Clique kommunikativ versichert wird. Die Interaktionsdynamiken in der Clique gehen jedoch über diesen Aspekt hinaus. Die Clique stellt unter anderem auch eine Leidensgemeinschaft dar, in der, wenn auch nur in begrenztem Ausmaß, zum Beispiel das mit den Hafterfahrungen verbundene Leid thematisiert werden kann. Dieser Aspekt wurde über den Zeitraum unserer Bekanntschaft tendenziell bedeutsamer.

So lässt sich in meinen Analysen der Prozess einer sukzessiven Verschiebung der Bedeutung der Clique für die jungen Männer von einer, Widerstands'- zu einer Leidensgemeinschaft rekonstruieren. Meine aus den Interviews und Beobachtungen gewonnene Lesart ist, dass für die jungen Männer die Betonung des ,Kampfes gegen Israel' und die Teilnahme an den Konfrontationen als Ernste Spiele während der Frühadoleszenz stärker handlungsleitend und als gültige Weltdeutungen angenommen waren und bereits zum Zeitpunkt der ersten Gespräche und Interviews im Frühjahr 2013 eine gewisse Ernüchterung und eine Verschiebung der biographischen Relevanzen und Handlungspläne in Richtung beruflicher Etablierung und Familiengründung eingesetzt hatte. Denn die biographische Situation der jungen Männer veränderte sich zunehmend: Sie wurden älter und hatten Schwierigkeiten, die eigene Bildungskarriere fortzusetzen oder eine berufliche Position zu finden, die über die gering qualifizierten Beschäftigungen in Restau-

\footnotetext{
107 Als Teil des Oslo-Prozesses werden in den im April 1994 in Paris unterzeichneten Abkommen die wirtschaftlichen Beziehungen zwischen Israel und den palästinensischen Territorien geregelt. In der Clique werden diese als ,ausbeuterisch' gewertet.
} 
rants und auf Baustellen im Westjordanland oder illegalisiert in Israel hinausging. Sie machten Erfahrungen mit Stigmatisierung in der eigenen Nachbarschaft und stellten angesichts des in Ramallah und in anderen Städten sichtbaren Wohlstands ihre eigene gesellschaftliche Stellung in Frage. Sie setzten diese Erfahrungen zu ihren, Widerstandserfahrungen' ins Verhältnis und verglichen sie mit der Wertschätzung und Bedeutung, die Widerstandshandlungen in ,früheren' kollektivgeschichtlichen Perioden hatten. Im Zuge dessen wurde die Clique als Zusammenhang zunehmend wichtiger, in welchem erlebte gesellschaftliche Marginalisierung verhandelt wird und folglich in die Deutungsmuster, Wir- und Sie-Bilder eingeht. Das erörterte Deutungsmuster ,marginalisierte Kämpfer und die mit diesem eng verbundene, Widerstandsbilanzierung' sind bereits Ausdruck dieser Entwicklung. Diese Verschiebung hin zu einer verstärkten Verhandlung gesellschaftlicher Marginalisierung im Cliquenkontext setzt sich während meiner Feldaufenthalte bis Herbst 2015 fort. Man kann in diesem Zusammenhang auch von einer Zuspitzung des Marginalisierungserlebens sprechen. Dies möchte ich im Folgenden ausführen.

\subsubsection{Zuspitzung des Marginalisierungserlebens}

Zunächst möchte ich auf ein Interview mit Mahmoud im Winter 2014 eingehen, bei dem auch Samad zugegen war. In diesem Gespräch wurde einerseits die Zuspitzung des Marginalisierungserlebens der jungen Männer deutlich, andererseits wurde die in den Lager-Gegenden erfahrene Stigmatisierung verhandelt. Ahmad Albaba und ich hatten Samad und Yousef bei einer Gelegenheit gefragt, ob sie auch einen Freund hätten, der bisher nicht im Gefängnis gesessen habe. Sie hatten uns unter anderen an Mahmoud verwiesen, aber scherzhaft hinzugefügt, dafür, dass er noch nicht im Gefängnis gesessen habe, könne nur eine Namensverwechslung bei den Israelis verantwortlich sein. ${ }^{108}$ Ahmad und ich fuhren auf dem Rückweg von einem Treffen mit Yousef, Samad und einigen anderen gemeinsam mit Samad bei Mahmoud vorbei und verabredeten uns zu einem Interview. Er war ohne große Nachfragen bereit mit uns zu sprechen. ${ }^{109}$ Das Interview fand in seinem Zimmer im Haus seiner Familie im Lager statt. Samad kam nach circa einer halben Stunde zu dem Interview dazu, hörte zunächst zu und beteiligte sich später mit eigenen Ergänzungen. Mahmoud hatte Samad und Yousef über die Teilnahme an den Straßenkämpfen besser kennen gelernt. Er war im Anschluss an eine gröBere Konfrontation zwischen jungen Männern aus der Lager-Gegend und der PA

\footnotetext{
${ }^{108}$ Mahmoud trägt den gleichen Vor- und Nachnamen wie ein bekannter Aktivist aus Nablus. Es ist ein Witz der Clique, der sich um seine ausbleibende Verhaftung etabliert hat.

${ }^{109}$ Ich vermute, dass sich zu dieser Zeit das Interviewformat in der Clique bereits herumgesprochen hat. Jedenfalls gab es Anspielungen, wir würden wollen, dass man ,das Leben erzählt', und dass wir auch die Details wissen wollen.
} 
für einige Tage bei der PA, bisher jedoch nicht bei ,den Israelis` inhaftiert gewesen. Er hatte zuvor zweimal erfolglos versucht, das Tawjihi ${ }^{110} \mathrm{zu}$ machen.

Im Interview sprach Mahmoud auch darüber, wie er versucht hatte eine Rohrbombe zu bauen, diese ihm jedoch bei der Herstellung explodiert sei. Aufgrund der Verbrennungen an den Händen, die er davongetragen hatte, war er einen Monat nicht zur Schule gegangen. Im Interview führte er sich sehr direkt über eine mit den anderen jungen Männern geteilte gesellschaftliche Position ein. Er folgte dabei dem Deutungsmuster der ,marginalisierten Kämpfer, allerdings mit deutlicher Betonung der prekären biographischen Situation der Freunde und der erlebten gesellschaftlichen Marginalisierung, die auch eine Stigmatisierung in der LagerGegend umfasse:

Mahmoud: „Über diese Sache sprechen wir jetzt $=$ auch $=$ ohne $=$ Interview wir sprechen täglich darüber mal viel mal nicht so viel, aber wir sprechen gerade über uns über uns als Jungs wohin gehen (2) wir sprechen täglich darüber es ist eine sehr wichtige Sache es ist schwer Worte zu finden darüber es zu beschreiben, wie schlimm es ist macht es einem schwer sich zu bewegen und voranzukommen ( ...) man ist 20 oder 21 Jahre man will vielleicht das Meer sehen und einen Ausflug machen nur ganz simpel du fährst nur drei Kilometer hin und her bis der Sprit alle ist du kannst nicht zum Beispiel du willst nach Jericho mit den Freunde und einer ist sowieso gesucht von Israel also kannst du eh nicht gehen würdest auch nicht ohne ihn gehen".

Unter dem Nenner der gemeinsamen Lage der „Jungs“ ging Mahmoud weiter problematische Lebensbereiche durch: „Einer wie ich arbeitet in $48^{\prime \prime 111}$, fuhr er fort und spielte damit auf die illegalisierte Beschäftigung von sich und seinen Freunden in Israel an. Sie seien deshalb „verstreut“ und könnten sich nur drei Tage die Woche treffen. Wenn man hier arbeite, dann bekomme man 70 Schekel, davon könne man keine Familie ernähren. Er habe auf verschiedenen Stellen gearbeitet, aber es sei nichts Längerfristiges dabei gewesen. „20 Jungs um dich herum und keiner hat Arbeit“. Man sitze nur seine Zeit ab. Es gäbe zwar offene Stellen, aber für die brauche man ein Führungszeugnis und entweder bekomme man das Zeugnis nicht oder eben die Stelle nicht. Wenn man das Tawjihi habe, dann sei es etwas besser, aber viel nütze es auch nicht, er habe es zwei Mal versucht, aber nicht geschafft. Ohnehin würden die Freunde immer weniger, sie dächten an Auswanderung, ans Heiraten, kämen ins Gefängnis oder fielen als ,Märtyrer'. Mahmoud sagte dann, andere „entwickeln sich auf deine Kosten“. Es sei bekannt, was man für echten Widerstand machen müsse, aber man sage sich ja auch, man

\footnotetext{
${ }^{110}$ Der nach 12 Schuljahren absolvierte Schulabschluss, der - entsprechende Abschlussnoten vorausgesetzt - zu einem Universitätsstudium berechtigen kann.

${ }^{111}$ Eine im Westjordanland auf die „Nakba“ anspielende gängige Bezeichnung für Israel oder in Israel lebende Palästinenser*innen (,48er“).
} 
müsse arbeiten, man müsse vernünftige Sachen machen. „Egal wohin man geht, man wird unter Druck gesetzt".

In dem Interview mit Mahmoud kamen nun auch jene Etablierten mit Kämpfergeschichten in den Lagern ausführlicher zur Sprache, die von den jungen Männern in den anderen Gesprächen meist nur angedeutet worden waren. Mahmoud erwähnte zunächst, dass manche Leute im Lager schlecht über sie „,reden" würden, ging jedoch zunächst nicht weiter auf diesen Schimpfklatsch ein. Im Rahmen einer Erzählung, wie er mit anderen Freunden aus der Clique nachts am Lagereingang gestanden habe, um zu warten, ob israelische Soldaten ins Lager kämen, erwähnte er nochmals, dass Leute aus dem Lager sie beschimpfen würden. Es seien diejenigen, die ,profitieren“ würden und wollten, dass „die Sache weiterhin so bleibt“. Als wir ihn aufforderten, von solch einer Situation zu erzählen, sprach Mahmoud darüber, wie er bei einer Veranstaltung im Lager ein Gespräch mitgehört habe: Einer aus dem Lager habe sie in dieser Unterhaltung als „Arbeitslose“ bezeichnet, die „,nachts am Lagereingang Haschisch und Drogen verkaufen“. Wütend über diese Bemerkung habe er die Person damit konfrontiert und ihr gesagt, sie würden am Lagereingang stehen, weil einige der Jungen „gesucht“ seien und sie nicht wollten, dass es zu Verhaftungen in den Häusern der Familien komme. Er habe der Person auch gesagt, sie solle doch gegen sie vorgehen, sie habe ja eine „Position“. Mahmoud habe dieser einflussreichen Person daraufhin seinen vollen Namen und die Namen der ,Jungs' gegeben, obwohl die Person ihm „Probleme bereiten“ könnte, weil sie über Kontakte zum Sicherheitsapparat verfüge. Als wir nach der Person fragten, gab Mahmoud an, die Person habe zwar keine Stelle bei den Behörden, könnte aber seine Verhaftung durch die palästinensischen Sicherheitsdienste veranlassen. Sie könnte auch dafür sorgen, dass er das für Arbeitsstellen häufig sehr wichtige gute Führungszeugnis nicht bekomme. Auf weitere Nachfrage unsererseits ließ er sich aber nicht auf eine konkrete Nennung der Person ein. Während des Gespräches hatte Samad Mahmoud angerufen und war inzwischen dazugekommen. Mahmoud und Samad kamen in der Folge auch auf Jugendliche aus der Nachbarschaft zu sprechen. Es gebe auch die Jugendlichen, die sie vermeiden und die nicht zu ihnen passen würden. Die aus „Familie so und so" kämen, die ein Auto oder so haben können, mit denen würde man sich nicht sehen lassen wollen. Als ich fragte, ob sie sich grüßen würden, warf Samad ein, man sei irgendwie dazu gezwungen, weil sie aus dem Camp seien. Sie, die Jungs, würden die Eigenschaft haben allen zuzulächeln: „Vielleicht hasse ich jemanden, aber ich zeige es ihm nicht.“ Aus ihrer Sicht sind die Besagten diejenigen,

Mahmoud: „die es geschafft haben weil ihr Vater so und so ist, weil sie diesen oder diesen kennen, weil sie es geschafft haben [...] dieses Elend kommt weil du das Land liebst und wenn du dies tust, dann bist du im Konflikt mit zwei Besatzungen und dann sind alle Türen $z u “$. 
In diesem Gespräch mit Mahmoud und Samad wurde deutlich, wie innerhalb der Clique zunehmend verhandelt wurde, inwiefern sie sich in einer prekären biographischen Situation und einer gesellschaftlich marginalisierten Stellung sehen (,bei den Jungs ein alltägliches Thema“"). Die Rahmung verblieb dabei im Wesentlichen im Deutungsmuster ,marginalisierte Kämpfer', Mahmoud und Samad sprachen nun aber in größerer Offenheit und in einem schärferen Ton sowie mit einer stärkeren Frustration über ihre gesellschaftliche Position. Auch die Erfahrungen mit Stigmatisierung und der Vergleich mit Familien aus der Gruppierung der ,behördennahen' etablierten Intifada-Veteranen kamen zur Sprache.

Im Folgenden möchte ich noch auf eine längere Feldszene ${ }^{112}$ von Herbst 2014 mit Yousef und Samad eingehen. Anhand dieses Treffens lässt sich exemplarisch aufzeigen, wie die jungen Männer mit anderen Lebensbereichen verbundene ,Niederlagen' in der Clique mittels des Deutungsmusters der ,Marginalisierung verdienter Kämpfer` verhandelten und als unter den jungen Männern geteilte Situation interpretierten. Außerdem verdeutlichte das Treffen nochmals das Grundgefühl der Frustration und der diffusen wie globalen Abwertung der gesellschaftlichen Phase, in welcher sie lebten. Samad hatte uns im Herbst 2014 zu einer Veranstaltung, einem Konzert einer lokal bekannten Sängerin, eingeladen, das im Rahmen eines mehrtägigen Festivals des Rückkehrrechtes ${ }^{113}$ stattfinden sollte. Die Organisatoren, Samad war einer von ihnen, hatten dafür einen größeren Saal im Nachbarort angemietet. Yousef war während der Veranstaltung außerordentlich schlecht gelaunt. Bereits zur Begrüßung hatte er uns fluchend mitgeteilt, er würde „seine Schwiegermutter umbringen“ wollen, und war dann kommentarlos weitergestapft. Samad erklärte uns Yousefs Verhalten damit, dass er seiner Freundin, eine entfernte Cousine, einen Heiratsantrag gemacht hatte und ihre Familie den Antrag abgelehnt hatte. Ich wunderte mich etwas über Yousefs Antrag, ich hatte bei meinem letzten Treffen nichts von seinen Plänen gehört. Aufgrund seiner finanziellen und familiären Situation war der Zeitpunkt meiner Einschätzung nach auch nicht naheliegend für einen Antrag: Sein Vater hatte aufgrund eines Unfalls in den letzten Monaten kaum arbeiten können und Yousef verdiente gerade illegal etwas Geld in Israel, um zum sehr knappen Familieneinkommen beizutragen (vgl. Kap. 6.3.3). Nach einem Besuch bei der Familie einige Wochen später hatte ich allerdings den Eindruck, dass Yousefs Mutter Yousef etwas unter Druck setzte, bald zu heiraten. Nach der Veranstaltung schlug Yousef vor, noch gemeinsam etwas trinken zu gehen. Ahmad Albaba und ich willigten ein. In der verabredeten Bar, ein altes Haus mit Steingewölbe und einem christlichen Besitzer, war Yousef

\footnotetext{
${ }^{112}$ Die folgende Schilderung basiert auf den ausführlichen Feldnotizen von Ahmad Albaba und mir.

${ }^{113}$ Das Festival, das kleinere Vorträge, vor allem aber Tanz- und Musikvorstellungen umfasste, wurde jährlich von dem Nachbarschaftszentrum veranstaltet, welches von Yousefs Vater und einigen anderen ehemaligen PFLP-Aktivisten gegründet worden war (vgl. Kap. 6.3.3). Die Jungs, insbesondere Samad und Yousef, hatten sich in den Jahren zuvor immer stark in die Vorbereitung involviert.
} 
weiterhin hitzig und aufgeregt. Sobald wir uns an einen Tisch gesetzt hatten, redete Yousef laut und schnell auf Samad ein, sagte wiederholt „sie“ beleidige ihn und er sei „kein Kind.“ Samad meinte, er müsse sie auch verstehen, sie sei „eine Mutter". Offensichtlich, so stellte sich heraus, gab Yousef der Mutter seiner Freundin die Hauptschuld an der Ablehnung des Heiratsantrags. Ahmad Albaba warf beschwichtigend ein, man müsse diplomatisch mit der Mutter seiner Geliebten umgehen. Alle redeten sehr schnell, Ahmad kam nicht ganz mit dem Übersetzen hinterher, aber einiges verstand ich auch so. Yousef beruhigte sich im weiteren Verlauf des Abends nicht wirklich, zwischendurch tippte er immer wieder Chatnachrichten in sein Handy. Nach einer Weile fragte ich, was denn das Problem sei. Nun brach es förmlich aus Yousef heraus, er erzählte laut, er habe ihr einen Antrag gemacht, aber ihre Mutter habe gesagt, sie seien noch zu jung, um zu heiraten. Sie lehne ihn ab, weil er „keinen Uniabschluss habe“. Er würde doch bald ins Ausland gehen, um zu studieren, nicht für sie, sondern für sich, fuhr er fort. Er kenne das Mädchen, seit er zwölf sei. Dann sagte er:

Yousef: „Wenn es um andere geht ist man liberal, aber wenn es um die eigene Schwester oder um die eigene Tochter geht, dann lese man aus dem Koran (2) alles wird von Sitten und Gebräuchen bestimmt aber über Sitten und Gebräuche bestimmt der Schekel“".

Eigentlich gehe es „nur ums Geld“. Yousef begann im Anschluss sarkastische Bemerkungen über Religiosität zu machen, in welche Samad einstieg. Da er nun die Kichererbsen in den Aschenbecher lege, müsse Gott wollen, dass er sie dort hineinlege. Samad meinte, wenn man sie esse, sage man, Gott habe das gewollt, und wenn man die Erbsen nicht esse, sage man ebenso, Gott habe das gewollt. Yousef und Samad machten noch weitere Sprüche in diese Richtung. Ich hatte die beiden bis zu diesem Zeitpunkt noch nie solche Sprüche machen hören und mich amüsierten ihre Bemerkungen. Allerdings empfand ich sie für den öffentlichen Raum des Lokals auch als etwas gewagt. Yousef sagte dann, die Jungs seien „total frustriert". Samad erzählte uns daraufhin, dass ein Freund ihn aus dem Gefängnis (möglich mittels eines geschmuggelten Handys) angerufen und ihm gesagt habe, dass die israelischen Sicherheitsbeamten im Verhör nach ihm gefragt hätten - ein Indiz für seine bevorstehende Verhaftung. Jetzt sei er „sehr deprimiert.“ Er sei seit zwei Jahren aus dem Gefängnis und habe sich „,nie richtig frei gefühlt.“ Jetzt, wo er wisse, dass sie nach ihm gefragt haben, stelle er sich, wenn er ein Auto sehe, vor: ,jetzt holen sie mich“. Wenn er abends einschlafe, träume er davon, dass sie vor der Tür stehen. Samad meinte zu Yousef, er habe uns bei dem Treffen mit Mahmoud gesagt, dass sie viel lachen würden, aber eigentlich nicht glücklich seien. Die Stimmung des Gespräches wurde zunehmend deprimierter. Ich wusste nicht so richtig, was ich sagen sollte, und meinte nur, dass es wirklich hart sei. ,Ja“, es sei „hart, hart, sehr hart“. Das Gespräch war im weiteren Verlauf davon geprägt, dass sich Yousef und Samad in ihren, zum Teil ironisierenden Bemerkungen ge- 
genseitig verstärkten und sie so ihre Frustration zum Ausdruck brachten. So unternahmen Yousef und Samad im Verlauf des Abends noch weitere Zuspitzungen. Als etwa Samad die Fortschritte meines Arabisch lobte, unterbrach ihn Yousef und meinte, ich solle Arabisch und die arabische Kultur vergessen. Er sei mein kleiner Bruder und ich solle auf ihn hören. In dieser Gesellschaft sei „alles falsch“, fuhr er fort und gab ein Beispiel von einer, seiner Ansicht nach völlig fehlgeschlagenen Behandlung seiner Bauchschmerzen im Krankenhaus vor ein paar Wochen (er hatte sich seiner Einschätzung nach auf der Baustelle, auf der er zuvor einige Wochen gearbeitet hatte, verhoben). Auch wenn Yousefs Wut und Frustrationsgefühle ihren konkreten Anlass in der Ablehnung seines Heiratsantrags hatten, macht diese Feldszene doch beispielhaft deutlich, wie eine ,persönliche ${ }^{6}$ Niederlage Yousefs von Yousef und Samad als exemplarisch für die Lage der Freunde verhandelt wurde. Sie verhandelten die mit verschiedenen Lebensbereichen verbundenen Erfahrungen (abgelehnter Heiratsantrag, Verhaftungsdrohung, Behandlung im Krankenhaus, Migrationsabsichten) unter dem ,gemeinsamen Nenner' des generellen Marginalisierungserlebens der ,Jungs'.

Die in diesem Abschnitt diskutierten Treffen mit Mahmoud, Samad und Yousef ab Herbst 2014 sind beispielhaft für die veränderte Bedeutung der Clique für die jungen Männer. Die Clique diente nun stärker als Zusammenhang, in welchem erlebte gesellschaftliche Marginalisierung verhandelt und gedeutet wurde. In den oben erörterten Gesprächen wird auch deutlich, dass sich die Frustration und das Marginalisierungserleben der jungen Männer über den Zeitraum unserer Bekanntschaft tendenziell zuspitzten. Das Marginalisierungserleben verdichtete sich zudem zunehmend zu einem diffusen und generalisierten Gefühl beziehungsweise einer Auffassung, in heuchlerischen und ,grundfalschen' gesellschaftlichen Verhältnissen/Bedingungen zu leben.

\subsubsection{Warum sprechen die jungen Männer mit uns? Unsere Position im Feld}

Warum sprachen Samad, Yousef und die anderen überhaupt in der geschilderten Weise mit uns und warum blieb der Kontakt über mehr als zweieinhalb Jahre bestehen? In dem in Abschnitt 6.1.3 diskutierten Feldzugang wurde deutlich, dass der Anlass, uns überhaupt anzusprechen, mit der Intention verbunden war, eine Teilnahme von Kindern und Jugendlichen aus der Lager-Gegend an sogenannten normalisierenden Programmen zu verhindern. Als im Verlauf des ersten Treffens deutlich wurde, dass wir nicht mit solchen Programmen verbunden sind, wurde der Kontakt mit uns für die jungen Männer eine Gelegenheit, den in den Deutungsmustern zum Ausdruck kommenden Wir-Bild der ,marginalisierten Kämpfer ${ }^{6}$ und den damit verbundenen Sie-Bildern Gehör zu verschaffen. Gerade im Deutungsmuster der vorgenommenen Widerstandsbilanzierung wird ja die Differenz zwischen der erlebten (marginalisierten) gesellschaftlichen Position und derjenigen, die einem der eigenen Auffassung nach zusteht, deutlich. Dieser Differenz, und der Unzufriedenheit, die aus ihr erwächst, Ausdruck zu verleihen, war 
einer der entscheidenden Gründe, warum sich die jungen Männer uns mitteilen wollten. Darüber hinaus waren die Gespräche mit uns eine Möglichkeit, sich durch das Sprechen zu entlasten und sich gehört zu fühlen - ähnlich wie in der Clique selbst. Dies wird auch an folgendem Zitat deutlich. Als ich Mahmoud fragte, wie es für ihn war, mit uns über sein Leben zu sprechen, antwortete er:

Mahmoud: „Ich bin froh dass sich jemand interessiert oder jemand kommt und mit mir spricht gerade über diese Sache [...] manche [der Jungs] fühlen sich schwach und so geben sie auf sie geben die Sache auf wir sagen sie wurden verrückt sogar es ist sehr gut und macht mich glücklich [...] es ist wie das tägliche Sprechen mit den Jungs und dass sich auch andere dafür interessieren es freut mich, ja“.

Das Zitat verdeutlicht exemplarisch, was sich auch in weiteren Bemerkungen und Gesprächen offenbarte. Nämlich, dass die jungen Männer unsere Treffen und Gespräche auch als eine Entlastung und eine Wertschätzung für sie empfanden.

Die gelegentliche Frage, ob ich in Deutschland über Palästina reden werde, beantwortete ich in der Regel damit, dass ich ein Buch schreiben würde, aber dass es ein wissenschaftliches Buch sein würde, das eher nur Forscher*innen lesen werden. Dieser Antwort folgten meist keine weiteren Fragen von den jungen Männern. Einerseits denke ich, dass die jungen Männer nicht unbedingt viel damit anfangen konnten und nur über eine rudimentäre Vorstellung von wissenschaftlichen Diskursen und Akteuren verfügten. Andererseits vermute ich, dass diese Antwort für sie nicht ganz zufriedenstellend war, da sie sich mehr politische Agitation gewünscht hätten. Dass ich es zudem vermied, mich politisch allzu deutlich zu positionieren, war meiner Ansicht nach allerdings nicht irritierend für die jungen Männer. Sie unterstellten mir mit der Zeit einfach, dass ich diffus, auf ihrer Seite' sei. Dies kam zum Beispiel in der gelegentlich von den Freunden vorgebrachten Konstruktion, manche würden „mit dem Stift kämpfen“, zum Ausdruck, die auf mich bezogen wurde. Gleichzeitig galt dies unter den jungen Männern als halbherzige ,Widerstandsform‘. „Für richtigen Widerstand ist klar was man machen muss", wie einer der jungen Männer bei einer Gelegenheit formulierte und damit selbstverständlich die Militanz meinte, die sie selbst ausübten.

Über den Zeitraum unserer Bekanntschaft etablierte sich, bis zu einem gewissen Grad, eine Selbstverständlichkeit im Umgang und eine Vertrauensbeziehung zwischen den jungen Männern, insbesondere zwischen Musa, Samad und Yousef, Ahmad Albaba und mir. Diese Beziehungsentwicklung verdeutlichte sich unter anderem in der Differenz der Gesprächssettings und -interaktionen zwischen dem in Abschnitt 6.2.2 diskutierten ersten Treffen, das noch recht stark von einer Inszenierung der ,Kampfbereitschaft ${ }^{`}$ der jungen Männer und ihres politischen Wissens geprägt war, und den in Abschnitt 6.2.4 erörterten Treffen, die vom Gesprächssetting, dem Umgang miteinander (in lockeren Scherzen, aber auch im Zeigen von Wut oder Ängsten) und den angesprochenen Themen (die Ablehnung 
eines Heiratsantrages, die Ängste aufgrund einer erneuten Verhaftungsdrohung und die Stigmatisierung durch Nachbar*innen) eine größere Vertrautheit miteinander offenbaren. Diese zunehmende Vertrautheit hatte noch eine weitere Konsequenz: Ich hatte im Jahr 2015 eigentlich vorgehabt, ausführlichere Abschlussinterviews mit Musa, Samad und Yousef zu machen. Diese Interviews kamen jedoch nicht zustande. Zwar willigten die jungen Männer in der Regel ein, mit mir die geplanten Interviews zu führen, aber die Termine ,platzten' in der Regel aufgrund von Terminverschiebungen, verpassten beziehungsweise nicht beantworteten Telefonanrufen und Ähnlichem. Unsere formloseren Treffen waren jedoch weiterhin ohne Probleme möglich. Ich interpretiere diese Differenz in der Interviewbereitschaft gegenüber dem ersten Feldaufenthalt dahingehend, dass die offene Interviewdynamik, die gegenüber anderen Gesprächsrahmungen stärker mit Erzählzwängen sowie mit eventuellem ,Anarbeiten' gegen deren Wirksamwerden verbunden ist (vgl. Kap. 3.4.2), für die jungen Männer unangenehmer und problematischer gegenüber einer Person ist, bei welcher man damit rechnen muss, dass sie periodisch im eigenen Umfeld auftaucht und mit den eigenen Freunden, Familienmitgliedern und Bekannten regelmäßig in Kontakt steht.

Auch mein Wohnort war meiner Einschätzung nach ein Faktor, der die Entwicklung einer Beziehung zu den jungen Männern stützte. Die jungen Männer grenzten sich, wie in Abschnitt 6.2.2 bis 6.2.4 diskutiert, gegenüber den wohlhabenden Städtern ab und hatten auch unseren Wohnort während des ersten Feldaufenthaltes in einem Hotel in einer Mittelschichts-Gegend in Ramallah negativ kommentiert. Während des zweiten Feldaufenthaltes im Jahr 2013 hatten dann ein deutscher Forschungskollege und ich bereits in einem anderen Flüchtlingslager, circa eineinhalb Autostunden entfernt von der Lager-Gegend, in der die jungen Männer lebten, Quartier bezogen. Zwar kam unser Wohnort bei den Treffen mit den jungen Männern nicht ausführlich zur Sprache, aber Samad hatte beispielsweise bei einer Gelegenheit unseren Wohnort mit der Bemerkung kommentiert, es sei „gut, dass ihr nun im Lager wohnt". Während meines längeren Feldaufenthaltes 2014 bis 2015 wohnte ich, aus verschiedenen, auch pragmatischen Gründen erneut in diesem Lager bei einer palästinensischen Familie zur Untermiete (vgl. Kap. 3.4.3). Die jungen Männer besuchten mich jedoch aufgrund der relativ langen und damit auch kostspieligen Anfahrt während meines längeren Feldaufenthaltes und des hohen Verhaftungsrisikos für die jungen Männer auf der Strecke in der Regel nicht. Es gab nur eine Gelegenheit, bei der Samad mich besuchte, nämlich als sein Onkel mich nach einem Treffen bei den jungen Männern nach Hause fuhr und wir alle gemeinsam noch einen Kaffee tranken. Bei späteren Treffen fuhr mich Samads Onkel ebenfalls nach Hause, Samad begleitete ihn jedoch aufgrund seines Status als von den israelischen Sicherheitsbehörden „Gesuchter“ und der Checkpoints auf dem Weg nicht wieder. Ein gewichtiger Faktor für die erfolgreiche Etablierung einer Beziehung zu den jungen Männern war auch meine Zusammenarbeit mit meinem Kollegen Ahmad Albaba, mit dem ich nicht nur viele 
der Gespräche und Interviews mit den jungen Männern gemeinsam führte, sondern dem es auch leicht fiel, mit den jungen Männern Zeit zu verbringen und mit ihnen zu scherzen. Während der ersten Treffen im Jahr 2013 arbeitete ich zum Beispiel auch mit einem Kollegen aus der urbanen Mittelschicht Ramallahs zusammen, der für uns ein Gespräch übersetzte. Ihm gegenüber verhielten sich die jungen Männer deutlich reservierter und es scheint schwer vorstellbar, in dieser Konstellation ein ähnliches Maß an Vertrautheit und Lockerheit im Umgang miteinander zu erreichen, wie es mit Ahmad der Fall war. Ich vermute, dass dazu auch die geringere soziale Distanz - Ahmad Albaba war in einer anderen Flüchtlingslager-Gegend im Westjordanland aufgewachsen - beigetragen hat. Im Zeitraum meiner Bekanntschaft mit den jungen Männern rückte ich allerdings nie in die Position eines Freundes oder Cliquenmitgliedes. Ein Grund dafür ist natürlich, dass mir ein wesentlicher geteilter Erfahrungshintergrund des Freundeskreises, nämlich die Beteiligung an Straßenkämpfen und Inhaftierungen, fehlte. Meine unvollkommenen Arabisch-Kenntnisse, meine nur episodische Anwesenheit und meine Altersdifferenz zu ihnen haben ebenso dazu beitragen. Außerdem ,verletzte ich die Homosozialität der Clique ganz wesentlich dadurch, dass ich auch Gespräche und Interviews mit den Eltern und anderen Familienmitgliedern der jungen Männer führte (vgl. Kap. 3.3). Im Folgenden möchte ich nun die wesentlichen Strukturkomponenten der Clique zusammenfassen.

\subsubsection{Zusammenfassung: Deutungsmuster, Interaktionsdynamik und} Konstitutionsprozess der Clique

In diesem Kapitel wurden die Handlungs- und Deutungsmuster, Wir- und SieBilder sowie der Konstitutionsprozess und die Interaktionsdynamik einer Clique junger Männer aus einer Flüchtlingslager-Gegend im Westjordanland herausgearbeitet. Es hat sich gezeigt, dass der Konstitutionsprozess und die Interaktionsdynamik in der Clique eng mit der Involvierung in die Straßenschlachten mit dem israelischen Militär und der PA verbunden sind. In diesen Interaktionen werden die Deutungs- und Handlungsmuster der jungen Männer hergestellt und als gültige Weltdeutungen angenommen. Sie sind verwoben mit den Konstruktionsprozessen von Männlichkeit in Ernsten Spielen im Sinne Meusers (2005). Und in den Interaktionen werden - wie ich in Kapitel 6.3 aufgreifen werde - leidvolle Erfahrungen verhandelt, die im Zusammenhang mit den Konfrontationen und den Inhaftierungen in israelischen Gefängnissen gemacht wurden, und die die Involvierung in die Straßenschlachten eher steigerten.

Weiterhin wird die Clique mit zunehmendem Alter der jungen Männer als ein Kontext relevant, in dem innerbalb der palästinensischen Gesellschaft im Westjordanland erlebte gesellschaftliche Marginalisierung verhandelt und gedeutet wird. In dem Deutungsmuster der ,marginalisierten Kämpfer' rechnen die jungen Männer ihren ,Einsatz für die palästinensische Sache' und ihre erlebte gesellschaftliche Position in einer Widerstandsbilanzierung gegeneinander auf. In dieser verhandeln 
die jungen Männer auch ihre Zugehörigkeit zur Flüchtlingsbevölkerung in Abgrenzung zu einer im Sie-Bild unpolitischen, aber wohlhabenden Stadtbevölkerung. Sie bringen zudem ihre fundamentale Ablehnung der PA und ihre mit Stigmatisierungsprozessen verbundene Gegnerschaft gegenüber einer kleinen ,Führungselite' von etablierten, ,behördennahen' Intifada-Veteranen in der eigenen Nachbarschaft in der Lager-Gegend zum Ausdruck. Das im Deutungsmuster verhandelte Marginalisierungserleben spitzte sich über den Zeitraum unserer Bekanntschaft tendenziell zu und verdichtete sich zu einer frustrationsgeladenen, generalisierten Ablehnung des gesellschaftlichen Kontextes, in welchem die jungen Männer lebten. Diese generalisierte Ablehnung ruht außerdem auf einem temporalen Vergleich, den die jungen Männer als eine weitere Komponente des Deutungsmusters vornahmen. Die jungen Männer sind der Auffassung, dass der ,Einsatz für die palästinensische Sache ${ }^{6}$ und im Speziellen für die politischen Gefangenen und die Märtyrer gegenüber, früheren' kollektivgeschichtlichen Perioden ein geringeres und abnehmendes gesellschaftliches Ansehen und geringe Wertschätzung erfahren.

In einer stärker verallgemeinernden Formulierung ist festzuhalten, dass im Rahmen der Widerstandsbilanzierung eine Ausstattung mit Lebenschancen sowie mit Sinnchancen - um Begriffe von Norbert Elias aufzunehmen (vgl. Kap. 2.5) verhandelt wird, die die jungen Männer als gering und gegenüber anderen gesellschaftlichen Gruppierungen als benachteiligt erleben. Während Lebenschancen vor allem die erlebte Ausstattung mit Bildungs-, Berufs- und Heiratschancen umfasst, ${ }^{114}$ die die jungen Männer mit anderen Gruppierungen vergleichen, umfassen die Sinnchancen unter anderem die Chance, den eigenen ,Einsatz für die palästinensische Sache ${ }^{6}$ als gesellschaftlich angesehen, erfolgreich und wertgeschätzt zu erleben. Die Deutungsmuster und das Erleben der eigenen Lebens- und Sinnchancen bringen die Interdependenzgeflechte beziehungsweise die Figurationen, in denen die jungen Männer verflochten sind, zum Ausdruck. Die Verflechtungen - um einen Aspekt der Diskussionen in den weiteren empirischen Kapiteln und in der Ergebnisdiskussion vorwegzunehmen - bestehen unter anderem in einer Figuration mit Teilen der städtischen Mittelschichten, denen gegenüber sich die Machtbalance seit den 1990er Jahren zuungunsten der Flüchtlinge in den Flüchtlingslager-Gegenden verschoben hat und die in sichtbarer Weise die Deutungsmuster, Wir- und Sie-Bilder der jungen Männer aus der Clique prägte und prägt.

Ein weiterer Aspekt des Interdependenzgeflechts, in das die jungen Männer eingebunden sind, schwingt in ihrem Deutungsmuster, ihren Wir- und Sie-Bildern und in den Aushandlungsprozessen in der Clique ebenfalls mit, kommt aber nur

\footnotetext{
${ }^{114} \mathrm{Im}$ Sinne von Ergreifen eines Studiums und eines Berufes, der einen Hausbau und eine Heirat sowie die Versorgung einer Familie und der Eltern im Alter ermöglicht. Dass bei mangelnder Ausstattung mit Lebenschancen eine gegenseitige Blockierung dieser unterschiedlichen Lebensbereiche droht, verdeutlicht das Konzept des, Waithood', welches von Singermann (2011) für die ägyptische Gesellschaft diskutiert wurde.
} 
in impliziter Weise zum Ausdruck - nämlich eine spezifische generationale Position. Zum Beispiel entstand bei den jungen Männern der Eindruck, dass die Bedingungen dafür, sich ,für die palästinensische Sache ${ }^{6}$ einzusetzen, zu ,anderen Zeiten ${ }^{`}$ besser waren und mit einem höheren Ansehen verbunden waren, etwa in der kollektivgeschichtlichen Phase breiter politischer Mobilisierung der palästinensischen Gesellschaft in den 1970er und 1980er Jahren (vgl. Kap. 4.4-4.5). Von zentraler Bedeutung für die von den jungen Männern erlebte Differenz zu den 1970er und 1980er Jahren und die von ihnen gezogenen Abwärtsvergleiche ist folgender Aspekt. Im näheren sozialen Umfeld der jungen Männer bewegen sich in großer Zahl Personen, die während der Mobilisierung der 1970er und 1980er Jahre politisch ,aktiv' waren, die im Gefängnis gesessen haben oder in ,Widerstandsaktionen' involviert waren. Sie sind, wie ich ausführen werde, Mitglieder einer historischen Generation Intifada.

\subsection{7 Überleitung: Beobachtungen zur Generation Intifada im weiteren Interaktionsfeld der jungen Männer}

Die Personen im Interaktionsfeld der jungen Männer, die zur historische Generation Intifada gehören, sind ihre Eltern, ihre weiteren Familienmitglieder, ihre Nachbar*innen oder Bekannten. Zum Beispiel partizipierten Mahmouds Eltern, Musas Mutter oder Yousefs Vater an der politischen Mobilisierung im Westjordanland in den 1970er und 1980er Jahren. Ebenso nahe Verwandte wie Yousefs Onkel oder Nachbar*innen wie etwa die in Abschnitt 6.6 erwähnte „Genossin Fatima“. Auf die sich aus dieser Konstellation ergebenden intergenerationalen (familialen) Dynamiken gehe ich ausführlich im folgenden Kapitel ein. Die jungen Männer aus der Clique wissen zwar im Allgemeinen von der Involvierung ihrer Eltern, der anderen Familienmitglieder und Nachbar*innen in die Mobilisierung der 1970er und 1980er Jahre. In Interaktionen zwischen Mitgliedern der Intifadageneration untereinander oder zwischen der Intifadageneration und den jungen Männern werden die Erlebnisse und Erfahrungen der Älteren meinen Analysen zufolge aber nur selten ausführlich erzählt und üblicherweise eher in Form von respektvoll-nostalgischen Anspielungen quasi ,nebenbei ${ }^{i}$ thematisiert. Um dies zu verdeutlichen, möchte ich eine kurze Feldszene schildern: Bei einem Feldaufenthalt im Sommer 2014 besuchte ich gemeinsam mit Murad, einem Freund und Arbeitskollegen aus Bethlehem, der selbst während der Ersten Intifada für 2 Jahre in israelischen Gefängnissen inhaftiert gewesen war, eine Dabke ${ }^{115}$-Vorstellung im Lager der jungen Männer. Auf der Veranstaltung traf ich Samad und Yousef, die in Begleitung von Faiez waren, der ungefähr im selben Alter wie Murad war. Er war ein Bekannter von Yousefs Vater Hafez und einer der Mitbegründer eines

\footnotetext{
115 Ein ruraler Folkloretanz, der in vielen Ländern im weiteren Nahen Osten verbreitet ist. Zur Geschichte und Funktion von Dabke als nationale palästinensische Selbstpräsentation vgl. Kaschl 2003.
} 
kleinen lokalen Nachbarschaftszentrums, in welchem auch Hafez aktiv war (vgl. Kap. 6.3.3). Faiez stellte sich uns vor und als er Murad sah, sagte er zu Samad und Yousef gewandt, er kenne ihn ,irgendwoher“. Er wisse nicht mehr, ob „aus dem Gefängnis oder ob von einer Demo“, wo er „vielleicht vermummt gewesen“ sei, aber er kenne ihn. Er zeigte dabei mit dem Finger auf Murad und grinste. Murad brach in Lachen aus und sagt etwas wie ,ausschließen könne man dies nicht", woraufhin wir alle auflachten. Ich gehe davon aus, dass es insbesondere diese beiläufigen Thematisierungen sind, in denen die ,Kämpfergeschichten“ der Generation Intifada für die jungen Männer in den Alltagsinteraktionen präsent werden. Diesen Aspekt werde ich auch im folgenden Kapitel aufgreifen. Zentral ist, dass in diesen Interaktionen sowohl die biographischen Gemeinsamkeiten und der geteilte Erfahrungshintergrund der Generationsmitglieder als auch das Netzwerk von Bekannten und Freunden aus ,Kampfzeiten', über das die Generation Intifada verfügt, gegenüber den jungen Männern wie Samad und Yousef aufscheinen. In den Interaktionen werden einerseits Respekt und die Wertschätzung der ,Kämpfergeschichten“ transportiert, andererseits werden insbesondere leidvolle Bestandteile der Erfahrungsgeschichten tendenziell nicht thematisiert.

Damit korrespondierend ließen die jungen Männer durchblicken, dass sie eigentlich nicht viel über die Geschichten der Ersten Intifada wissen. So bemerkte Samad nach dem oben bereits erwähnten Interview mit der „Genossin Fatima“, dass er sich immer freue, wenn wir (Ahmad Albaba und ich) kommen, weil wir dann mit unseren Interviewpartner*innen über die Erste Intifada sprechen. Man wisse zwar von der Ersten Intifada generell, aber „nichts Genaues“. Im intergenerationalen familialen Dialog zeigte sich in meinen Analysen eine ganz ähnliche Struktur: Häufig gehören die Eltern der jungen Männer zur Generation Intifada. Auch hier sind die ,Kämpfergeschichten“ der Eltern, etwa bei mitgehörten Gesprächen zwischen den Eltern und deren Bekannten untereinander, beiläufig Thema, aber insgesamt den jungen Männern kaum bekannt. Dabei erzeugt der familiale intergenerationale Dialog vor dem Hintergrund deutlich voneinander verschiedener kollektivgeschichtlicher Phasen ein Verhältnis unterschiedlicher historischer Generationen. Dies ist einer der zentralen Aspekte, die ich in der folgenden Falldarstellung erörtern möchte.

\subsection{Falldarstellung Familie Sasour: „Unsere Erfahrung ist anders als eure Erfahrung“}

\subsubsection{Einleitung}

In diesem Kapitel diskutiere ich exemplarisch am Fall der Familie Sasour die längerfristigen kollektiv-, familien- und lebensgeschichtlichen Prozesse in der Elternund Kindergeneration in der Flüchtlingslager-Gegend. Die rekonstruierten Pro- 
zesse stehen in Wechselwirkung mit den im vorangegangenen Kapitel vorgestellten Dynamiken in der Clique. Neben anderen wichtigen Aspekten werden die familialen Tradierungsprozesse und die intergenerationalen Interaktionen, in denen familiale Aufträge ,gespürt' und verhandelt werden, herausgearbeitet. Dabei sind die Tradierung der familialen Fluchtgeschichte in der Nakba und - darauf habe ich bereits hingewiesen - vor allem die Interaktion zwischen Familienmitgliedern, die die Mobilisierung der 1970er und 1980er Jahre als Jugendliche oder junge Erwachsene erlebt und in dieser gekämpft haben, und Familienmitgliedern, die diese, verpasst ${ }^{`}$ haben und der Generation Intifada nachfolgen, von zentraler Bedeutung. Indem ich die Befunde aus Kapitel 6.2 mit jenen, die in diesem Kapitel diskutiert werden, ins Verhältnis setze, wird auch deutlich werden, inwiefern Prozesse in der Familie und Prozesse in der Peergroup miteinander verbunden und inwiefern sie voneinander unabhängig sind.

Aufzeigen möchte ich dies an der Familie von Yousef Sasour, einem der in Kapitel 6 vorgestellten jungen Männer. Er lebte und lebt mit seiner Familie in einem an Jaddaliya angrenzenden Wohnviertel. Die Fallrekonstruktion der Familie Sasour basiert auf Interviews mit Yousefs Vater Hafez, Yousefs Mutter Fadja, seinem Onkel väterlicherseits Khaled und eben Yousef selbst. Im Zentrum der Falldarstellung zur Familie Sasour stehen Hafez und Yousef, deren Interaktion zentral für den biographischen Verlauf Yousefs ist. Yousef hatten meine Kolleg*innen und ich bereits im Frühjahr 2013 zusammen mit den anderen Freunden aus der Clique kennengelernt. Die biographisch-narrativen Interviews und Gespräche mit der Familie wurden im Zeitraum vom Frühjahr 2013 bis zum Herbst 2015 geführt. Die meisten Interviews in der Familie fanden aber im Herbst 2013 statt. Sie wurden auf Arabisch, meist in mehreren Sitzungen geführt. Außerdem sind in die Auswertung weitere Besuche bei der Familie sowie teilnehmende Beobachtungen insbesondere mit Yousef und seiner Freundesclique eingegangen. Bevor ich zur Darstellung der kollektiv-, familien- und lebensgeschichtlichen Verläufe komme, möchte ich zunächst auf die thematischen Felder und die Dynamiken, die in den Interviews und Gesprächen im Herbst 2013 mit den Familienmitgliedern deutlich wurden, und auf die damit verbundene familiale Situation zu jener Zeit eingehen.

\subsubsection{Thematische Felder und familiale Situation im Herbst 2013}

Die Situation von Yousefs Kernfamilie war im Herbst 2013 von der schlechten gesundheitlichen Situation und der damit verbundenen Arbeitsunfähigkeit seines Vaters Hafez bestimmt. Hafez war im Sommer 2012 auf dem Weg zwischen Ramallah und Jerusalem in einen Verkehrsunfall verwickelt gewesen und hatte seitdem mit den gesundheitlichen Folgen des Unfalls zu kämpfen. Hafez hatte einige Wochen auf der Intensivstation im Krankenhaus gelegen. Er litt seitdem unter starken Rücken- und Beinschmerzen. Außerdem war es durch den Blutverlust zu einer anhaltenden Beeinträchtigung seiner Sehkraft gekommen. In der Folge hatte 
er seine Arbeitsstelle in der Verwaltung eines größeren Technikhandels, die auch Lese- und Schreibtätigkeiten erforderte, aufgeben müssen. Yousef selbst war in dieser Zeit in einem israelischen Gefängnis inhaftiert gewesen und hatte von den anhaltenden gesundheitlichen Problemen und Beschwerden nach dem Unfall erst erfahren, als er das Gefängnis im Frühjahr 2013 verlassen hatte. Hafez' Gesundheitszustand und seine Arbeitsunfähigkeit sowie die daraus erwachsenden Belastungen und Fragen bezüglich der Einkünfte der Familie - Hafez hatte das Familieneinkommen bisher allein erwirtschaftet - waren auch im Herbst 2013 noch strukturgebend für die thematischen Felder der Interviews und Gespräche.

Die thematischen Felder waren zudem durch eine weitere familiale Dynamik strukturiert. Yousef hatte sich seit der Frühadoleszenz im Rahmen der in Kapitel 6.2 ausführlich vorgestellten Clique in die Straßenkämpfe zwischen dem israelischen Militär und den Sicherheitskräften der PA mit jungen Männern aus der Lager-Gegend involviert. In der Folge war er vom Shabak verhaftet worden und hatte, wie erwähnt, in verschiedenen israelischen Gefängnissen eine circa eineinhalbjährige Haftstrafe abgeleistet. Zum Zeitpunkt der Interviews in der Familie lag seine Entlassung aus dem Gefängnis ein gutes halbes Jahr zurück. Hafez und Fadja hatten Yousefs Involvierung in die Straßenkämpfe, auch wenn diese von Yousef gegenüber seinen Eltern wiederholt abgestritten worden war, geahnt und insbesondere Hafez hatte in mehreren Diskussionen versucht, ihn davon abzubringen. Yousef war seit seiner Entlassung aus dem Gefängnis arbeitslos. In den Gesprächen mit Hafez und Fadja im Herbst 2013 wurde dann deutlich, dass sie Yousefs Arbeitslosigkeit und seine stagnierende Bildungskarriere auch seiner Involvierung in die Straßenschlachten und seiner Haftstrafe zuschrieben. Vor dem Hintergrund von Hafez' Arbeitsunfähigkeit und der damit im Raum stehenden Frage der Versorgung der Familie bekam der weitere Bildungs- und Berufsverlauf Yousefs für Hafez und Fadja dann ein besonderes Gewicht. Hafez drängte Yousef zu einer zügigen Fortsetzung seiner Bildungskarriere, worauf Hafez auch im Interview einging. Ausführlich brachte Hafez seine Enttäuschung über Yousefs Inhaftierung und seine Involvierung in die Straßenkämpfe und deren Folgen für die Bildungsund Berufschancen seines Sohnes zum Ausdruck:

Hafez: ,aber ich wünschte Yousef wäre nicht inhaftiert gewesen und würde jetzt etwas studieren was ihm und seinem Land was bringt weil weil er auch ehrgeizig ist, ich bin sicher wenn ihr ihn interviewt habt hat er gesagt dass er ein paar Fehler gemacht hat im Leben (3) [...] er hat Energie aber es ist Verschwendung diese auf Dinge zu verwenden in diesem Land die einem nichts Gutes tun“.

Generell sprach Hafez im Interview kaum über den Hergang seines Unfalls und seine körperlichen Beschwerden. Hafez resümierte in Berichtform seine biographischen Leistungen, sprach in einer längeren Erzählung über den Haddsch, den er für seine Eltern organisiert und mit ihnen absolviert hatte. Ein lebensgeschicht- 
licher Bereich, den Hafez im Interview nur begrenzt thematisierte, ist seine eigene Involvierung in die politische Mobilisierung im Westjordanland in den 1970er und 1980er Jahren und seine eigene mehrjährige Inhaftierung in verschiedenen israelischen Gefängnissen. Unter anderem ließ er auch seine Mitgliedschaft und sein Engagement in der PFLP im Interview unerwähnt, von welcher ich erst später in Gesprächen mit Nachbar*innen und Verwandten, unter anderem mit Yousefs Onkel Khaled, Hafez' Bruder, erfuhr. Ich möchte in der Falldarstellung aufzeigen, dass die geringe Thematisierung und das teilweise Verschweigen seiner politisch aktiven Phase auch mit der Sorge in der Familie in Zusammenhang stand, Yousef könne sich mit seiner Involvierung in die Straßenkämpfe und seiner Ausrichtung auf den ,Kampf für die palästinensische Sache‘ an ihm als Mitglied der Generation Intifada orientieren beziehungsweise orientiert haben.

In dieser familialen Situation führten wir auch ein biographisch-narratives Interview mit Yousef. Insgesamt orientierte dieser sich vorwiegend am Deutungsmuster und Wir-Bild der Clique als ,Kämpfer für die palästinensische Sache‘, welches ich in Kapitel 6.2 herausgearbeitet habe. Vor dem Hintergrund der sich für ihn unter anderem mit der Arbeitslosigkeit abzeichnenden gesellschaftlichen Marginalisierung und der familialen Situation sowie der Erwartungen Hafez' und Fadjas kam er aber auch zu relativierenden Einschätzungen. Diese Spannung drückt sich auch in folgendem Zitat aus:

Yousef: „Also (1) ja vielleicht habe ich ein zwei Jahre meines Lebens verloren in denen ich auch an meiner Zukunft hätte arbeiten können aber ich als Yousef glaube das als Israel mich verhaftet hat (3) also ich denke sie haben einen Fehler gemacht weil Israel denkt dass das Gefängnis einen Palästinenser oder einen Kämpfer bricht aber es ist das totale Gegenteil, es produziert Kämpfer im Gefängnis, Gefängnis ist eine Schule (2) die unterrichtet dich Prinzipien und Werte".

In dieser Globalevaluation und insbesondere indem er das Gefängnis als, Widerstands- und Persönlichkeitsschule rahmte, betonte Yousef den ,patriotischen Wert' seiner Inhaftierung, der ja unter anderem durch die oben zitierten Bemerkungen Hafez' in Zweifel gezogen wurde, und setzte damit auch Hafez' und Fadjas Erwartungen bezüglich seines schulischen Erfolgs etwas entgegen. Im Interview äußerte Yousef zudem Stolz über die,nächtlichen Scharmützel' mit dem israelischen Militär sowie über einen Hungerstreik, an welchem er während seiner Haft teilgenommen hatte. Gleichzeitig wertete Yousef die Phase seiner Inhaftierung, wie im obigen Zitat, als, verlorene Jahre ${ }^{6}$ ab und brachte sie damit in eine stärker relativierende, an der Auffassung seiner Eltern und der zunehmend prekären biographischen Situation orientierte Perspektive.

Während es Hafez und Yousef in den Interviews im Herbst 2013 offenkundig vermieden hatten, Hafez' Gesundheitszustand zu thematisieren, sprach insbesondere Fadja ausführlich über seinen Unfall und über die Ängste und Unsicherheit 
gerade in den ersten Wochen danach sowie über die Belastungen, die sich daraus für sie und die Familie ergaben. Sie konzentrierte sich im Interview eher auf die gegenwärtige Situation der Familie seit dem Unfall Hafez', der hier die Gegenwartsschwelle darstellte. Sie sprach ausführlich über die ersten Wochen im Krankenhaus, die Rehabilitationsbehandlungen, zu denen sie Hafez begleitet hatte, und über ihr ,Management' der familialen Situation - welche Behandlungen für Hafez sinnvoll sein könnten, wie die Kinder auf Hafez' Unfall reagiert hätten und inwiefern ihre Brüder die Familie finanziell unterstützen würden. Sie stimmte, zumindest uns gegenüber, mit Hafez’ Enttäuschung über Yousefs Straßenkämpfe und seine Inhaftierung und mit Hafez' Hoffnungen, Yousef möge noch ,etwas aus sich machen', überein. Für sie stand außerdem der Entlastungscharakter des Gespräches mit uns im Vordergrund - sie betonte wiederholt, „, manchmal ist es gut zu reden".

\subsubsection{Familien- und Lebensgeschichte}

Wie schon mehrfach erwähnt, stammt Yousef, ebenso wie seine Freunde, aus einer Familie mit Fluchthintergrund. Yousefs Großeltern väterlicherseits waren während der Nakba Ende der 1940er Jahre aus dem Gebiet des späteren Israel ins Westjordanland geflüchtet. Yousefs Großvater väterlicherseits war circa 1930 in einem Dorf ${ }^{116}$ etwa 25 Kilometer nordöstlich von Gaza-Stadt geboren worden. Seine spätere Frau, Yousefs Großmutter, stammte aus demselben Dorf und war vermutlich etliche Jahre jünger. Das Dorf hatte nach einem zur britischen Mandatszeit in den 1920er Jahren durchgeführten Zensus circa 1.200 Bewohner*innen, die ausschließlich muslimischen Glaubens waren. Die Zusammensetzung der Dorfbevölkerung war im Wesentlichen von der Hamuleh dominiert, zu welcher auch die Familien des Großvaters und der Großmutter gehörten. Die Familien waren seit mehreren Generationen in der Region ansässig und hatten vorwiegend Landwirtschaft, unter anderem den Anbau von Oliven und Getreide, betrieben. Der Großvater und die Großmutter hatten vermutlich bis zur vierten Klasse die Grundschule im Dorf besucht. Im ersten Arabisch-Israelischen Krieg 1948/49 lag das Dorf während des Kriegsverlaufs die meiste Zeit in von ägyptischen Truppen gehaltenem Gebiet. Nach dem Waffenstillstandsabkommen zwischen Ägypten und Israel im Februar 1949 fiel das Dorf, wie auch andere angrenzende Dörfer, jedoch unter israelische Militärverwaltung und befand sich dann im Grenzgebiet zwischen Israel und Jordanien, dessen Truppen das Westjordanland besetzt hatten. Vor dem Hintergrund der Lage des Dorfes kam es zu einer von Benny Morris so benannten „short, sharp, well-orchestrated campaign of low key

\footnotetext{
${ }^{116}$ Wegen der notwendigen Maskierung der Familiengeschichte und des Lagerkontextes gehe ich nicht auf den Namen des Herkunftsdorfes ein und verändere im Folgenden auch einige Informationen zu diesem Kontext. Ich habe die Herkunftsgeschichte der Familie ebenso wie die Geschichte des Ortes sorgfältig recherchiert, kann aus den genannten Gründen allerdings hier nicht die entsprechende Literatur zitieren.
} 
violence and psychological warfare designed to intimidate the inhabitants into flight" (Morris 2004: 522). Infolge dieser Kampagne floh die gesamte Dorfbevölkerung, darunter Yousefs Großeltern, aus dem Ort. Nach dem Krieg zerstörten israelische Einheiten dann die verlassenen Gebäude des Dorfes. Darüber hinaus ist mir zum konkreten Erleben der Vertreibung und zu den näheren Umständen der Fluchtgeschichte der Familien der Großeltern kaum etwas bekannt.

Die Familien kamen circa 1950 in das Flüchtlingslager Jabel Ezrir im südlichen Westjordanland, in welchem später auch Yousefs Vater Hafez geboren wurde (in die in Kapitel 6.2 im Zentrum stehende Lager-Gegend Jaddaliya zogen Teile der Familie erst in späteren Jahren). Die UNRWA hatte das Lager 1949 dort gegründet, da sich eine größere Zahl von Flüchtlingen aufgrund der Nähe zu einer Wasserquelle und zu einer größeren Straße dort zusammengefunden hatte. Zunächst lebten die Familien, wie alle Bewohner*innen des Lagers, in Zelten, ab circa 1957 stellte die UNRWA einfache Steinhäuser zur Verfügung. Die Großeltern heirateten im Flüchtlingslager Ende der 1950er Jahre und lebten weiterhin im Lager, als ab 1967 im Zuge des Zweiten Arabisch-Israelischen Krieges das Westjordanland von Israel besetzt wurde. In den folgenden Jahren konstituierte sich das israelische Besatzungsregime und der Bau israelischer Siedlungen begann. Eine der Konsequenzen der israelischen Besatzung und der mit der Besatzungspolitik einhergehenden Politik der ,offenen Brücken' war, dass dadurch das israelische Territorium für Palästinenser*innen aus dem Westjordanland und Gaza wieder zugänglich wurde und die palästinensische Bevölkerung zudem Zugang zum israelischen Arbeitsmarkt bekam (vgl. Kap. 4.4). Yousefs Großvater war, wie viele andere palästinensische Männer aus dem Lager, ab Beginn der 1970er Jahre in verschiedenen israelischen Städten und Siedlungen in einfachen Tätigkeiten im Bausektor tätig.

Yousefs Vater Hafez war 1964 im Flüchtlingslager als erster Sohn der Familie geboren worden, vor ihm waren bereits drei Töchter geboren worden. Hafez wuchs im Lager auf und besuchte ab dem sechsten Lebensjahr eine UNRWAGrundschule im Lager. In den nächsten Jahren wurden in der Familie zwei weitere Söhne und eine weitere Tochter geboren. Der Großvater baute in dieser Zeit das Haus um zwei weitere Räume aus, um, wie Hafez angab, die Söhne und Töchter in getrennten Räumen unterbringen zu können. In den Gesprächen sowohl mit Hafez als auch mit Hafez' Bruder Khaled wurden die beschwerlichen Lebensbedingungen in den engen Lagerbauten betont: ,es war (3) schwierig für unsere Familien für unsere Eltern denn wir lebten in kleinen Häusern, wir waren sieben oder acht Kinder". Nach der neunten Klasse, der letzten Klasse in den UNRWASchulen, wechselte Hafez auf eine weiterführende Schule für Jungen in einem nahegelegenen Dorf. Die Schule wurde auch von Schülern aus den umliegenden Gemeinden besucht. Im Schulalltag kam es wiederholt zu Konflikten zwischen Schülern mit und Schülern ohne Flüchtlingshintergrund. Hafez selbst sprach im Interview nicht darüber, aber sein Bruder Khaled, der dieselbe Schule besucht 
hatte, deutete in seinem Interview an, dass es regelmäßig „Probleme gegeben“ habe. Als ich ihn im weiteren Verlauf des Interviews erneut danach fragte, erzählte Khaled, auf der Schule sei „Flüchtling“ ein Schimpfwort gewesen. Inzwischen gebe es das Problem nicht mehr, weil weiterführende Schulen für das Flüchtlingslager gebaut worden seien. Khaled deutete an, es habe während seiner Schulzeit auch das Gerücht gegeben, dass Flüchtlinge den Altansässigen „die Arbeit wegnehmen" und, so ein weiteres Gerücht, Ernteerträge stehlen würden. In Kapitel 4 hatte ich auf diese gängigen Stereotype gegenüber der Flüchtlingsbevölkerung bereits Bezug genommen. Für die Gegenwartsperspektive in den Interviews waren diese in jener zurückliegenden, kollektivgeschichtlichen Phase gängigen Abwertungen für Hafez, wie auch für Khaled, kaum relevant. Sie wurden von ihnen auch nicht im Rahmen von Wir-Bildern - etwa als Flüchtlinge - hervorgehoben. Dies ist unter anderem bemerkenswert, da das Wir-Bild als Flüchtlinge, die durch die Altansässigen diskriminiert werden, eine wesentliche Komponente des Deutungsmusters der Clique junger Männer ist, die ich in Kapitel 6.2 diskutiere - also auch von Hafez' Sohn Yousef. Dass Hafez und auch Khaled diese Erfahrungen nicht weiter thematisierten, hängt wahrscheinlich damit zusammen, dass die spätere Erfahrungsbildung während der Involvierung in die Mobilisierung in den 1970er und 1980er Jahren, die gesellschaftlich breit geteilt wurde, wie auch der nachträgliche Rekurs auf diese Erfahrungen in den Deutungsmustern und WirBildern von Khaled und Hafez dominierten. Die Zugehörigkeit zur Wir-Gruppe der Flüchtlinge trat und tritt, zumindest in Ansätzen, gegenüber der Zugehörigkeit zur Generation Intifada in den Hintergrund. Diese Befunde habe ich bereits in anderen Arbeiten diskutiert (Hinrichsen 2017). Sie sind ein Aspekt, in dem die Zugehörigkeit zur Generation Intifada zum Ausdruck kommt (vgl. Kap. 6.4; 9.2). Gestützt wurde die Dominanz der generationalen Zugehörigkeit gegenüber der Zugehörigkeit zu den Flüchtlingen in dieser kollektivgeschichtlichen Phase durch die soziale Aufwärtsmobilität, die viele Flüchtlingsfamilien in den 1970er Jahren und 1980er Jahren erfuhren und die auch eine Annäherung der Lebensbedingungen von Altansässigen und Flüchtlingen erwirkte (vgl. Kap. 4.4). Wie ich nun zeige, wurde dieser Aufstieg, trotz biographischer Unwägbarkeiten, auch von Hafez und seinen Geschwistern vollzogen.

Hafez' Vater hatte zunehmend gesundheitliche Probleme, die Hafez im Interview auf die körperliche Anstrengung und Belastung auf den israelischen Baustellen zurückführte. Hafez musste daher die weiterführende Schule bereits nach dem zweiten Schuljahr wieder verlassen. Laut Hafez war es nicht zu vermeiden, dass nun vorrangig er für die Familieneinkünfte zu sorgen hatte. Ihm kam diese Aufgabe vermutlich auch deshalb zu, weil es ihm, den sozialen Konventionen entsprechend, als männlichem Erstgeborenen oblag, diese Rolle auszufüllen. Hafez, zu diesem Zeitpunkt also erst 17 Jahre alt, versuchte in den nächsten Jahren dieser Rolle als ,Versorger" der Familie gerecht zu werden. Mit dieser Rolle nahm er eine mit Autorität verbundene Stellung in der Familie ein. Khaled sprach von seinem 
älteren Bruder in dieser Phase als „Vater nach dem Vater“. Hafez wurde in einem Betrieb im Lager ab circa 1981 als Klempner angelernt und bezog bereits ein geringes Gehalt. Nach kurzer Zeit begann er für eine Firma mit einem jüdischen Geschäftsführer in Jerusalem zu arbeiten.

Hafez: „Ich lernte Klempner [...] am Wochenende habe ich dann gearbeitet wir waren so sieben Kinder im Haus die die ehh in der Schule waren (2) oder vorhatten zu studieren es war anstrengend für mich aber $=\mathrm{Gott}=\mathrm{sei}=\mathrm{Dank}$ habe ich das geschafft und überwand die Schwierigkeiten ich war in der Lage zu heiraten und wir alle konnten Häuser bauen ich war in der Lage zu bauen und genauso meine Brüder in Jabel Ezrir und meine Schwestern konnten heiraten alle Mädchen waren in der Lage zu heiraten“.

Hafez gelang es, darauf nahm er in der zitierten Passage Bezug, die Lebenschancen - im Sinne von Bildungs-, Berufs- und Heiratschancen - seiner Geschwister $\mathrm{zu}$ sichern beziehungsweise im Vergleich zu seiner Elterngeneration sogar zu erhöhen: Seine beiden jüngeren Brüder mussten nicht schon als Jugendliche zum Familieneinkommen beitragen, sondern konnten das Tawjihi absolvieren und ein Studium an den palästinensischen Universitäten des Westjordanlandes abschlieBen. Hafez' Schwestern absolvierten alle das Tawjihi. Auch für die Heiraten der Geschwister konnte Hafez über die Jahre etwas Geld ansparen. Dazu war er insbesondere aufgrund der in jener Zeit sehr hohen Differenz zwischen den auch für geringqualifizierte Beschäftigung bezahlten Löhnen in Israel und den Lebenshaltungskosten in den palästinensischen Gebieten, insbesondere in den Flüchtlingslagern, in der Lage. Wie ich in Kapitel 4 ausgeführt habe, arbeitete in den 1970er und 1980er Jahren ein hoher Anteil der palästinensischen Erwerbspersonen aus Gaza und dem Westjordanland in geringqualifizierter, gut bezahlter Beschäftigung in Israel. Von dieser Integration in den israelischen Arbeitsmarkt, auch wenn diese ganz überwiegend eine Integration in die unteren oder untersten Arbeitsmarktsegmente bedeutete, profitierten insbesondere die unteren Einkommensschichten und die Flüchtlingsbevölkerung im Westjordanland (vgl. Kap. 4.4). Unter Hafez und seinen Geschwistern ergab sich so eine Art Arbeitsteilung, wodurch einigen Familienmitgliedern ein weiterer Bildungsaufstieg gelang. In Übereinstimmung mit dieser Einschätzung kommentierte Khaled, Hafez' Bruder, dieses Arrangement mit den Worten „damals war es so zwei gingen auf den Markt und einer konnte sich ausbilden". In der Familie folgte man mit dieser ,Arbeitsteilung" unter Geschwistern einer gerade unter der Flüchtlingsbevölkerung üblichen Strategie sozialer Mobilität. ${ }^{117}$ Auf die beschriebene Weise ,verpasste ${ }^{6}$ Hafez jedoch auch einen

\footnotetext{
117 In der Forschungsliteratur ist die Bedeutung familialer Aufstiegsprojekte durch Bildungskarrieren im Rahmen geschwisterlicher Arbeitsteilung, die auch die weiblichen Geschwister umfassen kann, hervorgehoben worden (Rosenfeld 2002). Für die Bedeutung der Bildungsaspirationen trifft Lisa Taraki die Einschätzung: „Education was a crucial avenue of social mobility for urban middle-class and rural and refugee youth for the first three decades after the Nakba“" (2008: 74).
} 
möglichen eigenen (weiteren) Bildungsaufstieg. Während eine zentrale biographische Dynamik in Hafez' Leben in dieser Phase darin bestand, die Rolle als primärer Versorger anzunehmen und auszufüllen, bestand eine andere, insbesondere in seiner Spätadoleszenz sowie im jungen Erwachsenenalter, darin, in die beginnende politische Mobilisierung involviert zu sein, die breite Teile der palästinensischen Gesellschaft ab den 1970er Jahren erfasste.

\section{Hafez in der politischen Mobilisierung der 1970er und 1980er Jabre}

Ab Ende der 1970er Jahre kam es in der palästinensischen Gesellschaft zu einer sich sukzessive ausweitenden politischen Mobilisierung gegen die israelische Besatzung und das israelische Siedlungsprojekt (vgl. Kap. 4.4-4.5). Mit dem Beginn der 1980er Jahre intensivierten sich die von Demonstrationen, Streiks, Boykotten und gewaltsamen Zusammenstößen zwischen Palästinenser*innen auf der einen und den israelischen Sicherheitsbehörden sowie jüdischen Siedler*innen auf der anderen Seite geprägten ,Spannungen' im Westjordanland. In Kapitel 4 habe ich darauf hingewiesen, wie hier der zunehmende ,Druck der Straße ${ }^{6}$ durch die Demonstrationen und die Straßenschlachten zwischen palästinensischen Jugendlichen, israelischem Militär und Siedler*innen zusammenwirkte mit der an Fahrt gewinnenden zivilgesellschaftlichen Mobilisierung, die auch die urbanen Professionellen und andere Gruppierungen umfasste. Die ,Konfrontationen' mündeten schließlich ab 1987 bis circa 1993 in der Ersten Intifada als zugespitzte Konfliktphase. Auch der Alltag im Flüchtlingslager, in welchem Hafez und seine Familienmitglieder lebten, war im Verlauf der 1980er Jahre zunehmend von diesen Auseinandersetzungen geprägt. ${ }^{118}$ Die israelische Armee baute einen Posten direkt vor dem Eingang des Lagers auf, an welchem es in der Folge häufig zu Straßenschlachten und ,Konfrontationen' zwischen der Lagerbevölkerung und israelischen Soldaten kam. ${ }^{119}$ Der über die Straßenschlachten hinausgehende Prozess breiter politischer Mobilisierung, der sich zum Teil entlang von in Familien- und Nachbarschaftsnetzwerken entstandenen zivilgesellschaftlichen Komitees und Parteigruppen vollzog, wurde auch und gerade in den Flüchtlingslagern sichtbar (vgl. Kap. 4.5). Auch Hafez und seine Geschwister wurden in diesen Jahren politisiert. Insbesondere Hafez' Bruder Khaled involvierte sich im Weiteren stark in die Mobilisierung vor und während der Ersten Intifada. Er wurde Mitglied der Fatah und wurde in den 1980er Jahren und Anfang der 1990er Jahre mehrfach verhaftet und in israelischen Gefängnissen gefangen gehalten - insgesamt fünf Jahre lang. Nach der Ersten Intifada und während der Aufbauphase der PA Mitte der 1990er

\footnotetext{
${ }^{118}$ Das Lager galt einigen älteren (israelischen) Zeitungsberichten, unter anderem in der „Haaretz“, zufolge als eine der ,Speerspitzen' des palästinensischen Widerstandes in der Ersten Intifada.

${ }^{119}$ Ich besuchte das Haus, in welchem Hafez aufgewachsen war, bei meinen Besuchen bei Hafez' Bruder Khaled in Jabel Ezrir. Khaled zeigte uns dort ein Fenster zur Straße, durch welches bei Auseinandersetzungen vor dem Haus im Verlauf der Jahre bereits sechsmal eine Gasgranate in die Wohnung geflogen sei.
} 
Jahre bekam Khaled dann einen Posten in einer neu gegründeten Eliteeinheit der Polizei.

Auch Hafez, der 1987 beim Ausbruch der Ersten Intifada 23 Jahre alt war, wurde Anfang der 1980er Jahre bereits als Schüler politisch ,aktiv': Er wurde Mitglied der PFLP und war in deren Parteigruppen im Lager engagiert. Und er war wie seine Geschwister in die Straßenschlachten und Konfrontationen verwickelt. Außerdem war er während der 1980er Jahre mehrfach in verschiedenen israelischen Gefängnissen inhaftiert, zum Teil im Rahmen sogenannter Verwaltungshaft (vgl. Kap. 4.5). Insgesamt umfasste der Zeitraum seiner Inhaftierung vermutlich zwei Jahre. Hafez' Bruder Khaled sprach mit uns über die hitzigen politischen Diskussionen, die er mit Hafez ob ihrer unterschiedlichen politischen Affiliation gehabt habe. Bei ihren Diskussionen sei es „häufig um die Politik von Abu Amar“ - der Kampfname Yassir Arafats - gegangen, dem Khaled zugeneigt gewesen war. Während er selbst zu Abu Amar gehalten habe, habe Hafez mit der PFLP sympathisiert. Trotz dieser Differenzen seien die Brüder jedoch auch „Freunde“ gewesen. Khaled war es auch, der uns ausführlicher von Hafez' Parteimitgliedschaft und seinem Engagement vor und während der Ersten Intifada berichtete. Hafez selbst blieb insgesamt bei eher allgemeinen und etwas nostalgisch wirkenden Ausführungen:

Hafez: „Alles was passierte in der Gegend würden wir wissen und waren aktiv [...] Alles was passierte in der Gegend und in den Dörfern, Was ist passiert $^{6}$, Wer wurde verletzt ${ }^{\prime}$ solche Dinge, wir waren neugierig, als ich verhaftet wurde sie $=$ haben $=$ viele $=$ junge $=$ Männer verhaftet und mich auch ich war da in Verwaltungshaft".

Trotz der Versorgerrolle partizipierte Hafez an der politischen Mobilisierung der 1970er und 1980er Jahre und verfügte über einen Bestand an ,Widerstandsgeschichten', ein generationales Wir-Gefühl und einen mit der Mobilisierung verbundenen Bekanntenkreis, wie er für die Mitglieder der Generation Intifada ${ }^{120}$ typisch ist, wie sich auch in den weiteren biographischen Dynamiken zeigt.

\footnotetext{
${ }^{120}$ Die Kernjahrgänge der Generation Intifada liegen Rekonstruktionen von meinen Kolleg*innen und mir zufolge zwischen 1960 und 1970, allerdings besteht ein fließender Überang zur Zugehörigkeit respektive Nichtzugehörigkeit zur Generation (zur Unterscheidung von Kern- und Grenzjahrgängen vgl. Rosenthal 1997: 73). Ich spreche im Rahmen meiner Arbeit von einer Generation Intifada und nicht - wie es unter Rückgriff auf die Mannheim'sche Terminologie präziser wäre - von einer Generationseinheit Erste Intifada. Dies liegt zum einen darin begründet, dass ich im Rahmen der in dieser Arbeit rekonstruierten Fälle, die sich der Generation Intifada in den Komponenten, die ihre Generationsmitgliedschaft bestimmen, ähneln - insbesondere im Hinblick auf ihre Wirkung auf und ihre Verflechtung mit der Generation Oslo. Allerdings stand auch in meiner Samplebildung die Generation Oslo und nicht die Generation Intifada im Vordergrund. Möglicherweise wären in einem noch deutlicher auf die Generation Intifada ausgerichteten Sampling in ihren typischen Wirkungszusammenhängen stärker differierende Fälle aufgetreten. Zum Teil sind in der Forschung außerdem bereits verschiedene Generationseinheiten für die Generation Intifada bestimmt worden. Folgt man
} 
Seine Ausführungen zur Ersten Intifada rahmend, gab Hafez an, dass er ebenso wie Yousef jetzt gegenüber seinen Eltern gesagt habe, „ich mache nichts ich mache nichts aber ich habe doch alles gemacht". Diese Bezugnahme auf Yousef gibt einen Hinweis darauf, warum Hafez die Thematisierung seiner Involvierung in die Mobilisierung der 1970er und 1980er Jahre im Interview herunterspielte: Im Zuge der Involvierung seines Sohnes Yousef und dessen Freunden in die Straßenschlachten mit den israelischen Sicherheitsbehörden stellte sich für Hafez auch die Frage, ob sich Yousef und seine Freunde an ihm und seiner Generation orientierten, was auch in der weiter unten diskutierten Interaktion zwischen Hafez und Yousef in dessen Jugendphase deutlich wird. Die Diskussion des familialen Dialogs wird auch zeigen, wie, auf der Erfahrungsqualität der Mobilisierung der 1970er und 1980er Jahre aufsitzend, Hafez' Zugehörigkeit zur Generation Intifada in der Interaktion zwischen den Generationen erzeugt wird. In der Gegenwart des Interviews war es ja gerade Bestandteil der Gegenwartsperspektive Hafez', Yousef seine Involvierung und seine Inhaftierung zum Vorwurf zu machen - zu dieser Rahmung passte daher die eigene Involvierung in die Mobilisierung der 1970er und 1980er Jahre nicht. Hafez' Involvierung in die politische Mobilisierung vor und während der Ersten Intifada in den 1970er und 1980er Jahren fiel aufgrund seiner Versorgerrolle für die Familie im Vergleich zu seinem Bruder Khaled geringer aus. Sein Erleben der Intifada war auch von den Schwierigkeiten geprägt, die diese für seine Rolle als primärer Versorger der Kernfamilie - seine Brüder waren Ende der 1980er Jahre noch in der Ausbildung und seine jüngste Schwester Nour hatte noch nicht geheiratet - mit sich brachten:

Hafez: „Wenn du morgens losgehst fünf Uhr morgens gehst zur Arbeit und die Armee verhaftet dich (2) den ganzen Tag oder von frühmorgens bis zehn oder irgendwas und fragen dich, wohin gehst du? wohin gehst du? sie verhaften dich du sagst ihnen du gehst zur Arbeit und sie verhaften dich bis zehn oder später und dann lassen sie dich nach Hause gehen“.

Diese verdichtete Situation verweist auf die alltäglichen Schwierigkeiten, die die hohe israelische Militärpräsenz für die Erwerbstätigkeit und die Tagesroutine von Hafez mit sich brachte. Wie Bornstein formuliert: „Checkpoints on the roads, and patrols on the back roads, made getting to work or doing business a daily confrontation with the Israeli state“ (Bornstein 2001b: 301).

Noch während der Intifada im Jahr 1990 heiratete Hafez im Alter von 26 Jahren Fadja, die aus einer Familie aus einem nördlich des Lagers gelegenen Dorf stammte. Die Konstellation in Fadjas Herkunftsfamilie zum Zeitpunkt ihrer Heirat möchte ich hier nur knapp umreißen: Zum Zeitpunkt ihrer Heirat war Fadja 21 Jahre alt, war also 1969 geboren worden und mit drei Brüdern und vier Schwestern aufgewachsen. Ihre Familie war seit mehreren Generationen im besag-

zum Beispiel der Einteilung von Loren Lybarger (2007), wären meine Fälle ganz überwiegend in der säkular-nationalistischen Generationseinheit der Generation Intifada anzusiedeln (vgl. Kap. 5; 10.2). 
ten Dorf ansässig und besaß Land, welches sie bewirtschaftete. Der Vater Fadjas arbeitete jedoch in den 1970er und 1980er Jahren zusätzlich in einfachen Tätigkeiten in Israel. Fadja hatte das Tawjihi in einer nahegelegenen Stadt absolviert und arbeitete zum Zeitpunkt ihrer Heirat in einer sozialen Einrichtung in Jerusalem. Im Interview gab Fadja ihre Einschätzung ab, dass ihre Familie sie nicht habe studieren lassen, da ihr dazu die finanziellen Mittel gefehlt hätten. Da ihre älteren Brüder zu dieser Zeit in der akademischen Ausbildung waren, kann man eine patriarchale Bevorzugung der männlichen Nachkommen bei der Finanzierung der Ausbildungen der Kinder in Fadjas Herkunftsfamilie vermuten. Hafez war mit einem ihrer Brüder bekannt und hatte über diesen um ihre Hand angehalten. Ihre Eltern hatten, wie Fadja im Interview anmerkte, zunächst „Bedenken ihre Tochter an einen Sohn des Lagers zu geben“. Allerdings sei Hafez' „finanzielle Situation gut gewesen". Die Heirat fand nach nur einem Treffen der beiden und wenige Tage nach der Verlobung statt. Die mit der Hochzeit verbundenen Feierlichkeiten blieben aufgrund der Ersten Intifada, in welcher es als ungebührlich galt, aufwendig zu feiern, in einem kleinen Rahmen. Fadja zog nun zu Hafez ins Lager. Für Fadja bestand die Möglichkeit, die Heirat zunächst als Abwärtsheirat zu erleben. Darauf weist ihre zum Teil demonstrative ,Aufwertung' des Lagerkontextes im Interview hin, die sie etwa in der Formulierung zum Ausdruck brachte, ,ich habe in der Stadt und im Lager gelebt und ich finde das Lager ist kultivierter". Fadja gab an, sie hätte in den ersten Jahren nach der Heirat noch Kontakt zu ihrer Familie gehalten, es sei dann aber immer weniger geworden. Die Partnerschaft mit Hafez sei „zum Glück eine gute Ehe“. Das erste Kind des Ehepaares, ihr Sohn Said, wurde 1991 geboren. Die junge Familie lebte nun mit den Eltern Hafez’ und den beiden mittlerweile erwachsenen Brüdern und Schwestern Hafez' in dem zweiräumigen Haus im Flüchtlingslager.

Die Bedingungen während der Ersten Intifada erschwerten es Hafez, seiner Arbeit in Jerusalem nachzugehen. Dies lag an den Straßenschlachten und Auseinandersetzungen, insbesondere aber an dem sich konstituierenden israelischen Grenzregime. Israel baute in dieser Zeit die ersten ,festen' Checkpoints entlang der grünen Linie und führte ein System von Aufenthaltsgenehmigungen ein, die den Zugang von Palästinenser*innen aus Gaza und dem Westjordanland nach Israel regelten und restringierten. Hafez bekam 1990 nach einer kurzen weiteren Inhaftierung den sogenannten ,grünen Ausweis“. ${ }^{121}$ Mit dem Erhalt des Ausweises ging das Verbot einher, sich in den nächsten drei Jahren in Israel, inklusive Jerusalem, aufzuhalten. Um dennoch weiter seiner Erwerbsarbeit nachgehen zu können, schmuggelte‘ sich Hafez täglich in die Stadt. Dies wurde im Verlauf der Intifada jedoch aufgrund der generell hohen israelischen Militärpräsenz, der stark zunehmenden Straßenkontrollen und der Schließung von Zugangsstraßen zur

121 Ab 1988 führte Israel zusätzlich zur orangenen Residenz-ID für die palästinensischen Gebiete eine grüne ID für ehemalige politisch Inhaftierte ein. Mit dieser ist ab Erhalt ein dreijähriges Aufenthaltsverbot auf israelischem Staatsgebiet verbunden. 
Stadt immer schwieriger. Außerdem war für ehemalige Inhaftierte wie Hafez die Wahrscheinlichkeit deutlich erhöht, dass eine Kontrolle bei illegalem Aufenthalt in Israel auch in einer Verhaftung und einer Haftstrafe münden würde (Bornstein 2001b: 302). Hafez wurde in dieser Phase tatsächlich mehrfach verhaftet und musste für einige Wochen erneut in Verwaltungshaft. Um nach seiner Entlassung die Wahrscheinlichkeit von Kontrollen (auf der Pendelstrecke) herabzusetzen, zog er für ein Jahr in einen Jerusalemer Stadtteil und lebte nur am Wochenende bei der Familie: ,sie gaben mir die Grüne (...) ich musste zurück zur Arbeit gehen also musste ich dorthin ziehen".

Trotz der Unwägbarkeiten der Ersten Intifada verfügte die Familie jedoch weiterhin über genügend Einkünfte aus Hafez' Tätigkeit in Israel, um für einen Hausbau finanzielle Mittel anzusparen: Zu Beginn der 1990er Jahre, noch während der Ersten Intifada, kauften Hafez und Fadja ein etwa $20 \mathrm{~km}$ vom Lager in nördlicher Richtung entferntes Baugrundstück, welches deutlich näher am Großraum Jerusalem und in unmittelbarer Nähe des Flüchtlingslagers Jaddaliya lag. Vermutlich war die Ortswahl mit der generellen Verfügbarkeit von Bauland sowie in der Nähe zu Jerusalem begründet. Die Familie begann, auf dem Grundstück ein auf zwei Stockwerke angelegtes Haus zu bauen, was sie in den nächsten Jahren sukzessive und je nach Zeit und finanzieller Lage weiterführten. In dieser Phase wurde 1993 das zweite Kind Hafez' und Fadjas, ihr Sohn Yousef, geboren. Yousef, darauf wurde eingangs bereits hingewiesen, ist im Rahmen des Kapitels 6.2 als Mitglied der Clique junger Männer eingeführt worden und wird im Folgenden gemeinsam mit Hafez im Zentrum der Falldarstellung stehen.

Insgesamt gelang der Herkunftsfamilie väterlicherseits eine Bearbeitung und Reduzierung der Armutsbelastungen und eine Erhöhung der Lebenschancen für Hafez und seine Geschwister, die sich auch für die Kernfamilie Hafez' und Fadjas, unter anderem mit dem Hausbau außerhalb des Lagers, fortzusetzen scheint. Gleichzeitig hatten sich Hafez und seine männlichen Geschwister aktiv in die breite politische Mobilisierung in der palästinensischen Gesellschaft in den 1970er und 1980er Jahren involviert. Für die Biographie Hafez', aber auch seines Bruders Khaleds, deutete sich eine zwar spannungsreiche, aber durchaus gelingende Balance zwischen politischer Involvierung und ,Versorgerrolle im Sinne der Sicherung und Erhöhung der familialen Lebenschancen an. Für die Kinder Hafez’ und Fadjas, insbesondere für die männlichen Nachkommen, stellte sich die Frage, wie sie die potentielle Spannung von politischer Involvierung und Lebenschancen annehmen und verhandeln würden.

\section{Verbesserung der Lebensumstände und Yousefs Geburt in den frühen Oslo-Jahren}

Etwa zwei Jahre nach Yousefs Geburt zog die Familie im Jahr 1995 in das nun weitestgehend fertiggestellte Haus in der Nähe Jaddaliyas. Der Umzug fiel in eine Phase umfassender politischer Transformation in den palästinensischen Gebieten: das Ende der Ersten Intifada und der Beginn des Oslo-Friedensprozesses (vgl. 
Kap. 4.6). Die ,Oslo-Jahre' brachten für den Ort, in welchem die Familie nun wohnte, sowie für das angrenzende Flüchtlingslager Jaddaliya, welches nun Teil der B-Zone war, einen Abzug der israelischen Soldaten und, im Vergleich zur Ersten Intifada, eine Abnahme der ,Konfrontationen' und politischen Spannungen mit sich. Mit dem Aufbau der PA veränderte sich die nun nicht mehr unter israelische Verwaltungshoheit fallende Erteilung von Baugenehmigungen, was dazu führte, dass im Laufe der 1990er durch den Zuzug aus dem angrenzenden Jaddaliya, aber auch aus anderen Flüchtlingslagern sowie aus den südlich von Jaddaliya gelegenen Dörfern die Einwohnerzahl des zuvor nur dünn besiedelten Ortes stark anwuchs. Die Familie Sasour verließ mit dem Umzug die schwierigen, sehr beengten Wohnverhältnisse des Flüchtlingslagers. Am neuen Wohnort spielten sich Straßenschlachten und ,Konfrontationen“ zwischen Anwohner*innen und israelischem Militär nun kaum noch in unmittelbarer Nähe des Hauses ab, blieben aber Teil des weiteren Wohnumfeldes im und um das Lager. Zum Lager sind es vom Haus der Familie knapp 10 Minuten Fußweg ins Tal. Die Anfahrt israelischer Armeeeinheiten für Einsätze im Lager führt in der Regel durch den Ort.

Hafez und Fadja wohnten nun näher an ihren Arbeitsplätzen in Jerusalem beziehungsweise im Jerusalemer Umland, was für Hafez auch die Gefahr senkte, auf dem Weg zum Arbeitsplatz in Kontrollen zu geraten. Ohnehin war der Zugang nach Jerusalem beziehungsweise nach Israel in den ersten ,Oslo-Jahren' wieder erleichtert worden. Zum einen vergaben die israelischen Behörden mehr Aufenthaltsgenehmigungen, zum anderen wurde insbesondere Ende der 1990er Jahre auch illegalisierter Aufenthalt in Jerusalem von der israelischen Armee vielfach ,sehenden Auges' toleriert (Bornstein 2001b: 300 f.). Insgesamt vollzogen Hafez, Fadja und ihre Kinder mit dem Umzug einen materiellen Aufstieg und entzogen sich den schwierigen Lebensbedingungen im Flüchtlingslager. Für die Familie begann nun vor dem Hintergrund der ,Oslo-Jahre‘ eine ruhigere Phase, die eine Konzentration auf die Familiengründung ermöglichte, wie Hafez und Fadja in den Gesprächen evaluierten. Fadja sprach etwa ganz explizit davon, dass sich nach der schwierigen Zeit im Lager Jabel Ezrir „mit dem Haus und der Besatzung“ ihr Leben mit dem Umzug in die Nähe Jaddaliyas ,stabilisiert" habe. In den nächsten zwei Jahren wurden mit Yousefs Schwester Hibba (geb. 1994) und seinem Bruder Yasser (geb. 1996) weitere Kinder geboren. Yousef besuchte zunächst einen örtlichen Kindergarten im Viertel und wurde dann, wie auch sein älterer Bruder, mit sechs Jahren in die UNRWA-Schule für Jungen im Flüchtlingslager Jaddaliya eingeschult. Dies war nach den Regelungen der UNRWA ohne Probleme möglich, da deren Dienstleistungen auch für Flüchtlinge außerhalb der Lager zugänglich waren und sind (vgl. Kap. 4.2). Seine Einschulung und die ersten Schuljahre in der UNRWA-Schule im Lager evaluierte Yousef generell als ,glückliche` Zeit:

Yousef: „In der Zeit war man immer müde vom vielen Lernen, aber jetzt beginnt man diese Tage wertzuschätzen wenn man seine Freunde am Morgen 
sieht und man geht zusammen zur Schule man bekommt ein bisschen Ärger diese Erinnerungen sind im Allgemeinen glückliche Erinnerungen“.

Die mit dem Umzug entstandene Möglichkeit, sich sozial stärker vom Flüchtlingslager und dessen Bewohner*innen zu distanzieren, ergriffen Hafez und Fadja nicht. Das wachsende Netz von Freund*innen und Bekannten sowohl der Eltern als auch der Kinder erstreckte sich vorwiegend ins angrenzende Lager. Einige der Nachbar*innen im Ort waren selbst im Lager geboren worden. Für die (späteren) Freund*innen der Kinder, für Yousef ist dies bereits im vorangegangenen Kapitel deutlich worden, galt dies ebenso. Yousef und seine Geschwister besuchten wie erwähnt eine der UNRWA-Schulen im Lager Jaddaliya.

Auch Hafez' Kontakte und sein zivilgesellschaftliches Engagement in den Jahren nach dem Umzug verdeutlichen die Nähe zum Lager: Zusammen mit einigen Bekannten gründete Hafez im Jahr 1999 ein kleines Kultur- und Nachbarschaftszentrum im Ort. Zunächst bot das Zentrum nur eine Tanzgruppe für Dabke an. ${ }^{122}$ In den folgenden Jahren wurde das Angebot des Zentrums um weitere Sportaktivitäten, Nachbarschaftsgruppen und ein regional bekanntes Musik-Festival erweitert. Hafez' Engagement für das Zentrum hing auch mit seinem Freundes- und Bekanntenkreis aus der Zeit der politischen Mobilisierung der 1970er und 1980er Jahre zusammen. Einige der anderen Gründungsmitglieder waren ebenfalls in der PFLP aktiv und ebenfalls während der 1980er Jahre inhaftiert gewesen. Fadja bemerkte in Zusammenhang mit dem Engagement Hafez' für das Zentrum, er sei gefragt worden, ob er mitmache, „weil man hier Hafez kenne“, was auch das ihm entgegengebrachte Ansehen andeutet. In der zweiten Hälfte der 1990er Jahre waren in vielen Flüchtlingslager-Gegenden in den palästinensischen Gebieten ähnliche Zentren gegründet worden, so auch im benachbarten Jaddaliya, wo im Verlauf der 1990er Jahre zwei größere Gemeinde- und Jugendzentren aufgebaut wurden, die im Gegensatz zu Hafez' Zentrum auch stärker international vernetzt waren und regelmäßig westliche Reisegruppen in Empfang nahmen. Das von Hafez mitgegründete Zentrum dagegen behielt auch in den folgenden Jahren eher den Charakter eines Nachbarschaftszentrums, dessen Bekanntheitsgrad nicht über das Viertel hinausreichte.

In der erwähnten Dabke-Gruppe tanzte Yousef ab dem Alter von sieben Jahren und seit deren Gründung mit. Die Interviewpassagen, in denen Yousef über deren Gründung und das Zentrum sprach, rahmte er mit dem Verhältnis, das er und die anderen Familienmitglieder zum Ort und zum angrenzenden Lager hätten. Sie hätten in der Familie den Wohnort immer „Friedhof ohne Grabsteine“ genannt, weil „hier nichts los“ sei und die Gegend, in der neben Familien aus Jaddaliya auch viele aus ländlichen Räumen zugezogene Familien lebten und leben, „konservativ“ sei. Er führte mit Bezug auf die Gründungsphase der Tanzgruppe aus, dass sie „Probleme“ gehabt hätten, Mädchen aus dem Ort für die 
Gruppe zu gewinnen, und dass zunächst nur Mädchen aus Jaddaliya teilgenommen hätten. Während des Tanzens würden sich Mädchen und Jungen an den Händen fassen, was einige der Nachbar*innen davon abgehalten habe, ihre Töchter teilnehmen zu lassen. Nach ihrem ersten und erfolgreichen Auftritt in der Stadt hätten sie aber auch zunehmend Mädchen aus der direkten Nachbarschaft in der Gruppe gehabt. Yousefs Ausführungen betonen nochmals die anhaltende Orientierung seiner Familie am Lager und an der Flüchtlingsbevölkerung.

Seine Erzählungen zur Dabke-Gruppe geben außerdem einen Hinweis darauf, wie selbstverständlich Bedeutungskonstruktionen über, Widerstandsthemen ' und die ,palästinensische Sache` in seinem Alltag waren: In einer längeren erzählerisch ausgestalteten Passage sprach Yousef über den bereits erwähnten ersten Auftritt der Tanzgruppe in der nahegelegenen Stadt. Der Auftritt, der auch eine kleinere Sprechrolle für Yousef umfasste, thematisierte

Yousef: ,generell die palästinensische Sache genauer gesagt spricht es über eine Mutter und einen Sohn im Gefängnis der Sohn heißt Khalil und die Mutter verkauft Obst und Gemüse damit sie ihn verheiraten kann wenn er aus dem Gefängnis kommt“".

Yousef hatte in diesem Stück die Rolle des Protagonisten inne („der Charakter um den die ganze Geschichte geht"). Zunächst gab er einen Eindruck von der inhaltlichen Programmatik der Dabke-Tänze. Diese umfassten neben dem Gefängnisaufenthalt der Hauptfigur auch romantisierende Darstellungen vom ländlichen Leben in den Herkunftsdörfern. Yousef kam auch auf sein ,Lampenfieber vor dem Auftritt zu sprechen:

Yousef: ,ich war nervös und es war mein erster Auftritt überhaupt aber im Moment war alles ok wir hatten uns in den Kopf gesetzt für die Freiheit zu tanzen als ich die Leute gesehen habe war ich geschockt und habe mich gefreut gleichzeitig, viele $=$ unterschiedliche $=$ Gefühle $=$ gehabt gedacht stopp zu machen und gedacht weiterzumachen viele unterschiedliche Gefühle ich war nervös und ich habe versucht meine Nervosität durch meine Schreie loszuwerden".

Diese Passage ist offenbar an der damaligen Perspektive des ambivalenten Gefühlshaushalts und der Nervosität vor der ersten ,Bühnenerfahrung ${ }^{6}$ orientiert. Yousefs Bemerkung, sie hätten sich in den Kopf gesetzt, „für die Freiheit zu tanzen“, vermittelt einen Eindruck von der Selbstverständlichkeit von ,Widerstandsthemen' in seinem Alltag. Außerdem gibt sie einen Hinweis darauf, in welcher Weise Situationen der Perspektivübernahme im kindlichen Spiel in der Rolle des Gefangenen und des, Widerstandskämpfers' Bestandteil davon waren.

Ein weiterer Alltagsbereich, der zur Ausbildung kollektiver palästinensischer Zugehörigkeit in Yousefs Kindheit beigetagen haben mag, waren Geschichten und die romantisierenden Darstellungen des Lebens im Herkunftsdorf, die durch die Eltern Hafez', also Yousefs Großeltern väterlicherseits, tradiert wurden. Auch 
nach dem Umzug war die Familie häufig bei den Eltern und Geschwistern im Lager zu Gast. Yousef berichtete uns über Geschichten der Großeltern aus dem Dorf und dem bäuerlichen Leben, die bei diesen Besuchen gelegentlich zur Sprache kamen. Er gab an, seine Großeltern hätten ihn im Zusammenhang mit diesen Geschichten immer wieder ermahnt:

Yousef: „pass auf du bist nicht aus Jaddaliya oder Jabel Ezrir du bist aus Quariye wir sind hier nur für eine Weile dann werden wir zurückkehren, man=man merkt ihnen ihren Frust an und wie bewegt sie sind“".

In Yousefs Erinnerung wurde er von seinen Großeltern in deren Erzählungen auf seine ,eigentliche' Herkunft aus dem heute im israelischen Staatsgebiet liegenden Dorf Quariye hingewiesen. Die im Zitat angedeuteten Gespräche Yousefs mit den Großeltern kann man typische Herkunftstradierungen zwischen der Großelterngeneration als Erlebnisgeneration der Nakba und ihren Enkeln interpretieren, in denen eine kollektive Zugehörigkeit zum Geburtsort der Großeltern interaktiv erzeugt und das kollektive Gedächtnis der palästinensischen Flüchtlinge eingeübt wird. Diese Herkunftstradierungen wurden auch von Rosenthal beobachtet (Rosenthal 2015: 32 f.). Sie wirkten darauf hin, dass Yousef sich mit der familialen Vertreibungsgeschichte und der Idee einer ,Rückkehr' in das heutige israelische Staatsgebiet identifizierte. In der Frage der familialen intergenerationalen Bedeutung der Herkunftstradierung möchte ich auch auf einen weiteren Aspekt zu sprechen kommen: Als Yousef über die Geschichten der Großeltern über den Herkunftsort sprach, erinnerte er auch ein Gespräch zwischen seinem Großvater, seinem Vater und ihm:

Yousef: „mein Großvater verlangt eine Zigarette zu rauchen und mein Vater lehnt ab ihm eine zu geben. Mein Vater hat gesagt vergiss die Zigarette denk an die Gesundheit in diesem Moment hat mein Großvater angefangen zu erzählen aus der Zeit der bilād ${ }^{123}$ wie sie anpflanzten und ernteten und wie sie die Produkte verkauft haben und ich erinnere mich nicht ganz detailliert aber mein Vater hat gesagt diese Zeit ist um diese Zeit ist vorbei (3) also mein Vater hat so reagiert weil er ihm sagen wollte du hast genug jetzt getan jetzt musst du nur an deine Gesundheit denken“".

Diese Passage steht im Kontext der Einschätzung Yousefs, sein Großvater sei manchmal recht unvermittelt auf die ,früheren Zeiten' im Herkunftsdorf zu sprechen gekommen. Diese in Yousefs Erinnerung gefallene Bemerkung Hafez', die „Zeit der bilād“ sei „vorbei“, kann man auch als Hinweis auf eine Distanzierung Hafez' von der Fluchtgeschichte der Familie werten. Yousefs Argumentation zur erinnerten Passage (,mein Vater hat das gesagt, weil'), diente womöglich zur Rati-

\footnotetext{
${ }^{123}$ Die wörtliche deutsche Übersetzung ist „Länder“. Hier bezieht es sich auf die durch Flucht und Vertreibung verlassenen Regionen und landwirtschaftlichen Besitztümer palästinensischer Flüchtlinge.
} 
onalisierung des latenten Sinns der Äußerung Hafez', die er wahrscheinlich zumindest partiell selbst bemerkte. Dass hier eine vorsichtige Distanzierung Hafez' von der familialen Fluchtgeschichte zum Ausdruck kommt, wird auch durch jene Passagen im Interview mit Hafez, in welchen er über das Verhältnis seiner Eltern zum Herkunftsdorf sprach, gestützt:

Hafez: „Sie haben alle ihr Leben lang gehofft, dass sie zurückkommen mein Vater meine Mutter beide haben ihr Leben lang gehofft sie kommen zurück bis heute wenn man sie trifft sie hoffen alle eines Tages kehren sie zurück“"

Auch in dieser Passage ist die Lesart einer vorsichtigen Distanzierung Hafez' von der Verortung im Herkunftsdorf im heutigen Israel möglich. So schloss er sich nicht in den Rückkehrwunsch ein und rahmte die Ausführungen auch nicht mit einer Betonung des ,Rückkehrrechts'. Insgesamt lassen sich diese und andere Passagen als eine bei Hafez gegenüber Yousef geringere Identifikation mit der Fluchtgeschichte, dem Herkunftsort und mit der Idee der Rückkehr lesen. Diese Lesart korrespondiert mit der bereits diskutierten, für Hafez gegenüber Yousef und seinen Freunden tendenziell geringeren Bedeutung des Wir-Bildes als palästinensische Flüchtlinge (vgl. Kap. 6.4; 9.2; vgl. Hinrichsen 2017).

\section{Die Zweite Intifada}

Im September des Jahres 2000 begann die Zweite Intifada. War diese in den Anfangsmonaten noch von größeren Demonstrationen in palästinensischen Ortschaften und „Konfrontationen an den Checkpoints und ,Berührungspunkten geprägt, militarisierte sich der Konflikt in den folgenden Monaten und Jahren zunehmend. Dies hatte unter anderem zur Folge, dass sich die eingesetzten Gewaltmittel verschärften, dass die israelische Armee etwa Hubschrauber und Scharfschützen zum Einsatz brachte und palästinensische Milizen wiederholt Attentate auch auf israelische Zivilist*innen durchführten. Insgesamt war die Zweite Intifada in puncto politischer Mobilisierung der palästinensischen Bevölkerung kaum mit der Ersten Intifada und der Mobilisierung der 1970er und 1980er Jahre vergleichbar (vgl. Kap. 4.7).

In Jaddaliya und dem Wohnort der Familie kam es ab Herbst 2000 vermehrt zu ,Konfrontationen'. Das israelische Militär führte in großer Zahl Verhaftungen und Hausdurchsuchungen durch und verhängte mehrwöchige Ausgangssperren. Im Wohnort der Familie wurden vom israelischen Militär zudem einige Häuser, in denen Familien von Attentätern lebten, zerstört. Yousef war bei Beginn der Zweiten Intifada gerade sieben Jahre alt geworden. Er habe nach der Zweiten Intifada „gewusst was Soldaten sind“ - diese waren ja seit den Oslo-Verträgen im Alltagsleben in den A- und B-Gebieten im Vergleich zu früheren Zeiten deutlich weniger präsent gewesen. Er sei aber „zu klein“ gewesen, um sich an der Intifada „zu beteiligen“. Auf meine Bitte im Interview hin, eine Situation mit Soldaten zu erzählen, an die er sich erinnern könne, sagte er, er habe sie immer nur von Weitem 
sehen können. Außerdem habe er während der Zweiten Intifada kaum das Haus verlassen dürfen: ,ich war klein und es gab Ausgangssperre und wir durften gar nicht rausgehen nur zu bestimmten Zeiten durften die Eltern rausgehen um Sachen zu kaufen.“

Insgesamt waren das Familienleben und auch Yousefs Erleben der Zweiten Intifada eher von jenem Bestreben geprägt, das Tobias Kelly mit Bezug auf die Zweite Intifada, und in deutlichem Kontrast zur breiten Politisierung der 1970er und 1980er Jahre, als Fokus auf „living an ordinary life“ (2008: 351) bezeichnet. Damit sind Umgangsweisen gemeint, die darauf zielen, die Erschwerungen des Alltags pragmatisch zu managen, statt zur Mobilisierung beizutragen (vgl. Kap. 4.7). Im Gegensatz zur Ersten Intifada in Jabel Ezrir lag das Haus der Familie nun außerhalb des unmittelbaren Lagerkontextes. Dadurch spielten sich deutlich weniger Straßenschlachten und Demonstrationen direkt vor der eigenen Haustür $\mathrm{ab}$ und die Gefährdung allein aufgrund unmittelbarer räumlicher Nähe war nun geringer. Yousef machte während der Zweiten Intifada nicht die Erfahrung, dass die israelische Armee stark in das Familienleben, eindrang'. So erlebte er zum Beispiel keine Hausdurchsuchungen oder nächtliche Verhaftungen der Geschwister oder der Eltern. Insgesamt wurden in der Zweiten Intifada keine Familienmitglieder, auch keine der erweiterten Familie, verhaftet oder verletzt. Dies lag auch daran, dass die Familie während der Besatzung der Region durch das israelische Militär 2002 und der Verhängung einer einmonatigen Ausgangssperre ebenso wie viele Nachbar*innen den Ort verließ und für einige Wochen zu Familienmitgliedern, vermutlich Verwandten von Fadja, in einer ländlichen Region zog:

Fadja: „40 Tage waren wir nicht hier, da Hafez nicht hier war und sie die Durchsuchungen gemacht haben und so (2) und als wir wiederkamen hatten wir fast vergessen wie das Haus aussieht ((lacht)) es war Frühling als wir kamen alles blühte um das Haus, es war schön anzusehen, unsere Nachbarn haben dasselbe gemacht".

Hafez verblieb zunächst im Haus der Familie und zog dann erneut, wie bereits Mitte der 1990er Jahre, für einige Wochen nach Jerusalem, um weiterhin seiner Erwerbsarbeit nachgehen zu können. Allerdings verlor Hafez im Laufe der Zweiten Intifada seine Arbeit in Jerusalem und damit eine gut bezahlte Beschäftigung und eine sichere Einkommensquelle für die Familie. In der Zweiten Intifada verschärfte Israel vor dem Hintergrund des bewaffneten Konfliktes das Grenzregime unter anderem durch den Bau der Sperranlage sowie durch die administrative Verschärfung und Durchsetzung des seit Beginn der 1990er Jahre existierenden Systems der Aufenthaltsgenehmigungen massiv. Nach circa 20 Jahren Beschäftigung bei einem jüdischen Unternehmer in Westjerusalem konnte Hafez nun nicht mehr nach Jerusalem einreisen. Insbesondere als ehemals politisch Inhaftierter erhielt er keine Aufenthaltsgenehmigung mehr und illegale Aufenthalte in Jerusa- 
lem waren nun, im Gegensatz zu Beginn der 1990er Jahre, aufgrund der verstärkten Kontrollen, der Sperranlage und der hohen Haftstrafen zu risikoreich geworden und schwer zu organisieren. Der Verlust der Möglichkeit, durch eine Tätigkeit in Israel auch mit geringqualifizierter Arbeit ein gehobenes Einkommen und damit den gegenüber der Elterngeneration erreichten materiellen Aufstiegs zu sichern, war eine sozial geteilte Konsequenz der Zweiten Intifada, die gerade die palästinensische Flüchtlingsbevölkerung traf. In besonderem Maße traf sie vermutlich, aufgrund des restriktiven Umgangs mit der Erteilung der Aufenthaltserlaubnisse, ehemalige politisch Inhaftierte in Gaza und im Westjordanland. Nach der Zweiten Intifada sicherte die Familie wahrscheinlich mit den Einkünften der Mutter und finanzieller Unterstützung durch Hafez' Bruder Khaled die Versorgung der Familie. Die Kinder, zwischen zwölf und acht Jahre alt, gingen zu dieser Zeit alle noch zur Schule. Nach einem gescheiterten Versuch eine Bäckerei zu eröffnen, fand Hafez circa 2005 eine Anstellung in der Verwaltung eines größeren Technikhandels im angrenzenden Stadtbezirk. Zusätzlich erledigte er nach Feierabend Aufträge als Klempner in der Nachbarschaft. Auch die Mutter arbeitete weiter in der pädagogischen Einrichtung als Sozialarbeiterin und blieb, wenn es der Schichtplan erforderte, auch über Nacht dort. Bald darauf gab sie diese Tätigkeit jedoch auf, um sich auf den Haushalt und die Betreuung der Kinder zu konzentrieren.

\section{Yousefs Integration in die Clique im Lager}

In der auslaufenden Intifada ab 2005 und den Jahren danach engagierte sich Hafez, vielleicht auch im Zusammenhang mit den Phasen des ,Leerlaufs' während seiner Arbeitslosigkeit, verstärkt in dem von ihm mitgegründeten Nachbarschaftszentrum. Neben dem Ausbau der Sport- und Nachbarschaftsaktivitäten konnte Hafez nun auch einige internationale Kontakte für das Zentrum knüpfen, die er auch für die Organisation von Reisen für seine Kinder nutzte. Hafez' Tochter Hibba erhielt so die Gelegenheit, an einem Austausch mit Jugendlichen aus palästinensischen Flüchtlingslagern im Libanon teilzunehmen. Auch Yousef konnte die Kontakte des Vaters nutzen, um 2006 nach Italien zu reisen. Er hatte eine Reisegruppe, die auf Betreiben des Vaters einige Tage im Zentrum zu Gast war, betreut und dieser den Ort und das Flüchtlingslager gezeigt. Im darauffolgenden Jahr hatten die Teilnehmer*innen ihn für freie Kost und Logis nach Italien eingeladen. Im Zentrum war Yousef außerdem weiterhin Teil der Dabke-Tanzgruppe und engagierte sich wie seine Geschwister in verschiedenen Aktivitäten des Zentrums. Durch das Zentrum lernte Yousef, über Umwege` auch einige der Freunde aus der in Kapitel 6.2 ausführlich diskutierten Clique kennen:

Yousef: „Der Bruder von Musa, Issa war bei uns im Zentrum und wir wussten dass er im Gefängnis war und wir sind auch zu seiner Familie gegangen aber aus Solidaritätsgefühl [...] also du weißt doch wie das geht man lernt Leute von ihm kennen und ein Fest organisiert zu seiner Entlassung und wir waren unterwegs hier und da und haben ihn besucht zu Hause und dann ist 
die Beziehung stärker geworden [...] einer der Ismael heißt wurde auch entlassen und wir haben uns dort getroffen und dann haben wir Musa getroffen“.

Yousef und Musa freundeten sich an - vermutlich ab 2007 - und wurden gemeinsam mit Samad, den Yousef bereits aus der UNRWA-Schule kannte, sowie Mahmoud und den anderen Freunden Teil der Clique. Unter den Freunden und Bekannten wurde es immer wichtiger, sich an Straßenschlachten und Konfrontationen mit dem israelischen Militär sowie mit den Sicherheitskräften der PA zu beteiligen. Die Möglichkeit, sich in die Straßenschlachten und Scharmützel zu involvieren, auch darauf habe ich in Kapitel 6 bereits hingewiesen, bestand und besteht, weil die weitere Umgebung, insbesondere Jaddaliya, auch Ende der 2000er Jahre Schauplatz von Auseinandersetzungen zwischen israelischen Soldaten und palästinensischen Jugendlichen war. Den Hergang dieser mal mehr, mal weniger intensiven Straßenkämpfe und Versuche, nächtliche Verhaftungen durch die israelische Armee zu verhindern, habe ich in Kapitel 6.2 beschrieben. Yousef blieb nun auch zunehmend nachts wach, um gemeinsam mit den Freunden die Soldaten ,abpassen` zu können:

Yousef: „Ich pflegte zur Schule zu gehen ohne geschlafen zu haben also wir haben tagsüber geschlafen und nachts waren wir wach und wir haben uns gesammelt in dieser Periode die šabāb und dann wussten wir dass die Soldaten irgendwo im Lager sind um Leute zu verhaften oder irgendwas zu machen und dann haben wir bei dieser Gelegenheit Steine geworfen“.

Auch der in diesen Straßenschlachten übliche Gebrauch von Molotow-Cocktails durch die Jugendlichen, der mit einer höheren Aufmerksamkeit der israelischen Behörden für die Werfenden und einer Erhöhung des Verhaftungsrisikos verbunden gewesen sei, wurde für Yousef zunehmend normal (vgl. Kap. 6.2.3). Yousef blieb in den nächsten Jahren Teil dieser Clique junger Männer aus Jaddaliya und der Umgebung. Sein Zimmer im Haus der Eltern, welches etwas abseits von der Wohnung der Familie im selben Haus lag, wurde zu einem häufigen Treffpunkt der jungen Männer. Verbunden mit einer Beteiligung an den ,Scharmützeln` sowie deren kommunikativer Bewertung und Verhandlung in der Clique bildeten die Mitglieder der Clique jene in Kapitel 6.2 diskutierten Deutungsmuster, Wir- und Sie-Bilder aus - unter anderem das Selbstverständnis als, Kämpfer für die palästinensische Sache'. Mit der zunehmenden Integration Yousefs in die Clique verschränkten sich familiale und auf die Peergroup beziehungsweise den männlichen Freundeskreis bezogene Dynamiken, die ineinander verflochten biographisch wirksam wurden. Auch für Yousef stellte die Integration in die Clique und die Involvierung in die Straßenschlachten in dieser biographischen Phase einen Kontext für die frühadoleszente Geschlechtssozialisation dar (vgl. Kap. 6.2.3). Darüber hinaus bot die Clique generell einen Kontext für die Ausbildung von und das InsVerhältnis-Setzen von Selbst- und Wir-Bildern. 
Im Folgenden möchte ich jedoch vorwiegend diskutieren, inwiefern Yousefs Involvierung in die Clique und in die Straßenschlachten mit der Interaktion in der Familie, mit familialen Tradierungsprozessen vor dem Hintergrund der Familiengeschichte und mit dem Erleben und Verhandeln familialer Aufträge in Wechselwirkung steht. Dabei ist, neben der Tradierung der familialen Fluchtgeschichte, die Interaktion zwischen Hafez und Yousef als Interaktion zwischen zwei historischen Generationen zentral - also die Interaktion zwischen einer Generation, die die Mobilisierung der 1970er und 1980er Jahre als Jugendliche erlebt hat und in dieser aktiv war, und einer Generation, die diese ,verpasst' hat und der Generation Intifada nachfolgt.

\section{Familialer Dialog um Yousefs Involvierung in die Straßenschlachten}

Im Interview im Herbst 2013 sprach Yousef von der Phase, in der er zunehmend nachts rausgegangen sei und an den Straßenschlachten teilgenommen habe. Dabei beschrieb er diese zunehmende Involvierung als Phase, in der die ,Probleme‘ begonnen hätten:

Yousef: „während (1) des gab Probleme als (2) während nach der Grundschule es gab Probleme weil ich anfing bewusster zu sein ich war bewusster was los ist in Palästina und die Besatzung und die Armee und all diese Dinge [...] da haben die Probleme angefangen und zogen sich bis oder ziehen sich bis heute“.

Die Rahmung der Involvierung in die Straßenschlachten in dieser Passage als „Probleme“ steht sicherlich mit den lebensgeschichtlich später gemachten Leidenserfahrungen, auch den Inhaftierungserfahrungen und den Schwierigkeiten für die eigene Bildungs- und Berufskarriere in Zusammenhang und ist auch eine an Hafez und Fadja orientierte, kritische‘ Perspektive auf seine Involvierung in die Straßenschlachten. Er führte weiterhin aus, er habe in dieser Zeit verstanden, dass

Yousef: „wir das Recht haben in Palästina zu leben und dass sie nicht das Recht haben in Israel zu leben natürlich dann beginnt in einem der Kämpfer zu (3) wachsen und vielleicht (2) kannst du Palästina verteidigen oder etwas von dir geben“.

Auf meine spätere Frage im Interview, ob er mehr über diese Phase, in der der „Kämpfer' gewachsen sei, erzählen könne, antwortete Yousef: „du lernst das intuitiv mein Vater hat erzählt von der Verhaftungszeit mein Großvater hat erzählt vom Quariye dem ursprünglichen Ort“. Zum einen deutete Yousef hier die familiale Vertreibungsgeschichte und die Idee der Rückkehr als Motivation an, sich in die Straßenschlachten zu involvieren. Auf die damit verbundenen familialen Tradierungsprozesse sind wir schon zu sprechen gekommen. Zum anderen schloss Yousef in der zitierten Passage explizit die Inhaftierungserfahrungen seines Vaters als Anstoß für das, Wachsen des Kämpfers' in ihm mit ein. Yousef gab an, er habe 
schon als Kind gewusst, dass der Vater „früher dabei gewesen“ und auch inhaftiert gewesen sei. Auf meine Frage nach einem Gespräch oder einer Situation, in der Hafez mit ihm darüber gesprochen habe, dass er im Gefängnis gewesen war, fiel Yousef trotz längeren Überlegens kein Gespräch ein. Auch kannte Yousef die Anzahl der Inhaftierungen und die Inhaftierungsdauer des Vaters nicht. Er sei noch nicht geboren gewesen, als der Vater im Gefängnis gewesen sei. Er sagte, mit ihm gesprochen habe er ,nicht direkt aber hat Freunde und manchmal komme ich mit und dann fangen sie an sich zu erinnern sie sich an lustige Sachen aber nicht so ausführlich“. Diese Passage deutet darauf hin, dass Yousef die Erlebnisse und die Zeit des Vaters in der Mobilisierung der 1970er und 1980er Jahre und im Gefängnis nicht vorwiegend durch einen Austausch mit ihm direkt, sondern über Gespräche gegenwärtig wurden, die Hafez mit seinen Freunden und Bekannten führte, mit denen er dieses Erleben der Ersten Intifada teilte. Diese von Yousef hier angedeuteten Interaktionen ähneln der in Abschnitt 6.2.7 diskutierten Interaktion zwischen meinem Bekannten Murad und Faiez, einem Freund Hafez', strukturell sehr, in der im Beisein von Samad und Yousef in nostalgischen Anspielungen auf die Demonstrationen und Straßenkämpfe sowie gemeinsame Inhaftierungserfahrungen eingegangen wurde. ${ }^{124}$ Diese Passage gibt somit einen Eindruck davon, wie Hafez und seine Freunde Yousef als Personen gegenübertraten, die, paraphrasiert, bei der Ersten Intifada ,damals dabei waren' und sich, von damals kennen. Yousefs Ausführungen lassen sich als Hinweis darauf deuten, dass sich zwischen Hafez und dessen Freunden eine „konjunktive Verständigung“" abspielte, die Ralf Bohnsack als ,unmittelbares Verstehen der anderen im Medium von Gemeinsamkeiten der Handlungspraxis und des sozialisationsgeschichtlichen Erlebens" (1998: 113) definiert. In enger Anlehnung an Karl Mannheims Arbeiten (1980) diskutiert Bohnsack diese spezifische Form der Verständigung, die gerade zwischen Mitgliedern einer historischen Generation möglich sei (vgl. Kap. 2.2; 9.2.1). Diese biographische Gemeinsamkeit von Hafez und seinen Freunden gründet im Erleben und in der Teilhabe an der politischen Mobilisierung der palästinensischen Bevölkerung in den 1970er und 1980er Jahren vor und während der Ersten Intifada.

Inwiefern Hafez einer historischen Generation Intifada angehört und in der familialen intergenerationalen Interaktion Yousef auch in dieser Zugehörigkeit gegenübertritt, macht der folgende familiale Dialog sehr deutlich. Fadja und insbesondere Hafez thematisierten Yousefs Involvierung in die Straßenkämpfe und die

\footnotetext{
${ }^{124}$ Diese Darstellung Yousefs ähnelt in frappierender Weise einem von meinen Kolleg*innen und mir im Rahmen einer anderen Arbeit diskutierten Fall: Raja, eine junge Frau in Yousefs Alter und aus derselben Flüchtlingslager-Gegend. Auf die Frage, ob ihr Vater mit ihr über seine Inhaftierungen in den 1980er Jahren gesprochen habe, antwortete sie: „yeah I mean he tells if $\mathrm{mm}=$ people talk about their stories in prison, shared and you know where he met his friends and talk about and laughing you know it's kind of like, it's sad but it's it makes you laugh sometimes just laugh about the old days".
} 
Freundesclique generell. Zwar verschwieg Yousef seine Involvierung gegenüber seinen Eltern, diese ahnten jedoch, dass er sich an den Straßenkämpfen beteiligte - etwa weil sie wussten, dass die israelische Armee im Lager gewesen und Yousef zur selben Zeit nicht zu Hause gewesen war. Im Interview ging Hafez auf ein Gespräch mit Yousef und auf die Worte ihm gegenüber ein, die ich hier in einer längeren Passage zitieren möchte:

Hafez: „mein Sohn diese Sachen und so was ich selbst habe eine Erfahrung gehabt und die Erfahrung unsere Erfahrung ist anders als eure Erfahrung [ittajriba tajribtna rer tajribtkum] und die Erfahrung mit der Intifada und die Erfahrung mit solchen Sachen die ist nicht erfolglos die Erfahrung in sieben acht und achtzig die allererste Erfahrung aber heutzutage entwickelte sich die Besatzung [...] du die bekämpfen wie manche Leute du kannst ehhe was das Thema angeht und solche Sachen aber du kannst nicht sagen bei Gott ich gehe Steine werfen und dafür kriegst du sechs sieben Monate Haft und du musst im Gefängnis dafür sitzen das ist doch zu schade was nutzt dir das und solche Sachen“.

Hafez berichtete, Yousef hätte ihm geantwortet: „,ich mach nichts ich mache nichts“, „aber er macht doch“. In dieser längeren Passage sind verschiedene Aspekte aufschlussreich. Im Zitat vergleicht Hafez die Straßenschlachten und Aktionen (Steinewerfen; ,,solche Sachen“) während der Ersten Intifada mit der Involvierung im gegenwärtigen gesellschaftlichen Kontext („heutzutage“). Mit der Markierung der Ersten Intifada als ,seine“ (,,ich selbst habe eine Erfahrung gehabt") als auch „unsere“ Erfahrung bringt Hafez seine Zugehörigkeit zur Generation Intifada zum Ausdruck. Die doppelte Verneinung in Hafez' Formulierung, die Erste Intifada sei ,nicht erfolglos gewesen', kann als eine Kompromissbildung gelesen werden. Einerseits sieht Hafez die Erste Intifada als (partiellen) Erfolg und stimmt damit mit dem gesellschaftlich geläufigen Bild der Ersten Intifada überein, die, obwohl sie in den Oslo-Prozess mündete, als herausragende Phase nationaler Solidarität und palästinensischer Selbstermächtigung gilt. Baruch Kimmerling und Joel Migdal bemerken in diesem Zusammenhang: Die Erste Intifada „still stands as the preeminent event in the Palestinians' recent history, galvanizing a sense of community and nationhood“" (2003: 303). Andererseits war es Hafez' Intention, die Intifada in ihrer orientierenden Wirkung auf Yousef zu begrenzen. Dadurch, dass Hafez gegenüber Yousef darauf insistierte, dass die Erste Intifada in ihrer Form nicht wiederholbar sei, wird klar, dass Hafez Yousefs Handeln als Orientierung an der Ersten Intifada versteht. Er sprach dabei nicht nur zu Yousef, sondern sprach von ,eurer Erfahrung' mit ,solchen Sachen', womit Hafez Yousef entlang einer nahegelegten sozial geteilten Erfahrung von Widerstandshandeln im gegenwärtigen gesellschaftlichen Kontext quasi in eine historische Generation ,einsortierte'. Hafez war der Auffassung, ,sie ${ }^{6}$ orientierten sich an ,ihren' Handlungen - mit anderen Worten an seinen vergangenen Handlungen als Mitglied der Generation Intifada. Der familiale Dialog wird und wurde so auch zu einer Inter- 
aktion zwischen zwei historischen Generationen. Gegen die Intention Hafez' bekommt der familiale Dialog auch ein bierarchisierendes Moment: Auf eine bistorische Generation Intifada, die gekämpft habe und ,nicht erfolglos' gewesen sei, folgt eine nachgelagerte Generation, die es der Vorgängergeneration nicht gleichtun könne und erst noch einen Weg finden müsse, erfolgreich zu kämpfen. Der familiale intergenerationale Dialog konstruiert damit auch eine, von der Generation Intifada aus negativ bestimmte, noch nicht ausgezeichnete nachfolgende historische Generation. Die implizite, nicht-intendierte Hierarchisierung der Generationen bildet einen Hintergrund für das in Kapitel 6.2 herausgearbeitete Deutungsmuster der marginalisierten Kämpfer, das von Yousef und seinen Freunden bedient wird. Sie kommt unter anderem darin zum Ausdruck, dass die jungen Männer von in der Vergangenheit besseren Zeiten für ,Kämpfe“ und von einem früher höheren Ansehen von Gefangenen und Märtyrern ausgehen. Die Hierarchisierung der Generationen ist so eine der Quellen, aus denen sich die erlebte Verringerung der Sinnchancen der jungen Männer speist (vgl. Kap. 9.2.1).

Diese Art der Interaktion zwischen historischen Generationen zeigt sich mit besonderer Wirkmächtigkeit im familialen Dialog, ist jedoch nicht auf diesen begrenzt. Sie entfaltete sich auch zwischen Nachbar*innen, Bekannten etc. Auch in Hafez' Ausführungen wird deutlich, inwiefern sich diese Interaktion nicht nur zwischen ihm und seinem Sohn, sondern zwischen Hafez' und Yousefs Generation abspielten:

Hafez: „ich arbeitete in einer Assoziation namens Kulturelle Assoziation für Jugendliche [das Nachbarschaftszentrum] wir hatten Dabke und solche Sachen wir pflegten die junge Leute zu unterrichten in solchen Themen $[\ldots]$ wenn du heutzutage Steine werfen willst könntest du einen Schuss von einem Soldaten bekommen oder halt im Gefängnis für sechs sieben Monaten landen und du hast nichts erreicht was diese Sache angeht also es ist nur Zeitverschwendung $[\ldots]$ ich erinnere mich dass Samad dabei war und andere“.

Yousef involvierte sich allerdings weiterhin in die Straßenschlachten, was er aber gegenüber Hafez, Fadja und den anderen Familienmitgliedern bestritt. Im Interview merkte Yousef dazu an, Hafez habe ihm zwar nicht geglaubt, aber ,was hat er in der Hand zu tun“. Obwohl Hafez und Fadja versuchten, Yousef von einer Involvierung in die Straßenschlachten abzubringen, und diese unter anderem als Zeitverschwendung abwerteten, zeigte sich, dass Hafez trotz der Diskussionen mit seinem Sohn dessen Involvierung in die Straßenschlachten durchaus ambivalent gegenüberstand und diese auch vor dem Hintergrund seiner eigenen Beteiligung in der Ersten Intifada interpretierte, bei welchen „man hat auch das Gefühl [hatte] dass man was machen muss aber man möchte was machen das eine Reaktion hat [...] eine Reaktion man will Widerstand leisten". Hafez führte aus, trotz seiner Diskussionen mit den „šabāb“ gebe es eigentlich auch „keinen anderen Weg außer 
dass sie eine Reaktion zeigen diese jungen Leute es gibt keinen Weg außer dass sie selbst dorthin gehen und was unternehmen".

Einen weiteren Aspekt des familialen Dialoges, der sich auf Basis der gegebenen Daten nicht umfassend belegen lässt, auf den es jedoch Hinweise gibt, möchte ich kurz diskutieren. Die Form, in welcher die Generation Intifada die politische Mobilisierung und die Kämpfe der 1970er und 1980er Jahre thematisiert - in knappen Anspielungen und nostalgisch-humorigen Anekdoten - stellt zwar, wie diskutiert, Gemeinsamkeit und Zugehörigkeit zwischen ihnen her. Sie stellt jedoch auch eine Form dar, die es ermöglicht, leidvolle und erniedrigende Erfahrungen im Zusammenhang mit den Kämpfen auszulassen. Eine solche Dethematisierung kann auch auf den familialen Dialog um die ,Widerstandsgeschichten' einwirken. Yousef hatte, darauf habe ich bereits hingewiesen, im Interview mit uns angegeben, er habe schon als Kind gewusst, dass der Vater ,damals dabei gewesen' und inhaftiert gewesen sei. Ihm war im Interview allerdings trotz mehrmaligen Nachfragens keine konkrete Situation eingefallen, in welcher der Vater mit ihm über dessen Inhaftierung gesprochen hätte, und hatte daraufhin die Anspielungen unter den Freunden des Vaters erwähnt. Er fügte aber hinzu:

Yousef: „aber natürlich war das Gefängnis in meines Vaters Generation war ganz anders als jetzt wie sie Leute verhafteten war anders Gefängnis war anders alles war anders es war schwierig damals es war sehr schwierig“.

Wie kommt er zu dieser Einschätzung? Zwar mag in dieser Formulierung ein allgemeiner Verweis auf die ,Standhaftigkeit' und die ,Leistungen“ der Generation Intifada zum Ausdruck kommen. Jedoch schwingt mit der Formulierung, wie sie Leute verhaftet haben' möglicherweise ein konkreter Bezug auf tradierte Erfahrungen mit. Möglich ist, dass Yousef Berichte des Vaters erinnert, zum Beispiel die Darstellung eines in der israelischen Haft leidenden und gedemütigten Vaters $^{125}$ - eine Erinnerung, die für Yousef in der Situation des Interviews zu bedrohlich und unangenehm ist und daher tabuiert wird. Möglich ist jedoch auch, dass hier nichtversprachlichte Fantasien Yousefs, die wiederum auf einer latenten Tradierung von belastenden und demütigenden Erfahrungen des Vaters basieren können, eine Rolle spielen. Jedenfalls ist die Wirksamkeit dieser möglichen leidvollen, erniedrigenden, aber dethematisierten Erfahrungen im familialen Dialog nicht zu unterschätzen. Sie erhöhen sozusagen die gebrachten Opfer und die ,Leistungen' Hafez' ,im Kampf' und können so zu Yousefs Loyalitätsbindung an den Vater und zu seiner eigenen biographischen Verpflichtung auf einen ,Kampfauftrag beitragen (vgl. Kap. 9.2.1).

125 Für Berichte über Prügel als Teil des Alltags in israelischen Gefängnissen in den 1980er Jahren vgl. Nashif 2008: 50, 80. 


\section{Zwischenfarit: Familiale Dynamik um Yousefs Involvierung in die Straßenkämpfe}

Insgesamt wurde deutlich, wie Hafez sowohl im familialen Dialog als auch über den familialen Kontext hinaus Yousef und seinen Freunden als Mitglied der Generation Intifada gegenübertritt beziehungsweise trat. Obwohl Hafez in nicht unerheblichem Maße während der 1970er und 1980er Jahre in eine Rolle als primärer Versorger der Kernfamilie eingebunden war, hatte er sich an der politischen Mobilisierung der palästinensischen Bevölkerung in dieser Phase beteiligt und wurde in dieser kollektivgeschichtlichen Phase politisch sozialisiert. Ihm gelang über lange Strecken seiner Biographie bis zur Zweiten Intifada sozusagen eine Balancierung von Kampf- und Versorgerrolle. Hafez teilte mit den Generationsmitgliedern der Ersten Intifada ein generationales Wir-Gefühl (,unsere Erfahrung?) und das Gruppencharisma derjenigen, die in den 1980er Jahren gekämpft hatten und ,nicht erfolglos' waren. Hafez verfügte und verfügt über einen biographischen Bestand an ,Widerstandsgeschichten ' und einen Bekannten- und Freundeskreis, mit dem er die Erfahrungen der 1980er Jahre teilt. Teil des Erfahrungsbestandes der Generation Intifada sind aber auch, dazu gibt es allerdings nur Hinweise in Hafez' Biographie, mit den Kämpfen verbundene erniedrigende und belastende Erfahrungen an den Checkpoints, im Gefängnis etc. Dieser Erfahrungshintergrund drückte sich auch im familialen Dialog aus, in welchem Yousef interaktiv zum Mitglied einer Nachfolge-Generation wurde, die einer Generation nachgelagert ist, die - allerdings unter anderen kollektivgeschichtlichen Bedingungen - kämpfte, erfolgreich war und litt. Es ist gerade der aus dieser Konstellation entstehende Druck auf Yousef, gegen den Hafez in der Interaktion mit ihm anargumentierte („eure Erfahrung ist anders als unsere“; ,ihr könnt nicht ..."). So verweist der intergenerationale Dialog gleichzeitig auf die nicht intendierte, aber interaktiv dennoch entstehende Hierarchie zwischen der Generation Intifada und der nachgelagerten Generation Oslo.

Aus Angst um sein Wohlergehen und aus Sorge um die Lebenschancen (Bildungs-, Berufs- und Heiratschancen) seines Sohnes versuchte Hafez Yousef zur ,Mäßigung` zu bewegen. Dennoch involvierte sich Yousef immer stärker in die Straßenschlachten und nahm im Rahmen der Freundesclique, Widerstandsthematiken' als priorisierte Bedeutungs- und Handlungsschemata an. Diese gegenläufigen Dynamiken spitzten sich in den folgenden Jahren (2008-2011) zu und belasteten zunehmend die Familie.

\section{Sich zuspitzende Militanz Yousefs}

Die Zuspitzung ergab sich auch, weil 2009, Yousef war 16 Jahre alt, ein Bekannter Yousefs bei einer der Straßenschlachten mit der israelischen Armee von einem israelischen Soldaten erschossen wurde. Im Zuge der Zerstörung eines Hauses eines bereits verhafteten Mitglieds des Islamischen Jihad in der Nachbarschaft durch israelische Militäreinheiten hatte eine Gruppe junger Männer aus dem Ort, darunter Yousef, Samad und andere, die Einheiten mit Steinen und Molotow- 
Cocktails beworfen und so in Scharmützel verwickelt. Im Laufe der Auseinandersetzungen feuerten die israelischen Soldaten einzelne Schüsse auf die jungen Männer ab. Basel, ein Freund Yousefs, wurde im Bauchbereich getroffen und erlitt eine schwere Verletzung, an welcher er einige Stunden später im Krankenhaus verstarb:

Yousef: ,wir haben versucht ihn zum Krankenhaus zu bringen und auf dem Weg er konnte nicht so richtig atmen er hat sehr stark geamtet und das Krankenhaus war weit ungefähr einen halben Kilometer und als wir ankamen hat er fast seinen letzten Atemzug genommen vor dem Krankenhaus, sie haben versucht ihn zu retten mit einer Operation aber sie konnten nicht (2) $=\mathrm{er}$ war schon näher daran ein Märtyrer zu sein als am Leben zu sein (3) also, danach in derselben Nacht war eine Demonstration im Lager das ganze Lager war war trauerte, und am zweiten Tag haben wir es war seine Beerdigung und es hat geschneit ein bisschen an dem Tag wir haben ihn beerdigt auf dem Friedhof für Märtyrer“".

Yousef sprach im Interview über die Verwundung Basels in den Straßenschlachten - er hatte den verletzten Basel mit einigen anderen jungen Männern getragen und die Beerdigung Basels. Die Evaluation oder Einordnung des Ereignisses in den eigenen Emotionshaushalt fiel dabei sehr knapp aus, was auf ein sehr hohes Belastungserleben hinweisen kann. Die jungen Männer trafen sich in den Wochen nach der Beerdigung regelmäßig am Grab Basels und sprachen über ihn und die Geschehnisse. Sie hätten auf diese Weise, so Yousef, ,angefangen zu fühlen dass wir Basel verloren haben yani also Palästina hat einen Märtyrer bekommen aber wir haben einen einen Freund von uns verloren." Yousef, wie auch andere Freunde, deuteten für die Zeit nach Basels Tod Rachegefühle und eine intensivierte Beteiligung an den Konfrontationen und Demonstrationen an:

Yousef: „Die Demonstrationen die dann waren (3) Ich werde nicht sagen dass wir zu den Demonstrationen gegangen sind um Rache zu üben für Basel weil das hat man uns vorgeworfen damit du's weißt aber (3) wir sind gegangen weil wir Basel niemals vergessen werden und, sein Blut wird nicht umsonst vergossen worden sein".

Yousef fuhr fort, er könne für das Rachemotiv von den israelischen Behörden verurteilt werden und das wäre daher alles, was er dazu sagen könne (wobei unklar bleibt, auf wen Yousef den, Vorwurf' bezieht). Im Interview rahmte Yousef seine Erzählungen vom Tod Basels außerdem mit dem „Märtyrertum Al Hakims“, also mit dem 2008 kurz zuvor gestorbenen George Habash als der zentralen Führungsfigur der PFLP, und wertete den Tod Basels dadurch auf. Im weiteren Gesprächsverlauf hob Yousef wiederholt Basels ,Widerstandsbilanz' hervor. Er sprach - in Rekurs auf die Ernsten Spiele - in heroisierender Weise von Basels hoher Toleranz gegenüber israelischem Tränengas (vgl. Kap. 6.2.3). Yousef sprach 
außerdem davon, wie er durch die Straßenschlachten nach dem Tod Basels auch seine Wut etwas habe verringern können:

Yousef: „Wenn du die israelischen Jeeps oder Panzer siehst an dir vorbeikommen und du kannst deine Gefühle nicht ausdrücken also die Steine sind ein Weg dich auszudrücken [...] du drückst die Wut die du in dir hast wird ein Stückchen weniger wenn du dies rauslässt".

Das von Yousef empfundene Leid über den Tod Basels und die Wut und Vergeltungswünsche, die er im Zusammenhang mit dessen Tötung äußerte, trugen bei Yousef und anderen Freunden, die Basel nahegestanden hatten, dazu bei, dass die Involvierung in die Straßenschlachten biographisch noch an Relevanz gewann und die in der Clique kursierenden Deutungsmuster und Wir-Bilder als ,Kämpfer in ihrer Bedeutung für Yousef bestärkt wurden. Diese Dynamik zeigte sich generell bei den Freunden in der Clique: Die Deutung, einen ,Kampfauftrag für die palästinensische Sache ${ }^{6} \mathrm{zu}$ haben, vertiefte und verstetigte sich für die Mitglieder der Clique vor dem Hintergrund der mit steigendem ,Cliquenalter ${ }^{6}$ zunehmenden Leidenserfahrungen durch die Verhaftung, Verletzung oder gar Tötung von Freunden und Bekannten und den damit verbundenen Rachegefühlen und Vergeltungswünschen.

Diese wachsende biographische Verstrickung Yousefs in die Cliquendynamik wirkte sich zunehmend auf seine anderen Lebensbereiche aus: Yousef hatte nach dem 9. Schuljahr mit 15 Jahren auf eine weiterführende Schule gewechselt. Der nach zwölf Schuljahren vorgesehene allgemeine Schulabschluss, das sogenannte Tawjihi, berechtigt bei entsprechenden Abschlussnoten zur Aufnahme eines Hochschulstudiums. Yousef wählte in der nun im Schulsystem anstehenden Spezialisierung den naturwissenschaftlich orientierten Zweig, der generell als anspruchsvoller gilt, jedoch eine prestigeträchtige Studien- und Berufswahl (etwa ein Medizin- oder Ingenieursstudium) ermöglichen kann - sehr gute Abschlussnoten vorausgesetzt. Yousefs älterer Bruder Said absolvierte im selben Jahr sein Tawjihi mit eher bescheidenen Ergebnissen. In der Folge waren die Optionen für Said, im Westjordanland an einer der palästinensischen Hochschulen, etwa in Nablus oder Bir Zeit, zu studieren, sehr begrenzt. Said begann daher ein Studium der Rechtswissenschaften in Ägypten. Die dafür nötigen finanziellen Aufwendungen wurden zum Teil von der Familie und zum Teil durch ein Stipendium getragen, das Hafez vermutlich über seine Parteikontakte organisiert hatte. Auch vor dem Hintergrund der bescheidenen Tawjihi-Noten des erstgeborenen Sohnes konzentrierten sich die Bildungserwartungen nun stärker auf Yousef. Hafez sagte, er hätte sich gewünscht, dass „Yousef Arzt oder Ingenieur“ würde und dass er „ein Tawjihi macht bei dem er sich das Studium aussuchen“ könne. Diese Erwartungen wurden jedoch enttäuscht. Yousef sprach im Interview kaum über sein Erleben des Schulwechsels und betonte, in den letzten zwei Schuljahren hätten sie „nur noch Steine geworfen“. Während Yousef darüber sprach, dass er aufgrund der nächtli- 
chen Aktionen gelegentlich gar nicht zur Schule gegangen sei, erwähnte Hafez uns gegenüber, dass Yousef in der Schule unkonzentriert gewesen und Hafez häufig von Lehrern angerufen worden sei mit der Begründung, Yousef habe sich in der Schule „respektlos" ihnen gegenüber verhalten. Vor diesem Hintergrund kann man Yousefs Entscheidung für den naturwissenschaftlichen Zweig als erheblich durch die familialen Erwartungen bedingt annehmen. Sein eigener Fokus lag zu diesem Zeitpunkt auf dem ,Einsatz für die palästinensische Sache“ im Rahmen der Clique. Zusätzlich war Yousefs fortgesetzte Involvierung in ,Widerstandsaktionen“ jetzt auch mit der Bearbeitung des Todes Basels verbunden.

\section{Drobende Verbaftung und, Unterbringung' im PA-Gefängnis}

Ab Anfang des Jahres 2011, Yousef war mit 18 Jahren nun in seinem letzten Schuljahr, entwickelte sich eine von Yousef als stark fremdbestimmt erlebte Dynamik, die durch die zunehmend drohende Verhaftung durch die israelischen Sicherheitsbehörden bestimmt war: Aus dem Gefängnis hatte Yousef einen Anruf von einem Jugendlichen, der aus einer Familie aus der Nachbarschaft stammte, erhalten mit der Information, dass die Israelis in dessen Verhör explizit nach Yousef gefragt hätten. Ich habe an anderer Stelle schon darauf hingewiesen, dass diese Art Anrufe aus dem Gefängnis mit geschmuggelten Mobiltelefonen erfolgten und personenbezogene Nachfragen in Verhörsituationen in der Regel als Indiz für eine bevorstehende Verhaftung galten und gelten. Im dem Zeitraum nach dem Anruf inhaftierte das israelische Militär außerdem mehrere Freunde aus der Clique, darunter Yousefs engeren Freund Samad. Einige Tage später versuchten israelische Soldaten dann tatsächlich Yousef zu verhaften und durchsuchten dafür das Haus der Familie. Die israelischen Einheiten fanden Yousef jedoch nicht vor, da er anlässlich Samads Verhaftung die darauffolgenden Nächte vorsorglich auBerhalb des Hauses bei Bekannten verbracht hatte. Die Soldaten übergaben Hafez bei der Hausdurchsuchung eine Vorladung für Yousef, die diesen aufforderte, für eine Befragung bei der Besatzungsverwaltung vorstellig zu werden. In der Familie und in der Clique wurde in den nächsten Tagen diskutiert, ob Yousef der Vorladung, aus welcher nicht ersichtlich war, ob sie eine längere Inhaftierung zur Folge haben würde, nachkommen sollte. Auf Betreiben Hafez' kam es zu einer anderen ,Lösung‘: Um einer drohenden Verhaftung durch das israelische Militär zu entgehen, wurde Yousef für einige Monate in einem Gefängnis der palästinensischen Autonomiebehörde ,untergebracht', um sich dort auf sein einige Monate später zu absolvierendes Tawjihi vorzubereiten. Diese Strategie, ,gesuchte“ Personen durch PA-Inhaftierung dem israelischen Militärzugriff zumindest temporär zu entziehen, ist selten, aber im Westjordanland nicht beispiellos und etwa während der Zweiten Intifada häufiger vorgekommen. Auch von der in Kapitel 7 diskutierten Clique entzogen sich einige junge Männer durch eine Inhaftierung bei der PA der israelischen Verfolgung. Dort wird die Verfolgung aber von einem Gerichtsprozess der palästinensischen Behörden begleitet, der auf eine Löschung des Gesucht-Status 
hinwirken soll - was auf ein deutlich höheres Maß an klientelistischen Chancen verweist. Hafez sprach im Interview über das seinen Sohn betreffende Arrangement wie folgt:

Hafez: „Wenn Yousef ins Gefängnis geht macht er kein Tawjihi das also dasselbe ist meinem Neffen passiert mein Neffe auch genau wie Yousef wenn du in der Zeit ins Gefängnis gehst dann machst du nie Tawjihi du kannst heutzutage kein Tawjihi machen im Gefängnis und die Situation ist miserabel und du sagt morgen mache ich es danach mache ich es (2) Ich habe vorgeschlagen ich habe einen Freund (2) der in der PA arbeitet ich hab ihm gesagt mein Sohn ist das und das habe ihm die Situation erklärt könnt ihr ihn nehmen, für drei oder vier Monate damit er sein Tawjihi machen kann zum Offizier und der Mann hat uns nicht enttäuscht er sagte bring ihn uns, wir können ihn nehmen, kein Problem in der Situation ok in der Situation wie kann Yousef ins Gefängnis der PA gehen er war absolut dagegen aber wir haben ihn überzeugt".

Hafez fügte noch hinzu, dass er die Leute „von 1987“, also aus der Ersten Intifada, gekannt habe. In der zitierten Passage hatte Hafez darauf hingewiesen, dass Yousef den Vorschlag zunächst ablehnte. Letztendlich ließ er sich dann doch auf diese Kooperation mit der PA ein, obwohl er diese politisch ablehnte (ich habe diese Überzeugung als Komponente des in Kapitel 6.2 herausgearbeiteten Deutungsmusters in Yousefs Clique diskutiert):

Yousef: „wir sprachen so lange bis ich abends zu einer endgültigen Entscheidung kam ehhe dass ich zu den Behörden gehe und dort eine Weile sitze und danach können wir eine Lösung für unsere Sache bei den Behörden über die Sicherheitskooperation suchen, obwohl ich persönlich als Yousef Sasour ehhe ehhe die Behörden ablehne“.

Yousef wurde zunächst in Räumen für die Vollzugsbeamten eines Gefängnisses der PA untergebracht. Hafez, Fadja und seine Geschwister kamen zu regelmäßigen Besuchen und statteten ihn mit Lernmaterialien für das Tawjihi aus. Fadja sprach im Zusammenhang mit der Unterbringung Yousefs bei der PA davon, dass es Hafez damit gelungen sei, „Yousef zu schützen“. Allerdings setzte das israelische Militär die Familie während der Abwesenheit Yousefs massiv unter Druck. Die Soldaten durchsuchten wiederholt das Haus nach Yousef und zerstörten Teile der Einrichtung. Außerdem gab Fadja an, dass Hafez von den Soldaten bei einer Durchsuchung geschlagen und für ein paar Tage inhaftiert worden sei. Über diese Phase wiederholter Durchsuchungen, die sich über einen Zeitraum von ungefähr vier Wochen erstreckten, sagte Fadja, dass die Familie aufgrund der nächtlichen Armeeoperationen ,nun tagsüber schlief und nachts wach war“.

Yousef kam gut mit den Beamten der PA zurecht, stand jedoch zu sehr unter dem Eindruck der dramatischen Ereignisse um die Verhaftungen seiner Freunde, um sich konzentriert auf die Tawjihi-Prüfungen vorbereiten zu können: 
Yousef: „,ich hatte die Schule überhaupt nicht im Kopf also ich hatte sogar nicht im Sinn gehabt lernen zu wollen eine Sache ich habe nur daran gedacht ehhe was wird passieren und wie wird es passieren wie geht es Samad und wie geht es Ismail wie geht es Khaled wie geht es allen“.

Nach drei Monaten im Gefängnis der PA absolvierte Yousef die Abschlussprüfungen und bestand diese sehr knapp. Hafez war trotz der widrigen Umstände, unter denen Yousef sich auf das Tawjihi vorbereitet hatte, enttäuscht: „Mit seinem Notenschnitt kommt er in keine Universität".

Yousef verließ in der Folge das Gefängnis und lebte wieder im Haus seiner Familie. Für Yousef wie für die Familie war nun intransparent, ob er weiterhin vom israelischen Militär „gesucht" wurde und inwiefern mit weiteren Versuchen, Yousef zu verhaften, zu rechnen sei. Da Yousef angemerkt hatte, er habe nach seiner Rückkehr nach Hause in Straßenkleidung geschlafen - eine übliche Vorbereitung, um im Falle einer Verhaftung nicht in Unterwäsche abgeführt zu werden -, ist anzunehmen, dass Yousef weiterhin mit seiner nächtlichen Verhaftung rechnete. Hafez versuchte in der Folge, eine Ausreise Yousefs aus dem Westjordanland zu organisieren: Er nutzte die Kontakte des Zentrums und seine Parteikontakte, um für Yousef ein Visum und einen Studienplatz in Russland zu erwirken. Bei dem Versuch, für eine Weiterreise nach Russland über den von den israelischen Behörden gesicherten Grenzübergang an der Allenby-Brücke nach Jordanien auszureisen, wurde Yousef jedoch im September 2011 durch das israelische Militär verhaftet:

Yousef: „Wir sind am Checkpoint der PA vorbei und sind zur Grenze zum israelischen Teil der Grenze und ich habe ihnen meinen Pass gegeben bevor mein Vater ihn gab und als der Sicherheitsmann meinen Namen im Computer checkte hab ich auf den Bildschirm geschaut und eine Lämpchen hat aufgeleuchtet er hat mich so von der Seite angeschaut und hat mich nach meinem vollen Namen gefragt er meinte er hat irgendwie ein X auf meinen Pass gemacht und meinte ich solle sitzen bleiben er hat ein $\mathrm{X}$ drauf gemacht und meinte ich soll sitzen da meinte ich zu meinem Vater das war's der Trip ist hier zu Ende (3) ich habe ein paar Leute vom Shabak gesehen mit drei Agenten er hat ein Dokument dabei gehabt er fragte Yousef ich sagte ja und er meinte ich solle meinen vollen Namen sagen und ich musste ihnen folgen“.

Hafez, der Yousef zum Grenzübergang gebracht hatte, war in der Folge sehr ,mitgenommen'. Hafez sprach im Interview kaum über die Verhaftung Yousefs: „Wir sind zur Brücke und sie haben ihn verhaftet er wollte ausreisen, auf der Brücke, das war's“. Fadja sprach im Interview ausführlicher über die Phase nach Yousefs Rückkehr aus der ,Unterbringung' bei der PA und die letztliche Verhaftung durch die israelischen Behörden. Laut ihren Ausführungen habe Hafez seinen Sohn nach der Rückkehr aus dem PA-Gefängnis nicht einfach den Israelis überlassen können. Er habe versucht, seine Ausreise zu organisieren. Für Hafez sei es „eine Ka- 
tastrophe“ gewesen, als sie Yousef verhafteten. Er habe unter „Schock“ gestanden und sei gar nicht in der Lage gewesen, selbst mit dem Auto von der Grenze zurückfahren. Sein Bruder Khaled habe ihn abgeholt.

Nach den in den vergangenen Jahren geführten Diskussionen mit Yousef um seine Involvierung in die Straßenschlachten und den in den letzten Monaten unternommenen Anstrengungen, Yousef einer Verhaftung zu entziehen, die auch mit physischer Gewalt und Drohungen durch die israelischen Soldaten während wiederholter Hausdurchsuchungen verbunden gewesen waren, wurde Yousef Hafez quasi ,aus der Hand' verhaftet, nachdem dieser intensiv auf eine Ausreise durch Beschaffung eines Visums und ,Überzeugungsarbeit‘ bei Yousef - hingewirkt hatte. In dieser Verhaftung kulminierten die Ereignisse und verdichteten sich auch zu einem großen persönlichen Schlag für Hafez, der vermutlich mit dem Erleben, seinen Sohn nicht geschützt haben zu können, und einem Gefühl von Ohnmacht oder Hilflosigkeit verbunden war:

Hafez: „Ich wusste sie würden ihn verhaften ich wusste dass sie ihn verhaften würden ich bin einfach hin und vielleicht kommt er raus aus dem Land fürs Studieren aber die Besatzung (2) wenn die Besatzung jemanden bestrafen will dann bestraft sie die auch“.

\section{Haft und Phase nach der Entlassung}

Yousef war nach seiner Verhaftung für etwa eine Woche in der sogenannten Verhörphase, ${ }^{126}$ in welcher er gemäß den üblichen Vorgehensweisen der israelischen Sicherheitsbehörden zunächst in Isolationshaft war und in welcher er täglich vom israelischen Sicherheitspersonal befragt wurde. Dabei wurde er mit Bildern konfrontiert, auf denen er beim Werfen von Molotow-Cocktails zu sehen war. Yousef gab im Interview an, er habe sich nicht auf eine Preisgabe von Namen oder insgesamt auf eine Kooperation eingelassen. Nach der Verhörphase wurde er in ein reguläres israelisches Gefängnis für politische Gefangene im Großraum Jerusalem verlegt. Der Gefängnisalltag war von dem Zusammenleben auf engstem Raum mit zehn anderen Gefangenen in der Zelle sowie von der nach Parteizugehörigkeit im Rahmen der Gefangenenhierarchie organisierten Tagesroutine bestimmt. Diese umfasste neben den verschiedenen häuslichen Arbeiten (Putzen, Kochen für die anderen Gefangenen) auch politische Schulungen im Rahmen von Lesekreisen (vgl. Rosenfeld 2004: 253). In diesem Gefängnis traf Yousef außerdem mehrere Bekannte aus Jaddaliya wieder. Bereits wenige Tage nach seiner Verlegung beteiligte sich Yousef an einem von PFLP-Mitgliedern im Gilboa-Gefängnis im September 2011 initiierten Hungerstreik, der unter anderem ein Ende der Isolations-

\footnotetext{
${ }^{126}$ Ziel war es, Yousef zum Geständnis der eigenen Beteiligung und zur Belastung anderer zu bewegen. Das übliche Prozedere, welches bis zu mehreren Monaten dauern kann, umfasst Isolationshaft, Schlafentzug, Verweigerung der Nutzung sanitärer Anlagen und manchmal körperliche Misshandlungen.
} 
haft für Ahmad Saad, den inhaftierten Anführer der Partei, und andere Gefangene forderte und der nach und nach Insassen verschiedener Gefängnisse mobilisierte. Yousef zufolge wollten die anderen Gefangenen ihn aufgrund seines Alters zunächst nicht teilnehmen lassen, er habe sie jedoch überreden können. In dem Gefängnis, in dem Yousef inhaftiert war, war seinen Angaben nach die Zahl der Gefangenen, die am Streik teilnahmen, gering. In Yousefs Trakt nahmen von circa 100 Personen nur drei oder vier Personen teil. Die Streikenden, darunter Yousef, wurden für die Streikdauer in ein anderes Gefängnis verlegt. Nach der Verlegung traf Yousef zu seiner Überraschung Samad wieder, welchen er seit dessen Verhaftung nicht gesprochen hatte und der sich, ohne dass Yousef davon Kenntnis gehabt hätte, ebenfalls am Streik beteiligte. Samad war zufällig in einer der Zellen neben Yousefs Zelle untergebracht worden:

Yousef: „Sie haben uns neue Kleidung gegeben dadurch haben wir das Salz verloren, ${ }^{127}$ das wir eingenäht hatten (4) dann haben sie uns in Zellen nebeneinander gebracht diejenigen von uns aus demselben Gefängnis waren waren in einer Zelle und die aus der anderen Gefängnis haben sie in die andere Zelle gebracht, natürlich $=$ die $=$ Zelle $=$ ist (2) zwei Meter mal zwei Meter es gab ein Fenster ein kleines Fenster wir haben versucht mit den Gefangenen in der anderen Zelle zu sprechen und da habe ich entdeckt dass Samad in der anderen Zelle war, in der Zelle neben mir und an diesem Punkt habe ich Samad wiedergetroffen wir waren sehr glücklich auch wenn die Situation in der wir waren weil es ist eine schwierige Situation in der wir waren, wir werden sterben zusammen werden wir sterben".

Zum einen zeigt die zitierte Passage erneut, wie sich die Bekanntschaften und Freundschaften Yousefs und der Freunde in der Clique generell mit ihrem ,Kampf für die palästinensische Sache ${ }^{6}$ verknüpften. Yousef machte nun, zusätzlich zur gemeinsamen Involvierung in die Straßenschlachten, nicht nur seinen Freunden ähnliche, sondern mit ihnen gemeinsam Hafterfahrungen. Zum anderen deutete Yousef in der zitierten Passage die Erwartung an, im Hungerstreik „zu sterben“. Diese beinahe beiläufig angesprochene Erwartung findet sich auch in anderen Passagen, etwa wenn Yousef den Hungerstreik mit ähnlichen Worten kommentierte: „wenn man nicht stirbt eh ich wollte als Märtyrer sterben (3)“. Möglich ist, dass Yousef im Interview Opferbereitschaft, für die palästinensische Sache“ demonstrieren möchte. Allerdings ist vor dem Hintergrund der biographischen Eskalationsdynamik die Ausbildung eines Wunsches nach Märtyrerschaft nicht unwahrscheinlich. Yousef nahm jedenfalls die Möglichkeit zu sterben in Kauf und mag diese im Vorfeld des Hungerstreiks auch als anziehend empfunden haben. Man kann die Teilnahme Yousefs am Hungerstreik als gravierende Zuspitzung

\footnotetext{
${ }_{127}$ Mit dem Einnähen in ihre Kleidung hatten Yousef und die anderen Streikenden versucht, Salz in das andere Gefängnis zu ,schmuggeln`. Die Einnahme von Salz hätte ihnen eventuell eine längere Streikdauer ermöglicht.
} 
seiner Identifikation mit dem „Kampf für die palästinensische Sache` und daran orientierter Handlungsentwürfe und Deutungsmuster interpretieren.

Der Streik dauerte circa drei Wochen. Dabei gelang es den Streikenden, vermittelt über das Rote Kreuz, die israelische Gefängnisadministration zu Lockerungen der Isolationshaft zu bewegen. Auf seine Teilnahme am Hungerstreik war Yousef stolz und er erlebte für diese auch Wertschätzung von anderen, älteren Gefangenen:

Yousef: „Wir haben Leute getroffen, die für viele Jahre im Gefängnis waren einige für zehn und 15 und elf Jahre [...] als sie uns sahen haben sie sich sehr gefreut dass wir am Streik teilgenommen haben und eh weil wir so jung waren".

Nach dem Streik und nach einer Phase der körperlichen Erholung normalisierte sich Yousefs Alltag im Gefängnis. Nach einigen Wochen erlaubte die Gefängnisadministration Besuche durch Fadja und Yousefs Geschwister. Hafez allerdings blieb als ehemaliger Inhaftierter davon ausgeschlossen.

Im Zeitraum von Yousefs Inhaftierung ereignete sich nun der eingangs erwähnte Autounfall Hafez'. Bei dem Unfall - ein anderer Wagen war in hohem Tempo seitlich in den Wagen gefahren, in dem auch Hafez gesessen hatte (er war nicht am Steuer gewesen) - hatte Hafez schwere Verletzungen erlitten und daher acht Wochen auf der Intensivstation im Krankenhaus gelegen. Zwar war, zumindest soweit ich hierzu Kenntntnis habe, Hafez' Leben nicht in Gefahr gewesen, aber es war lange unklar, welche langfristigen gesundheitlichen Folgen er davontragen würde. Die familiale Situation war in der Folge zunächst vom Bangen um Hafez' Gesundheitszustand bestimmt. Hafez konnte das Krankenhaus schließlich verlassen, war jedoch in den darauffolgenden Wochen und Monaten von wiederkehrenden starken Schmerzen geplagt. Außerdem hatte ein großer Blutverlust zu einer Minderversorgung von Teilen des Gehirns und dadurch zu einer dauerhaften Beeinträchtigung seiner Sehfähigkeit geführt. In der Folge konnte er seiner Tätigkeit in der Verwaltung des Technikhandels nicht mehr nachgehen. Hafez unterzog sich verschiedenen Rehabilitationsbehandlungen, unter anderem in Jordanien, für die die Familie finanziell aufzukommen hatte, die jedoch nicht den gewünschten Behandlungserfolg brachten. Hafez und Fadja hatten ihrem Sohn Said, der weiterhin in Ägypten studierte, nichts von den Unfallfolgen mit den anhaltenden gesundheitlichen Problemen und der Arbeitsunfähigkeit Hafez' erzählt, „,weil er in der Examensphase“ gewesen sei. Auch Yousef, der zu dieser Zeit noch im Gefängnis saß, hatten sie nicht in Kenntnis gesetzt. Yousef wurde im Frühjahr 2013, zwei Wochen bevor wir ihn bei unserem ersten Feldaufenthalt das erste Mal trafen, aus dem Gefängnis entlassen und erfuhr nun von dem Unfall.

Yousef: „Dann kam ich nach Hause ich war so glücklich zu Hause zu sein aber ich war dann schockiert zu erfahren dass der Vater ist (2) nicht wieder gesund ist und dass er schon eine ganze Weile krank ist (3) wir sind mit ihm 
zu den Behandlungen gefahren aber mir wurde nichts erzählt oder ich wusste nicht davon weil ich nicht da war ich war nicht verfügbar, und er wollte auch nichts sagen".

Aufgrund der anhaltenden gesundheitlichen Beschwerden Hafez' geriet die Familie zunehmend in finanzielle Schwierigkeiten. Fadja hatte ihre Position als Sozialarbeiterin bereits nach der Zweiten Intifada aufgegeben und war nun mit der Versorgung der Kinder und Hafez' voll ausgelastet. Hafez' Bruder Khaled unterstützte die Familie finanziell.

Außerdem begann Yousef, wie einige seiner Freunde, illegal auf einer Baustelle in einer israelischen Ortschaft südlich von Jerusalem zu arbeiten. Dafür überquerte er jede Woche in einem längeren Fußmarsch den Bereich des südlichen Hebroner Hügellandes, in welchem die Sperranlage nie fertiggestellt worden war und es daher keine physische, gesicherte Grenze zwischen Israel und dem Westjordanland gab. Aufgrund der gegenüber den 1980er Jahren heute sehr viel geringeren Differenz zwischen Lebenshaltungskosten im Westjordanland und Löhnen für illegale palästinensische Arbeiter war es Yousef nicht möglich, einen Großteil des Familieneinkommens zu erwirtschaften. Außerdem waren das wöchentliche Pendeln nach Israel und die Arbeitsbedingungen sehr anstrengend und zudem verbunden mit der ständigen Gefahr der Entdeckung durch Grenztruppen oder bei Kontrollen in Israel. Nach einigen Monaten wurde Yousef von einer Patrouille an der Grenze aufgegriffen. Nach Yousefs Angaben hatten sie ihm zu verstehen gegeben, dass er mit einer langen Inhaftierung rechnen müsse, wenn sie ihn noch einmal aufgreifen. Aufgrund dessen unterließ er es zunächst, nach Israel zu pendeln, und arbeitete vorübergehend bei deutlich schlechterer Bezahlung auf Baustellen im Westjordanland. Während einer größeren israelischen Militäroperation im Juni 2014 in der Region, bei der das Militär auch mehrere Wohnblöcke im Ort durchsuchte, wurden Yousef sowie sein jüngerer Bruder Yasser für einen Tag verhaftet.

Im Herbst 2014 hielt Yousef um die Hand einer entfernten Verwandten an. Deren Familie lehnte jedoch eine Heirat der beiden ab. In Kapitelabschnitt 6.2.4 wurde unter anderem ein Treffen mit Yousef und Samad diskutiert, welches an dem Tag, an dem Yousef von der Ablehnung des Antrags erfuhr, stattgefunden hatte. Die Frustration und Kränkung, die Yousef im Zusammenhang mit dem abgelehnten Heiratsantrag erlebt hatte, waren von ihm und den Freunden als für die Situation der Clique repräsentative Erfahrung diskutiert und im Rahmen des Deutungsmusters und des Wir-Bildes der ,marginalisierten Kämpfer' verhandelt worden (vgl. ausführlich Kap. 6.2). Bei weiteren Treffen im Frühjahr und Herbst 2015, bei denen ich Yousef sah, hatte sich seine Situation kaum verändert. 


\subsubsection{Zusammenfassung: Familiale und lebensgeschichtliche Dynamik}

Die wesentlichen familiengeschichtlichen und biographischen Dynamiken von Hafez und Yousef lassen sich wie folgt zusammenfassen. Hafez' Biographie war zumindest bis zur Zweiten Intifada von einer durchaus gelingenden Verhandlung von politischer Kampf- und familialer Versorgerrolle gekennzeichnet. Hafez und seinen Geschwistern gelang im Vergleich zur Elterngeneration eine Bearbeitung und Reduzierung der Armutsbelastungen und eine Steigerung der Lebenschancen im Sinne von Bildungs-, Berufs- und Heiratschancen. Hafez war in die politische Mobilisierung in den 1970er und 1980er Jahren vor und während der Ersten Intifada involviert und teilte und teilt die zentrale generationale Erfahrung eines breiten gesellschaftlichen, Widerstandsprojekts` gegen die israelische Besatzung. Als Mitglied der Generation Intifada teilt er, trotz der von ihm ebenfalls ausgefüllten familialen Versorgerrolle, mit den Generationsmitgliedern ein generationales WirGefühl und Gruppencharisma, welches unter anderem in der Verortung in einem generationalen Wir-Bild und in der lokalen Bekanntheit Hafez' zum Ausdruck kommt. Hafez verfügt über einen biographischen Bestand an ,Widerstandsgeschichten' und einen mit der politischen Mobilisierung in den 1970er und 1980er Jahren verbundenen Bekannten- und Freundeskreis. Teil des Erfahrungsbestandes der Generation Intifada waren und sind aber auch - dazu gibt es allerdings nur Hinweise in Hafez' Biographie - mit den Kämpfen verbundene erniedrigende und belastende Erfahrungen in den Konfrontationen mit den Soldaten und Siedler*innen, an den Checkpoints und insbesondere in den Gefängnissen. Hafez' generationale Zugehörigkeit und das mit dieser verbundene Gruppencharisma schlug sich auch in seiner Interaktion mit Yousef und Yousefs Freunden nieder. Yousef und seine Freunde wurden in der Interaktion mit Hafez, gerade gegen dessen Intention, zu einer an der als erfolgreich wahrgenommenen Generation Intifada gemessenen Generation, die jener nachfolgt und sich im Kampf erst noch beweisen muss.

Yousefs Biographie war insbesondere ab der Frühadoleszenz von einem sich intensivierenden Prozess politischer Militanz gekennzeichnet, der ab dem jungen Erwachsenenalter in eine zunehmende gesellschaftliche Marginalisierung mündete. Den Hintergrund für die Dynamik bildete zunächst schlicht die mit Yousefs Wohnort gegebene hohe Frequenz von Operationen der israelischen Sicherheitsbehörden im geographischen Umfeld. Zentral für Yousefs Politisierung und seine Involvierung in die Straßenschlachten war seine Integration in die Clique junger Männer, deren Interaktionsdynamik und Deutungsmuster in Kapitel 6.2 ausführlich erörtert wurden. Die Attraktivität der Clique für Yousef (und für die anderen Mitglieder) sowie die Aushandlungsprozesse in der Clique standen wiederum in Wechselwirkung mit dem familialen Dialog und familialen Tradierungsprozessen: Zum einen ist hier die Tradierung der, eigentlichen' familialen Herkunft durch die Großeltern an Yousef zu nennen. Noch bedeutender war und ist meiner Ansicht nach aber die familiale intergenerationale Interaktion zwischen Hafez als Mitglied 
der Generation Intifada und Yousef als Mitglied der nachfolgenden Generation, die wesentlich dazu beitrug, dass Yousef es als Auftrag erlebte und annahm, ebenfalls ,für die palästinensische Sache zu kämpfen'.

An den Fällen zeigt sich auch, wie Dynamiken in der Clique und familiale Dynamiken ineinander wirken: Familiales Interaktionsfeld und Peergroup stehen einerseits in Wechselwirkung und sind andererseits eigendynamisch. Einerseits stützen die Tradierung der Fluchtgeschichte im Herkunftsdialog und insbesondere die Dynamik aus dem intergenerationalen Verhältnis zur Generation Intifada die Attraktivität der Clique. Die Clique stellt einen Rahmen dar, in dem ein in familialen intergenerationalen Interaktionen und familialen Tradierungen gestützter Auftrag zu ,kämpfen' als Pflicht zum Straßenkampf gedeutet und in der wiederholten Kommunikation in der Clique vertieft wird. Die Interaktionsdynamik weist andererseits eine über die Umsetzung des familial gestützten Kampfauftrags hinaus gehende eigenlogische Dynamik auf. Sie setzt den Auftrag um und verbindet diesen mit ohnehin stärker an die Peergroup gebundenen adoleszenten Bildungsprozessen von Selbst- und Wir-Bildern und Männlichkeitskonstruktionen. Der Kampfauftrag vertieft und verselbstständigt sich vor dem Hintergrund von sukzessive gemachten Leidenserfahrungen und Rache- beziehungsweise Vergeltungswünschen. Im weiteren biographischen Verlauf werden in der Clique dann zunehmend innerhalb der palästinensischen Gesellschaft im Westjordanland erlebte gesellschaftliche Marginalisierungserfahrungen verhandelt und gedeutet. In diesen Aushandlungen nahmen die jungen Männer zunehmend Widerstandsbilanzierungen vor, in denen sie ihren, Einsatz für die palästinensische Sache und die erlebte gesellschaftliche Position mit den geringen Lebenschancen (im Sinne von Berufs-, Bildungs-, Heiratschancen, aber auch Ansehenschancen) gegeneinander aufrechneten. In diesem Zusammenhang werden und wurden verschiedene eigene Zugehörigkeiten - auch jene als Flüchtling - ,mitverhandelt‘.

Insgesamt wurden in den Kapitelabschnitten 6.2.1 bis 6.3.4 die peergroup- und generationsbezogenen Aushandlungsprozesse als längerfristige kollektiv-, familienund lebensgeschichtliche Dynamiken herausgearbeitet. Im Ergebniskapitel werden sie ausführlich in ihren Komponenten und stärker theoretisierend als Komponenten einer Generationenfiguration sowie im Rahmen einer Typenbildung zu den biographischen Verläufen der jungen Männer als Nachfolgegeneration Oslo diskutiert (vgl. Kap. 9). 


\subsection{Falldarstellung Muna: „This thinking has changed dramatically in the Intifada“"}

Als Abschluss des Kapitel 6 zu den Bewohner*innen der FlüchtlingslagerGegenden möchte ich in einer knappen Darstellung den globalanalytisch ausgewerteten Fall Muna (geb. 1968) vorstellen. ${ }^{128}$ Muna und ihre Familie lebten und leben nicht in Jaddaliya, sondern in einer anderen Flüchtlingslager-Gegend im Umland Bethlehems. Muna ist, wie deutlich werden wird, der Generation Intifada zuzurechnen und hat, wie Hafez und die anderen zur Sprache gekommenen Generationsmitglieder in Kapitel 6, einen Flüchtlingshintergrund. Sie hat an der breiten Mobilisierung der 1970er und 1980er Jahre partizipiert und teilt mit den anderen ein generationales Wir-Bild und Wir-Gefühl. Munas generationsbezogene Erfahrungen und ihr Wir-Bild sind allerdings mit dem Erleben von Autonomiegewinnen für Frauen in der Mobilisierung der 1970er und 1980er Jahre akzentuiert. Ihre Betonung der in der zivilgesellschaftlichen Mobilisierung erlebten Handlungsmacht kombiniert mit ihrer Emphase für egalitäre Geschlechterbeziehungen rücken sie in die Nähe der in Kapitel 5 erörterten Arbeiten von Frances Hasso (2001) zur „Feminist Generation“ der Intifada. Ihren Flüchtlingshintergrund und die mit diesem verbundenen Stigmatisierungserfahrungen greift sie aber - dies teilt sie ebenfalls mit Hafez und den anderen vorgestellten Fällen - kaum in den von ihr bedienten Wir- und Sie-Bilder auf. Das Interview mit ihr ist von meinen Kolleg*innen Arne Worm und Aida Saifi im Frühjahr 2014 in englischer Sprache geführt worden.

Munas Eltern waren in den 1930er Jahren in einem Dorf in Zentralpalästina in der Nähe Ramlas geboren worden. Sie hatten bereits während der Mandatsperiode geheiratet und flüchteten während der Nakba ins Westjordanland. Die Familie lebte zunächst in einem Flüchtlingslager bei Bethlehem, in den 1960er Jahren zog sie in ein angrenzendes Stadtviertel. Muna wurde 1968 geboren, sie besuchte eine Schule vor Ort und studierte in den 1980er Jahren an der Universität Bethlehem. Die palästinensischen Hochschulen in Bir Zeit, Nablus, aber auch Bethlehem waren , mittendrin' in der politischen Mobilisierung im Westjordanland dieser Zeit: Die sogenannten Freiwilligenkomitees waren von den Hochschulen ausgegangen und viele parteipolitische Hochschulgruppen waren sehr aktiv (vgl. Kap. 4.4-4.5). Muna engagierte sich bereits als Schülerin sowie später als Studentin in den Komitees, beteiligte sich etwa an Demonstrationen, an Kampagnen für Spendensammlungen oder unterstütze die Landbevölkerung bei der Kultivierung von landwirtschaftlichen Flächen - eine Maßnahme, die die Konfiszierung von Land durch die israelischen Behörden erschweren sollte. Muna stellte ihr Engagement für die ,nationale Sache in den Kontext einer die eigene Persönlichkeit prägenden Phase und eines Erlebens von Handlungsmacht:

${ }^{128}$ Dieser wurde von mir bereits im Rahmen einer anderen Veröffentlichung diskutiert (Hinrichsen 2017). 
Muna: „Whenever we used to hear about confiscating a land we used to go to that land and get it prepared for agriculture work in order to have it ready for agriculture because a neglected land ehh [...] exposes more to get confiscated $[\ldots]$ it was good yani it sharpens the personalities of young students [...] eh we were young and eh matters of occupation and matters of confiscating land [...] but when you do something you feel that oh my god I'm brave I did this and that, I did something for my country."

Die von ihr in dieser Passage erwähnten Landwirtschaftskomitees sollten neben der Verringerung der Gefahr der Konfiszierung auch durch die Erhöhung der landwirtschaftlichen Produktion eine größere Unabhängigkeit von israelischen Waren erreichen (Robinson 1997). Sie waren Teil des Netzes an Komitees, das sich in den palästinensischen Gebieten in den 1970er und 1980er Jahren sukzessive gebildet hatte und die Bevölkerung in Flüchtlingslager-Gegenden mit der Stadtund der Landbevölkerung in Kontakt brachte (vgl. Kap. 4.5). Muna sprach in diesem Zusammenhang auch von den Demonstrationen und Straßenschlachten mit israelischen Soldaten, etwa während der Verhaftung ihrer Schwägerin, die ebenfalls in der Intifada aktiv gewesen war. Ihre Schwägerin sei schon von den Israelis ,gesucht“ und schließlich, unter heftiger Gegenwehr, verhaftet worden: „she kicked the soldier in the stomach, she was a brave woman!“ Muna rahmte ihre Erzählungen von den Ereignissen während der 1980er Jahre generell in einem generationalen Wir: „Everybody was supposed to get involved in these student committees, it was good, now whenever I meet my colleagues and my mates in my age we remember all those days, we remember them and we look at ourselves as braver than the others in this generation."

An ihrer Darstellung ihres Engagements in den Komitees sowie ihrer Bildungskarriere lässt sich aufzeigen, wie sie die politische Mobilisierung auch mit einem Zugewinn an Autonomie und Handlungsmacht für Frauen in Zusammenhang bringt. Muna war auch in den Gesundheitskomitees der 1980er Jahre aktiv gewesen, die Erste-Hilfe-Schulungen und Gesundheitsschulungen für die palästinensische Bevölkerung durchführten. Muna arbeitete später als Sozialarbeiterin, zuvor jedoch - wozu sie auch an der Universität Bethlehem ausgebildet worden war - als Krankenschwester:

Muna: „I decided more and more I want this career yes I want nursing before the intifada people looked at this differently this is for bad girls who stay at nights with the doctors they I don't know [...] this stuff tradition of discrimination women from men and , what woman will go and spend the night with male doctors they show their bodies' miš 'arif [Ich weiß nicht] this thinking has changed dramatically in the intifada [...] a nurse became like a soldier and many ordinary small girls became trained on first aid because of the first intifada we used to train community women on health issues“. 
In der Komiteearbeit und den damit verbundenen Netzwerken lernte Muna auch ihren späteren Ehemann kennen. Ihre Ehe passt ins Schema der während der Ersten Intifada bedeutsamen „political marriages“ (Johnson/Abu Nahleh/Moors 2009: 16), in denen die Partnerwahl, verglichen mit anderen historischen Phasen, in höherem Maße durch politische Affiliation bestimmt war (vgl. Kap. 4.5). Im Interview präsentierte sie die Heirat als autonome Partnerwahl und erläuterte, in Anspielung auf familial arrangierte Ehen, die damit verbundenen Vorzüge: ,getting married of someone I know is better than someone you don't know you no nothing about". Ihr späterer Mann habe ihr mehrfach einen Antrag gemacht, aber sie habe älter sein, ihre Ausbildung beendet haben und beruflich etabliert sein wollen. Insgesamt lässt sich Muna - etwa mit ihrem Fokus auf politische und berufliche Partizipation und die Autonomie von Frauen - der von Hasso diskutierten feministischen Generation der Ersten Intifada zurechnen. Diese unterscheide sich durch ,its egalitarian gender ideology and sense of self-efficacy“ (2001: 587).

Allerdings nutzte Muna ihren Flüchtlingshintergrund - und dies hat sie mit dem oben dargestellten Hafez und den anderen in Kapitel 6 vorgestellten Flüchtlingen in der Generation Intifada gemein - weder in ihren Darstellungen ihrer Aktivitäten und der Ereignisse während der Mobilisierung der 1970er und 1980er Jahre noch in ihren Ausführungen zu anderen Bereichen ihrer Lebensgeschichte in Zusammenhang mit einem Wir-Bild. Als Rahmen für die Selbstthematisierung diente ihr ihr Flüchtlingshintergrund nur oberflächlich zu Beginn des Interviews in einer kurzen Darstellung ihrer Familiengeschichte. Als sie im Interview über den Umzug der Familie aus dem Lager in ein städtisches Viertel sprach, kam sie kurz auf Spannungen zwischen Flüchtlingen und der altansässigen Bevölkerung zu sprechen:

Muna: „When they [die Eltern] moved to Bethlehem they were exposed to silly thoughts of people all over the world it happens when they give you names like laije [Flüchtling] till now refugee you are refugee“.

Sie erwähnte außerdem, es habe auch Konflikte um das Land gegeben. Die Altansässigen hätten Angst gehabt, dass ihnen für die Ansiedelung von palästinensischen Flüchtlingen Land abgenommen werde; dies passiere aber „everywhere in the world“. Der im Zitat anklingende Bezug auf eine gegenwartsbezogene Erfahrung (,till now") wurde von Muna nicht weiter aufgegriffen oder ausgeführt. Insgesamt rahmte sie diese zum Teil tradierten, zum Teil selbst erlebten Erfahrungen mit einer relativierenden Argumentation, die das Handeln der altansässigen, städtischen Bevölkerung tendenziell entschuldigt. In jedem Fall fasste Muna diese Erfahrungen nicht in die Darstellung einer marginalisierten Position von Flüchtlingen und der Bewohner*innen der Flüchtlingslager-Gegenden im Westjordanland ein. 
Resümierend kann man festhalten, dass die Mitglieder der Generation Intifada aus den Lager-Gegenden - Hafez, Muna und die anderen - zwar Erfahrungen von Stigmatisierung und Marginalisierung durch die altansässige Bevölkerung des Westjordanlandes machten. Diese Erfahrungen treten aber in ihrer Relevanz für die Deutungsmuster, Wir- und Sie-Bilder tendenziell hinter die mit der Zugehörigkeit zur Generation Intifada verbundenen Wir-Bilder zurück. Dies ist eine deutliche Differenz zu den Deutungsmustern und Wir-Bildern der im vorangegangenen Kapitel beschriebenen Kindergeneration der Flüchtlinge um Yousef, Musa, Samad und den anderen, in der das Differenz- und Marginalisierungserleben als Flüchtlinge stärker ausgeprägt und deutlich präsenter in den Deutungsmustern, Wir- und Sie-Bildern ist. Diese Differenz zwischen der Generation Intifada und ihrer Nachfolgegeneration hinsichtlich Deutungsmustern, Wir- und Sie-Bildern steht mit den sozialen Transformationsprozessen im Westjordanland insbesondere ab Mitte der 1990er Jahre nach den Osloer Abkommen und dem Aufbau der PA in Zusammenhang und hatte Auswirkungen sowohl auf das Verhältnis der Bevölkerung in den Flüchtlingslager-Gegenden und Teilen der städtischen Bevölkerung als auch auf die Generationenverhältnisse im Westjordanland, wie ich im Fortgang der Arbeit weiter verdeutlichen werde. 



\section{Die Rückkehrer in Ramallah: Wir- und Sie- Bilder, Interaktionsdynamiken und biographische Verläufe}

\subsection{Einleitung}

Im folgenden Kapitel möchte ich die Deutungsmuster, Wir- und Sie-Bilder einer Clique junger Männer aus Ramallah vorstellen. Die Clique aus Ramallah teilt einige Ähnlichkeiten mit der in Kapitel 6 vorgestellten Clique aus der FlüchtlingslagerGegend. Auch die jungen Männer aus Ramallah involvierten sich ab der Frühadoleszenz häufig in Straßenschlachten mit dem israelischen Militär. Ihre Involvierung wurde flankiert von der Ausbildung und interaktiven Herstellung eines Deutungsmusters und Wir-Bildes als ,Kämpfer für die palästinensische Sache‘. Eine Komponente des Deutungsmusters stellt die Orientierung an und Sehnsucht nach einer ,früher besseren Zeit zum Kämpfen‘ während der Mobilisierung der 1970er und 1980er Jahre dar. Außerdem charakterisiert das Deutungsmuster eine entschiedene Ablehnung der PA und ihrer Sicherheitsdienste, die als repressiv und von westlichen Interessen bestimmt angesehen werden.

Zwischen der Clique aus Ramallah und der Clique junger Männer aus der Flüchtlingslager-Gegend bestehen jedoch auch einige wesentliche Unterschiede. Die jungen Männer in Ramallah verbanden ihr Wir-Bild als ,Kämpfer für die palästinensische Sache' zwar durchaus mit einem Sie-Bild einer vermeintlich unpoli- 
tischen, hedonistischen Bevölkerung Ramallahs, rekurrierten jedoch nicht darauf, selbst gesellschaftlich benachteiligt und marginalisiert zu werden. Unter dem zunehmenden Verfolgungsdruck der israelischen Sicherheitsbehörden schwankten die jungen Männer aus Ramallah in ihren Deutungen zwischen einer Aufrechterhaltung des Wir-Bildes als Kämpfer - und der damit verbundenen demonstrativen Bereitschaft zur Straßenmilitanz - und einem (vorläufigen) pragmatischen Arrangieren mit der PA und der israelischen Besatzung. Ihre Handlungspläne rückten zunehmend vom einem, Widerstandsprojekt ${ }^{6}$ in Richtung der Sicherung der eigenen Lebenschancen (Ausbildung, Beruf, Heirat). In diesem Zusammenhang kann man von einer sich abzeichnenden biographischen Reorientierung der jungen Männer sprechen, die wiederum auf ihre figurationale Positionierung verweist. So bestand und besteht, trotz ihrer ebenfalls grundsätzlich ablehnenden Haltung gegenüber der PA, ein zentraler Unterschied der Clique junger Männer aus Ramallah zu denen aus der Flüchtlingslager-Gegend in ihren nochmals deutlich stärkeren persönlichen und familialen Verbindungen in die PA - und in dem Ausmaß der klientelistischen Chancen, die damit einhergehen. Außerdem sind sie im Vergleich zu den jungen Männern aus der Flüchtlingslager-Gegend mit einem höheren $\mathrm{Maß}$ an kulturellem Kapital ausgestattet. Ihre höheren Lebenschancen und ihre klientelistischen Chancen erlauben ihnen, wie ich zeigen werde, eine pragmatische Verhandlung ihrer historisch-generationalen Position.

Der Aufbau des Kapitels folgt - analog zur Gliederung von Kapitel 6 - einerseits der Chronologie der Feldaufenthalte und der Treffen mit den jungen Männern zwischen 2010 und 2015. Andererseits werden in den Unterabschnitten jeweils verschiedene Cliquenmitglieder sowie verschiedene Aspekte der Deutungsmuster, Wir- und Sie-Bilder diskutiert. Im folgenden Abschnitt (7.2.1) gebe ich zunächst aufgrund der Vielzahl der dargestellten Personen und der Komplexität der Situation der jungen Männer einen Überblick über deren familiale Hintergründe und biographische Situationen zum Zeitpunkt der ersten Treffen und Interviews im Jahr 2010. Dabei möchte ich erneut, wie in Kapitel 6, insbesondere drei junge Männer ins Zentrum rücken - nämlich Iyad (*1987), Hamzeh $\left({ }^{* 1989)}\right.$ und Alaa $(* 1989)$, wie ich sie genannt habe. Im Weiteren gehe ich auf den Feldzugang und das erste Treffen mit den zwei jungen Männern aus der Clique im Frühjahr 2010 ein und erörtere anschließend die Komponenten der Deutungsmuster, Wirund Sie-Bilder und der sich abzeichnenden biographischen Handlungsstrategien (7.2.2).

In dem darauffolgenden Kapitel 7.3 setzte ich dann - auch dies analog zu Kapitel 6 - Deutungsmuster, Wir- und Sie-Bilder aus der Clique zu langfristigen kollektiv-, familien- und lebensgeschichtlichen Prozessen ins Verhältnis. Diese diskutiere ich exemplarisch an der Biographie Alaas sowie der Geschichte seiner Familie, Rückkehrer aus Jordanien, insbesondere seines Vaters Hussam Haziin. Im Rahmen der Darstellung der Biographie Alaas gehe ich auch, zumindest in Ansätzen, auf die Interaktionsgeschichte der Clique junger Männer aus Ramallah ein, die 
von mir globalanalytisch und nicht ganz im Detaillierungsgrad der Clique junger Männer aus der Flüchtlingslager-Gegend rekonstruiert wurde. Das heißt, das folgende Kapitel konzentriert sich auf die Deutungsmuster, Wir- und Sie-Bilder und auf die gegenwärtige Situation der jungen Männer. Wie die Kapitel 6.2 und 6.3 stellen auch die Kapitel 7.2 und 7.3 zusammen eine Rekonstruktion der Wechselwirkung von kollektivgeschichtlichen und biographischen Prozessen in der Elterngeneration wie auch in der Kindergeneration unter Rückkehrern sowohl im familialen Kontext als auch im Kontext der Peergroup dar.

\subsection{Die Rückkehrer: Eine Clique militanter junger Männer in Ramallah}

\subsection{1 Überblick und Kontextualisierung}

Die in diesem Kapitel vorgestellten Analysen basieren auf den teilnehmenden Beobachtungen und biographisch-narrativen Interviews, die von meinen Kolleg*innen und mir zwischen 2010 und 2015 mit den jungen Männern und deren Familienmitgliedern und Nachbar*innen geführt worden sind. Wie bereits erwähnt, konzentriere ich mich bei der Darstellung auf drei junge Männer aus der Clique: Iyad (*1987), Hamzeh (*1989) und Alaa (*1989). Sie sind in Ramallah in demselben, nahe dem Stadtzentrum gelegenen Wohnviertel aufgewachsen und kennen sich seit dem Kindesalter beziehungsweise seit dem frühen Jugendalter. Die Kernfamilien der jungen Männer waren in den 1980er und 1990er Jahren nach Ramallah gekommen. Aufgrund der Land-Stadt-Migration im Westjordanland, aber insbesondere aufgrund des Zuzugs von Palästinenser*innen aus der Diaspora in den 1990er Jahren im Zuge des sogenannten Oslo-Friedensprozesses, wuchs Ramallah zu dieser Zeit stark und verdichtete sich zunehmend (vgl. Kap. 4.6). Iyads Eltern waren bereits Mitte der 1980er Jahre vor der Ersten Intifada aus dem ländlichen Umland Hebrons nach Ramallah gezogen. Die Eltern Alaas und Hamzehs immigrierten in den 1990er Jahren ins Westjordanland. Generell werden im Westjordanland die ab den 1990er Jahren eingereisten Immigrant*innen mit palästinensischem Hintergrund als sogenannte Rückkehrer (,al'aā' adīn') bezeichnet - Palästinenser*innen, die selbst oder deren Vorfahren in der Nakba oder Naksa geflüchtet waren oder vertrieben worden waren und die in den Oslo-Jahren aus der Diaspora ins ,Heimatland', zurückkehrten'. Die insgesamt circa 200.000 Rückkehrer migrierten auch aus westlichen Ländern, insbesondere den USA, in die palästinensischen Gebiete, die meisten Rückkehrer hatten zuvor jedoch im arabischen Raum gelebt (vgl. Kap. 4.6). Zu letzteren gehören auch die Eltern Hamzehs und Alaas. Im Falle von Hamzehs Vater vollzog sich die Rückkehr sehr wahrscheinlich im Rahmen ,alter ${ }^{6}$ PLO-Netzwerke, die im Zuge des Aufbaus der PA Positionen im Sicherheitsapparat vermittelt bekamen. Nicht nur 
die Kernfamilie Hamzehs, sondern auch die Familien Iyads und Alaas sowie die jungen Männer selbst waren und sind mit der PA verbunden. Der Vater Iyads ist Polizist und der Vater Alaas ist in einer, von der PA hauptfinanzierten NGO tätig. Zum Zeitpunkt der Interviews war Hamzeh, wie sein Vater, bei einem der palästinensischen Geheimdienste beschäftigt. Alaa, und vermutlich auch Hamzeh, waren zudem Mitglieder der Fatah und waren in der Jugendorganisation der Fatah, der Shabibah, aktiv.

Iyad, Hamzeh und Alaa sowie andere Freunde und Bekannte hatten sich ab der Frühadoleszenz bis ins junge Erwachsenenalter in Straßenschlachten mit dem israelischen Militär involviert. Während der Zweiten Intifada, zu deren Beginn Iyad, Hamzeh und Alaa zwischen elf und 13 Jahre alt waren, nahmen sie noch kaum an den Demonstrationen und Straßenschlachten teil, und schon gar nicht an den bewaffneten Auseinandersetzungen zwischen israelischem Militär und palästinensischen Milizen. Ab dem letzten Jahr der Zweiten Intifada um 2005 und insbesondere danach waren sie dann in zunehmendem Maße und häufig gemeinsam an Straßenschlachten oder ,Konfrontationen' mit dem israelischen Militär beteiligt. $\mathrm{Da}$ es im Stadtgebiet Ramallahs, und insbesondere im Stadtzentrum, nach der Zweiten Intifada nur noch sporadisch zu Einsätzen des israelischen Militärs beziehungsweise israelischer Sicherheitskräfte kam, ,suchten' die jungen Männer im Verlauf ihrer Jugend zunehmend die Auseinandersetzung mit den israelischen Sicherheitskräften an den sogenannten Berührungspunkten, etwa an der israelischen Sperranlage oder an Checkpoints im Umland Ramallahs, oder etwa indem sie israelische Militärkonvois, die in der Nacht das Stadtgebiet Ramallahs durchquerten, abfingen.

Im Frühjahr 2010 kam es in einer Phase stärkerer israelischer Militärpräsenz in Ramallah und der damit verbundenen Straßenschlachten zwischen den palästinensischen Jugendlichen und dem israelischen Militär zu einem auch für die jungen Männer mit größeren biographischen Folgen verbundenen Vorfall. Eine Gruppe junger Männer, darunter Alaa und Hamzeh, hatten einen nächtlichen Miliärkonvoi abgepasst, durch Barrikadenbau vorübergehend aufgehalten und massiv mit Molotow-Cocktails beworfen. Dabei wurde ein Militärfahrzeug völlig zerstört, israelische Soldat*innen wurden jedoch keine verletzt. ${ }^{129}$ In den Wochen nach diesen ,Auseinandersetzungen' wurden einige der beteiligten Jugendlichen von israelischen Sicherheitskräften verhaftet und in der Folge drohte nun im Frühjahr 2010 auch die Verhaftung und eine voraussichtlich mehrjährige Inhaftierung Hamzehs und Alaas - Iyad war an jener Aktion nicht beteiligt gewesen - durch die israelischen Behörden. Daraufhin wurden Alaa und Hamzeh, einer möglichen Verhaftung durch israelische Einheiten zuvorkommend, durch Sicherheitskräfte der PA festgenommen und zunächst für sechs Monate inhaftiert. Während der

\footnotetext{
${ }^{129}$ In der Regel halten die israelischen Militärfahrzeuge dem Bewurf mit Molotow-Cocktails stand. Dass dies in diesem Fall nicht so war, ist ein Hinweis auf die große Anzahl an geworfenen Brandbomben. Vgl. Fußnnote 150.
} 
ersten Gespräche mit meinen Kolleg*innen waren sie seit einem Monat im ,offenen Vollzug, also nur nachts inhaftiert, und erwarteten ihr Urteil durch ein Gericht der Autonomiebehörde.

Welchen Hintergrund hatten diese Verhaftung und insbesondere der Gerichtsprozess und das bevorstehende Urteil durch die PA? Grundsätzlich ist die sogenannte Sicherheitskooperation zwischen den israelischen Sicherheitsdiensten und jenen der palästinensischen Autonomiebehörde, und damit auch die Koordination bei Verhaftungen, Teil der Oslo-Vereinbarungen (vgl. Kap. 4.6). Ziel der Verhaftung und insbesondere der bevorstehenden Verurteilung durch die PA war in diesem Fall jedoch vermutlich, so gaben es auch die jungen Männer und einige ihrer Familienmitglieder explizit an, sie einer Verhaftung durch die israelischen Behörden zu entziehen und durch die Verurteilung vor einem Gericht der PA auf eine Aufhebung des Status als „Gesuchte“ durch die israelischen Behörden hinzuwirken beziehungsweise zu ,spekulieren‘. Dieser Vorgang ist eher als ein mit unsichereren Erfolgsaussichten versehener Versuch eines informellen und klientelistischen ,Verhandelns' der Fälle der jungen Männer denn als administrativ üblicher Prozess einzuschätzen und ist Ausdruck der relativen Nähe der Familien der jungen Männer zur PA und deren Sicherheitsbehörden. Wie ich im Weiteren diskutieren werde, kann diese Intervention der PA als Ausdruck der auch familial vermittelten Nähe zur PA und der damit einhergehenden klientelistischen Chancen und biographischen Ressourcen gesehen werden. Auch die Clique aus der Flüchtlingslager-Gegend konnte gelegentlich lose Kontakte der Familien in die PA nutzen. So war auch Yousef durch den Aufenthalt in einem PA-Gefängnis für einige Wochen dem möglichen Zugriff durch das israelische Militär entzogen worden (Kapitel 6.3.3). Wie im Folgenden deutlich werden wird, sind im Fall der Clique in Ramallah und ihrer Familienmitglieder die Verbindungen - die sich unter anderem in der versuchten Aufhebung des Status als „Gesuchte“, der Bereitstellung von Posten in der PA und anderen Ressourcen ausdrücken - deutlich ausgeprägter und ihre Einsetzbarkeit im Sinne klientelistischer Chancen höher, was sich auch in den Lebenschancen der jungen Männer niederschlägt.

\subsubsection{Deutungsmuster, Wir- und Sie-Bilder in der Clique}

\section{Interview mit Iyad: Romantisierung der Ersten Intifada}

Die ersten Treffen und Gespräche mit den jungen Männern, auf die ich im Folgenden eingehe, fanden im Spätsommer 2010 während der Inhaftierung Hamzehs und Alaas - sie waren zu diesem Zeitpunkt beide 21 Jahre alt - in einem Gefängnis der PA statt. Während eines Feldaufenthaltes in Ramallah hatte das deutschpalästinensische Forscher*innenteam erstmalig Kontakt zur Clique um Iyad, Hamzeh und Alaa geknüpft (vgl. Kap. 3.3). Die jungen Männer waren zu jener Zeit in einem Sport- und Nachbarschaftsverein in ihrem Viertel aktiv und bei einem Sportfest, welches der Verein ausrichtete, kam eine deutsche Forscherin aus 
dem Team bei einem Spaziergang zufällig mit Boutros, einem der ehrenamtlichen Vorsitzenden des Vereins, ins Gespräch. Auf den von ihr vorgebrachten Wunsch der Forscher*innen, in Interviews mehr über den Verein und das Stadtviertel, in welchem der Verein lag, zu erfahren, vermittelte Boutros ihnen Iyad als Ansprechpartner und Kontaktperson für den Verein, vermutlich aufgrund seiner guten Englischkenntnisse. Über Iyad, mit dem sich der Kontakt in den nächsten Wochen und Monaten intensivierte, lernten die Forscher*innen weitere Freunde Iyads, darunter Hamzeh und Alaa, sowie Familienmitglieder und Nachbar*innen Iyads kennen. Bevor ich auf dieses erste, durch Boutros vermittelte Interview mit Iyad, bei welchem auch Hamzeh anwesend war, eingehe, möchte ich zunächst einen kurzen Überblick zu Iyads familiengeschichtlichem Hintergrund geben. Diesen skizziere ich auch auf Basis von Interviews, die wir mit seinen Eltern geführt haben.

Die Familien von Iyads Großeltern väterlicher- wie mütterlicherseits waren seit mehreren Generationen in demselben Dorf bei Hebron ansässig und hatten einen bäuerlichen Hintergrund. Iyads Eltern wurden 1966 und 1967 im Dorf geboren. Iyads Vater hatte, wie viele andere Palästinenser in jener Phase, die Gelegenheit auf eine gut bezahlte Beschäftigung bei jüdischen Arbeitgebern genutzt und arbeitete ab Ende der 1970er Jahre in einer jüdischen Siedlung in der Nähe Hebrons als Packer bei einem Gemüsehändler. Iyads Eltern heirateten 1984 und zogen kurz darauf nach Ramallah. Iyads Vater war zunächst als Straßenhändler für Kleinwaren tätig und ein Großonkel Iyads väterlicherseits, der ebenfalls in Ramallah wohnte, unterstützte das Paar zu Beginn finanziell. Die Familie zog in eine kleine Mietwohnung in der Nachbarschaft, in welcher die Familie auch noch zum Zeitpunkt der ersten Gespräche mit Iyad im Jahr 2010 lebte. Iyad wurde 1987 als erstes Kind der Familie geboren. Iyads Vater engagierte sich in den 1980er Jahren mit einigen Nachbar*innen in dem erwähnten Nachbarschafts- und Sportverein. Er war in die politische Mobilisierung der 1970er und 1980er Jahre - zum Teil durch über den Verein organisierte Aktionen - involviert und wurde während der Ersten Intifada wiederholt verhaftet. Zum Beispiel kam es zu einer mehrmonatigen Inhaftierung nach Auseinandersetzungen in Tulkarem, die im Anschluss an eine vom Verein organisierte Demonstration entstanden waren. ${ }^{130} \mathrm{Zu}$ Beginn der 1990er Jahre wurde Iyads Vater im Rahmen der Massenverhaftungen anlässlich der Entführung eines israelischen Soldaten erneut inhaftiert. Er wurde von den israelischen Behörden zunächst verdächtigt, an der Entführung beteiligt gewesen zu sein, wurde jedoch nach sechs Wochen freigelassen. In der Haft war er wiederholt vom Shabak verhört worden. Die Mutter Iyads erwähnte bei einem Gespräch im Herbst 2011 außerdem, dass Iyads Vater während dieser Haftzeit gefoltert worden sei und dass israelische Soldaten währenddessen Zigaretten auf seinem Körper ausgedrückt hätten, deren Narben man heute noch sehen könne. Nach

${ }^{130}$ Die Involvierung des Clubs in die politische Mobilisierung während der 1980er Jahre ist von mir recherchiert worden, kann hier jedoch aus Gründen der Anonymisierung nicht näher belegt werden. 
der Inhaftierung erhielt er den sogenannten grünen Ausweis, der ihn als ExGefangenen auswies und der unter anderem die Verweigerung von Aufenthaltsgenehmigungen in den israelischen Gebieten und in Ostjerusalem zur Folge hatte. ${ }^{131} \mathrm{Im}$ Zuge des Aufbaus der Palästinensischen Autonomiebehörde bekam Iyads Vater einen Posten in der ebenfalls im Aufbau befindlichen Polizei. Seine Anstellung als Polizist brachte Iyads Vater mit seiner ,Kampfgeschichte ${ }^{6}$ und seinen Inhaftierungen in Zusammenhang, denn, wie er im Interview im Herbst 2011 formulierte, „als Polizeibeamter in Palästina sollte man genug Zeit in israelischen Gefängnissen verbracht haben.“"132 Die Familie verfügte in der Folge über ein geregeltes, wenn auch kleines Einkommen und zog in eine größere Wohnung in derselben Nachbarschaft. Iyad wuchs in Ramallah auf und besuchte eine öffentliche Schule im Viertel. Im Nachbarschaftsverein spielte er Fußball. Nach dem Tawjihi im Jahr 2005 absolvierte Iyad ein Studium der Politikwissenschaften in Istanbul. Seit circa 2008 war Iyad zurück in Ramallah, er jobbte in verschiedenen Cafés und war nun verstärkt als Betreuer im Nachbarschaftsverein aktiv.

Das Gespräch mit Iyad im Spätsommer 2010 war mit ihm als eine Art Experteninterview über den Verein und das Wohnviertel, in dem der Verein aktiv war, verabredet worden. Allerdings kam er in diesem Gespräch auch auf die (tradierten) Erlebnisse seiner Familie in der Ersten Intifada und auf seine zu dieser Zeit bei der PA im ,offenen Vollzug' inhaftierten Freunde Hamzeh und Alaa zu sprechen. Das Interview wurde von Nicole Witte, Filip Habib und Gabriele Rosenthal mit Iyad in einem Café in der Innenstadt Ramallahs geführt, in welchem er jobbte und sich häufig mit Alaa, Hamzeh und anderen Freunden traf. Auf die von Filip Habib eingangs gestellte Frage, ob er über den Verein erzählen könne, gab Iyad einen Überblick über die ,Funktionen' des Vereins im Viertel. Der Verein sei, neben dem Angebot der Sport- und Nachbarschaftsaktivitäten, schon vor dem Aufbau der Autonomiebehörde und der NGOs eine Art sozialer Dienst für das Viertel gewesen. Man habe die Nachbar*innen in Notlagen unterstützt, etwa im Winter bei Reparaturen geholfen. Sie würden außerdem Kurse anbieten, etwa Erste-Hilfe-Kurse. Sie würden auch helfen, wenn aus den Familien aus der Nachbarschaft jemand inhaftiert wurde, und würden dann den Betroffenen Besuche abstatten und Geschenke machen.

Bereits kurz nach Beginn des Interviews betrat Iyads Freund Hamzeh das Café. Iyad signalisierte ihm, sich zu ihnen zu setzen, und führte ihn mit der Bemerkung ein, er sei im Gefängnis gewesen, was von den anderen Anwesenden aber zunächst nicht aufgegriffen wurde. Hamzeh hörte im weiteren Gespräch anfangs vorwiegend zu und gab später einige Kommentare ab. Das Interview kreiste zunächst weiter um die Organisation des Vereins und dessen verschiedene Aufgaben

\footnotetext{
131 Vgl. Hafez in Kap. 6.3.3.

132 Entsprechend, dies habe ich in Kapitel 4 bereits ausgeführt, kennzeichnete die Rekrutierungspolitik der PA gerade für die Sicherheitsdienste ein ,explicit focus on Palestinian prisoners and detainees jailed by Israel for political and/or security-related offences“ (Lia 2006: 138).
} 
und Aktivitäten in der Nachbarschaft. Nach einer halben Stunde bemerkte Filip, dass Iyad ja erwähnt habe, dass sein Vater auch im Sportverein aktiv gewesen sei, und fragte, ob er mit ihm darüber gesprochen habe, welche sozialen Aktivitäten er im Club unternommen habe. Iyads Antwort möchte ich hier in einer längeren Passage zitieren:

Iyad: „their life was more interesting and more activity because the Jewish were against them (2) here is nobody against us, like we are free to do too many activities but for them like if you go in the street doing marching and=this=thing maybe you get arrested maybe you get kicked by the Jewish you didn't know you didn't know what gonna happen to you“.

Interviewer: „Do you think it was more adventurous?“

Iyad: „yeah it was more beautiful, I mean you do something like ehhh and you didn't know what's gonna happen to you but we know every year what we gonna do like we go marching we $=$ know $=$ everything like we become like bored from this, yeah but for them like we go maybe in this year we march maybe not in Ramallah we march in Jenin we have fun we have dinner together my father get arrested three times".

Er ergänzte, wenn man in jener Zeit Familien von Inhaftierten unterstützte, habe man dafür verhaftet werden können. Anhand der zitierten Passage möchte ich verschiedene Aspekte diskutierten. Es wird deutlich, dass Iyad auf die Demonstrationsteilnahmen und Verhaftungen seines Vaters anspielte, die dieser im Rahmen der politischen Mobilisierung im Westjordanland in den 1970er und 1980er Jahren erlebt hatte. Iyad hob mit der Formulierung „them“ auf den von den anderen Zeitgenossen seines Vaters - etwa den älteren Mitgliedern im Club - geteilten Charakter dieser Erfahrungen ab. Außerdem sind die Anspielungen Iyads romantisierend: Die Konfrontationen, das mit der Teilnahme an Demonstrationen verbundene Risiko und die Inhaftierungen machten das damalige Leben für Iyad ,interessanter ${ }^{6}$ und ,schön'. Iyad geriet hier mit Bezug auf die 1980er Jahre und die Erste Intifada sozusagen ,ins Schwärmen'. Von dieser Zeit grenzte er die eigene Gegenwart in negativer Weise ab: Die eigene Zeit sei irgendwie, langweilig', man gehe nicht solche Unwägbarkeiten ein und sie sei nicht so sehr von der offenen Gegnerschaft gegen ,die Juden' bestimmt. Auch diese Erfahrungen hob er mit den Formulierungen „we“ oder „us" als geteilt hervor und schloss hier vermutlich den anwesenden Hamzeh und die anderen im Verein aktiven Freunde mit ein. Die Zuordnung zum ,Sie ${ }^{\varsigma}$ und zum ,Wir ${ }^{\varsigma}$ vollzog Iyad hier entlang des Umstandes, unterschiedliche kollektivgeschichtliche Kontexte erfahren zu haben. Die Differenzkonstruktionen basieren somit auf einer Einschätzung der Unterschiedlichkeit der historisch-generationalen Erfahrungsräume. In Iyads Äußerungen kommt außerdem eine Hierarchisierung dieser generationalen Erfahrungsräume zum Ausdruck: Mit dem idealisierenden Blick auf die 1980er Jahre und der damit ver- 
bundenen Sehnsucht nach Abenteuer und Sinnerfüllung brachte Iyad gleichzeitig das Defizit der ,eigenen Zeit' zum Ausdruck, der diese Sinnerfüllung weitestgehend fehle. In einer stärker theoretisierenden Formulierung kann man zusammenfassen, dass Iyad in expliziter Weise eine generationale Differenz in der Ausstattung mit Sinnchancen - um einen Begriff von Norbert Elias aufzugreifen (1989: 320; vgl. Kap. 2.5) - zum Ausdruck brachte. Diesen für das Generationenverhältnis zentralen Aspekt, der in ähnlicher Weise auch in der intergenerationalen Interaktion in den in Kapitel 6 diskutierten Fällen in der Flüchtlingslager-Gegend auftauchte, werde ich in der abschließenden Ergebnisdiskussion dieser Arbeit erneut aufgreifen (vgl. Kap. 9).

Darüber hinaus zeigt sich in dieser Passage etwas, was sich auch durch die anderen Gespräche mit Iyad zog. Sein idealisierender Blick ist tendenziell bagatellisierend gegenüber dem mit der Ersten Intifada verbundenen Leid. Rekurse auf Tradierungen von leidvollen und demütigenden Erfahrungen bleiben in dem hier wie auch in weiteren Gesprächen von Iyad erzeugten Bild von der Ersten Intifada ausgespart. Dies ist auch vor dem Hintergrund der Berichte seiner Mutter bemerkenswert. Sie hatte, wie bereits erwähnt, in den Interviews davon gesprochen, dass Iyads Vater im israelischen Gefängnis körperliche Misshandlung erfahren hatte. Die tendenzielle Dethematisierung solcher Erfahrungen zeigte sich in ähnlicher Weise auch im familialen Dialog der Familie Sasour aus der FlüchtlingslagerGegend, wie in Kapitel 6 erörtert wurde.

Iyads Ausführungen konzentrierten sich im weiteren Gesprächsverlauf des ersten Interviews zunächst wieder auf die gegenwärtigen Aktivitäten des Vereins. Im Zusammenhang mit Ausführungen zu den Medaillen, die in den Wettkämpfen im Verein von seinen Freunden erworben worden waren, kam er auch auf einige junge Männer im Verein zu sprechen, die „gegen die Israelis kämpfen“ würden:

Iyad: „fighting like I am against them if they come I throw stones if they come I shoot I they come I do this because of this our club is not developing $[\ldots]$ like these guys they are in the prison now but they go everyday until night time and out in the night time and they go back to the prison".

Bei seinen Ausführungen deutete Iyad auf Hamzeh. Hamzeh sei momentan nachts im Gefängnis bei der PA und tagsüber habe er Freigang. Hamzeh nickte und erklärte, in etwas brüchigem Englisch, dass er nur nachts inhaftiert sei, weil nachts die Gefahr, durch die Israelis verhaftet zu werden, größer sei. Iyad fuhr fort, die PA wolle mit Israel verhandeln, wenn man aber auf andere Weise gegen die Besatzung kämpfe, sei man in ihren Augen ,against the system“. Die Jungs im PA-Gefängnis hätten noch Glück, woraufhin Hamzeh anmerkte, sie seien im „VIP-Prison“, wie er es nannte. Andere würden fünf oder sieben Jahre in israelischen Gefängnissen sitzen. Zwar beschütze die PA sie vor der Verhaftung durch die Israelis, aber die Situation sei trotzdem schlecht, man werde von „den eigenen Leuten“ verhaftet. Das weitere Gespräch drehte sich zunächst um die Modalitäten 
der Haft der jungen Männer bei der PA, etwa um den ,offenen Vollzug', kam jedoch aufgrund des Schichtbeginns Iyads im Café und dem Eintreffen weiterer Gäste zu einem baldigen Ende. Die Interviewer*innen verabredeten jedoch Termine für weitere Gespräche mit Iyad und Hamzeh in den nächsten Tagen.

Bereits im gerade besprochenen ersten Gespräch mit Iyad und Hamzeh wurden zum einen die nostalgisch-romantisierenden Bezüge auf ,frühere Zeiten', insbesondere auf die politische Mobilisierung der 1970er und 1980er Jahre in den palästinensischen Gebieten, die die jungen Männer auch in anderen Gesprächen vornahmen, deutlich. Diese dienten dabei in der Regel als Kontrastfolie zu der als ,unpolitisch oder demobilisiert erlebten gegenwärtigen kollektivgeschichtlichen Phase seit der Zweiten Intifada, in welcher die jungen Männer den Großteil ihrer Jugend und ihres jungen Erwachsenenalters erlebt hatten und erlebten. Des Weiteren zeichnet sich bereits in diesem ersten Interview die ambivalente Stellung zwischen politisch abzulehnender Institution und zentraler biographischer Ressource, die die Sicherheitsdienste der PA für die jungen Männer darstellen, ab. Diese ambivalente Stellung wird auch in den weiteren Gesprächen und Interviews mit den jungen Männern deutlich, wie ich in den folgenden Abschnitten an einer Diskussion mit Hamzeh und Alaa sowie an dem mit Hamzeh wenige Tage nach dem ersten Gespräch mit Iyad geführten biographisch-narrativen Interview deutlich machen möchte.

\section{Diskussion mit Alaa und Hamzeh: Wir-Bild als, Kämpfer'}

Im Folgenden möchte ich auf den Ausschnitt eines Gesprächs mit Alaa, Hamzeh und anderen befreundeten jungen Männern eingehen, welches sich wenige Tage nach dem soeben skizzierten Gespräch mit Iyad und Hamzeh ebenfalls im Spätsommer 2010 ergab. Das Gespräch, das den Charakter einer Gruppendiskussion annahm, wurde von Gabriele Rosenthal und Anan Sour in jenem Café geführt, in welchem auch das Interview mit Iyad stattgefunden hatte. Dieses Café war sowohl Arbeitsplatz als auch häufiger Treffpunkt der Freunde. Über das gegen Hamzeh und Alaa laufende Gerichtsverfahren der PA und die bald zu erwartende Verurteilung ergab sich mit den jungen Männern eine Diskussion über die Sinnhaftigkeit des ,Kämpfens für die palästinensische Sache ${ }^{\varsigma}$ in der gegenwärtigen kollektivgeschichtlichen Situation. Die Diskussion entstand, als einer der jungen Männer, ein Freund Alaas und Hamzehs, der ebenfalls im Café war und sich zur Gruppe gesetzt hatte, zu Anan Sour und Gabriele Rosenthal gewandt bemerkte, er sei gerade acht Monate bei den Israelis inhaftiert gewesen und diese hätten ihm im Verhör „ganz direkt" gesagt, die Idee einer eigenen Nation oder eines Heimatlandes (,wațan“) könne er vergessen. Auf die Frage der Interviewerin, ob sie sich ein anderes Projekt vorstellen könnten, versicherten die jungen Männer ihre ,Kampfbereitschaft für die palästinensische Sache`. 
Hamzeh: „Wir wollen etwas was man Heimatland nennt man muss das machen nach der persönlichen nach unserer Moral wir haben Patrioten geschaffen und wir werden Patrioten bleiben [...] für uns und unsere Generation wird das Heimatland nicht enden wir werden Widerstand leisten“.

Hamzeh fuhr fort, von den bisherigen sogenannten Friedensverhandlungen zwischen Israel und den Palästinenser*innen würden sie nicht viel halten. Es würde verhandelt, aber das sei sinnlos.

Alaa: „Den Frieden wird es nicht geben“.

Interviewer: „Wie meinst du das Alaa?“

Alaa: „Ich meine dass der Frieden sowieso nicht durchsetzbar sein die Israelis räumen nicht Ariel ${ }^{133}$ räumen es nicht [...] Ariel ist riesig=riesig es ist eine große Stadt sie haben Schulen gebaut und alles in der Stadt".

Hamzeh: „Wenn es jetzt eine Demonstration gibt wie viele Leute würden hingehen nur 20 Leute würden mitmachen $[\ldots]^{\text {‘، }}$.

Alaa: „Die Leute sind machtlos, also nur wenn die Israelis in die Stadt kommen werden wir was machen“.

Hamzeh: „Ich war jetzt ein halbes Jahr im Gefängnis und es war keine Abschreckung für mich das meint wenn die Israelische Armee reinkommt wir werden uns nicht schlafen legen oder uns verstecken“.

Über die weiterhin beschworene Kampfbereitschaft hinaus deuteten die jungen Männer in dieser Passage wie auch im Folgenden an, dass sie sich aufgrund der PA und der Verhaftungen in der Gruppe in Zukunft mit ,Widerstandsaktionen zurückhalten würden. Im Anschluss an die zitierte Passage meinte Hamzeh ironisch überspitzt: „wenn ich jetzt hören würde, dass Al-Aqsa brennt, würde ich nichts machen wir haben ja die PA“. Im Anschluss kam Alaa auf die PA zu sprechen. Die PA mache aufgrund der Sicherheitskooperation nur noch das, was die Israelis wollen. Wenn jemand einen israelischen Soldaten umbringe und Israel ihn nicht finde, würde die PA ihn zu ihnen bringen, warf einer der Freunde von Alaa und Hamzeh ein. Alaa ergänzte, er habe ja versucht Widerstand gegen die Israelis zu leisten und zu kämpfen und dann habe die PA ihn verhaftet - zu Hause bleiben wäre eigentlich viel besser für ihn. Auf die Frage der Interviewer*innen, unter welchen Umständen die anderen denn nun etwas ,machen' würden, betonten die jungen Männer, sie würden nur noch kämpfen, wenn die Israelis in die Stadt kämen oder wenn die PA verschwunden sei und es eine neue Intifada gäbe.

Außerdem könne man, so merkte Hamzeh an, inzwischen sogar zweimal ins Gefängnis kommen, erst bei der PA und dann bei den Israelis. Die PA oder

\footnotetext{
${ }^{133}$ Bezug nehmend auf die zentral im nördlichen Westjordanland gelegene circa 20.000 Einwoh-
} ner*innen umfassende israelische Siedlung. 
Mahmoud Abbas seien auch gar nicht diejenigen, die entscheiden, sondern „Müller", wie Alaa in Anspielung auf einen typisch deutschen Namen formulierte. Wenn „Müller“ nicht zufrieden sei, dann bekomme Mahmud Abbas kein Geld. Wenn die Hamas tun würde, was die EU und die „,on außen“ wollen, bekämen sie auch Geld, aber die Hamas leiste ,Widerstand", daher bekämen sie das Geld vom Iran und aus Syrien. Mahmud Abbas („Abu Mazen“) könne gar nicht mehr für, Widerstand' sein:

Alaa: „Wenn Abu Mazen morgen sagt er will eine neue Intifada wie würde die PA für ihre Beamten zahlen und wie würde Abu Mazen sein Gehalt bekommen auch er wird keins bekommen, ich meine es ernst dies sind nicht nur meine Worte sondern auch von meinem Vater mein Vater dies hab nicht ich verstanden sondern mein Vater [...] alle Leute haben Angst vor der PA und die PA hat jetzt mehr Macht das ist der Grund warum die Leute nicht ihre Meinung sagen können, sie $=$ sie werden ruhiggestellt" .

Alaa bezog sich an dieser Stelle seiner Einschätzung, inwiefern die PA und Abu Mazen von westlichen Interessen bestimmt seien, explizit auf seinen Vater. Diese Bemerkungen weisen darauf hin, dass Alaa sich in seinen Positionen durchaus in Übereinstimmung mit seinem Vater erlebte. Und die Bemerkung deutet auch auf die mögliche Relevanz von Diskussionen in der Familie, den familialen Dialog und familiale Tradierung hin, die ich in Kapitel 7.3 anhand einer Falldarstellung zur Biographie Alaas und seines Vaters Hussam aufzeigen werde. In der zitierten Passage wird außerdem sehr deutlich, was sich auch durch die Diskussionsbeiträge der anderen jungen Männer zog und sich bereits in dem oben dargestellten ersten Gespräch mit Iyad und Hamzeh andeutete: Die Sicherheitsdienste der PA werden als gegenüber der palästinensischen Bevölkerung repressiv und von westlichen und israelischen Interessen dominiert gedeutet. Die sich auch durch die anderen Gespräche mit den jungen Männern ziehende massive Kritik an der PA, die sogar in den Kontext einer Unterdrückung eines weiteren Aufstands gestellt wird, ist auch vor dem Hintergrund des Schutzes vor israelischer Verhaftung, den die PA Hamzeh und Alaa zum Zeitpunkt der Gespräche gewährte, sowie vor dem Hintergrund der familialen und der eigenen Nähe zur PA und zur Fatah bemerkenswert. So gibt die massive Abwertung der PA einen Eindruck von deren Legitimitätsverlust, der bis in das Milieu der wahrscheinlichsten Unterstützer der PA, der Familien der Beamten in den Sicherheitsorganen und der Fatah-Jugend, zu reichen scheint.

Insgesamt bedienten die jungen Männer ein Wir-Bild von ,Kämpfern für die palästinensische Sache', das vor allem auf einer Bereitschaft zu und Teilnahme an Straßenmilitanz, insbesondere wenn die israelische Armee im ,eigenen Raum Ramallahs operiert, zu basieren scheint. Dabei sehen sie sich tendenziell auch in der Linie der generationalen Weitergabe eines Kampfauftrages (,mit unserer Generation endet es nicht'). Dabei stellt das Gesprächssetting in der männlichen 
Peergroup sicher einen Kontext dar, in welchem die eigene Kampfbereitschaft in besonderem Maße betont wird und man sich dieser unter den anderen jungen Männern, mit denen man wie im Falle von Hamzeh und Alaa auch gemeinsam in Straßenkämpfe involviert war, gegenseitig versichert. Jedoch stellten die jungen Männer auch vereinzelt ein ,Arrangieren auf Zeit ${ }^{6}$ mit der PA und den momentanen gesellschaftlichen Rahmenbedingungen in Aussicht. Inwiefern diese Bereitschaft abzuwarten und sich zu arrangieren in einem anderen Gesprächssetting deutlicher geäußert wird und eine mögliche pragmatische Reorientierung der eigenen Handlungspläne mit den familial vermittelten biographischen Ressourcen verbunden ist, möchte ich im folgenden Abschnitt am Fall Hamzehs genauer diskutieren.

\section{Arrangieren mit den Verbältnissen und klientelistische Chancen}

Die Bereitschaft, sich mit der PA und den gegenwärtigen politischen Rahmenbedingungen zu arrangieren und auf eine für das ,Kämpfen' bessere kollektivgeschichtliche Konstellation zu,warten', wird exemplarisch an einem Interview mit Hamzeh deutlich. Darin wird auch die Relevanz des Dialogs mit seinem Vater, einem Offizier in einem der palästinensischen Geheimdienste, für Hamzehs Sinneswandel sichtbar. Das biographisch-narrative Interview mit Hamzeh wurde ebenfalls während des Feldaufenthaltes im Spätsommer 2010 von Gabriele Rosenthal geführt. Es fand in englischer Sprache in jenem Café statt, in dem die meisten Interviews mit den Cliquenmitgliedern geführt wurden. In diesem Gespräch waren allerdings keine anderen Freunde zugegen. Zunächst möchte ich knapp auf dem kollektiv- und familiengeschichtlichen Kontext Hamzehs eingehen, ehe ich seine Deutungsmuster und die Wir- und Sie-Bilder vor dem Hintergrund seiner Inhaftierung bei der PA diskutiere.

Hamzehs Familie hat einen palästinensischen Fluchthintergrund. Die Familien der Großeltern väterlicherseits waren vor dem Ersten Arabisch-Israelischen Krieg im Umland Lyds ansässig und flüchteten während der Nakba - der genaue Zeitpunkt ist unbekannt - nach Jordanien. Sie lebten in den 1950er Jahren im palästinensischen Flüchtlingslager Al-Whedat im Ammaner Umland. Die Familie von Hamzehs Mutter stammt aus einem Dorf in der Nähe von Tulkarem. Die Eltern waren Mitte der 1960er Jahre geboren worden und hatten Anfang der 1980er Jahre in Amman geheiratet. Mitte der 1980er Jahre zogen sie nach Tunesien, wo zu jener Zeit das Hauptquartier der PLO angesiedelt war. Große Teile der ,alten PLO-Kader um Yassir Arafat waren ab 1982 im Libanesischen Bürgerkrieg nach dem Einmarsch der israelischen Armee aus dem Libanon nach Tunesien übergesiedelt. Es ist sehr wahrscheinlich, dass Hamzehs Vater sich bereits in Jordanien und in Tunesien in der Nähe dieser PLO-Netzwerke bewegt hatte. Jedenfalls rekrutierte sich ab 1994 der ganz überwiegende Teil des Personals des Nationalen Sicherheitsdienstes der PA aus dem ehemaligen PLO-Kader, das außerhalb der 
palästinensischen Gebiete gelebt hatte. ${ }^{134}$ Im Zuge des Aufbaus der verschiedenen Sicherheitsdienste der PA nach dem Oslo-Abkommen ab Mitte der 1990er Jahre und der mit dem Institutionenaufbau verbundenen Immigration ,alter ${ }^{`}$ PLOAktiver bekam auch Hamzehs Vater bereits 1994 eine berufliche Stellung in einem der Sicherheitsdienste der PA vermittelt. Er immigrierte ebenfalls ins Westjordanland und stieg im Laufe der nächsten Jahre in einen höheren Offiziersgrad auf (Parsons 2005: 134). Etwa 1998 zog die Mutter Hamzehs mit den Kindern, darunter der zu dieser Zeit neunjährige Hamzeh, nach. Hamzeh und seine Geschwister besuchten fortan eine Schule in Ramallah. Hamzeh wuchs in derselben Nachbarschaft wie Iyad und Alaa auf, Alaa war zudem ein Mitschüler. Während der Zweiten Intifada wurde Hamzehs Vater beim Einmarsch der israelischen Armee 2002 in Ramallah für einige Wochen inhaftiert. Insbesondere nach der Zweiten Intifada involvierte sich Hamzeh unter anderem gemeinsam mit Iyad und Alaa in Straßenschlachten mit israelischen Sicherheitskräften. In Kapitel 7.3 gehe ich im Rahmen der Falldarstellung zur Biographie Alaas näher auf die Umstände ein. Hamzeh absolvierte 2007 das Tawjihi. Er arbeitete danach zunächst bei Orange, einem Unternehmen der Mobilfunkbranche. Zum Zeitpunkt des biographisch-narrativen Interviews im Spätsommer 2010 hatte er seinen Angaben zufolge eine Anstellung in einem der palästinensischen Sicherheitsdienste in Aussicht - etwas, wie er sagte, „arranged with my father" über einen mit ihm bekannten Offizier.

In dem biographisch-narrativen Interview konzentrierte sich Hamzeh stark auf Ereignisse um die Konfrontation mit dem israelischen Militär und die Zerstörung des Jeeps im Frühjahr 2010 sowie seine Erfahrungen im Gefängnis der PA. Er beschrieb die Hafterfahrungen bei der palästinensischen Autonomiebehörde als einen Anstoß für Reinterpretationsprozesse. Die Inhaftierung durch die PA habe ihm zu denken gegeben, führte Hamzeh aus. Bei den Israelis im Gefängnis zu sein, wäre etwas anderes gewesen, die seien schließlich seine Feinde, aber die PA sei doch eigentlich seine eigene Regierung. Er habe erkannt, dass es ,keine gute Zeit' sei für ,Widerstandsaktionen': ,like I was thinking it's different it's very different, this time is not for fighting (4) and and a- a I say to myself, I'm a fool I was fighting alone why nobody care about me." Es sei dumm, allein zu kämpfen, wenn es niemanden interessiere. In diesem Zusammenhang ging er auch auf die Nacht, in der sie den Jeep zur Explosion gebracht hatten, ein:

Hamzeh: ,you know that in that night when I blow up the jeep (1) after I (2) I did it when I came back to the neighborhood I saw ahh some guys, who were eating in a restaurant, they were very happy, they were drinking, even they didn't $\mathrm{f}-=$ eel the the blow, they didn't pay any attention to this but at that time I didn't understand it, thought what they did, a:nd what I did“".

\footnotetext{
${ }^{134}$ Zur Sicherheitspolitik Arafats, auf die bereits in Kapitel 4 verwiesen wurde, und die schwerpunktmäßige Besetzung des Nationalen Sicherheitsdienstes mit ,Rückkehrern' ab 1994 vgl. Frisch 2008: 80 f. Dies galt nicht für den sogenannten Präventiven Sicherheitsdienst, der auch mit Palästinensern aus den palästinensischen Gebieten besetzt wurde.
} 
In der Situation sei ihm dies nicht klar gewesen, aber nun denke er, ,, all the people in Ramallah, don't care they don't be- do anything [...] they want to be: happy, just“. In dieser Passage klingt einerseits an, inwiefern Hamzeh die Straßenschlachten zunehmend als eigentlich wirkungslose und von umfassender politischer Mobilisierung der palästinensischen Bevölkerung isolierte Unternehmungen begreift. Andererseits klingt in diesen Passagen auch ein Bild der Bevölkerung Ramallahs als politisch indifferent und hedonistisch an. Anstatt eine deutliche Abgrenzung gegenüber diesem Sie-Bild vorzunehmen, fasste Hamzeh vielmehr den Vorsatz, sich nun daran zu orientieren: ,when I went to prison (2) my mind changed (3) after the prison I didn't want to do anything, I want to stay cool like the people, I wanna be happy too“. In seinen Ausführungen grenzte Hamzeh in knappen Zügen die gegenwärtige kollektivgeschichtliche Konstellation, die eben ,keine gute Zeit fürs Kämpfen' sei, gegenüber der politischen Mobilisierung in den palästinensischen Gebieten der 1980er Jahre ab, als man ,auf eigene Faust' an den Straßenschachten habe teilnehmen und machen können, was man wollte:

Hamzeh: „it's a different situation than before, before everybody could do anything he wanted but now no, cause you know it's peace and something I don't, eh it's shit, so: I said what I did it is not the right time, for it' it's not a good time“"

In dieser Passage klingt bei Hamzeh, vergleichbar mit Iyads romantisierender Idealisierung der Ersten Intifada, wenn auch ohne familiengeschichtlichen Bezug, eine positive Bezugnahme auf eine zurückliegende ,Kampfzeit ${ }^{\star}$ und das damit verbundene Erleben von Abenteuer und Handlungsmacht an („,could do anything $\left.{ }^{6}\right)$.

Insgesamt zeichnet sich ab, dass die Straßenkämpfe und insbesondere die Inhaftierung durch die PA als Haft bei den ,eigenen Leuten' bei Hamzeh einen Reinterpretationsprozess angestoßen haben, die ihm das Gefühl gaben, in den Widerstandsaktionen isoliert zu sein und sich nicht an vergangenen Phasen palästinensischer politischer Mobilisierung der 1970er und 1980er Jahre und der Ersten Intifada orientieren zu können. Im Reinterpretationsprozess scheinen seine Handlungspläne nun eher auf ein pragmatisches Arrangieren mit der kollektivgeschichtlichen Konstellation hinauszulaufen. Hamzeh sah diesen Reinterpretationsprozess auch durch den Dialog mit seinem Vater angestoßen, mit dem er in den letzten Wochen häufig gesprochen habe. Er führte aus, sein Vater habe ihm gesagt, „I am not (2) saying what you what you did is wrong, cause it's not wrong“". Es sei aber nicht die richtige Zeit für diese Dinge. Derzeit mache er sich damit nur Probleme und seine Gelegenheit, sich ,für die palästinensische Sache einzusetzen, werde noch kommen. Sein Vater habe weiterhin gesagt:

Hamzeh: ,you will take, have another chance to do what you want, I promise (2) what you want will happen soon, if not now after, ten years twenty years $[\ldots]$, but now the time is, not good to do these things". 
Hamzeh selbst fand dies, wie er angab, nachvollziehbar, gerade sei tatsächlich nicht die ,richtige Zeit fürs Kämpfen'. Es wurde deutlich, dass sowohl Hamzeh als auch sein Vater seine pragmatische Reorientierung auch als Abwarten kollektivgeschichtlich günstigerer Bedingungen für Widerstandsaktionen sahen. Hamzehs Erzählungen lassen sich hier zudem als Hinweis darauf lesen, wie gering das Vertrauen seines Vaters, immerhin Geheimdienstoffizier, gegenüber dem Bestand der Autonomiebehörde und gegenüber dem Stand des palästinensischen Staatsbildungsprojektes war. Hamzeh deutete auch in anderen Zusammenhängen Sympathien seiner Eltern für seine ,Widerstandsaktionen' an, auch seine Mutter habe ihm nie gesagt, es sei falsch, was er tue.

In den weiteren Gesprächen mit Hamzeh, etwa bei einem Feldaufenthalt im Herbst 2011 sowie bei späteren Treffen mit den anderen jungen Männern im Frühjahr 2015, zeichnete sich ab, dass die Reinterpretationsprozesse in eine biographische Reorientierung Hamzehs mündeten. Hilfreich dafür waren auch die berufliche Position seines Vaters und die mit dieser verbundenen klientelistischen Chancen. Hamzeh verließ einen Monat nach der Verurteilung durch ein Gericht der PA im Oktober 2010 das Gefängnis der PA. Durch die Verbindungen seines Vaters, auf die er schon im Interview im Spätsommer 2010 hingewiesen hatte, bekam er nach der Entlassung zunächst eine kleinere Beamtentätigkeit in der PA vermittelt (,with my father and a general who's owning the place there"). Er blieb offenbar einige Monate von den israelischen Sicherheitsbehörden "gesucht", konnte sich jedoch in dieser Zeit versteckt halten. Nach einiger Zeit wurde sein Status als „Gesuchter“" wohl aufgehoben, jedenfalls berichtete der Vater eines der anderen, im Zusammenhang mit dem Vorfall um den Jeep gesuchten jungen Männer in einem Gespräch im Frühjahr 2015, dass es Hamzehs Vater gelungen sei, die Akten des Sohnes zu ,bereinigen“ und den Status „gesucht“" aufheben zu lassen. Ebenfalls im Jahr 2015 erzählte mir Iyad, dass er seit einer Weile keinen Kontakt mehr mit Hamzeh habe. Dieser habe geheiratet und arbeite selbst weiterhin für den Geheimdienst. Ein weiteres Treffen mit Hamzeh, das ich versuchte über Iyad zu arrangieren, kam nicht zustande.

Der Abschnitt machte deutlich, inwiefern Hamzeh vor dem Hintergrund seiner Inhaftierungserfahrungen seine Involvierung in die Straßenschlachten reinterpretierte. Er deutete die Straßenschlachten dabei zunehmend als in der gegenwärtigen Situation im Westjordanland sinnlose, nicht in den größeren gesellschaftlichen Rahmen einer politischen Mobilisierung der palästinensischen Gesellschaft eingefasste Aktionen. Dabei kontrastierte er - analog zu den oben diskutierten Äußerungen Iyads - Phasen breiter politischer Mobilisierung, in denen die Involvierung in die Straßenschlachten erwünscht und mit dem Erleben von Handlungsmacht verbunden war, mit der kollektivgeschichtlichen Gegenwart, die ,keine Zeit fürs Kämpfen' sei. Sein Selbst-Bild als ,Kämpfer für die palästinensische Sache ${ }^{6}$ und seine ambivalente Stellung gegenüber der PA zwischen politischer Ablehnung der von westlichen und israelischen Interessen bestimmten Institution, 
die ihre ,eigenen Leute' verhafte, auf der einen Seite und erheblicher biographischer Ressource, die ihn vor Verfolgung schützte und, familial vermittelt, auch mit Lebenschancen versorgte, auf der anderen Seite verhandelte er mit einem pragmatischen Arrangieren auf Zeit und einem Abwarten auf eine ,bessere Zeit zu kämpfen'. Dieses Abwarten rechtfertigte er mit der Annahme, dass es in absehbarer Zeit zu einem neuen palästinensischen Aufstand kommen würde, der sich auch gegen die PA richten und deren Zerfall zur Folge haben würde. Hamzeh fühlte sich in dieser Annahme auch von seinem Vater gestützt. All das weist außerdem, wie ich bereits an anderer Stelle erwähnt habe, auf den Legitimitätsverlust der PA hin, der hier offenbar bis in das Milieu ihrer wahrscheinlichsten Unterstützer im Sicherheitsapparat reicht.

\subsubsection{Zusammenfassung: Deutungsmuster, Wir und Sie-Bilder der Clique}

In den vorangegangenen Abschnitten sind die Deutungsmuster und die Wir- und Sie-Bilder einer Clique junger Männer aus Ramallah diskutiert worden. Diese umfassen folgende Aspekte: In den Deutungsmustern der jungen Männer offenbart sich (a) ein Wir-Bild als ,Kämpfer für die palästinensische Sache`, in welchem die eigene Bereitschaft zum ,Kampf auf der Straße und zur ,Verteidigung Ramallahs` demonstrativ hervorgehoben und beschworen wird. In den Deutungsmustern kommt (b) eine Orientierung an und eine Sehnsucht nach der ,verpassten' Ersten Intifada oder - in manchen Bedeutungskonstruktionen auch diffuser bleibend nach einer ,verpassten Kampfzeit' zum Ausdruck. Diese ,frühere Phase‘ dient als Kontrastfolie für die Deutung der kollektivgeschichtlichen Periode seit den OsloVerträgen und seit der Zweiten Intifada als langweilig, hedonistisch und als ,falsche Zeit fürs Kämpfen'. Die jungen Männer verbinden (c) ihr Selbstbild als „Kämpfer für die palästinensische Sache` zwar durchaus mit einer Abgrenzung gegen eine vermeintlich ,unpolitische', hedonistische Bevölkerung Ramallahs, jedoch nicht mit einer als gesellschaftlich marginalisiert erlebten eigenen sozialen Position. Dieser Aspekt stellt einen deutlichen Unterschied zu den Deutungsmustern und Wir-Bildern der Clique junger Männer aus der Flüchtlingslager-Gegend dar.

Zudem schwankten die jungen Männer in den Gesprächen und Interviews unter dem Verfolgungsdruck durch die israelischen Behörden zwischen einer demonstrativen Aufrechterhaltung des Wir-Bildes als Kämpfer und der damit verbundenen demonstrativen Bereitschaft zum ,Kampf auf der Straße einerseits und einem pragmatischen Arrangieren ,auf Zeit ${ }^{`}$ mit der PA und der israelischen Besatzung andererseits. Im diskutierten Datenmaterial deutet sich zudem an, dass die biographischen Handlungsorientierungen sich von diesem Fokus auf, Widerstand in Richtung der ,Sicherung der eigenen Lebenschancen (Ausbildung, Beruf, Heirat) ${ }^{6}$ verschieben. In diesem Zusammenhang kann man von einer biographischen Reorientierung sprechen, die im Hinblick auf die familiale und biographische Nähe zur PA zu interpretieren ist. Die Nähe zur PA, die die jungen Männer eigent- 
lich dezidiert ablehnen und sogar in die Nähe der Unterdrückung des ersehnten Aufstands stellen, bringt für die jungen Männer klientelistische Chancen mit sich, die sie pragmatisch nutzen. Die Verbindungen von Familienmitgliedern gerade in die Sicherheitsdienste der PA erhöhen nicht nur Lebenschancen, sondern auch die Chance, sich einer Verfolgung durch die israelischen Sicherheitsbehörden zu entziehen. Die familiale Nähe zur PA als biographische Ressource nutzen zu können, findet sich auch im Kontext der Clique aus der Flüchtlingslager-Gegend, ist aber im Kontext der Ramallah-Clique von Rückkehrern und Zugezogenen deutlich ausgeprägter vorhanden.

\subsection{Falldarstellung Familie Haziin: „Alles ist weggegangen nach ein paar Jahren hier"6}

In diesem Kapitel möchte ich die oben herausgearbeiteten Deutungsmuster, Wirund Sie-Bilder der Clique junger Männer aus Ramallah zu längerfristigen kollektiv, familien- und lebensgeschichtlichen Prozessen ins Verhältnis setzen. Besondere Bedeutung haben hier die familialen Tradierungsprozesse und die Verhandlung familialer Aufträge, die vor dem Hintergrund der Kollektiv- und Familiengeschichte mit der ,Rückkehr' ins Westjordanland in Zusammenhang stehen. Meine Rekonstruktionen haben ergeben, dass die familiale Verhandlung eines desillusionierten Immigrationsprojektes in das Westjordanland und die damit einhergehenden krisenhaften palästinensischen Zugehörigkeitsgefühle in der Elterngeneration zur Entstehung und Tradierung eines ambivalenten ,Kampfauftrauftrags ${ }^{6}$ beitragen. Im Unterschied zu der in Kapitel 6 diskutierten Falldarstellung aus der Flüchtlingslager-Gegend ist die familiale Interaktion in der hier dargestellten Familie Haziin jedoch kaum von einer Herstellung und Verhandlung unterschiedlicher historisch-generationaler Zugehörigkeiten und damit einhergehender Differenzen in den Deutungsmustern, Wir- und Sie-Bildern geprägt.

Für diese Dynamiken exemplarisch stelle ich im Folgenden die Falldarstellungen von Alaa und seinem Vater Hussam Haziin vor. Alaa wurde bereits im vorangegangenen Kapitel erwähnt. Er war mit den ebenfalls bereits vorgestellten Iyad und Hamzeh befreundet und zum Zeitpunkt der Interviews und Gespräche mit den jungen Männern im Spätsommer bis Herbst 2010 gemeinsam mit Hamzeh bei der PA im offenen Vollzug inhaftiert, um sich einer möglichen Verhaftung durch die israelischen Behörden zu entziehen (vgl. Kap. 7.2). Alaas Vater Hussam wurde von Ahmad Albaba und mir im Frühjahr 2015 in mehreren Sitzungen interviewt. Im Folgenden gehe ich zunächst auf die in den Interviews und Gesprächen entwickelten thematischen Felder ein. Daran anschließend stelle ich die Familien- und Lebensgeschichten von Alaa und Hussam vor, die in der chronologischen Darstellung verflochten werden. Dabei möchte ich im Rahmen der Fallgeschichte Alaas auch einige über Alaas Biographie hinausgehende Hinweise auf den Konstituti- 
onsprozess der Clique von Hamzeh, Iyad und Alaa und auf die Interaktionsgeschichte unter den jungen Männern geben.

\subsubsection{Thematische Felder und Interaktionsdynamiken im Interview}

Im Interview und in weiteren Gesprächen bewegte sich Alaa vorwiegend innerhalb der ,Koordinaten“ des Deutungsmusters, welches für Alaa, Hamzeh, Iyad und deren Freunde im vorangegangenen Kapitel herausgearbeitet worden ist (vgl. Kap. 7.2). Das biographisch-narrative Interview mit Alaa wurde im Oktober 2010 von Anan Srour und Filip Habib in arabischer Sprache geführt. Es fand im selben Café statt, in welchem bereits die ersten Treffen mit Iyad und Hamzeh stattgefunden hatten. Beide waren zum Zeitpunkt des Interviews mit Alaa anwesend, saßen jedoch mit Bekannten in einer anderen Ecke des Cafés. Das Gespräch fand kurz nach Alaas und Hamzehs Verurteilung durch ein Gericht der PA statt. Alaa befand sich zu dieser Zeit weiterhin im ,offenen Vollzug', war also nachts inhaftiert (vgl. Kap. 7.2.1-7.2.2). Alaa nutzte das Interview, um erneut seine Bereitschaft zur ,Verteidigung Ramallahs auf der Straße zu unterstreichen, und ordnete sich hier in das Wir-Bild jener ,Kämpfer ${ }^{6}$ ein, die sich für den Zusammenbruch der PA und einen absehbaren palästinensischen Aufstand bereithielten:

Alaa: „Sie [das israelische Militär] wollen dass alles schön ruhig ist wenn sie in die Städte kommen und ohne irgendwelchen Widerstand, wir akzeptieren das nicht die PA akzeptiert das einfach [...] die Situation wird so nicht weitergehen es wird sowas wie (2) yani eine chaotische Situation entstehen, das wird bald kommen und die PA ist jetzt immer stärker aber wird bald bedroht sein und eine andere Intifada auch wird auch bald passieren wir leben ein ruhiges Leben für fünf sechs Jahre dann passiert eine weitere Intifada“.

Weiterhin war Alaas demonstrative Betonung der eigenen ,Kampfbereitschaft ${ }^{6}$ auch hierin besteht eine Parallele zum herausgearbeiteten Deutungsmuster und zu den Selbstpräsentationen Iyads und Hamzehs - von Anspielungen auf eine vergangene ,Kampfphase' durchzogen, die Alaa leider ,verpasst ${ }^{‘}$ habe:

Alaa: ,aber wenn Fatah sagt, dass sie den Widerstand stoppen, ich höre auf jeden Fall nicht auf ich bleibe Fatah und höre nicht auf du weißt ja von meinem Leben dies ist mein halbes Leben wenn wenn ich meine Kindheit hier verbracht hätte ich hätte die Erste Intifada gelebt aber ich hab nicht hier gelebt".

Alaas Bemerkung zu seinem ,halben Leben` bezog sich darauf, dass er erst seit dem Alter von ungefähr zehn Jahren im Westjordanland lebte. Alaa stammt, wie Hamzeh, aus einer Rückkehrer-Familie, die erst in den 1990er Jahren aus Jordanien ins Westjordanland immigriert war. Ähnlich wie Iyad und Hamzeh deutete Alaa eine Art Wehmut darüber an, nicht die Chance gehabt zu haben, in der auch von Straßenkämpfen gekennzeichneten und von den jungen Männern allgemein mit 
,Abenteuer ${ }^{\varsigma}$ verbundenen Ersten Intifada gekämpft und sich in dieser verdient gemacht zu haben (vgl. Kap. 4.5; 7.2.2). Auch in einem anderen Zusammenhang bezog er sich positiv auf die ,Kampfphase“ der Ersten Intifada, etwa wenn er lobte, dass man in jener Zeit rigoros gegen Kollaborateure vorgegangen sei.

Zum Zeitpunkt des Interviews war Alaa bereits seit einigen Jahren im Ministerium für Tourismus der PA beschäftigt. Im Interview war diese Beschäftigung trotz deren offensichtlicher Distanz zu sicherheitspolitischen Beschäftigungsfeldern für ihn rechtfertigungsbedürftig: „Ich habe hier im Land keine andere Chance ich bin gerade aus dem Gefängnis also habe ich keine Aussicht auf eine andere Arbeit“. Alaa war außerdem bekannt, dass Hamzeh eine Beschäftigung beim palästinensischen Geheimdienst in Aussicht hatte (vgl. Kap. 7.2.2), die er im Gespräch ebenfalls zu legitimieren versuchte. Die Tätigkeit für den Geheimdienst sei kein Problem, denn sie verändere Hamzehs innere Haltung nicht:

Alaa: „er hat nach einer Arbeit geguckt er wird Soldat bei der PA sein da ist kein Problem Soldat zu sein aber also keiner kann wegnehmen was in dir ist es ist möglich vom Äußeren dass du Uniform trägst und Kalaschnikow aber dein Inneres wird nicht verändert".

Insgesamt waren die von Alaa im Interview angesprochenen lebensgeschichtlichen Themen vorwiegend von den im Deutungsmuster als ,Kämpfer für die palästinensischen Sache' zum Ausdruck kommenden Relevanzen bestimmt. Dabei waren diese Themen, die sich auf die Teilnahme an den Straßenschlachten, die Inhaftierung durch die PA und die Reaktionen seines Umfelds auf seine Verhaftung bezogen, durchaus in längeren Passagen erzählerisch ausgestaltet. Andere lebensgeschichtliche Bereiche, wie etwa Alaas in Jordanien verlebte Kindheit, kamen im Interview dagegen kaum zur Sprache und konnten dementsprechend in der Auswertung nur in Ansätzen rekonstruiert werden.

Einige Jahre nach dem Interview mit Alaa trafen wir erneut Alaas Vater Hussam. Er war bereits Filip Habib als Teil des deutschen Forschungsteams im Herbst 2010 begegnet. Mit Verweis auf dieses Treffen einige Jahre zuvor hatten Ahmed Albaba und ich Hussam während eines mehrmonatigen Feldaufenthaltes in Ramallah im Frühjahr 2015 kontaktiert und ihn gefragt, ob er uns, wie sein Sohn damals, ein „Interview über seine Lebensgeschichte“ geben würde. Hussam hatte einem Treffen zugestimmt, ohne sich vorab weiter nach unserem Anliegen und dem Interviewformat zu erkundigen. Das Interview führten Ahmad Albaba und ich in der ersten Sitzung in Hussams Büro, das in einem Appartementblock am Stadtrand Ramallahs lag. Es war der Redaktionssitz einer kleinen NGO, die ein lokales Kulturmagazin herausgab und dessen Herausgeber Hussam war. Das Kulturmagazin war darüber hinaus auch eine Plattform für - wie ich später aufgreifen werde - Hussams eigene schriftstellerische Tätigkeiten. Weitere Sitzungen des Interviews führten wir in Hussams Wohnung in Ramallah durch, in der er mit 
seiner Frau und seinen zwei jüngsten Kindern lebte. Die Interviews und Gespräche wurden in arabischer Sprache geführt.

Zu Beginn der ersten Interviewsitzung im Frühjahr 2015 wurde deutlich, dass sich Hussam von dem Kontakt zu uns auch Aufmerksamkeit und Empathie für das erhoffte, was in seinen Augen seinem Sohn Alaa nach der Verhaftung durch die PA widerfahren war. Alaa war nach der bei der PA abgesessenen Haftstrafe von den israelischen Behörden verhaftet und zu einer weiteren fünfjährigen Haftstrafe verurteilt worden, von der er zum Zeitpunkt unseres Treffens im Frühjahr 2015 noch circa acht Monate zu verbüßen hatte. Nach einer kurzen Vorstellung unsererseits, wir seien von einer deutschen Universität und Teil des Teams, das damals auch mit Alaa und ihm gesprochen hätte, kam Hussam auf die Beteiligung seines Sohnes an den Straßenkämpfen und seine Verhaftung durch die PA sowie auf die spätere erneute Verhaftung durch die israelischen Behörden zu sprechen. Hussam machte der PA schwere Vorwürfe: Man habe ihnen zugesichert, dass es bei der Verurteilung durch die PA bleiben würde, dann aber sei Alaa nach acht Monaten Inhaftierung durch die PA von den israelischen Behörden verhaftet und erneut zu einer fünfjährigen Haftstrafe verurteilt worden. Man könne sich nicht vorstellen, zu was die PA im Stande sei:

Hussam: „Als Vater von Alaa bin ich nicht traurig, dass er bei den Israelis [inhaftiert] ist, ich bin traurig, weil die PA ihn verhaftet hat [...] Jedes Jahr wird der Widerstandsgeist schwächer, weil die Leute Angst vor der PA bekommen, aber wenn ein Patriot auftaucht dann schließe ich mich an auch wenn ich 60 Jahre bin“.

Er sei auch skeptisch, was mich angehe, sagte Hussam zu mir gewandt. Die meisten Bilder von Jugendlichen, die Steine und Molotow-Cocktails werfen, würden von Ausländern gemacht, die diese an den israelischen Geheimdienst weiterleiten würden. Als ich ihn fragte, ob er uns irgendetwas fragen möchte, was ihm diese Skepsis nehmen könnte, antwortete er, es gehe schon, manche Ausländer seien auch solidarisch, aber es gebe mit ihnen immer diese Unsicherheit. Außerdem sei mein palästinensischer Kollege, gemeint war Ahmad Albaba, dabei, das gebe ihm Vertrauen. Aufgrund dieses Gesprächbeginns hatte ich wenig Hoffnung, dass sich aus unserem Treffen ein längeres lebensgeschichtliches Interview ergeben würde. Im Laufe des Treffens entwickelte sich die Gesprächsrahmung aber, vermutlich aufgrund des ,raumgebenden“ Interviewformats, zunehmend zu einem biographisch-narrativen Interview mit langen erzählerisch ausgestalteten Passagen allerdings deutlich unterstützt durch mein beständiges narratives Nachfragen. So ließ sich Hussam zunehmend auf Erinnerungsprozesse ein - nach etwa drei Stunden Interviewdauer sagte er im Nachfrageteil an mich gewandt:

Hussam: „frag ((lacht)) es ist eine großartige Gelegenheit für dich (3) also eh du hast viele= viele von meinen Erinnerungen aktiviert". 
Interviewer: „Und wie ist das für dich?“

Hussam: „schön, sehr schön“.

Mit der Verschiebung der Interaktionsrahmung entwickelte Hussam ein thematisches Feld, das einerseits um sein mit der verpassten Chance auf formale Bildung verbundenes Selbstbild als Schriftsteller und andererseits um seine mit diesem Selbstbild verbundene tiefe Enttäuschung als ,Rückkehrer' über das stagnierende palästinensische Staatsgründungsprojekt und die politischen Verhältnisse in den palästinensischen Gebieten kreiste.

Hussam: „Vielleicht wenn du irgendeinem Palästinenser in Jordanien sagst gib mir 50.000 Dollar dafür dass du ins Westjordanland zurückkehren kannst wird er irgendwie dieses Geld besorgen damit er ins Westjordanland zurückkehren kann, und ich als einer der diese Erfahrung gemacht hat also zurückgekommen ist hab ich festgestellt dass dieser Traum den wir hatten in Amman zu einem Albtraum geworden ist, eigentlich ein Albtraum den wir leben".

Hussam zählte in der Folge die ,Verfehlungen' der PA auf: Sie hätten kein Gesundheitssystem, keine Arbeitspolitik und ein Gesetz, das die Rechte von Frauen betreffe, liege seit 20 Jahren in den Schubladen des Palästinensischen Legislativrats. Es gebe überhaupt keine richtigen staatlichen Institutionen, derjenige, der das Sagen habe, sei „der Obrist in Beit Il“, eine Anspielung auf einen israelischen Verwaltungssitz in der nahe gelegenen Siedlung.

Die Verurteilung und Inhaftierung seines Sohnes hatten Hussams Ablehnung der PA sowie seine Entfremdung von den politischen Verhältnissen im Westjordanland sicherlich zugespitzt und zur Krise seiner nationalen Zugehörigkeit und seines nationalen Wir-Gefühls beigetragen. Biographisch setzte diese Krise bereits früher ein, insbesondere in der stagnierenden politischen Phase seit der zweiten Hälfte der 2000er Jahre. Diese Zugehörigkeitskrise ist jedoch nur versteh- und erklärbar vor dem Hintergrund der ,Rückkehr' Hussams und seiner Kernfamilie ins Westjordanland aus der Diaspora in Jordanien im Zuge des Oslo-Prozesses Ende der 1990er Jahre und der figurationalen Positionierung Hussams in Jordanien vor der Migration. Sie bildet auch den Hintergrund für die Tradierung an und die Interaktion mit Alaa, die in dessen Wir-Bild als ,Kämpfer ${ }^{6}$ und in seine Involvierung in die Straßenschlachten hineinspielen. Diese zugrunde liegenden kollektiv-, familien- und biographischen Prozesse möchte ich im Folgenden aufzeigen.

\subsubsection{Familien- und Lebensgeschichte}

\section{Umzug nach Zarqa}

Die Familien von Hussams Eltern waren seit mehreren Generationen im ländlich geprägten Umland Hebrons ansässig und bewirtschafteten dort Felder. Abdelma- 
jid, Hussams Vater, war 1932 geboren worden. Er hatte eine vierjährige schulische Ausbildung im Dorf absolviert, danach war er zunächst in die landwirtschaftliche Tätigkeit der Familie eingebunden worden. Hind, Hussams Mutter, war ebenfalls in den 1930er Jahren geboren worden und stammte aus demselben Dorf. Sie hatte vermutlich keine schulische Bildung. Abdelmajid und Hind heirateten circa 1950, das erste Kind der Familie, Nabil, Hussams älterer Bruder, wurde 1952 geboren. Abdelmajid fand wohl 1955 mit 23 Jahren eine Anstellung in der Arabischen Legion. Von der ehemaligen britischen Kolonialmacht Anfang der 1920er Jahre gegründet, wurde die Legion Ende der 1940er Jahre nach dem verlorenen Krieg von 1948/49 in die regulären Streitkräfte Jordaniens überführt und gleichzeitig massiv ausgebaut. Im Zuge des weitreichenden Ausbaus wurde Personal gerade für den im Aufbau befindlichen logistischen und technischen Dienst, der etwa die Wartung der motorisierten Einheiten umfasste, angeworben. In jenen neuen Abteilungen fanden auch viele Palästinenser aus dem Westjordanland eine Anstellung (Vatikiotis 1967: 26 f.). Voraussetzung war hier unter anderem eine rudimentäre Schulbildung, die Abdelmajid aufweisen konnte. Die Arbeitsstelle Abdelmajids erforderte einen Ortswechsel der Familie. Die Kernfamilie bestehend aus Abdelmajid, Hind und Nabil zog Mitte der 1950er Jahre nach Hebron. Hier wurde 1955 auch Hussam als zweites Kind der Familie geboren. Bereits circa 1960 zog die Familie, vermutlich im Zusammenhang mit einer Truppenverlegung, nach Zarqa, welches bereits zu jener Zeit größere Stützpunkte für die Polizei- und Militärkräfte Jordaniens beherbergte. Dort wurden in den folgenden Jahren auch weitere Geschwister Hussams geboren. Hussam wuchs in Zarqa auf und besuchte eine Schule in der Stadt. Das Gehalt des Vaters bot der Familie in den 1960er Jahren ein verlässliches, allerdings geringes Einkommen. Im Interview sprach Hussam davon, in seiner Kindheit hätten sie in „Armut“ gelebt. Regelmäßig sei nach der Hälfte des Monats das Geld ausgegangen.

Der Ausbau der Armee in den 1950er Jahren fiel in eine politisch instabile Phase des erst 1946 von britischer Mandatsherrschaft unabhängig gewordenen Königreichs Jordanien (vgl. Kap. 4.3). Die Armee hatte sich aus eng an das Königshaus gebundenen beduinischen Verbänden sowie britischen Truppen rekrutiert und mit dem Ausbau stellte sich die Frage der Loyalität gerade der neuen palästinensischen Truppenteile. ${ }^{135}$ Die Frage stellte sich insbesondere vor dem Hintergrund des Bedeutungsgewinns panarabistischer Ideen in der arabischen Welt in den 1950er Jahren, die auf die Vereinigung selbiger in einem Nationalstaat

\footnotetext{
135 Das Haschemitische Königshaus, das sich seit der Mandatsgründung auf beduinische und britische Verbände stützte, hegte Misstrauen gegenüber den Städtern und, Westjordanländlern', die sie in die nicht-kämpfenden Einheiten schob: „But the Hashemites had developed a very strong relationship with the Bedouin population during the 1930s and 1940s and felt less comfortable with the Jodanian Hadaris [Städter]; they did not trust the Palestinians at all [...] recruits were strictly segregated within the military. Ultimately ,West Bankers“ were related to technical services" (Pollack 2002: 286).
} 
zielten $^{136}$ und in die gerade arabische Offizierskorps involviert waren. Hussam beschrieb seinen Vater als in den 1950er und 1960er Jahren überzeugten Anhänger des ägyptischen Führers Gamal Abdel Nasser, der als einer der wesentlichen Protagonisten des panarabistischen Nationalismus galt und der unter vielen palästinensischen Jordaniern populär war. In der Familie wurde der ägyptische Radiosender Sawt al Arab ${ }^{137}$ gehört. Hussam erinnerte auch, dass Abdelmajid und Nabil, zu dieser Zeit bereits in jugendlichem Alter, an ,panarabistischen' Demonstrationen teilgenommen hätten, etwa anlässlich des Besuches des damaligen tunesischen Staatschefs Habib Bourguiba in Jordanien:

Hussam: „Ich erinnere mich noch an diese Sache weil mein Vater dabei war und auch mein Bruder bei dieser Kampagne er ist drei Jahre älter als ich [...] sie waren bei einer Demo in Hebron gegen den Tunesier Bourguiba ehhh als Bourguiba das Westjordanland besuchte und die Villen sah von Palästinensern in Quds und in Beit Hanina hat er gesagt ich denke ihr solltet eigentlich Frieden schließen mit Israel es gebe keinen Grund für weitere Kriege mit ihnen und deshalb haben die Palästinenser eine Demo gemacht und die Polizei hat sie zerschlagen was dafür sorgte dass also dass viele verletzt waren und ins Krankenhaus mussten ja das ist in meiner Erinnerung seit 50 Jahren“.

Hussam erinnerte sich hier vermutlich an die Proteste im Anschluss an die sogenannte Jerichoer Rede Habib Bourguibas, die dieser anlässlich eines Besuches in Jordanien 1965 gehalten hatte. In der Rede hatte Bourguiba Friedensverhandlungen und eine mögliche Anerkennung Israels durch die arabischen Staaten ins Spiel gebracht. Die Rede war in den arabischen Medien auch als Angriff auf die Position Abdel Nassers gewertet worden und hatte Proteste in Jordanien und anderen arabischen Ländern, etwa im Libanon, zur Folge gehabt (Kassir 2011: 459). Insgesamt kann man in dieser Phase vermutlich von einer panarabistischen Orientierung des Vaters und des Bruders Hussams sprechen. Im Interview sprach Hussam auch von Anekdoten über die Familiengeschichte, die ihm seine Eltern während seiner Kindheit in Zarqa erzählt hätten und die inhaltlich unter anderem auf den Arabischen Aufstand von 1936-1939 und auf eine familiale ,Verwurzelung' im Westjordanland Bezug nahmen:

\footnotetext{
${ }^{136}$ Ideen arabisch-nationaler Einigung waren bereits in den 1920er und 1930er Jahren von arabischen Intellektuellen im Kontext antikolonialer, antiimperialistischer und antizionistischer Auseinandersetzungen aufgegriffen worden (vgl. Böhme/Sterzing 2012: 22). Auch die Niederlage im Ersten Arabisch-Israelischen Krieg war einer fehlenden arabischen Einigung zugeschrieben worden (vgl. Kimmerling/Migdal 2003: 225-227).

${ }^{137}$ Ein aus Kairo ab 1953 ausgestrahlter Radiosender, der insbesondere in den 1950er und 1960er Jahren in der arabischen Welt populär war. Der Sender galt als Sprachrohr der Politik des ägyptischen Führers Gamal Abdel Nasser und insgesamt für arabische Einigung. Mit Bezug auf Jordanien mobilisierte der Sender unter anderem gegen Jordaniens Beitritt zum Bagdad Pakt und die damit verbundene Orientierung am, Westen'.
} 
Hussam: ,,ich erinnere mich sie hat uns erzählt wir hätten eine Festung in unserem Dorf vor 400 Jahren gebaut von unseren Vorfahren [...] die ganze Dar ${ }^{138}$ Haziin lebte dort in der Festung sie hat uns die Geschichte erzählt die 1936 während des britischen Mandats passierte sie hat uns von der Revolution von 1936 erzählt gegen die Briten und wie die Briten ins Dorf gekommen seien und einen von den Alten von der Hamula Haziin töteten weil unser Dar die $=$ die Rebellen versorgt hat mit Proviant und Wasservorräten und daher haben die Briten den Namen verändert es wird noch gekannt als Beit Haziin von den Leuten die älter als 80 Jahre sind“.

In den vereinzelten Angaben in der Forschungsliteratur, die zum Herkunftsort in der britischen Mandatsphase existieren, die ich hier aber aufgrund der Nähe zum Familiennamen nicht nennen kann, habe ich keine Hinweise auf die von Hussam erwähnte Rolle der Mandatstruppen gefunden. Allerdings finden sich Hinweise auf eine in verschiedenen Berichten auftauchende Tötung eines Sheiks im Dorf, die entweder einer Auseinandersetzung zwischen Clans oder den Truppen Ibrahim Paschas während der ,ägyptischen Besatzung' 1831-1840 zugeschrieben wird. An dieser Stelle ist vor allem interessant, in welcher Weise die Tradierung gerahmt wird. Die hier vorgebrachte Variante der Familiengeschichte ,passt' in ihrer Rahmung mit ihrem gegen die britische Mandatsmacht gerichteten Antikolonialismus in die panarabistische Orientierung der Familie in jener Phase. Gleichzeitig konstruieren die Geschichten der Mutter den Eindruck familialen Wohlstandes und einer machtvollen Position der Familie in ihrer ,Herkunftsregion'. Hussam evaluierte diese Passagen im Interview mit der Einschätzung, aufgrund der Erzählungen der Mutter habe er „Liebe zum Land“ gehabt. Es ist nicht unwahrscheinlich, dass solche familiengeschichtlichen Anekdoten Hussams idealisiertes Bild von und eine romantische Bindung an ,Palästina' förderten. Diese idealisierte nationale Zugehörigkeit geht auch in die Erwartungen ein, die Hussam zu einer späteren Phase seiner Biographie gegenüber einer Migration in das Westjordanland hegte.

\section{Nach dem jordanischen Bürgerkrieg: Prekäre berufliche Stellung und nationale Wir-Gefüble}

Um 1967 schied Abdelmajid aus mir nicht weiter bekannten Gründen aus dem Militärdienst aus. Nur wenige Monate nach Abdelmajids Ausscheiden erlitt Jordanien im Juni 1967 im nur wenige Tage geführten zweiten Arabisch-Israelischen Krieg zwischen Israel und Ägypten, Jordanien sowie Syrien eine massive militärische Niederlage. Die Niederlage Jordaniens und der anderen arabischen Staaten gegen Israel war insbesondere auch eine Niederlage Nassers und des Panarabismus, der in den folgenden Jahren erheblich an Popularität einbüßte (vgl. Kap. 4.3). In der zweiten Hälfte der 1960er Jahre wurde die bereits erstarkende PLO in Jordanien mit zunehmender Deutlichkeit zu einer Bedrohung für die Souveränität des Königs und des jordanischen Staates (Shlaim 2008: 312). Der sich abzeich-

138 Arabisch für Haus beziehungsweise Heim oder für die (ganze) erweiterte Familie. 
nende Konflikt zwischen der PLO und dem Staat kulminierte schließlich im sogenannten Jordanischen Bürgerkrieg zwischen circa Juni 1970 und Juli 1971. Im Juni kam es in mehreren jordanischen Städten, zunächst in Zarqa und insbesondere in Amman, zu mehrtägigen bewaffneten Auseinandersetzungen zwischen palästinensischen Milizen der PLO und der jordanischen Armee. Nach zwei fehlgeschlagenen Attentaten auf den jordanischen König, dem Artilleriebeschuss von palästinensischen Flüchtlingslagern und einer brüchigen Waffenstillstandsphase führte die jordanische Armee ab September 1970 (,Schwarzer September") eine Großoffensive durch, die im Ergebnis zur Zerschlagung der palästinensischen paramilitärischen Gruppierungen in Jordanien und dem Umzug der PLO vorwiegend in den Libanon führte. Auch in Zarqa kam es, etwa im Juni 1970 und während der Septemberoffensive, zu Kämpfen zwischen jordanischen Truppenverbänden und palästinensischen Milizen. Von den Mitgliedern von Hussams Familie war jedoch vermutlich niemand in die direkten Kampfhandlungen involviert oder von diesen in größerem Ausmaß, etwa durch Verletzungen, betroffen. Hussam, zu jener Zeit um die 15 Jahre alt, evaluierte im Interview diese Phase folgendermaßen:

Hussam: ,schlimm war es in den 70ern in der Zeit des Krieges zwischen Palästinensern und Jordaniern, wie du weißt die meisten der Neuigkeiten die die Leute bekommen während Bürgerkriegen sind nicht wahr, ich meine wir haben in einer Gegend gelebt in der 90 Prozent Jordanier waren vielleicht haben sie uns gut behandelt weil wir ein gutes Verhältnis hatten es war aber eine Periode der Angst es war schwer vorherzusehen was für uns als Palästinenser in Jordanien ehh wo es hingeht"“.

Die Beziehungen zwischen jordanischen Palästinensern und Transjordaniern wurden mit dem Bürgerkrieg zu einer kritischen Frage für die Stabilität des jordanischen Staates. Die jordanische Regierung reduzierte nach dem Bürgerkrieg den Anteil der im Sicherheits- und Staatsapparat beschäftigten jordanischen Palästinenser, insbesondere in den Kampfeinheiten im jordanischen Militär, deutlich (Gieler/Keller 2014: 38; Massad 2001: 213, 218). Gerade neue palästinensische Rekruten mussten aufwendige Sicherheitskontrollen durchlaufen (Plascov 1981: 96-113). In dieser kollektivgeschichtlichen Phase fand Hussam - wenn auch im weniger sicherheitsrelevanten zivilen Dienst - eine Anstellung bei den jordanischen Streitkräften, was man als Hinweis auf eine geringe (öffentliche) Parteinahme der Familie für die PLO werten kann. Hussam hatte nach dem Bürgerkrieg 1973 das Tawjihi absolviert und mit circa 19 Jahren, vermutlich über die Beziehungen des Vaters, eine Beschäftigung als Logistiker des jordanischen Militärs in Zarqa gefunden. Hussams Bruder Nabil hatte ebenfalls das Tawjihi absolviert und ein Studium der Ingenieurswissenschaften in Amman aufgenommen. Hussam trug somit schon früh zum Familieneinkommen bei und unterstützte dadurch den weiteren Bildungsaufstieg seines Bruders. Hussams berufliche Position als im Militär beschäftigter Palästinenser in einem ohnehin überwiegend transjordani- 
schen Umfeld in den nächsten Jahren war - das untenstehende Zitat deutet darauf hin - heikel und vermutlich ohnehin nur aufgrund der geringen sicherheitspolitischen Relevanz seiner Beschäftigung möglich. Im Interview verortete Hussam jene Phase nach dem Jordanischen Bürgerkrieg, in der er die berufliche Tätigkeit bei der jordanisches Armee aufgenommen hatte, auch als jene Phase, in welcher er angefangen habe, sich mit ,politischen Dingen' zu beschäftigen und auch eine dezidiert palästinische Zugehörigkeit zu empfinden:

Hussam: „zwar also hat sich meine politische ehh Persönlichkeit geformt als ich in Jordanien in der Armee war aber die Situation war beängstigend um über Politik zu reden als Militär und als Zivilist hatte man Angst zu reden, über Politik zu reden während du in der Armee bist das ist ein Tabu oder also dir ist es nicht erlaubt überhaupt daran zu denken und wenn einer sagen wir aus as-Salt ${ }^{139}$ den König verunglimpft und einer aus Palästina den König verunglimpft dann glauben sie dass der Palästinenser ist derjenige, der den König beschimpft hat und nicht der Jordanier (3) wir hatten diese Erfahrung als es die Zeit des Misstrauens gegenüber den Palästinensern war welche nach den 70er Jahren begann".

Vor dem Hintergrund dieser gesellschaftlichen ,Atmosphäre' und seiner ,heiklen beruflichen Position verschob Hussam sozusagen sein politisches Artikulationsbedürfnis in eine zunächst noch vollständig privat bleibende künstlerische Tätigkeit: Er begann Kurzgeschichten und kleinere politische Kommentare, etwa zur Schlacht von Karameh von 1968, ${ }^{140}$ zu verfassen, die er jedoch nicht veröffentlichte.

Hussam: ,so richtig bewusst geworden bin ich in den 1970ern [...] ich war in einer zivilen Position die mir erlaubte als Zivilist zu erscheinen, nicht als Militär ich habe in der Logistik gearbeitet für 18 Jahre, aber wegen der sehr strikten Kontrolle von Palästinensern im Militär habe ich mein Hobby zu Schreiben nicht ausgelebt weil ich Angst hatte“.

Seine private schriftstellerische Tätigkeit behielt er auch in den nächsten Jahren bei. Mitte der 1970er Jahre heiratete er. Hussam hatte einen Freund gebeten, ihm bei der Vermittlung einer Heiratspartnerin zu helfen - einer Palästinenserin, wie Hussam hervorhebt. Über die Vermittlung des Freundes lernten sich Hussam und Nayfe kennen und heirateten nur wenige Wochen später. Nayfe zog entsprechend der patrilokalen Normen zu Hussams Herkunftsfamilie. Das Paar bekam in den

\footnotetext{
${ }^{139}$ Salt gilt in Jordanien - im Gegensatz zu Amman - als , urjordanische‘, durch eine altansässige Bevölkerung geprägte Stadt.

${ }^{140}$ Diese bezeichnet Kampfhandlungen am 21. März 1968 zwischen israelischen Militäreinheiten auf der einen sowie palästinensischen Milizen und dem jordanischen Militär auf der anderen Seite. Sie spielten sich um die Fatah-Basis Karameh, die sich nahe der israelischen Grenze im Jordantal auf jordanischer Seite befand, ab. Von palästinensischer Seite wurde das Gefecht im Nachhinein als militärischer Erfolg gewertet.
} 
folgenden Jahren drei Kinder, zunächst die beiden Mädchen Youssr und Samira, dann den ersten Sohn der Familie namens Aram. Die Kinder wuchsen in Zarqa auf und wurden dort eingeschult. Für Hussam stand in diesen Jahren zunächst die Familiengründung im Vordergrund und nicht eine stärkere auch öffentliche politische Positionierung. Im Verlauf der 1970er und 1980er Jahre änderte sich dies jedoch. In dieser Zeit vollzog sich eine politische Mobilisierung der palästinensischen Bevölkerung in Gaza und dem Westjordanland gegen die israelische Besatzung, die schließlich in der sogenannten Ersten Intifada von 1987 bis circa 1993 mündete (vgl. Kap. 4.4-4.5). Die Erste Intifada, die die jordanische Führung unter anderem dazu bewog, 1988 den Anspruch auf das Westjordanland aufzugeben, erfuhr auch in der palästinensischen Bevölkerung innerhalb der jordanischen Gesellschaft große Aufmerksamkeit und Sympathien. In verschiedenen Städten, insbesondere in Amman, gab es in den späten 1980er Jahren und zu Beginn der 1990er Jahre Solidaritätskundgebungen und -demonstrationen mit den Aufständischen in den palästinensischen Gebieten, wobei es gelegentlich zu Auseinandersetzungen zwischen den Demonstrierenden und den jordanischen Sicherheitskräften kam. ${ }^{141}$ Auch Hussam nahm an diesen Demonstrationen teil:

Hussam: „Ich sage immer dass der Palästinenser außerhalb seiner Heimat ist Palästina am zugehörigsten ich erinnere mich an während der Ersten Intifada haben wir immer Demos gemacht los von der Gewerkschaftsvertretung nach Atta Ali nach Shmeisani142 wo die US-Botschaft ist und die Polizei hat uns unterdrückt in Atta Ali Gegend und uns geschlagen".

Die Erste Intifada schlug sich in Form von kleineren Aufsätzen und Texten auch in Hussams schriftstellerischer Tätigkeit nieder, die er inzwischen intensiv verfolgte. Im Interview gab er an, dass er mit den Ereignissen in den palästinensischen Gebieten ,mitgefühlt' und sich mit den Aufständischen sehr verbunden gefühlt habe. Am Fernseher habe der die Ereignisse in Palästina aufmerksam verfolgt:

Hussam: „dein Heimatland du hast nicht drin gelebt hast nicht deine Jugend in ihm verbracht und bist in ihm aufgewachsen du du siehst es nur auf der Karte oder in den Nachrichten so wirst du eine innere Liebe für deine Heimat haben, nur die die weit von ihrer Heimat gelebt haben fühlen dies“.

Diese Passage verdeutlicht, inwiefern Hussam auch in Jordanien, sozusagen aus der Distanz, an der Phase der politischen Mobilisierung in den palästinensischen Gebieten in den 1980er Jahren im Sinne einer Intensivierung eines palästinensischen Wir-Gefühls und nationaler Zugehörigkeit teilhatte. Man kann hier von einem Erleben der Ersten Intifada ,aus der Distanz' sprechen. Während dieser Phase wurde 1989 Hussams zweiter Sohn Alaa geboren.

141 Zum Beispiel in Chronology MEJ 1988a: 468; Chronology MEJ 1988b: 274.

142 Hussam nahm hier sehr wahrscheinlich auf den früheren Standort des bekannten Restaurants Atta Ali Bezug. Al-Shmeisani bezeichnet ein Stadtviertel in Westamman. 


\section{Migration ins Westjordanland in der ,Aufbruchsstimmung' des ,Friedensprozesses"}

Die Erste Intifada mündete in den sogenannten Oslo-Friedensprozess zwischen Israel und den Palästinenser*innen und stieß für die palästinensischen Gebiete weitreichende gesellschaftliche Transformationsprozesse an (vgl. Kap. 4). Der mit den Oslo-Abkommen vereinbarte Aufbau quasi-staatlicher palästinensischer Institutionen in den 1990er Jahren wurde begleitet von der Migration von ,alten' PLOKadern und anderen Palästinenser*innen aus arabischen und westlichen Ländern, insbesondere den USA, in die palästinensischen Gebiete (vgl. Kap. 4.6). Die frühen ,Oslo-Jahre' wurden dabei durchaus von einer von Optimismus und Aufbruchsstimmung geprägten Atmosphäre in den palästinensischen Gebieten begleitet. Diese kollektivgeschichtliche Entwicklung bildete den Hintergrund für eine Phase der biographischen Reorientierung Hussams, in dem verschiedene kollektiv- und lebensgeschichtliche Prozesse ineinandergreifen - nämlich die familiale Tradierung eines idealisierten Palästina-Bildes, Hussams berufliche und gesellschaftliche Position als Palästinenser, unter Beobachtung 'im jordanischen Sicherheitsapparat, die ihm auch eine Restriktion seiner palästinensischen Zugehörigkeitsgefühle abverlangte, sowie Hussams Politisierung der 1980er Jahre während der Ersten Intifada in den palästinensischen Gebieten. Diese Komponenten wirkten dahingehend zusammen, dass Hussam Ende der 1990er Jahre den Entschluss fasste, dauerhaft in das Westjordanland zu migrieren. Die Migration war dabei auch verbunden mit einem biographischen Projekt zur späten ,intellektuellen Selbstverwirklichung, für das Hussam die Aufbruchstimmung und den Wandel der frühen Oslo-Jahre als Opportunitätsfenster erlebte. Hussam ließ sich circa 1992, also bereits im Alter von circa 37 Jahren, vom Armeedienst pensionieren. ${ }^{143}$ Fortan bezog er eine kleine Rente vom jordanischen Staat:

Hussam: „Minimum war 18 Jahre konsekutiver Dienst, ich will nicht sagen ich war der jüngste der pensioniert wurde aber ich war einer der jüngsten Militärs der pensioniert wurde ich habe meinen Dienst dies ist ein wichtiger Punkt also erstens ich war 37 Jahre alt im also in der ehh Blüte meines Lebens zweitens hatte ich einem Wendepunkt wo ich ein dreimonatiges militärisches Training hätte machen müssen um Offizier zu werden aber ich wollte es nicht ich verweigerte das Training und den Offiziersrang aber damit ich dabei bleibe haben sie mir angeboten mich zum Offizier zu machen ohne das Training aber die Idee habe ich=auch=abgelehnt [...] Ich wollte nicht weitermachen ich hatte meine Pension garantiert und ich wollte mein Leben draußen suchen".

\footnotetext{
${ }^{143}$ Eine frühe Pensionierung aus dem jordanischen Militär ist nicht ungewöhnlich: „The military itself was seldom a life-long career. Upon retirement around age 30, former army personnel were free to seek other employment while continuing to receive a pension. Health and social security benefits covered the entire family of the employee, if male" (Baylouny 2008: 289).
} 
Er konzentrierte sich auf seine schriftstellerische Tätigkeit und veröffentliche kurze Zeit später erstmalig eine seiner Arbeiten, eine Sammlung von Kurzgeschichten, bei einem kleinen Verlag in Amman. Im Verlauf der 1990er Jahre besuchte Hussam das Westjordanland mehrfach für Reisen und kürzere Aufenthalte. Schließlich beantragte er eine längerfristige Aufenthaltsgenehmigung und circa 1997 erhielt er ein für eineinhalb Jahre gültiges Visum für das Westjordanland. Auch Hussams Bruder Nabil, der in der Fatah war, war zunächst in den 1990er Jahren ins Westjordanland migriert. Allerdings hatte er Ende der 1990er Jahre, als Hussam ins Westjordanland kam, selbiges bereits wieder verlassen. Er hatte eine Position in der diplomatischen Auslandsvertretung der PA und lebte daher - auch in den folgenden Jahren - in Südamerika. Hussam migrierte zunächst ohne seine Frau und seine Kinder. Er zog in eine Mietwohnung in Ramallah und begann eine redaktionelle Tätigkeit bei einer NGO in Ramallah, die die Betreuung von Publikationen umfasste. In seiner Freizeit ging er intensiv seinen schriftstellerischen Neigungen nach, er schrieb Gedichte und kleinere politische Kommentare. Auch nahm er einige Aufträge als freiberuflicher Lektor an. Im Laufe des Jahres begann Hussam eine Beziehung mit seiner Arbeitskollegin Mariam, einer israelischen Palästinenserin, die Politikwissenschaften in Bir Zeit studiert hatte und nun bei einer NGO in Ramallah arbeitete. Hussam spielte mit dem Gedanken, erneut zu heiraten, ${ }^{144}$ und nutzte die neue Beziehung, um Druck auf seine Frau auszuüben:

Hussam: „Als ich hierher bin war meine Frau, also total dagegen mitzukommen ins Westjordanland sie meinte zu mir du kannst gehen und uns Geld schicken aber wir gehen nicht mit dir weil ihre Familie lebt in Amman ich bin hierher von November 1999 bis 2000 ich lebte wie ein Single ich hab gekocht und die Wäsche gemacht und so dann habe ich eine Frau kennengelernt sie war 32 Jahre und studierte Politikwissenschaft sie hat in einer NGO gearbeitet mit gutem Gehalt und hatte eine israelische ID wir vereinbarten zu heiraten wir haben vereinbart mein Gehalt geht nach Amman zu Frau und Kinder und sie würde die restlichen Ausgaben tragen [...] dann habe ich meiner großen Tochter erzählt entweder du kannst deine Mutter überzeugen herzukommen ins Westjordanland oder ich mache weiter mit der Heirat sie hat ihrer Mutter gesagt entweder du kommst oder ich unterstütze die Heirat und dann sind sie alle gekommen [...] sie war wütend und dagegen hier zu leben weil sie die palästinensische ID nicht bekam also konnte sie nicht nach Amman“.

Hussam setzte also mit der Drohung einer zweiten Heirat das familiale Migrationsprojekt in das Westjordanland durch: Nayfe gab ihren Widerstand gegen den Umzug auf und Hussam beendete die Beziehung zu Mariam. Circa 2000 zog die Familie in eine Wohnung in einem Innenstadtviertel Ramallahs. Nur die älteste Tochter Youssr, die bereits in Zarqa verheiratet war, blieb in Jordanien. Alaa, zu

144 Polygynie ist in den palästinensischen Gebieten rechtlich möglich, aber selten. 
dieser Zeit elf Jahre alt, und Aram besuchten nun eine Schule in Ramallah. Samira, die bereits eine Ausbildung zur Lehrerin in Jordanien absolviert hatte, bekam eine Arbeitsstelle im Bildungsministerium der PA.

In der Nähe der Familie lebten auch die Familien der in den obigen Abschnitten eingeführten jungen Männer Iyad und Hamzeh, die zu jener Zeit 13 und elf Jahre alt waren. Hamzehs Familie war zwei Jahre zuvor aus Tunesien nach Ramallah gekommen, Iyads Familie lebte bereits seit den 1980er Jahren im Viertel. Hamzeh war zudem ein Schulkamerad Alaas. Iyad lernte Alaa wiederum über jenen Sport- und Nachbarschaftsverein kennen, über den sich auch der Feldzugang zu den jungen Männern ergab (vgl. Kap. 7.2.2). Insbesondere Hamzeh wurde in den kommenden Jahren ein enger Freund Alaas. Die nachgezogenen Familienmitglieder überzogen wie auch Hussam zuvor ihre mehrmonatigen Visa und verblieben im Westjordanland, ohne über langfristige Aufenthaltsgenehmigungen oder palästinensische Ausweise zu verfügen. Die Familienmitglieder lebten in den nächsten Jahren illegalisiert im Westjordanland, da ihren Anträgen auf palästinensische Ausweise nicht stattgegeben wurde. Dies hatte zur Konsequenz, dass Aufenthalte außerhalb des Stadtgebiets beziehungsweise der A-Zone oder gar Besuche bei der Familie in Amman die Gefahr der Deportation oder der verwehrten Wiedereinreise mit sich brachten (siehe unten). Anträge auf palästinensische Ausweise und langfristige Aufenthaltsgenehmigungen, die seit den Oslo-Verträgen sowohl von der Palästinensischen Autonomiebehörde als auch von den israelischen Behörden geprüft und genehmigt werden mussten, wurden, von israelischer Seite ohnehin restriktiv gehandhabt, mit dem Ausbruch der Zweiten Intifada einige Monate später gar nicht mehr bearbeitet (Kårtveit 2008).

\section{Zweite Intifada: Alltagspräsenz des israelischen Militärs}

Wenige Monate, nachdem die Familie ins Westjordanland migriert war, begann die Zweite Intifada und hielt bis circa 2005 an. Während der Intifada war das Stadtgebiet Ramallahs insbesondere von der großen israelischen Militäroperation im März 2002 betroffen, in welcher die israelischen Streitkräfte nach kurzen Kämpfen mit palästinensischen Milizen die Stadt besetzt hatten und Hausdurchsuchungen und Massenverhaftungen durchführten sowie Ausgangssperren verhängten (vgl. Kap. 4.7). Die während der Zweiten Intifada von verschiedenen militanten palästinensischen Gruppierungen durchgeführten Anschläge auf israelische Zivilist*innen, die die Zweite Intifada prägten, empörten Hussam. Als er im Fernsehen die Leichen gesehen habe von den Anschlägen, sei es „zu viel“ für ihn gewesen, Soldaten könne man in die Luft sprengen, aber Zivilisten nicht, sagte er.

Alaa erinnerte sich, wie er, zu jener Zeit circa zwölf Jahre alt, während der Wiederbesetzung Ramallahs durch die israelische Armee 2002 gemeinsam mit seinen Eltern an einer Großdemonstration, einer aufgrund der mit Haushaltsgeschirr erzeugten Geräuschkulisse sogenannten Topf- und Pfannen- 
Demonstration, in Ramallah anlässlich der Umstellung des Muqata'a, ${ }^{145}$ des Amtssitzes Yassir Arafats („Abu Amar"), durch die israelische Armee teilgenommen hatte:

Alaa: „die Sache mit Abu Amar also ehh wir sind alle raus als die Israelis ihn umstellt haben und sie ihn umbringen wollten sind wir raus mit den Kochtöpfen und Löffeln und so wollten wir zum Muqata'a weil sie ihn umbringen würden wir sind während der Ausgangssperre rausgegangen sogar mein Vater und meine Mutter alle hatten entschieden rauszugehen“".

Insgesamt erlebte Alaa, wie auch Hamzeh, der ebenfalls aus einer RückkehrerFamilie stammt (vgl. Kap. 7.2.2), während der Zweiten Intifada erstmalig die Präsenz israelischer Soldaten im Alltag. So wurde das Hauptgebäude des Sport- und Nachbarschaftsvereins, in dem Alaa, Hamzeh und Iyad aktiv waren, während der Besetzung Ramallahs von israelischen Militäreinheiten durchsucht und die Einrichtung des Clubs dabei weitestgehend zerstört: „Sie durchsuchen nicht nur sie schlagen alles kurz und klein ich bin zum Verein zwei Tage danach.“ Während der vom israelischen Militär verhängten Ausgangssperren schlichen Alaa und seine Freunde gelegentlich durch die Straßen.

Alaa: „Wir sind ab und zu raus während der Ausgangssperre ohne dass sie uns sehen wir sind schwimmen gegangen in Al-Serreyeh dann sind wir zwischen den Bäumen durch zurück nach Hause einmal hat einer der Soldaten mich gekriegt als ich zum Laden wollte er war hinter mir ich hatte ihn nicht gesehen er hat mir eine Ohrfeige gegeben ich erinnere mich bis heute vielleicht ist es auf meinem Gesicht geblieben bis jetzt (2) jedenfalls bin ich raus während der Ausgangssperre“.

Alaa deutete in dieser Passage an, inwiefern er den Schlag des Soldaten, vermutlich auch aufgrund der Nähe zu paternalistisch-erzieherischer Bestrafung, als erniedrigend erlebte. Aber diese Passage verdeutlicht noch einen weiteren Aspekt, der den Alltag der jungen Männer im Umgang mit dem israelischen Militär charakterisiert. Alaas Ausführungen dazu, mit den Freunden ,unentdeckt durch die Bäume geschlichen' zu sein, um ,schwimmen zu gehen', lassen sich auch im Sinne eines zwar risikoreichen, aber bis zu einem gewissen Grad auch einen spielerischen Aspekt tragenden Umgangs mit der israelischen Militärpräsenz im Sinne von ,Mutproben' oder eines Sich-Messens mit den israelischen Soldaten lesen. Dieser Aspekt zieht sich auch durch andere Erzählungen der jungen Männer, etwa wenn Alaa davon berichtete, wie er "ohne Angst“ einen verlassenen israelischen Panzer erklettert habe, oder etwa Hamzeh mit Stolz davon sprach, dass er und Alaa während einer Ausgangssperre in die Nähe eines mobilen Checkpoints geschlichen und „ganz alleine“ auf der Straße gewesen seien. Die israelischen Soldaten bilden

\footnotetext{
145 Ein seit britischer Mandatszeit bestehender Kasernenkomplex in Ramallah/Al-Bireh und Sitz des
} Präsidenten der Palästinensischen Autonomiebehörde. 
so auch ein, wenn auch massiv machtüberlegenes, interaktives Gegenüber für kleinere ,Wettkämpfe' und ein Sich-Messen mit ,dem Feind'. Teil dieses alltäglichen Umgangs mit der israelischen Militärpräsenz wurde für Alaa und seine Freunde auch, die Soldaten mit Steinen zu bewerfen. Dabei ging es in diesem Zusammenhang allerdings nicht um die Teilnahme an den Demonstrationen und Straßenschlachten, die nach den Anfangsmonaten der Zweiten Intifada ohnehin gegenüber den lokal begrenzten Gefechten zwischen dem israelischen Militär und palästinensischen Milizen an Bedeutung verloren hatten (vgl. Kap. 4.7). Vielmehr wurde etwa der Bewurf von zufällig passierenden israelischen Militärkonvois auf dem Schulweg mehr oder weniger ,normal'. Darauf spielte Hamzeh in folgender Passage an:

Hamzeh: „I used to do so, all the people did it ehh I want to be, for example I'm walking me and Alaa and his=brother, we walk, and we saw a jeep all of us will will catch stones and throw (2) I coudn't prepare it's sudden, that's it, everybody don't care about, they don't think, if I want to do it or not“.

Die Formulierung, dass dies alle machen würden und man nicht darüber nachdenke, ob man dies wolle, kann man als Ausdruck der lebensweltlichen Selbstverständlichkeit lesen, die das Steineschmeißen für Alaa, Hamzeh und die anderen sukzessive erhielt. Die bisher besprochenen Passagen deuten außerdem an, dass die Aktionen Peergroup-Aktivitäten waren. Sie wurden nicht allein und nicht gemeinsam mit Mädchen oder jungen Frauen oder älteren Männern, sondern im Rahmen einer Gruppe von männlichen Jugendlichen unternommen. Insgesamt kann man annehmen, dass in diesen Jahren die israelischen Soldaten für Hamzeh, Alaa, Iyad und die anderen zu einem feindlichen, auch physisch präsenten Gegenüber wurden, das ,im Kleinen bekämpft' und mit dem sich gemessen' werden konnte. Die ,Scharmützel' mit den israelischen Soldaten wurden in den nächsten Jahren sukzessive zu einem immer wichtigeren Aspekt in den Alltagsaktivitäten der Freunde. Bevor ich genauer darauf eingehe, wie sich Alaa, aber auch Hamzeh und andere Freunde aus der Clique auch nach der Zweiten Intifada in die Straßenschlachten und ,Konfrontationen' mit dem israelischen Militär involvierten, komme ich zunächst auf die Umstände zu sprechen, in denen sich die Familie in Ramallah ,einlebte'.

\section{Zugehörigkeitskrise Hussams in der gesellschaftspolitischen Stagnation nach der Zweiten Intifada}

In den Jahren der auslaufenden Intifada konnten sich Hussam und die anderen Familienmitglieder zunehmend in Ramallah etablieren. Kollektivgeschichtlich wechselten sich nach der Zweiten Intifada ab circa 2005 und nach dem ,Bruch“ zwischen der Hamas und Fatah 2007 im Westjordanland Phasen der Intensivierung der ,Spannungen“ - etwa im Zuge der Gaza-Kriege 2008/09, 2012, 2014 sowie Phasen der relativen Ruhe ab (vgl. Kap. 4.8). Das Stadtgebiet Ramallahs 
blieb nach der Zweiten Intifada weitestgehend von israelischen Militäroperationen verschont. Die insbesondere ab Mitte der 1990er Jahre angestoßene, kosmopoliti-

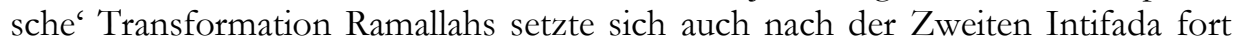
und sorgte, in Verbindung mit der Entwicklung der NGO-Landschaft im Westjordanland, für eine Zunahme und eine größere Sichtbarkeit der urbanen palästinensischen Mittelschicht und der westlichen Expats sowie der von diesen in Anspruch genommenen städtischen Infrastruktur (vgl. Kap. 4.6).

Hussam war nach der Migration der anderen Familienmitglieder zunächst weiterhin freiberuflich als Lektor tätig. Gemeinsam mit der vom jordanischen Staat ausgezahlten Pension bildeten diese Einkünfte das Einkommen der Familie. Dann bekam Hussam circa 2003 eine Anstellung bei einer größeren NGO, die Bildungsprojekte durchführte. Auch Aram fand eine Anstellung, im Hotelsektor. Alaa absolvierte 2007 das Tawjihi und nahm im Anschluss ein Studium im Bereich Betriebswirtschaft an der Bir Zeit Universität auf. Durch Gelegenheitsarbeiten als Bedienung im Café und als Tankwart trug er zudem zum Familieneinkommen bei. Ab circa 2008 arbeitete er parallel zu seinem Studium als Aushilfe im Ministerium für Tourismus, wo er, wie er versicherte, „gutes Geld“ verdiente: „Ich habe einen Job gefunden bei der PA ich hatte mich beworben und da ich studiere haben sie zugesagt, sie wollen gebildete Leute“. Die Familie zog in eine größere Neubauwohnung, verblieb aber im selben Wohnviertel. Die Bemühungen der Familie, ihren Aufenthalt im Westjordanland zu legalisieren, blieben allerdings auch nach der Zweiten Intifada zunächst erfolglos. Alaa sprach auch davon, dass die israelischen Grenzposten anderen Familienmitgliedern aus Jordanien Visa für die Einreise ins Westjordanland mit der Begründung verweigert hätten, dass sich ihre Familie illegal im Westjordanland aufhalte:

Alaa: ,als dann mein Vater und mein Bruder ihre Jobs gekriegt haben haben wir unsere Wohnung gekauft und die Situation wurde insgesamt besser, meine Schwester hat geheiratet aber wir hatten immer noch keine ID und meine verheiratete Schwester die in Jordanien lebte sie hat versucht uns zu besuchen aber an der Brücke haben sie ihr gesagt wenn deine Familie zurück nach Jordanien geht geben wir eine also erlauben wir dir ins Westjordanland zu kommen, es ist bei ihnen im Computer gewesen dass wir gegen das Visum verstoßen sie haben ihr gesagt es sei ihr nicht erlaubt uns zu besuchen und dass sie uns nicht erlauben würden zurückzugehen wenn wir sie besuchen also dass ist der Grund warum wir sie ehh zehn=zehn Jahre nicht gesehen haben die ersten Jahre hier waren wie im Gefängnis weil ich war ein Kind und meine Familie ist nirgendwohin und als ich größer wurde durfte ich nirgendwohin wegen der ID“.

Aufgrund des illegalen Aufenthalts waren Reisen im Westjordanland außerhalb des Stadtgebiets Ramallahs, auch mit von Freunden und Bekannten ,geliehenen Pässen, mit dem Risiko der Verhaftung und Deportation durch die israelischen Behörden verbunden und blieben daher sporadisch. Die Familie unterließ daher 
auch Reisen nach Jordanien, etwa für Besuche bei der Tochter beziehungsweise Schwester oder anderen Familienmitgliedern. Auch Anträge auf begrenzte Aufenthaltsgenehmigungen in Jerusalem beziehungsweise Israel waren so nicht möglich. Hussam gab ebenfalls an, dass sie versucht hätten, möglichst im Stadtgebiet zu bleiben. Viele andere ,Rückkehrer' hätten es jedoch nicht ausgehalten, nur in Ramallah zu sein, und seien wieder zurück in die Herkunftsländer gegangen. Insgesamt ist diese mit der Illegalisierung des Aufenthalts verbundene, schwierige Situation für die Familie typisch für viele Rückkehrer-Familien, die in den 1990er Jahren ins Westjordanland migriert sind. ${ }^{146}$ Für Alaa, Hussam und die anderen Familienmitglieder trug diese Konstellation auch nach der Zweiten Intifada dazu bei, sich in Ramallah schwer einzufinden und Gefühle von Fremdheit zu empfinden - ein Umstand, der für Hussam vor dem Hintergrund seiner Konstruktion des Westjordanlandes beziehungsweise Palästinas als ,Heimat' schwer zu akzeptieren war. Im Interview zitierte Hussam zunächst aus einer von ihm verfassten Kurzgeschichte, in der zwei Freude ihre Auffassung von Fremdheit diskutieren, und fügte hinzu: „das habe ich mal geschrieben es ist das Schwierigste überhaupt dass du dich fremd in deiner Heimat fühlst [...] Ich hab das geschrieben als ich lange Jahre ohne Ausweis hier lebte.“

Hussam deutete im Interview sowie in anderen Gesprächen an, dass sich die Sozialkontakte der Familie im Westjordanland vorrangig auf die Familienmitglieder beschränkten. Als wir etwa im Zuge eines Besuches bei der Familie im Frühjahr 2015 bei einem gemeinsamen Essen in der Wohnung der Familie auf die Nachbar*innen zu sprechen kamen, meinte Hussam, er kenne die anderen Bewohner des Hauses, ein mehrstöckiges Appartementgebäude, nicht, es sei besser, nicht mit ihnen in Kontakt zu sein, dann „hat man seine Ruhe“. Er selbst komme durch seinen Beruf gelegentlich ,unter Leute', aber seine Frau habe in Ramallah eher wenige Kontakte. Die mit der jahrelangen Illegalisierung verbundenen Schwierigkeiten, die Fremdheitsgefühle und die tendenzielle Zurückgezogenheit Hussams und Nayfes trugen dazu bei, dass Hussam nach der Zweiten Intifada zunehmend eine Desillusionierung seines nationalen Wir-Gefühls empfand. Die aufenthaltsrechtliche Situation der Familie verbesserte sich erst ab circa 2007, als zunächst Alaa und seine Geschwister palästinensische Pässe erhielten und 2010 auch Hussam und Nayfe.

Zur Desillusionierung von Hussams palästinensischem Wir-Bild und WirGefühlen trug insbesondere auch die in den nächsten Jahren trotz der ,kosmopolitischen` Transformation Ramallahs (vgl. Kap. 4.6-4.8) deutlich werdende Stagna-

\footnotetext{
146 Das mit der Illegalisierung verbundene Dilemma der Rückkehrer bringt Bart Kårtveit in einem Aufsatz pointiert zum Ausdruck, den ich hier in einer längeren Passage zitieren möchte: „Palestinian returnees who have brought foreign born spouses to the West Bank have had to go through the same process. For more than ten years, thousands of people have either left the country every third or sixth month, with the fear of being denied re-entry, or they have chosen to overstay their visas and stay illegally in the territories, with the constant fear of being caught and deported by the Israeli authorities" (2008: 27).
} 
tion des palästinensischen Staatsgründungsprojekts bei. Diese Stagnation assoziierte Hussam mit der Korruption der politischen Führungselite der PA und dem für die ,palästinensische Sache` aus seiner Perspektive schädlichen westlichen Einfluss im Westjordanland. Die Veränderung des Stadtbildes von Ramallah, in welchem die auf die Konsumgewohnheiten der urbanen Mittelschicht zugeschnittene Infrastruktur von Cafés, Bars und Fitnessstudios nach der Zweiten Intifada deutlicher hervortrat, nahm Hussam eher als Ausdruck der Korruption der PA-Kader und der Stagnation wahr:

Hussam: „die meisten in der PA-Führung haben ihre eigenen Privatgeschäfte sie kooperieren und für diese Kooperation bekommen sie ihre Geschäfte, alle zwei Wochen oder einmal im Monat macht hier eine neue Bar oder ein Coffee Shop auf in einer der guten Gegenden wo nur Söhne von reichen Leuten oder Söhne der PA-Führung hingehen“.

Ein weiterer Aspekt, der zu Hussams Frustration beitrug, sind seine beruflichen Erfahrungen mit den Vertreter*innen der westlichen Geberorganisationen, die die großen NGOs der palästinensischen Gebiete und insbesondere Ramallahs seit den Oslo-Verträgen finanzieren (vgl. Kap. 4.6). Nach der Zweiten Intifada kam Hussam selbst beruflich vermehrt mit den westlichen Gebervertretungen in Kontakt. Hussam hatte nach der Zweiten Intifada begonnen, ein kleines Kulturmagazin in Ramallah herauszugeben. In dem Magazin wurden kleinere Reportagen über die lokale Kulturszene, Interviews mit Galerist*innen oder Theaterschaffenden, Veranstaltungshinweise, aber auch Kurzgeschichten, Gedichte von Schriftsteller*innen aus den palästinensischen Gebieten und in der Diaspora publiziert. Mit einigem Stolz berichtete Hussam im Interview und bei anderen Gesprächen von den Veröffentlichungen, unter denen auch eigene Arbeiten waren. Er habe die Aufsicht über die Veröffentlichungen und er freue sich, diese Arbeit machen zu können, aber wenn er etwas von Hamas-Leuten zugeschickt bekomme, dann „landet das im Mülleimer". Hussam hatte sich sehr stark in die zivilgesellschaftliche Arbeit für das Magazin involviert und war und ist einer der Herausgeber. Neben einer Basisfinanzierung durch die PA warb Hussam wiederholt von, westlichen' Geberorganisationen Gelder für das Magazin ein. Die Erfahrungen mit den Geldgebern und deren Förderkriterien empfand er als schwer mit seinen politischen Überzeugungen in Übereinstimmung zu bringen:

Hussam: „Lass mich über die Geberstaaten sprechen in meiner Meinung geben die Geberstaaten den Palästinensern große Summen um die Besatzung aufrechtzuerhalten als NGO wir haben an die Tür vieler Geber geklopft und eine war USAID sie haben zugstimmt uns das notwendige monatliche Funding zu geben aber wir hätten ein sechsseitiges Papier auf Englisch aber du musst es lesen und unterschreiben in der selben Session natürlich dass alle Papiere drehen sich um Terrorismus und alles was Palästinenser machen gegen Israel nennen sie Terrorismus entweder unterschreibst du das Papier auf 
der Stelle oder sie lehnen das Funding ab du darfst es nicht mitnehmen um sie zu lesen oder es dir von jemandem erklären lassen denn es ist eine komplizierte Sache (3) leider unterschreiben 90 Prozent der Palästinensischen Institutionen ohne sie zu lesen“.

Seiner Auffassung nach geht es bei dem Engagement der westlichen Staaten und der Präsenz der NGOs ohnehin um die Aufrechterhaltung des Status Quo. In den frühen Oslo-Jahren habe man ,viel versprochen, dass man in fünf Jahren einen Staat hat mit Ausweis Grenzen und so weiter alles leere Rede und Israel will nur einen Mukhtar ${ }^{147}$ haben."

Insgesamt erlebte Hussam in der kollektivgeschichtlichen und biographischen Phase nach der Zweiten Intifada eine Desillusionierung der vor der Migration in das Westjordanland gehegten nationalen Wir-Gefühle:

Hussam: „am Ende ist der Mensch eine Summe an Gefühlen und Eindrücken vielleicht als ich die Bilder der Ersten Intifada sah und meine Traurigkeit Liebe Sympathie stiegen all die großen Sachen aber leider all die ja Ansätze die ich vorher hatte bevor ich dachte hierherzukommen ins Westjordanland alles ist weggegangen nach ein paar Jahren hier".

Hussams krisenhaft werdendes nationales Zugehörigkeitserleben und seine Frustration über die politische Stagnation im Westjordanland trugen nun im familialen Dialog dazu bei - darauf gibt es zumindest einige Hinweise -, dass Alaa eine Delegation ,zu kämpfen'spürte, die allerdings auf manifester Ebene verneint wurde. Im Folgenden möchte ich daher auf Alaas Involvierung in die Straßenschlachten nach der Zweiten Intifada und die Relevanz der intergenerationalen familialen Dynamik und des familialen Dialogs eingehen.

\section{Alaas Involvierung in die Straßenschlachten und familialer Dialog}

Ich komme nun zu Alaa und seinen Freunden zurück. Nach der Zweiten Intifada involvierten sich Alaa, aber auch Hamzeh und andere Freunde aus der Clique zunehmend in die Straßenschlachten und ,Konfrontationen' mit dem israelischen Militär. In den erhobenen Daten finden sich einige Hinweise auf diesen Prozess der Involvierung.

Während das unmittelbare Stadtgebiet Ramallahs nach der Zweiten Intifada von israelischen Militäroperationen, insbesondere nächtlichen Verhaftungen, weitestgehend verschont blieb, waren in den an Ramallah angrenzenden Flüchtlingslagern und an den sogenannten Berührungspunkten an den Checkpoints ,Konfrontationen' zwischen israelischem Militär und Palästinenser*innen auch in Phasen geringer allgemeiner Konfliktintensität häufig. Alaa nahm nun unter anderem regelmäßig an den Demonstrationen an der mit Betonmauern und Wachtürmen

\footnotetext{
147 Eine Anspielung auf die Kooptierung der Mukhtars in den 1970er Jahren durch die israelische
} Besatzungsverwaltung (vgl. Kap. 4.4). 
abgesicherten israelischen Sperranlage am Qalandia-Checkpoint teil: „Wir pflegten zu den Freitags-Demonstrationen ${ }^{148}$ in Qalandia zu gehen“. Zunächst kann man, ausgehend von Alaas Erfahrungen mit der Alltagspräsenz israelischer Soldaten während der Zweiten Intifada, in der Teilnahme an den Konfrontationen eine Fortsetzung des ,Messens' mit den israelischen Soldaten auch nach der Zweiten Intifada sehen. Die Involvierung in die Straßenschlachten wird jedoch zunehmend von selbsterlebten, leidvollen Erfahrungen im Zusammenhang mit den Konfrontationen begleitet, die die biographische Erlebens- und Motivverstrickung der Jugendlichen in die Konfrontationen steigern. Diese Erfahrungen können die Verhaftung, Verletzung oder gar Tötung von Freunden oder Bekannten umfassen. Alaa berichtete, er habe zwar nie mitbekommen, wie jemand "getötet" wurde, aber sie hätten in Qalandia die „Verwundeten getragen“. Auch er selbst sei bei einer Konfrontation angeschossen worden. So berichtete Alaa, wie er zum Beispiel anlässlich des Gaza-Krieges 2008 an ,Konfrontationen“ am QalandiaCheckpoint teilgenommen habe. Sie hätten zunächst in der Nähe Al Birehs demonstriert, seien dann aber nach Qalandia gezogen:

Alaa: „was passiert ist dass ungefähr 15 šabāb und ich sind nach Qalandia und haben angefangen Steine zu werfen mit großen Schlingen, da war ein Soldat saß im Turm am Checkpoint und hat gerufen auf Ivrit dass wahrscheinlich dass wir wenn wir näher kommen er wird auf uns schießen aber wir haben ihn auch nicht verstanden naja die Zwille ist mir aus der Hand geflogen und ich bin hin um sie zu holen und da hat der Scharfschütze auf mich geschossen mit scharfer Munition und dann haben sie mich ins Krankenhaus gebracht (3) es war eine harte Zeit ich musste eineinhalb Monate im Haus bleiben also wenn mein Bein gebrochen gewesen wäre hätte es schneller geheilt aber meine Muskeln waren durchtrennt tief und es hat eine lange Zeit gebraucht zu heilen“.

Er habe aufgrund der Verletzung sechs Wochen zu Hause bleiben müssen. Die Verletzung sei gut ausgeheilt und bereite ihm keinerlei Probleme, aber ihm sei total langweilig gewesen in der langen Zeit zu Hause. Er habe danach eigentlich aufhören wollen, sich in die Straßenschlachten zu involvieren, aber:

Alaa: ,ich konnte nicht ich war jung um die zwanzig ich wollte leben wie alle in meinem Alter (2) als die Israelis monatlich kamen war es für uns eine Provokation [innā 'istifzāz] und und ich hab weitergemacht wie vorher bis ich dann verhaftet wurde im April“c.

Alaa griff hier in seiner Evaluierung seiner Involvierung in die Straßenschlachten auf die spätere Verhaftung durch die palästinensische Autonomiebehörde im April

\footnotetext{
148 Alaa spielt hier auf die wöchentlichen Demonstrationen am Freitagnachmittag an, die an den Berührungspunkten stattfinden. Je nach den jüngsten Ereignissen sind sie mehr oder weniger gut besucht und von Krawallen begleitet.
} 
2010 vor (siehe unten). Sein Verweis in der zitierten Passage darauf, ,wie alle' seine Altersgenossen weitermachen zu wollen, kann als Indiz für die lebensweltliche Selbstverständlichkeit, die die Teilnahme an den Straßenschlachten für Alaa und seine Freunde hatte, gewertet werden. Seiner Auffassung nach war die Involvierung in die Straßenschlachten im Freundeskreis normal und für seine Lebensphase für ihn ,angemessen‘. Die Formulierung, sich durch die Präsenz des israelischen Militärs in Ramallah ,provoziert' gefühlt zu haben, deutet darauf hin, dass die israelische Militärpräsenz gerade im Stadtgebiet Ramallahs als eine ,persönliche Angelegenheit' gedeutet wurde, auf die ,reagiert' werden musste. Diese Deutung steht auch in Übereinstimmung mit dem im vorangegangenen Kapitel herausgearbeiteten Deutungsmuster, in welchem im Rahmen des Wir-Bildes als ,Kämpfer für die palästinensische Sache` von den jungen Männern gerade der Wille zur ,Verteidigung' Ramallahs betont wurde (vgl. Kap. 7.2.3). In den bisher zitierten Passagen deutet sich zudem ein Eskalationsprozess in der Intensität der Auseinandersetzungen und der genutzten Mittel in den Straßenkämpfen an. Die Steigerung reicht dabei vom ,Rausschleichen' während der Ausgangssperren in der Zweiten Intifada über die Verwendung von Zwillen bei Demonstrationen bis zum nächtlichen Abpassen von Militärkonvois und deren Bewurf mit Molotow-Cocktails, wie auch im folgenden Abschnitt deutlich wird.

Im Frühjahr 2010 kam es insbesondere in Jerusalem anlässlich der Genehmigung weiteren Siedlungsbaus in Ostjerusalem und der Eröffnung einer Synagoge in der Jerusalemer Altstadt zur Intensivierung von Auseinandersetzungen und Konfrontationen im Westjordanland. In diesem Zusammenhang fanden auch einige israelische Militäroperationen im Stadtgebiet Ramallahs statt. Die jungen Männer lauerten den Militärkonvois auf und bewarfen diese mit Steinen und Molotow-Cocktails.

Alaa: „Die Jeeps kamen da alle zwei oder drei Tage nicht jeden Tag aber ja (2) also haben wir die Molotows vorbereitet und versteckt und als sie dann zwei=drei Tage später kamen yani, das Gute ist dass wenn die Soldaten kommen weiß es jeder zum Beispiel wenn sie kommen nach Beitunia bekommen wir einen Anruf während wir hier sind und sagen uns dass die Soldaten in Beitunia sind und aufpassen sollen wenn sie in der Nähe vom Rukab sind wir wussten dass die Armee da ist also müssen wir alarmiert sein (3) wir haben die Molotows geholt und haben da gewartet von wo sie immer kommen wir=wir wissen von wo sie kommen und gehen da sie waren zehn Jeeps und als der erste vorbei ist haben wir fünf Molotows geworfen nicht einen ich weiß nicht mehr ob es der fünfte oder siebte war wo dann der Jeep brannte auf jeden Fall brannte der ganze Jeep die Molotows waren nicht nur mit Benzin sondern auch mit was was man Kalkal nennt was das länger brennen lässt und Schaden macht der schwieriger zu reparieren ist, also auf einmal haben uns dann die Soldaten verfolgt und haben geschossen [...] sie wollten dass wir anhalten und haben wir nicht dann zwei Wochen später 
wussten die Israelis wer die Molotows geworfen hat und wer das Ganze gemacht hatte". 149

Einige der an der Aktion beteiligten jungen Männer seien danach von den Israelis verhaftet worden. In den Verhören beim Shabak hätten die Verhafteten dann Namen von anderen beteiligten jungen Männern preisgegeben. Danach seien Hamzeh und Alaa von den Israelis ,gesucht“ gewesen. Daraufhin habe ihn die PA verhaftet, Hamzeh und ein anderer Junge hätten sich der PA gestellt, als sie erfahren hätten, dass die Israelis sie suchen. Die PA verhörte sie und inhaftierte sie zunächst für ein halbes Jahr.

Hussam hatte, so hatte er mir gegenüber geäußert, schon vor Alaas Schussverletzung von dessen Involvierung in die Straßenschlachten gewusst. Hussam hatte zufällig ein Gespräch von Jugendlichen aus der Nachbarschaft, die vor ihm auf der Straße gingen, mitgehört. Die Jugendlichen, Bekannte von Alaa, hatten Hussam nicht erkannt und sich über Alaa und seine Beteiligung an den ,Konfrontationen' in Qalandia unterhalten. Hussam gab ab, er habe mit Alaa darüber gesprochen und ihm gesagt, er sei für Widerstand gegen die Besatzung, aber ,jetzt in diesen Umständen in denen wir leben ist keine Phase der Befreiung (2) daher, warum soll ich Widerstand leisten und ins Gefängnis gehen die anderen arbeiten als Mafia und verdienen Geld.“ Alaa habe ihm zugehört, aber „,nicht groß etwas dazu gesagt“". Als im April 2010 die Verhaftung durch die israelischen Sicherheitsbehörden drohte, sprach Alaa mit Hussam über die nächtlichen Aktionen. Alaa erlebte die Reaktion seines Vaters dabei als ambivalent. So habe Hussam ihm schon zuvor gesagt, er müsse „die Jeeps der Israelis waschen“, statt sie mit Steinen zu bewerfen. Als er ihm von dem Vorfall mit dem Jeep erzählte, sei seine Reaktion allerdings folgende gewesen:

Alaa: ,aber im Gegenteil, er war sehr glücklich als er erfuhr dass ich das war die den Jeep zur Explosion gebracht haben dann hat er mir gesagt für wen $=$ wen hast du das gemacht die PA hat dich verhaftet".

Alaas Ausführungen zufolge äußerte sein Vater einerseits Unverständnis und verwies auf die negativen Konsequenzen von Alaas Handeln, andererseits meinte Alaa, eine positive emotionale Reaktion seines Vaters zu erleben (,sehr glücklich"), die aber in der Darstellung Alaas diffus bleibt. In Alaas Erleben treten also emotionaler und verbal explizierter Sinngehalt der Reaktion Hussams auseinander. Diese Passage verweist damit auf einen Aspekt, der mir in der intergenerationalen

\footnotetext{
${ }^{149} \mathrm{Zu}$ dem Angriff auf den Konvoi, welchen ich umfassend recherchiert habe, finden sich keine Angaben zu Verletzungen der Insassen, die in diesen Fällen in der Regel durch israelische und palästinensische Zeitungsberichte, Bekanntmachungen der israelischen Armee sowie durch NGOs gut dokumentiert sind. Meiner Einschätzung nach ,gelingt` es den jungen Männern bei den Krawallen sehr selten, die israelischen Militärfahrzeuge in Brand zu setzten. Yousef aus der Clique aus der Flüchtlingslager-Gegend (vgl. Kap. 6) etwa hatte angegeben, dass es ihnen bei den Straßenkämpfen in all den Jahren nie gelungen sei, eines der israelischen Fahrzeuge in Brand zu setzen.
} 
familialen Interaktion um die, Widerstandsthematik ${ }^{`}$ zentral zu sein scheint. So erlebte Alaa seine Involvierung in die Straßenkämpfe im familialen Kontext als latent positiv besetzt, auch wenn verbale Äußerungen und explizite Handlungsanweisungen Hussams die, Widerstandsaktionen' abwerteten. Diese implizite positive Besetzung ist Ausdruck einer ambivalenten familialen Delegation zum, Widerstand leisten', die, neben den eigendynamischen Prozessen im Freundeskreis, dazu beitrug, dass sich Alaa in die Straßenschlachten involvierte.

\section{Haft und Verurteilung durch die $\mathrm{PA}$}

Nach der Inhaftierung durch die PA verblieben Alaa und Hamzeh zunächst für ein halbes Jahr im Gefängnis. Die Erfahrungen in der Haft, die Verhöre durch die PA und allgemein die Haftbedingungen beschrieb Alaa als unproblematisch: „ehrlich gesagt sie haben uns nicht geschlagen oder uns erniedrigt sie im Gegenteil sie haben uns gut behandelt sie haben uns befragt". In den Verhören verteidigte er seine ,Widerstandsaktionen' (,,ich bin stolz darauf warum sollte ich sie anlügen"), kooperierte allerdings auch mit den Beamten, indem er ihnen die Orte von Sauerstoffflaschen, die die jungen Männer als mögliche Sprengmittel für die Straßenkämpfe verwahrt hatten, preisgab. Dabei wertete er die PA als ,Handlanger' der Israelis ab: „also haben wir ihnen die Gasflaschen, die Kugeln und alles gegeben was sie dann weggebracht haben die PA und die Israelis sind das Gleiche inzwischen". Nach circa fünf Monaten waren Alaa und Hamzeh für circa zwei Monate im ,offenen Vollzug, in welchem sie zwar die Nächte im Gefängnis verbringen mussten, sich jedoch tagsüber im Stadtgebiet Ramallahs frei bewegen konnten (vgl. Kap. 7.2.2). Im Oktober 2010 verurteilte sie ein PA-Gericht zu einem weiteren Monat Gefängnis, also zu insgesamt acht Monaten Haft, die Alaa und Hamzeh weiterhin im Freigang verbüßten. Alaa bewertete das Vorgehen der PA auch als einen Versuch, einerseits den Anschein der Sicherheitskooperation zu wahren und andererseits durch die Verurteilung den „Gesucht“-Status der Israelis aufzuheben. Dass die Verurteilung und zum Beispiel nicht nur die Verwahrung der jungen Männer als notwendig angesehen wurde, hing laut Hamzeh mit den Aussagen derjenigen Männer zusammen, die von den Israelis verhaftet worden waren:

Alaa: „Das Problem ist dass die Jungs die von den Israelis geschnappt wurden uns belastet haben, also hat die PA uns aufgrund dessen dass wir einen palästinensischen Polizeijeep verbrannt haben und dass Werfen gegen die PA war und, also dass wir eine Zelle gebildet haben gegen die PA natürlich stimmt das nicht wir haben einen israelischen Jeep verbrannt und haben eine Zelle gegen die Israelis gebildet aber die PA hat das fingiert die Sache vor den Israelis und sie haben uns für acht Monate verurteilt nachdem wir sieben Monate drin waren sie haben uns für einen weiteren Monat verurteilt es war wie eine Vorführung [masrahiyya]“". 
Die Einschätzung Alaas (und der anderen) ${ }^{150}$ zur Verhaftung und zum Gerichtsverfahren ist auch vor dem Hintergrund der sicherheitspolitischen Tendenz der PA zu dieser Phase interessant. So fallen die Verhaftung und Verurteilung Alaas und Hamzehs durch die PA eigentlich in eine Phase der Reform des Sicherheitsapparates unter Salam Fayyad ab Ende der 2000er Jahre, die in der Forschungsliteratur auch als Phase repressiver Konsolidierung der PA gewertet wird: „the campaigns can be seen as the early stages of the PA's authoritarian transformation, manifest in the excessive use of arbitrary detention and torture in PA prisons" (Tartir 2017: 8; vgl. Sayigh 2011). Im Falle Alaas und Hamzehs, deren Inhaftierung und Verurteilung kaum in den Rahmen willkürlicher Repression passt oder gar von Folter begleitet wurde, kommt die Beurteilung der Haft eher in jener Bezeichnung als „VIP-Prison“ zum Ausdruck, mit welcher Iyad die Haftbedingungen seiner Freunde umschrieben hatte (vgl. Kap. 7.2.2). Die Inhaftierung und Verurteilung Alaas und Hamzehs kann man daher vielmehr als einen Versuch verstehen, die beiden einer Verhaftung durch die israelischen Behörden zu entziehen und durch die Verurteilung durch ein Gericht der PA auch auf eine Aufhebung ihres Status als „Gesuchte" durch die israelischen Behörden zu ,hoffen'. Dieser Vorgang ist eher als ein Bemühen informellen und klientelistischen, Verhandelns' der Fälle Alaas und Hamzehs denn als üblicher administrativer Prozess einzuschätzen und ist Ausdruck der relativen Nähe der jungen Männer und ihrer Familien zur Fatah - Alaa und Hamzeh verstehen sich als zur Fatah gehörig (vgl. Kap. 7.3.1) - und zum Sicherheitsapparat der PA. Auch wenn mehrere Familienmitglieder aus dem Umkreis der Freunde zum Sicherheitsapparat der PA gehörten - Iyads Vater etwa war Polizist -, hat vermutlich vor allem die Position von Hamzehs Vater als Offizier im Geheimdienst eine Rolle dabei gespielt, dass in jener aufwendigen Weise versucht wurde, die jungen Männer vor der Verfolgung durch die israelischen Sicherheitsbehörden zu schützen. Zu einer solchen Einschätzung kam auch Hussam, der ganz explizit davon ausgeht, dass Hamzehs Vater auf eine Aufhebung der Haftbefehle hingewirkt hat.

Inwiefern hier die Nähe zur Fatah und zur PA eine Rolle spielte, wird auch an Alaas ,unproblematischer' Fortsetzung seiner Bildungs- und Berufskarriere deutlich. Im offenen Vollzug konnte Alaa seinen Job als Bürohilfe im Tourismusministerium wieder aufnehmen. Zunächst hätten seine Kolleg*innen befürchtet, dass er bei der Hamas sei:

Alaa: „Ich bin zum Ministerium gegangen ich bin gegangen und sie dachten dass ich im Gefängnis war weil ich Hamas bin und weil ich Ärger hätte mit der PA sie haben das missverstanden und deshalb hatten sie mich gefragt ein Dokument zu bringen um zu belegen dass ich Fatah bin (2) also habe ich ein

\footnotetext{
${ }^{150}$ Hamzeh hatte die Verhaftung und das Gerichtsverfahren ebenso charakterisiert: „they said we have now finished with you you will go to court, they moved you to court, cause if we take a judge from the court from the: judgment Israel will not arrest us this is what they say, you=you=you stay here in prison in our roofs and Israel have no business with you".
} 
versiegeltes Dokument von der Fatah und ein anderes vom militärischen Geheimdienst das belegt dass ich im Gefängnis war wegen den Israelis nicht wegen der PA ich hatte gar keine Probleme mit der PA, als sie die Geschichte verstanden haben und die Dokumente gesehen hatten haben sie mir gesagt dass sie mich zurück an die Arbeit lassen sie haben mich sogar mehr geliebt als vorher und da bin ich und mache meinen Job“.

Alaa gab an, dass es an der Universität ähnlich gelaufen sei, dort sei er wegen der während seiner Haftzeit verpassten Kurse abgemahnt worden. Aufgrund der Papiere von der PA seien die Mahnungen aber wieder aufgehoben worden und er habe sein Studium ohne Verzögerungen fortsetzen können. Im Hinblick auf die Zeit nach Alaas Studienabschluss erwägten Alaa und Hussam, dass Alaa für einige Zeit nach Südamerika gehen könnte, um bei seinem Onkel in der diplomatischen Vertretung eine Anstellung zu finden. In jener Phase, in der Alaa im offenen Vollzug seine Arbeit bei der PA und sein Studium wieder aufgenommen hatte, fanden das biographisch-narrative Interview und andere, informelle' Treffen mit ihm statt.

\subsubsection{Zusammenfassung: Familiale und lebensgeschichtliche Dynamik}

Die biographische Dynamik Hussams ist von einem Prozess gekennzeichnet, in welchem die palästinensische Zugehörigkeit zunächst an Relevanz für Selbstbild und Wir-Gefühle gewann, nach der Migration ins Westjordanland aber krisenhaft wurde: Vor dem Hintergrund (a) der familialen Tradierung eines idealisierten, auch die territoriale Herkunft romantisierenden Palästina-Bildes, (b) der Entwicklung eines dezidiert palästinensischen Selbstverständnisses im Rahmen der in den 1960er und 1970er Jahren kollektivgeschichtlich erheblich an Bedeutung gewinnenden palästinensisch-transjordanischen Zugehörigkeitsfrage in Jordanien, (c) der Zurückhaltung der Artikulation der palästinensischen Zugehörigkeit als im jordanischen Militär nach dem Bürgerkrieg 1970/71 beschäftigter Palästinenser und (d) einer weiteren Politisierung in den 1980er Jahren, gestützt durch ein Erleben der Ersten Intifada ,aus der Distanz', migrierte Hussam verbunden mit einem Vorhaben beruflicher Selbstverwirklichung Ende der 1990er Jahre ins Westjordanland. Die Öffnung der palästinensischen Gebiete für sogenannte Rückkehrer während der frühen Oslo-Jahre und die mit dem Friedensprozess verbundene Aufbruchsstimmung ergaben ein Opportunitätsfenster für Hussams ,Rückkehrprojekt‘. Verbunden mit der jahrelangen Illegalisierung im Westjordanland, den Fremdheitsgefühlen, der Stagnation des palästinensischen Staatsgründungsprojektes und der von Hussam als destruktiv erlebten Rolle der PA und der westlichen Geberorganisationen erfuhren Hussams Zugehörigkeitserleben und -gefühle nach der Zweiten Intifada eine Desillusionierung und wurden zunehmend frustrationsbesetzt. 
Die Frustration Hussams gab auch den Rahmen für die ambivalente Delegation eines ,Kampfauftrages' an Alaa, in welcher der Auftrag zwar manifest verneint, die Involvierung in die Straßenmilitanz aber dennoch implizit positiv besetzt wurde. Vor dem Hintergrund dieses familialen Dialogs und in Verbindung mit der Dynamik im Freundes- und Bekanntenkreis als männlicher Peergroup involvierte sich Alaa nach der Zweiten Intifada in Straßenschlachten mit dem israelischen Militär. Alaa und seine Freunde entwickelten ein Wir-Bild als ,Kämpfer für die palästinensische Sache', die ,Ramallah verteidigen'. Auch für die Deutungen Alaas, der ja keine direkten familiengeschichtlichen Bezüge zur politischen Mobilisierung in den palästinensischen Gebieten in den 1980er Jahren hat, ist die Erste Intifada ein Bezugspunkt als ,verpasste Kampfphase“, die er leider „nicht gelebt“ habe. Den Friedensprozess, die Sicherheitskooperation der PA und generell die Rolle der PA im „Kampf für die palästinensische Sache` wertete Alaa entsprechend der Deutungsmuster unter den Freunden ab, dennoch war die PA auch für Alaa eine pragmatisch genommene biographische Ressource. Auch Alaa, für den seine $\mathrm{Zu}$ gehörigkeit zur Fatah nicht in Frage stand, schwankte - unter dem Verfolgungsdruck durch die israelischen Sicherheitsbehörden - zwischen einer Fortsetzung der ,Widerstandsaktionen' und einem Arrangieren auf Zeit mit den politischen Verhältnissen der Oslo-Jahre nach der Zweiten Intifada. 


\section{Die Altansässigen in Ramallah: Wir- und Sie- Bilder, Interaktionsdynamiken und biographische Verläufe}

\subsection{Einleitung}

Im Folgenden möchte ich einen Einblick in die Deutungsmuster und die Wir- und Sie-Bilder von einigen jungen Männern und Frauen (Geburtsjahrgänge 19881991) aus Ramallahs altansässiger Mittelschicht geben. Diese beteiligten sich nicht an den Straßenschlachten mit dem israelischen Militär und der PA, in welche die jungen Männer aus Kapitel 6 und 7 so umfassend involviert waren. Auf die Altansässigen zielen insbesondere die von den jungen Männern aus der Flüchtlingslager-Gegend vorgebrachten Sie-Bilder der, wohlhabenden Städter ${ }^{6}$, die sich angeblich nicht ,für die palästinensische Sache ${ }^{6}$ einsetzen. Inwiefern dies in den Deutungsmustern und biographischen Orientierungen der Altansässigen sich spiegelt und verhandelt wird, ist Gegenstand des Kapitels. Es ist - analog zu den Kapiteln 6 und 7 - in zwei Unterkapitel untergliedert.

In Kapitelabschnitt 8.2 diskutiere ich zunächst ausführlich ein Treffen mit Bekannten aus Ramallahs altansässiger Mittelschicht, in dem Deutungsmuster, Wirund Sie-Bilder sowie Hinweise auf die zentralen biographischen Orientierungen exemplarisch herausgearbeitet werden. Es wird deutlich, wie die Mitglieder dieses Freundeskreises erlebte Zuschreibungen als ,konsumorientierte‘ apolitische Gene- 
ration verhandeln und wie sie selbst Jugendliche in den Flüchtlingslager-Gegenden mit abwertenden Sie-Bildern versehen. Auch der Fokus jener Altansässigen auf die Umsetzung der eigenen hohen Lebenschancen als zentrale biographische Orientierung zeichnet sich in diesem Gespräch bereits ab. Schließlich finden sich Hinweise darauf, dass die Verhandlung der eigenen generationalen Position von einem Verhältnis zur Generation Intifada geprägt ist, das in einigen Aspekten mit jenem vergleichbar ist, das ich in Kapitel 6 mit Bezug auf die Flüchtlingslager-Gegend zwischen der Generation Intifada und der Nachfolgegeneration Oslo diskutiert habe.

In Kapitelabschnitt 8.3 erörtere ich am Fall Haithams die kollektiv-, familienund lebensgeschichtliche Herstellung der Deutungsmuster und der biographischen Orientierungen. Anhand der Falldarstellung zeige ich auf, wie im lebensgeschichtlichen Verlauf eine innere Distanzierung vom palästinensischen Politikbetrieb und eine biographische Orientierung, die vorwiegend eine die Realisierung der eigenen (familial gegebenen) Lebenschancen fokussiert, entstanden.

Die teilnehmenden Beobachtungen und biographisch-narrativen Interviews, auf denen die Analysen dieses Kapitels basieren, habe ich zwischen 2013 und 2015 in Ramallah erhoben. Insgesamt basiert der Teil meiner Stichprobe zu den urbanen Altansässigen, der die Grundlage für die vorgestellten Analysen bildet, im Vergleich zu den anderen Forschungskontexten in stärkerem Maße auf teilnehmenden Beobachtungen und in geringerem Maße auf biographisch-narrativen Interviews. Die in diesem Kapitel vorgestellten empirischen Analysen sind gegenüber den in den vorangegangenen Kapiteln diskutierten Analysen weniger empirisch gesättigt und sind als empirisch unterfütterte Hinweise zu verstehen, die weiterer Forschungstätigkeit bedürfen.

\subsection{Die ,wohlhabenden Städter‘: Die urbane altansässige Mittelschicht und die Generation Intifada in Ramallah}

Im Herbst 2014 war ich mit Salwa $(* 1991)$ und einigen Freund*innen für den Abend in Ramallah verabredet. Salwa und ich kannten uns von der gemeinsamen Projektarbeit für die Universität Göttingen in den Vorjahren. Sie hatte meinen Kolleg*innen und mir während zweier Feldaufenthalte im Jahr 2013 bei der Übersetzung und Organisation von Interviews geholfen und wir hatten uns bei diesen Aufenthalten etwas angefreundet. Ich war für meinen sechsmonatigen Feldaufenthalt ab Herbst 2014 bereits seit einigen Wochen in Ramallah, jedoch nicht dazu gekommen, Salwa zu treffen. Wir verabredeten uns dann im Oktober 2014 dazu, unser ,überfälliges' Treffen nachzuholen. Verabredet waren wir im Café Masyon, einem von Ramallahs teureren italienisch orientierten Restaurants. Es war der Tag des „Clásico“, also des Aufeinandertreffens von Real Madrid und FC Barcelona in der spanischen Fußballiga. Im Westjordanland schlugen und schla- 
gen viele Herzen für einen der beiden Clubs, daher ist das Clásico für gewöhnlich ein Ereignis, bei dem die Cafés und Restaurants, die das Spiel zeigen, gut besucht sind. So war es auch an diesem Abend im Café Masyon. Als ich das Restaurant betrat, war Salwa, in ein Real-Madrid-Trikot gekleidet, bereits dort und hatte für uns einen Tisch besetzt. Als wir uns begrüßten, kamen Salwas Freundin Mariam (*1990), die ich bereits kannte, sowie Lutfi (*1988), Salwas Freund, dazu.

Salwa und die anderen waren aus Familien, die man im erweiterten Sinne als Altansässige im Westjordanland bezeichnen kann - ihre Familien gehörten zwar nicht zu den städtischen Eliten, aber auch nicht zur Flüchtlingsbevölkerung, und waren im Westjordanland seit mehr als drei Generationen ansässig. Ihre Eltern kann man zu den sogenannten „urban professionals“ (Robinson 1993) im Westjordanland zählen, also Teilen der (landlosen) städtischen Mittelschichten, die in den 1970er und 1980er Jahren Universitätsabschlüsse absolviert hatten und nun in akademischen Jobs tätig waren. Salwas Familie war aus dem Jerusalemer Umland, sie hatte eine Jerusalem ID und lebte in Kufr Aqab. ${ }^{151} \mathrm{Ihr}$ Vater war als Anwalt tätig, ihre Mutter Krankenschwester. Mariams Familie war aus dem Umland Ramallahs und ihr Vater arbeitete als Arzt. Sie lebten in Ramallah, genau wie Lutfis Familie, die seit mehreren Generationen in Ramallah ansässig war. Lutfis Eltern hatten allerdings für einige Jahre in Chile in der palästinensischen Diaspora gelebt und waren erst im Zuge des Oslo-Prozesses nach Ramallah remigriert. Lutfi war noch in Chile geboren worden.

Bei unserem Treffen kam das Gespräch schnell auf die nicht allzu lang zurückliegende Schließung des Cafés Beit Anisseh, einem anderen Café in Ramallahs Innenstadt, durch die PA zu sprechen. Bei meinen früheren Verabredungen mit Salwa hatten wir uns meist im Beit Anisseh getroffen. Auf meine Bemerkung, dass wir uns nicht wie sonst dort treffen konnten, bemerkte Salwa, „I really miss it“ und es sei ihr „place“ gewesen. Nun würden sie zwischen dem Café Azur und dem Café Masyon pendeln und es sei etwas langweilig. Das Beit Anisseh war eines jener Cafés und Bars in Ramallahs Nachtleben gewesen, in denen DJs vor einem gemischten Publikum auflegten, in denen getanzt und Alkohol ausgeschenkt wurde. Es war jedoch stärker als andere Cafés und Bars in der Öffentlichkeit umstritten gewesen. ${ }^{152}$ Wiederholt waren Gerüchte aufgekommen, die die ,Moralität ${ }^{6}$ des Ortes in Zweifel zogen - etwa Behauptungen, dass Frauen und Männer sich bei Parties öffentlich küssen würden. Auch Gerüchte um Prostitution hatten ,die Runde gemacht'. Mit einigen anderen Bekannten aus Ramallah hatte ich aufgrund ihrer Vorbehalte, dort womöglich ,gesehen' zu werden, das Beit Anisseh als Treffpunkt vermieden. Als Begründung für die Schließung war Drogenhandel angegeben worden, aber Salwa und die anderen waren sich einig, dass dies nur ein vorge-

\footnotetext{
151 Jerusalemer Stadtteil, der auf der billigeren ,palästinensischen Seite ' der israelischen Sperranlage liegt und der in den städtischen Raum Ramallah/Al-Bireh sowie Qalandias unmittelbar übergeht (vgl. Becker/Worm 2015).

152 Vgl. Maira 2013: 90 f., die ebenfalls auf diesen Ruf des Beit Anisseh zu sprechen kommt.
} 
schobener Grund war. Salwa bemerkte, dass in Ramallah nur die „corrupted minister kids“ auf Parties mit Drogen und Prostituierten zu Gange seien. Im Beit Anisseh sei es so gewesen, dass zwar jemand, gedealt habe, aber der Besitzer davon nichts mitbekommen habe. Lutfi fügte eine andere Variante an Gerüchten hinzu: Er habe gehört, jemand mit Drogen sei in der Nähe Qalandias, einem Flüchtlingslager in der Nähe des Qalandia-Checkpoints zwischen Jersualem und Ramallah, kontrolliert worden und als sie ihn gefragt hätten, wo er die verkaufen würde, habe der einfach das Beit Anisseh angegeben. Auch ein anderer Vorfall kam in Zusammenhang mit dem Beit Anisseh nun zur Sprache. Etwa zwei Jahre vorher war ein Molotow-Cocktail in den Garten des Cafés geworfen worden. In den Gerüchten hatte man Jugendliche aus den Flüchtlingslagern verdächtigt und auch Salwa und die anderen äußerten diesen Verdacht.

Zwar gaben Salwa und die anderen der PA die Schuld an der Schließung des Cafés, brachten in ihren Äußerungen aber auch junge Männer aus den Flüchtlingslager-Gegenden mit den Vorfällen in Verbindung. Damit griffen Salwa und die anderen - wenn auch implizit bleibend - auf ein Sie-Bild gegenüber den Jugendlichen aus den Flüchtlingslager-Gegenden zurück, das mir gegenüber von meinen Bekannten aus Ramallahs Mittelschicht häufig, aber meist nur ,hinter vorgehaltener Hand' geäußert wurde - nämlich ein Bild von den Bewohner*innen der Flüchtlingslager-Gegenden, das diese als irgendwie, wild' und roh bis hin zu gewaltbereit, kriminell und zum Teil auch als konservativ darstellte. Ich hatte Anspielungen und Bemerkungen dieser Art schon mehrfach in Gesprächen mit altansässigen städtischen Bewohner*innen gehört. Einer der Anlässe für Bemerkungen jener Art war die Nennung meines Wohnorts in einer solchen Lager-Gegend. Die Irritationen und Fragen, ob ich „dort Probleme“ hätte, hatten mich schnell auf die Fährte gebracht, mit welchem Bild die Bevölkerung in den Flüchtlingslagern versehen war. Manchmal machte ich dieses Fremdbild im Alltag auch zum Thema, etwa als ich im Frühjahr 2015 bei einem Gespräch mit meiner Arabischlehrerin - einer Palästinenserin, die in den 1990er Jahren aus Kuweit nach Ramallah gekommen war - von den Reaktionen auf meinen Wohnort erzählte und sie daraufhin sagte, dass ,viele hier so denken“. Als Beispiel für die, Wildheit“ der Lagerbewohner*innen gab sie dann jene Besetzungen von Verbindungsstraßen an, von denen auch die jungen Männer aus der Flüchtlingslager-Gegend in Kapitel 6 berichtet hatten, in welche sie bereits mehrfach auf ihrem Weg zur Arbeit geraten war. ${ }^{153}$ In manchen Gesprächen und Interviews wurde mir mitgeteilt, dass manche

\footnotetext{
${ }^{153}$ Bei einer anderen Gelegenheit ebenfalls im Frühjahr 2015 sprach ich mit einem alten Bekannten der Familie, bei der ich im Flüchtlingslager lebte. Als er mich fragte, wo in Ramallah ich lebte, und ich antwortete, dass ich bei jener Familie im Lager lebe, zog er die Augenbrauen hoch. Er komme aus dem Lager, er wohne inzwischen in Masyon (auch der Name eines Stadtviertels), aber er schlafe am besten im Lager. Als er nach Masyon gezogen sei, hätten die Nachbar*innen Angst vor ihm gehabt und geglaubt, er sei von der Mafia, aber inzwischen kämen sie gut aus.
} 
Altansässige ihren Kindern nicht erlaubten, Schulfreunde und Bekannte im Lager zu besuchen.

In unserer Unterhaltung im Café Masyon fuhr Salwa fort, dass sie nun nach der Schließung des Beit Anisseh selbst Parties in Mieträumen von Hotels in der Stadt organisierten. Für nächsten Freitag sei wieder eine Feier geplant, es werde eine Motto-Party und sie werde sich als Polizistin verkleiden. Wir seien herzlich eingeladen, wir müssten nur mit einem Eintrittspreis von 20 Schekeln für die Miete und die Unkosten rechnen. Nun, da sich die Situation in Gaza etwas entspannt habe - eine Anspielung auf den Gaza-Krieg 2014, der nur wenige Wochen zurücklag (vgl. Kap. 4.8) -, könne man auch wieder feiern. Es gebe Leute, „who say you just make parties, you don't do anything“, sagte dann Salwa, aber es sei schwierig für sie, „was sollen sie machen“. Salwa deutete hier eine Zuschreibung als apolitisch und konsumorientiert an, die im weitesten Sinne das Sie-Bild spiegelt, das die jungen Männer aus den Flüchtlingslager-Gegenden von den ,wohlhabenden Städtern', die ,nicht kämpfen', vorbrachten und welches ich in Kapitel 6 herausgearbeitet habe. Im weiteren Gesprächsverlauf wurde indirekt dieses SieBild verhandelt.

Das Gesprächsthema veränderte sich nun in Richtung Involvierung in die ,palästinensische Sache'. Gerade habe sie ihren Trainer aus dem Fitnessstudio getroffen, fuhr Salwa fort, der habe sie gefragt, wo sie in letzter Zeit gewesen sei. Sie berichtete ihm und nun uns, dass sie in den letzten Wochen kaum rausgegangen sei und sie sei weder hierher noch ins Beit Anisseh gefahren: „50 days only facebook and crying“". Es sei schwer auzuhalten gewesen, die Bombardierungen und die vielen Toten. Sie fragte sich, was man nur machen könne, ,shooting people in the street is not an option for me“. Das Gespräch drehte sich zunächst noch weiter um die deprimierende Situation der letzten Wochen. Allerdings brachte Lutfi nach einer Weile die Differenz zwischen der Situation in Ramallah und in anderen Regionen und Orten im Westjordanland zur Sprache. Er sagte in einer einschränkenden Formulierung an Salwa gewandt, in Ramallah you are not oppressed I don't feel oppressed in Ramallah people are spoiled." Er sei nicht vertraut mit meiner Forschung, aber ich solle nicht Ramallah oder Jerusalem als Ausgangspunkt nehmen, ich solle in die Flüchtlingslager gehen. Er zählte einige Lager auf. Salwa hatte mir bei Lutfis Aufzählung einen wissenden Blick zugeworfen - offensichtlich hatte sie die Verschwiegenheit um unsere Interviewpartner*innen sehr ernst genommen und ihrem Freund nichts von meinen Erhebungen in verschiedenen Flüchtlingslagern, an denen sie einige Male teilgenommen hatte, erzählt. Als Salwa dann fragte, warum er dies sage, wiederholte Lutfi seine Einschätzung, in Ramallah seien die Leute, wie auch er selbst, „spoiled“, sie seien wohlhabend, man komme ins Masyon und trinke Cocktails. Er fügte hinzu, es gebe keine richtige Jugend, „no youth, no successor youth“. Mariam und Salwa waren sichtlich verletzt durch Lutfis Kommentar. Er mache alles klein, was sie gerade gesagt hätten. Mariam sagte, Bezug nehmend auf die zur Sprache gebrachte Zuschreibung, 
„some people say we just do parties we do nothing [...] but we my parents and I lived through the Intifadas“. „Except Lutfi“, warf Salwa ein. Er habe, so formulierte sie scherzhaft, von „Fiesta zu Siesta zu Fiesta“ gewechselt, während hier gekämpft worden sei. Die Bemerkung war eine Anspielung auf Lutfis palästinensisch-lateinamerikanischen Hintergrund und die Abwesenheit von ihm und seinen Eltern während der 1980er Jahre. Diese spitze Bemerkung nahm Lutfi lachend hin. Mariam fuhr auf ihre Bemerkung, ihre Eltern hätten die Intifadas durchlebt, fort:

Mariam: ,also my father was in prison he he was in prison every time one of his daughters was born he is proud proud that he was in prison now he is in a project here in Ramallah about democracy he doesn't speak about prison and how they organized the party he was in DFLP and others in my family in others [anderen Parteien] and in prison also I try to push him to talk“".

Das Gespräch drehte sich im Folgenden um die Haltung der Eltern zu Salwas, Mariams und Lutfis Generation. Mit Salwa war ich schon bei anderen Gelegenheiten auf dieses Thema zu sprechen gekommen. Ihr Vater war ebenfalls während der Ersten Intifada inhaftiert gewesen. Salwas Mutter war in einer der linken Frauengruppen aktiv gewesen, die eine wichtige Rolle in der Mobilisierung der 1970er und 1980er Jahre gespielt hatten (vgl. Kap. 4.4-4.5; 6.4). Salwa hatte auch erwähnt, dass ihre Mutter ihr nie sagte, wenn sie heute auf Demonstrationen in Ramallah ging, und außerdem anmerkte, dies würde Salwa doch ohnehin nicht interessieren, was sie wiederum als eine Unterstellung empfand. In ihrer Familie habe sie in ihrer Elterngeneration häufig den Satz gehört: „we served at the right time" - was einerseits implizierte, dass momentan nicht die richtige Zeit sei, seinen ,Dienst ' zu leisten, aber andererseits auch festhält, dass sie ihn geleistet haben. Mariam fuhr fort, vor Kurzem seien sie demonstrieren gewesen, in Gaza sei es so ein „Blutbad“ gewesen, da seien sie mitgelaufen bei dem Marsch. ${ }^{154}$ Es seien viele mitgelaufen, die sonst im Beit Anisseh seien. Lutfi gab jedoch erneut kontra: Was die Demonstration betreffe, sei es nur ein „outburst“ gewesen und es sei danach nichts mehr unternommen worden. Salwa und Mariam stimmten zu und wirkten nun geknickt. „At least we are educated“, fügte Salwa dann an. Mariam stimmte zu und meinte:

Mariam: „either you are disappointed because you do something and it yani nothing changes or it will cost you or you don't do anything and people are disappointed because you don't do anything for the country".

\footnotetext{
${ }^{154}$ Mariam bezog sich hier auf eine größere Gaza-Solidaritätsdemonstration mit circa 20.000 Teilnehmer*innen, die im Juli 2014 in der Nähe Ramallahs stattgefunden hatte und die in Richtung des Qalandia-Checkpoints gezogen war. Nach der Demonstration war es auch zu Auseinandersetzungen und zu Verletzungen und zur Tötung zweier Palästinenser durch israelischen Beschuss gekommen.
} 
Dieses Zitat verweist auf das Dilemma, in dem sich Mariam und die anderen sehen. Involvieren sie sich in den „Kampf für die palästinensische Sache', müssen sie mit zum Teil erheblichen Nachteilen und negativen Konsequenzen für den eigenen Lebensweg - Mariam spricht von „costs“ - rechnen. Gleichzeitig schätzen sie ihre Handlungsmacht beziehungsweise ihre Chancen, auf die gegenwärtigen politischen Rahmenbedingungen einwirken zu können, als ausgesprochen gering ein („,nothing changes“). Der Gedanke an die von mir rekonstruierten Lebenswege der jungen Männer aus der Flüchtlingslager-Gegend liegt hier nicht fern. Involvieren sich Mariam und die anderen hingegen nicht, haben sie mit Stigmatisierungen und Fragen nach ,ihrem Beitrag' für die palästinensische Sache - und mit entsprechenden Schuldgefühlen - zu rechnen. Altansässige lösen dieses Dilemma vor dem Hintergrund ihrer hohen Lebenschancen beziehungsweise ihres kulturellen und sozialen Kapitals eher in Richtung der Umsetzung ihrer Chancen und der Vermeidung biographischer Kosten auf, was jedoch auch zur Folge hat, die ,Enttäuschung der Leute‘, man ,mache nichts fürs Land', hinzunehmen. Dieses Dilemma bringt, diese Anmerkung sei hier bereits gemacht, generell die Ausstattung mit geringen Sinnchancen im Sinne Norbert Elias’ zum Ausdruck, die für die Erfahrungen der Generation Oslo typisch ist (vgl. Kap. 9).

Insgesamt werden an diesem Gespräch verschiedene typische Aspekte der Deutungsmuster und der Wir- und Sie-Bilder deutlich, denen ich bei meinen Feldaufenthalten bei Treffen und Gesprächen mit den Altansässigen aus Ramallahs Mittelschicht wiederholt begegnet bin. Auf den Aspekt der abwertenden Sie-Bilder gegenüber den Bewohner*innen der Flüchtlingslager-Gegenden bin ich bereits zu sprechen gekommen - Salwa und die anderen versehen die Bewohner*innen in den Flüchtlingslager-Gegenden, wenn auch recht implizit und in beiläufigen Bemerkungen, mit abwertenden Sie-Bildern. Hier kommt aber ein weiterer Aspekt hinzu, der etwa in Lutfis Tipps für meine Forschungsrichtung (geh in die Lager') zum Ausdruck kam. Die Lager und ihre Bewohner*innen werden in Sie-Bildern zwar abgewertet, haben aber gleichzeitig hohen symbolischen Wert im nationalen Narrativ. Sie symbolisieren die Nakba, die mit dieser verbundene Armut und Enteignung der Betroffenen, das Leiden unter der israelischen Besatzung und den Widerstand gegen diese und stellen so einen der Kristallisationspunkte des dominanten palästinensischen Nationalnarrativs dar. Diese symbolische Bedeutung sorgte in den Interaktionen, gerade mit westlichen Interaktionspartnern und bei oberflächlicher Bekanntschaft immer wieder dafür, dass die Spannungsbalance zwischen Lager-Gegenden und städtischer Mittelschicht von den altansässigen ,Städtern' nur vorsichtig thematisiert wurde und wird.

Gleichzeitig verhandelten Salwa und die anderen im Gespräch das erlebte Fremdbild mit dem darin enthaltenen Vorwurf, ,sie ${ }^{6}$ würden nicht, für die palästinensische Sache kämpfen und seien stattdessen konsumorientiert und hedonistisch (,machen nur Parties). Dieser Vorwurf zielte und zielt auch auf ihren Lebensstil, der im Gespräch mit den Erwähnungen von Parties, Besuchen in Bars 
und Fitnesscentern ebenfalls an Plastizität gewann. Einerseits mag diese erlebte Zuschreibung mit dem Sie-Bild der, wohlhabenden Städter', die ,nicht kämpfen', verbunden sein, das die jungen Männer aus der Flüchtlingslager-Gegend vorbringen (vgl. Kap. 6) und das Salwa und die anderen verhandeln. Andererseits steht die Verhandlung eines solchen Fremdbildes auch in Zusammenhang mit ihrer Position in einem Generationenverhältnis. Vor dem Hintergrund der, ungelösten Frage palästinensischer Nations- und Staatsbildung verhandelten Salwa, Mariam und Lutfi die Erwartungshaltung, sich ,für die palästinensische Sache‘ einzusetzen, mit der sie sich im Alltag konfrontiert sahen. In dem Gespräch finden sich außerdem Hinweise auf das intergenerationale Verhältnis zwischen einer vorgelagerten Kampfgeneration und der Generation von Salwa, Mariam und Lutfi, worin sich einige Parallelen zu dem intergenerationalen Verhältnis zwischen einer Generation Intifada und der nachfolgenden Generation, wie es in Kapitel 6 beschrieben worden ist, andeuten. So klingt ein ähnlich gelagertes Generationenverhältnis mit einer, verdienten' Generation Intifada an, die sich in einer kollektivgeschichtlich ,günstigen' Phase hoher gesellschaftlicher Mobilisierung ,für die palästinensische Sache ${ }^{6}$ eingesetzt und ,verdient' gemacht hat und einer an dieser Generation indirekt gemessenen Nachfolgegeneration Oslo (,we served at the right time“). Berücksichtigt man außerdem die Stigmatisierung ihrer Generation, die Salwa, Mariam und Lutfi nicht nur thematisierten, sondern zum Teil auch annahmen - Lutfi sprach sogar davon, dass es keine „successor youth“ gebe - wird das hierarchisierte Verhältnis einer, verdienten' Generation Intifada und einer an dieser gemessenen und gegenüber der Generation Intifada abfallenden Nachfolgegeneration sehr deutlich. Und ein weiterer Aspekt taucht an dieser Stelle auf, der ebenso das Generationenverhältnis in der Flüchtlingslager-Gegend kennzeichnet - der Eindruck, von den Eltern relativ wenig über die Erste Intifada erzählt zu bekommen.

Mit dem ,Druck', sich ,für die palästinensische Sache' einzusetzen, der in den intergenerationalen Interaktionen und den Stigmatisierungen erzeugt wird, entsteht ein Dilemma. Es besteht darin, in einer generell demobilisierten gesellschaftlichen Phase entweder die Risiken für die eigenen Lebenswege und Lebenschancen oder die Stigmatisierungen und Fragen nach ,ihrem Beitrag für die palästinensische Sache ${ }^{6}$ - und entsprechende Schuldgefühle - in Kauf nehmen zu müssen. Salwa, Mariam und Lutfi orientieren sich eher in Richtung einer Umsetzung der eigenen Lebenschancen und eines hedonistischen Lebensstils. Im Folgenden möchte ich am Beispiel eines Interviews aus diesem Bekanntenkreis aufzeigen, wie sich diese Deutungsmuster und Handlungsorientierungen biographisch herstellen. 


\subsection{Falldarstellung Haitham: „I always avoid to talk to someone who belongs to a party about my own views"}

Im Folgenden möchte ich die Deutungsmuster sowie die biographische Dynamik Haithams diskutieren. Haitham ist ein etwa gleichaltriger Freund Salwas, die im vorangegangenen Abschnitt zur Sprache kam. Der Fokus der Falldarstellung liegt darauf, aufzuzeigen, wie Haithams Biographie, exemplarisch für die urbane altansässige Mittelschicht, kollektivgeschichtlich in die Post-Oslo-Phase eingebettet ist. Meine Rekonstruktion macht deutlich, wie die Ausstattung mit hohen Lebenschancen familial gegeben ist und wie eine biographische Orientierung auf deren Realisierung - die in der Beobachtung im vorangegangenen Kapitel anhand der Diskussion mit Salwa, Mariam und Lutfi als wesentliche Orientierung bereits anklang - biographisch hergestellt wird. Es wird aufgezeigt, welche lebensgeschichtlichen Erfahrungen hinter einer entstehenden generellen Aversion gegenüber dem Politikbetrieb ,nach Oslo' stehen und inwiefern ein möglicher ,Einsatz für die palästinensische Sache' unter Vermeidung ,biographischer Kosten' verhandelt wurde. Dabei spielt auch eine Rolle, wie sich ein Erleben geringer politischer Handlungsmacht und eine relative Distanz zu anderen palästinensischen Milieus biographisch ergibt.

\subsubsection{Thematisches Feld und Interaktionsdynamik im Interview}

Das biographisch-narrative Interview mit Haitham (*1991), das zwei Sitzungen umfasst, habe ich im Frühjahr 2015 in englischer Sprache geführt. ${ }^{155}$ Ich hatte Salwa gebeten, bei ihren Bekannten zu fragen, ob jemand Lust hätte, mir ein Interview zu geben. Wie genau sie auf Haitham gekommen war, hatte sie mir nicht gesagt, nur bemerkt, sie hätte sich umgehört und er hätte sich gemeldet. Haitham und ich hatten telefonisch einen Termin für das Interview verabredet - er war bei der Arbeit und recht kurz angebunden gewesen - und trafen uns im Masyon. Am Interviewbeginn war Haitham irritiert von der offenen Frage nach seiner Lebensgeschichte - er habe die Fragestellung nicht verstanden, merkte er an - ließ sich dann aber zunächst auf das Format ein.

Haithams Selbstpräsentation war insgesamt davon bestimmt, sich mir gegenüber in eine Experten- und Informantenrolle für die palästinensische Gesellschaft, „Palestinian culture“ und den israelisch-palästinensischen Konflikt zu begeben. Er begann seine lebensgeschichtliche Präsentation mit einem Bericht seiner biographischen Stationen: Er sei „originally from Ramallah“, in Ramallah geboren und aufgewachsen, „,was lucky enough to get a quality education as I was attending private school", habe studiert und koordiniere nun bei einer NGO in Ramallah

\footnotetext{
155 Die Falldarstellung zu Haitham basiert im Unterschied zu der Datenbasis der anderen in dieser Arbeit diskutierten Falldarstellungen nicht auf mehreren Interviews mit Familienmitgliedern unterschiedlicher Generationen, sondern nur auf den Interviews und Treffen mit Haitham.
} 
verschiedene Projekte zur Gesundheitsfürsorge. In Ramallah sei er in der „beautiful coexistence" von Christen und Muslimen aufgewachsen. Im Verlauf des Gesprächs positionierte er sich außerdem ausführlich zu aktuellen politischen Vorfällen und nahm kleinere, politische Analysen'vor - etwa zu den Protesten der Palästinenser*innen in Israel im Vorfeld des Gaza-Krieges 2014 (vgl. Kap. 4.8). Er erklärte dabei ebenfalls, dass er seine Haltung auch gegenüber westlichen Reisegruppen, mit welchen er in seinem Berufsalltag zu tun habe, oder gegenüber israelischen Soldat*innen an den Checkpoints äußere. Er setzte sich in seinen Einlassungen wiederholt und in moderater Weise von im palästinensischen Diskurs dominierenden Positionen ab. So ließ er Distanz zur sogenannten Antinormalisierung (vgl. Kap. 6.2.2) erkennen, die dafür sorge, dass Palästinenser*innen das israelische Narrativ nicht kennen. Viele politische Strategien der PA beziehungsweise der palästinensischen Führung, aber auch die Kritik der Bevölkerung an der PA seien ihm nicht „smart“ genug. Neben dieser Experten- und Informantenrolle lag sein Präsentationsinteresse darin, mir in Andeutungen und Anmerkungen zu versichern, dass er sich seiner gegenüber anderen Palästinenser*innen vergleichsweise privilegierten gesellschaftlichen Stellung bewusst sei (er stamme aus einer „ok family“; er sei „lucky enough“, auf eine Privatschule gegangen zu sein). Ein weiterer Strang seines Präsentationsinteresses war zudem, seine Berufswahl als ,Erfolgsstory' und als genuinen Ausdruck seiner Interessen und Fähigkeiten zu inszenieren - eine Einschätzung, die wahrscheinlich in seiner Familie nicht voll geteilt wurde (siehe unten).

Insgesamt griff Haitham im Interview zunächst auf eine Gesprächsrahmung zurück, die sich in Haithams Arbeitsleben, aber auch in Alltagsgesprächen in Ramallahs Bars und Restaurants mit seinen Bekannten und Freund*innen aus der Szene westlicher Expats häufig ergab und die Haitham gut kannte: Er vertrat gegenüber ,Westlern“ - oder „Internationals“, wie Haitham sie nannte -, ,palästinensische Perspektiven':

Haitham: „I love to sit with an international for hours talking about the conflict from a Palestinian point of view [...] because for an international it must be very confusing in hearing this contradictory views from both sides who the fuck is right you know".

Die Interviewrahmung hatte zudem Ähnlichkeiten mit einem Kneipengespräch und Haitham gab sich auch locker und scherzhaft. Allerdings markierte Haitham im Verlauf des Gesprächs auch sehr klar die Grenzen, in denen sich die Gesprächsrahmung und meine Rolle als „International“ bewegen dürfe. Die Anspielungen auf „heated up discussions“ mit „Internationals“, die er während des Gespräches bei einigen politischen Themen machte, galten auch als Aufforderung an mich, den von ihm gesteckten Bereich des, respektvollen Umgangs' mit ,der palästinensischen Perspektive' nicht zu verlassen. 
Die Haupterzählung des Interviews schloss Haitham mit einer relativierenden Einschätzung zur eigenen thematischen Gestaltung des Gesprächs:

Haitham: „on the bright side of things yes I don't go home before midnight Yes I love dancing and partying yes I have too many friends and love socializing [...] finding the balancing between working hard hard hard hard hard and having this one day of whohooo you just letting yourself out I don't want it to sound like my life is only about like us and the nation not really this would be very exaggerating“"

Die Passage offenbart eine von Haitham getroffene Selbsteinschätzung über die vermeintliche thematische ,Schlagseite‘ der Haupterzählung. Haithams Evaluation, er wolle nicht den Eindruck vermitteln, in seinem Leben gehe es nur um ,uns und die Nation', gibt einen Eindruck davon, inwiefern im Interview die nationale Zugehörigkeit die thematischen Felder dominierte und Haitham eine palästinensische Sprecherposition für sich reklamierte. Sie gibt auch einen Hinweis auf die biographischen Orientierungen Haithams, die sein Leben als Jugendlicher und junger Erwachsener dominieren und die in der unten diskutierten Fallgeschichte sehr deutlich werden: der Fokus auf Statuswettkampf und die Realisierung von (familial gegebenen) Lebenschancen einerseits und ein hedonistischer Lebensstil andererseits.

Als Haitham mir nach dem Nachfrageteil und insgesamt etwa eineinhalb Stunden Interview mitteilte, dass er später noch arbeiten müsse und daher das Gespräch beenden wolle, fragte ich ihn, ober er sich ein zweites Gespräch vorstellen könnte. Er antwortete:

Haitham: „I have no problem sitting again in a real less bourgeois place like this having the real urban coffee not the cappuccino and discuss other stuff whether it was for your doctoral thingy or your research or not [...] I always love to show internationals the more simpler life of Palestinians not the NGO people sitting here“".

Als ich antwortete, er habe den Ort als Treffpunkt vorgeschlagen, versicherte er mir, er mache nur Späße. Dennoch fühlte ich mich von der impliziten Vermutung, mein Eindruck von der palästinensischen Gesellschaft könnte sich auf das Milieu der Restaurantgäste beschränken, und der von mir als etwas arrogant empfundenen Anspielung auf mein Getränk - ich hatte einen Cappuccino bestellt - herausgefordert und gab ihm einen Eindruck von meinen bisherigen Forschungstätigkeiten in den Flüchtlingslagern um Ramallah und Bethlehem. Ich sagte, dass ich nun jedoch in einem anderen „Milieu“ forschen wolle. Er stellt einige Nachfragen zu meinen Tätigkeiten und meinte, hätte ich dies vorher gesagt, wäre es wahrscheinlich eine andere Unterhaltung geworden. Da wir bereits dabei waren zu gehen habe ich hier nicht nachgehakt. Was ändern meine Forschungserfahrungen an Haithams Zuschreibungen mir gegenüber? Einerseits hätten diese Kontextinformationen sicherlich dazu beigetragen, dass Haitham sich etwas zurückgehalten 
hätte, für ein palästinensisches Wir zu sprechen. Zum anderen wäre er von dieser Rolle der ,richtigen' Repräsentation auch entlastet gewesen, das unterstellte, Vorwissen' hätte ihn aus der Verantwortung genommen, im Kontext der „contradictory views" oder des Perspektivenwettbewerbs in der westlichen Öffentlichkeit die ,palästinensische Sache` zu vertreten. In unserem zweiten Interview, das wir zwei Tage später durchführten und welches mit fünf Stunden wesentlich länger war als die erste Sitzung, veränderte sich jedenfalls unsere Gesprächsdynamik merklich. Zwar unternahm Haitham auch weiterhin lange argumentative Einlassungen zur politischen Situation, allerdings kam er, unterstützt durch mein narratives Nachfragen, über weite Phasen des Interviews auch in einen Erinnerungs- und Erzählprozess von Geschichte zu Geschichte. Dies war meiner Einschätzung nach auch dadurch möglich, dass er in unserer zweiten Interviewsitzung zumindest in Teilen aus jener Repräsentationsrolle entlassen war, die er, wie deutlich werden wird, insbesondere im Arbeitskontext eingeübt hatte.

\subsubsection{Familien- und Lebensgeschichte}

Haitham wurde 1991 in eine muslimische Familie in Ramallah geboren. Seine Familie väterlicherseits lebte in der vierten Generation in Ramallah, die weiter zurückliegenden, Wurzeln ${ }^{`}$ der Familie liegen im Umland Ramallahs. Haithams Großvater väterlicherseits war 1937 geboren worden, Haithams Großmutter väterlicherseits vermutlich 1938. Ab Anfang des 20. Jahrhunderts waren mehrere Mitglieder der Familie, auch der erweiterten Familie, nach Nord- und Lateinamerika migriert und zum Teil später remigriert. Haithams Urgroßvater und sein Großvater hatten in den 1940er Jahren einige Jahre in Chile gelebt, als der Großvater ein Kind war. Generell hatten Migrationsbewegungen nach Nord- und Lateinamerika aus Palästina bereits im Osmanischen Reich ab etwa 1880 eingesetzt. ${ }^{156}$ Diese Migrationsbewegungen hatten Anfang des 20. Jahrhunderts auch Auswirkungen auf Ramallah. Die Migrationen waren mit Rücküberweisungen sowie mit dem Knüpfen von Handelsbeziehungen verbunden, die Ramallah allmählich den Status eines regionalen Handelszentrums verliehen und auch einen stärker städtischen Charakter annehmen ließen (Taraki/Giacaman 2006: 21). Auch Haithams Familie nutzte die entstandenen familialen Netzwerke für den Handel mit Südamerika, insbesondere für den Im- und Export von Lebensmitteln. Ins innerstädtische Gebiet zog die Familie erst in den 1950er Jahren. Die Urgroßeltern bauten ein Haus in der heutigen ,Altstadt', also im am westlichen Hang gelegenen Ramallah Tahta. Sie gehören damit nicht zu den altansässigen städtischen Fami-

\footnotetext{
${ }^{156}$ Schätzungen zufolge migrierten 250.000 Menschen zwischen 1880 und 1920 aus der arabischen Levante nach Nord- und Süddamerika (Mussallam 2006: 5). Die Migration und die entstandenen familialen translokalen Netzwerke wurden in der Forschung meist vorwiegend mit Blick auf die christliche Bevölkerung Palästinas diskutiert (ebd.).
} 
lien, ${ }^{157}$ waren und sind in Ramallahs Stadtgesellschaft aber gut vernetzt. Haithams Urgroßvater war in den 1950er Jahren zudem in der jordanischen Verwaltung tätig gewesen. Nach dem Arabisch-Israelischen Krieg von 1967 und der Besetzung des Westjordanlandes durch Israel betrieb er in den 1960er und 1970er Jahren ein größeres Einzelhandelsgeschäft in der Stadt. Das Geschäft war einträglich und Familie finanziell relativ gut gestellt. Die Migration von Familienmitgliedern nach Amerika setzte sich im 20. Jahrhundert fort, zwei Onkel Haithams väterlicherseits migrierten in den 1980er Jahren nach Kanada. Haithams Eltern, beide in den 1960er Jahren geboren, heirateten Ende der 1980er Jahre. Haithams Mutter hatte keinen städtischen Hintergrund, sondern stammte aus einer vorwiegend bäuerlichlandwirtschaftlich tätigen Familie, die zu jener Zeit in einem Dorf westlich von Ramallah lebte. Haithams Vater stieg in das Geschäft der Familie ein.

Für die Familie väterlicherseits berichtete Haitham von keiner umfassenderen politischen Involvierung, auch wenn sein Vater, wie er angab, mit der Fatah sympathisierte. Einige Geschwister der Mutter Haithams waren aber Haithams Angaben zufolge in der Fatah aktiv gewesen. In die politische Mobilisierung der 1980er Jahre und die Erste Intifada (1987-1993) war die Familie über die kommerziellen Streiks und Boykotte, die Bestandteil der zivilgesellschaftlichen Mobilisierung in jener Phase waren, eingebunden. Die städtischen Händler und Ladenbesitzer hatten sich - auch unter dem ,Druck der Straße ${ }^{r}$ - für eine Weile in den Aufstand einbinden lassen, obwohl dies mit einem nicht unerheblichen finanziellen und geschäftlichen Risiko verbunden gewesen war (vgl. Kap. 4.5). Salim Tamari hat die erfolgreiche Einbindung dieser gesellschaftlichen Gruppierung als Beispiel für die breite gesellschaftliche Beteiligung und die Wucht der Mobilisierung der 1980er Jahre diskutiert (Tamari 1990; vgl. Kap. 4.5). Haitham erzählte im Interview, wie sein Großvater ihm gegenüber die ökonomische ,Zwickmühle ${ }^{`}$ hervorgehoben habe, in der er sich befunden hätte:

Haitham: „he told me until in the Intifada we would respect all the decisions made by the informal committees the community committees of ,today is a strike no one opens' but on the contrary the Israelis charged him for not opening right $[\ldots]$ there was is a there was a big strike screwed him up where talking the goods out of his shop because he had not have the cash to pay the taxes so everyone resists in his own way but back in the day it was useful resistance".

Haitham ging auch darauf ein, wie sie im Verlauf der Ersten Intifada die Streiks aufgrund der hohen finanziellen Ausfälle nicht hatten durchhalten können.

\footnotetext{
157 Einige Familien in Ramallah können ihre Ansässigkeit in der Stadt, als Teil des Gründungsmythos der Stadt, bis ins 16. Jahrhundert oder länger zurückführen. Andere Familien zogen, vergleichbar mit den Migrationsbewegungen nach Jerusalem, in den 1920er Jahren insbesondere aus dem Hebroner Umland zu.
} 
Möchte man die Familie Haithams sozialräumlich verorten, kann man von einer Zwischenstellung zwischen den altansässigen Familien Ramallahs und den sogenannten „urban professionals“ (Robinson 1993) sprechen, die als Ärzt*innen, Lehrer*innen und Rechtsanwält*innen vermehrt seit der Gründung der palästinensischen Universitäten in den 1970er Jahren die urbane Mittelschicht im Westjordanland stellten. Haithams Familie gehört so, auch aufgrund geschäftlicher Erfolge der Familie, seit den 1990er Jahren zur oberen urbanen Mittelschicht mit entsprechendem ökonomischem und sozialem Kapital und, aufgrund der relativ langen Ansässigkeit in der Stadt, mit gewissen Ansehenschancen. In den 1990er Jahren expandierte die Familie ihre Unternehmungen nach Jerusalem und eröffnete dort einige Geschäfte. Haithams Mutter führte später eine kleine Schneiderei. Haitham selbst sprach von seiner „well respected family“, die „a little bit of money" habe.

Haitham wuchs in Ramallah auf. Er war das erstgeborene Kind, nach ihm wurden sein Bruder und seine Schwester geboren. Er besuchte mit drei Jahren einen Kindergarten im Zentrum. Das Verhältnis zu seinen Eltern beschrieb Haitham als von Offenheit geprägt. Sie seien konservativ, aber sie würden sich auf Ratschläge beschränken und ihn zu nichts zwingen:

Haitham: „my family does not actually force you to pray cover your head come home early blabla gives you more space than living in a family that is conservative $[\ldots] \mathrm{do}=$ this and $=$ that $=\mathrm{do}=$ this $=$ and $=$ that because we had an honest open relationship with the parents we grew up on the fact than ehh of sharing things and not not telling parents".

Er habe ihnen auch später von Treffen mit Frauen erzählt oder wenn er ausgegangen sei, um Alkohol zu trinken. Haitham besuchte ab 1997 eine der besseren christlichen Privatschulen in Ramallah, die sich unweit des Wohnortes der Familie befand. In der informellen Schulhierarchie Ramallahs gehörte Haithams Schule zu den besseren und als säkular geltenden, jedoch nicht zu den besten beziehungsweise teuersten Schulen. Generell stand und steht der Privatschulsektor in Ramallah nicht (allein) den palästinensischen Funktionseliten offen. Vielmehr rekrutierte und rekrutiert sich dessen Schülerschaft ganz überwiegend aus Familien aus Ramallahs Mitteschicht. ${ }^{158}$ Auch die Schüler- und Lehrerschaft von Haithams Schule rekrutierte sich aus einem relativ homogenen Milieu der liberalen städtischen Mittelschicht. Einen Hinweis auf die Homogenität von Haithams sozialem Umfeld gibt seine Haltung gegenüber Frauen, die er als diffus ,religiös' verortete:

Haitham: „I did not study in school with girls that had a hijab on their head a veil on their head and that was a little bit of ((zieht Luft ein)), I was racist I

\footnotetext{
${ }^{158}$ Für eine gute Charakterisierung von Ramallahs Privatschulsektor und dessen Bedeutung für die Mitteschicht vgl. Taraki 2008: 72. Eine ganz ähnliche Funktion nehmen die christlichen Privatschulen auch in Bethlehem ein (Tushyeh 1999).
} 
was like I am not sure if you are too religious I don't want to be in this ehh social unknown square I would rather not speak to you“".

In einer späteren Phase seines Lebens, während des Studiums, als er mit einer heterogeneren Studierendenschaft konfrontiert war, habe er bemerkt, dass er Vorurteile gehabt habe, so Haitham. Seine stereotypen Vorbehalte und seine Unsicherheit im Umgang mit Frauen, die den Hijab tragen, verdeutlichen die relative Distanz von Haithams sozialen Umfeld zu anderen Milieus der palästinensischen Gesellschaft. So war und ist das Tragen von Hijabs im Westjordanland, auch in Ramallah, ganz üblicher Bestandteil des öffentlichen Lebens.

\section{Zweite Intifada}

Im Herbst 2000, als Haitham neun Jahre alt war, begann die Zweite Intifada. Diese war in den ersten Monaten durchaus von Massendemonstrationen und ,Konfrontationen' in Jerusalem und den palästinensischen Gebieten geprägt, jedoch fand bald eine Militarisierung des Aufstands statt (vgl. Kap. 4.7). Im Oktober 2000 kam es zu einem Lynchmord an zwei israelischen Soldaten in Ramallah, woraufhin das israelische Militär eine in den Mord involvierte Polizeistation beschoss. Haitham erinnert dies so: ,that day in $2000 \mathrm{I}$ was only 9 or $10 \mathrm{I}$ was in the street helicopter is running in the sky of Ramallah a missile would be down in the street and we are running home like oh my god“. Das Stadtgebiet Ramallahs war von der Zweiten Intifada in besonderem Maße im März 2002 betroffen. In einer groBen Kampagne rückte das israelische Militär großräumig in das Westjordanland ein und besetzte zwischen März und April größere Ortschaften. Haitham erinnerte sich an die langen Schlangen, die sich vor den Lebensmittelläden bildeten, wenn die Gerüchte über eine bevorstehende Ausgangssperre ,die Runde machten`. Für ihn waren diese Gerüchte immer mit der Hoffnung verbunden gewesen, dass dann, wie häufig, auch die Schule ausfallen würde. Er erinnerte sich auch daran, wie er die Bombeneinschläge, mit denen das israelische Militär gezielt Mitglieder der palästinensischen Parteien tötete, hörte. Beim Einrücken der israelischen Armee ins Stadtgebiet kam es auch zu Gefechten mit palästinensischen Paramilitärs und Haitham sah vom Haus der Familie aus, wie ein palästinensischer Kämpfer erschossen wurde, der in einen Schusswechsel mit einem israelischen Panzer verwickelt war:

Haitham: „there was probably four five guys and three of them managed to jump of the wall and go run away listen it was very=very scary to even look out of the window they shot at my house because my uncle removed like moved the curtain and look at so it was very dangerous and I have no idea why I was stupid enough to go look but I have seen someone trying to climb a wall to run away and bullet in his head bam smashing on the ground not something I did really want to see but I don't know [... $]^{\text {‘. }}$ 
Er fuhr fort, ,it wasn't great for me to be honest I didn't have feelings about it that time I will be like oh wow someone got shot but mentally I was not aware of someone someone is dead someone is shot". Im Interview beschäftigte Haitham der Gedanke, dass ihn der Tote irgendwie nicht interessiert habe: „didn't care that someone got shot". Er glaubte, dadurch, dass man die ganze Zeit in den Nachrichten davon hörte, dass dieser oder jener gestorben oder erschossen worden sei, sei man an den Gedanken gewöhnt gewesen. Außerdem sorge vielleicht auch die Idee, die Märtyrer zu ehren, dafür, dass man den Tod anderer hinnehme. Seine bekundete Distanz mag auch mit Abwehr gegen eine lebensbedrohliche Situation verbunden sein und auch mit der Erleichterung, selbst nicht betroffen gewesen zu sein - ein Gefühl, dass gerade in einer kollektiven Rahmung von ,nationalem Widerstand' und Märtyrerschaft schwer einzugestehen sein dürfte. Außerdem bleiben diese Ereignisse in relativer Distanz zu Haithams unmittelbarem Umfeld und zu seinen Bezugspersonen. Seine Familie und seine Freunde und Schulkameraden seien relativ unbehelligt geblieben: „I was lucky that non of my classmates got shot and I did not experience that in my school“. An die eingangs erwähnten Massenverhaftungen, Hausdurchsuchungen und Ausgangssperren erinnerte sich Haitham folgendermaßen:

Haitham: ,we were so young if there was a curfew me and the neighbourhood guys we are like ey let's play soccer in the street no cars nothing (2) we would play it by ear until we hear a tank you know usually the Israeli jeeps have loud voices you play it by hearing when you hear something we would run home“.

Die israelische Militärkampagne war nach einigen Wochen beendet, im Verlauf des Jahres 2002 gab es jedoch weitere Operationen in Ramallah. Die bewaffneten Auseinandersetzungen und Anschläge im Westjordanland setzten sich in den folgenden Jahren fort, verloren aber bis 2005 und 2006 merklich an Intensität (vgl. Kap. 4.7). Insbesondere Ramallah blieb nach der Zweiten Intifada, im Gegensatz zu einigen ländlichen Regionen und den Gegenden der Flüchtlingslager im Westjordanland, von israelischen Militäroperationen weitestgehend verschont (vgl. Kap. 4; 7). Außerdem veränderte sich das Stadtbild Ramallahs in den folgenden Jahren weiter. Die Stadt wuchs, es eröffneten viele Bars und Restaurants, die Zahl westlicher Expats stieg.

Haitham war Ende der Zweiten Intifada circa 13 Jahre alt. Generell mündeten die Erfahrungen der Zweiten Intifada bei Haitham nicht in eine biographische Hinwendung zu ,politischen' Themen während seiner Adoleszenz. Vielmehr konzentrierte sich Haitham in den folgenden Jahren darauf, die Lebenschancen zu realisieren und zu steigern, die sich ihm durch seinen familialen Hintergrund und sein Milieu darboten. Dies steht auch, darauf sei an dieser Stelle bereits hingewiesen, mit desillusionierenden Erfahrungen im Studium und Berufsalltag und mit Erfahrungen, die ihm seine geringen politischen Spielräume vor Augen hielten, in 
Zusammenhang. Sie führten, wie ich zeigen werde, vor dem Hintergrund seiner Lebenschancen tendenziell zu einer generellen inneren Distanz zur palästinensischen Institutionen- und Parteienlandschaft und zu einem Rückzug, ins Privatec.

\section{Jugend in Ramallah: Statuswettkampf und Konsumorientierung}

Haitham hatte in den folgenden Jahren schulischen Erfolg. „I remember myself caring about nothing except studying getting high grades remember fighting with my other friends if they get higher grades than me". Da Haitham eine Privatschule besuchte, drückte sich seine sich abzeichnende soziale Stellung auch in Gefühlen von Überlegenheit aus, die er gegenüber Schüler*innen von öffentlichen Schulen empfand: „It [der Besuch von Privatschulen] gives you more of a scope of a better person or $=$ not $=a$ better person but an advanced personality of dealing with different people“. Zu diesem Gefühl trug auch der Umstand bei, dass palästinensische Politiker und öffentliche Personen aus der Gemeinde regelmäßig in der Schule präsent waren. Ihre Kinder gingen zum Teil dort zur Schule, manchmal erschienen Repräsentanten der Stadt oder der PA zu offiziellen Anlässen und Feierlichkeiten in der Schule. Der Umgang mit diesen Menschen habe zu seiner Selbstsicherheit beigetragen, gab Haitham an. Auch habe die Schule zu einer Vertrautheit mit westlichen Sprachen beigetragen, er hatte dort umfassenden Englisch- und Französischunterricht. Außerdem sei man regelmäßig mit ,Internationals' in Kontakt gekommen. Zu Haithams guten Englischkenntnissen trug zudem insbesondere ein längerer Auslandsaufenthalt bei. Er verbrachte ein halbes Jahr in Toronto und ging dort zur Schule. In Kanada besuchte er mehrfach seine Verwandten, etwa seinen Onkel, der in der Nähe Ottawas lebte. ${ }^{159}$

Als Jugendlicher lernte Haitham zunehmend das Nachtleben in Ramallah kennen, das er, wie er angab, ausgiebig nutzte. Hier kam er auch in regelmäßigen Kontakt mit der großen westlichen ,Expat-Szene' in Ramallah - also mit Austauschstudierenden, Mitarbeiter*innen und Praktikant*innen von NGOs -, zu denen er aufgrund seiner Sprachkenntnisse und seiner Freizeitaktivitäten leicht Zugang fand. Seine Familie tolerierte Haithams Aktivitäten, solange er das „social environment", in welchem er sich bewegte, berücksichtigte. Abends auszugehen, Alkohol zu trinken und gemischtgeschlechtliches Publikum waren und sind auch in der relativ liberalen Atmosphäre Ramallahs nicht ohne Weiteres sozial akzeptiert. Insgesamt trug die skizzierte soziale Verortung Haithams dazu bei, dass er ein Selbstbild als ,Städter', als „city boy“ wie er sich nannte, entwickelte. Haitham gab an, er könne sich nur ein Leben in Ramallah vorstellen: „I would not favour living in any other city but Ramallah and if I am traveling in the West Bank the

\footnotetext{
${ }^{159}$ Haithams englische Sprachkenntnisse sind im Vergleich zu seinen Altersgenossen gut, in Ramallah jedoch nicht außergewöhnlich. Signifikante Teile der Mittelschicht Ramallahs haben einen amerikanischen Migrationshintergrund, haben zum Teil Doppelstaatsbürgerschaften und/oder besuchen die lokalen Privatschulen, die großen Wert auf das Erlernen westlicher Sprachen legen. Zum Teil bieten die Schulen SAT-Prüfungen an.
} 
only city I would have fun in going to is Bethlehem (2) for it's international context as well." In anderen Städten würden die Leute herumschnüffeln und hätten Vorurteile, gab er als Begründung an. Auch mit seinen Cousins mütterlicherseits, die in einem Dorf im Umland Ramallahs lebten, könne er, wie er angab, wenig anfangen. Man besuche sich gelegentlich, aber sie fühlten sich in Ramallah nicht wirklich wohl. Insgesamt deutete Haitham eine ,Außenorientierung ${ }^{6}$ an, die nach Abourahme (2009) typisch für Ramallahs Mittelschicht ist. Letztere sei „better linked to Amman, the Gulf, Europe and North America than it is to the rest of the West Bank“ (ebd.: 505), und habe einen „outward gaze and strong transnational links" (ebd.). An Haithams Fall wurde deutlich, wie sich dieser „outward gaze" über den familialen Hintergrund und die Milieuverortung biographisch herstellt.

Im Jahr 2009, Haitham war zu dem Zeitpunkt 18 Jahre alt, absolvierte er das Tawjihi. Die Vorbereitungen auf die Abschlussprüfungen nahm Haitham sehr ernst und er besuchte auch einige schulexterne Kurse zur vertiefenden Vorbereitung. Er empfand in dieser Phase erheblichen Erfolgsdruck, der auch durch die Erwartungshaltung seiner Familie, nicht zuletzt aufgrund seiner bisherigen Noten, geschürt wurde. Haitham bestand das Tawjihi mit moderaten Abschlussnoten, die, wie er andeutete, seinen eigenen Erwartungen und denen seiner Familie nicht ganz gerecht wurden:

Haitham: „I am the oldest son I should be getting good grades $[\ldots]$ all your uncles and aunts are this kid is very successful he is going to have a high grade, yes ok people give me a break I had an average of 80 percent in scientific stream in tawjihi which is relatively a high grade for scien= for physics and math and all this stuff it is (2), good (gedehnt) regardless of the obsession of our parents in the $\mathbf{9 9}$ percent grade yeah“".

\section{Studium in Bir Zeit: Distanzierung vom palästinensischen ,Politikbetrieb‘}

$\mathrm{Da}$ die Zulassung zu den Studienfächern der palästinensischen Universitäten im Wesentlichen auf Basis der Abschlussnoten erfolgt, bedeuteten die moderaten Abschlussnoten für Haitham innerhalb des palästinensischen Bildungssystems eine Einschränkung der Universitäts- und Studienfachwahl. Allerdings kam Haitham hier die Ausstattung seiner Familie mit ökonomischem und sozialem Kapital zugute. Er hatte den Plan gefasst, ein rechtswissenschaftliches Studium an der Bir Zeit Universität aufzunehmen:

Haitham: ,we go there to the application office got all the papers blablabla and then I find out can't sign up because they are requiring like a 90\% of eh of eh of a grade only for grades right and I was like damn what I am going to do and I spent a week going back and forth back and forth I should get a seat in the college and into Bir Zeit it is highly competitive (2) and then someone put in my ear this parallel education system they have in Bir Zeit where you actually pay twice the tuition and you get in regardless of your grades". 
Haithams Eltern zahlten die Gebühren für den ,parallelen` Zugang und Haitham nahm sein Studium auf. In den ersten Semestern seines Studiums nutzte Haitham außerdem weiterhin ausgiebig das Nachtleben Ramallahs: „in my first year was meeting people and girls and partying every single day". Er besuchte auch Parties in dem oben erwähnten Café Masyon, in welchem er Salwa und ihre Clique kennenlernte. Im Interview sprach Haitham auch darüber, wie er nach ,durchzechten Nächten gelegentlich bei einer ,Abendbekanntschaft' in Nablus oder Bethlehem aufgewacht sei. In den folgenden Semestern engagierte sich Haitham stärker in seinem Studium und hatte zunehmend gute Noten. Er begann außerdem sich im studentischen Debattierclub zu engagieren. In den Semesterferien nach dem dritten Semester absolvierte er ein längeres Praktikum bei einer NGO in Ramallah. Außerdem verdiente er sich etwas Geld im Betrieb des Vaters dazu.

Für Haithams biographische Deutungs- und Handlungsmuster zeichneten sich eine Leistungs- und Karriereorientierung einerseits und hedonistische Konsumgewohnheiten andererseits an. Haithams Habitus korrespondierte mit den Orientierungen, die Lisa Taraki für die urbane Mittelschicht Ramallahs nach der Zweiten Intifada als ,normalization of a new individualistic ethos embracing leisure, self-enhancement, and social mobility" (2008: 65) beschrieben hat. Politische Involvierung ist hingegen bisher kein Bestandteil von Haithams biographischer Dynamik, oder wie er es für seine Schul- und Studienzeit formulierte: „I don't remember myself thinking about the occupation". Diese Einschätzung Haithams, die auch mit den Bemerkungen Lutfis in Kapitelabschnitt 8.2 korrespondiert, ist auch vor dem Hintergrund der gegenüber einigen Lager-Gegenden und ländlichen Gegenden, insbesondere in den C-Gebieten, relativ geringen israelischen Militärpräsenz in Ramallah nach der Zweiten Intifada zu interpretieren.

Die relative Indifferenz gegenüber den palästinensischen politischen Fraktionen zeigt sich auch daran, wie Haitham die Hochschulkultur erlebte. Studentische Organisationen der palästinensischen Parteien waren und sind integraler Bestandteil des palästinensischen Universitätswesens und der palästinensischen Hochschulkultur. Für die politische Mobilisierung der palästinensischen Bevölkerung in den 1970er und 1980er Jahren waren die studentischen Gruppen sehr bedeutsam gewesen. ${ }^{160}$ Die Hochschulgruppen hatten eine wichtige Rolle in der Mobilisierung der „nonlanded urban professionals“ (Robinson 1997: 38) - also auch der Eltern Salwas und Mariams (vgl. Kap. 8.2) - für die Landwirtschafts- und Frauenund Gesundheitskomitees gespielt, die die Stadtbevölkerung mit der Flüchtlingslager- und Landbevölkerung in Kontakt brachten (ebd.: 39). Auf Haitham entfalteten die politischen Gruppen, die auch in seiner Studienzeit in den 2010er Jahren Teil des Campuslebens waren, jedoch keinerlei politisierende Wirkung. Die regelmäßigen Debatten zwischen den studentischen Vertretern erlebte Haitham

160 Zur Rolle der Hochschulgruppen in der massiv politisierten Atmosphäre der 1980er Jahre im Westjordanland vgl. Fußnote 81. 
nicht als Beitrag zu seiner politischen Meinungsbildung, sondern eher als lächerlich: „this representative curses at the other representative and this representative brings facts of the corruption of that representatives party $[\ldots]$ it is funny to watch these guys but I don't want to support these people." Auch die jährlichen Universitätswahlen waren in Haithams Verständnis weit davon entfernt, eine Chance zu sein, politischen Überzeugungen Ausdruck zu verleihen:

Haitham: „they would approach you social pressure you know your friend your relative blablabla please vote for this party please vote for this party $[. .$. I would say yesyesyes and would hand in an empty eh empty paper in the box in the end of the day and honestly during my four years I have only voted once and it was an empty paper and then I have never approached any election place $[\ldots]$ more and more youth lost interest in those parties the same bullshit happens every year".

An Haithams Verweigerung der Wahlen wird deutlich, dass er sich von der palästinensischen Parteienlandschaft nicht repräsentiert fühlte. Dies zeigte sich auch im Zusammenhang mit anderen Erfahrungen, etwa wenn er die politischen Hochschulgruppen für illegitim erklärte, da sie die geringe Wahlbeteiligung und die mit dieser verbundenen Regelungen für die Zusammensetzung der Studierendenvertretung ignoriert hätten (,this is nothing different than the PA is doing ${ }^{6}$ ), oder an Haithams Aufregung über Streikbeschlüsse der Hochschulgruppen (,five or four students decided out of fucking nowhere that this is a strike and they you know

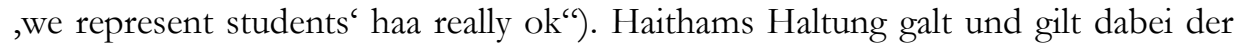
gesamten Parteienlandschaft. So gab Haitham an, mit der Hamas und dem Islamischen Jihad könne er sich nicht identifizieren, er denke nicht, dass Religion in der Politik eine solche Rolle spielen sollte. Die linken Parteien wiederum seien schwach und nicht ernst zu nehmen, in die gingen seiner Ansicht nach bezeichnenderweise nur „cute girls“. Die Fatah, mit der seine Eltern, insbesondere seine Familie mütterlicherseits, sympathisierte, wertete Haitham ebenfalls ab. Dies hing vermutlich auch mit Erfahrungen mit den klientelistischen Netzwerken zusammen, die auf Haitham eine distanzierende Wirkung hatten. In eine dieser Erfahrungen möchte ich in der folgenden, ausführlich zitierten Passage einen Einblick geben. Haitham war von einem entfernten Verwandten - und Kassenwart der Fatah-Hochschulgruppe - ein Stipendium angeboten worden:

Haitham: „this relative of mine said listen bring me your grades for the first semester and I can give you a little bit of a scholarship (1) I said how he said I am the treasury person for this and I am in charge of all these things and I am a relative of yours blablabla I wanna help you because you are in parallel education and your dad pays a lot of money [...] I have never showed up again although I told my parents and my parents said if you don't feel you should get a scholarship don't if you don't do then don't deep inside me I felt 
I am making my family paying a lot of money for my education however we are not dying out of hunger".

Haitham, der das Stipendium ablehnte, bemerkte zu dieser Erfahrung noch lapidar, es gebe immer jemanden in der Familie, der zur Partei gehöre, egal ob er deren Ideologie kenne. Diese Erfahrungen von Klientelismus oder „Korruption“, wie er dies an anderer Stelle nannte, die zudem auch das soziale Kapital seiner Familie verdeutlichen, haben vermutlich dazu beigetragen, dass Haitham, obwohl potentieller Profiteur, sich von der palästinischen Parteienlandschaft abwandte und eine eher indifferente und herablassenden Haltung entwickelte. Jedenfalls blieb Haitham während seines Studiums den Hochschulgruppen gegenüber distanziert („I didn't deem them [die Hochschulgruppen] interesting I said ok I didn't want to be with any of the parties"). Diese Umgangsweise zeigte Haitham auch im familialen Kontext:

Haitham: ,it is unlikely for me to have great engagement with my uncles in the village not because they don't respect me in what I do I just because [...] I always avoid to getting into an argument about this party or that party and I always avoid to talk to someone who belongs to a party about my own views because those guys will never get it".

Haitham ging zu Teilen der Familie, die sich stärker mit der Fatah identifizierten, auf Distanz und blieb in Diskussionen oder Gesprächen mit ihnen, die um diese Fragen kreisten, passiv.

\section{Arbeit im NGO-Sektor: Distanqierung von Gebern und „Internationals“}

Zum Ende seines Studiums leistete Haitham, dann 22 Jahre alt, Freiwilligenarbeit bei einer weiteren NGO in Ramallah, die umfangreiche Projekte zur Gesundheitsprävention und -versorgung durchführte. Nach dem Universitätsabschluss absolvierte er ein sechswöchiges Praktikum in dieser NGO und wurde anschlieBend als Projektbetreuer eingestellt. Zu seinen Aufgabengebieten gehörte das Durchführen von Workshops und Trainings, die Betreuung der Geber sowie die Betreuung von westlichen Studierenden- und Expertengruppen. Bei diesen Tätigkeiten kamen ihm seine Sprachkenntnisse und sein selbstbewusstes Auftreten entgegen. Allerdings machte Haitham mit den Reisegruppen wiederholt Erfahrungen, die er als ,respektlos` empfand und empfindet. Wie Haitham diese Gruppen erlebte, wird etwa in folgender Erzählung deutlich, in welcher er eine Studierendengruppe aus den USA betreute:

Haitham: „I went there to find out that they have spent 3 days to what is called Israel speaking 3 days to Israelis about the situation and their lovely program is dedicating one hour two hours to speak to Palestinians so I didn't favour that at all and I spoke out about it but I was mistaken by playing the emotion card it was too much it was a huge mistake, look at what they are 
doing you just passed Qalandia look at this the checkpoints the settlements“ (2) ok what's after that, listen dude you guys are racist you don't want Jews living here I think you should make good friends with Jews otherwise you go to Jordan you guys' (2) can you hear a stronger comment on this one, I don't think so, but maybe what settlements are saying, death to Arabs' that's stronger but an American who is supposed to be have read at least two papers about the thing and came here on a purpose on a tour and I got really pissed off in the classroom and I said ok guys, this conversation has end has ended that's it I am not willing to speak to you anymore that was very disrespectful thank you very much I I shake hand of the coordinator of them and left the room very stupid yeah very very stupid“.

Zum einen empfand Haitham das Auftreten der westlichen Reisegruppe als kränkend. Dieses Erleben verstärkte sich in den folgenden Jahren. Haitham erlebte die westlichen Delegationen als anmaßend und uninformiert und hatte den Eindruck, dass diese ihm ,nicht richtig zuhörten'. Diese Erfahrungen bezogen sich etwa auch auf Diskussionen mit den Vertretungen der westlichen Geberorganisationen, deren Vorschläge und Regularien er zum Teil für absurd hielt. Zum anderen bewertete Haitham diese und andere Erfahrungen als lehrreich für die ,richtige' Repräsentation der ,palästinensischen Sache ${ }^{6}$ im Kontext westlicher Reisegruppen und Delegationen.

Haitham: „I should be strong enough and smiling and saying out loud my points because I am not a victim first it makes you look weak and second it makes people think haa I mean everyone can be a victim so you play a very old card right $[. .$.$] you don't go there having tons of papers don't know how$ to say two words and speaking stupidly English“.

Haitham legte sich also Strategien zum höflichen Umgang und zum selbstbewussten Auftreten zurecht. Im Arbeitskontext erlernte er nach und nach den ,richtigen Umgang mit den westlichen Delegationen und den Spendern. Er passte sich in seiner Repräsentation des „palestinian case“ damit generell der Aufmerksamkeitsökonomie westlicher Delegationen und dem Perspektivenwettbewerb auf den Nahostkonflikt in den westlichen Öffentlichkeiten an. Bei den mit der Repräsentationsrolle verbundenen Anforderungen an souveränes Auftreten und Gewandtheit im Umgang mit ,Internationals', das Argumentieren in westlichen Sprachen und emotionale Distanzierung kommen Haitham seine biographisch erworbenen Deutungs- und Handlungsorientierungen zugute. Haithams Tätigkeiten und sein Berufshabitus korrespondieren dabei mit einer generellen Transformation der Zivilgesellschaft seit den 1980er Jahren zugunsten einer ,professionalisierten ' und nicht mehr auf eine Unterstützung des palästinensischen ,Widerstandsprojektes', sondern an westlichen Geberkriterien ausgerichteten NGO-Landschaft (Jad 2008: 
100). ${ }^{161}$ Die in den Komitees, Organisationen und Vereinen der 1980er Jahre eingebundene Landbevölkerung und die Bevölkerung aus den FlüchtlingslagerGegenden wurden in dieser transformierten Zivilgesellschaft eher marginalisiert (ebd.; vgl. Kap. 4.6). Dennoch war auch für Haitham die Anpassung an diese mit der NGO-Arbeit verbundenen Repräsentationsrolle mit dem Erleben von Dissonanz verbunden: „It is hard it is hard all time because you need make this impossible balance of being respectful but being smart at the same time listen but also reply diplomatically“. Die Rolle kam ihm zunehmend schematisch und beizeiten etwas aufgesetzt vor: ,represent your people but not be too giving up on your cause [...] standing up for what you believe blablabla“.

Die Erfahrungen mit respektlosen ,Internationals', die sich seiner Auffassung nach ohne ausreichende Orts- und Kontextkenntnisse ein Urteil anmaßten, zogen sich auch durch Haithams Kontakte mit der Expat-Szene in Ramallah. Seitdem er in der NGO arbeite, vermehrten sich hitzige Diskussionen mit seinen ,westlichen“ Freunden, gab er an. Eine Belegerzählung, in welcher diese Diskussionen zur Sprache kamen, möchte ich in einer längeren Passage zitieren:

Haitham: ,it is very irritating to explain yourself in very much people to those people who don't know what the situation is (2) or who favour the Israeli side If you are an international don't not favour any party right (3) ,but listen you guys have used women and children in Gaza why would you do that ((verstellt Stimme)), ok so are you giving the legitimacy for killing of women and children is that what what are you telling me, at that point I go out of my mind dude fuck off (..) and (2) it calls me more from inside because I am aware what the international community and donors are doing to this country so sorry I don't want this international person to come to play smart on me, this country has had enough of (2) people bullshitting on it (..) and it calls me more from inside because I am aware what the international community and donors are doing to this country [...] and this is only a recent belief I have added to my values".

Insgesamt trug Haithams Verhältnis zu seiner NGO-Arbeit und zur westlichen Expat-Szene in der Stadt zunehmend auch zynische Züge und wurde von ihm mit wachsender innerer Distanz gesehen. In der Art und Weise, wie Haitham unser Interview im Frühjahr 2015 gerahmt hat, spiegeln sich diese Arbeitserfahrungen mit westlichen Studierenden- und Expertengruppen und den Expats in Ramallah. Gerade die Rahmung der ersten Interviewsitzung, in welcher er mir gegenüber eine dezidierte Experten- und Informantenrolle für ,Palästinensische Kultur ${ }^{6}$ und den Nahostkonflikt einnahm und in welcher er auch auf den Wissensstand und

\footnotetext{
161 Jad geht an einer Stelle explizit darauf ein, wie Tätigkeitsanforderungen in den NGOs mit den Anforderungen an Auftreten, ,komunikative Kompentenzen' für Workshops und Konferenzen, das Verfassen von Berichten in englischer Sprache und so weiter gerade zu jenem Set an Handlungskompetenzen ,passen', das Vertreter*innen der urbanen Mittelschicht wie Haitham mitbringen (2008: 100).
} 
die Respektlosigkeiten von manchen ,Internationals ${ }^{\star}$ anspielte, verweist auf die skizzierten Kontexte im Berufsalltag in der NGO und in Haithams Freundes- und Bekanntenkreis.

Für Haitham mehrte sich mit wachsender Berufserfahrung der Eindruck, dass die hohe NGO-Präsenz im Westjordanland und die damit verbundene Abhängigkeit von den Spenderorganisationen, der palästinensischen Sache ${ }^{6}$ schaden. Er habe mit Gebern und Projekten aus der EU, den USA und auch arabischen Gebern verschiedener Größe gearbeitet und habe einen umfassenden Einblick. Unter seinen Arbeitskolleg*innen und Bekannten sei man sich in dieser Hinsicht einig, gab er mir gegenüber an: ,like I am saying very personal stuff here like I have too many friends in international NGOs whether they are internationals or locals [...] and we were just making fun the other day that development did nothing in this country“. Es sei wirklich frappierend, aber im Ergebnis mehr als deutlich: ,in the past 20 years there is almost almost zero real change from the projects they use". Haitham war generell misstrauisch hinsichtlich der Gründe, warum die internationale Gemeinschaft so viel Geld ins Westjordanland ,pumpec. Vielleicht werde in ein paar Jahren argumentiert, man habe nun genug gezahlt, um für das Land, das die Israelis genommen hätten, aufgekommen zu sein. Zum Zeitpunkt unserer Gespräche im Frühjahr 2015 wirkte Haitham in Bezug auf seine Tätigkeit, wie in den erörterten Erfahrungen und geäußerten Haltungen zum Ausdruck kommt, etwas ,abgekämpft ${ }^{t}$ und desillusioniert. Die Kolleg*innen und er würden zwar versuchen, sich mit den gegebenen Spielräumen zu arrangieren und das viele Geld zu nutzen, aber für ihn gebe es auch eine Alternative: „I can always go work with my family."

Haithams Frustration speiste sich noch aus einem anderen Erfahrungszusammenhang - nämlich dem Kontakt mit den Offiziellen der PA. Haitham stieg in der NGO auf und hatte zunehmend auch die Verantwortung für die Bewilligung und Lenkung der Finanzen für größere Projekte. Für die Planungen koordinierte er sich auch mit Angestellten verschiedener Ministerien und Behörden der PA. Die Treffen mit den Behördenmitarbeitern bewertete Haitham allerdings als ,very disappointing". Er beschrieb die Beamten als arrogant:

Haitham: „be an official Palestinian who eh is a part of the PLO obviously who were somewhere with them in Lebanon Jordan $=$ Syria $=$ Tunesia $=$ Algeria $=$ fighting the occupation and come here come back here and do not really know the community here very well or the situation right now very well I am saying it is not only disappointing to me it gives me a point that you are not interested [...] I went in and he said to me,you want me to listen to a taxi driver commenting on my policy?' that taxi driver is the one that is running this country".

Haitham gab jedoch an, er habe sich in der NGO erfolgreich dafür eingesetzt, die Finanzierung dieser mit einem Ministerium der PA verbundenen Projekte zu streichen. Das Sie-Bild des desinteressierten Ex-PLO-Exilanten, das Haitham hier 
bemühte, ist Ausdruck einer Figuration von Rückkehrern und alteingesessenen Palästinenser*innen. Sie schlägt sich in der tendenziellen Besetzung von Berufsund Statuspositionen in der palästinensischen Gesellschaft des Westjordanlandes nieder: „The sense of difference between the two groups [...] manifests itself in such matters as the predominance of returnees in government and political leadership positions and the predominance of ,locals" in NGOs" (Hilal 2010: 32).

Im Rahmen seiner Berufstätigkeit hatte Haitham wiederholt Expertenstatements für lokale Nachrichtenportale und TV-Sender gegeben und war regelmäßig in die Verfassung von Berichten involviert gewesen. Sein Sendungsbewusstsein und seinen Einblick in einen Politikbereich im Austausch mit der PA nutzte Haitham, um einen eigenen Nachrichten- und Kommentarblog zu pflegen. In dem Blog verwendete er Teile der Berichte und Medienbeiträge, die er in seinem Arbeitsalltag zu erstellen hatte. Im Wesentlichen bloggte er zu Gesundheitsthemen, etwa zur Gesundheitsversorgung der palästinensischen Beduinen im Jordantal. Wiederholt kommentierte er aber auch die generelle politische Entwicklung im Westjordanland und übte dabei wiederholt öffentliche Kritik an verschiedenen Entscheidungen der PA und an einzelnen Funktionären. Nach einigen Monaten wurde der Blog lokal relativ bekannt. Ein halbes Jahr, nachdem Haitham den Blog ins Leben gerufen hatte, wurde Haithams Vater von einem Bekannten aus einem der Sicherheitsdienste der PA angesprochen, sein Sohn würde, sich ja viel über die Sulta [arab.: Behörde] beschweren'.

Haitham: ,so to get back to me that media thingy clicked an alarm to my family $[. .$.$] a friend of my dad came it was an informal meeting cup of tea$ and he said your son is in the media a lot (2) you know how Palestinians work your neighbour is a in mubābarāt [arab.: Geheimdienst] your uncle is in the sulta $[\ldots]$ your son really bitches about the PA a lot and my dad laughed $[\ldots]$ but my parents were like do you have to talk about the PA all the time?"

Haithams Eltern baten ihn nach dem Besuch des Freundes des Vaters, mit dem Bloggen vorsichtiger zu sein. Haitham fügte sich den Wünschen seiner Eltern. Er entschärfte seine Beiträge in der Folge und hörte schließlich ganz auf zu schreiben. Im Interview legitimierte er diesen Rückzug damit, er habe im Beruf gelernt diplomatisch zu sein und es habe ihn ohnehin zunehmend gelangweilt zu bloggen: „my activities ehh I started to do less it became a boring thing to me." Haithams Geschichte spiegelt wider, wie klein die Spielräume für politische Artikulation und Äußerung der eigenen Unzufriedenheit sind und wie dies tendenziell - Haitham spricht von Langeweile - zu einer indifferenten und passiven Haltung gegenüber dem palästinensischen Politikbetrieb beiträgt. Generell mündeten Haithams Erleben im palästinensischen Hochschulbetrieb, im familialen und im beruflichen Kontext, seine Erfahrungen im NGO-Sektor und im Austausch mit der PA, die ihn frustrierten und ihm die geringen Spielräume für politische Artikulation vor Augen führten, in eine allgemeine innere Distanz zur palästinensischen Institutio- 
nen- und Parteienlandschaft und in einen passiven Umgang mit selbiger. Er konzentriert sich fortan auf die Umsetzung der eigenen Lebenschancen. Als ich Haitham bei meinem letzten Feldaufenthalt im Herbst 2015 traf, war er weiterhin bei der NGO tätig und hatte sich mit einer ehemaligen Schulkameradin verlobt.

\subsubsection{Zusammenfassung: Familiale und lebensgeschichtliche Dynamik}

In der rekonstruierten biographischen Dynamik wurde deutlich, inwiefern die Ausstattung mit hohen Lebenschancen familial gegeben ist und wie eine biographische Orientierung, die vorwiegend auf die Realisierung dieser Lebenschancen zielt, sich kollektivgeschichtlich und biographisch herstellt. So ist Haitham auf einen (scheinbar gelingenden) Statuswettkampf im Sinne (privat-)schulischer, universitärer und beruflicher Erfolge sowie auf eine intensive Nutzung der im ,kosmopolitischen' Ramallah seit dem Ende der Zweiten Intifada gegebenen FreizeitInfrastruktur orientiert. Die von ihm dabei erworbenen Fremdsprachenkenntnisse, seine hohe Mobilität über die Landesgrenzen hinweg und seine Verbindungen zur großen westlichen Expat-Szene in Ramallah ermöglichten sich wechselseitig und trugen zur einer Reproduktion seines hohen kulturellen und sozialen Kapitals bei. Generell zeichnet sich damit eine Habitusformation ab, die auch von Lisa Taraki als typisch für die ,neue' urbane Mittelschicht Ramallahs hervorgeboben wurde (2008).

Außerdem konnte rekonstruiert werden, welche Erfahrungen aus verschiedenen lebensgeschichtlichen Bereichen - im schulischen, familialen und beruflichen Kontext sowie im Studium - dazu beitragen, dass eine generell abwertende Haltung gegenüber der palästinensischen Parteien- und Institutionenlandschaft, die in Gänze als delegitimiert und korrupt erfahren wird, entsteht. Bei Haitham waren das etwa die familial gegebene Einbindung in klientelistische Netzwerke in die PA, die auch einen entfremdenden Effekt hatten, sowie die mit Repression verbundenen Erfahrungen mit Sicherheitsdiensten der PA. Dazu zählen auch Haithams Erfahrungen im große NGO-Sektor, der im Zuge der Transformation der palästinensischen Zivilgesellschaft in den 1990er Jahren entstanden war und der Haitham seinen Fähigkeiten entsprechende Arbeitsmöglichkeiten bot, der von ihm aber zunehmend kritisch als internationale Finanzierung der Aufrechterhaltung der israelischen Besatzung gesehen und abgewertet wird.

Diese sich aus verschiedenen Lebensbereichen speisenden Erfahrungen trugen bei Haitham zu einem Erleben geringer Handlungsmacht und der Ausbildung einer mit dem Rückzug, ins Private‘ ringenden Orientierung bei, im Rahmen derer - vor dem Hintergrund der eigenen hohen Lebenschancen - er versuchte, die biographischen Kosten im Hinblick auf politische Involvierung möglichst gering zu halten. In diesem Zusammenhang ist auch Haithams demonstrative Präsentation seiner Diskussionen an den Checkpoints und Ähnliches zu interpretieren, die seinen Einsatz ,für die palästinensische Sache ',im Kleinen` in kompensatorischer Weise hervorheben soll. Gleichzeitig bringen diese Orientierungen auch die relativ 
geringen politischen Sinnchancen, die Haitham - aber auch Salwa und den anderen (vgl. Kap. 8.2) - gegeben sind, zum Ausdruck (vgl. Kap. 9). Außerdem wird in den Orientierungen, der Kapitalausstattung und im Lebensstil auch eine erhebliche Distanz zu anderen palästinensischen Milieus deutlich - etwa zu den von mir diskutierten jungen Männern in der Flüchtlingslager-Gegend (vgl. Kap. 6), aber auch zur ebenfalls diskutierten Clique junger Männer aus Ramallah (vgl. Kap. 7). Generell wird in der Falldarstellung deutlich, wie sich die von den jungen Männern aus der Flüchtlingslager-Gegend vorgebrachten Sie-Bilder der ,wohlhabenden Städter', die sich nicht ,für die palästinensische Sache' einsetzen würden, in den biographischen Orientierungen Haithams und der anderen spiegeln und wie diese mit der kollektivgeschichtlichen Periode ,nach Oslo“ verbunden sind. 



\section{Generationenfiguration und biographische Verlaufstypen in der Nachfolgegeneration Oslo}

\subsection{Die Nachfolgegeneration Oslo}

Die Ausgangsfrage dieser Forschungsarbeit war, aufzuzeigen, inwiefern sich in der Generationslagerung Oslo generationale Erlebnisschichtungen, generationale Integrations- und Vergemeinschaftungsprozesse entwickelten und entwickeln. Ferner sollte die Forschungsarbeit, empirisch begründet, mittels der Verknüpfung von figurationssoziologischer und biographietheoretischer Perspektive zu einer theoretischen Ausdifferenzierung der Konzeptualisierung historischer Generationen beitragen. Ein zentrales Analyseergebnis meiner Arbeit besteht - um auf die folgende Diskussion vorzugreifen - in der Rekonstruktion einer EtabliertenAußenseiter-Figuration von Generationengruppierungen. In der Generationslagerung Oslo ist die Zugehörigkeit zu einer Generationengruppierung bedeutsam, die als nachgelagerte Generation mit einer vorgelagerten ,Kampfgeneration', vornehmlich der Generation Intifada (geb. 1960-1970), verflochten ist und gegenüber letzterer in einer Außenseiterposition steht. In diesem Zusammenhang kann man auch von einer „Nachfolgegeneration Oslo“ (geb. 1985-1995) sprechen, wie ich sie im Folgenden nennen werde. Die Position in der Generationenfiguration formt die Erlebnisschichtungen, Lebenswege, Wir- und Sie-Bilder der Mitglieder 
der Nachfolgegeneration Oslo. Ein zentrales, gemeinsames Charakteristikum der Erlebnisschichtung besteht darin, gegenüber der Generation Intifada ein Absinken von Sinnchancen und eine Verschiebung der Verteilung von Lebenschancen zu erleben - Erfahrungen, die biographisch verhandelt werden müssen.

Die Zugehörigkeit zur Nachfolgegeneration Oslo ist für alle in dieser Arbeit in den Bick genommenen lebensgeschichtlichen Verläufe in der Post-Oslo-Lagerung biographisch relevant. Allerdings wirkt sie sich in den von mir rekonstruierten Kontexten in der Flüchtlingslager-Gegend, unter den Rückkehrern und unter den urbanen Altansässigen in unterschiedlicher Stärke und in unterschiedlicher Art und Weise auf die Biographien aus. Die Zugehörigkeit zur Nachfolgegeneration Oslo entfaltet ihre Wirkung jeweils vermittelt durch andere Zugehörigkeiten, Ausstattungen mit Lebenschancen und gesellschaftliche Positionen und wird von diesen zum Teil überlagert. Neben geschlechtlicher Zugehörigkeit wirkt insbesondere eine weitere Figuration in vermittelnder Weise auf die generationale Zugehörigkeit ein. So verschob sich im Westjordanland seit den 1970er Jahren die Machtbalance zwischen der palästinensischen Bevölkerung in den FlüchtlingslagerGegenden und der urbanen, in sich heterogenen Mittelschicht, die sich verstärkt seit den 1990er Jahren in Ramallah formierte und formiert. Die Verschiebung der Machtbalance in dieser Figuration stellt ein weiteres zentrales Ergebnis der empirischen Analysen dieser Arbeit dar. Der weitere Aufbau des Ergebniskapitels ist daher wie folgt.

Die Bedeutung der Generationenfiguration zeigt sich in besonderem Maße im Kontext der Flüchtlingslager-Gegend. Die einzelnen Aspekte der Generationenfiguration werden daher für diesen Kontext ausführlich diskutiert (9.2). Über den Kontext der Flüchtlingslager-Gegenden hinaus ist die Generationenfiguration auch bei den untersuchten Fällen im Kontext der Rückkehrer und der urbanen Altansässigen biographisch relevant. Auch für diese Kontexte diskutiere ich die biographische Bedeutung der Generationenfiguration und insbesondere deren Wechselwirkung mit anderen Zugehörigkeiten (9.3-9.4). In den Kontexten werde ich dezidiert die verschiedenen Komponenten der Generationenfiguration bestimmen. Dazu gehören die Rolle inter- und intragenerationaler Interaktion für die Entstehung historischer Generationszugehörigkeit, die damit verbundenen latenten und ungeplanten Handlungsfolgen der Generationenfiguration und ihr spezifisches Machtdifferenzial, sowie die generationalen Differenzen in der Erlebnisschichtung, den Deutungsmustern, Wir- und Sie-Bildern.

Neben der figurationalen Ebene diskutiere ich die Ergebnisse auch auf der Ebene biographischer Verläufe. Im Hinblick auf die Frage, wie die Zugehörigkeit zur Nachfolgegeneration Oslo mit anderen Zugehörigkeiten, Lebenschancen und gesellschaftlichen Positionen zusammenwirkt, bilde ich biographische Verlaufstypen, die ich ebenfalls in den einzelnen Abschnitten vorstelle (9.2.2; 9.3.2; 9.4.2). In Abschnitt 9.5 erörtere ich gesondert die Figuration von palästinensischer Bevölkerung in den Flüchtlingslager-Gegenden und Teilen der ,neuen' urbanen Mittel- 
schicht. Ich diskutiere die Verschiebungen in der Machtbalance der Figuration und den weiteren Transformationsprozess, der sie begleitete und begleitet. In Abschnitt 9.6 erörtere ich die Frage, inwiefern die Nachfolgegeneration Oslo als ein in der Forschungsliteratur zu historischen Generationen wenig beachtetes Phänomen gradueller historischer Generationenbildung - etwa als eine Zwischengeneration beziehungsweise stille Generation - angesehen werden kann. Indem ich sie auf die Mannheim'sche Generationenterminologie beziehe, ordne ich den Grad beziehungsweise das Ausmaß generationaler Integrations- und Vergemeinschaftungsprozesse in der Nachfolgegeneration Oslo ein. In Abschnitt 9.7 hebe ich resümierend den Gewinn für die theoretische Konzeptualisierung hervor, den meine empirischen Analysen für eine figurationssoziologische und biographietheoretische Perspektive auf historische Generationen haben.

Bevor ich die Ergebnisdiskussion fortführe, möchte ich den Gebrauch bestimmter Begriffe in den folgenden Unterkapiteln erläutern. Diese begrifflichen Regelungen sind insbesondere nötig, da ich nun in der Darstellung der Komponenten der Figurationen und der kollektiv-, familien- und lebensgeschichtlichen Prozesse stärker von den Fällen abstrahiere. Es werden in der Diskussion verschiedene Kategorien analytisch voneinander getrennt und bezeichnet, die empirisch gekoppelt auftreten:

- In den einzelnen Forschungskontexten unterscheide ich jeweils zwischen genealogischen Generationen, das heißt zwischen Elterngeneration und Kindergeneration. Ich bezeichne diese also als „Elterngeneration in den Flüchtlingslager-Gegenden“, „Kindergeneration in den Flüchtlingslager-Gegenden“, als „Elterngeneration unter den Rückkehrern“ und so weiter. ${ }^{162}$ Auf eine reine Bezeichnung nach Kohorten verzichte ich. Sie würde den zahlreichen Erhebungen in Familien und familialen Beziehungen, einer der Erhebungsschwerpunkte dieser Arbeit, nicht gerecht.

- Die Differenz zwischen genealogischen und historischen Generationen muss begrifflich abgebildet werden: Wenn ich die bistorische Generationenbildung und die historische Generationenfiguration thematisiere, greife ich auf die Bezeichnungen „Generation Intifada“ und „Nachfolgegeneration Oslo“ zurück. Diese an den historischen Generationen orientierten Kategorien überschneiden sich dann sowohl mit den Forschungskontexten als auch den Eltern- und

\footnotetext{
${ }^{162}$ Damit weiche ich von einer in anderen Forschungsarbeiten gewählten Orientierung an der Nakba - also Erlebnisgeneration, Kinder- und Enkelkindergeneration - ab. Dies hat den Vorteil, dass die Bezeichnung der genealogischen Generationen über die Forschungskontexte hinweg einheitlich bleibt (denn es ließe sich kaum von Enkelkindergeneration unter den Rückkehrern und Altansässigen sprechen).
} 
Kindergenerationen. Also spreche ich dann zum Beispiel von der „Generation Intifada in der Elterngeneration der Flüchtlingslager-Gegend“ und so weiter. ${ }^{163}$

\subsection{Generationenfiguration und Verlaufstypus in der Flüchtlingslager-Gegend}

\subsubsection{Diskussion der Generationenfiguration}

Die Verflechtung von einer Generation Intifada mit hohen Sinnchancen und einer Nachfolgegeneration Oslo, die das Absinken von politischen Sinnchancen erlebt und $\mathrm{zu}$ verhandeln hat, zeigt sich in besonderem Maße an meinen Erhebungen und Auswertungen in der Flüchtlingslager-Gegend. Für diesen Kontext soll die Generationenfiguration im Folgenden ausführlich diskutiert werden. Zunächst gehe ich auf die rekonstruierten Wirkungszusammenhänge in der Eltern- und Kindergeneration ein. Für letztere werden die Fallebene Biographie und die empirisch ebenfalls herausgearbeitete Ebene der Peergroup-Clique verzahnt dargestellt. Im Anschluss diskutiere ich ausführlich die Komponenten der Generationenfiguration und stelle schließlich die Typenbildung auf der Ebene des biographischen Verlaufs vor.

Die Generation Intifada in der Elterngeneration in der FlüchtlingslagerGegend. Für die in Kapitel 6 exemplarisch diskutierten Vertreter*innen der Elterngeneration der in der Flüchtlingslager-Gegend lebenden palästinensischen Flüchtlinge zeigten sich die biographische Herstellung und die, mindestens bis zur Zweiten Intifada, durchaus gelingende Verhandlung von Partizipation in der politischen Mobilisierung einerseits und eine Steigerung der Lebenschancen andererseits. In der Elterngeneration vollzog sich gegenüber der Großelterngeneration, die die Nakba erlebt und in den 1950er Jahren in Zeltstädten der palästinensischen Flüchtlingslager gelebt hatte, eine erfolgreiche Bearbeitung und Überwindung der ärmlichen Lebensverhältnisse, womit auch der Auszug aus dem unmittelbaren Lagerkontext verbunden war. In der Elterngeneration gelang eine partielle gesellschaftliche Etablierung im Sinne einer Steigerung von Bildungs-, Berufs- und Heiratschancen für die Herkunfts- und Kernfamilienmitglieder, die zum Teil im Rahmen geschwisterlicher Arbeitsteilung organisiert war. Die gesellschaftliche Etablierung gelang vor dem Hintergrund des in den 1970er und 1980er Jahren für

\footnotetext{
163 Diese weitgehende Überlappung von familialer und historischer Generationeneinteilung ist empirisch nicht immer trennscharf gegeben. So tritt empirisch durchaus die Konstellation auf, dass ein Geschwisterkind in der Generation Intifada anzusiedeln wäre und ein jüngeres in der Nachfolgegeneration Oslo. Gerade bei der im Westjordanland zum Teil hohen Anzahl von Geschwistern und etlichen Jahren Abstand zwischen deren Geburtsdaten ist dies möglich. Generell trifft diese Einteilung jedoch die im Rahmen dieser Arbeit erhobenen Stichproben und ist für den Zweck meiner Arbeit genau genug.
} 
Palästinenser*innen aus Gaza und dem Westjordanland offenen israelischen Arbeitsmarktes, der gerade für die unteren gesellschaftlichen Schichten, darunter viele Flüchtlinge aus den Lagern, erhebliche Einkommenssteigerungen ermöglichte. Gleichzeitig waren jene in Kapitel 6 in den Blick genommenen Vertreter der Elterngeneration umfassend in die politische Mobilisierung großer Teile der palästinensischen Bevölkerung im Westjordanland in den 1970er und 1980er Jahren vor und während der Ersten Intifada involviert, wie in der Teilnahme an den StraBenschlachten mit dem israelischen Militär und Siedler*innen, im Engagement in Parteigruppen (in den diskutierten Fällen waren dies die PFLP und Fatah) und in den Inhaftierungen in israelischen Gefängnissen zum Ausdruck kam. In der Elterngeneration wurde so, trotz einer zum Teil ebenfalls ausgefüllten familialen Versorgerrolle, an einem breiten, gesellschaftlichen, Widerstandsprojekt ' gegen die israelische Besatzung partizipiert. Die in dieser Weise gegebene Zugehörigkeit zu einer Generation Intifada umfasst ein mit den Generationsmitgliedern geteiltes generationales Wir-Gefühl und Gruppencharisma, einen biographischen Bestand an ,Widerstandsgeschichten' sowie einen mit der politischen Mobilisierung in den 1970er und 1980er Jahren verbundenen Bekannten- und Freundeskreis, der in späteren Phasen auch als soziales Kapital diente. Teil des Erfahrungsbestandes der Generation Intifada sind auch mit den Kämpfen verbundene erniedrigende und belastende, leidvolle Erfahrungen an den Checkpoints, im Gefängnis und in anderen Kontexten.

Kindergeneration in der Flüchtlingslager-Gegend und Dynamik in der Peergroup. Bei den in Kapitel 6 exemplarisch erörterten Vertretern der Kindergeneration der Flüchtlinge in der Flüchtlingslager-Gegend vollzog sich insbesondere ab der Frühadoleszenz ein sich intensivierender Prozess politischer Militanz, der eng sowohl mit familialen Tradierungsprozessen als auch mit Interaktionsdynamiken in der Peergroup verbunden war. Diese Prozesse mündeten ab dem jungen Erwachsenenalter zunehmend in eine gesellschaftlich marginalisierte Position. Vor dem Hintergrund der gegebenen Risiken ${ }^{164}$ in der Flüchtlingslager-Gegend involvierten sich die in den Blick genommenen Vertreter der Kindergeneration in hoher Frequenz in Straßenschlachten mit dem israelischen Militär und den Sicherheitsdiensten der PA. Die Attraktivität der Involvierung in die Straßenschlachten steht einerseits in Wechselwirkung mit dem familialen Dialog und familialen Tradierungsprozessen: Hier ist die Tradierung der ,eigentlichen' familialen Herkunft aus dem heutigen israelischen Staatsgebiet insbesondere durch die Großeltern, in diesem Fall die ,Erlebnisgeneration“ der Nakba, zu nennen, die in Richtung einer

\footnotetext{
${ }^{164}$ Den Hintergrund für diese lebensgeschichtliche Dynamik bildet zunächst einfach die mit dem Wohnort der Flüchtlingslager-Gegend auch nach den Oslo-Vereinbarungen Mitte der 1990er Jahre gegebene hohe Frequenz von Operationen der israelischen Sicherheitsbehörden im Wohnumfeld. Auch der Aufbau der PA als neuer sicherheitspolitischer Akteur und dessen Versuche, den Herrschaftsanspruch auch auf die Flüchtlingslager und deren Bevölkerungen auszudehnen, gehören zu den mit dem Wohnort verbundenen Spezifika.
} 
Identifikation mit der Idee der Rückkehr wirkt. Noch bedeutender ist meiner Ansicht nach aber die familiale intergenerationale Interaktion zwischen der Elterngeneration als Mitglieder der Generation Intifada und der Kindergeneration als Mitglieder einer Nachfolgegeneration. Die Interaktionstypik, auf welche ich im Weiteren noch ausführlich zu sprechen kommen werde, trägt wesentlich dazu bei, dass, gegen die Intention der Beteiligten, in der Kindergeneration eine Delegation für die palästinensische Sache zu kämpfen', erlebt und angenommen wird. Diese Delegation wird angenommen, obwohl sie nicht im Kontext eines breiten politischen Mobilisierungsprozesses der palästinensischen Bevölkerung des Westjordanlandes steht.

Zentral für die Politisierung und Involvierung in die Straßenschlachten in der Kindergeneration ist andererseits die Integration in männliche Cliquen, die sich über die Involvierung in die Straßenschlachten definieren. In Kapitel 6.2 sind Deutungsmuster, Interaktionsdynamik und Konstitutionsprozess einer solchen Clique junger Männer umfassend rekonstruiert worden. Es hat sich gezeigt, dass das (familiale) intergenerationale Interaktionsfeld und das Interaktionsfeld der Peergroup einerseits in Wechselwirkung stehen und andererseits eigendynamisch sind. Das heißt, die Peergroup stellt hier einen Kontext dar, in dem ein wesentlich in der familialen intergenerationalen Interaktion und in der familialen Tradierung gestützter, diffuser Auftrag, zu kämpfen' als Pflicht zum „Kampf auf der Straße gedeutet wird. Er wird in den Handlungsmustern in der Clique vertieft und verbindet sich mit stärker an die Peergroup gebundenen adoleszenten Bildungsprozessen von Selbst- und Wir-Bildern und Männlichkeitskonstruktionen. So stellen die Straßenschlachten für die Jugendlichen zunächst auch Ernste Spiele - also einen homosozialen Raum für den risikoaffinen Erwerb und die Erprobung von Männlichkeit - dar. Die Clique organisiert sich im Prozessverlauf zunehmend um die Involvierung in die Straßenschlachten. Die Beteiligung an diesen Straßenschlachten ist, anders als dies zum Teil während der Ersten Intifada der Fall war, eine ausschließliche Angelegenheit junger Männer. Im Cliquenverband werden die Versuche von weiblichen Mitgliedern der (erweiterten) Familie sich zu involvieren, etwa durch die Teilnahme an Demonstrationen, tendenziell sanktioniert. Im biographischen Verlauf wie auch mit zunehmendem ,Cliquenalter' vertieft und verselbstständigt sich die Deutung des Kampfauftrags in der Peergroup vor dem Hintergrund von sukzessive in den Konfrontationen und Haftaufenthalten gemachten Leidenserfahrungen und von Rache- beziehungsweise Vergeltungswünschen, etwa aufgrund der Verhaftung, Verletzung oder gar Tötung von Freunden und Bekannten. Sie können sich im Prozessverlauf auch zu einem Wunsch nach Märtyrerschaft zuspitzen. Die Leidenserfahrungen - etwa die Angst vor weiteren Verhaftungen - werden eher in der Clique als im familialen Kontext thematisiert.

Weiterhin kommt der Clique im Zeitverlauf zunehmend die Bedeutung zu, eine innerhalb der palästinensischen Gesellschaft im Westjordanland erlebte gesellschaftliche Marginalisierung zu verhandeln und zu deuten. Das in diesem Zusam- 
menhang herausgebildete Deutungsmuster der ,marginalisierten Kämpfer ${ }^{`}$ folgt einer bestimmten Logik. So werden in einer von mir so benannten Widerstandsbilanżierung der ,Einsatz für die palästinensische Sache ${ }^{`}$ und die erlebte gesellschaftliche Position gegeneinander aufgerechnet und den eigenen geringen Lebenschancen (im Sinne von Berufs-, Bildungs-, Heiratschancen, aber auch Sinnchancen) gegenübergestellt. In diesem Zusammenhang werden verschiedene eigene Zugehörigkeiten und gesellschaftliche Positionen, mitverhandelt'. So wird die Zugehörigkeit zur in den Lager-Gegenden lebenden Flüchtlingsbevölkerung in Abgrenzung zu einer im Sie-Bild ,unpolitischen', aber wohlhabenden Stadtbevölkerung, die ,nicht kämpfe', gedeutet. Die jungen Männer der Clique verhandeln zudem ihre fundamentale Ablehnung der PA, die sie als eine Art ,zweite Besatzung' bezeichnen. Und sie deuten ihre Gegnerschaft gegenüber einer Gruppierung von etablierten, ,behördennahen' Intifada-Veteranen in der Lager-Gegend, durch welche sie Stigmatisierung in Form von ,Schimpfklatsch' erfahren, an. Schließlich wird im Deutungsmuster die kollektivgeschichtliche Phase, in welcher sie ,kämpfen', abgegrenzt gegenüber , anderen Zeiten', in denen die Bedingungen dafür besser gewesen seien und in denen im Gegensatz zu ,ihrer Zeit kein ,Vergessen der Palästinenser in Haft und der Märtyrer' gedroht habe. Das im Deutungsmuster verhandelte Marginalisierungserleben erfährt im Zeitverlauf tendenziell eine Zuspitzung und verdichtet sich zu einer frustrationsgeladenen, generalisierten und diffusen Ablehnung, der Gesellschaft'. Im Deutungsmuster ,marginalisierte Kämpfer und in dem mit diesen verknüpften Wir- und Sie-Bildern sowie Erfahrungsgeschichten verhandelt diese Gruppierung der Kindergeneration unter anderem die Figuration von Flüchtlingen in den Flüchtlingslager-Gegenden und urbaner Mittelschicht sowie ihre figurationale Position innerhalb der FlüchtlingslagerGegenden. Im Folgenden komme ich nun stärker theoretisierend auf die einzelnen Aspekte der Generationenfiguration zu sprechen, wie sie sich in der Flüchtlingslager-Gegend zeigen.

Generationale Zugehörigkeit, intra- und intergenerationale Interaktion. Die Zugehörigkeit in der Elterngeneration zur historischen Generation Intifada und das mit dieser Zugehörigkeit verbundene Gruppencharisma schlägt sich in Interaktion mit der Generation der Kinder, gerade im familialen Dialog, aber auch außerhalb dessen, etwa in nachbarschaftlichen Zusammenhängen, nieder. In der Interaktion zwischen der Elterngeneration als Mitgliedern der Generation Intifada und der Kindergeneration in den Flüchtlingslager-Gegenden wird die Zugehörigkeit letzterer zur Nachfolgegeneration Oslo konstruiert und verfestigt. Die Mitglieder der Generation der Kinder werden in diesen Interaktionen zu einer an der Generation Intifada indirekt gemessenen historischen Nachfolgegeneration. Die Generation der Kinder als Nachfolgegeneration kann unter den Bedingungen eines weiterhin unverwirklichten palästinensischen Staatsbildungsprojektes und angesichts fehlender breiter politischer Mobilisierung in der palästinensischen Bevölkerung die Erste Intifada nicht einfach, wiederholen‘. Dennoch steht ihr 
generationaler ,Beitrag' zur ,palästinensischen Sache in verschiedenen Situationen und Interaktionen im Alltag schnell ,im Raum'.

Zum einen ist dies in Interaktionen der Fall, in denen die Mitglieder der Kindergeneration, sozusagen aus der Position der Beobachter, Gespräche zwischen Mitgliedern der Generation Intifada erleben. In diesen Gesprächen und kurzen Interaktionen tauscht sich die Generation Intifada über ,frühere Zeiten' aus. Sie bringt die mit der Mobilisierung der 1970er und 1980er Jahre verbundenen Geschichten und biographischen Fragmente in nostalgisch-respektvoller Weise, manchmal in Form von Scherzen oder kurzen Anspielungen, zur Sprache (vgl. Kap. 6.2.7; 6.3.3). Der Austausch vollzieht sich im Rahmen „konjunktiver Verständigung“ beziehungsweise „unmittelbaren Verstehens“, wie es von Ralf Bohnsack in enger Anlehnung an Karl Mannheims Arbeiten (1980) diskutiert worden ist (vgl. Kap. 2.2). Die auf dem gemeinsamen Erleben der vergangenen Handlungspraxis begründete Verständigung erzeugt hier ein generationales Wir und generationale Zugehörigkeitsgefühle zwischen den Generationsmitgliedern, wovon die Nachfolgegeneration Oslo ausgeschlossen ist. Zum anderen entstehen die generationalen Zugehörigkeiten auch in direkten Gesprächen zwischen der Generation Intifada und der Nachfolgegeneration Oslo. Gegen die Intention der Mitglieder der Generation Intifada, die sich in der Regel explizit gegen die Beteiligung der Generation Oslo an den Straßenschlachten aussprechen (,Ihr könnte es nicht so machen wie wir"), bekommen diese intergenerationalen Interaktionen auch ein hierarchisierendes Moment. Auf eine historische Generation Intifada, die gekämpft hat und erfolgreich war, folgt eine nachgelagerte Generation, die es der Vorgängergeneration in der gegebenen kollektivgeschichtlichen Situation nicht gleichtun kann und erst noch einen Weg finden muss, ,erfolgreich ${ }^{`}$ zu kämpfen. Der intergenerationale Dialog konstruiert damit eine durch die Generation Intifada negativ bestimmte, noch nicht ausgezeichnete nachfolgende historische Generation. Negativ bestimmt ist hier im doppelten Sinne zu verstehen als einerseits ,die Generation Intifada als Maßstab nehmend' und andererseits, gegenüber dieser Generation Intifada abfallend‘. Die Interaktionen ergeben sich vor allem und mit besonderer Wirkmächtigkeit im familialen Dialog zwischen Familienmitgliedern in Kern- und erweiterter Familie (zwischen Eltern und Kindern, Onkeln, Tanten und Neffen), aber auch in Nachbarschafts- und Bekanntenverhältnissen. Da in diesen Interaktionen, sozusagen hinter dem Rücken der Beteiligten und gegen deren Intentionen, (familial) eine Hierarchisierung historischer Generationenzugehörigkeiten und eine Tradierung von Kampfaufträgen entstehen, kann man von den ungeplanten Folgen der Verflechtung von Generationengruppierungen sprechen. In diesen Interaktionen wird nicht nur die Zugehörigkeit zur Nachfolgegeneration Oslo konstruiert und verfestigt, sondern - auf der Erfahrungsqualität der Ersten Intifada aufruhend - auch die Zugehörigkeit zur Generation Intifada.

Für eine generationstheoretische Ebene zeigt sich hier erneut, worauf die interpretative Forschung und insbesondere die biographietheoretische Forschung zu 
historischen Generationen hingewiesen hat: Dass historisch-generationale Zugehörigkeit gerade in Interaktionsverhältnissen (Matthes 1985a) und eben auch im familialen Dialog und in der Verhandlung von familialer Delegation (Rosenthal 1997, 2000) erzeugt und biographisch relevant wird (vgl. Kap. 2.7). Die Interaktionen sorgen dafür, dass aus der Generationslagerung Oslo, also der Position der Jahrgänge im historisch-geographischen Kontext, mit der ein Nicht-Erleben der politischen Mobilisierung der 1970er und 1980er Jahre einhergeht, ein Erleben generationaler Zugehörigkeit wird. Insgesamt kommt so in der Erfahrungsbildung die relative Stellung von Generation Intifada und Nachfolgegeneration Oslo zueinander zum Ausdruck und kann nur durch Kenntnis dieser Stellung zueinander verstanden und erklärt werden. Die Erfahrungsbildung steht in Wechselwirkung mit einer Position in einer Generationenfiguration. Die nachgelagerte Stellung in der Generationenfiguration wird in dieser Weise zum Bestandteil der typischen Erlebnisschichtung der Nachfolgegeneration Oslo.

Gegenseitige Abhängigkeiten in der figurationalen Machtbalance. Die Art des intergenerationalen Dialogs bringt einerseits die Machtbalance zwischen den Generationen zum Ausdruck, andererseits wirkt sie auf diese ein. Weitere Charakteristika der Generationenfiguration verdeutlichen deren Machtbalance zugunsten der Generation Intifada. So kann man in diesem Zusammenhang davon sprechen, dass die Wunschträume beziehungsweise das „Zentrum der Sinnerfüllung“" (Elias 1993: 50) der Nachfolgegeneration Oslo in den FlüchtlingslagerGegenden an der Generation Intifada ausgerichtet sind. Dies zeigt sich unter anderem an der hohen Wertschätzung des ,Kampfes auf der Straße', die in der Frühadoleszenz ausgebildet wird. Darin kommt gerade das mythisierende Bild der Ersten Intifada als ,Intifada der Steine` zum Ausdruck, das sich zum Beispiel nicht so stark am bewaffneten Kampf der Fedaijin orientiert, der palästinensischen Milizen aus der Diaspora aus den 1960er und 1970er Jahren, der grundsätzlich ebenso einen Ankerpunkt bilden könnte. ${ }^{165}$ Auch die Generation Intifada erlebt die Deutungs- und Handlungsmuster der Nachfolgegeneration Oslo als Orientierung an ihnen (,er will werden wie sein Vater"), was dazu beiträgt, dass die Elterngeneration ihre Involvierung in die Intifada im familialen Dialog untertreibt. Insgesamt wird hier auch eine Orientierung an den mit der Generation Intifada verbundenen Deutungsmustern und Standards durch die Nachfolgegeneration Oslo in den Flüchtlingslager-Gegenden deutlich.

Ein weiterer Aspekt der Machtasymmetrie in dieser Generationenfiguration besteht in der spezifischen Verteilung der Lebenschancen (Bildungs-, Berufs-, Heiratschancen) zwischen den Generationen in den Flüchtlingslager-Gegenden. Zum einen waren die Möglichkeiten, auch ohne oder mit geringeren Bildungsund Berufsabschlüssen ein Einkommen zu erzielen, das eine Reproduktion oder Verbesserung der Lebenschancen für sich und die Familienmitglieder ermöglicht,

165 Zur Veränderung des Bildes des ,Kämpfers‘ in der Ersten Intifada, welches von den Fedaijin abrückte, siehe auch die Diskussion bei Amireh 2003: 754. 
für die Bevölkerung in den Flüchtlingslager-Gegenden in der Generation Intifada in stärkerem Maße gegeben als in der Nachfolgegeneration Oslo. Dies hing insbesondere, wie bereits erwähnt, mit den in den 1970er und 1980er Jahren in erheblichem Ausmaß gegebenen legalen Verdienstmöglichkeiten in Israel sowie in geringerem Maße auch mit der palästinensischen Arbeitsmigration in die Golfregion zusammen. Die dann weitgehende Schließung des israelischen Arbeitsmarktes ab den 1990er Jahren traf und trifft zwar auch Mitglieder der Generation Intifada, dennoch war für jene eine Balancierung von politischer Involvierung und der Reproduktion oder Steigerung der Lebenschancen über weite Strecken der Biographie letztlich leichter als für die Nachfolgegeneration Oslo. So veränderte sich - um auf Abschnitt 9.5 vorzugreifen - die Verteilung der Lebenschancen ab den 1990er Jahren nicht nur in Bezug auf die Figuration zwischen den Flüchtlingen in den Flüchtlingslager-Gegenden und den urbanen Mittelschichten, sondern auch zwischen verschiedenen Generationen innerhalb der Flüchtlingslager-Gegenden. Zum anderen, und dieser Aspekt ist wichtiger als der vorangegangene, ist für die Frage der intergenerationalen Verteilung von Lebenschancen, die sich auf die PA und die mit ihr verbundenen Arbeitsstellen und Netzwerke beziehen, die Rolle familialer Autorität aufgewertet worden. In der Aufbauphase der PA Ende der 1990er Jahre waren noch durchaus Palästinenser*innen rekrutiert worden, die zwar weder zur Fatah gehörten noch Rückkehrer waren, aber dafür eine „Kämpferbiographie‘ aufweisen konnten, die auf die Mobilisierung der 1970er und 1980er Jahre in den palästinensischen Gebieten zurückging (vgl. Kap. 4.6). Damit erhielt die Generation Intifada die Chance auf Positionen in der PA oder Netzwerke in sie hinein. Danach ist aber die Rolle von familial vermittelten PatronageNetzwerken für die mit der PA verbundene Allokation von Ressourcen und Machtchancen deutlich aufgewertet worden (vgl. Pasquetti 2012: 121 f.). Dadurch sank die Möglichkeit der Nachfolgegeneration Oslo, vergleichbare Positionen oder Netzwerke auf der Basis ihrer ,Kämpferbiographien' zu erlangen, und gleichzeitig steigerte sich ihre familiale Abhängigkeit von der Elterngeneration als Generation Intifada, über welche die Ressourcen und Machtchancen vermittelt werden.

Hier wirken familiale und historisch-generationale Zugehörigkeit in spezifischer Weise zusammen. Denn im Verhältnis von familialen Generationen ist zu Beginn des Lebens in der Regel ohnehin eine Machtasymmetrie zugunsten der Elterngeneration gegenüber den eigenen (jungen) Kindern gegeben (die sich wiederum im Laufe des Lebens beziehungsweise mit ,hohem Alter ${ }^{\star}$ der Elterngeneration tendenziell umdreht). Diese Machtasymmetrie zwischen familialen Generationen wird hier durch die Machtasymmetrie in einer bistorischen Generationenfiguration zusätzlich verstärkt. Auf einer stärker theoretischen Ebene formuliert, stehen die Machtchancen der Generation Intifada in Zusammenhang mit dem ,Vorteil' von Altansässigen gegenüber Zugezogenen, wie es Elias für die EtabliertenAußenseiter-Figuration diskutiert hat (vgl. Kap. 2.5) - nämlich in der zeitlich früheren Anwesenheit der Etabliertengruppe und der damit verbundenen Chance 
auf die Integration der Gruppe, die Ausbildung eines Wir-Bildes und die Besetzung von Statuspositionen. Nur erwächst im Fall von historischen Generationenfigurationen dieser Vorteil der Etabliertengruppe - wie im Fall der Generation Intifada - aus dem Umstand, zu einer bestimmten historischen Periode in einem bestimmten Alter gewesen zu sein.

Allerdings wirken sich einige Aspekte der Abhängigkeitsverhältnisse zwischen den Generationen auch zugunsten der Machtchancen der Nachfolgegeneration Oslo in den Flüchtlingslager-Gegenden aus. So erzeugt die Nachfolgegeneration Oslo in ihrer Jugend jenen ,Druck auf der Straße', der der Bevölkerung in den Flüchtlingslager-Gegenden gegen die Lokalverwaltung der angrenzenden Bezirke oder gegen die PA Machtchancen sichert. Letztere wird durch die Nachfolgegeneration Oslo zum Beispiel bei Auseinandersetzung um die Bezahlung der Stromund Energiekosten, die in der Regel von den angrenzenden Gemeinden für die Lager übernommen werden, oder bei Wohnraumkonflikten im Umfeld der Lager mittels Demonstrationen, Besetzungen wichtiger Verbindungsstraßen oder vergleichbaren Aktionen unter Druck gesetzt (vgl. Kap. 6.2). Die Nachfolgegeneration Oslo stützt in dieser Weise auch die Interessen und die Position auch der älteren Generationen in den Flüchtlingslager-Gegenden gegenüber der Lokalverwaltung und den Altansässigen. Im Kontext der Flüchtlingslager-Gegenden stellen die damit verbundenen Machtchancen ein Gegengewicht zugunsten der Nachfolgegeneration Oslo dar, das die Machtasymmetrie der Generationenfiguration abschwächt. Vermutlich liegt in den Machtchancen der jungen Männer einer der Gründe, warum sie es wagen, wenn auch zurückhaltend, in den Interviews und Gesprächen mit uns überhaupt Kritik an der Gruppierung von ehemaligen ErsteIntifada-Aktivist*innen in der Lager-Gegend, die nun der PA nahestehen, zu äuBern.

Einen weiteren Aspekt möchte ich im Zusammenhang mit der Machtbalance zwischen den Generationen kurz erläutern. Die Art und Weise, wie die Generation Intifada über die mit der Intifada verbundenen Erfahrungsgeschichten in Form von Witzen, Anspielungen und Anekdoten spricht, ermöglicht eine Dethematisierung der mit der Mobilisierung der 1970er und 1980er Jahre verbundenen Leidenserfahrungen. Auf die Dethematisierung weist auch, wie sich in den Gesprächen und Interviews gezeigt hat, das relativ geringe Wissen der Nachfolgegeneration Oslo über die konkreten Erfahrungen der Eltern, Onkel, Tanten, Nachbar*innen in jener Phase hin. Die dethematisierten Erfahrungen können insbesondere erlebte Erniedrigungen und Folter in der Haft umfassen. Diese Überlegungen sind als vorläufige, noch weiter zu belegende Befunde aus den Fallanalysen zu betrachten (vgl. Kap. 6.3; 7.2.2). Die Leidenserfahrungen der Generation Intifada können die Orientierung der Nachfolgegeneration Oslo an ihr und den empfunden Druck, sich für die ,palästinensische Sache einzusetzen, verstärken und zwar gerade weil diese Erfahrungen dethematisiert sind und so in noch stärkerem Maße den Vorstellungen und Fantasien der Nachfolgegeneration Oslo 
überlassen werden. Man kann diese Konstellation im Sinne einer familialen Rechnung von Schuldkonten fassen, wie dies von Iván Böszörményi-Nagy (1981) diskutiert worden ist. ${ }^{166}$ Familien kann man Böszörményi-Nagy zufolge verstehen als „Konzept eines Mehrpersonen-Loyalitätsgewebes[, das] das Vorhandensein strukturierter Gruppenerwartungen voraus[-setzt], zu deren Erfüllung alle Mitglieder aufgerufen sind“ (1981: 66). Vor dem Hintergrund der weiterhin ,unerledigten palästinensischen Sache ${ }^{夭}$ erhöhen die Leidenserfahrungen der Elterngeneration ihre Verdienste und damit die ,Vorverschuldung' und Loyalitätsbindung der Kindergeneration - und im Falle einer Nichterfüllung die Schuldgefühle letzterer (ebd.: 67). Auf diese Weise treiben die Leidenserfahrungen der Generation Intifada die Schuldkonten der Nachfolgegeneration Oslo nach oben und tragen zur Machtasymmetrie der Generationenfiguration bei. In dieser Hinsicht ist es ein Bestandteil der Generationenfiguration, dass es der Nachfolgegeneration Oslo schwerfällt, für einen Ausgleich der Schuldbilanz zu sorgen.

Generationale Differenzen in Sinnchancen, Wir- und Sie-Bildern. Die Deutungsmuster, Wir- und Sie-Bilder der Generation Intifada und der Nachfolgegeneration Oslo weichen in verschiedenen Aspekten deutlich voneinander ab. In ihren Differenzen spiegeln sie die jeweilige Position, die die Generationen in ihrer Figuration einnehmen. Einer dieser Aspekte besteht darin, dass die Deutungsmuster, Wir- und Sie-Bilder der Nachfolgegeneration Oslo die gegenüber der Generation Intifada als geringer erlebten Sinnchancen zum Ausdruck bringen. Die Nachfolgegeneration Oslo nimmt - im Rahmen des Deutungsmusters der ,marginalisierten Kämpfer' - Bezug auf einen ihrer Ansicht nach drohenden gesellschaftlichen Niedergang der, Widerstandsbereitschaft ${ }^{\star}$ und eine geringer werdende gesellschaftliche Wertschätzung der Inhaftierten und der Märtyrer (vgl. Kap. 6.2). In diesem Topos dient die politische Mobilisierung der 1970er und 1980er Jahre als Kontrastfolie (,früher war es besser), in der diese Wertschätzung in größerem Maße gegeben war als in ihrer kollektivgeschichtlichen Gegenwart. Die Einschätzung zur Entwicklung des Status von Inhaftierten und Märtyrern korrespondiert mit den Befunden anderer Forschungen. Auf die veränderte und niedrigere Stellung politisch Inhaftierter in der palästinensischen Gesellschaft verweisen zum Beispiel Penny Johnson und Rita Giacaman unter Bezug auf das Westjordanland: „the value of political incarceration held by communities and society in general has also diminished" (2013: 69). An anderer Stelle betont Johnson, dass Folgendes in der Phase politischer Mobilisierung in den 1970er und 1980er Jahren noch anders gewesen war: „If one had imagined a Palestinian social contract in the 1980s, prisoners (and martyrs) would perhaps have been at its center - those who had sacrificed much for the nation and to whom much was owed" (2012: 88). In diesem Aspekt des Deutungsmusters in der Nachfolgegeneration Oslo kommt das Erleben einer Abdrosselung von politischen Sinnchancen explizit zum Ausdruck.

166 Ich danke Prof. Dr. David Becker für diesen Hinweis. 
Aber auch in der sozialen ,Logik‘ insgesamt, die dem Deutungsmuster der Widerstandsbilanzierung und dem Wir-Bild ,marginalisierter Kämpfer ${ }^{6}$ inhärent ist, lässt sich das Erleben von geringen Sinn- und Lebenschancen erkennen. So wird im Rahmen der mit dem Deutungsmuster verbundenen Widerstandsbilanzierung, in welcher der eigene ,Einsatz für die palästinensische Sache“ und die erlebte gesellschaftliche Position gegeneinander aufgerechnet werden, ja gerade ein wahrgenommener Mangel an Sinn- und Lebenschancen verhandelt. Jenes Wir-Bild der ,marginalisierten Kämpfer wird von der in dieser Arbeit in den Blick genommenen Generation Intifada in den Flüchtlingslager-Gegenden hingegen nicht oder kaum bedient. Dies gilt auch, wenn sie ihre Involvierung in die Mobilisierung der 1970 er und 1980er Jahre kaum in sozio-ökonomische und berufliche Statusgewinne ummünzen konnten. Grund dafür sind - das machen meine Rekonstruktionen deutlich - die generationalen Integrationsprozesse, gestützt durch eine allgemeine Verbesserung der Lebenschancen in der Generation Intifada, die die Deutungsmuster, Wir- und Sie-Bilder geprägt hat (vgl. Kap. 9.6). Dieser Punkt zeigt sich auch im Folgenden.

Die Deutungsmuster, Wir- und Sie-Bilder der Nachfolgegeneration Oslo und der Generation Intifada differieren in einem weiteren zentralen Aspekt. Im Deutungsmuster der ,marginalisierten Kämpfer verhandelt die Nachfolgegeneration Oslo auch das Wir-Bild als Flüchtling. Das Wir-Bild wird gerade in Abgrenzung zum komplementären Sie-Bild der unpolitischen, wohlhabenden Städter, die auf Kosten der ,palästinensischen Sache leben würden, bedient. In der Generation Intifada hingegen wird der eigene Flüchtlingsstatus in geringerem Maße in die eigenen Wir-Bilder aufgenommen. Dies ist auch deswegen interessant, weil die Generation Intifada in den Flüchtlingslager-Gegenden im Laufe ihres Lebens durchaus mit der Position als Flüchtling verbundene Diskriminierungserfahrungen durch die altansässige Bevölkerung gemacht hat. Nur werden diese Erfahrungen von ihr, im Gegensatz zur Generation Oslo, nicht oder kaum für die Konstruktion eines darauf bezogenen Deutungsmusters genutzt. In den Deutungsmustern, Wir und Sie-Bildern der Elterngeneration in den Flüchtlingslager-Gegenden dominiert die Zugehörigkeit zur Generation Intifada (vgl. Kap. 6.3; 6.4). Gestützt werden diese Ergebnisse unter anderem durch die Forschung George Bisharats (1994). Er kommt in einem Aufsatz von 1994, also kurz nach der Ersten Intifada, mit Blick auf die palästinensichen Gebiete zu folgendem Urteil:

„,ultimately the distinction between the refugee and the non-refugee communities in the region [...] has been eroded by socioeconomic forces and political developments [...]. The once unifying experience of the collective flight from Palestine has faded, and been superseded by the gripping drama of life under, and opposition to, Israeli occupation" (1994: 183).

Ein Vierteljahrhundert später und vor dem Hintergrund meiner Befunde muss man konstatieren, dass dies ein Ausdruck der Konstellation und Erfahrungsauf- 
schichtung für die historische Generation Intifada, nicht jedoch für die Nachfolgegeneration Oslo in den Flüchtlingslager-Gegenden ist.

\subsubsection{Biographischer Verlaufstypus A: Von der Orientierung am ,Kampf auf der Straße' zur Verschärfung einer gesellschaftlichen Außenseiterposition}

Wie wirkt die Position in der Generationenfiguration als Nachfolgegeneration Oslo mit anderen Zugehörigkeiten auf biographischer Ebene zusammen und mit welchen typischen biographischen Verläufen ist sie verknüpft? Die Position in der Generationenfiguration steht in Zusammenhang mit der Position als Flüchtling in der Figuration der Bevölkerung in den Flüchtlingslager-Gegenden und der urbanen Mittelschicht sowie mit weiteren, insbesondere geschlechtlichen Zugehörigkeiten. Diese mehrfachen figurationalen Positionen und Zugehörigkeiten münden in einen typischen biographischen Prozess, den ich „Verschärfung gesellschaftlicher Außenseiterposition“ genannt habe. Diesen Verlaufstypus charakterisiert die Realisierung einer mehrfachen Zugehörigkeit zu Außenseitergruppierungen.

Im Verlaufstypus „Verschärfung gesellschaftlicher Außenseiterposition“ schlägt ein in intergenerationalen (insbesondere in der Familie) und intragenerationalen (insbesondere in der Peergroup) Tradierungs- und Interaktionsprozessen erzeugter, militant gedeuteter ,Kampfauftrag für die palästinensische Sache ${ }^{6}$ im Zusammenspiel mit Konstruktionsprozessen adoleszenter Männlichkeit in einen tendenziell verlaufskurvenartigen biographischen Prozess um (vgl. Schütze 2006). In diesem Verlauf verringern sich Handlungsoptionen, Sinn- und Lebenschancen und das Erleben von Handlungsmacht. Die biographischen Komponenten Involvierung in die Straßenschlachten, Gewalt- und Leidenserfahrungen sowie Vergeltungswünsche, Abbruch schulischer Karrieren, illegalisierte Beschäftigung in Israel, geringe Chancen auf Heirat und Familiengründung, (wiederholte) Inhaftierungserfahrungen in israelischen Gefängnissen und Gefängnissen der PA, Erfahrung von Stigmatisierung und Benachteiligung sowohl im Kontext der Flüchtlingslager-Gegenden als auch im weiteren gesellschaftlichen Kontext wirken zusammen. Der biographische Verlauf ist damit verbunden, in eine marginalisierte Position innerbalb der palästinensischen Gesellschaft zu geraten und Stigmatisierungen in selbiger zu erleben. Außerdem kommt es auch im Vergleich zur Generation Intifada zu einer intergenerationalen Reduzierung von politischen Sinnchancen und familial und biographisch ohnehin geringen Lebenschancen (Bildungs-, Einkommens-, Heiratschancen). Dabei kann der Verlaufskurvencharakter der Biographien auch eine traumatische Erlebensqualität bekommen. ${ }^{167} \mathrm{Im} \mathrm{Zu}$ sammenwirken der biographischen Komponenten kann eine Konstellation eintre-

\footnotetext{
${ }^{167}$ Die verschiedenen kollektiv-, familien- und lebensgeschichtlichen Prozesskomponenten machen deutlich, dass Trauma hier nicht als Ereignis, sondern als sowohl individueller als auch gesellschaftlicher Prozess verstanden werden muss. Trauma wird hier im Anschluss an David Becker und Barbara Weyermann, die wiederum wesentlich auf dem Traumakonzept von Hans Keilson aufbauen, verstanden (Becker/Weyermann 2006; Becker 2014: 177 ff.).
} 
ten, in welcher massive Entmächtigung erlebt wird. Diese kann sich vor dem Hintergrund der biographischen Komponenten wie Gewalt- und Leidenserfahrungen, wiederholten Inhaftierungen, gesellschaftlicher Exklusion und Stigmatisierung auch chronifizieren und so über längere biographische Phasen eine anhaltend traumatische Konstellation darstellen (Becker 2014: 179). Der Verlaufstypus ergibt sich vor dem Hintergrund der fragmentierenden israelischen Besatzungspolitik (Zonenregelung, territorialisierte Militärpräsenz, Grenzregime), der organisationalen Architektur der Oslo-Vereinbarungen (PA, Klientelismus, Sicherheitskooperation) und der im Vergleich zu den 1970er und 1980er Jahren allgemeinen palästinensischen Demobilisierung. Die Zugehörigkeit zur Nachfolgegeneration Oslo ist so eingebunden in einen Prozess der intergenerationalen Verschärfung einer gesellschaftlichen Außenseiterposition. Schließlich basiert die Rekonstruktion des Typus auch auf von meinen Kolleg*innen und mir unternommenen Forschungsarbeiten, die auf Erhebungen in der Kindergeneration in anderen FlüchtlingslagerGegenden im Westjordanland basieren. Diese zeigen dieselbe biographische Verlaufsdynamik, dieselben Deutungsmuster und dieselbe Bilanzierungslogik. ${ }^{168}$

Die überschaubare Forschungsliteratur zur Generation Oslo, die ich in Kapitel 5 diskutiert habe, thematisiert nur am Rande Ergebnisse und Themen, die auf den Verlaufstypus „Verschärfung gesellschaftlicher Außenseiterposition“ verweisen würden. Die Arbeiten konzentrieren sich eher auf marginal bleibende Versuche zivilgesellschaftlicher Mobilisierung in der Nachfolgegeneration Oslo und machen nur periphere Bemerkungen zur ,Jugend' in den FlüchtlingslagerGegenden und zu deren Involvierung in die Straßenschlachten (vgl. Høigilt 2016: 469 f.). Diese Hinweise - Høigilt spricht von ,uncoordinated and violent outbursts of anger" (ebd.) - gehen kaum mit weiterer analytischer Durchdringung einher, welche die Verwicklung des Verlaufstypus in die Figurationen und die damit verbundenen kollektiv-, familien- und lebensgeschichtlichen Prozesse aufdecken würde.

Auch wenn das Auftreten der Typuskomponenten in den FlüchtlingslagerGegenden wahrscheinlicher ist, bleibt der Typus nicht notwendig auf die Flüchtlingslager-Gegenden beschränkt. Er mag durchaus auch in ländlichen Gebieten des Westjordanlandes, die in der C-Zone israelischer administrativer und sicher-

\footnotetext{
${ }^{168}$ Für die exemplarische Diskussion eines solchen, in einem anderen Flüchtlingslager erhobenen Falls sei hier auf einen 2015 erschienenen Aufsatz verwiesen, den ich gemeinsam mit meinen Kollegen Ahmad Albaba und Arne Worm verfasst habe (Worm/Hinrichsen/Albaba 2015: 79 ff.). Die an diesem Fall diskutierten exemplarischen Deutungsmuster und biographischen Erfahrungen sind zu denen in dieser Arbeit diskutierten Fällen aus einer Flüchtlingslager-Gegend homolog. Sie zeigen sich in den mit der Involvierung in die Straßenschlachten gemachten Erfahrungen, in den Erfahrungen gesellschaftlicher Marginalisierung und in den familialen Tradierungsprozessen. Ebenso sind die Parallelen auf der Ebene der Deutungsmuster sichtbar, in welchem eigener Kampfeinsatz und gesellschaftliche Stellung gegenüber den ,Städtern' bilanziert werden. Zum anderen zeigt sie sich in der massiven Abwertung der PA und auch in den vorsichtigen Andeutungen einer Frontstellung gegen die PA-nahen Intifada-Veteranen, die als klientelistisch erlebt werden.
} 
heitspolitischer Kontrolle unterliegen, auftreten. In diesen Gegenden finden sich einige Frontier-Dörfer, die sich in längeren Prozessen intensiver Kämpfe mit den israelischen Sicherheitsbehörden um die Landnutzung befinden und die nach sich ziehenden Militäroperationen erleben. Die hohe Frequenz dieser israelischen Militäroperationen und die relative Stellung gegenüber den urbanen Mittelschichten weisen in eine ähnliche Richtung. Dies ist eine empirische Frage, der im Rahmen einer Erweiterung der ersten theoretischen Stichprobe nachgegangen werden könnte (vgl. Kap. 10.2). In umgekehrter Richtung können auch nicht alle Mitglieder der Nachfolgegeneration Oslo in den Flüchtlingslager-Gegenden unter den Typus subsumiert werden. So kommt es, wie in manchen erhobenen und analysierten Fällen, trotz vergleichbarer familialer Tradierungs- und Interaktionsprozesse, nicht zu einem biographischen Verlauf im Sinne dieses Typus. In diesen Fällen ist es biographisch nicht zu einer Integration in eine um die Involvierung in die Straßenschlachten formierten Clique gekommen. Dieser Umstand verdeutlicht die Wichtigkeit des Zusammenwirkens der verschiedenen Typuskomponenten. Die Verläufe in der Flüchtlingslager-Gegend, die von relativ hohen klientelistischen Chancen gekennzeichnet sind, ähneln Typus B (siehe unten). ${ }^{169}$

Schließlich ist nochmals auf den männlichen Charakter des rekonstruierten Verlaufstyps A hinzuweisen. Erstens ist die Bedeutung von Männlichkeitskonstruktionen und des homosozialen Charakters der Peergroup für die biographischen Verläufe rekonstruiert worden. Und zweitens unterstreichen andere, von meinen Kolleg*innen und mir im Rahmen des Projektes unternommene Auswertungen die Bedeutung geschlechtlicher Zugehörigkeit für die Deutungsmuster und biographischen Verläufe der ,marginalisierten Kämpfer', da sie auf andere, weibliche Verläufe in der Nachfolgegeneration Oslo in der Flüchtlingslager-Gegend hinweisen (vgl. Kap. 10.2).170

\footnotetext{
${ }^{169}$ Exemplarisch für diese biographischen Wirkungszusammenhänge sei hier der Fall Ra'ed genannt, der in derselben Flüchtlingslager-Gegend erhoben wurde, wie die in Kapitel 6 und 7 vorgestellten jungen Männer. Dieser Fall wird von mir auch in einem 2017 erschienenen Aufsatz diskutiert (Hinrichsen 2017). In diesem Fall ist Ra'ed in familiale Interaktionen und Tradierungen mit den Großeltern als Nakba-Generation und der Elterngeneration als Generation Intifada eingebunden, die mit jenen der jungen Männer aus Kapitel 6 vergleichbar sind. Biographisch kommt es jedoch nicht zur umfassenden Einbindung in eine an den Straßenschlachten orientierte männliche Peergroup und in der Folge auch nicht zu einer Involvierung in die Straßenschlachten. Dies ist unter anderem seiner relativen sozialen Isolation im Lagerkontext geschuldet, die wiederum mit einer Aufstiegsdynamik (Privatschulbesuch) sowie den klientelistischen Netzwerken der Kernfamilie in die PA verbunden ist. Dies verdeutlicht, welche Bedeutung die relative Eigendynamik der Peergroup für die Ausbildung der Deutungsmuster und die biographischen Verläufe hat.

${ }^{170}$ Hier sei exemplarisch auf den Fall Raja verwiesen, der von meinen Kolleg*innen Gabriele Rosenthal, Arne Worm und mir in einem 2013 erschienenen Aufsatz vorgestellt wird. Der diskutierte Fall Raja ist exemplarisch für einen biographischen Verlauf in der Kindergeneration der ,Flüchtlin$\mathrm{ge}^{6}$, in welchem ein diffus tradierter Kampfauftrag nicht militant, sondern im Rahmen einer breiteren Repräsentationsrolle gedeutet wird und mit bildungsbezogener und beruflicher Aufwärtsmobilität zusammenwirkt. Eine Involvierung in die Straßenkämpfe ist hier auch aufgrund von entsprechender Sanktionierung junger Frauen in der Generation Oslo abwegig.
} 


\subsection{Generationenfiguration und Verlaufstypus unter den Rückkehrern in Ramallah}

\subsubsection{Diskussion der Generationenfiguration}

Die Bedeutung der Generationenfiguration von vorgelagerter Generation Intifada und Nachfolgegeneration Oslo ist für die Lebenswege der Eltern- und Kindergeneration der Rückkehrer deutlich geringer als im Kontext der FlüchtlingslagerGegend. Ausdruck dieser geringeren Bedeutung ist unter anderem, dass in der intergenerationalen familialen Interaktion zwischen Eltern- und Kindergeneration tendenziell keine historisch-generationalen Zugehörigkeiten entstehen und verhandelt werden. Ein Grund ist schlicht der Umstand, dass beide Generationen aufgrund der sozio-historischen Lagerung - die Elterngeneration, einige von ihnen PLO-Kader, zog erst zwischen circa 1995 und 2000 in das Westjordanland - nicht an der Mobilisierung in den palästinensischen Gebieten in den 1970er und 1980er Jahren partizipierten. Dennoch teilt die Erfahrungsbildung der Kinder der Rückkehrer, in abgeschwächter Form, einige Aspekte mit der Kindergeneration der Flüchtlinge in den Flüchtlingslager-Gegenden, wozu auch das Erleben von gegenüber der Generation Intifada verringerten Sinnchancen gehört. Ich gehe zunächst erneut auf die rekonstruierten Wirkungszusammenhänge in der Eltern- und Kindergeneration ein. Im Anschluss diskutiere ich die Aspekte der Generationenfiguration, wie sie sich für diesen Kontext zeigen, und stelle abschließend einen biographischen Verlaufstypus vor.

Elterngeneration der Rückkehrer. Die rekonstruierte biographische Dynamik in der Elterngeneration der Rückkehrer ist von einem Prozess gekennzeichnet, in welchem die palästinensische nationale Zugehörigkeit für die außerhalb der palästinensischen Gebiete Lebenden biographisch an Relevanz für Selbstbild und Wir-Gefühle gewann, nach ihrer Migration ins Westjordanland in den 1990er Jahren aber desillusioniert und krisenhaft wurde. Zum Aufbau der biographischen Relevanz palästinensischer Zugehörigkeit vor der Migration trugen verschiedene Aspekte bei: In der Herkunftsfamilie wurde ein idealisiertes, die territoriale Herkunft romantisierendes Palästina-Bild tradiert. Die tradierten nationalen Zugehörigkeitsentwürfe und -gefühle artikulierten sich zunächst in einem eher panarabistischen Rahmen, wurden jedoch im Verlauf der 1960er und 1970er Jahren zunehmend in den Kontext eines palästinensischen Nationalismus gestellt. In dem in Kapitel 7 exemplarisch diskutierten Fall Hussam wurde das Bedürfnis nach Artikulation des nationalen Wir-Bildes und -gefühls in einer kollektivgeschichtlichen Phase Jordaniens, in der dies heikel und risikoreich wurde, zurückgestellt und ,ins Private' verlegt. ${ }^{171}$ Eine weitere Politisierung der palästinensischen Zugehörigkeit

\footnotetext{
${ }^{171}$ So erfuhr in Jordanien die palästinensisch-transjordanische Zugehörigkeitsfrage im Verlauf der
} 1960er und 1970er Jahre, insbesondere nach dem Jordanischen Bürgerkrieg 1970/71, der zwischen 
in den 1980er Jahren war mit dem Erleben der Ersten Intifada ,aus der Distanz verbunden. Die Öffnung der palästinensischen Gebiete insbesondere für ,alte PLO-Kader, aber auch andere Rückkehrer aus arabischen und westlichen Ländern während der frühen Oslo-Phase Mitte der 1990er Jahre sowie die mit dem Friedensprozess verbundene Aufbruchsstimmung ergaben dann ein entsprechend genutztes Opportunitätsfenster für die Immigration. Diese Nutzung konnte auch mit anderen Handlungsentwürfen und biographischer Reorientierung verbunden sein; im in Kapitel 7.3 diskutierten Fall Hussam war die Migration zusätzlich mit einer Gelegenheit zu einer beruflich-künstlerischen Neuausrichtung verknüpft.

Die kollektiv- und lebensgeschichtlichen Prozesse nach der Rückkehr mündeten jedoch nach und nach in Gefühle der Enttäuschung und Frustration und eine Desillusionierung des nationalen Wir-Bildes. Dazu trug zum einen die jahrelange Illegalisierung vieler Rückkehrer im Westjordanland bei, die mit der restriktiven israelischen Aufenthalts- und Zuwanderungspolitik für die palästinensischen Gebiete während und nach der Zweiten Intifada zusammenhingen. Die damit verbundenen Mobilitätseinschränkungen beförderten das Erleben sozialer Isolation und Gefühle der ,Fremdheit ${ }^{\varsigma}$ im als ,Heimat ${ }^{\star}$ erwarteten Westjordanland. Dazu trug auch die Stagnation des palästinensischen Staatsgründungsprojektes und die als destruktiv erlebte Rolle der PA und der westlichen Geberorganisationen im entstandenen NGO-Sektor bei. Die Frustration schuf dann den Rahmen für die ambivalente Delegation eines ,Kampfauftrages' an die Generation der Kinder der Rückkehrer, in welchem eine solche Delegation zwar manifest verneint, der ,Kampf auf der Straße‘ aber dennoch implizit positiv besetzt wurde und wird. Im Westjordanland sind die Rückkehrer tendenziell durch eine große Nähe zur Fatah und zur PA gekennzeichnet. Diese Nähe kann durch berufliche Positionen - eigene oder von Familienmitgliedern - im Sicherheitsapparat oder anderen Ministerien der PA, in der Fatah, oder generell durch engen, indirekten Einbezug in die Patronage-Netzwerke gegeben sein. Hussam aus dem in Kapitelabschnitt 7.3 exemplarisch diskutierten Fall aus der Elterngeneration der Rückkehrer war nicht im Rahmen der Immigration von ,alten' PLO-Kadern ins Westjordanland migriert, sondern , auf eigene Faust', aber dennoch ebenfalls in die Patronage-Netzwerke der PA eingebunden. Der rekonstruierte Prozess der frustrationsgeladenen Desillusionierung im Westjordanland mag in dieser Konstellation in besonderer Weise, etwa aufgrund der als PLO-Kader nicht gegebenen Illegalisierung im Westjordanland, entstanden sein. Allerdings gibt der in Kapitelabschnitt 7.2.2 diskutierte Fall Hamzeh Hinweise darauf, inwiefern sich in der Elterngeneration der PLO-Kader ähnliche Vorgänge der Desillusionierung und des Legitimitätsverlustes der PA und

verschiedenen PLO-Milizen und dem Jordanischen Militär ausgetragen wurde, einen erheblichen Bedeutungszuwachs. Vor dem Hintergrund der beruflichen Position des Biographen als Palästinenser im jordanischen Militär, die nach dem Bürgerkrieg unter besonderer Beobachtung standen und zum Teil in ,Säuberungen' aus den öffentlichen Organisationen entfernt wurden, gewann seine Zugehörigkeit zusätzlich an Brisanz. 
der gesamten ,Oslo'-Architektur in der Untergruppierung ihrer wahrscheinlichsten Unterstützer, der Beamten im Sicherheitsapparat, abspielen.

Kindergeneration der Rückkehrer und Dynamik in der Peergroup. Der Prozess zunehmender politischer Militanz bei den in Kapitel 7 exemplarisch diskutierten Vertretern der Kinder der Rückkehrer ist vergleichbar mit jenem der Generation der Kinder in der Flüchtlingslager-Gegend. Dieser Prozess nahm aber vor dem Hintergrund der klientelistischen Chancen, die sich im Einbezug in die Patronage-Netzwerke der PA ausdrücken, bei den Kindern der Rückkehrer einen anderen Verlauf und mündete eher in eine pragmatische Reorientierung eigener Deutungsmuster und biographischer Handlungspläne in Richtung der Realisierung der eigenen Lebenschancen. So erlebten Mitglieder der Generation der Kinder der Rückkehrer in der Frühadoleszenz erstmalig das israelische Militär beziehungsweise eine Präsenz israelischer Soldaten im Alltag, die im Kontext der Zweiten Intifada und in den Jahren danach zu einem konkreten feindlichen Gegenüber wurden. Auch zur weiteren Interaktionsdynamik in der Peergroup finden sich in meinen Rekonstruktionen einige Hinweise. ${ }^{172}$ Es deutet sich an, dass sie - vergleichbar mit der Clique in Kapitel 6 - für die Ausbildung und Erprobung adoleszenter Männlichkeitsentwürfe relevant ist (,Sich-Messen' mit den Soldaten). Zudem wird eine Eskalationsdynamik sichtbar, in der sich sowohl die Konfliktintensität als auch die eingesetzten Gewaltmittel (Steine, Zwillen, Molotow-Cocktails und später ,primitive' Sprengmittel) im Verlauf der biographischen Jugendphase tendenziell steigern. Dies hängt auch damit zusammen, dass die jungen Männer Gewalt- und Leidenserfahrungen machen, die ihre biographische Verstrickung in die Straßenschlachten eher steigern, als sie von einer weiteren Involvierung in die Straßenschlachten abzuschrecken. Vor dem Hintergrund der ambivalenten familialen Delegation eines Kampfauftrages in Verbindung mit der Interaktionsdynamik in der Peergroup erfolgt daher die (fortgesetzte) Involvierung in die Straßenschlachten. Dabei kommt es bei den in dieser Arbeit in den Blick genommenen Cliquenmitgliedern zur Ausbildung eines Deutungsmusters, in welchem im Rahmen eines Wir-Bildes als ,Kämpfer für die palästinensische Sache die Bedeutung des StraBenkampfes betont und als, Verteidigung Ramallahs' gedeutet wird.

Im Deutungsmuster wird das Wir-Bild als ,Kämpfer für die palästinensische Sache“ zwar durchaus mit einer Abgrenzung gegen eine vermeintlich ,unpolitische', hedonistische Bevölkerung Ramallahs verbunden, jedoch nicht mit einer als gesellschaftlich marginalisiert erlebten sozialen Position. Dieser Aspekt stellt einen deutlichen Unterschied zum Deutungsmuster in der Kindergeneration der Flüchtlingslager-Gegend dar. Im Rahmen des Deutungsmusters der Rückkehrer-Kinder wird die PA, trotz der biographischen und familialen Nähe zu selbiger, massiv abgewertet und in die Nähe der Unterdrückung eines palästinensischen Aufstan-

172 In der in Kapitel 7 diskutierten Clique waren neben den Rückkehrern auch einige Zugezogene, deren Familien in den 1980er Jahren aus ländlichen Gegenden, insbesondere um Hebron, nach Ramallah migriert waren. 
des gestellt. Unter dem sich infolge der Involvierung in die Straßenschlachten ergebenden Verfolgungsdruck durch israelische Sicherheitsbehörden wird im jungen Erwachsenenalter die mit dem Wir-Bild als ,Kämpfer ${ }^{6}$ verbundene Handlungsorientierung brüchig und pendelt zwischen demonstrativer Aufrechterhaltung der Straßenmilitanz und einem pragmatischen Arrangieren auf Zeit mit den politischen Verhältnissen der Oslo-Jahre („I'm a fool I was fighting alone“). Diese Reorientierung ist vor dem Hintergrund der Nähe zur PA zu interpretieren, die pragmatisch genommene klientelistische Chancen bietet und als biographische Ressource dient, die nicht nur die Lebenschancen erhöht, sondern auch die Chance, sich einer Verfolgung durch die israelischen Sicherheitsbehörden zu entziehen (etwa durch den Einfluss von Familienmitgliedern im palästinensischen Sicherheitsapparat). Die familiale Nähe zur PA als biographische Ressource nutzen zu können, findet sich auch im Kontext der Clique aus der Flüchtlingslager-Gegend, ist aber bei den im Kontext Ramallahs in den Blick genommenen Rückkehrern und Zugezogenen deutlich ausgeprägter vorhanden. Bevor ich auf weitere Parallelen und Unterschiede zwischen der Kindergeneration in der FlüchtlingslagerGegend und unter den Rückkehrern sowie auf Chancen auf Vergemeinschaftung zwischen ihnen eingehe, komme ich zunächst auf die intergenerationale Interaktion unter den Rückkehrern zu sprechen.

Familiale Interaktion und Abwesenheit historisch-generationaler Zugehörigkeit. Vor dem Hintergrund dieser kollektiv- und lebensgeschichtlichen Prozesse in der Eltern- und Kindergeneration werden im familialen Dialog, infolge der Frustration über die Stagnation des palästinensischen Staatsbildungsprojektes und einer krisenhaften nationalen Zugehörigkeit durchaus ,Kampfaufträge für die palästinensische Sache ${ }^{6}$ verhandelt. Für die Elterngeneration ist dabei der ,Kampf auf der Straße' implizit positiv besetzt. In der intergenerationalen familialen Erzeugung einer Kampfdelegation liegen damit durchaus Parallelen zur intergenerationalen Interaktion zwischen der Generation Intifada und der Nachfolgegeneration Oslo in der Flüchtlingslager-Gegend. Allerdings werden die ungeplant entstehenden Kampfdelegationen im Kontext der Eltern und Kinder der Rückkehrer nicht entlang einer historisch-generationalen Differenzierung in ,Wir ${ }^{6}$ und ,Ihr ${ }^{6}$ verhandelt. Potentiale für eine Ausbildung historischer Generationenzugehörigkeit wären mit den differierenden lebensgeschichtlichen Erfahrungen der Eltern- und Kindergeneration der Rückkehrer zwar gegeben. Diese hängen mit Blick auf die Lagerungen der Biographien der Eltern und der Kinder der Rückkehrer im historischen Prozess etwa damit zusammen, in welcher biographischen Phase die Migration ins Westjordanland in den jeweiligen Lebensgeschichten angesiedelt ist, ob man in der Diaspora oder im Westjordanland aufwuchs. Diese aus den unterschiedlichen Generationslagerungen resultierenden Potentiale für die Ausbildung historisch-generationaler Zugehörigkeiten werden von den in dieser Arbeit in den Blick genommenen Rückkehrern aber nicht in Prozesse historischer Generationenbildung ,umgesetzt'. Biographisch unterschiedliche Erfahrungsbestände gehen 
hier nicht beziehungsweise kaum in nach historisch-generationalen Zugehörigkeiten differenzierte Deutungsmuster, Wir- und Sie-Bilder ein, Zugehörigkeitsgefühle sind nicht vorwiegend intragenerational besetzt. Markante Differenzen in den Deutungsmustern, Wir und Sie-Bildern fehlen. Das heißt, bei den Rückkehrern sind, anders als in der Flüchtlingslager-Gegend, zumindest die Interaktion zwischen familialen Generationen und der familiale Dialog nicht von einer Interaktion historischer Generationen geprägt.

Differenzen in den Sinnchancen und Bezug zur Generation Intifada. Welche biographische Bedeutung aber hat die Erste Intifada für die Eltern- und Kindergeneration der Rückkehrer und wie ist das Verhältnis zur Generation Intifada? Im Falle der Rückkehrer waren - aufgrund der Lagerung im soziohistorischen Raum - sowohl die Elterngeneration als auch die Kindergeneration nicht direkt in die Mobilisierung der 1970er und 1980er Jahre im Westjordanland involviert. Wie meine Rekonstruktionen zeigen, weisen die Deutungsmuster und Wir-Bilder der Kinder der Rückkehrer als ,Kämpfer für die palästinensische Sache und ,Verteidiger Ramallahs' durchaus Bezüge auf die Generation Intifada auf. Die Erste Intifada dient als Referenzpunkt, als eine romantisierte Kampfphase, die man ,verpasst' habe (,wenn ich die Erste Intifada erlebt hätte). So kommt unter den Kindern der Rückkehrer in der Involvierung in die Straßenschlachten und der Ausbildung eines Wir-Bildes als ,Kämpfer' auch eine Orientierung an der Generation Intifada als vorgelagerter Kampfgeneration zum Ausdruck. In den Deutungsmustern, Wir- und Sie-Bildern dient die kollektivgeschichtliche Periode seit den Oslo-Verträgen und seit der Zweiten Intifada als Kontrastfolie. Sie wird als ,falsche Zeit fürs Kämpfen', zum Teil auch als langweilig und hedonistisch gedeutet. Hierin kommt eine erlebte Abdrosselung der politischen Sinnchancen zum Ausdruck, die unter den Rückkehrern ebenso wie in der Flüchtlingslager-Gegend die Erlebnisschichtung der Generation Oslo kennzeichnet. In dieser Hinsicht teilen die Kinder der Rückkehrer Erfahrungen und Deutungen mit der Kindergeneration der Flüchtlinge in den Flüchtlingslager-Gegenden - als Mitglieder der Nachfolgegeneration Oslo, die auf eine vorgelagerte Kampfgeneration Erste Intifada folgt. Es zeigen sich in diesem Aspekt Ansätze in Richtung einer strukturidenten generationalen Erfahrungsbildung zwischen Flüchtlingslager-Gegend und Rückkehrern. Jedoch gibt es diese Bezüge auf die, verpasste' Mobilisierung der 1970er und 1980er Jahre auch in der Elterngeneration der Rückkehrer (,als ich die Bilder der Ersten Intifada sah"). Vermutlich müsste hier analytisch stärker zwischen jenen Rückkehrern unterschieden werden, die vor der Migration ins Westjordanland in die Milizen der PLO in der palästinensischen Diaspora eingebunden waren, und jenen, die dies kaum oder nicht waren. Die Milizen, die sich aus der von Rosemary Sayigh „Gil al Thawra“ genannten Gruppierung rekrutierten, waren in den 1970er und 1980er Jahren auf palästinensischer Seite in die Operationen, Anschläge und bewaffneten Konflikte eingebunden (vgl. Kap. 5). Sie stellen einen Teil der Rückkehrer (vgl. Kap. 4.6; 7.2.2). Zum Teil beziehen sich die Bilder und 
Orientierungspunkte der Nachfolgegeneration Oslo, wenn auch in diffuser Weise, auch auf diese Gruppierung als vorgelagerte Kampfgeneration - gerade wenn eine familiale Involvierung in diese Milizen gegeben war (vgl. Kap. 7.2.2). Tendenziell war aber die Generation Intifada als Orientierungspunkt für die Erfahrungsbildung und die Deutungsmuster auch für die Kindergeneration der Rückkehrer von größerer Bedeutung. Dies bedarf jedoch weiterer empirischer Fundierung.

Vergemeinschaftung mit der Nachfolgegeneration Oslo in der Flüchtlingslager-Gegend? In welchem Verhältnis stehen die Nachfolgegeneration Oslo unter den Rückkehrern und die Nachfolgegeneration Oslo in den FlüchtlingslagerGegenden? Betrachtet man die biographische Phase der Frühadoleszenz, die Dynamik in der Peergroup und die Deutungsmuster, Wir- und Sie-Bilder, fallen schnell einige Gemeinsamkeiten zwischen den im Kontext der FlüchtlingslagerGegend rekonstruierten ,marginalisierten Kämpfern' und der diskutierten Clique in Ramallah ins Auge: Die anfängliche Bedeutung von Ernsten Spielen im Sinne Meusers, die biographische Verstrickung in die Straßenschlachten und damit verbundene Leidenserfahrungen, die Bedeutung des ,Kampfs auf der Straße', das Wir-Bild als ,Kämpfer für die palästinensische Sache` und die stark ablehnende Haltung gegenüber der Rolle der Sicherheitskooperation und der PA. Auch das Erleben von absinkenden Sinnchancen gegenüber vorgelagerten Kampfgenerationen, vornehmlich der Generation Intifada, teilen sie. In Bezug auf die Nachfolgegeneration Oslo in den Flüchtlingslager-Gegenden und jener Ramallah-Clique liegen hier, wenn man so möchte, eigentlich generationale Integrations- und Vergemeinschaftungspotentiale. Das heißt, es wäre möglich, dass sie sich über die Trennung von urbanem und Flüchtlingslager-Kontext hinweg als einander ähnlich in Deutungs- und Handlungsmustern erleben, sich einander zugehörig fühlen. Darauf könnte auch ein gemeinsames generationales Wir-Bild aufbauen, das ihnen ermöglichen würde, sich stärker in Richtung einer Generationengruppe zu integrieren. Allerdings fehlt den Kindern der Rückkehrer eine für die ,marginalisierten Kämpfer ${ }^{\varsigma}$ zentrale vergemeinschaftende Erfahrung: die Erfahrung von Marginalisierung und Stigmatisierung innerhalb der palästinensischen Gesellschaft im Westjordanland. Zudem besteht in der tendenziell größeren Nähe der Nachfolgegeneration Oslo der Rückkehrer zu den mit der PA verbundenen klientelistischen Netzwerken eine Differenz in der biographischen Ressourcenausstattung. Sie ermöglicht der Nachfolgegeneration Oslo der Rückkehrer eine pragmatische Reorientierung der eigenen Deutungsmuster und Handlungspläne in Richtung Umsetzung der biographisch gegebenen Lebenschancen. In der Folge werden die im lebensgeschichtlichen Verlauf herausgebildeten Deutungsmuster und die Involvierung in die Straßenschlachten von der Nachfolgegeneration Oslo in der Flüchtlingslager-Gegend und den Rückkehrern letztlich biographisch unterschiedlich verhandelt. Insgesamt dominieren gegenwärtig (noch) die Unterschiede in den Zugehörigkeiten, klientelistischen Chancen und Lebenschancen gegenüber den geteilten Erfahrungsbeständen und den damit verbundenen Chancen auf Zugehö- 
rigkeitserleben und -gefühle - und damit gegenüber weitergehenden, generationalen Integrations- und Vergemeinschaftungsprozessen zwischen Rückkehrern und Flüchtlingen in der Nachfolgegeneration Oslo.

\subsubsection{Biographischer Verlaufstypus B: Vom ,Kampf auf der Straße zum} gelingenden Arrangieren mit den Verhältnissen

Wie wirkt sich in der Kindergeneration der Rückkehrer die spezifische Position in der Generationenfiguration als Nachfolgegeneration Oslo im Wechselspiel mit anderen Zugehörigkeiten auf biographischer Ebene aus und mit welchen typischen biographischen Verläufen steht sie in Zusammenhang?

Im Verlaufstypus „Vom „Kampf auf der Straße‘ zum gelingenden Arrangieren mit den Verhältnissen" steht die Position in der Generationenfiguration als Nachfolgegeneration Oslo in Wechselwirkung mit familial vermittelten hohen klientelistischen Chancen sowie wiederum mit geschlechtlicher Zugehörigkeit. In diesem Verlaufstypus wird ebenfalls im Zusammenspiel von intergenerationalen (insbesondere in der Familie) und intragenerationalen (insbesondere in der Peergroup) Tradierungs- und Interaktionsprozessen sowie Konstruktionsprozessen adoleszenter Männlichkeit ein ,Kampfauftrag für die palästinensische Sache“ erzeugt. Mit diesen Komponenten gleicht der Verlaufstypus dem Verlaufstypus „Von der Orientierung am ,Kampf auf der Straße $e^{\varsigma}$ zur Verschärfung einer gesellschaftlichen Außenseiterposition“. Allerdings geht mit ersterem gegenüber letzterem die deutlich größere Chance einher, längere verlaufskurvenartige Phasen der massiven Einschränkung von Handlungsmacht, der Reduzierung von Lebenschancen und hohen biographischen ,Kosten' zu vermeiden. Dafür sind insbesondere die klientelistischen Chancen beziehungsweise das soziale Kapital, das in der persönlichen oder familial vermittelten Nähe zu hegemonialen politischen Akteuren (Fatah und PA) zum Ausdruck kommt, sowie das Ausbleiben von Marginalisierung innerhalb der palästinensischen Gesellschaft verantwortlich. Dadurch ist die Möglichkeit zu einer Reorientierung der biographischen Handlungspläne länger offengehalten. Der Prozess biographischer Reorientierung wird von legitimierenden Deutungen - etwa auf ,bessere Zeiten fürs Kämpfen' warten zu wollen - begleitet. Einer der Präsentationsschwerpunkte liegt daher auf einer Demonstration anhaltender Kampfbereitschaft und Bereitschaft zur ,Verteidigung Ramallahs', die mit der Reorientierung ja gerade in Frage steht. Im Rahmen dieses Verlaufstypus wird zwar ein intergenerationales Absinken von Sinnchancen erlebt, das auch in expliziten Vergleichen mit vorangegangenen ,Kampfphasen' zum Ausdruck kommt. Familial und biographisch gegebene Lebenschancen werden aber tendenziell erhalten und umgesetzt. Das soziale Kapital moderiert nicht nur den Verfolgungsdruck durch die israelischen Sicherheitsbehörden und jene der PA, sondern ermöglicht auch in anderen Lebensbereichen die Umsetzung von Lebenschancen (berufliche Positionen, Heiratschancen oder Ähnliches). Der Verlaufstypus tritt tendenziell in der Konstellation auf, in welcher sich die Kinder der Rückkehrer 
bewegen, er ist jedoch nicht auf diesen Kontext limitiert. Auch in FlüchtlingslagerGegenden kann er auftreten, unter anderem deshalb, weil sich die klientelistischen Netzwerke der PA in die Flüchtlingslager-Gegenden erstrecken.

\subsection{Generationenfiguration und Verlaufstypus unter den Altansässigen in Ramallah}

\subsubsection{Diskussion der Generationenfiguration}

Im Kontext der urbanen Altansässigen sind die Generationen in ähnlicher Weise verflochten wie in der Flüchtlingslager-Gegend. Die Generation Intifada mit hohen Sinnchancen steht in einer Figuration mit der Nachfolgegeneration Oslo, die das Absinken von Sinnchancen erlebt und zu verhandeln hat. Allerdings unterscheidet sich aufgrund der vergleichsweise hohen Kapitalausstattung und generell der sozialen Position der urbanen Altansässigen die Art und Weise, in der die Generationenfiguration biographisch verhandelt wird. Ich diskutiere im Folgenden zunächst die Aspekte der Generationenfiguration und anschließend den biographischen Verlaufstypus.

Generationenzugehörigkeit, generationale Machtbalance und Verteilung von Lebenschancen. Die Elterngeneration der Altansässigen war in die politische Mobilisierung der 1970er und 1980er Jahre in den palästinensischen Gebieten involviert. Teile von ihnen zählen zu den sogenannten „non-landed urban professionals" (Robinson 1993), deren Rolle in der Mobilisierung in verschiedenen Studien herausgearbeitet worden ist (vgl. Kap. 4.5; 8). Sie charakterisiert ein biographischer Bestand an ,Widerstandsgeschichten', der etwa die Mobilisierung in den zivilgesellschaftlichen Komitees und häufig auch Inhaftierungen in israelischen Gefängnissen umfasst, ein mit der politischen Mobilisierung in den 1970er und 1980er Jahren verbundener Bekannten- und Freundeskreis sowie ein von den Generationsmitgliedern geteiltes generationales Wir-Gefühl und Gruppencharisma. Diese Charakteristika der Generation Intifada zeigen sich auch in den von meinen Kolleg*innen und mir durchgeführten empirischen Analysen zur Generation Intifada unter der zu den Altansässigen zählenden christlichen Bevölkerung des Westjordanlandes, die ich in dieser Arbeit nicht diskutiere, die aber an anderer Stelle veröffentlicht sind (Hinrichsen/Rosenthal/Becker 2015). Insgesamt bilden die urbanen Altansässigen in der Generation Intifada - als Lehrer*innen, Ärzt*innen, Händler*innen - einen Teil der Mittelschicht im Westjordanland in und um Ramallah. Manche von ihnen, gerade wenn sie mit den linken Parteien verbunden waren, besetzten in der Aufbauphase des professionalisierten NGOSektors in den 1990er Jahren Führungspositionen in den größeren NGOs (HonigParnass/Haddad 2007: 46). 
In meinen empirischen Analysen finden sich einige Hinweise darauf, dass das intergenerationale Verhältnis zwischen der Generation Intifada und der Nachfolgegeneration Oslo unter den Altansässigen einige Parallelen zu dem Verhältnis zwischen den Generationen in der Flüchtlingslager-Gegend aufweist. In ganz ähnlicher Weise ist eine Generation Intifada, die sich in einer kollektivgeschichtlich ,günstigen“ Phase hoher gesellschaftlicher Mobilisierung für die ,palästinensische Sache' eingesetzt und dadurch ,verdient' gemacht hat, mit einer Nachfolgegeneration Oslo verflochten. Gegen die Intentionen der Beteiligten entsteht eine Hierarchisierung der Generationen, in welcher die Nachfolgegeneration in indirekter Weise an der ,verdienten“ Vorgängergeneration gemessen wird und ihr gegenüber abfällt („we served at the rigth time“). Aus dieser Verflechtung von Generationengruppierungen erwächst ein von den Altansässigen in der Nachfolgegeneration Oslo erlebter Druck, sich für die ,palästinensische Sache` einzusetzen.

Ein zentraler Unterschied zur Nachfolgegeneration Oslo in den Flüchtlingslager-Gegenden besteht allerdings darin, dass die Nachfolgegeneration Oslo der Altansässigen diesen Druck - vor dem Hintergrund der vergleichsweise besseren Ausstattung mit familial vermittelten Lebenschancen - mit Fokus auf eine Vermeidung biographischer ,Kosten“ auflöst (vgl. Kap. 8). Eine der Folgen dieser Orientierung ist es, Schimpfklatsch als das Absprechen von Mut (im Vergleich zur Generation Intifada) oder als Vorwurf der Konsumorientierung und des Hedonismus zu erleben. Auf der Seite der Nachfolgegeneration Oslo finden sich gerade bei den Altansässigen auch Hinweise auf Schuldgefühle, sich nicht stärker in den ,Kampf für die palästinensische Sache ${ }^{6}$ zu involvieren. Formen betonter Präsentation des nationalen Wir-Bildes und eines, Einsatzes für die palästinensische Sache als ,Kampf im Kleinen“ lassen sich in diesem Zusammenhang als kompensatorische Leistungen interpretieren. Auch präsentierte Formen des ,Kampfes im Kleinen' (zum Beispiel in Form von Diskussionen am Checkpoint) lassen sich in diesem Sinne auslegen. Generell kommt in diesen Aspekten auch die Machtasymmetrie zwischen der Generation Intifada und der Nachfolgegeneration Oslo im Kontext der Altansässigen zum Ausdruck.

Die Generationenfiguration ist - anders als in der Flüchtlingslager-Gegend nicht von einer Asymmetrie in der Verteilung der Lebenschancen zwischen den Generationen geprägt. Dazu hat sicherlich der relative Aufstieg der ,neuen` urbanen Mittelschicht beigetragen, zu welcher die urbanen Altansässigen der Nachfolgegeneration Oslo gehören (vgl. Kap. 9.5). Die Ausstattung mit hohen Lebenschancen ist tendenziell familial gegeben, und im biographischen Verlauf entsteht eine Orientierung, die auf deren Realisierung konzentriert ist. Hierin kommt eine Habitusformation zum Ausdruck, die auch von Lisa Taraki (2008) als in Ramallahs neuer urbaner Mittelschicht stark verbreitet angesehen wird. Diese umfasst zum Beispiel einen Fokus auf privatschulische, universitäre und berufliche Erfolge und einen Lebensstil, der eine intensive Nutzung der gerade im ,kosmopolitischen“ Ramallah vorhandenen Freizeit-Infrastruktur umfasst. Ein weiteres Charakteristi- 
kum besteht in der hohen Mobilität über die Landesgrenzen hinweg bei gleichzeitiger Distanz zu anderen palästinensischen Milieus und gerade zu den ländlichen Regionen und den Flüchtlingslager-Gegenden im Westjordanland (vgl. Abourahme 2009). Der seit den 1990er Jahren stark gewachsene und professionalisierte NGO-Sektor, der besonders in Ramallah sehr sichtbar ist, bietet den Altansässigen in der Nachfolgegeneration Oslo mit ihrer hohen Austattung mit kulturellem und sozialem Kapital häufig berufliche Positionen.

Wir- und Sie-Bilder sowie generationale Differenzen in Sinnchancen. Die Deutungsmuster, Wir- und Sie-Bilder der Altansässigen in der Nachfolgegeneration Oslo kennzeichnet eine innere Abwendung vom palästinensischen Politikbetrieb und der palästinensischen Parteienlandschaft, die als völlig delegitimiert erlebt werden. Dies ist auch der Fall, wenn sie selbst in die Patronage-Netzwerke der PA und der Fatah eingebunden sind und von diesen profitieren. In diesem Zusammenhang entsteht auch eine Abgrenzung gegenüber den Rückkehrern im Verwaltungsapparat der PA, die als an der palästinensischen Gesellschaft im Westjordanland desinteressiert gesehen werden. Ähnlich ist das Verhältnis zum NGOSektor in den palästinensischen Gebieten, der den Altansässigen zwar häufig berufliche Positionen bietet, generell jedoch als internationale Finanzierung der Aufrechterhaltung der israelischen Besatzung gesehen und abgewertet wird. Auch das Sie-Bild gegenüber den Flüchtlingslager-Bewohner*innen ist abwertend. Insbesondere die jungen Männer werden als ,kriminell', ,wild' und ungebildet stigmatisiert, auch wenn dies vor dem Hintergrund der symbolischen Bedeutung der Flüchtlingslager-Gegenden für das nationale palästinensische Narrativ selten offen ausgesprochen wird.

In der Nachfolgegeneration Oslo der Altansässigen wird eine intergenerationale Verringerung der Sinnchancen erlebt. Neben den romantisierenden Bezügen auf, frühere Zeiten' wird dies insbesondere in der abwertenden Haltung gegenüber der palästinensischen Parteien- und Institutionenlandschaft, die in Gänze als delegitimiert und korrupt erfahren wird, sowie in dem Erleben geringer politischer Handlungsmacht und Betätigungsspielräume zum Ausdruck gebracht. Auch die generell apolitischen, konsumorientierten Deutungs- und Handlungsmuster der Nachfolgegeneration Oslo der urbanen Altansässigen lassen sich im Sinne geringer Sinnchancen interpretieren. Um hier ein Beispiel zu nennen: Vergleicht man etwa das Ansehen der palästinensischen politischen Hochschulgruppen und deren Bedeutung für die Mobilisierung von urbaner Mittelschicht und Akademiker*innen in den 1980er Jahren (Robinson 1997; Hasso 2005) mit der heutigen Haltung der urbanen Altansässigen diesen gegenüber, fällt der Verlust an, Optionen' für ,politische Sinnstiftung' deutlich ins Auge. An dieser Stelle möchte ich einen weiteren Verweis auf die Befunde meiner Kolleg*innen und mir zu der christlichen Bevölkerung im Westjordanland machen, die eine interessante generationale Differenz in den Wir- und Sie-Bildern offenbaren. So zeigt sich in der Nachfolgegeneration Oslo in der christlichen Bevölkerung eine deutlich stärkere 
Betonung religiöser Zugehörigkeit und eine Distanzierung von anderen Bevölkerungsteilen im Westjordanland, als dies in der Generation Intifada unter den Christen der Fall ist. Diese generationale Differenz in den Wir- und Sie-Bildern gleicht jener Differenz, die ich für die Generation Intifada und die Nachfolgegeneration Oslo in der Flüchtlingslager-Gegend diskutiert habe (vgl. Kap. 9.2.1). Sie ist im Zusammenhang mit den generationalen Integrations- und Vergemeinschaftungsprozessen der Generation Intifada zu sehen.

\subsubsection{Biographischer Verlaufstypus C: Risikovermeidung und Konzentration auf die Umsetzung von Lebenschancen}

In welcher Weise steht in der Kindergeneration der urbanen Altansässigen die Position in der Generationenfiguration als Nachfolgegeneration Oslo in Wechselwirkung mit weiteren Zugehörigkeiten und in welcher Weise wirkt sich dies auf der Ebene biographischer Prozesse aus?

In diesem Verlaufstyp ist die Zugehörigkeit zur Generationengruppierung Nachfolgegeneration Oslo verknüpft mit der Zugehörigkeit zu den Altansässigen der urbanen Mittelschicht. Mit Blick auf die in den anderen Kontexten relevanten Männlichkeitskonstruktionen zeigt sich im Kontext der Altansässigen eine deutlich geringere Relevanz geschlechtlicher Konstruktionsprozesse und die Verläufe bei (jungen) Männern und Frauen ähneln einander stärker. Die intergenerationale Interaktion deutet, darauf wurde bereits hingewiesen, auf eine mit dem Kontext der Flüchtlingslager-Gegend vergleichbare Hierarchisierung der Generationen. Auf den empfundenen Druck , sich einzusetzen' wird mit einer weitgehenden Vermeidung biographischer „Kosten“ reagiert („,or it will cost you“). Dazu trägt auch das Fehlen einer am ,Kampf auf der Straße' orientierten Peergroup bei, die in den anderen Kontexten als Deutungsinstanz für familiale Tradierungen und Delegation fungiert. Damit zusammenhängend kann gerade im Rahmen dieses Verlaufstypus die Position in der Generationenfiguration mit dem Erleben von Stigmatisierung als ,materialistisch ' beziehungsweise ,feige“ sowie mit dem Empfinden von Schuldgefühlen verbunden sein. Insgesamt zeigt sich eine biographische Orientierung in Richtung Hedonismus und Statuswettkampf. Dabei werden in diesem Verlaufstypus die familial und biographisch ohnehin hohe Lebenschancen tendenziell auch realisiert. Dies ist auch mit dem Erleben geringer Sinnchancen verbunden, was in einer Verachtung der palästinensischen Parteien- und Institutionenlandschaft, in dem Erleben geringer Handlungsmacht und in einer generell apolitischen Orientierung zum Ausdruck kommt. Dieser Typus spiegelt sich zum Teil in den Forschungsergebnissen von Jacob Høigilt (2012; 2016), die von mir bereits in Kapitel 5 diskutiert wurden, wider. Høigilt hat einen „exodus from politics“ (2016: 466) unter palästinensischen Jugendlichen identifiziert, welchen er als Reaktion auf die gesellschaftlichen und politischen Bedingungen der Oslo-Phase interpretiert: „Widespread discontent with their situation among the youth does not translate into increased political interest or engagement. Instead, the majority have aban- 
doned organised politics and what they consider a political class associated mostly with Fatah and Hamas and to which few seem to see any alternative" (Christophersen/Høigilt/Tiltnes 2012: 1). Die von den Autor*innen genannten Gründe - unter anderem die Repression der israelischen und palästinensischen Behörden, der Wandel der Zivilgesellschaft, mitbedingt durch Entwicklungshilfe, die für Teile der Bevölkerung passablen sozio-ökonomischen Bedingungen und die damit verbundene Tendenz, eher den (inneren) Ausstieg als die Konfrontation zu suchen - gehen in die Richtung der Strukturkomponenten des von mir diskutierten Verlaufstypus. Er stellt jedoch einen Typus unter anderen Typen dar und ist geknüpft an eine mit spezifischen (geringen) Sinnchancen und (hohen) Lebenschancen verbundene figurationale Position sowie eingebettet in die Wandlungen generationaler und anderer Figurationen und Machtverhältnisse im Westjordanland. $\mathrm{Zu}$ diesen sich wandelnden Figurationen gehört, dies wird gerade an diesem Verlaufstypus sehr deutlich, jene zwischen der Bevölkerung in den FlüchtlingslagerGegenden und der sich seit den 1990er Jahren verstärkt formierenden ,neuen städtischen Mittelschicht. Sie soll im Folgenden nochmals in kondensierter Form herausgestellt werden. An ihr lässt sich auch das Zusammenspiel von Figurationen aufzeigen.

\subsection{Figuration von Bevölkerung in den Flüchtlingslager- Gegenden und urbaner Mittelschicht}

Im Folgenden möchte ich ein weiteres zentrales Ergebnis dieser Forschungsarbeit erörtern, welches sich in den empirischen Analysen wiederholt gezeigt hat - nämlich die Bedeutung der Figuration der Bevölkerung in den FlüchtlingslagerGegenden und der sich seit den 1990er Jahren verstärkt formierenden ,neuen städtischen Mittelschicht. Die Figuration wurde in der bisherigen Ergebnisdarstellung immer wieder erkennbar und soll nun explizit herausgestellt werden. Sie steht in Wechselwirkung mit der rekonstruierten Generationenfiguration und wirkt so in vermittelnder Weise auf die Lebenswege, Wir- und Sie-Bilder der Nachfolgegeneration Oslo und der Generation Intifada ein.

Mit dem Beginn des sogenannten Friedensprozesses zwischen Israel und der PLO Anfang der 1990er Jahre wurden tiefgreifende Transformationsprozesse in der palästinensischen Gesellschaft des Westjordanlandes angestoßen, die auch die Figuration der Bevölkerung in den Flüchtlingslager-Gegenden und der urbanen Mittelschicht zuungunsten ersterer verändert haben. In der Forschungsliteratur sind diese Veränderungen unter der Chiffre einer Verschärfung von Ungleichheits- beziehungsweise Klassenverhältnissen im Westjordanland diskutiert worden. So konstatiert der palästinensische Soziologe Jamil Hilal im Hinblick auf diese Entwicklungen: 
„It is worth noting that class and status distinctions based on wealth and position have never been as glaring as they have come to be in recent years [...]. In the 1st Intifada, the glaring distinctions were largely between the occupier and the occupied. Now, they are very noticeable between different segments of the occupied and besieged population" (2014).

Auch Lisa Taraki spricht mit Blick auf die veränderten gesellschaftlichen Rahmenbedingungen ,nach Oslo“ im Laufe der 1990er und 2000er Jahre von „transformations in the class structure, primarily the consolidation of a new and aspiring modernist middle class“ (2008: 62; vgl. Grandinetti 2015: 4 f.; Krieger 2015). Auf die meisten Faktoren, die in diese Transformationen hineinspielen, habe ich im Rahmen meiner Arbeit wiederholt hingewiesen. Von größerer Relevanz für diese Entwicklung ist unter anderem der Aufbau der PA generell, die Immigration der PLO-Rückkehrer und deren Bedeutung innerhalb der PA sowie die erheblichen finanziellen Aufwendungen einer internationalen Gebergemeinschaft. Letztere finanzieren nicht nur die PA, sondern stützen auch einen zivilgesellschaftlichen Wandel hin zu einem großen ,professionalisierten' NGO-Sektor, der nicht mehr primär auf die Unterstützung des palästinensischen ,Widerstandsprojektes‘, sondern an westlichen Geberkriterien ausgerichtet ist. Dies ging wiederum zum Teil auf Kosten der Bevölkerung in den Flüchtlingslager-Gegenden, die an der Mobilisierung der Zivilgesellschaft der 1970er und 1980er Jahre teilgehabt hatte und in der transformierten Zivilgesellschaft eher marginalisiert wurde. Gleichzeitig trugen auch die sukzessive Schließung des israelischen Arbeitsmarktes ab Anfang der 1990er Jahre und die Abschwächung der Arbeitsmigration in die Golfregion zu einer Verringerung der Lebenschancen vieler Flüchtlinge aus den FlüchtlingslagerGegenden bei. Schließlich entfalteten sich diese Prozesse auch im Zusammenhang mit einer seit der Ersten Intifada, insbesondere jedoch seit der Zweiten Intifada (2000 bis circa 2005) auf Segregation zielenden Besatzungspolitik Israels, die die territoriale und soziale Fragmentierung der palästinensischen Gesellschaft förderte und fördert (Gordon 2008: 34 ff.). Die ,neue' städtische Mittelschicht ist vorwiegend in dem seit den 1990er Jahren stark gewachsenen und veränderten Ramallah lokalisiert. Diese in sich heterogene Gruppierung erzielt ihr vergleichsweise hohes Einkommen unter anderem durch berufliche Positionen in der PA und im ,professionalisierten' NGO-Sektor. In meinen empirischen Analysen sind die in Kapitel 7 diskutierten Rückkehrer und die in Kapitel 8 diskutierten Altansässigen dieser Gruppierung zuzuordnen. Mit den gesellschaftlichen Transformationsprozessen verschoben sich auch die Machtbalancen innerhalb der Flüchtlingslager-Gegenden. Dort war ein Teil der Generation Intifada in der Phase des Aufbaus der PA in den 1990er Jahren in die Behörde integriert worden, sei es in Form von Anstellungen oder durch Einbeziehung in die entstehenden Patronage-Netzwerke. In der Aufbauphase der PA bis Ende der 1990er Jahre war es dafür auch nicht unbedingt notwendig gewesen, zu den ,alten' PLO-Kadern oder der dominierenden Fatah zu gehören, wohl aber als ,Widerstandskämpfer` zu gelten (vgl. Kap. 4.6). 
Die skizzierten Transformationsprozesse bilden sich auch in den Befunden dieser Arbeit ab. Sie werden von mir als Verschiebung der Machtbalance der Figuration der Bevölkerung in den Flüchtlingslager-Gegenden und der urbanen Mittelschicht zuungunsten ersterer gefasst. Sie stehen in Wechselwirkung mit den im vorangegangenen Abschnitt vorgestellten biographischen Verläufen und Erfahrungsgeschichten, etwa den unterschiedlichen Lebenschancen oder der unterschiedlichen Betroffenheit durch die israelischen Militäroperationen. Diese Wechselwirkung wird aber vor allem sichtbar in den rekonstruierten Deutungsmustern, Wir- und Sie-Bildern insbesondere der Generation der Kinder der Flüchtlinge in den Flüchtlingslager-Gegenden, aber auch der Kindergeneration der Rückkehrer und der urbanen Altansässigen. So zielt das von der Nachfolgegeneration Oslo in den Flüchtlingslager-Gegenden gepflegte Sie-Bild der, unpolitischen, wohlhabenden Städter, die ,nicht kämpfen' auf die Altansässigen in der Nachfolgegeneration Oslo. Das Sie-Bild reflektiert in gewisser Weise den Lebensstil, den Fokus auf Statuswettkampf und Konsum sowie die Vermeidung von biographischen Kosten im ,Einsatz für die palästinensische Sache', die bei den urbanen Altansässigen als biographische Orientierung tendenziell dominant sind. Bei der Stigmatisierung in der Gegenrichtung wiederum versehen insbesondere die urbanen Altansässigen die jungen Männer in der Flüchtlingslager-Gegend mit den abwertenden, anomisierenden Sie-Bildern (, wild ${ }^{6}$, ,kriminell'). Das von den ,marginalisierten Kämpfern ${ }^{6}$ in den Flüchtlingslager-Gegenden gepflegte Sie-Bild von den PA-Kadern, „die davon profitieren“ würden, „dass die Sache so bleibt", reflektiert wiederum in gewisser Weise das höhere Ausmaß, in welchem die Mitglieder der in Ramallah angesiedelten Clique von Zugezogenen und Rückkehrern die PA und die Fatah als biographische Ressource nutzen können (,,die Jungs, die es geschafft haben, weil ihr Vater soundso ist"). Diese mit der Positionierung als Rückkehrer verbundenen biographischen Ressourcen kommen auch in den Deutungsmustern der Kinder der Rückkehrer zum Ausdruck und zwar insofern, als die eigenen Wir-Bilder zwar durchaus mit einer Abgrenzung gegen eine vermeintlich unpolitische, hedonistische Bevölkerung Ramallahs verbunden werden, jedoch nicht mit einer Verhandlung einer als gesellschaftlich marginalisiert erlebten sozialen Position. Schließlich verweist die Nachfolgegeneration Oslo in den Flüchtlingslager-Gegenden auf jene Gruppierung der kooptierten Ex-Kämpfer als Quelle des sie in den LagerGegenden treffenden Schimpfklatsches (vgl. Kap. 6.2). Insgesamt lässt sich festhalten, dass die Deutungsmuster, Wir- und Sie-Bilder die Verschiebung der Machtbalance zugunsten der urbanen Mittelschicht und zuungunsten der Bevölkerung in den Flüchtlingslager-Gegenden als Teil der sozialen Transformationsprozesse im Westjordanland seit den Oslo-Verträgen reflektieren.

Die Figuration steht in Zusammenhang mit der hier rekonstruierten Generationenfiguration. Generell wird diese Wechselwirkung an dem Zusammenspiel der unterschiedlichen Zugehörigkeiten und gesellschaftlichen Positionen in den biographischen Verlaufstypen deutlich, die ich in den vorangegangenen Abschnitten 
diskutiert habe (Kap. 9.2.2; 9.3.2; 9.4.2). An dieser Stelle möchte ich dieses Zusammenwirken der Figurationen an zwei auf die Flüchtlingslager-Gegenden bezogenen Aspekten verdeutlichen. Erstens wirkt die relative Verringerung der Lebenschancen - als ein Aspekt der Figuration - zuungunsten der FlüchtlingslagerGegenden und zugunsten der städtischen Mittelschichten auch auf das Verhältnis der Generationen ein. Die eigenen Lebenschancen gegenüber der Elterngeneration zu reproduzieren oder zu verbessern war, wie meine Rekonstruktionen zeigen, in der Generation Intifada in der Flüchtlingslager-Gegend über weite Strecken ihres Lebens in größerem Maße gegeben als in der Nachfolgegeneration Oslo in der Flüchtlingslager-Gegend. Hier vertieft die Verschiebung in der Figuration von Flüchtlingslager-Gegenden und städtischer Mittelschicht auch eine generationale Differenz. Auch die Chancen des Einbezugs in die Netzwerke der PA waren und sind zwischen den Generationen unterschiedlich, was, wie ich diskutiert habe, ihr Machtdifferenzial mitbewirkt. Darüber hinaus zeigt sich zweitens der Zusammenhang der Figuration der Bevölkerung in den Flüchtlingslager-Gegenden und der städtischen Mittelschichten mit der Generationenfiguration auch in der generationalen Differenz in den Deutungsmustern, Wir- und Sie-Bildern. Die Generation Intifada und die Mitglieder der Nachfolgegeneration Oslo in den FlüchtlingslagerGegenden blicken in unterschiedlicher Weise auf diese Transformationsprozesse. Während die Deutungsmuster, Wir- und Sie-Bilder der Nachfolgegeneration Oslo die Verschiebung in der Figuration reflektieren, sind die Deutungsmuster, Wirund Sie-Bilder der Generation Intifada - deutlich wird dies an der geringeren Bedeutung des Wir-Bildes als Flüchtling oder der religiösen Zugehörigkeit - vom Einfluss der Mobilisierung der 1970er und 1980er Jahre auf die Transformationsprozesse geprägt.

Generell zeigen diese Aspekte auf, wie Transformationsprozesse beziehungsweise sozialer Wandel mit der Formierung von historisch-generationalen Erlebnisschichtungen, Deutungsmustern, Wir- und Sie-Bildern verbunden sein kann. Die besondere ,Gelegenheit ${ }^{`}$ sozialer Transformationsprozesse für die Ausbildung historischer Generationen liegt darin begründet, dass aufgrund der Transformation später geborene Gesellschaftsmitglieder die aktuelle gesellschaftliche Periode, anders als die früher geborenen Gesellschaftsmitglieder, nicht vor dem Hintergrund der in einer früheren gesellschaftlichen Periode gemachten Erfahrungen erleben (können). Aufgrund der Relevanz der Gesamtorganisation von Erfahrungen für deren Interpretation (vgl. Kap. 2.2; 2.6) können so abhängig von der Generationszugehörigkeit die ,gleichen' Ereignisse unterschiedlich erlebt werden. In figurationssoziologischer Lesart kommen die Transformationsprozesse darin zum Ausdruck, dass Veränderungen in der einen (klassen- beziehungsweise schichtbezogenen) Figuration die Formierung einer Generationenfiguration beeinflussen und stützen. 


\subsection{Die Nachfolgegeneration Oslo als graduelles Phänomen historischer Generationenbildung: Außenseitergeneration und Zwischengeneration}

Im Folgenden möchte ich die Befunde der Arbeit auf die stärker theoretisierende Frage beziehen, inwiefern die Nachfolgegeneration Oslo ein graduelles Phänomen historischer Generationenbildung darstellt. In diesem Zusammenhang greife ich die von Mannheim geprägten Begriffe des Generationszusammenhangs und der Generationseinheit auf. Zwar sprechen einige Gemeinsamkeiten in der Erfahrungsbildung in der Nachfolgegeneration Oslo für eine Interpretation im Sinne der Mannheim'schen Terminologie. Dennoch komme ich in der folgenden Erörterung zu der Einschätzung, dass die Nachfolgegeneration Oslo - und die in ihr rekonstruierten Kontexte - nicht den Grad an Integration und Vergemeinschaftung erreicht, der eine Benennung als Generationszusammenhang und -einheit rechtfertigen würde. In diesem Zusammenhang werde ich auch diskutieren, inwiefern die Nachfolgegeneration Oslo als Zwischengeneration gelten kann.

Gemeinsame Erfahrungen als Außenseitergeneration. Zunächst seien die Gemeinsamkeiten genannt, die die Nachfolgegeneration Oslo in der Erfahrungsbildung aufweist. Diese stehen damit in Zusammenhang, dass die Nachfolgegeneration Oslo im figurationssoziologischen Sinne eine Außenseitergeneration darstellt. Sie befindet sich in einer Generationenfiguration mit der vorgelagerten Kampfgeneration, der gegenüber sie mit geringeren Machtchancen sowie mit geringeren Sinn- und Lebenschancen ausgestattet ist, was sich in typischen Charakteristika der Erlebnisschichtungen niederschlägt: das Gefühl ,im Schatten“ der früheren Kampfgeneration zu stehen sowie die Frustration, die Desillusionierung, die Romantisierung vergangener Perioden oder die Schuldgefühle, die mit dieser figurationalen Position verbunden sind. Damit sind auch eine Orientierung der Bewertungsmaßstäbe und der Wunschträume an dieser vorangegangenen Kampfgeneration sowie entsprechende Loyalitätsbindungen verbunden. Auch das Erleben von Stigmatisierung durch die Generation Intifada kann Bestandteil der Erlebnisschichtung sein. Die Frage ist nun, ob die geteilte Außenseiterposition in der Generationenfiguration und die damit einhergehenden geteilten Erfahrungen Anlass genug geben, um von einem Generationszusammenhang und von Generationseinheiten im Sinne Mannheims zu sprechen.

Generationszusammenhang und Generationseinheiten? Trotz der Gemeinsamkeiten, die sich in den typischen Erfahrungen der Nachfolgegeneration Oslo finden, liegt meines Erachtens das Ausmaß, in welchem die Nachfolgegeneration Oslo integriert und vergemeinschaftet ist, gleichwohl unterhalb des Niveaus eines entwickelten Generationszusammenhangs beziehungsweise entwickelter Generationseinheiten. Diese Schlussfolgerung möchte ich kurz erläutern: Denkbar wäre es, auf Basis meiner Forschungsergebnisse eine Kategorisierung der Nachfolgegeneration Oslo und der verschiedenen, von mir rekonstruierten Typen bio- 
graphischer Verläufe entlang der von Mannheim geprägten Begriffe des Generationszusammenhangs und der Generationseinheiten vorzunehmen. Wie in Kapitel 2.2 erörtert, spricht Mannheim mit Bezug auf den Generationszusammenhang vom ,gemeinsamen Schicksal“ (1964: 547), welches dessen Mitglieder verbindet, auch wenn sie in Generationseinheiten ,in jeweils verschiedener Weise diese Erlebnisse verarbeiten“ (ebd.: 544). Eine für die rekonstruierte Generationenfiguration passende Zuspitzung besteht in der von Heinz Bude aufgegriffenen Formulierung Hans Jaegers, der den Generationszusammenhang auch als „Problemgemeinschaft" (Bude 1987: 38), also von einer generational als geteilt erlebten Problemstellung her definiert. Für die Nachfolgegeneration Oslo bestünde eine im Generationszusammenhang geteilte Problemstellung im Erleben der im Vergleich zur Generation Intifada zurückgesetzten gesellschaftlichen Stellung und im geteilten Erleben der Verringerung der Sinnchancen. Hier läge also in der Position in der Generationenfiguration, der Notwendigkeit, diese biographisch zu verhandeln, und den Folgen, die für die Lebenswege daraus erwachsen, die für einen Generationszusammenhang charakteristische Problemstellung.

Folgt man dieser Lesart weiter, wären die rekonstruierten Typen biographischer Verläufe wiederum die unterschiedlichen Antworten auf die Problemstellung im Rahmen von Generationseinheiten. In diesem Sinne ausgelegt, würde zum Beispiel der Typus der Marginalisierten (Typus A) eine Generationseinheit darstellen. Diese Lesart wäre vor dem Hintergrund der diskutierten Ergebnisse aber nur dann plausibel, wenn man davon ausgeht, dass sich Generationseinheiten auch bei starker gleichzeitiger Wirksamkeit anderer Zugehörigkeiten beziehungsweise figurationaler Positionen zeigen können. Man könnte von historisch-generationaler Differenz als Bestandteil einer, umgangssprachlich formuliert, mehrfachen, Einkästelung des sozialen Phänomens sprechen: Der Typus A der Marginalisierten grenzt sich in schicht- beziehungsweise klassenbezogener Zugehörigkeit (gegen die urbane Mittelschicht), in geschlechtlicher Zugehörigkeit (er ist an die Konstruktionsprozesse von Männlichkeit gebunden) und eben generationsbezogener Zugehörigkeit (in den gegenüber der Generation Intifada differierenden Erfahrungen, Deutungsmustern, Wir- und Sie-Bildern) ab.

Auch wenn diese Charakterisierungen als Generationszusammenhang und Generationseinheit durchaus plausibel erscheint, komme ich dennoch zu einer anderen Einschätzung, wie ich im Folgenden begründen möchte. So plädiere ich in Abgrenzung zu diesem Argumentationsgang für eine strengere Auslegung des Konzepts des historischen Generationszusammenhangs und der Generationseinheit. Meiner Ansicht nach wäre eine Kategorisierung der Nachfolgegeneration Oslo als Generationszusammenhang mit verschiedenen Generationseinheiten erst dann gerechtfertigt, wenn sich in der Nachfolgegeneration Oslo zumindest in Ansätzen ein Erleben der Gleichförmigkeit der Erfahrungen und ein ZugehörigFüblen über andere Gruppierungen beziehungsweise Zugehörigkeiten binweg abzeichnen würde. Zumindest in meinen Befunden deutet empirisch nur wenig auf 
eine über ,Klassen-` beziehungsweise Schicht- und Geschlechtszugehörigkeiten hinweggehende generationale Integration und Vergemeinschaftung hin. Zwar zeigen sich innerhalb der einzelnen Gruppierungen, etwa innerhalb der Gruppierung der Flüchtlinge in den Flüchtlingslager-Gegenden, Differenzierungen nach historisch-generationaler Zugehörigkeit, jedoch (bisher) kaum über die jeweilige Gruppierung hinweg. Darin unterscheidet sich die Nachfolgegeneration Oslo auch von der Generation Intifada. In der Generation Intifada war zumindest in Ansätzen eine Integration und Vergemeinschaftung des Generationszusammenhangs und verschiedener Generationseinheiten über klassen- und geschlechtsbezogenene Gruppierungen beziehungsweise Zugehörigkeiten hinweg sichtbar. Dies kam in meinen empirischen Analysen etwa darin zum Ausdruck, dass in den Deutungsmustern, Wir- und Sie-Bildern die Figuration von Flüchtlingen in den Flüchtlingslager-Gegenden und Altansässigen hinter die generationalen Wir-Bilder und gefühle zurücktrat (Kap. 6.3 und 6.4). Darüber hinaus kann die Integration der Generation Intifada als relativ gesicherter Befund der Forschungen gelten, die von mir in Kapitel 4 und Kapitel 5 diskutiert worden sind. ${ }^{173}$ Die generationalen $\mathrm{Zu}$ gehörigkeitskonstruktionen und -gefühle, die Wir-Bilder und Netzwerke, die im Zuge der Mobilisierung der 1970er und 1980er Jahre an Bedeutung gewannen, konnten bis zu einem gewissen Grad andere Differenzlinien in der palästinensischen Gesellschaft überschreiten. Damit ist keineswegs gesagt, dass es in der Generation Intifada keine interne Differenzierung gegeben habe. Sie trat nur in stärkerem Maße hinter eine generationale Zugehörigkeit zurück. Und sie vollzog sich entlang der Zugehörigkeit zu Generationseinheiten, die zum Teil quer zu den klassen- und geschlechtsbezogenen Differenzierungen lagen. Diese Differenzierung nach Generationseinheiten in der Generation Intifada ist zum Beispiel ausführlich von Loren Lybarger (2007) mit ihrer Unterteilung in eine säkularnationalistische Generationseinheit und eine islamistische Generationseinheit diskutiert worden (vgl. Kap. 5).

In der Nachfolgegeneration Oslo zeigt sich, wie bereits betont, kaum eine ,Klassen-“ beziehungsweise Schicht- und Geschlechtszugehörigkeiten übergreifende generationale Integration und Vergemeinschaftung. Erst recht finden sich keine manifesten generationalen Wir-Bilder, die über Gruppierungen hinweg geteilt würden. Nimmt man dieses Kriterium als Voraussetzung dafür, Generationszusammenhänge und Generationseinheiten konstatieren zu können, erfüllt die Nachfolgegeneration Oslo die Vorgabe streng genommen nicht. Da sich, dies

\footnotetext{
173 An dieser Stelle sei noch einmal an einige Aspekte des generationalen Integrationsschubs in den 1970er und 1980er Jahren erinnert, die in Kapitel 4, 5 und 6 diskutiert wurden: die relative Angleichung von Flüchtlingen und Nicht-Flüchtlingen (Bisharat 1994), der Einbezug von Frauen in die Mobilisierung und deren Zugewinn an Spielräumen, die Beteiligung und Initative der „urban professionals" und anderer in den Landwirtschafts-, Gesundsheits- und Frauenkomitees (Robinson 1993), die partielle Mobilisierung der urbanen (Klein-)Unternehmer (Tamari 1990), der umfassende Einbezug der palästinensischen Christen, die zumindest in dieser Phase gegebene Bedeutung politischer Heiraten (Johnson/Abu Nahleh/Moors 2009).
} 
wurde durch das Bisherige deutlich, trotz dieses Mangels an Integrationsprozessen dennoch einige typische Aspekte der Erlebnisschichtung der Nachfolgegeneration Oslo ausmachen lassen, die mit der geteilten Position in der Generationenfiguration einhergehen und sich auch über verschiedene Differenzierungen hinweg in der palästinensischen Gesellschaft finden (insbesondere das Erleben eines Mangels an politischer Sinnerfüllung), kann man meines Erachtens von einem graduellen Phänomen von Generationsbildung sprechen. Zumindest auf dem gegenwärtigen Stand des generationalen Bildungsprozesses ist, trotz geteilter Position in der Generationenfiguration und einiger geteilter Aspekte der Erlebnisschichtung, unter den Mitgliedern der Nachfolgegeneration Oslo das biographisch Trennende dominanter als das biographisch Gemeinsame.

Graduelle Phänomene und Zwischengeneration. Mit graduellen Phänomenen sind, um dies hier nochmals zu betonen, Generationen gemeint, die keinen klaren Generationszusammenhang und keine klaren Generationseinheiten aufweisen, bei denen aber auf der Ebene der Erfahrungsbildung durchaus Ansätze generationaler Erlebnisschichtungen gegeben sind. An dieser Stelle komme ich auf die Ausführungen zu sprechen, die ich in Kapitel 2, insbesondere Kapitel 2.9, diskutiert habe. Mannheim selbst hat mit dem Begriff der Zwischengenerationen die Frage nach graduellen Phänomenen von historischen Generationen berührt. Impulse neuer Generationen, um Mannheim noch einmal zu zitieren,

„schließen sich möglicherweise einer früheren Generation an, die die Formung bereits vollzogen hat [...] So können oft frühere oder spätere Generationsimpulse und -regungen durch das Vorhandensein einer geprägten Form fremder Generationen verdeckt werden“ (1964: 552).

Mannheim legt hier nahe, dass Ansätze für eine Generationenbildung aufkommen können, die sich dann an bereits formierten Generationszusammenhängen und einheiten orientieren, obwohl sie sich in deren Erlebnisschichtungen nicht voll wiederfinden. Im Anschluss an Karl Mannheims Zwischengenerationen hat Bernd Weisbrod von „stillen Generationen“ gesprochen. Ihm zufolge sind dies Generation, die in ihrer Bedeutung für den sozialen Wandel zwar nicht zu unterschätzen seien, die jedoch „keinen hegemonialen Deutungsanspruch geltend machen konnten" (Weisbrod 2005: 5). Auch Ulrike Jureits mehr oder weniger ad hoc getroffene Definition einer „verlorenen Generation“, „die sich nicht öffentlich artikulieren kann, die wenig Möglichkeit hat sich zu artikulieren, wahrgenommen zu werden" (2013: 13), kreisen um eine ähnliche Frage. Diese verschiedenen Begriffe - Zwischengeneration, stille Generation, verlorene Generation - heben Aspekte gradueller Phänomene von historischer Generationenbildung hervor, die sich nur leicht voneinander abheben: die nur in Ansätzen gegebene generationale Erlebnisschichtung, die Orientierung an vorangegangenen, großen' Generationen, die relativ machtschwache Position und eine geringe Sicht- und Hörbarkeit. Diese Aspekte kreisen die Charakteristika der Nachfolgegeneration Oslo durchaus treffend ein. 
Latenz der Generationenfiguration. Die Charakterisierung der Nachfolgegeneration Oslo als stille Generation oder Außenseitergeneration, die wenig integriert ist und sich kein Gehör verschaffen kann, kommt noch in einem weiteren Aspekt zum Ausdruck: der relativen Latenz der generationalen Spannungsbalance. Sie ist latent in dem Sinne, dass die Verflechtung von Generation Intifada und Nachfolgegeneration Oslo und deren Folgen von ihren Mitgliedern meist nicht voll realisiert werden und, wenn sie realisiert werden, kaum thematisiert werden was letztlich zur Aufrechterhaltung der Machtasymmetrie zwischen den Generationen beiträgt. So wurde die Generationenfiguration in den Gesprächen und Interviews, die ich im Westjordanland geführt habe, von Seiten der Nachfolgegeneration Oslo so gut wie gar nicht explizit thematisiert. Dieser Umstand wird leichter nachvollziehbar, wenn man sich vor Augen führt, wie man die relative Stellung der Nachfolgegeneration Oslo gegenüber der Generation Intifada aus der Perspektive ersterer versprachlichen könnte. Aus der Perspektive der Nachfolgegeneration Oslo wäre eine mögliche Paraphrase gegenüber der Generation Intifada: ,Euer Verdienst an der palästinensischen Sache lässt uns schlecht aussehen und setzt uns unter Druck'. Die Reflexion oder Thematisierung dieser Spannungsbalance hieße, der Generation Intifada ihr Engagement für die nationale Wir-Gruppe und die damit verbundenen in Kauf genommenen Risiken zum Vorwurf zu machen. Allerdings schließt die anhaltende Frontstellung gegenüber ,den Israelis' die unterschiedlichen Generationenfigurationen in einer gemeinsamen nationalen Gruppierung zusammen. Daher ist die generationale Spannungsbalance für die Generation Oslo schwer zu reflektieren - geschweige denn gegenüber der Generation Intifada offensiv zu kommunzieren. Norbert Elias hat, wie ich in Kapitel 2.5 ausgeführt habe, eine ähnliche Konstellation unter der Figuration von Wehrmachtsoffizieren und jüngeren Freikorps-Kämpfern in der Weimarer Republik erkannt, die er in seinen Studien über die Deutschen diskutiert hat. Aufgrund eines gemeinsamen Gegners ist die Konkurrenzsituation in der Generationenfiguration nicht offen ausgetragen worden (Elias 1989: 322 ff.):

„Auf dieser Ebene ließ sich der Kampf der jüngeren Außenseitergruppen gegen die älteren Etablierten um die Eröffnung abgedrosselter Sinn- und Lebenschancen nicht austragen. Bei allen Interessenunterschieden jedoch hatten diese jüngeren und älteren Generationen eine gemeinsame Front" (ebd.: $323 \mathrm{f}$.$) .$

Elias hat auch davon gesprochen, dass der Generationenkonflikt daher „unauslebbar" gewesen sei (ebd.: 323). In der von mir rekonstruierten Generationenfiguration im Westjordanland liegt meines Erachtens eine vergleichbare Konstellation vor. Die anhaltende Figuration mit ,den Israelis' trägt sicherlich dazu bei, dass die Spannungsbalance zwischen Kampfgeneration und Nachfolgegeneration im Westjordanland nicht offener thematisiert und nicht stärker reflektiert wird. Sie trägt auf diese Weise zum ,stillen' Charakter der Generation bei, der ihre Außenseiter- 
stellung stützt. In diesem Sinne stellt angesichts der in diesem Kapitel diskutierten Charakteristika die Nachfolgegeneration Oslo auch eine Zwischengeneration, eine stille Generation dar.

\subsection{Integration einer biographietheoretischen und figurationssoziologischen Perspektive auf historische Generationen}

Diese Forschungsarbeit liefert empirisch begründete Anregungen dafür, die theoretische Konzeptualisierung historischer Generationen weiter auszudifferenzieren. Diese Anregungen liegen in der Integration einer figurationssoziologischen und biographietheoretischen Perspektive begründet.

Zusammenhang von generationaler Erfahrungsbildung, Interaktion und Figuration. Die Rekonstruktion der Verflechtung von Generation Intifada und Nachfolgegeneration Oslo hat deutlich gemacht, dass es mit der sich wandelnden relativen Stellung der Generationengruppierung zusammenhängt, welche geteilten generationalen Erfahrungen Gesellschaftsmitglieder machen, welche Deutungsmuster sie ausbilden und inwiefern sie sich in Richtung einer Generationengruppe integrieren und vergemeinschaften. Diese relationale Betrachtung ist im Mannheim'schen Generationskonzept und generell in seiner Wissenssoziologie bereits angelegt (vgl. Kap. 2.2-2.3). Sie ist jedoch insbesondere in der figurationssoziologischen Perspektive Norbert Elias' ausbuchstabiert worden (vgl. Kap. 2.4-2.5). Auch in der rekonstruktiven Sozialforschung, insbesondere in der Biographieforschung, ist die Bedeutung von Generationenverhältnissen hervorgehoben worden. Dabei lag der Fokus meist auf der Bedeutung von Interaktionen und Interaktionsgeschichten von Mitgliedern derselben historischen Generation als auch von Mitgliedern unterschiedlicher Generationen (vgl. Kap. 2.2; 2.7). Mit meiner Forschungsarbeit betone ich darüberhinausgehend, wie Erfahrungsbildung und Interaktionsprozesse in und zwischen Generationen mit der Bilanz ihrer gegenseitigen Abhängigkeiten - ihrer Machtbalance - in Wechselwirkung stehen und so als Figurationen konzeptualisiert werden können. Die Machtbalancen sind, figurationssoziologisch konsequent, immer als Ausdruck von sowie in ihrer Einwirkung auf die Gruppen- und Gruppierungsverflechtungen insgesamt zu interpretieren. Diese Wechselwirkung von auf der einen Seite Erfahrungen und Deutungsmustern - beziehungsweise generationalen Erlebnisschichtungen, um den Mannheim'schen Begriff aufzugreifen - und auf der anderen Seite der Machtbalance der Figuration wird auch daran deutlich, dass diese Erfahrungen und Deutungsmuster die Möglichkeit umfassen, andere Gruppierungsmitglieder überhaupt zu erkennen und sich ihnen gegenüber zugehörig zu füblen. Die Koppelung der Erfahrungen und Deutungsmuster an die Machtbalance wird auch an den Formen des ,StigmaManagements', an der Organisation von Wir- und Sie-Bildern und - wie im Fall 
der Nachfolgegeneration Oslo - am Erleben von Sinnchancen deutlich (vgl. Kapitel 2.4-2.5). In dieser Perspektive sind auch durch andere Generationen dominierte Generationen möglich, die gar nicht oder nur rudimentär integriert und vergemeinschaftet sind - Außenseitergenerationen im figurationssoziologischen Sinne. Generationenverhältnisse können so als Etablierten-Außenseiter-Figurationen von vorgelagerten Generationen und nachgelagerten Generationen verstanden werden.

Historische Generation als Prozess. Meine Forschungsarbeit unterstreicht außerdem den Prozesscharakter historischer Generationenbildung. Die Position der Nachfolgegeneration Oslo in der Generationenfiguration ist ein Zwischenresultat eines anhaltenden Prozesses. Die nachgelagerte Stellung der Generation Oslo ist eine Folge der Integration und Vergemeinschaftung der Generation Intifada vor dem Hintergrund der kollektivgeschichtlichen Entwicklung im Westjordanland (mindestens) seit den 1970er Jahren. Die Verflechtung von Generationen ist somit Ausdruck eines Prozesses, in dem sich Gruppen und Gruppierungen formieren, mehr oder weniger stark integrieren (oder desintegrieren) und in dem sich die Machtbalancen zwischen ihnen wandeln. Die Rekonstruktion sozialer Prozesse ist nicht nur ein zentraler Bestandteil der Figurationssoziologie, sondern auch ein Kernanliegen der Biographieforschung, welche dafür üblicherweise den Erhebungs- und Auswertungsfokus über mehrere Generationen ausdehnt - so auch meine Forschungsarbeit, der dadurch eine Rekonstruktion des Zusammenhangs langfristiger kollektiv- und lebensgeschichtlicher Prozesse gelingt (vgl. Kap. 2.4-2.7).

Graduelle Phänomene und Wechselwirkung. In der Nachfolgegeneration Oslo wird zwar die relative Stellung in der Generationenfiguration geteilt, was mit entsprechender Erfahrungsbildung - insbesondere im Erleben sinkender Sinnchancen - einhergeht. Die Integration und Vergemeinschaftung in Richtung einer generationalen Wir-Gruppe bleibt dennoch relativ gering. Dies liegt darin begründet, wie die generationale Zugehörigkeit zur Generation Oslo von anderen Zugehörigkeiten beziehungsweise Figurationen überlagert wird und mit ihnen in Wechselwirkung steht. Die Zugehörigkeit zur Nachfolgegeneration Oslo wird nicht in einem Ausmaß biographisch dominant, dass sie andere Zugehörigkeiten deutlich in den Hintergrund treten lassen würde. Damit wird deutlich, dass die empirisch vorliegenden unterschiedlichen Grade beziehungsweise Ansätze generationaler Erfahrungsbildung sowie generationaler Integrations- und Vergemeinschaftungsprozesse theoretisch reflektiert werden müssen. Auch für diese Überlegungen finden sich nicht nur in der Figurationssoziologie, sondern auch bei Mannheim und in der Biographieforschung wichtige Anknüpfungspunkte. Mannheim trifft in den begrifflichen Differenzierungen, die er in seinem Generationskonzept vornimmt, eine, wenn auch implizit bleibende, Unterscheidung von Integrations- und Vergemeinschaftsungsniveaus (vgl. Kap. 2.2; 2.8). Dieses Unterscheidungstaster kann man sich - von Generationslagerung über den Generationszusammenhang bis zu den Generationseinheiten - durchaus als Kontinuum von einer gering inte- 
grierten Generationengruppierung am einen Pol bis zur integrierten und stärker kollektiv handlungsfähigen Generationengruppe am anderen Pol vorstellen (vgl. Kap. 2.9). Mannheim diskutiert ferner, darauf habe ich bereits hingewiesen, verschiedene Ansätze historischer Generationen als Zwischengenerationen, die zwar Ansätze neuer Erlebnisschichtungen aufweisen können, welche aber relativ verdeckt bleiben, und die sich an vor- oder nachgängigen, dominanteren Generationen orientieren - wie die Nachfolgegeneration Oslo. Solche feinen Differenzierungen in der Erfahrungsbildung herauszuarbeiten, ist gerade eine der Stärken der Biographieforschung. Indem sie historische Generationen im Gesamtzusammenhang von Lebensgeschichten analysiert, bestimmt sie empirisch, ob und wenn ja welche biographischen - und damit auch kollektivgeschichtlichen - Erfahrungen in welchen lebensgeschichtlichen Phasen in welchen Interaktionsbeziehungen konstitutiv für historische Generationen werden. Nicht nur die biographische Bedeutung, sondern auch die Wechselwirkung von Zugehörigkeiten und Figurationen kann analysiert werden - wie in dieser Arbeit anhand der vermittelnden Bedeutung der Figuration von Flüchtlingslager-Gegenden und urbaner Mittelschicht für die Generationenfiguration rekonstruiert wurde.

Insgesamt analysiert meine Forschungsarbeit Prozesse historischer Generationenbildung, indem sie den Zusammenhang von unterschiedlichen Prozessen der Erfabrungsbildung, von Interaktionsprozessen und sich wandelnden Machtdifferenzialen in Figurationen von sich mehr oder weniger integrierenden Gruppierungen aufzeigt. Sie arbeitet damit, empirisch begründet, den theoretischen Gewinn heraus, der in einer Verbindung einer figurationssoziologischen und einer biographietheoretischen Perspektive auf Prozesse historischer Generationenbildung liegt. 



\section{Fazit und Ausblick}

\subsection{Fazit}

Ziel dieser Forschungsarbeit war es, eine möglichst differenzierte Antwort auf die Frage zu geben, inwiefern es zur Ausbildung einer typischen Erlebnisschichtung, zu generationalen Integrations- und Vergemeinschaftungsprozessen in der Generation Oslo kam oder kommt und durch welche sozialen Prozesse sie gegebenenfalls erzeugt und vermittelt wurden. Darüberhinausgehend sollten die empirischen Analysen dazu beitragen, die theoretische Konzeptualisierung von historischen Generationen zu schärfen. Dafür wurden drei Kontexte diskutiert - eine Flüchtlingslager-Gegend sowie die Rückkehrer und die Altansässigen in Ramallah.

Ein zentrales Ergebnis dieser Forschungsarbeit besteht in der Rekonstruktion einer Generationenfiguration. Die Mitglieder der Generation Oslo sind als nachgelagerte Generation mit einer vorgelagerten ,Kampfgeneration“, vornehmlich der Generation Intifada, in einer Etablierten-Außenseiter-Figuration von Generationengruppierungen verflochten. Ich spreche in diesem Zusammenhang von einer Nachfolgegeneration Oslo, die im figurationssoziologischen Sinne in einer Außenseiterposition gegenüber der Generation Intifada steht. Das zentrale Charakteristikum, das mit dieser Position in der Generationenfiguration verbunden ist und das sich in den Erlebnisschichtungen der Mitglieder der Generation Oslo spiegelt, besteht darin, ein generationales Absinken von Sinnchancen und zum Teil von Lebenschancen zu erleben und biographisch zu verhandeln. 
Die ,Kampfgeneration' Intifada und die mit ihr verbundene spezifische Erlebnisschichtung zeichnen bis heute ein generationales Wir-Bild und Wir-Gefühl, ein Gruppencharisma und ein Bestand sowohl an ,Widerstandsgeschichten', aber auch an dethematisierten Leidenserfahrungen sowie mit der Mobilisierung verbundene Netzwerke aus. Trotz des unterschiedlichen Ausmaßes, mit dem die politische Involvierung in sozio-ökonomische und berufliche Statusgewinne umgemünzt werden konnte, kann man bei der Generation Intifada dennoch von einer generell mit erheblichen politischen Sinnchancen und einem Gefühl von politischer Sinnerfüllung verknüpften Generationenzugehörigkeit sprechen.

Die Zugehörigkeit zur Nachfolgegeneration Oslo ist hingegen mit dem Erleben des Absinkens von Sinnchancen verbunden. Dieses Absinken kommt in einem Gemessen-Werden an der Generation Intifada zum Ausdruck, das von den Beteiligten nicht intendiert ist, in der Verflechtung der Generationen aber dennoch entsteht. Zum Teil kommt es auch in expliziter generationaler Stigmatisierung zum Ausdruck. Weiterhin zeigt sich das Absinken der Sinnchancen in einem erlebten Statusverlust von Kämpfer*innen und Aktivist*innen, in einer nostalgischen und romantisierenden Haltung gegenüber der politischen Mobilisierung in den 1970er und 1980er Jahren und in einer generalisierten Abwertung der palästinensischen Parteien- und Institutionenlandschaft sowie einem erlebten Absinken (politischer) Handlungsmacht. Empfindungen von Frustration und Desillusionierung sowie Schuldgefühle können mit dieser figurationalen Position verbunden sein.

Diese Charakteristika, die die Erlebnisschichtungen der Generationen kennzeichnen, sind Ausdruck ihrer spezifischen Verflechtung. In meinen Analysen habe ich detailliert die Rolle intergenerationaler Interaktion für die Entstehung historischer Generationszugehörigkeit, die damit verbundenen latenten und ungeplanten Handlungsfolgen der Generationenfiguration und ihr spezifisches Machtdifferenzial sowie die generationalen Differenzen in der Erlebnisschichtung, den Deutungsmustern, Wir- und Sie-Bildern herausgearbeitet. Diese verschiedenen Aspekte der Generationenfiguration sind integral mit den kollektivgeschichtlichen Prozessen im Westjordanland verwoben - der israelischen Besetzung des Westjordanlandes und der politischen Mobilisierung in den 1970er und 1980er Jahren sowie den sozialen Transformationsprozessen im Zuge der Oslo-Verträge in den 1990er Jahren.

Die Zugehörigkeit zur Nachfolgegeneration Oslo ist zwar tendenziell in allen in dieser Generationslagerung vorgenommenen Fallrekonstruktionen für die Erlebnisschichtungen, Deutungs- und Handlungsmuster relevant, sie ist aber nicht unbedingt biographisch dominant. Die Position als nachgelagerte Generation Oslo steht in Wechselwirkung sowohl mit geschlechtlicher Zugehörigkeit als auch mit einer Figuration von klassen- beziehungsweise schichtbezogenen Gruppierungen. Letztere Figuration bezeichnet eine zentrale Richtung der gesellschaftlichen Transformationsprozesse, die sich im Westjordanland seit den Oslo-Verträgen 
Mitte der 1990er Jahre verfestigt: der relative Abstieg der Bevölkerung der Flüchtlingslager-Gegenden gegenüber der ,neuen` urbanen Mittelschicht. Diese in der Literatur mit Blick auf die zunehmende Fragmentierung und Ungleichheit sowie verstärkte ,Klassenkonflikte، diskutierte Entwicklung trat auch im Zuge meiner Analysen zutage und stellt ein weiteres zentrales Ergebnis meiner Forschungen dar. Sie spiegelt sich hier in den Deutungsmustern, Wir- und Sie-Bildern, in der Ausstattung mit Lebenschancen und mit klientelistischen Chancen im Bezug auf die PA.

Jene klassen- beziehungsweise schichtbezogene Figuration und die Generationenfiguration kreuzen sich und interagieren gemeinsam mit geschlechtlicher Zugehörigkeit. Um die Frage nach der Relevanz generationaler Zugehörigkeit in der Generation Oslo vor dem Hintergrund dieser Wechselwirkung zu bestimmen, habe ich eine Typologie biographischer Verläufe gebildet. Ich habe Prozesse militanter Involvierung in der Nachfolgegeneration Oslo rekonstruiert, die entweder in einen tendenziell in Flüchtlingslager-Gegenden auftretenden Marginalisierungsprozess (Typus A) oder in einen tendenziell mit den Rückkehrern verbundenen Prozess des Arrangierens mit den Verhältnissen auf Basis klientelistischer Chancen (Typus B) mündeten. Außerdem habe ich einen auf Vermeidung zielenden Verlauf (Typus C) rekonstruiert, der tendenziell mit den Altansässigen verbunden ist und in welchem der Fokus auf einer Umsetzung von Lebenschancen liegt.

Abschließend bin ich zu einer Einschätzung bezüglich des Grades beziehungsweise Ausmaßes historischer Generationenbildung gekommen, die sich in der Generation Oslo zeigt. Einerseits lassen sich typische Erfahrungen in der Erlebnisschichtung bestimmen, die in der Generation Oslo über verschiedene Zugehörigkeiten beziehungsweise Gruppierungen hinweg geteilt werden. Andererseits zeigen sich, zumindest in meinen Analysen, nur geringe Integrations- und Vergemeinschaftungsprozesse in Generationseinheiten über verschiedene Zugehörigkeiten beziehungsweise Gruppierungen hinweg. Daher spreche ich mit Bezug auf die Generation Oslo von einem graduellen Phänomen historischer Generationenbildung. Die empirischen Analysen dieser Arbeit rücken die Generation Oslo damit in die Nähe von Zwischengenerationen, die in der Generationenforschung bisher nur am Rande diskutiert wurden und werden.

Diese empirischen Ergebnisse haben Implikationen für die theoretische Konzeptualisierung historischer Generationen. Die vorliegende Forschungsarbeit macht empirisch begründet deutlich, wie in Bildungsprozessen historischer Generationen Prozesse der Erfahrungsbildung, Interaktionsprozesse und sich wandelnde Machtdifferenziale zwischen sich integrierenden oder desintegrierenden Gruppierungen und Gruppen auf kollektiv-, familien- und lebensgeschichtlicher Ebene miteinander zusammenwirken. Die Arbeit unterstreicht so - im Rahmen der Erforschung historischer Generationenbildung und darüber hinaus - den Gewinn, der in einer Verbindung von figurationssoziologischer und biographietheoretischer Perspektive für die Erforschung sozialer Phänomene liegt. 


\subsection{Limitierungen der Arbeit und Ausblick}

Im Folgenden möchte ich einige Limitierungen dieser Forschungsarbeit, die die Verallgemeinerbarkeit beziehungsweise Reichweite ihrer Ergebnisse einschränken, sowie einige mögliche Weiterführungen und Vertiefungen der Forschung diskutieren.

Für eine weitere Ausdifferenzierung der Forschungsergebnisse wäre eine Erweiterung der Typologie auf Basis der bereits gezogenen ersten theoretischen Stichprobe denkbar. Einige mögliche Erweiterungen der Typologie sind schon in Kapitel 9 angedeutet worden. In der Forschungsarbeit habe ich, neben der Rekonstruktion der Figurationen, eine Typologie entlang der Frage gebildet, wie die geteilte generationale Zugehörigkeit beziehungsweise die geteilte Position der Generation Oslo in der Generationenfiguration in ihrer Wechselwirkung mit anderen Zugehörigkeiten jeweils biographisch verhandelt wird. Auf der Ebene biographischer Verläufe habe ich Prozesse militanter Involvierung rekonstruiert, die entweder in einen Marginalisierungsprozess (Typus A) oder in ein Arrangieren mit den Verhältnissen (Typus B) umschlugen, sowie einen auf Vermeidung zielenden Verlauf (Typus C), in welchem der Fokus auf einer Umsetzung von Lebenschancen liegt. Im typologischen Feld, das die Fragestellung nach der Verhandlung der Generation Oslo aufspannt, ist das Vorhandensein (mindestens) eines weiteren Typus wahrscheinlich. Diese Einschätzung basiert sowohl auf meiner Kenntnis der ersten theoretischen Stichprobe als auch auf den Befunden anderer Forschungsarbeiten. Dieser fehlende Typus verhandelt das mit der Position in der Generationenfiguration verbundene Absinken von Sinnchancen und das Gemessen-Werden an der Kampfgeneration vermutlich mittels eines zivilgesellschaftlichreformerischen Deutungs- und Handlungsmusters. Die Forschungsarbeiten, die auf das Vorhandensein dieses Typus hinweisen, habe ich bereits in Kapitel 5 diskutiert. Dies betrifft insbesondere die Untersuchungen von Sunaina Maira (2013) und die Studie von Jacob Høigilt (2016). Sie kreisen unter anderem um die Aktivitäten der palästinensischen Jugendbewegung nach dem sogenannten Arabischen Frühling ab 2011, die jedoch nicht an Momentum gewinnen konnte. Nach Høigilt kennzeichnet sie, um dies noch einmal aufzugreifen, ein (erneuerter) ,right based, non-violent activism“ (2016: 466). Høigilt verortete diese Jugendbewegung auch in einer neuen Generation von Fatah-Aktivisten. Dieser Typus artikuliert seine Orientierungen gerade auch im Rahmen künstlerischer Ausdrucksformen, also etwa in den von Maira analysierten Rap-Texten oder in visuellen Kunstformen. Er ist soweit ich dies auf Basis der Erhebungen bestimmen kann - auch in der ersten Stichprobe vorhanden, die meine Kolleg*innen und ich gezogen haben. Zu dieser Einschätzung komme ich insbesondere auf Basis der Erhebungen, die ich im Umfeld einiger Studierender der Kunstakademie Ramallahs zwischen 2014 und 2015 durchgeführt habe, und auf Basis der Memos, die ich in diesem Zusammenhang angefertigt habe. Aufgrund der bereits vorhandenen Studien und aus forschungs- 
pragmatischen Gründen habe ich diesen Typus nicht mehr in die zweite Stichprobe gezogen.

Für eine weitere Fundierung und Ausdifferenzierung der Forschungsergebnisse sollte stärker herausgearbeitet werden, wie historische Generationenbildung mit weiblicher Zugehörigkeit interagiert. Meine Arbeit berücksichtigt zwar den vergeschlechtlichten Charakter historischer Generationenbildung - allerdings nicht für alle durchgespielten Positionen in der Generationenfiguration und der Figuration von Flüchtlingslager-Bevölkerung und urbaner Mittelschicht in gleichem Maße. Meine Ergebnisse weisen auf einige Parallelen in der historischen Generationenbildung sowohl hinsichtlich weiblicher als auch hinsichtlich männlicher Zugehörigkeit hin. Mitglieder der Generation Intifada sind sowohl Frauen als auch Männer, ihre Mitgliedschaft in der ,Kampfgeneration' wirkt auf die Generation Oslo in ähnlicher Weise (vgl. Kap. 6.4; 8.2). Dennoch könnte noch stärker herausgearbeitet werden, auch unter Berücksichtigung existierender Forschungsarbeiten (Sabbagh 1998; Hasso 2001, 2005), wie die generationsbildende Teilhabe an der Mobilisierung der 1970er und 1980er Jahre durch geschlechtliche Zugehörigkeit vermittelt ist und welche Bedeutung hier zum Beispiel die palästinensische Frauenbewegung für eine weibliche Generationsmitgliedschaft auch in meinen Erhebungen hat. Für die Generation Oslo unter den Altansässigen liefern meine Ergebnisse deutliche Hinweise darauf, dass die Wirkung, die die Position in der Generationenfiguration für die Erfahrungen und Deutungsmuster entfaltet, nicht sehr stark durch geschlechtliche Zugehörigkeit vermittelt ist. So ist für den Typus $\mathrm{C}$ geschlechtliche Zugehörigkeit kein strukturbildendes Merkmal. Hingegen ist für die Typen A und B die strukturbildende Bedeutung der Konstruktionsprozesse von Männlichkeit, die in die Verhandlung der Position in der Generationenfiguration hineinspielen, herausgestellt worden. Weibliche Vertreterinnen in der Kindergeneration aus Flüchtlingslager-Gegenden und unter den Rückkehrern sind zwar Teil der ersten theoretischen Stichprobe und haben unter anders gelagerten Fragestellungen im weiteren Kontext des Forschungsprojektes Berücksichtigung gefunden, könnten jedoch noch stärker im Bezug auf die hier vorgestellten Ergebnisse diskutiert werden.

Eine weitere Limitierung meiner Forschungen liegt möglicherweise in ihrer ,säkularen Schlagseite؛. Lebensgeschichten von Menschen, die sich stark im islamistischen Milieu (Lybarger 2007) verorten, sind gerade in der Generation Oslo sowohl in der ersten als auch in der zweiten Stichprobe kaum vorhanden. Die Samplebildung zur Generation Intifada umfasst einige Fälle aus diesem Milieu, die zum Teil mit einer Parteizugehörigkeit, etwa zum Islamischen Jihad, verbunden sind (vgl. Rosenthal/Albaba 2015). In meinen Untersuchungen zur Generation Oslo sind Fälle mit starker islamistischer Verortung nicht vorhanden beziehungsweise tauchten nur am Rande meiner Kontakte während der Feldaufenthalte auf. Ein gezieltes Sampling in diesem Milieu wäre für die weitere Fundierung der Forschungsergebnisse sicherlich gewinnbringend. Ich vermute auf Basis der bisheri- 
gen Ergebnisse nicht unbedingt, hierbei auf gänzlich neue Falldynamiken zu treffen. Die vergleichsweise höheren Sinnchancen der Generation Intifada, das implizite Messen der Nachfolgegeneration Oslo an der Mobilisierung in den 1970er und 1980er Jahren, an welcher das islamistische Milieu teilhatte, ist auch für diese Fälle nicht unwahrscheinlich. Dies gilt auch für einen möglichen, nochmals gesteigerten Verfolgungsdruck durch die PA und die israelischen Behörden. Fehlen würde hingegen die klientelistische Bindung an die PA. Auf Basis der durch meine Befunde gestützten Vorerwartungen würde ich daher für das islamistische Milieu im Westjordanland ein Auftreten von Typus A und Typus C erwarten. Klären lassen sich diese Fragen nur durch weitere Erhebungen im Sinne einer Erweiterung der ersten und zweiten Stichprobe.

In vergleichbarer Weise wäre für eine weitere Fundierung und Ausdifferenzierung der Ergebnisse eine Ausweitung der Forschung auf ländlich-periphere Regionen interessant. Die Frage wäre, inwiefern sich dort den anderen Kontexten ähnelnde Verflechtungen zeigen. Zwar sind die ländlichen Gegenden im Westjordanland sehr heterogen und gerade im Umland Ramallahs auch in den städtischen Raum eingebunden. Manche der ländlichen Gegenden, insbesondere in den CGebieten, weisen jedoch den Charakter von ,Frontier'-Dörfern auf, in denen die Auseinandersetzung mit israelischen Behörden um die Landnutzung und konfiszierung, der Verfolgungsdruck durch die israelischen Sicherheitsbehörden und der relative Verlust an Status, Macht- und Lebenschancen gegenüber der neuen urbanen Mittelschicht Ramallahs jener Konstellation in den Flüchtlingslager-Gegend ähneln könnte. Dies ist allerdings eine empirisch zu beantwortende Frage. 


\section{Transkriptionszeichen}

$$
\begin{aligned}
& =\text { kurzes Absetzen } \\
& \text { (4) = Dauer der Pause in Sekunden } \\
& \text { Ja: } \quad=\text { Dehnung } \\
& (\text { (lachend })) \quad=\text { Kommentar der Transkribierenden } \\
& \text { / = Einsetzen des kommentierten Phänomens } \\
& \text { nein }=\text { betont } \\
& \text { viel- } \quad=\text { Abbruch } \\
& \mathrm{Ja}=\mathrm{ja} \quad=\text { schneller Anschluss }
\end{aligned}
$$





\section{Literaturverzeichnis}

Ababsa, Myriam (2011). Introduction. Citizenship and Urban Issues in Jordan. In: Myriam Ababsa und Rami Farouk Daher (Hg.): Villes, pratiques urbaines et construction nationale en Jordanie. Beyrouth: Presses de l'Ifpo, 39-64.

Abdo, Nahla (1999). Gender and Politics under the Palestinian Authority. In: Journal of Palestine Studies 28 (2), 38-51.

Aboim, Sofia/Vasconcelos, Pedro (2014). From Political to Social Generations. A Critical Reappraisal of Mannheim's Classical Approach. In: European Journal of Social Theory 17 (2), 165-183.

Abourahme, Nasser (2009). The Bantustan Sublime. Reframing the Colonial in Ramallah. In: City 13 (4), 499-509.

Abu Shakrah, Jan (1986). The „Iron Fist“, October 1985 to January 1986. In: Journal of Palestine Studies 15 (4), 120-126.

Ajluni, Salem (2003). The Palestinian Economy and the Second Intifada. In: Journal of Palestine Studies 32 (3), 64-73.

Al-Hardan, Anaheed (2016). Palestinians in Syria. Nakba Memories of Shattered Communities. New York: Columbia University Press.

Alheit, Peter (2018). Biographieforschung und Figurationstheorie. In: Helma Lutz, Martina Schiebel und Elisabeth Tuider (Hg.): Handbuch Biographieforschung. 2., korrigierte Auflage. Wiesbaden: Springer VS, 23-36. 
Al-Husseini, Jalal (2011). The Evolution of the Palestinian Refugee Camps in Jordan. Between the Logics of Exclusion and Integration. In: Myriam Ababsa und Rami Farouk Daher (Hg.): Villes, pratiques urbaines et construction nationale en Jordanie. Beyrouth: Presses de l'Ifpo, 181-204.

Al-Husseini, Jalal (2013). The Exodus of Palestinian Refugees. In: Myriam Ababsa (Hg.): Atlas of Jordan: History, Territories and Society. New edition [online]. Beyrouth: Presses de l'Ifpo, 230-245.

Amireh, Amal (2003). Between Complicity and Subversion. Body Politics in Palestinian National Narrative. In: The South Atlantic Quarterly 102 (4), 747-772.

Anderson, Benedict R. (1983). Imagined Communities. Reflections on the Origins and Spread of Nationalism. London: Verso.

Anderson, Betty (2005). Nationalist Voices in Jordan. The Street and the State. Austin: University of Texas Press.

Apitzsch, Ursula/Inowlocki, Lena (2000). Biographical Analysis. A ,German“ School?. In: Prue Chamberlayne, Joanna Bornat und Tom Wengraf (Hg.): The Turn to Biographical Methods in Social Science. Comparative issues and examples. London [u.a.]: Routledge, 53-70.

Aruri, Nasser H. (1972). Jordan. A Study in Political Development (1921-1965). Den Haag: Martinus Nijhoff.

Aruri, Natasha (2013). From „Sumud“ [Resilience] to Corporate Identity. In: Planum. The Journal of Urbanism 26, 1-13, http://www.planum.net/planummagazine/cities-to-be-tamed/section-2 < letzter Zugriff: 9.10.2016>.

Bahl, Eva/Worm, Arne (2018). Biographische und ethnographische Zugänge zu Wir- Bildern, Sie-Bildern und Handlungspraktiken in einer Organisation. Die spanische Polizeieinheit Guardia Civil in Ceuta und Melilla. In: Zeitschrift für Qualitative Forschung 19 (1-2), 233-251.

Barboza, Amalia (2009). Karl Mannheim. Konstanz: UVK-Verlagsgesellschaft.

Baumgarten, Helga (2006). Hamas. Der politische Islam in Palästina. Kreuzlingen [u.a.]: Hugendubel Verlag.

Bayat, Asef (2010). Life as Politics. How Ordinary People Change the Middle East. Amsterdam: Amsterdam University Press.

Baylouny, Anne M. (2008). Militarizing Welfare. Neo-liberalism and Jordanian Policy. In: Middle East Journal 62 (2), 277-303.

Becker, David (2014). Die Erfindung des Traumas. Verflochtene Geschichten. Neuauflage der 2. Auflage. Gießen: Psychosozial-Verlag.

Becker, David/Weyermann, Barbara (2006). Gender, Konflikttransformation und der psychosoziale Ansatr. Arbeitshilfe. Direktion für Entwicklung und Zusammenarbeit \& Eidgenössisches Department für Auswärtige Angelegenheiten. Bern: DEZA. 
Becker, Johannes (2013). Old Men's Truth. The „Poverty Generation” of Neighborhood Men Talk about Life in Jerusalem's Old City. In: Middle East Journal of Culture and Communication 6 (3), 264-285.

Becker, Johannes (2017). Verortungen in der Jerusalemer Altstadt. Lebensgeschichten und Alltag in einem engen urbanen Raum. Bielefeld: Campus.

Becker, Johannes/Rosenthal, Gabriele (in Vorbereitung). Ethnographie und Biographieforschung. Erscheint in: Angelika Poferl und Norbert Schröer (Hg.): Handbuch soziologische Ethnographie. Wiesbaden: Springer VS.

Becker, Johannes/Worm, Arne (2015). PalästinenserInnen in Ostjerusalem. In: Gabriele Rosenthal (Hg.): Etablierte und Außenseiter zugleich. Selbst- und Fremdbilder in den palästinensischen Communities im Westjordanland und in Israel. Frankfurt am Main: Campus, 149-165.

Benninghaus, Christina (2005). Das Geschlecht der Generation. Zum Zusammenhang von Generationalität und Männlichkeit um 1930. In: Ulrike Jureit und Michael Wildt (Hg.): Generationen. Zur Relevanz eines wissenschaftlichen Grundbegriffs. Hamburg: HIS Verlag, 127-159.

Benvenisti, Meron (1986). Demographic, Economic, Legal, Social and Political Developments in the West Bank. Boulder: Westview Press.

Ben-Ze'ev, Efrat (2011). Remembering Palestine in 1948: beyond national narratives. Cambridge [u.a.]: Cambridge University Press.

Berger, Peter L./Luckmann, Thomas (2007). Die gesellschaftliche Konstruktion der Wirklichkeit. Frankfurt am Main: Fischer.

Bisharat, George E. (1994). Displacement and Social Identity. Palestinian Refugees in the West Bank. In: Center for Migration Studies 11 (4), Special Issue: Population Displacement and Resettlement: Development and Conflict in the Middle East, 165-188.

Bogner, Artur (2003). Macht und Genese sozialer Gruppen. Sociologus 53 (2), $167-$ 181.

Bogner, Artur/Rosenthal, Gabriele (2017). Biographien - Diskurse - Figurationen. Methodologische Überlegungen aus einer sozialkonstruktivistischen und figurationssoziologischen Perspektive. In: Tina Spies und Elisabeth Tuider (Hg.): Biographie und Diskurs. Methodisches Vorgehen und methodologische Verbindungen von Biographie- und Diskursforschung. Wiesbaden: Springer VS, 43-67.

Böhme, Jörn/Sterzing, Christian (2012). Kleine Geschichte des israelisch-palästinensischen Konflikts. Schwalbach: Wochenschau Verlag.

Bohnenkamp, Björn (2011). Doing Generation. Zur Inszenierung von generationeller Gemeinschaft in deutschsprachigen Schriftmedien. Bielefeld: Transcript.

Bohnsack, Ralf (1998). Rekonstruktive Sozialforschung und der Grundbegriff des Orientierungsmusters. In: Dirk Siefkes, Peter Eulenhöfer, Heike Stach und Klaus Städtler (Hg.): Sozialgeschichte der Informatik. Kulturelle Praktiken und Orientierungen. Wiesbaden: Deutscher Universitätsverlag, 105-121. 
Bohnsack, Ralf (2017). Praxeologische Wissenssoziologie. Opladen/Toronto: Verlag Barbara Budrich.

Bohnsack, Ralf/Nentwig-Gesemann, Iris/Nohl, Arnd-Michael (2001). Die dokumentarische Methode und ihre Forschungspraxis. Grundlagen qualitativer Sozialforschung. Opladen: Leske + Budrich.

Bohnsack, Ralf/Schäffer, Burkhard (2002). Generation als konjunktiver Erfahrungsraum. Eine empirische Analyse generationsspezifischer Medienpraxiskulturen. In: Günter Burkart und Jürgen Wolf (Hg.): Lebenszeichen. Erkundungen zur Soziologie der Generationen. Opladen: Leske + Budrich, 249-273.

Bornstein, Avram (2001a). Ethnography and the Politics of Prisoners in PalestineIsrael. In: Journal of Contemporary Ethnography 30, 546-574.

Bornstein, Avram (2001b). Border Enforcement in Daily Life. Palestinian Day Laborers and Entrepreneurs Crossing the Green Line. In: Human Organization 60 (3), 298-307.

Böszörményi-Nagy, Iván (1981). Unsichtbare Bindungen. Die Dynamik familiärer Systeme. Stuttgart: Klett-Cotta.

Bowker, Robert (2003). Palestinian Refugees. Mythology, Identity and the Search for Peace. Boulder/London: Lynne Rienner Publishers.

Brand, Lauri A. (1988). Palestinians in the Arab World. Institution Building and the Search for State. New York: Columbia University Press.

Brandhorst, Rosa (2015). Migration und transnationale Familien im sozialen Wandel Kubas. Berlin: Springer.

Bröning, Michael (2013). Political Parties in Palestine. Leadership and Thought. New York: Palgrave Macmillan.

Brynen, Rex (1995). The Neopatrimonial Dimension of Palestinian Politics. In: Journal of Palestine Studies 25 (1), 23-36.

B'tselem (1994). Collaborators in the Occupied Territories. Human Rights Abuses and Violations. Jerusalem,

https://www.btselem.org/sites/default/files/publications/199401_collaborat ion_suspects_eng.pdf < letzter Zugriff: 20.6.2019>.

Bucaille, Laetitia (2004). Growing up Palestinian. Israeli Occupation and the Intifada Generation. Princeton: Princeton University Press.

Bude, Heinz (1987). Deutsche Karrieren. Lebenskonstruktionen sozialer Aufsteiger aus der Flakhelfer-Generation. Frankfurt am Main: Suhrkamp.

Bude, Heinz (2006). Fallrekonstruktionen. In: Ralf Bohnsack, Winfried Marotzki und Michael Meuser (Hg.). Hauptbegriffe qualitativer Sozialforschung. Opladen [u.a.]: Leske + Budrich, 60-61.

Bude, Heinz (2008). Qualitative Generationsforschung. In: Uwe Flick, Ernst von Kardorff und Ines Steinke (Hg.): Qualitative Forschung. Ein Handbuch. 6., durchges. und aktualisierte Auflage. Reinbek bei Hamburg: Rowohlt, 187-194. 
Caplan, Neil (2010). The Israel-Palestine Conflict. Contested Histories. Malden, MA [u.a.]: Wiley-Blackwell.

Challand, Benoit (2009). Palestinian Civil Society. Foreign Donors and the Power to Promote and Exclude. London [u.a.]: Routledge.

Christophersen, Mona/Høigilt, Jacob/Tiltnes, Åge A. (2012). In: Palestinian Youth and the Arab Spring. NOREF Report. NOREF Norwegian Peacebuilding Resource Centre, https://www.files.ethz.ch/isn/ 140730/ 562d62ccb 49d92227 b6865a8b2d11e1a.pdf <letzter Zugriff: 4.5.2019>.

Chronology MEJ (1988a). Chronology January 16, 1988 - April 15, 1988. In: Middle East Journal 42 (3), 447-478.

Chronology MEJ (1988b). Chronology October 16, 1988 - January 15, 1989. In: Middle East Journal 43 (2), 247-288.

Cohen, Michael J. (1982). Palestine and the Great Powers, 1945-1948. Princeton: Princeton University Press.

Collins, John (2004). Occupied by Memory. The Intifada Generation and the Palestinian State of Emergency. New York [u.a.]: New York University Press.

Coston, Bethany M./Kimmel, Michael (2012). Seeing Privilege Where it Isn't. Marginalized Masculinities and the Intersectionality of Privilege. In: Journal of Social Issues 68 (1), 97-111.

Crenshaw, Kimberle W. (1991). Mapping the Margins. Intersectionality, Identity Politics and Violence Against Women of Color. In: Stanford Law Review 43 (6), 1241-1299.

Damir-Geilsdorf, Sabine (2008). Die Nakba erinnern. Palästinensische Narrative des ersten arabisch-israelischen Kriegs 1948. Wiesbaden: Reichert.

Dausien, Bettina/Kelle, Helga (2009): Biographie und kulturelle Praxis. Methodologische Überlegungen zur Verknüpfung von Ethnographie und Biographieforschung. In: Gabriele Rosenthal, Bettina Völter, Bettina Dausien und Helma Lutz (Hg.): Biographieforschung im Diskurs. 2. Auflage. Wiesbaden: Springer VS, 189-212.

Doumani, Beshara B. (1992). Rediscovering Ottoman Palestine. Writing Palestinians into History. In: Journal of Palestine Studies 21 (2), 5-28.

Dunning, Eric/Hughes, Jason (2013). Norbert Elias and Modern Sociology. Knowledge, Interdependence, Power, Process. London: Bloomsbury Academic.

Elias, Norbert (1970). W as ist Soziologie?. München: Juventa.

Elias, Norbert (1977a). Über den Prozess der Zivilisation. Soziogenetische und psychogenetische Untersuchungen. Erster Band: Wandlungen des Verbaltens in den weltlichen Oberschichten des Abendlandes. 2. Auflage. Frankfurt am Main: Suhrkamp.

Elias, Norbert (1977b). Über den Prozess der Zivilisation. Soziogenetische und psychogenetische Untersuchungen. Zweiter Band: Wandlungen der Gesellschaft Entwurf zu einer Theorie der Zivilisation. 2. Auflage. Frankfurt am Main: Suhrkamp. 
Elias, Norbert (1977c). Zur Grundlegung einer Theorie sozialer Prozesse. In: Zeitschrift für Soziologie 6 (2), 127-149.

Elias, Norbert (1983). Engagement und Distanzierung. Arbeiten zur Wissenssoziologie I. Herausgegeben und übersetzt von Michael Schröter, Frankfurt am Main: Suhrkamp.

Elias, Norbert (1989). Studien über die Deutschen. Machtkämpfe und Habitusentwicklung im 19. und 20. Jahrhundert. Herausgegeben von Michael Schröter. Frankfurt am Main: Suhrkamp.

Elias, Norbert (1993). Mozart. Zur Soziologie eines Genies. Herausgegeben von Michael Schröter. 4. Auflage. Frankfurt am Main: Suhrkamp.

Elias, Norbert/Scotson, John L. (1993). Etablierte und Außenseiter. Übersetzt von Michael Schröter. Frankfurt am Main: Suhrkamp.

Eyerman, Ron/Turner, Bryan S. (1998). Outline of a Theory of Generations. In: European Journal of Social Theory 1 (1), 91-106.

Farsakh, Leila (2005). Palestinian Labour Migration to Israel. Labour, Land and Occupation. London [u.a.]: Routledge.

Farsakh, Leila (2009). Revisiting the Palestinian Economy after 40 Years of Israeli Occupation. Present Economic Realities and Future Challenges. In: Magda Seewald (Hg.): Conference Report. Perspectives Beyond War and Crisis II Food Aid, Poverty Administration and Development Policy in the Israeli-Palestinian Conflict, 17-38, http:/ /www.vidc.org/fileadmin/Bibliothek/DP/pdfs/

PalaestinaVA/Perspectives_beyond_War_and_Crisis_II.pdf < letzter Zugriff: 9.10.2016>.

Feldman, Ilana (2012). The Challenge of Categories. UNRWA and the Definition of a Palestine Refugee. In: Journal of Refugee Studies 25 (3), 387-406.

Fischer, Wolfram (1978). Struktur und Funktion erzählter Lebensgeschichten. In: Martin Kohli (Hg.): Soziologie des Lebenslaufs. Darmstadt/Neuwied: Luchterhand, 311-336.

Fischer-Rosenthal, Wolfram (1990). Von der „biographischen Methode“ zur Biographieforschung. Versuch einer Standortbestimmung. In: Peter Alheit, Wolfram Fischer-Rosenthal und Erika M. Hoerning (Hg.): Biographieforschung. Eine Zwischenbilanz in der deutschen Soziologie. Bremen: Universität Bremen, 9-32.

Fischer, Wolfram/Kohli, Martin (1987). Biographieforschung. In: Wolfgang Voges (Hg.): Methoden der Biographie- und Lebenslaufforschung. Opladen: Leske + Budrich, 25-49.

Fischer-Rosenthal, Wolfram/Rosenthal, Gabriele (1997). Warum Biographieanalyse und wie man sie macht. In: Zeitschrift für Sozialisationsforschung und Erziebungssoziologie 17, 405-427.

Fogt, Helmut (1982). Politische Generationen. Empirische Bedeutung und theoretisches Modell. Opladen: Westdeutscher Verlag. 
Frisch, Hillel (2008). The Palestinian Military. Between Militias and Armies. London [u.a.]: Routledge.

Gazit, Nir (2015). State-Sponsored Vigilantism. Jewish Settlers' Violence in the Occupied Palestinian Territories. In: Sociology 49 (3), 438-454.

Gazit, Shlomo (1995). The Carrot and the Stick. Israel's Policy in Judaea and Samaria, 1967-68. Washington [u.a.]: B'nai B'rith Books.

Giacaman, Rita/Johnson, Penny (1989). Palestinian Women. Building Barricades and Breaking Barriers. In: Zachary Lockman und Joel Beinin (Hg.): Intifada. The Palestinian Uprising against Israeli Occupation. Boston: South End Press, 155169.

Giacaman, Rita/Abdul-Rahim, Hanan F./Wick, Laura (2003). Health Sector Reform in the Occupied Palestinian Territories (OPT). Targeting the Forest or the Trees? In: Health Policy Plan 18 (1), 59-67.

Gieler, Wolfgang/Keller, Sabrina (2014). Jordanien. Eine Einfübrung in Politik und Geschichte unter besonderer Berücksichtigung der Ära Abdullah II. Berlin: Lit-Verlag.

Glaser, Barney G./Strauss, Anselm (2008 [1967]). The Discovery of Grounded Theory. Strategies for Qualitative Research. New Brunswick/London: Aldine.

Goffman, Erving (1975). Stigma. Über Techniken der Bewältigung beschädigter Identität. Frankfurt am Main: Suhrkamp.

Gordon, Neve (2008). From Colonization to Separation. Exploring the Structure of Israel's Occupation. In: Third World Quarterly 29 (1), 25-44.

Grandinetti, Tina (2015). The Palestinian Middle Class in Rawabi. Depoliticizing the Occupation. In: Alternatives: Global, Local, Political 40 (1), 1-16.

Gurwitsch, Aron (1975). Das Bewußtseinsfeld. Berlin [u.a.]: de Gruyter.

Hahn, Alois (1987). Identität und Selbstthematisierung. In: Alois Hahn und Volker Kapp (Hg.): Selbstthematisierung und Selbstzeugnis. Bekenntnis und Geständnis. Frankfurt am Main: Suhrkamp, 9-24.

Hajjar, Lisa (2005). Courting Conflict. The Israeli Military Court System in the West Bank and Gaza. Berkeley: University of California Press.

Halper, Jeff (2015). War Against the People. Israel, the Palestinians and Global Pacification. London: Pluto Press.

Hammami, Rema (1990). Women, the Hijab and the Intifada. In: Middle East Report (164-165), 24-28.

Hammami, Rema/Tamari, Salim (2001). The Second Uprising. End or New Beginning? In: Journal of Palestine Studies 30 (2), 5-25.

Hanafi, Sari (2007). The Sociology of Return. Palestinian Social Capital, Transnational Kinships and the Refugee Repatriation Process. In: Eyal Benvenisti, Chaim Gans und Sari Hanafi (Hg.): Israel and the Palestinian Refugees. Berlin/Heidelberg: Springer, 3-40. 
Hanafi, Sari (2009). Palestinian Refugee Camps in the Palestinian Territory. Territory of Exception and Locus of Resistance. In: Adi Ophir, Michal Giovanni und Sari Hanafi (Hg.): The Power of Inclusive Exclusion. Anatomy of Israeli Rule in the Occupied Palestinian Territories. New York: Zone Books, 495-517.

Hanafi, Sari (2010). Governing Palestinian Refugee Camps in the Arab East. Governmentalities in Search of Legitimacy. In: The Issam Fares Institute for Public Policy and International Affairs (IFI): Working Paper Series 1, $1-40$.

Hasso, Frances S. (2001). Feminist Generations? The Long-Term Impact of Social Movement Involvement on Palestinian Women's Lives. In: American Journal of Sociology 107 (3), 586-611.

Hasso, Frances S. (2005). Resistance, Repression, and Gender Politics in Occupied Palestine and Jordan. Syracuse: Syracuse University Press.

Heller, Mark (1980). Politics and Social Change in the West Bank Since 1967. In: Joel S. Migdal (Hg.): Palestinian Society and Politics. Princeton, N.J.: Princeton University Press, 185-211.

Herbert, Ulrich (2003). Generationenfolge in der deutschen Geschichte des 20. Jahrhunderts. In: Jürgen Reulecke (Hg.): Generationalität und Lebensgeschichte im 20. Jabrbundert. München: Oldenbourg, 95-114.

Heÿn, Hans M./Schroeder, Bastian (2015). An End to the Status Quo? A Contribution to the Normalisation and Anti-Normalisation Discourse in Palestinian Society. In: KAS INTERNATIONAL REPORTS 5, 95-109.

Hilal, Jamil (2010). The Polarization of the Palestinian Political Field. In: Journal of Palestine Studies 39 (3), 24-39.

Jamil Hilal (2014). What's Stopping the 3rd Intifada?. In: Al-Shabaka, https://alshabaka.org/commentaries/whats-stopping-the-3rd-intifada/<letzter Zugriff: 19.10.2016>.

Hiltermann, Joost R. (1990). Work and Action. The Role of the Working Class in the Uprising. In: Jamal R. Nasser und Roger Heacock (Hg.): Intifada. Palestine at the Crossroads. New York [u.a.]: Praeger Publishers, 143-157.

Hinrichsen, Hendrik (2017). Re-Marginalisierung der palästinensischen Flüchtlinge? Transformation von Wir-Bildern in der palästinensischen Gesellschaft im Westjordanland seit den 1970er Jahren. In: Österreichische Zeitschrift für Geschichtswissenschaften 28 (2), 74-99.

Hinrichsen, Hendrik/Rosenthal, Gabriele/Becker, Johannes (2015). Zum Brüchig-Werden des homogenisierenden Wir-Diskurses. Christen in Bethlehem und Ramallah. In: Gabriele Rosenthal (Hg.): Etablierte und Außenseiter zugleich Selbst- und Fremdbilder in den palästinensischen Communities im Westjordanland und in Israel. Frankfurt am Main/New York: Campus, 43-61. 
Hinrichsen, Hendrik/Rosenthal, Gabriele/Worm, Arne (2013). Biographische Fallrekonstruktionen. Zur Rekonstruktion der Verflechtung ,individueller“ Erfahrung, biographischer Verläufe, Selbstpräsentationen und „kollektiver“ Diskurse. PalästinenserInnen als RepräsentantInnen ihrer Wir-Bilder. In: Sozialer Sinn 14 (2), 157-184.

Hoffmann-Riem, Christa (1980). Die Sozialforschung einer interpretativen Soziologie. In: Kölner Zeitschrift für Soziologie und Sozialpsychologie 32 (2), 339-372.

Hofmann, Wilhelm (1996). Karl Mannheim zur Einführung. Hamburg: Junius Verlag.

Høigilt, Jacob (2016). Fatah from Below. The Clash of Generations in Palestine. In: British Journal of Middle Eastern Studies 43 (4), 456-471.

Honig-Parnass, Tikva/Haddad, Toufic (2007). Introduction. In: Dies. (Hg.): Between the Lines. Readings on Israel, the Palestinians, and the U.S. ,war on terror". Chicago: Haymarket Books, 17-54.

Honold, Alexander (2005). ,,Verlorene Generation“. Die Suggestivität eines Deutungsmusters zwischen Fin de siècle und Erstem Weltkrieg. In: Ohad Parnes, Ulrike Vedder und Sigrid Weigel (Hg.): Generation. Zur Genealogie des Konzepts Konzepte von Genealogie. Paderborn: Wilhelm Fink Verlag, 31-56.

Husserl, Edmund (1976): Noesis und Noema. In: Ders.: Ideen zu einer reinen Phänomenologie und phänomenologischen Philosophie I. Herausgegeben von Karl Schuhmann. Den Haag: Nijhoff, 200-224.

Ilieva, Radostina (2010). Soziologie und Lebensstil des Mannheim-Kreises in Frankfurt. In: Felicia Herrschaft und Klaus Lichtblau (Hg.): Soziologie in Frankfurt. Eine Zwischenbilanz: Wiesbaden: Springer VS, 123-140.

Inhetveen, Katharina (2012). Translation Challenges. Qualitative Interviewing in a Multi-Lingual Field. In: Qualitative Sociology Review 8 (2), 28-45.

Jabr, Hisham (1989). Housing Conditions in the Refugee Camps of the West Bank. In: Journal of Refugee Studies 2 (1), 75-87.

Jad, Islah (1998). Patterns of Relations within the Palestinian Family during the Intifada. In: Suha Sabbagh (Hg.): Palestinian Women of Gaza and West Bank. Bloomington, Ind.: Indiana University Press, 53-62.

Jad Islah (2007). NGOs. Between Buzzwords and Social Movements. In: Development in Practice 17 (4/5), 622-629.

Jad, Islah (2008). Palestinian Women's Movements. From Active Militants to Stateless Citizens. In: MIT Electronic Journal of Middle East Studies 8, 94-112.

Jean-Klein, Iris (2003). Into Committees, out of the House? Familiar Forms in the Organization of Palestinian Committee Activism during the First Intifada. In: American Ethnologist 30 (4), 556-577. 
Johnson, Penny (2012). In Search of the Social. Prisoners and the Poor in an Emerging Palestinian Social Contract. In: Review of Women's Studies 7, 85-95, http://iws.birzeit.edu/sites/default/ files/2016-

10/7th\%20issue_\%20English.pdf < letzter Zugriff: 27.03.19>.

Johnson, Penny/Abu Nahleh, Lamis/Moors, Annelies (2009). Weddings and War. Marriage Arrangements and Celebrations in Two Palestinian Intifadas. In: Journal of Middle East Women's Studies 5 (3), 11-35.

Johnson, Penny/Giacaman, Rita (2013). Our Life is Prison. The Triple Captivity of Wives and Mothers of Palestinian Political Prisoners. In: Journal of Middle East Women's Studies 9 (3), 54-80.

Jõesalu, Kirsti (2016). We Were the Children of a Romantic Era. Nostalgia and the Nonideological Everyday Through the Perspective of a 'Silent Generation'. In: Journal of Baltic Studies 47 (4), 557-577.

Jureit, Ulrike (2013). „Eigentlich geht es um Strahlkraft“. Ein Gespräch mit Ulrike Jureit über Generationen. In: INDES 4, 8-18.

Kårtveit, Bård (2008). A Regime of Uncertainty: Rights of Residency in the Occupied West Bank. In: Review of Women's Studies. Special Issue 1, 24-34.

Kaschl, Elke (2003). Dance and Authenticity in Israel and Palestine. Performing the Nation. Leiden/Boston: Brill.

Kassem, Fatma (2011). Palestinian Women. Narrative Histories and Gendered Memory. London: Zed Books.

Kassir, Samir (2011). Beirut. Berkeley, Calif. [u.a.]: University of California Press.

Kelly, Tobias (2008). The Attractions of Accountancy. Living an Ordinary Life during the Second Palestinian Intifada. In: Ethnography 9 (3), 351-376.

Kettler, David/Meja, Volker/Stehr, Nico (1980). Karl Mannheims frühe kultursoziologische Arbeiten. In: Karl Mannheim: Strukturen des Denkens. Herausgegeben von David Kettler, Volker Meja, Nico Stehr. Frankfurt am Main: Suhrkamp, 9-31.

Kettler, David/Meja, Volker/Stehr, Nico (1984). Karl Mannheim and Conservatism. The Ancestry of Historical Thinking. In: American Sociological Review 49 (1), 71-85.

Khalidi, Walid (1992). All That Remains. The Palestinian Villages Occupied and Depopulated by Israel in 1948. Washington: Institute for Palestine Studies.

Kilminster, Richard (1993). Norbert Elias and Karl Mannheim. Closeness and Distance. In: Theory, Culture \& Society 10 (3), 81-114.

Kilminster, Richard (2007). Norbert Elias. Post-philosophical Sociology. London [u.a.]: Routledge.

Kimmerling, Baruch/Migdal, Joel S. (2003). The Palestinian People. A History. Cambridge/London: Harvard University Press. 
Knoblauch, Hubert (2001). Fokussierte Ethnographie. Soziologie, Ethnologie und die neue Welle der Ethnographie. In: Sozialer Sinn 2 (1), 123-141.

Kohli, Martin (1978). Soziologie des Lebenslaufs. Darmstadt/Neuwied: Luchterhand.

Kohli, Martin/Szydlic, Marc (2000). Einleitung. In: Martin Kohli und Marc Szydlic (Hg.): Generationen in Familie und Gesellschaft. Opladen: Leske + Budrich, 718.

Kossaifi, George (1980). Demographic Characteristics of the Arab Palestinian People. In: Khalil Nakhleh und Elia Zureik (Hg.): The Sociology of the Palestinians. London: Croom Helm, 13-46.

Köttig, Michaela (2004). Lebensgeschichten rechtsextrem orientierter Mädchen und junger Frauen: biographische Verläufe im Kontext der Familien- und Gruppendynamik. GieBen: Psychosozial-Verlag.

Köttig, Michaela (2018). Biographie- und Interaktionsanalyse. In: Helma Lutz, Martina Schiebel und Elisabeth Tuider (Hg.): Handbuch Biographieforschung. 2., korrigierte Auflage. Wiesbaden: Springer VS, 525-535.

Krämer, Gudrun (2006). Geschichte Palästinas. 5. Auflage. München: C.H.Beck.

Krieger, Helmut (2015). Umkämpfte Staatlichkeit. Palästina zwischen Besatzung, Entwicklung und politischem Islam. Wiesbaden: Springer VS.

Kuttab, Daoud (1988). A Profile of the Stonethrowers. In: Journal of Palestine Studies 17 (3), 14-23.

Latte-Abdallah, Stéphanie (2011). Exile, Familial Ideology, and Gender Roles in Palestinian Camps in Jordan, 1948-2001. In: Christopher H. Johnson, David Warren Sabean, Simon Teuscher und Francesca Trivellato (Hg.): Transregional and Transnational Families in Europe and Beyond. Experiences Since the Middle Ages. New York [u.a.]: Berghahn Books, 271-294.

Laube, Reinhard (2004). Karl Mannheim und die Krise des Historismus. Historismus als wissenssoziologischer Perspektivismus. Göttingen: Vandenhoeck \& Ruprecht.

Lesch, Ann M. (1979). Israeli Deportation of Palestinians from the West Bank and the Gaza Strip, 1967-1978. In: Journal of Palestine Studies 8 (2), 101-131.

Lewin, Kurt (1967 [1927]). Gesetz und Experiment in der Psychologie. Sonderausgausgabe, unveränd. reprogr. Nachdruck. Darmstadt: Wissenschaftliche Buchgesellschaft.

Lia, Brynjar (2006). A Police Force Without a State. A History of the Palestinian Security Forces in the West Bank and Gaza. Reading: Ithaca Press.

Liebau, Eckart (1997). Generation - ein aktuelles Problem?. In: Ders. (Hg.): Das Generationenverbältnis. Über das Zusammenleben in Familie und Gesellschaft. Weinheim/München: Juventa, 15-37. 
Luckmann, Thomas (2003). Von der alltäglichen Erfahrung zum sozialwissenschaftlichen Bewusstsein. In: Ilja Srubar/Steven Vaitkus (Hg.): Phänomenologie und soziale Wirklichkeit. Entwicklungen und Arbeitsweisen. Opladen: Leske + Budrich, 13-26.

Lüders, Christian (2008). Beobachtungen im Feld und Ethnographie. In: Uwe Flick, Ernst von Kardorff und Ines Steinke (Hg.): Qualitative Forschung. Ein Handbuch. 6., durchges. und aktualisierte Auflage. Reinbek bei Hamburg: Rowohlt, 384-401.

Lybarger, Loren D. (2005). Palestinian Political Identities during the Post-Oslo Period. A Case Study of Generation Effects in a West Bank Refugee Camp. In: Social Compass 52 (2), 143-156.

Lybarger, Loren D. (2007). Identity and Religion in Palestine. The Struggle Between Islamism and Secularism in the Occupied Territories. Princeton/New Jersey: Princeton University Press.

Maira, Sunaina (2013). Jil Oslo. Palestinian Hip Hop, Youth Culture, and the Youth Movement. Washington, DC: Tadween Publ.

Maira, Sunaina (2017). Freedom is a Daily Practice. The Palestinian Youth Movement and Jil Oslo. In: Mark Muhannad Ayyash und Ratiba HadjMoussa (Hg.): Protests and Generations. Legacies and Emergences in the Middle East, North Africa and the Mediterranean. Leiden/Boston: Brill, 171-197.

Maiwald, Kai-Olaf (2013). Der Mikroskopische Blick. Rekonstruktion in der Objektiven Hermeneutik. In: Sorialer Sinn (2), 185-205.

Mannheim, Karl (1952). Ideologie und Utopie. 3., vermehrte Auflage. Frankfurt am Main: Schulte-Bulmke.

Mannheim, Karl (1964). Wissenssoziologie: Auswabl aus dem Werk. Eingeleitet und herausgegeben von Kurt H. Wolff. Berlin [u.a.]: Luchterhand.

Mannheim, Karl (1980). Strukturen des Denkens. Herausgegeben von David Kettler, Volker Meja und Nico Stehr. Frankfurt am Main: Suhrkamp.

Mannheim, Karl (2009 [1928]). Die Bedeutung der Konkurrenz im Gebiete des Geistigen. In: Karl Mannheim: Schriften zur Wirtschafts- und Kultursoziologie. Herausgegeben von Amalia Barboza und Klaus Lichtblau. Wiesbaden: Springer VS, 81-120.

Mansour, Sylvie (1996). The Intifada Generation in the Schoolroom. In: Prospects $26(2), 293-310$.

Ma'oz, Moshe (1984). Palestinian Leadership on the Westbank. The Changing Role of the Arab Mayors under Jordan and Israel. London/Totowa: Frank Cass.

Massad, Joseph A. (2001). Colonial Effects. The Making of National Identity in Jordan. New York [u.a.]: Columbia University Press. 
Matthes, Joachim (1985a). Karl Mannheims „Das Problem der Generationen“, neu gelesen. Generationen-,,Gruppen“ oder ,gesellschaftliche Regelung von Zeitlichkeit“?. In: Zeitschrift für Soriologie 14 (5), 363-372.

Matthes, Joachim (1985b). Zur transkulturellen Relativität erzählanalytischer Verfahren in der empirischen Sozialforschung. In: Kölner Zeitschrift für Soziologie und Sozialpsychologie 37 (2), 310-326.

Meuser, Michael (2005). Strukturübungen. Peergroups, Risikohandeln und die Aneignung des männlichen Geschlechtshabitus. In: Vera King und Karin Flaake (Hg.): Männliche Adoleszenz: Sozialisation und Bildungsprozesse zuischen Kindheit und Erwachsensein. Frankfurt am Main: Campus, 309-323.

Miaari, Sami H./Sauer, Robert M. (2006). The Labor Market Costs of Conflict. Closures, Foreign Workers and Palestinian Employment and Earnings. In: IZA Discussion Paper 2282, http://repec.iza.org/dp2282.pdf <letzter Zugriff: 10.09.2016>.

Migdal, Joel S. (1980). Palestinian Society and Politics. New Jersey: Princeton University Press.

Milton-Ewards, Beverly/Farrell, Stephen (2010). Hamas. The Islamic Resistance Movement. Cambridge: Polity Press.

Mishal, Shaul (1978). West Bank/East Bank. The Palestinians in Jordan, 1949-1967. New Haven/London: Yale University Press.

Misselwitz, Philipp (2010). Palästinensische Flüchtlingslager neu denken. Von Abhängigkeit zu ziviler Selbstverwaltung. In: Margarete Misselwitz und Klaus Schlichte (Hg.): Politik der Unentschiedenheit. Die internationale Politik und ihr Umgang mit Kriegsflüchtlingen. Bielefeld: Transcript, 197-234.

Morris, Benny (1988). The Birth of the Palestinian Refugee Problem, 1947-1949. Cambridge: Cambridge University Press.

Morris, Benny (2004). The Birth of the Palestinian Refugee Problem Revisited. Cambridge: Cambridge University Press, 2004.

Musallam, Adnan (2006). Palestinian Diaspora in Latin America. The Formative Stages, 19th Century to Early 20th Century. Bethlehem, http://admusallam.bethlehem.edu/conf-workshop/pdla.htm <letzter Zugriff: $6.8 .2014>$.

Nashif, Esmail (2008). Palestinian Political Prisoners. Identity and Community. London [u.a.]: Routledge.

Neslen, Arthur (2011). In Your Eyes a Sandstorm. Ways of Being Palestinian. Berkeley: University of California Press.

Niethammer, Lutz (2009). Die letzte Gemeinschaft. Über die Konstruierbarkeit von Generationen und ihre Grenzen. In: Bernd Weisbrod (Hg.): Historische Beiträge zur Generationsforschung. Göttingen: Wallstein, 13-38. 
Norman, Julie M. (2010). The Second Palestinian Uprising. Civil Resistance. London [u.a.]: Routledge.

Oevermann, Ulrich/Allert, Tilman/Konau, Elisabeth/Krambeck, Jürgen (1979). Die Methodologie einer „objektiven Hermeneutik“ und ihre allgemeine Bedeutung in den Sozialwissenschaften. In: Hans-Georg Soeffner (Hg.): Interpretative Verfahren in den Sozial- und Textwissenschaften. Stuttgart: Metzler, 352-434.

Oevermann, Ulrich (1981). Fallrekonstruktionen und Strukturgeneralisierung als Beitrag der objektiven Hermeneutik zur soziologisch-strukturtheoretischen Analyse, Frankfurt am Main, unveröffentlichtes Manuskript, http://publikationen.ub.uni-frankfurt.de/volltexte/2005/537 <letzter Zugriff: 3.5.2019>.

Oevermann, Ulrich (1986). Kontroversen über sinnverstehende Soziologie. Einige wiederkehrende Probleme und Mißverständnisse in der Rezeption der „objektiven Hermeneutik“. In: Stefan Aufenhanger und Margit Lenssen (Hg.): Handlung und Sinnstruktur. Bedeutung und Anwendung der Objektiven Hermeneutik. München: Peter Kindt Verlag, 19-83.

Oevermann, Ulrich (1991). Genetischer Strukturalismus und das sozialwissenschaftliche Problem der Erklärung der Entstehung des Neuen. In: Steffen Müller-Doohm (Hg.): Jenseits der Utopie. Theoriekritik der Gegenwart. Frankfurt am Main: Suhrkamp, 267-336.

Oevermann, Ulrich (1996). Theoretische Skizze einer revidierten Theorie professionalisierten Handelns. In: Arno Combe und Werner Helsper (Hg.): Pädagogische Professionalität. Untersuchungen zum Typus pädagogischen Handelns. Frankfurt am Main: Suhrkamp, 70-182.

Oevermann, Ulrich (2000). Die Methode der Fallrekonstruktion in der Grundlagenforschung sowie der klinischen und pädagogischen Praxis. In: Klaus Kraimer (Hg.): Die Fallrekonstruktion. Frankfurt am Main: Suhrkamp, 58-153.

Olmsted, Jennifer C. (2008). Post-Oslo Palestinian (Un)Employment. A Gender, Class, and Age-Cohort Analysis. In: The Economics of Peace and Security Journal 3 (2), 33-38.

Palestinian Central Bureau of Statistics (2014). Statistical Abstract of Palestine 15. Ramallah.

Palestinian Central Bureau of Statistics (2016). Palestinian Youth Survey. 2015 Main Findings. Ramallah, http://www.pcbs.gov.ps/Downloads/book2179.pdf $<$ letzter Zugriff: 10.9.2016>.

Palestine Economic Policy Research Institute (MAS) (2007). Mapping Palestinian Non-Governmental Organizations in the West Bank and the Gaza Strip. Ramallah, http://www.palestineeconomy.ps/files/server/20151405162310-2.pdf <letzter Zugriff: 1.7.2018>.

Pape, Elise (2016). Transmissions Intergénérationnelles dans des Familles d'Origine Marocaine en France et en Allemagne. „L a Fierté d'être Soi“. Paris: L'Harmattan. 
Pappe, Ilan (2006). The Ethnic Cleansing of Palestine. Oxford: Oneworld Publications.

Parsons, Nigel (2005). The Politics of the Palestinian Authority. From Oslo to al-Aqsa. New York [u.a.]: Routledge.

Pasquetti, Silvia (2012). The Reconfiguration of the Palestinian National Question. The Indirect Rule Route and the Civil Society Route. In: Political Power and Social Theory (23), 103-146.

Peretz, Don (1977). Palestinian Social Stratification. The Political Implications. In: Journal of Palestine Studies 7 (1), 48-74.

Peteet, Julie (1994). Male Gender and Rituals of Resistance in the Palestinian „Intifada“. A Cultural Politics of Violence. In: American Ethnologist 21 (1), 31-49.

Peukert, Detlev J. K. (1985). Die Erwerbslosigkeit junger Arbeiter in der Weltwirtschaftskrise in Deutschland 1929-1933. In: Vierteljahrsschrift für Sozial- und Wirtschaftsgeschichte 72 (3), 305-328.

Plascov, Avi (1981). The Palestinian Refugees in Jordan, 1948-1957. London: Frank Cass.

Pierce, Charles S. (1980 [1933]). Collected Papers. Herausgegeben von Charles Hartshorne und Paul Weiss. Cambridge: Belknap.

Pollack, Kenneth M. (2002). Arabs at War. Military Effectiveness, 1948-1991. Lincoln/London: University of Nebraska Press.

Qumsiyeh, Mazin B. (2011). Popular Resistance in Palestine. A History of Hope and Empowerment. London/ New York: Pluto Press.

Rabinowitz, Dan/Abu-Baker, Khawla (2005). Coffins on Our Shoulders. The Experience of the Palestinian Citizens of Israel. Berkeley: University of California Press.

Radenbach, Niklas/Rosenthal, Gabriele (2012). Das Vergangene ist auch Gegenwart, das Gesellschaftliche ist auch individuell. Zur Notwendigkeit der Analyse biographischer und historischer ,Rahmendaten'. In: Sozialer Sinn 13 (1), 338.

Rehberg, Karl-Siegbert (1979). Form und Prozeß. Zu den katalysatorischen Wirkungschancen einer Soziologie aus dem Exil. Norbert Elias. In: Peter Gleichmann, Johan Goudsblom und Hermann Korte (Hg.): Materialien zu Norbert Elias' Zivilisationstheorie. Frankfurt am Main: Suhrkamp, 101-169.

Reichertz, Jo (2011). Die Sequenzanalyse in der Hermeneutik. Unkorrigiertes Manuskript für das Methodenfestival in Basel, http://www.soziologieley.eu/mediapool/112/1129541/data/Sequenzanalyse.pdf <letzter Zugriff: 4.7.20>.

Reichertz, Jo (2016). Qualitative und interpretative Sozialforschung. Eine Einladung. Wiesbaden: Springer VS.

Rintala, Martin (1968). Generations. Political Generations. In: The International Encyclopedia of the Social Sciences 6, 88-96. 
Robinson, Glen E. (1993). The Role of the Professional Middle Class in the Mobilization of Palestinian Society. The Medical and Agricultural Committees. In: International Journal of Middle East Studies 25 (2), 301-326.

Robinson, Glen E. (1997). Building a Palestinian State. The Incomplete Revolution. Bloomington/Indianapolis: Indiana University Press.

Roseman, Mark (2005). Generationen als „Imagined Communities“. Mythen, generationelle Identitäten und Generationenkonflikte in Deutschland vom 18. bis zum 20. Jahrhundert. In: Ulrike Jureit und Michael Wildt (Hg.): Generationen. Zur Relevanz eines wissenschaftlichen Grundbegriffs. Hamburg: HIS Verlag, 180199.

Rosenfeld, Maya (2002). Power Structure, Agency, and Family in a Palestinian Refugee Camp In: International Journal of Middle East Studies 34 (3), 519-551.

Rosenfeld, Maya (2004). Confronting the Occupation. Work, Education, and Political Activism of Palestinian Families in a Refugee Camp. Stanford: Stanford University Press.

Rosenthal, Gabriele (1987). ,... wenn alles in Scherben fällt ... “. Von Leben und Sinnwelt der Kriegsgeneration. Opladen: Leske + Budrich.

Rosenthal, Gabriele (1995). Erlebte und erzählte Lebensgeschichte. Gestalt und Struktur biographischer Selbstbeschreibungen. Frankfurt am Main [u.a.]: Campus-Verlag.

Rosenthal, Gabriele (1997). Zur interaktionellen Konstitution von Generationen. Generationen-abfolgen in Familien von 1890-1970 in Deutschland. In: Jürgen Mansel, Gabriele Rosenthal und Angelika Tölke (Hg.): GenerationenBeziehungen, Austausch und Tradierung. Opladen: Westdeutscher Verlag, 57-73.

Rosenthal, Gabriele (2000). Historische und familiale Generationsabfolgen. In: Martin Kohli und Marc Szydlic (Hg.): Generationen in Familie und Gesellschaft. Opladen: Leske + Budrich, 162-179.

Rosenthal, Gabriele (2009). Die Biographie im Kontext der Familien- und Gesellschaftsgeschichte. In: Bettina Völter, Bettina Dausien, Helma Lutz und Gabriele Rosenthal (Hg.): Biographieforschung im Diskurs. 2. Auflage. Wiesbaden: Springer VS, 46-64.

Rosenthal, Gabriele (2010). Die erlebte und erzählte Lebensgeschichte. Zur Wechselwirkung zwischen Erleben, Erinnern und Erzählen. In: Birgit Griese (Hg.): Subjekt - Identität - Person? Reflexionen zur Biographieforschung. Wiesbaden: Verlag für Sozialwissenschaften, 197-218.

Rosenthal, Gabriele (2011). Interpretative Sozialforschung. Eine Einfübrung. 3., aktualisierte und erg. Auflage. Weinheim [u.a.]: Juventa.

Rosenthal, Gabriele (2012). Methodische Herausforderungen interkultureller Studien. Mehrfach verschränkte Figurationen von Etablierten und Außenseitern im Westjordanland. In: Zeitschrift für Qualitative Forschung 13 (1/2), 125-149. 
Rosenthal, Gabriele (Hg.) (2015). Etablierte und Außenseiter zugleich. Selbst- und Fremdbilder in den palästinensischen Communities im Westjordanland und in Israel. Frankfurt am Main/New York: Campus.

Rosenthal, Gabriele/Albaba, Ahmad (2015). Stimmen von ehemaligen politischen Häftlingen und von ihren Familien im Westjordanland. In: Gabriele Rosenthal (Hg.): Etablierte und Außenseiter zugleich - Selbst-und Fremdbilder in den palästinensischen Communities im Westjordanland und in Israel. Frankfurt am Main/ New York: Campus, 117-145.

Rosenthal, Gabriele/Hinrichsen, Hendrik (2017). Biographie und Familie. In: Helma Lutz, Martina Schiebel und Elisabeth Tuider (Hg.): Handbuch Biographieforschung. Wiesbaden: Springer, 245-255.

Rosenthal, Gabriele/Hinrichsen, Hendrik/Becker, Johannes (2015). Zur interaktiven und kollektiven (Selbst-)Vergewisserung eines brüchig werdenden WirBildes. "Wir Christen in Palästina haben keine Konflikte mit den Muslimen!" In: Sven Grebenstein und Sidney H. Griffith (Hg.): Christsein in der islamischen Welt. Festschrift für Martin Tamcke. Wiesbaden: Harrassowitz Verlag, 567-586.

Rothenberg, Celia E. (1999). A Review of the Anthropological Literature in English on the Palestinian Hamula and the Status of Women. In: The Journal of Arabic and Islamic Studies 2 (2), 24-48.

Roy, Sara (1987). The Gaza Strip. A Case of Economic De-Development. In: Journal of Palestine Studies 17 (1), 56-88.

Sabbagh, Suha (1998). Palestinian Women of Gaza and West Bank. Bloomington, Ind.: Indiana University Press.

Sahliyeh, Emile (1988). In Search of Leadership. West Bank Politics since 1967. Washington, D.C.: The Brookings Inst.

Sawalha, Aseel (1996). Identity, Self and the Other Among Palestinian Refugees in East Amman. In: Jean Hannoyer und Seteney Shami (Hg.): Amman. The City and its Society. Beirut: CERMOC.

Sayigh, Rosemary (1979). Palestinians. From Peasants to Revolutionaries. London: Zed Press.

Sayigh, Yezid (1989). The Intifadah Continues. Legacy, Dynamics and Challenges. In: Third World Quarterly 11 (3), 20-49.

Sayigh, Yezid (2011). Policing the People, Building the State. Authoritarian Transformation in the West Bank and Gaza. In: The Carnegie Papers, https://carnegieendowment.org/files/ gaza_west_bank_security.pdf < letzter Zugriff: 10.9.2018>.

Sa'di, Ahmad H./Abu-Lughod, Lila (2007a). Introduction. The Claims of Memory Nakba. In: Dies. (Hg.): Palestine, 1948, and the Claims of Memory. New York: Columbia Univ. Press, 1-24.

Sa'di, Ahmad H./Abu-Lughod, Lila (2007b). Palestine, 1948, and the cCaims of Memory. New York: Columbia Univ. Press. 
Schäbler, Birgit (2011). Vertreibung, Nostalgie und nationales Bewusstsein. Das Land (al - ard) im politischen Gedächtnis der Generationen. In: Heinrich Böll Stiftung und Christian Sterzing (Hg.): Palästina und die Palästinenser. 60 Jabre nach der Nakba. Heinrich Böll Stiftung, 62-85, http://www.boell.de/downloads/ Palaestina_und_die_Palaestinenser_ kommentierbar.pdf < letzter Zugriff: 09.09.13>.

Schütz, Alfred (1971). Wissenschaftliche Interpretation und Alltagsverständnis menschlichen Handelns. In: Ders.: Gesammelte Aufsätz̧ I, Den Haag: Nijhoff, 3-54.

Schütz, Alfred/Luckmann, Thomas (1975). Strukturen der Lebenswelt. Neuwied/Darmstadt: Luchterhand.

Schütze, Fritz (1977). Die Technik des narrativen Interviews in Interaktionsfeldstudien. Arbeitsberichte und Forschungsmaterialien No. 1, Universität Bielefeld, Fakultät für Soziologie.

Schütze, Fritz (1976). Zur Hervorlockung und Analyse von Erzählungen thematisch relevanter Geschichten im Rahmen soziologischer Feldforschung. Dargestellt an einem Projekt zur Erforschung von kommunalen Machtstrukturen. In: Ansgar Weymann (Hg.): Kommunikative Sozialforschung: Alltagswissen und Alltagshandeln, Gemeindemachtforschung, Polizei, politische Erwachsenenbildung. München: Fink, 159-260.

Schütze, Fritz (1983). Biographieforschung und narratives Interview. In: Neue Praxis 13 (3), 283-293.

Schütze, Fritz (1984). Kognitive Figuren des autobiographischen Stegreiferzählens. In: Martin Kohli und Günther Robert (Hg.): Biographie und Soziale Wirklichkeit: neue Beiträge und Forschungsperspektiven. Stuttgart: Metzler, 78-117.

Schütze, Fritz (1987). Das narrative Interview in Interaktionsfeldstudien I. Studienbrief der Fern-Universität Hagen.

Schütze, Fritz (2006). Verlaufskurven des Erleidens als Forschungsgegenstand der interpretativen Soziologie. In: Heinz-Hermann Krüger und Winfried Marotzki (Hg.): Handbuch erziehungswissen-schaftliche Biographieforschung. Wiesbaden: Springer VS, 205-237.

Shamir Shimon (1980). West Bank Refugees. Between Camp and Society. In: Joel S. Migdal (Hg.): Palestinian society and politics. New Jersey: Princeton University Press, 146-165.

Shapira, Anita (2015). Israel. A History. London: Weidenfeld \& Nicolson.

Shlaim, Avi (2008). Lion of Jordan. The Life of King Hussein in War and Peace. London: Penguin.

Silies, Eva-Maria (2009). Die stille Generation mit der Pille. Verhütung als weibliche Generationserfahrung in England und der Bundesrepublik (1960-1975). In: Bernd Weisbrod (Hg.): Historische Beiträge zur Generationsforschung. Göttingen: Wallstein-Verlag, 77-116. 
Silver, Efrat (2010). Israel's Policy of House Demolitions During the First Intifada, 1987-1993. In: Terrorism and Political Violence 23 (1), 89-107.

Singerman, Diane (2011). The Negotiation of Waithood. The Political Economy of Delayed Marriage in Egypt. In: Samir Khalaf und Roseanne S. Khalaf (Hg.): Arab Youth. Social Mobilisation in Times of Risk. London: Saqi, 67-78.

Soeffner, Hans-Georg/Hitzler, Ronald (1994). Hermeneutik als Haltung und Handlung. Über methodisch kontrolliertes Verstehen. In: Norbert Schröer (Hg.): Interpretative Sozialforschung. Auf dem Wege zu einer hermeneutischen Wissenssoriologie. Opladen: Westdeutscher Verlag, 28-54.

Spradley, James P. (1980). Participant Observation. New York [u.a.]: Holt, Rinehart \& Winston.

Srubar, Ilja (1979). Die Theorie der Typenbildung bei Alfred Schütz. Ihre Bedeutung und ihre Grenzen. In: Walter M. Sprondel und Richard Grathoff (Hg.): Alfred Schütz und die Idee des Alltags in den Sozialwissenschaften. Stuttgart: Ferdinand Enke Verlag, 43-64.

Swedenburg, Ted (2003). Memories of Revolt. 1936-1939 Rebellion in the Palestinian Past. Fayetteville: University of Arkansas Press.

Tamari, Salim (1983). In League with Zion. Israel's Search for a Native Pillar. In: Journal of Palestine Studies 12 (4), 41-56.

Tamari, Salim (1990). The Revolt of the Petite Bourgeoisie. Urban Merchants and the Palestinian Uprising. In: Jamal R. Nassar und Roger Heacock (Hg.): Intifada. Palestine at the Crossroads. New York [u.a.]: Praeger, 159-174.

Taraki, Lisa (2008). Urban Modernity on the Periphery. A New Middle Class Reinvents the Palestinian City. In: Social Text 26 (2), 61-81.

Taraki, Lisa/Giacaman, Rita (2006). Modernity Aborted and Reborn. Ways of being urban in Palestine. In: Lisa Taraki (Hg.): Living Palestine. Family Survival, Resistence, and Mobility under Occupation. New York: Syracuse University Press, $1-51$.

Tartir, Alaa (2017). Criminalizing Resistance. The Cases of Balata and Jenin Refugee Camps. In: Journal of Palestine Studies 46 (2), 7-22.

Tessler, Mark (2009). A History of the Israeli-Palestinian Conflict. Bloomington: Indiana University Press.

Thomas, William I./Znaniecki, Florian (1918). The Polish Peasant in Europe and America. Monograph of an Immigrant Group. Boston: R.G. Badger.

Tolan, Sandy (2007). The Lemon Tree. The True sSory of a Friendship Spanning Four Decades of Israeli-Palestinian Conflict. London: Bantam Press.

Turner, Mandy (2014). The Political Economy of Western Aid in the Occupied Palestinian Territory Since 1993. In: Mandy Turner und Omar Shweiki (Hg.): Decolonizing Palestinian Political Economy: De-development and Beyond. Basingstoke [u.a.]: Palgrave Macmillan, 32-52. 
Tushyeh, Hanna (1999). The Education System in the Bethlehem Area. In: AlLiqa' Journal 13, 65-84.

Van Krieken, Robert (1998). Norbert Elias. London [u.a.]: Routledge.

Vatikiotis, Panayiotis J. (1967). Politics and the Military in Jordan. A Study of the Arab Legion 1921-1957. Guildford/London: Frank Cass.

Walsh, David (2004). Doing Ethnography. In: Clive Seale (Hg.): Researching Society and Culture. 2. Ausgabe. London [u.a.]: Sage, 225-237.

Weber, Max (1982). Die Objektivität sozialwissenschaftlicher und sozialpolitischer Erkenntnis. In: Ders. (Hg.): Gesammelte Aufsätze Wissenschaftslehre. Herausgegeben von Johannes Winckelmann. 5., erneut durchgesehene Auflage. Tübingen: Mohr, 146-214.

Weisbrod, Bernd (2005). Generation und Generationalität in der Neueren Geschichte. In: Aus Politik und Zeitgeschichte 8, 3-9.

Weisbrod, Bernd (2007). Cultures of Change. Generations in the Politics and Memory of Modern Germany. In: Stephen Lovell (Hg.): Generations in twentieth-century Europe. Houndmills [u.a.]: Palgrave Macmillan, 19-35.

Weizmann, Eyal (2007). Hollow Land. Israel's architecture of occupation. London/New York: Verso.

Wernet, Andreas (2006). Einführung in die Interpretationstechnik der Objektiven Hermeneutik. 2. Auflage. Opladen: Leske + Budrich.

Wertheimer, Max (1922): Untersuchungen zur Lehre von der Gestalt. In: Psychologische Forschung 1, 47-58.

White, Jonathan (2013). Thinking Generations. In: British Journal of Sociology 64 (2), 216-247.

Wick, Livia (2011). The Practice of Waiting under Closure in Palestine. In: City \& Society 23 (1), $24-44$.

Wohlrab-Sahr, Monika (2015). Theorie fürs Große, Methoden fürs Kleine? Überlegungen zum methodisch gestützten Stabhochsprung in der Kultursoziologie. In: Sociologia Internationalis 53 (1), 1-19.

Wolff, Kurt H. (1964). Karl Mannheim in seinen Abhandlungen bis 1933. In: Karl Mannheim: Wissenssoziologie: Auswabl aus dem Werk. Eingeleitet und herausgegeben von Kurt H. Wolff. Berlin [u.a.]: Luchterhand, 166-235.

Wolff, Kurt H. (1978). Karl Mannheim. In: Dirk Käsler (Hg.): Klassiker des soziologischen Denkens II. Von Weber bis Mannbeim. München: Beck, 286-387.

Wolff, Stephan (2008). Wege ins Feld und ihre Varianten. In: Uwe Flick, Ernst von Kardorff und Ines Steinke (Hg.): Qualitative Forschung. Ein Handbuch. Hamburg, 334-349. 
Worm, Arne/Hinrichsen, Hendrik (2015). Das Sprechen von Außenseitern. Gegendiskurse, Selbst- und Wir-Bilder stigmatisierter schwuler Männer im Westjordanland. In: Gabriele Rosenthal (Hg.): Etablierte und Außenseiter zugleich Selbst- und Fremdbilder in den palästinensischen Communities im Westjordanland und in Israel. Frankfurt am Main/New York: Campus, 91-116.

Worm, Arne/Hinrichsen, Hendrik/Albaba, Ahmed (2015). Der homogenisierende Wir-Diskurs und die gesellschaftliche Positionierung der Flüchtlingslager. In: Gabriele Rosenthal (Hg.): Etablierte und Außenseiter zugleich - Selbst- und Fremdbilder in den palästinensischen Communities im Westjordanland und in Israel. Frankfurt am Main/New York: Campus, 63-90.

Yahya, Adil (1990). The Role of the Palestinian Refugee Camps. In: Jamal R. Nassar und Roger Heacock (Hg.): Intifada. Palestine at the Crossroads. New York [u.a.]: Praeger, 91-106.

Zureik, Elia (1980). Reflections on Twentieth-Century Palestinian Class Structure. In: Khalil Nakhleh und Elia Zureik (Hg.): The Sociology of the Palestinians. London: Croom Helm, 47-63. 
n den letzten 50 Jahren veränderte sich die palästinensische Gesellschaft im Westjordanland tiefgreifend. Die israelische Besatzung ab 1967, die politische Mobilisierung der 1970er und 1980er Jahre und der sogenannte Friedensprozess ab den 1990er Jahren gingen mit massiven gesellschaftlichen Transformationen einher, die nicht nur die israelisch-palästinensische Konfliktdynamik, sondern auch die Figurationen und Konfliktlinien zwischen verschiedenen gesellschaftlichen Gruppen innerhalb der palästinensischen Gesellschaft wiederholt veränderten. Die vorliegende soziologische Forschungsarbeit arbeitet diese Wandlungsprozesse heraus und greift dafür theoretisch-konzeptionell auf die Figurationssoziologie Norbert Elias', die sozialkonstruktivistische Biographieforschung sowie die Wissens- und Generationssoziologie Karl Mannheims zurück.

Neben dem von Konflikten und Spannungen geprägten Verhältnis zwischen der Bevölkerung in den Flüchtlingslager-Gegenden von 1948 und den (neuen) urbanen Mittelschichten im Westjordanland nimmt der Autor insbesondere einen latenten palästinensischen Generationenkonflikt in den Blick. Denn den Mitgliedern der ,Generation Oslo“ - also denjenigen Palästinenser*innen, die im Zuge des Oslo-Friedensprozesses ab den 1990er Jahren geboren wurden und aufwuchsen - stehen geringere Macht-, Lebens- und insbesondere Sinnchancen zur Verfügung als ihren Vorgängern aus der ,Kampfgeneration“ der 1970er und 1980 er Jahre. 